\title{
Utilization Assessment of Target Electrification Vehicles at Marine Corps Base Camp Lejeune: Task 3
}

Stephen Schey Jim Francfort

November 2015

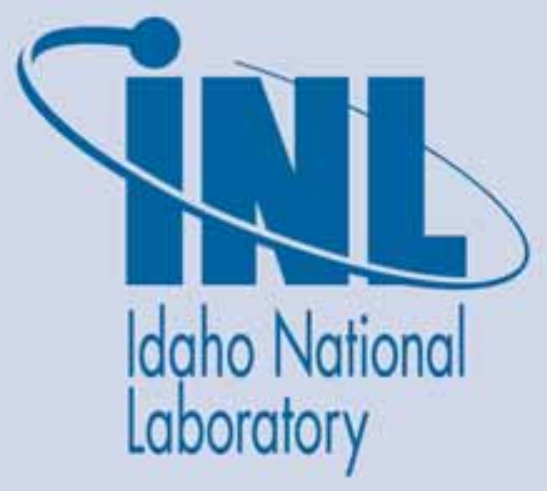

The INL is a U.S. Department of Energy National Laboratory operated by Battelle Energy Alliance 


\section{DISCLAIMER}

This information was prepared as an account of work sponsored by an agency of the U.S. Government. Neither the U.S. Government nor any agency thereof, nor any of their employees, makes any warranty, expressed or implied, or assumes any legal liability or responsibility for the accuracy, completeness, or usefulness, of any information, apparatus, product, or process disclosed, or represents that its use would not infringe privately owned rights. References herein to any specific commercial product, process, or service by trade name, trade mark, manufacturer, or otherwise, does not necessarily constitute or imply its endorsement, recommendation, or favoring by the U.S. Government or any agency thereof. The views and opinions of authors expressed herein do not necessarily state or reflect those of the U.S. Government or any agency thereof. 
INL/EXT-15-36485

\title{
Utilization Assessment of Target Electrification Vehicles at Marine Corps Base Camp Lejeune: Task 3
}

\author{
Stephen Schey \\ Jim Francfort ${ }^{2}$ \\ ${ }^{1}$ Stephen Schey, Project Manager, Infrastructure Planning and Analysis, Intertek Testing Services, \\ North America, Phoenix, Arizona \\ ${ }^{2}$ Jim Francfort, Vehicle Systems Principal Investigator, Idaho National Laboratory operated by \\ Battelle Energy Alliance, Idaho Falls, Idaho
}

November 2015

Idaho National Laboratory
Idaho Falls, Idaho 83415

http://avt.inl.gov

Prepared for the

U.S. Department of Energy

Office of Nuclear Energy

Under DOE Idaho Operations Office

Contract DE-AC07-05ID14517 


\section{ABSTRACT}

Battelle Energy Alliance, LLC, managing and operating contractor for the U.S. Department of Energy's Idaho National Laboratory, is the lead laboratory for the U.S. Department of Energy's advanced vehicle testing. Battelle Energy Alliance, LLC contracted with Intertek Testing Services, North America (Intertek) to conduct several U.S. Department of Defense-based studies to identify potential U.S. Department of Defense transportation systems that are strong candidates for introduction or expansion of plug-in electric vehicles (PEVs).

Task 1 consisted of a survey of the non-tactical fleet of vehicles at Marine Corps Base Camp Lejeune to begin the review of vehicle mission assignments and types of vehicles in service. Task 2 involved identifying daily operational characteristics of select vehicles and initiating data logging of vehicle movements in order to characterize the vehicle's mission. Individual observations of these selected vehicles provided the basis for recommendations related to PEV adoption and whether a battery electric vehicle or plug-in hybrid electric vehicle (collectively referred to as PEVs) can fulfill the mission requirements and provide observations related to placement of PEV charging infrastructure.

This report provides the results of the data analysis and observations related to replacement of current vehicles with PEVs. This fulfills part of the Task 3 requirements. Task 3 also includes an assessment of the charging infrastructure required to support this replacement, which is the subject of a separate report.

Intertek acknowledges the support of Idaho National Laboratory, Marine Corps headquarters, and Marine Corps Base Camp Lejeune Fleet management and personnel for participation in this study. 


\section{EXECUTIVE SUMMARY}

Federal agencies are mandated ${ }^{a}$ to purchase alternative fuel vehicles, increase consumption of alternative fuels, and reduce petroleum consumption. Available plug-in electric vehicles (PEVs) provide an attractive option in the selection of alternative fuel vehicles. PEVs, which consist of both battery electric vehicles (BEVs) and plug-in hybrid electric vehicles (PHEVs), have significant advantages over internal combustion engine (ICE) vehicles in terms of energy efficiency, reduced petroleum consumption, and reduced production of greenhouse gas (GHG) emissions, and performance benefits with quieter, smoother operation. This study intended to evaluate the extent to which Marine Corps Base Camp Lejeune (MCBCL) could convert part or all of their fleet of vehicles from petroleum-fueled vehicles to PEVs.

It is likely that more fuel-efficient ICE vehicles, including hybrid electric vehicles, exist that may provide improvements for the current fleet; however, this study's focus is on replacing ICE vehicles with suitable PEVs.

BEVs provide the greatest benefit when it comes to fuel and emissions savings because all motive power is provided by the energy stored in the onboard battery pack. These vehicles use no petroleum and emit no pollutants at their point of use. PHEVs provide similar savings when their battery provides motive power, but they also have the ability to extend their operating range with an onboard ICE. Because a PHEV can meet all transportation range needs, the adoption of a PHEV will be dependent on its ability to meet other transportation needs such as cargo or passenger carrying. Operation of PHEVs in battery-only mode can be increased with opportunity charging at available charging stations; however, it should be noted that not all PHEVs have a mode in which the battery provides all motive power at all speeds. This study focuses on the mission requirements of the fleet of vehicles with the objective of identifying vehicles that may be replaced with PEVs, with emphasis on BEVs that provide maximum benefit.

MCBCL borders on the Atlantic Ocean near Jacksonville, North Carolina. The base and surrounding community is home to an active duty, dependent, retiree, and civilian employee population of approximately 170,000 people. Camp Lejeune contains 156,000 acres and 11 miles of beaches. ${ }^{b}$

The geographic size of MCBCL and close proximity to other related facilities in the area create significant opportunities for conversion of some vehicles to PEVs. MCBCL identified 862 vehicles in its fleet of which 784 were selected to be part of this study. From these selected vehicles, 60 vehicles that are representative of the full fleet were selected for closer monitoring. Fleet vehicle mission categories are defined in Section 4 of this report and, while the MCBCL vehicles conduct many different missions, four (i.e., pool, support, enforcement, and specialty missions) were selected to be part of this fleet evaluation. The selected vehicles included many vehicle types.

\footnotetext{
${ }^{a}$ Energy Policy act of 1992, Energy Policy Act of 2005, Executive Order 13423, and Energy Independence and Security Act of 2007.

${ }^{\mathrm{b}}$ www.lejeune.marines.mil/About.aspx accessed January 22, 2015.
} 
The Motor Transport Division manages the non-tactical fleet of vehicles on MCBCL. For purposes of this study, vehicles are identified as assigned to Marine Corps Installations East (MCIE) departments and divisions or to tenant commands (Commands). The Commands group operates 266 vehicles and MCIE operates the remaining 596 vehicles, which includes all pool vehicles. Of the vehicles in the study group, the Commands group operates 249 vehicles and MCIE operates 535 vehicles.

This report actually provides three reports: one for the Commands group, one for the MCIE group, and an overall report. It observes that a mix of BEVs and PHEVs are capable of performing most of the required missions and of providing an alternative vehicle for the pool, support, and enforcement vehicles. Because some vehicles travel long distances, the group could support some BEVs for the short trips and PHEVs for the longer trips. The specialty heavy-duty trucks where potential replacement PEVs have been demonstrated were also considered. The recommended mix of vehicles will provide sufficient range for individual trips and time is available each day for charging to accommodate multiple trips per day. Replacement of vehicles in the current fleet could result in significant reductions in the emissions of GHGs and in petroleum use, as well as reduced fleet operating costs.

PEVs currently commercially available cannot replace certain vehicles and missions (such as those requiring heavy-duty trucks and certain specialty usage vehicles). However, based on data collected for the monitored vehicles, the 60-vehicle fleet subset could possibly consist of one conventional heavy-duty

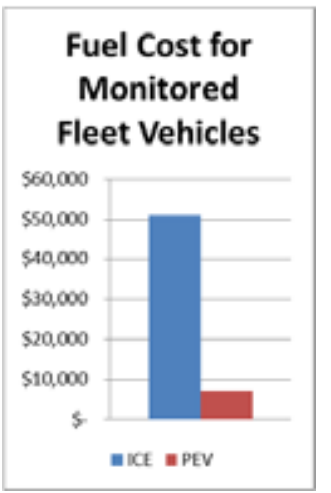
specialty truck, $25 \mathrm{BEVs}$, and 34 PHEVs. Greater emphasis on BEVs may be possible as more BEVs of different types become commercially available.

Duke Energy Progress provides electric power for MCBCL and its generation mix provides lower electrical costs and lower generation of GHG emissions than the national averages. Replacement of the 59 ICE vehicles with PEVs potentially results in an annual fuel savings of over $\$ 43,000$ (i.e., $86 \%$ reduction) and GHG savings of over $200,000 \mathrm{lb}-\mathrm{CO}_{2} \mathrm{e}$ (i.e., $58 \%$ reduction).

The monitored vehicles represent 59 of the 784 on-road-rated vehicles in these represented fleets. Assuming that the balance of the fleet operates in a manner similar to those monitored and without consideration of specific cargo or other mission requirements not previously identified, Intertek suggests that the total fleet composition could consist of 53 conventional heavy-duty specialty trucks, 418 BEVs, and 313 PHEVs. This replacement of ICE vehicles with PEVs could result in an annual fuel savings of over $\$ 645,000$ (i.e., $87 \%$ reduction) and annual GHG savings of over 3,140,000 $\mathrm{lb}-\mathrm{CO}_{2}$ e (i.e., $61 \%$ reduction).

The average monitored vehicle travelled approximately 8,000 miles per year. This is an average of 667 miles per month or 154 miles per week. This may 
reflect the opportunity to increase the percentage of BEVs over that analyzed in Section 5. Intertek suggests MCBCL may wish to move forward in the near future with replacement of pool, support, and enforcement vehicles with PEVs as current budget and vehicle replacement schedules allow. Certainly, the vehicle types studied in this report may be candidates for immediate replacement. 


\section{CONTENTS}

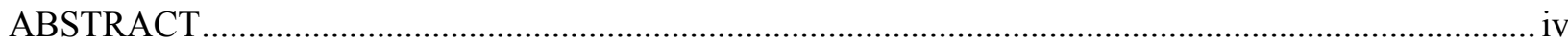

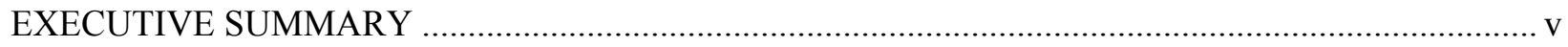

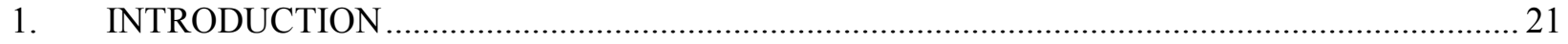

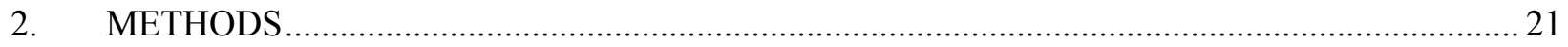

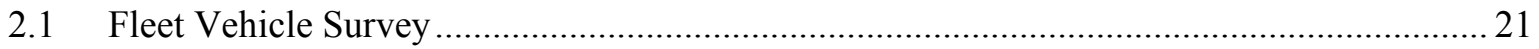

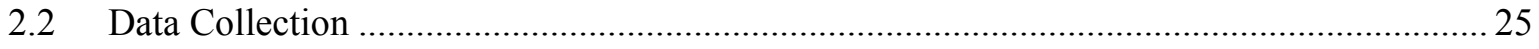

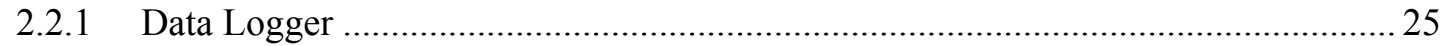

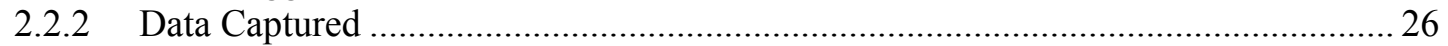

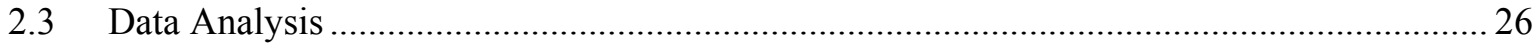

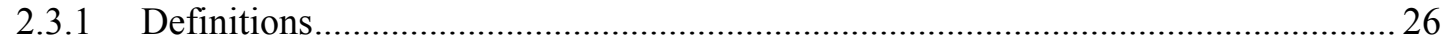

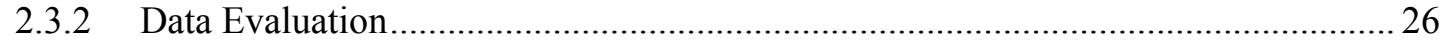

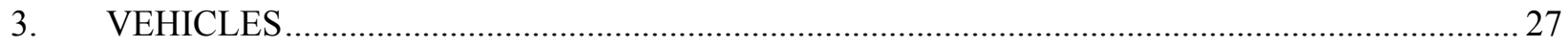

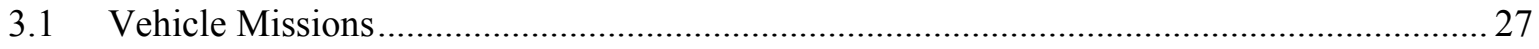

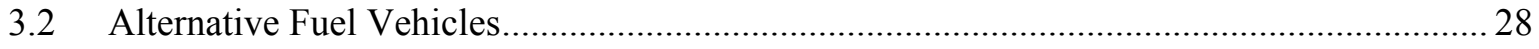

3.3 Battery Electric Vehicle and Plug-In Hybrid Electric Vehicle Benefits/Challenges ........... 29

3.3.1 Battery Electric Vehicle Benefits/Challenges .....................................................29

3.3.2 Plug-In Hybrid Electric Vehicle Benefits/Challenges ............................................. 30

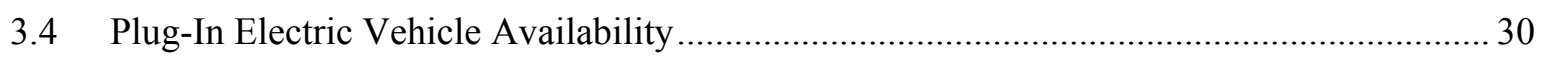

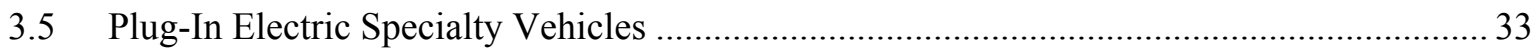

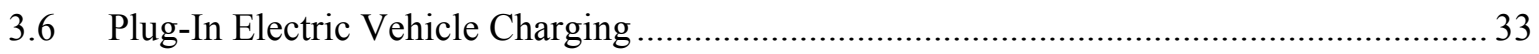

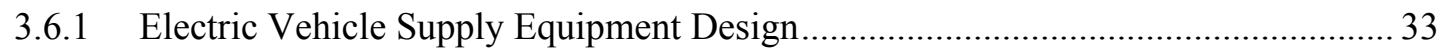

3.6.2 Electric Vehicle Supply Equipment Stations ...................................................... 37

4. MARINE CORPS BASE CAMP LEJEUNE ANALYSIS …..................................................... 38

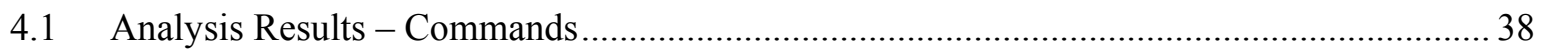

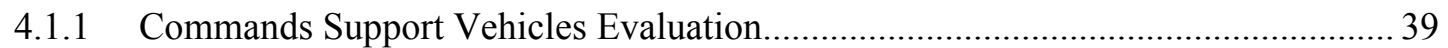

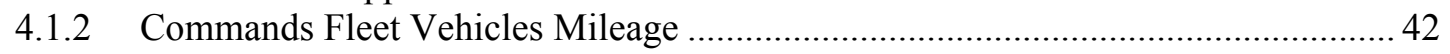

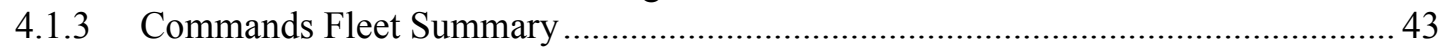

4.2 Analysis Results - Marine Corps Installations East Fleet................................................... 43 
4.2.1 Marine Corps Installations East Pool Vehicles Analysis ........................................ 44

4.2.2 Marine Corps Installations East Support Vehicles Analysis..................................... 46

4.2.3 Marine Corps Installations Enforcement Vehicles Analysis...................................... 49

4.2.4 Marine Corps Installations East Specialty Vehicles Analysis ................................. 52

4.2.5 Marine Corps Installations East Group Vehicles Mileage ....................................... 52

4.2.6 Marine Corps Installations East Group Summary ….............................................. 52

4.3 Analysis Results - Combined Groups..................................................................... 53

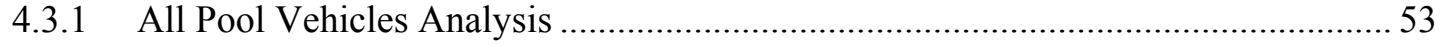

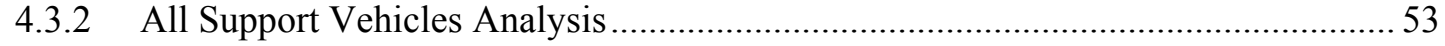

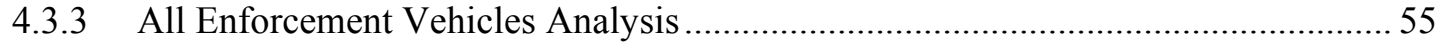

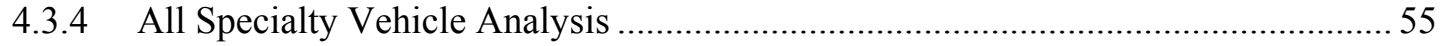

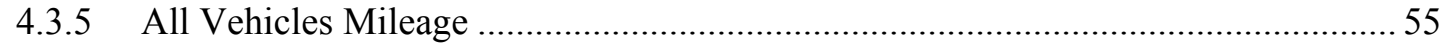

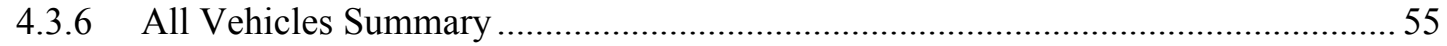

5. GREENHOUSE GAS EMISSIONS AVOIDED AND FUEL COST REDUCTION

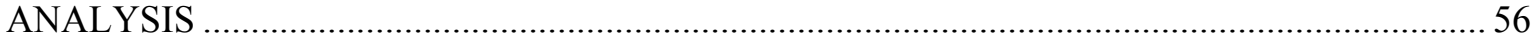

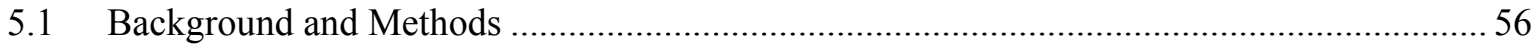

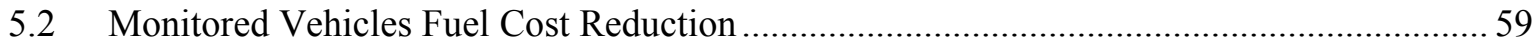

5.3 Monitored Vehicles Greenhouse Gas Emissions Reduction ............................................. 60

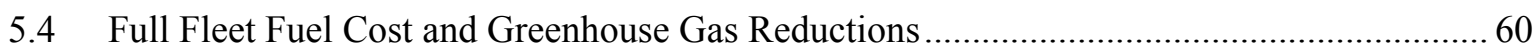

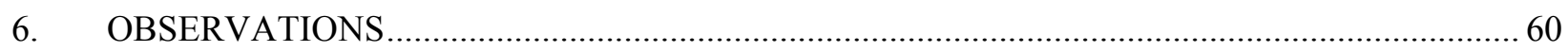

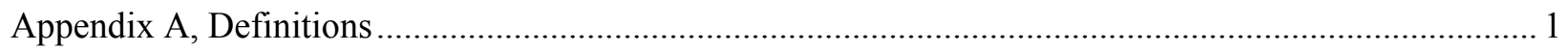

Appendix B, Marine Corps Base Camp Lejeune Commands Group Vehicle Data Sheets ......................... 1

Appendix C, Marine Corps Installations East Vehicle Data Sheets ................................................... 1

Appendix D, Greenhouse Gas Emissions Avoided and fuel Cost Reduction Analysis -

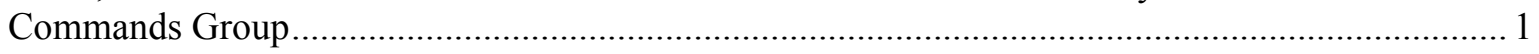

Appendix E, Greenhouse Gas Emissions Avoided and Fuel Cost Reduction Analysis - Marine

Corps Installations East Group ........................................................................................... 1

\section{FIGURES}

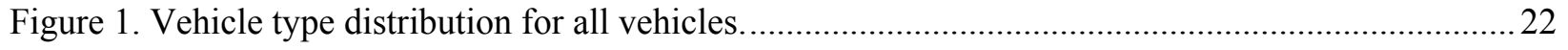

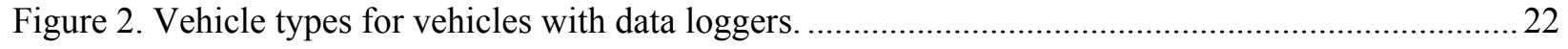

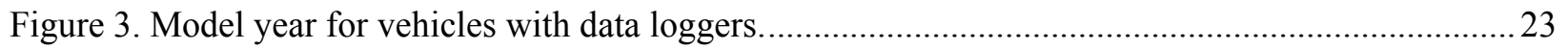


Figure 4. Monthly mileage for vehicles with data loggers.............................................................. 23

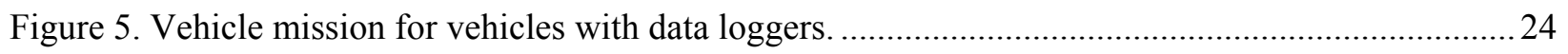

Figure 6. Distribution of monthly distance driven for vehicles with data loggers.................................. 24

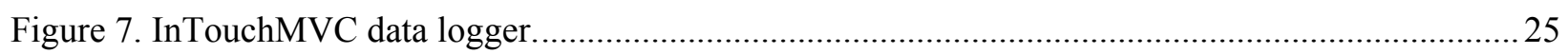

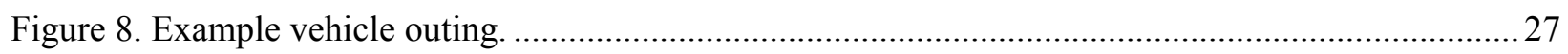

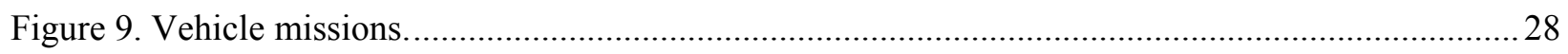

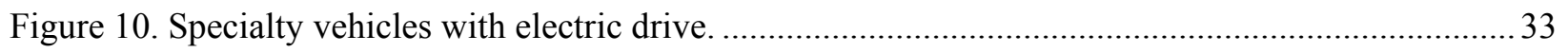

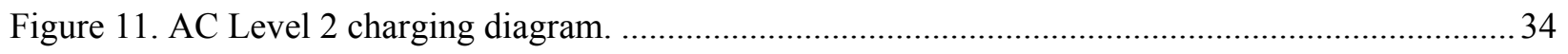

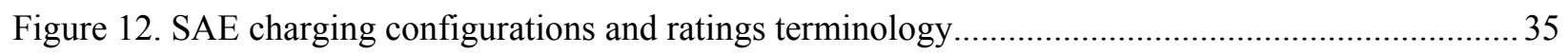

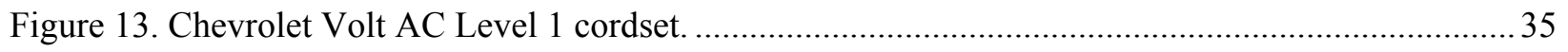

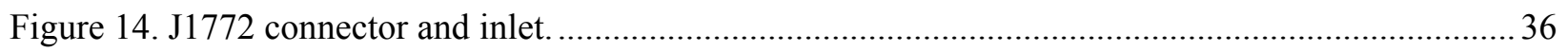

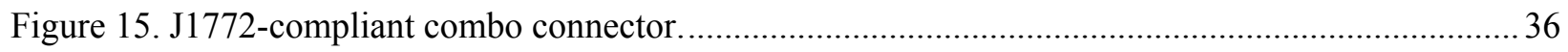

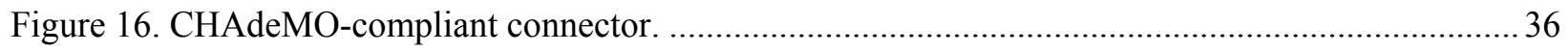

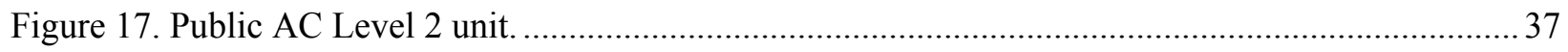

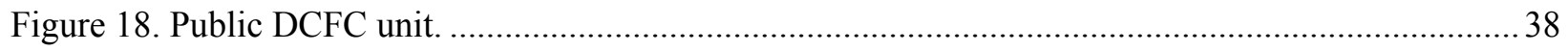

Figure 19. Command support vehicle daily travel miles (all vehicles) .............................................. 40

Figure 20. Command support vehicle combined outings. Note that the three longest outings of

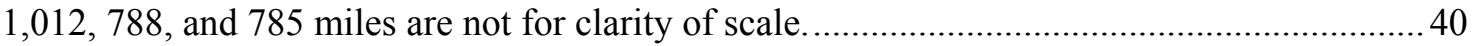

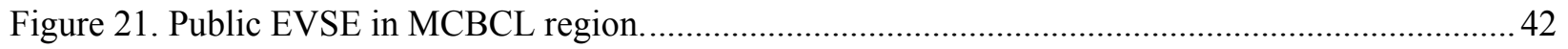

Figure 22. Pool vehicle daily travel miles (all vehicles) ….............................................................. 45

Figure 23. Pool vehicle combined outings. Note that the single longest outing of 537 miles was

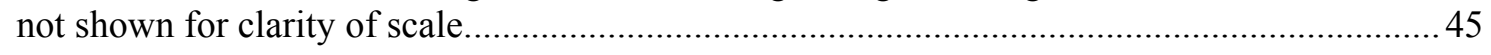

Figure 24. Support vehicle daily travel miles and usage time (all vehicles) ........................................4 47

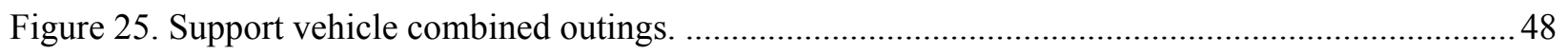

Figure 26. Enforcement vehicle daily travel miles and usage time (all vehicles) ..................................50

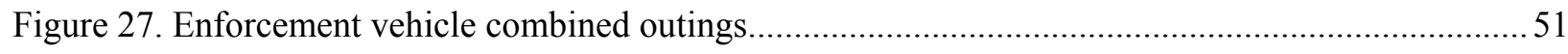

Figure 28. Support vehicle daily travel miles (all vehicles)............................................................5 
Figure 29. Support vehicle combined outings for all vehicles. Note that the longest outings of $1,012,788$, and 785 miles are not shown in the figure for clarity.

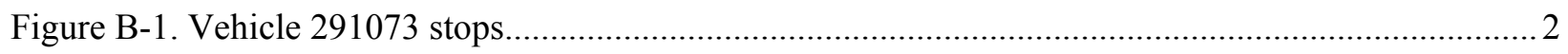

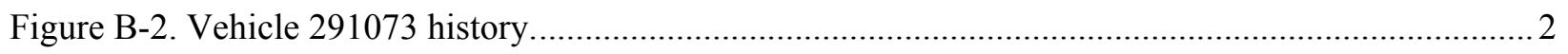

Figure B-3. Vehicle 291073 travel graphs. ................................................................................... 3

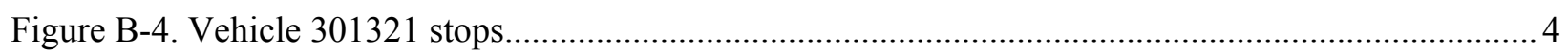

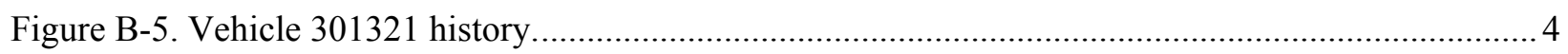

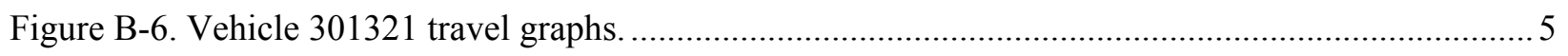

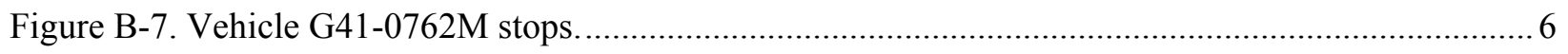

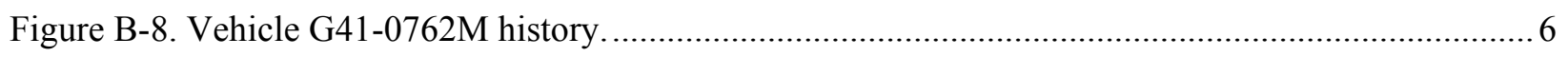

Figure B-9. Vehicle G41-0762M travel graphs. ..........................................................................

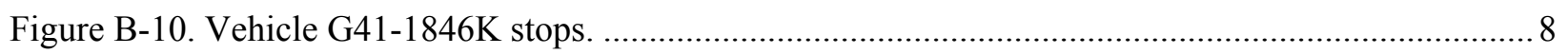

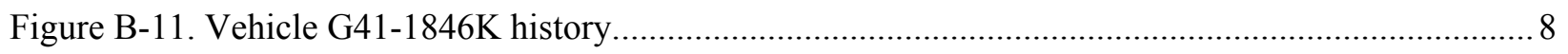

Figure B-12. Vehicle G41-1846K travel graphs. Note that the maximum outing of 788 miles is

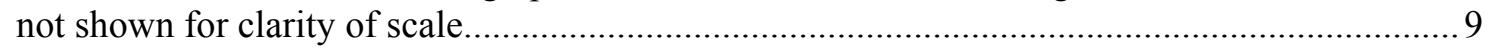

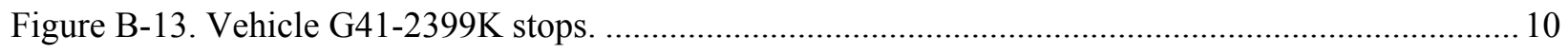

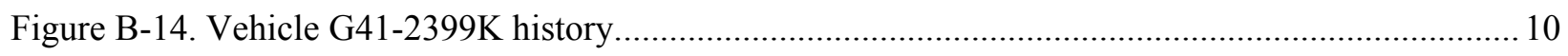

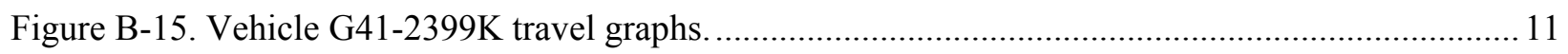

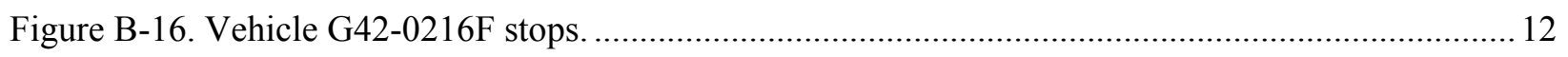

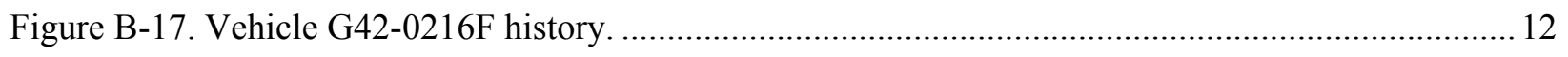

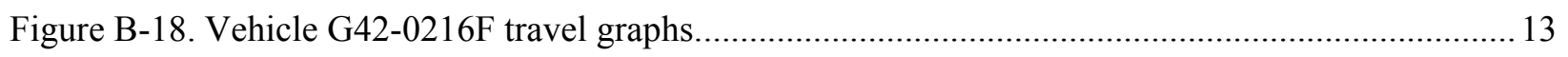

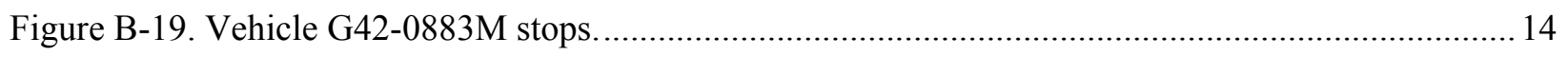

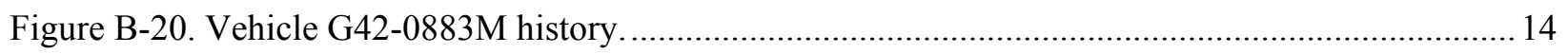

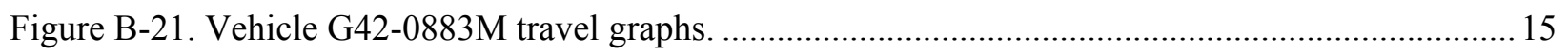

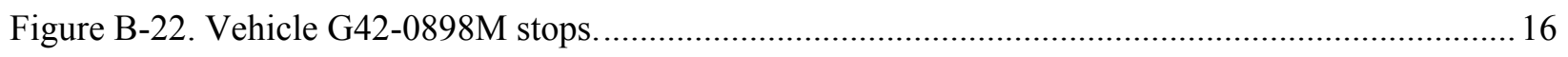

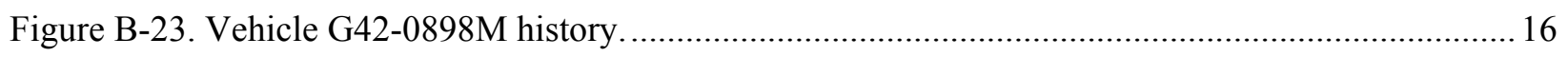

Figure B-24. Vehicle G42-0898M travel graphs. The maximum outing of 143.8 miles is not clearly visible on the above graph because of scale. .......................................................... 17 


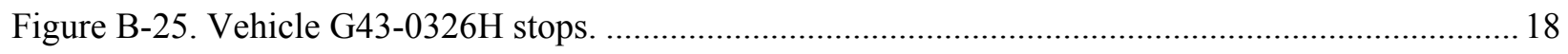

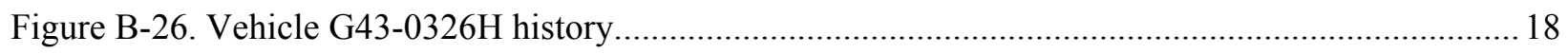

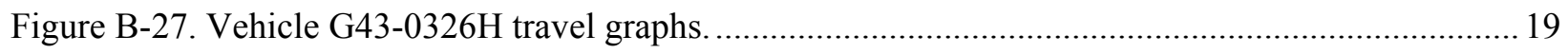

Figure B-28. Vehicle G43-1453G stops. .................................................................................... 20

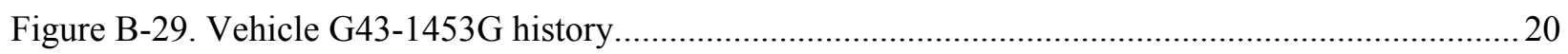

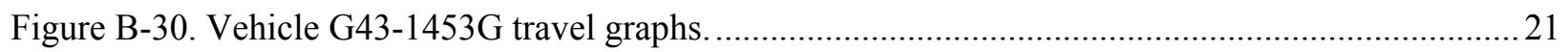

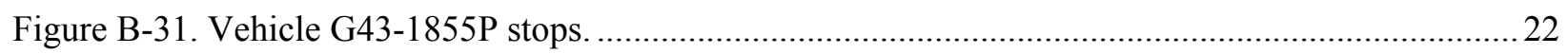

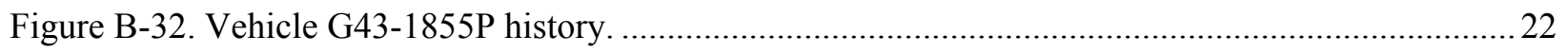

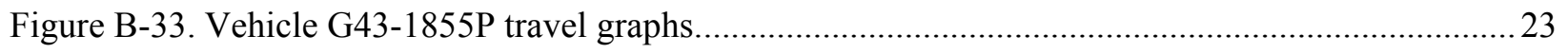

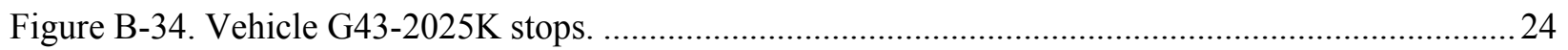

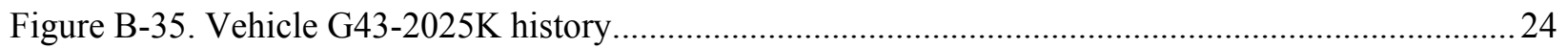

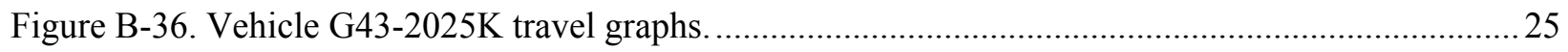

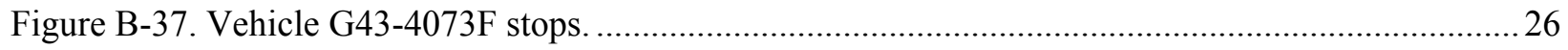

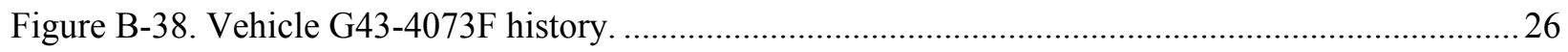

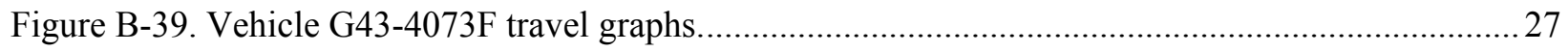

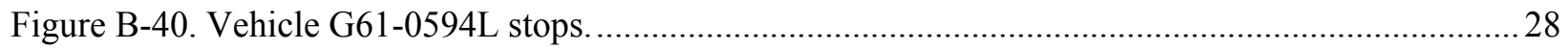

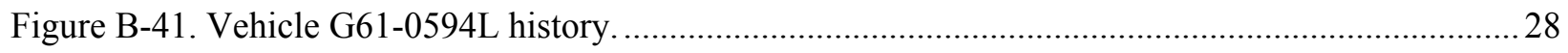

Figure B-42. Vehicle G61-0594L travel graphs. Note that the outing graph does not show the

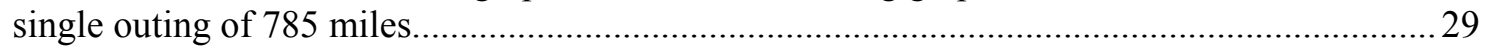

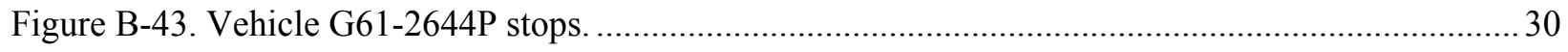

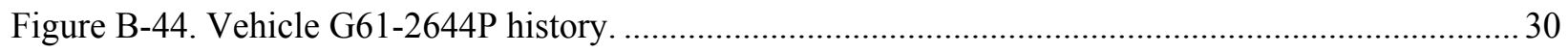

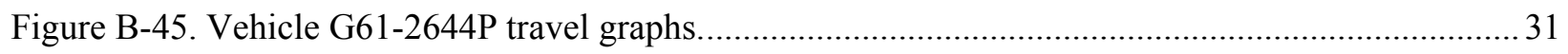

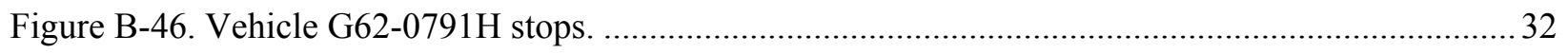

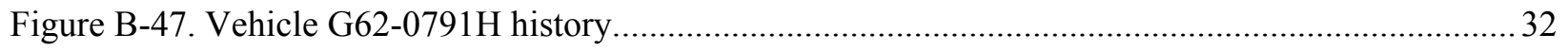

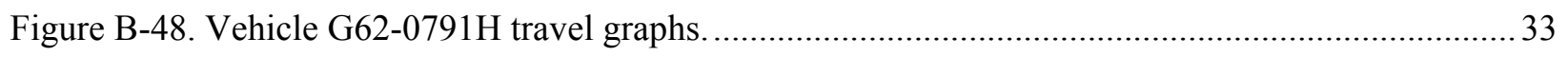

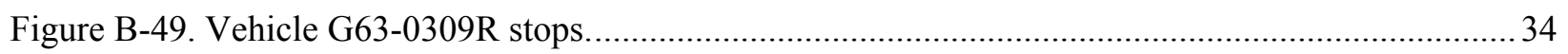

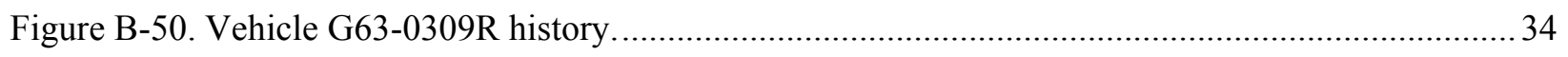




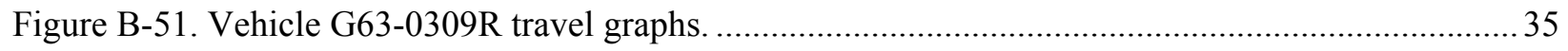

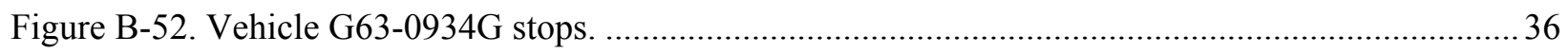

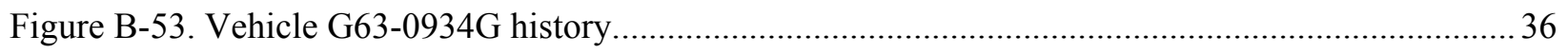

Figure B-54. Vehicle G63-0934G travel graphs. Note that the outing graph does not show the

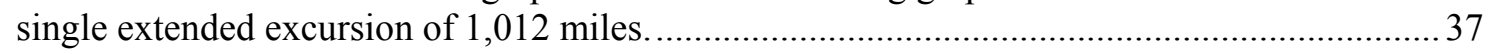

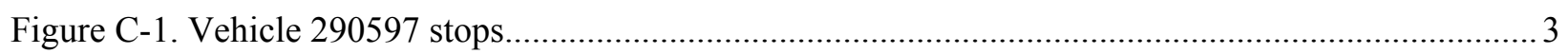

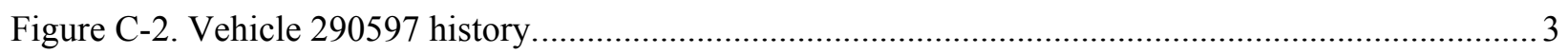

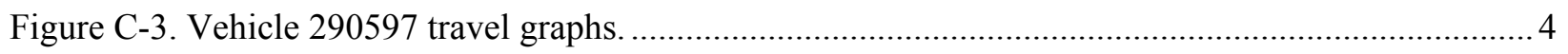

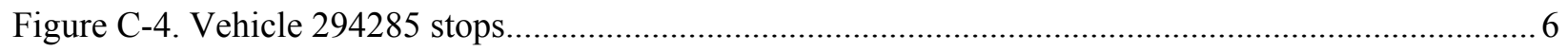

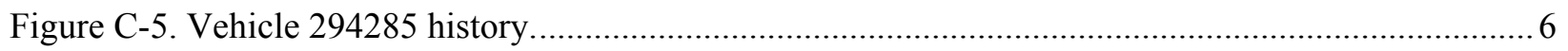

Figure C-6. Vehicle 294285 travel graphs. .................................................................................

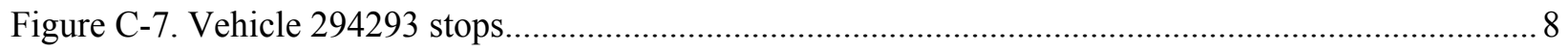

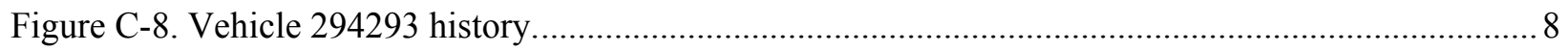

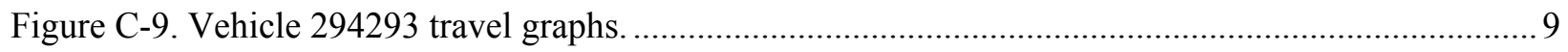

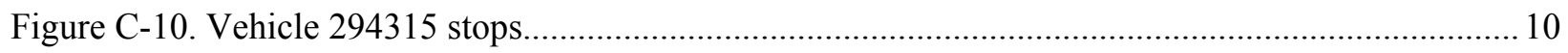

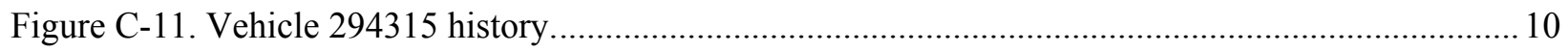

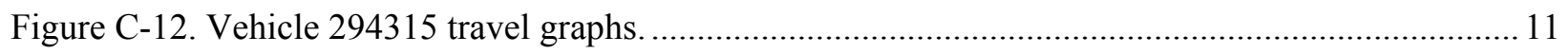

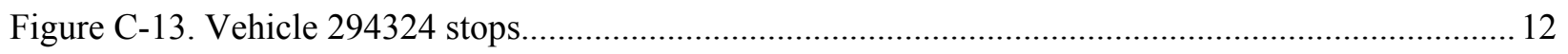

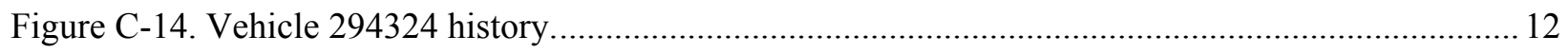

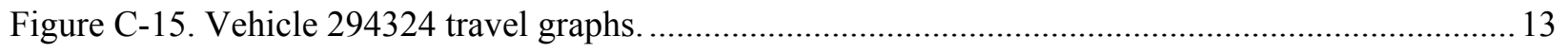

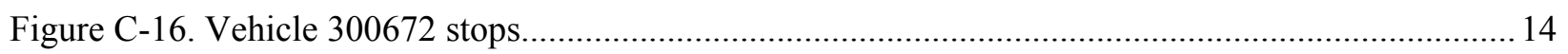

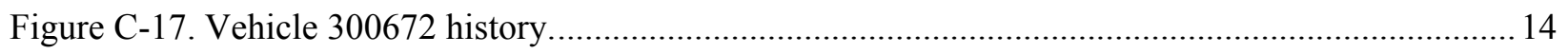

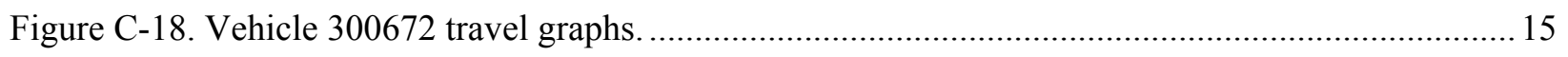

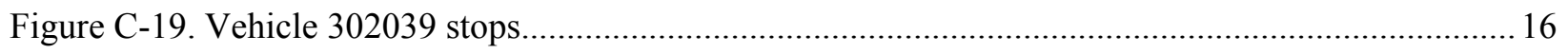

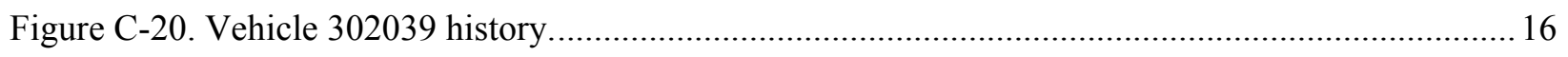

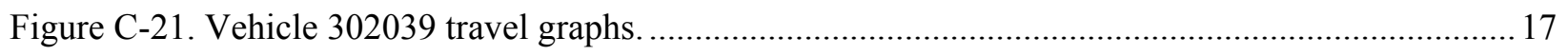

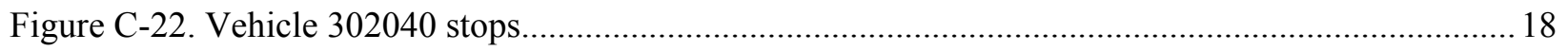




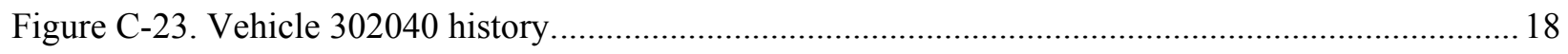

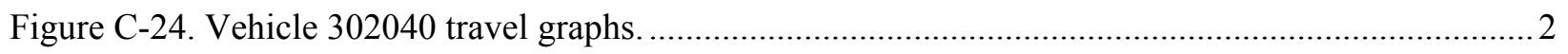

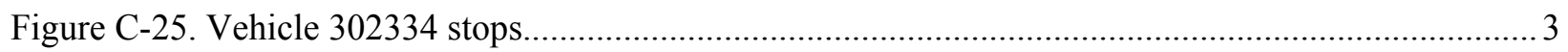

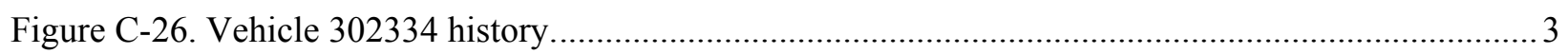

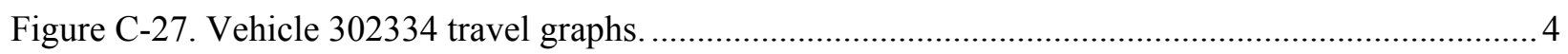

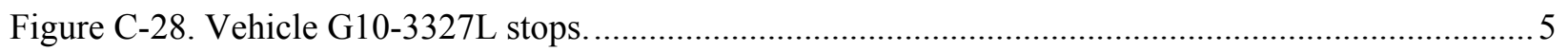

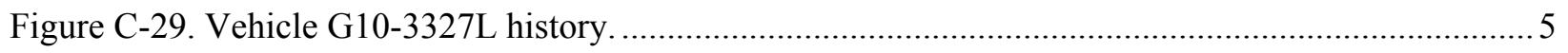

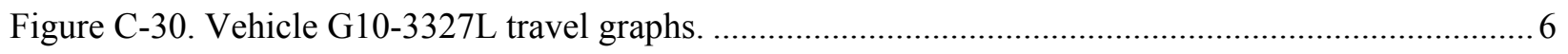

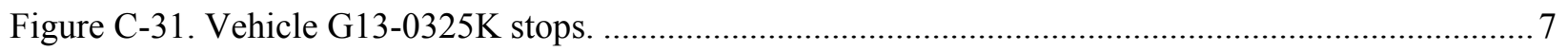

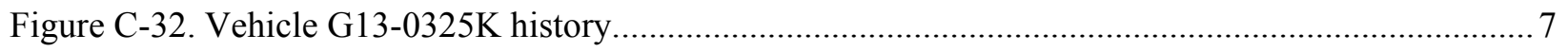

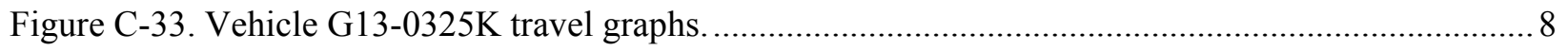

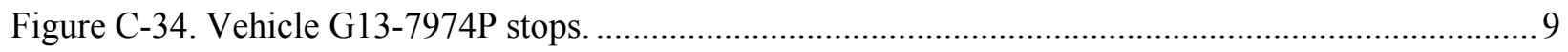

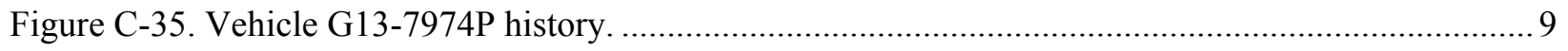

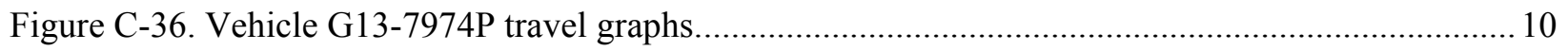

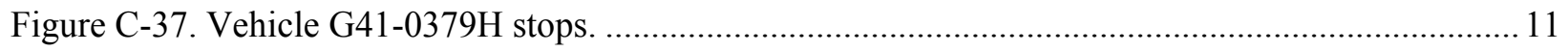

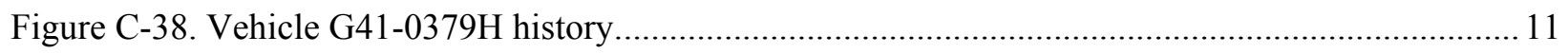

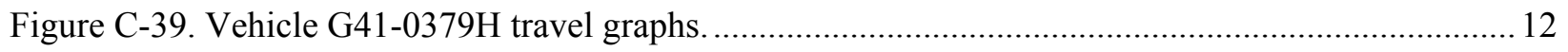

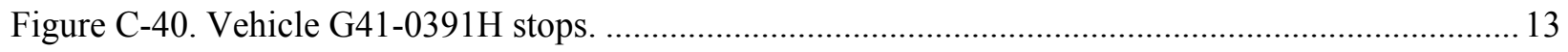

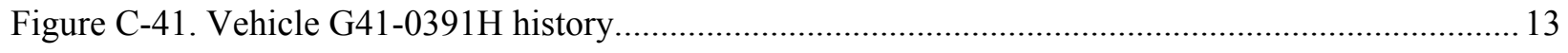

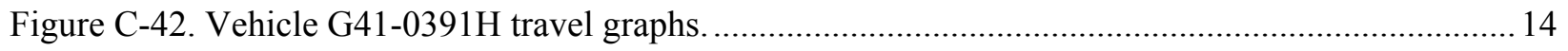

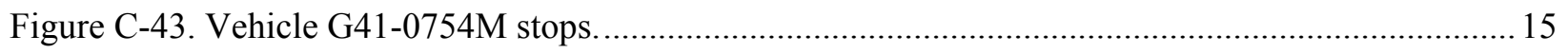

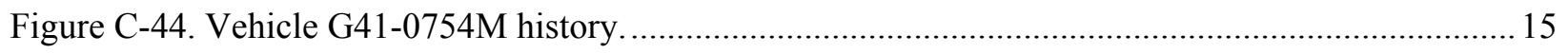

Figure C-45. Vehicle G41-0754M travel graphs. Note that the outing graph does not show the

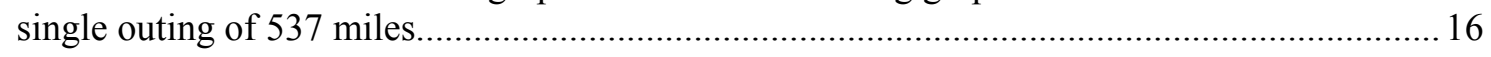

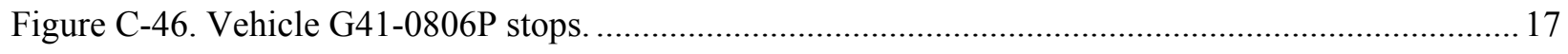

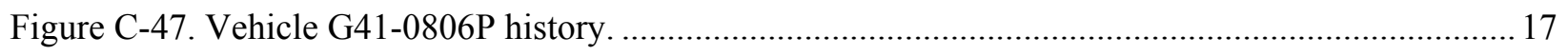

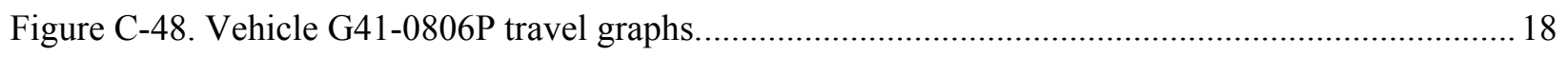




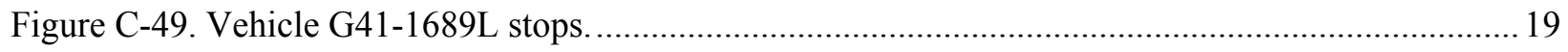

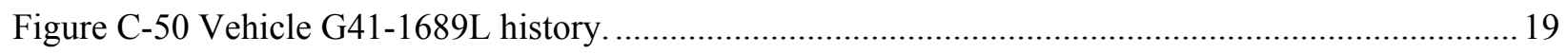

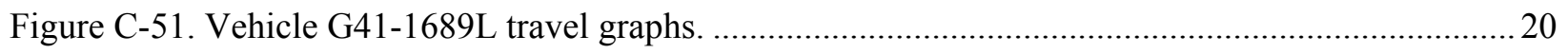

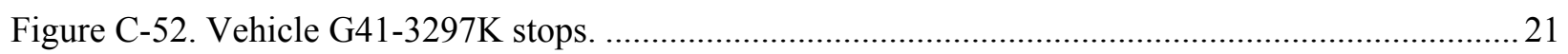

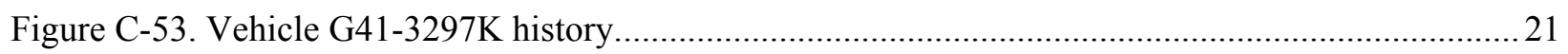

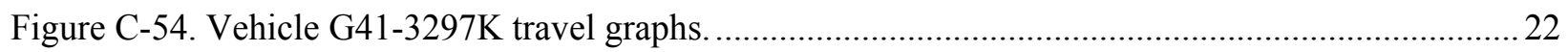

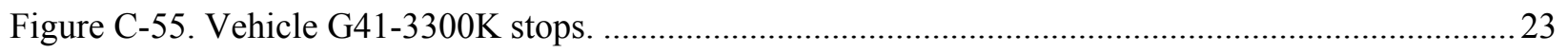

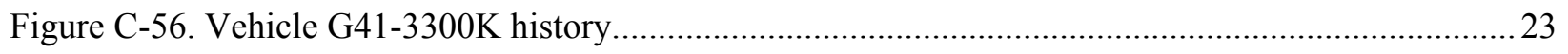

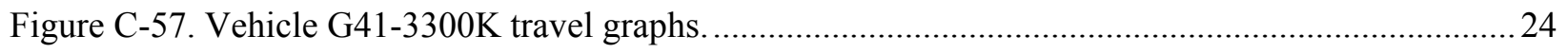

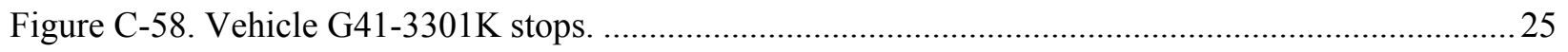

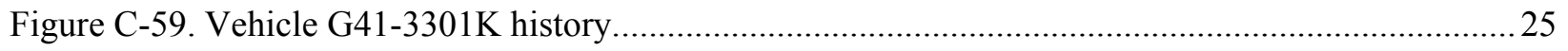

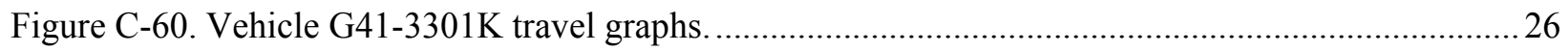

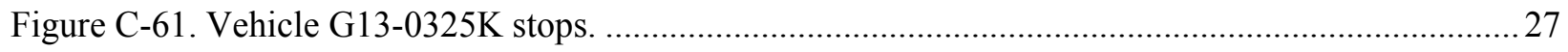

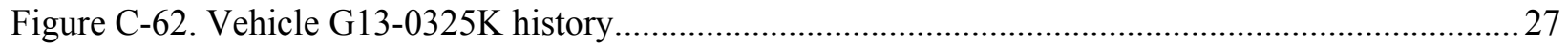

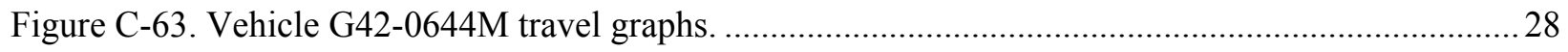

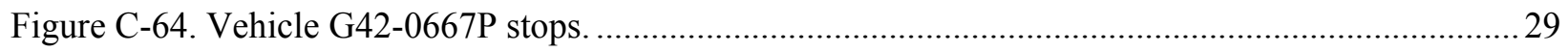

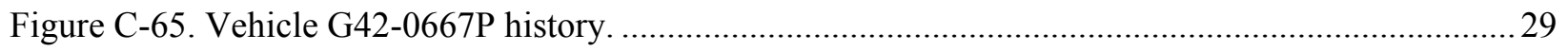

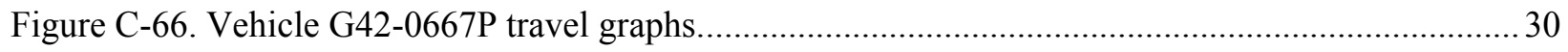

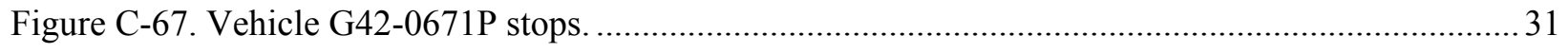

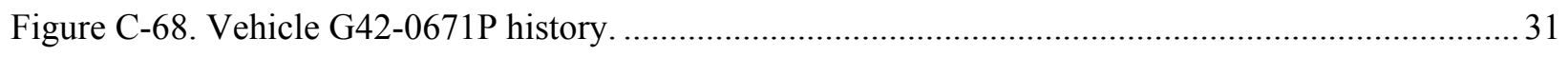

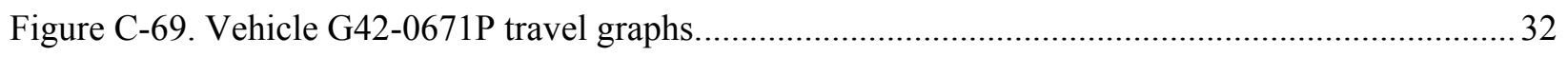

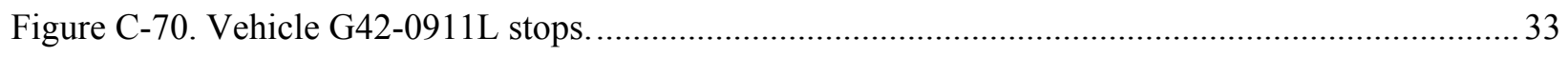

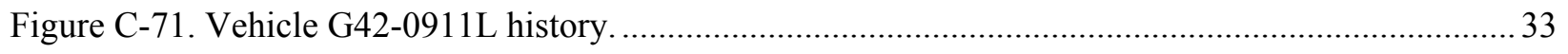

Figure C-72. Vehicle G42-0911L travel graphs. Daily travel time graph does not show maximum

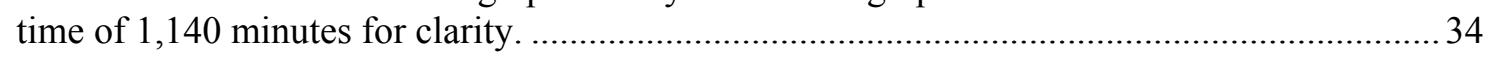

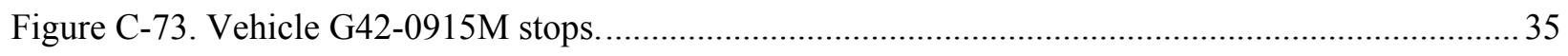

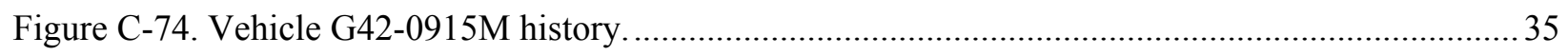




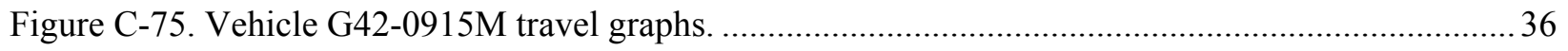

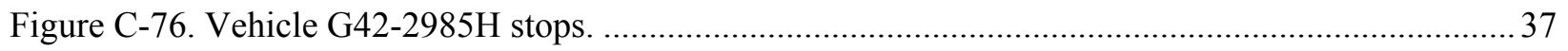

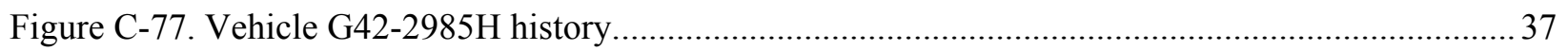

Figure C-78. Vehicle G42-2985H travel graphs. Note that the daily travel time graph does not

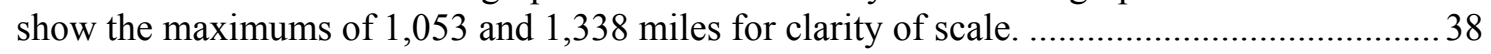

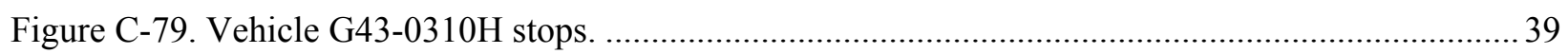

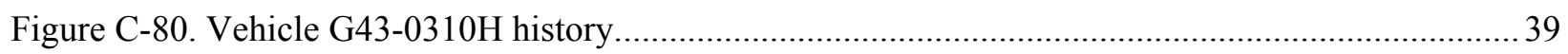

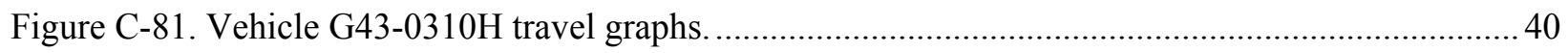

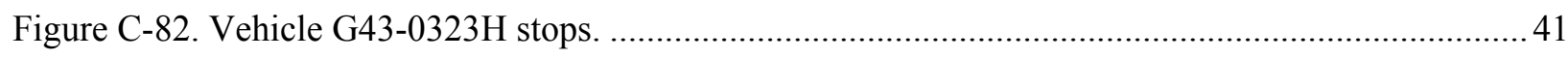

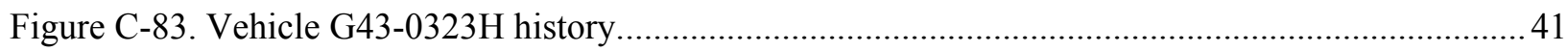

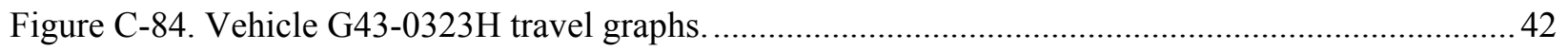

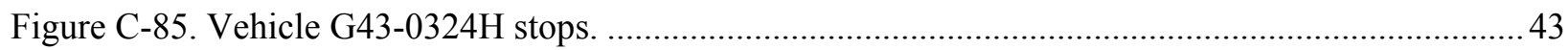

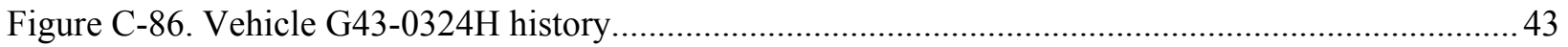

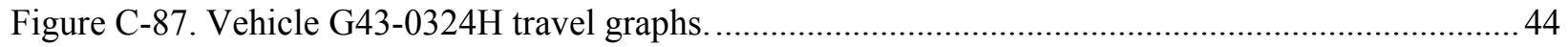

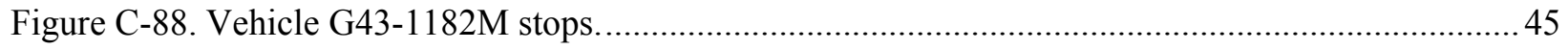

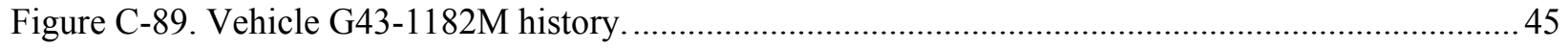

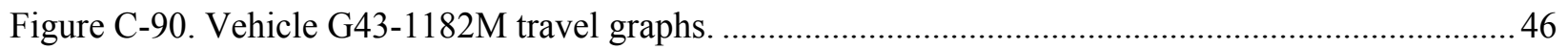

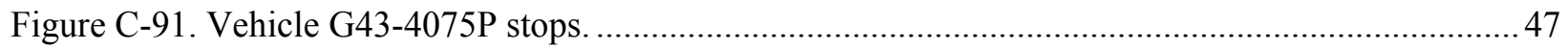

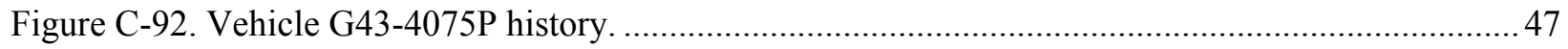

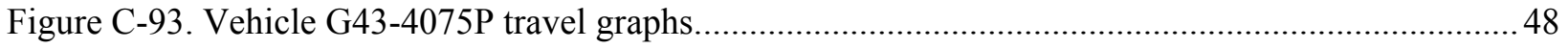

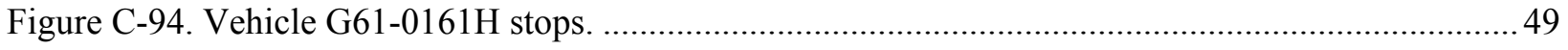

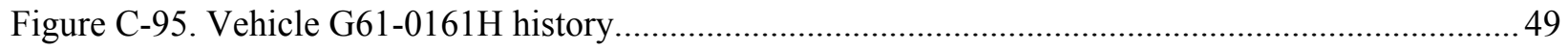

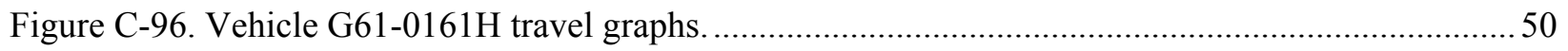

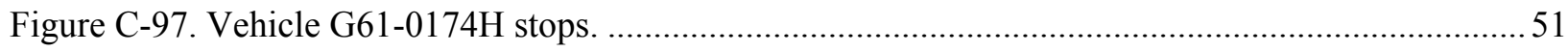

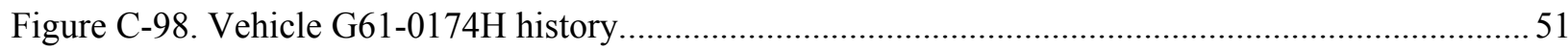

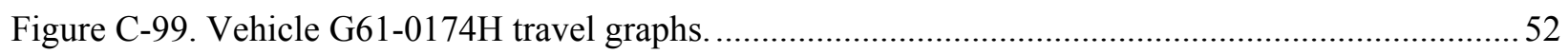

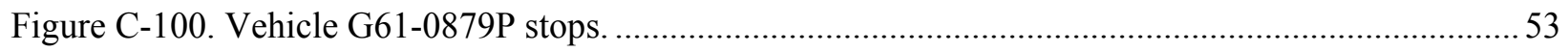




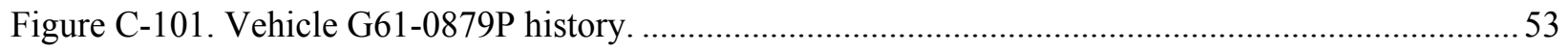

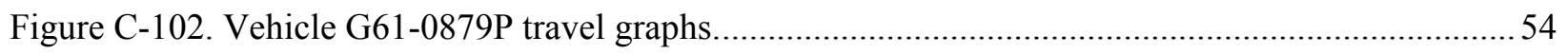

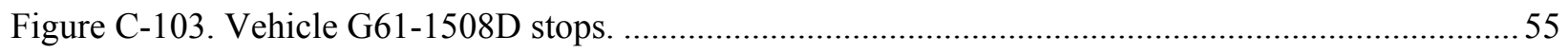

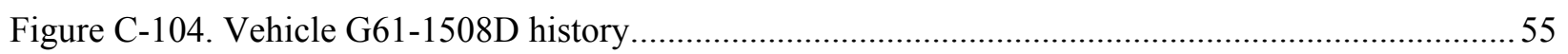

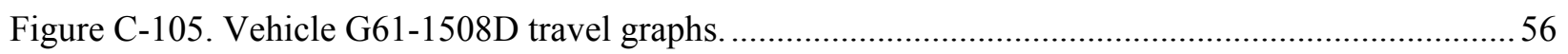

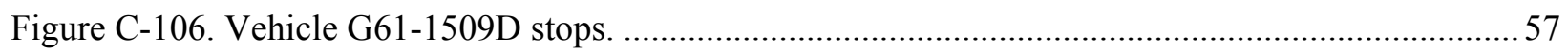

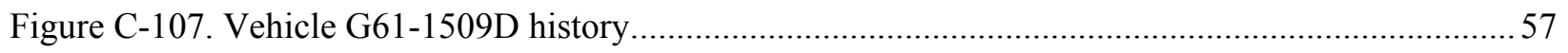

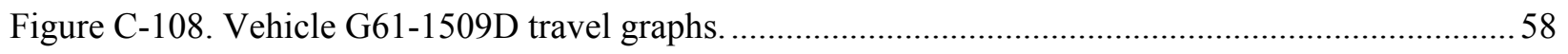

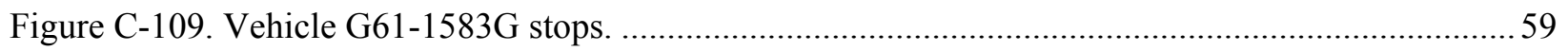

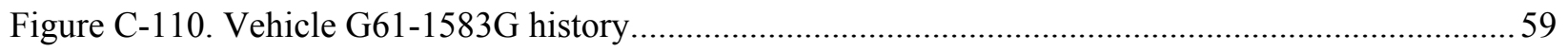

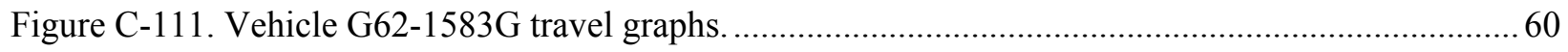

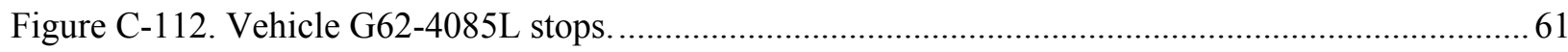

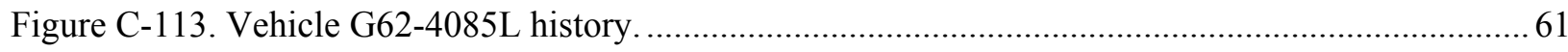

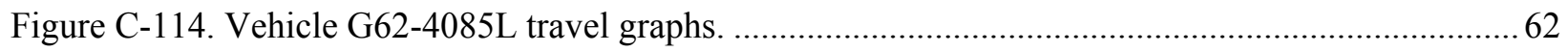

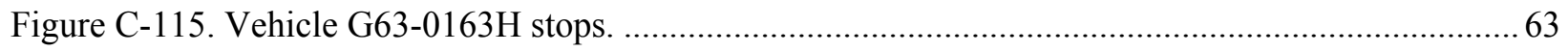

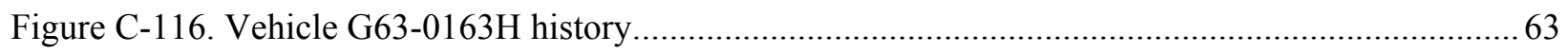

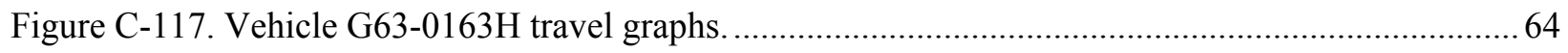

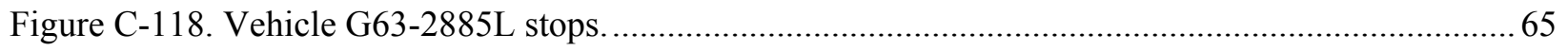

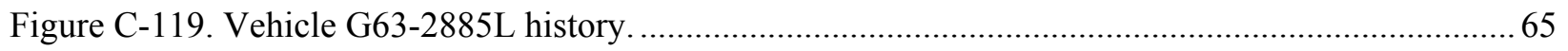

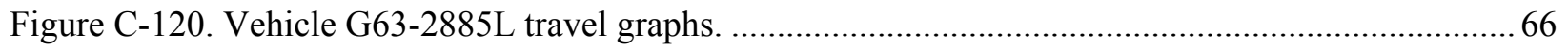

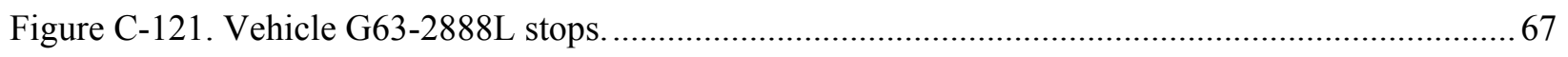

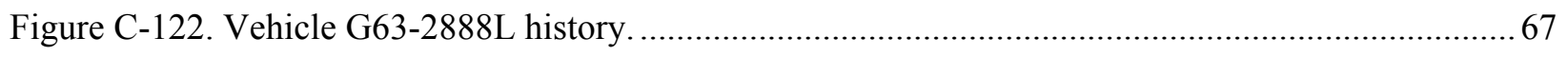

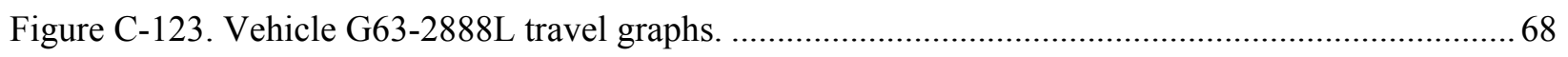

TABLES

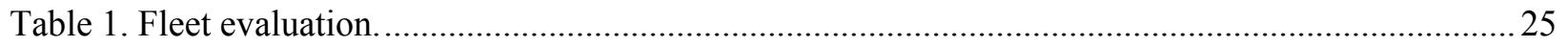




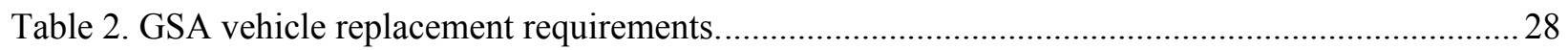

Table 3. GSA-certified PHEVs for 2014 ............................................................................................ 31

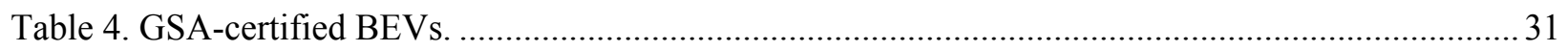

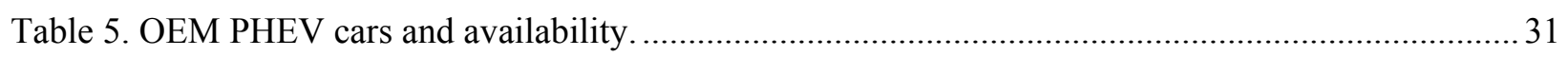

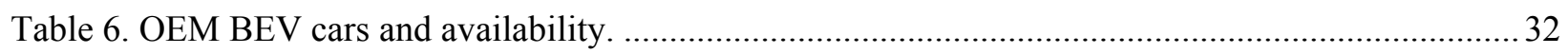

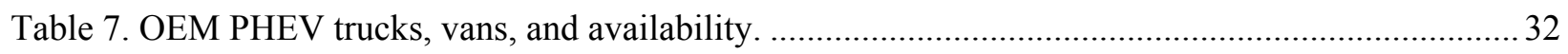

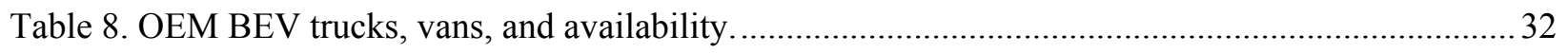

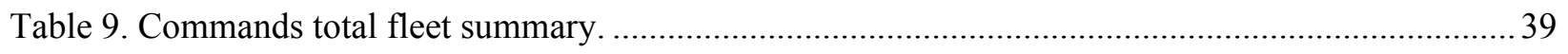

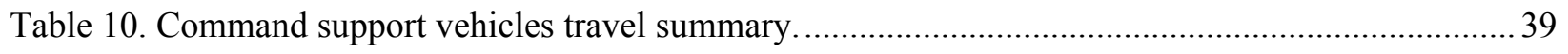

Table 11. Commands PEV potential replacements.......................................................................... 41

Table 12. Commands group monitored vehicle mileage. .................................................................. 42

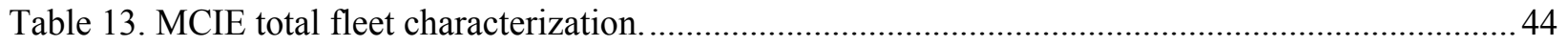

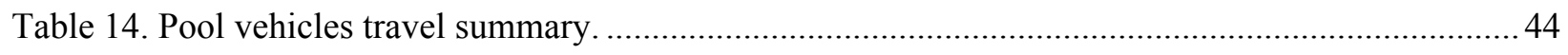

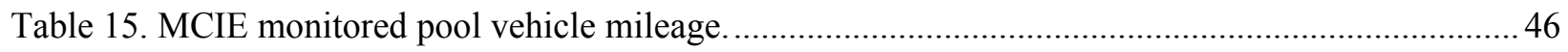

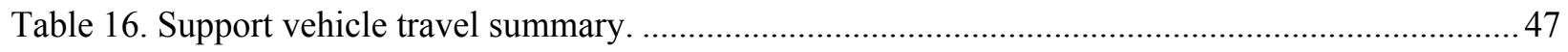

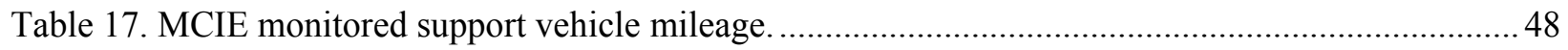

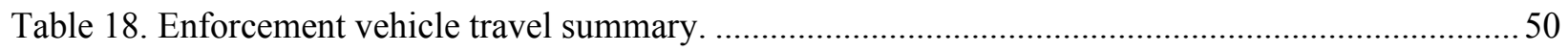

Table 19. MCIE monitored enforcement vehicle mileage ................................................................ 51

Table 20. All fleet vehicles by type and mission. ….....................................................................5

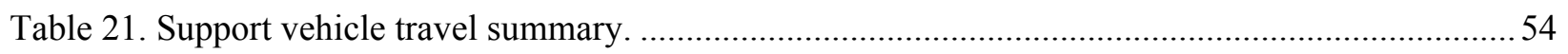

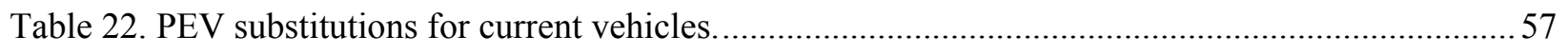

Table 23. Fuel cost reduction of monitored vehicles with PEV replacements. .......................................59

Table 24. GHG emissions reduction of monitored vehicles with PEV replacements.............................. 60

Table 25. Projected fuel costs and GHG reduction potential for all vehicles in monitored fleets..............60

Table B-1. MCBCL Commands Group vehicle index.................................................................. 1

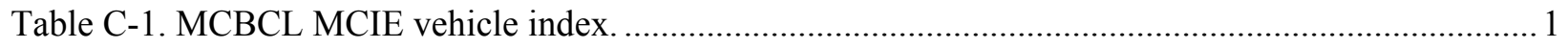


Table D-1. MCBCL Commands Group PEV replacements. ............................................................... 1

Table D-2. Monitored vehicle PEV replacement fuel savings.........................................................2

Table D-3. Monitored vehicle PEV replacement fuel savings (North Carolina and national

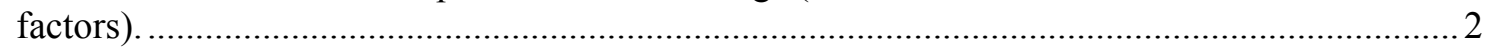

Table D-4. Monitored vehicle replacement on GHG emissions reduction (Jacksonville, North

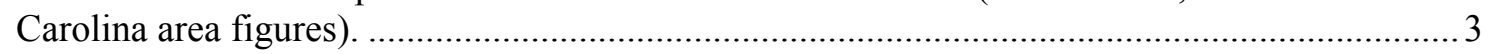

Table D-5. Monitored vehicle replacement on GHG emissions reduction (national figures). .................... 4

Table D-6. Commands Group full fleet PEV replacement reductions (Jacksonville, NC area

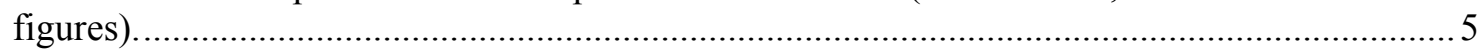

Table D-7. Commands group full fleet PEV replacement reductions (national figures)............................5

Table D-8. Average fuel savings values for the Commands group's monitored vehicles (North

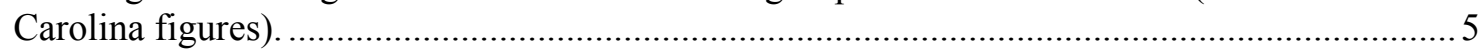

Table D-9. Average GHG emissions savings values for the Commands group's monitored

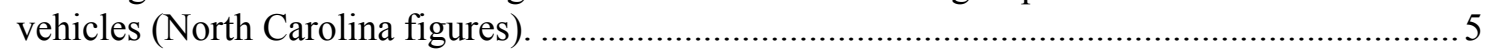

Table E-1. MCBCL MCIE fleet PEV replacements. ....................................................................... 1

Table E-2. Fuel savings for PEV replacement of monitored vehicles. .................................................2

Table E-3. Monitored vehicle PEV replacement fuel savings (North Carolina and national

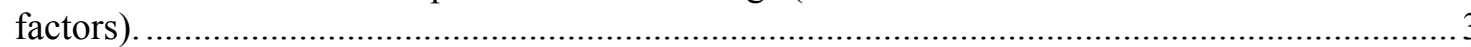

Table E-4. GHG emissions reduction for replacement of monitored vehicles (Jacksonville, North

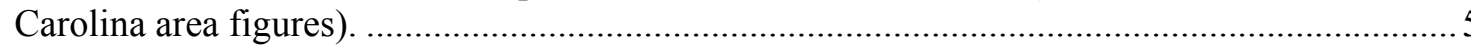

Table E-5. GHG emissions reduction for replacement of monitored vehicles (national figures)................5

Table E-6. MCIE group's full fleet PEV replacement reductions (Jacksonville, North Carolina

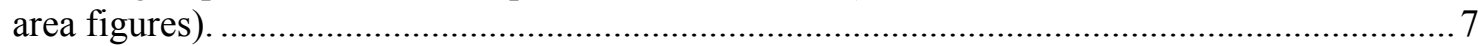

Table E-7. MCIE group's full fleet PEV replacement reductions (national figures)................................. 7

Table E-8. MCIE group's monitored vehicles average fuel savings values (North Carolina

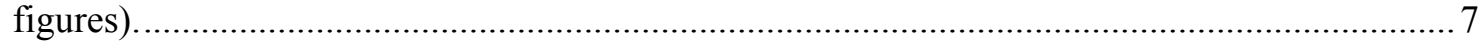

Table E-9. MCIE group's monitored vehicles average GHG savings values (North Carolina

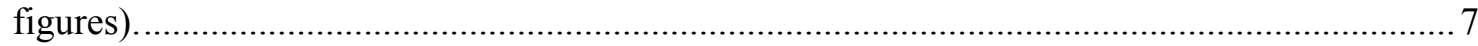




\section{ACRONYMS}

$\mathrm{AC} \quad$ alternating current

BEV battery electric vehicle

CD charge depletion

CS charge sustaining

DC direct current

EPA U.S. Environmental Protection Agency

EVSE electric vehicle supply equipment

GHG greenhouse gas emissions

GSA General Services Administration

ICE internal combustion engine

Intertek Intertek Testing Services, North America

MCBCL Marine Corps Base Camp Lejeune

MCIE Marine Corps Installations East

OEM original equipment manufacturer

PEV plug-in electric vehicle (includes BEVs and PHEVs, but not hybrid electric vehicles)

PHEV plug-in hybrid electric vehicle

SAE Society of Automotive Engineers

SUV sports utility vehicle 


\section{Utilization Assessment of Target Electrification Vehicles at Marine Corps Base Camp Lejeune: Task 3}

\section{INTRODUCTION}

The U.S. Department of Energy and the U.S. Department of Defense signed a memorandum of understanding on July 22, 2010, for strengthening the coordination of efforts to enhance national energy security and to demonstrate federal government leadership in transitioning the United States to a low-carbon economy. The memorandum of understanding included efforts in the areas of energy efficiency, fossil fuels, alternative fuels, efficient transportation technologies and fueling infrastructure, grid security, smart grid, and energy storage.

In support of the memorandum of understanding, the Idaho National Laboratory, with funding provided by the U.S. Department of Energy's Vehicle Technologies Office and Federal Energy Management Program, directed Intertek Testing Services, North America (Intertek) to conduct several U.S. Department of Defense-based studies to identify potential transportation systems that are strong candidates for introduction or expansion of plug-in electric vehicles (PEVs). Intertek previously has conducted similar fleet, city, state, and countrywide studies using their micro-climate assessment process, which consists of the following four main tasks:

- Task 1: Conduct a non-tactical fleet and infrastructure assessment

- Task 2: Select vehicles for mission and fleet characterizations

- Task 3: Perform detailed assessment of selected vehicles and charging infrastructure needs

- Task 4: Prepare adoption approach for PEV and charging infrastructure.

Assessment of the potential for replacing Marine Corps Base Camp Lejeune (MCBCL) fleet vehicles with PEVs starts with assessment of the fleet vehicles' missions and vehicle characteristics. This assessment was conducted through a thorough review of fleet records and discussions with MCBCL personnel. The Task 1 report titled, Assessment of Fleet Inventory for Marine Corps Base Camp Lejeune, dated January 2015, provided a summary and fleet assessment.

PEVs generally are classified into two vehicle types: battery electric vehicles (BEVs) and plug-in hybrid electric vehicles (PHEVs). A BEV contains an onboard battery that provides all motive power. PHEVs also have an onboard battery that provides some motive power, but this is supplemented by another power source (such as a gasoline engine). Collectively, BEVs and PHEVs are referred to as PEVs.

The Task 1 effort led to identification of fleet vehicles that appear to be good candidates for replacement by PEVs. The Task 2 report titled, Identification of Vehicles for Installation of Data Loggers for Marine Corps Base Camp Lejeune, dated February 2015, identified the 60 vehicles within the candidate groups for further monitoring and analysis through addition of vehicle data loggers. These data loggers were installed and data were collected on the selected vehicles. This Task 3 report provides a summary and details of that data collection effort. Assessment of the charging infrastructure is the subject of a separate report.

\section{METHODS}

\subsection{Fleet Vehicle Survey}

MCBCL and Intertek identified 60 vehicles for further study, as identified in the Task 2 report. This subset of vehicles contains four sedans, five minivans, nine sports utility vehicles (SUV), 28 pickup trucks, four cargo vans, eight passenger vans, and two specialty vehicles. This distribution is 
approximately representative of the entire non-tactical fleet. Figure 1 shows vehicle type distribution for all vehicles for comparison.

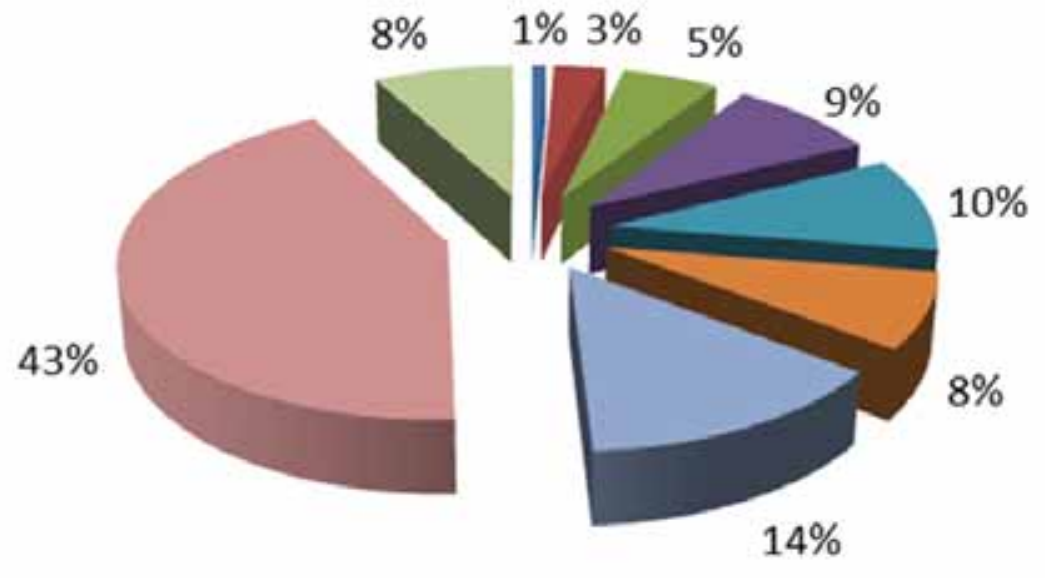

- Sedan - Compact

- Sedan - Midsize

E Sedan - Large

Minivan

SUV

- Van - Cargo

Van - Pass

Pickup

Specialty

Figure 1. Vehicle type distribution for all vehicles.

Figures 2 through 6 present comparisons of model year, cumulative distance driven, and monthly distance driven of the vehicles monitored to the full fleet. The figures show that the selected vehicles are representative of a wide range of vehicle and mission types.

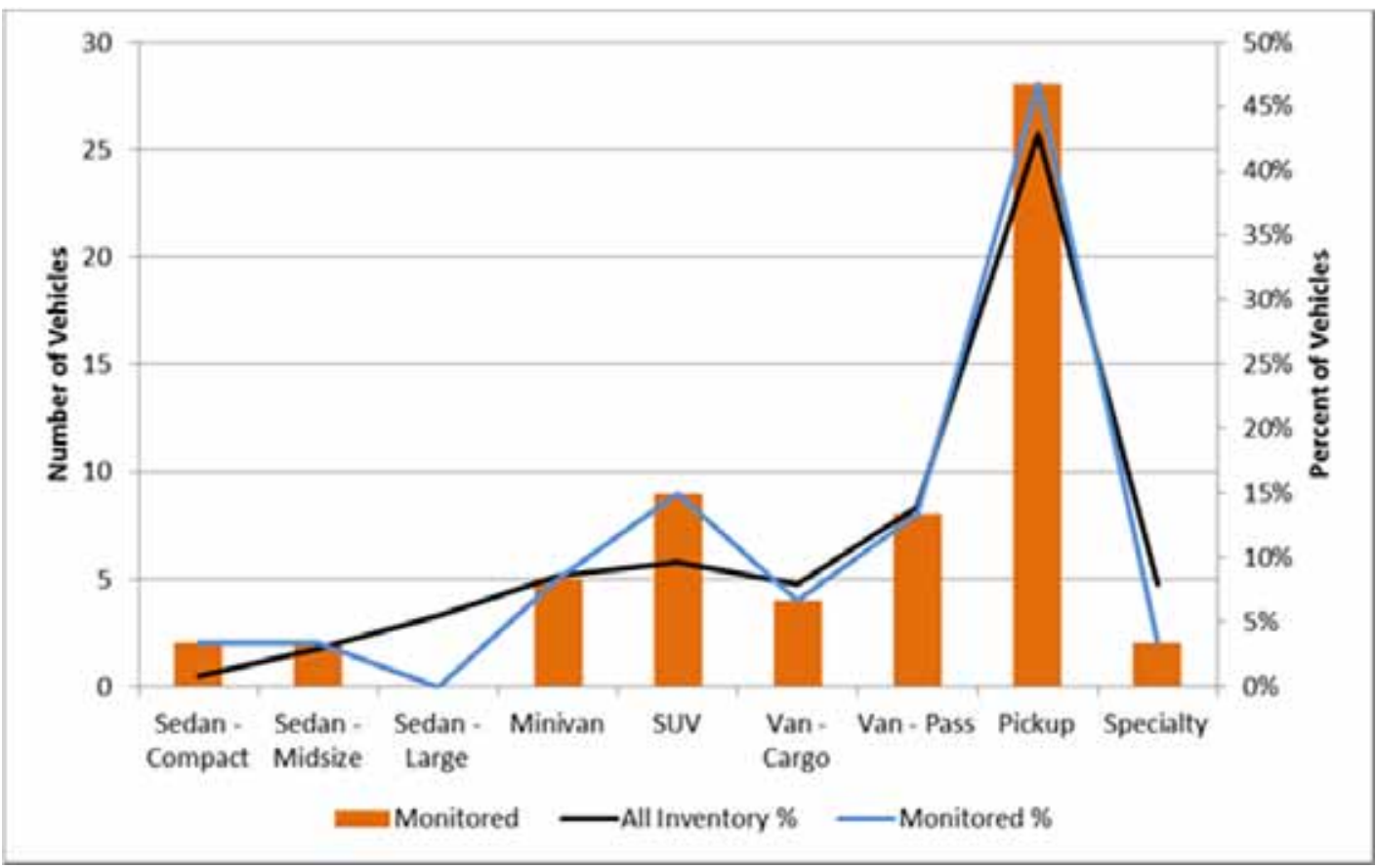

Figure 2. Vehicle types for vehicles with data loggers. 


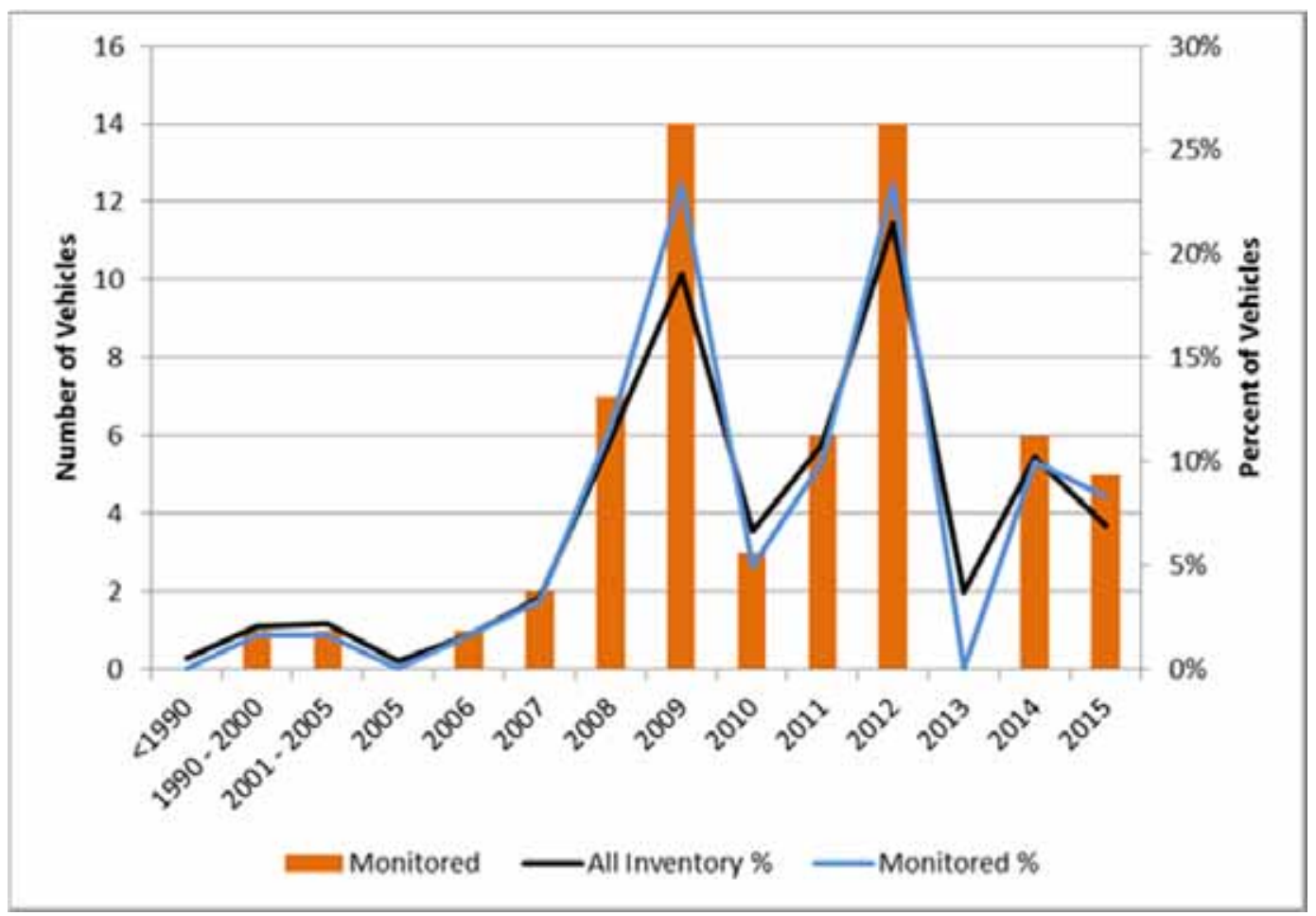

Figure 3. Model year for vehicles with data loggers.

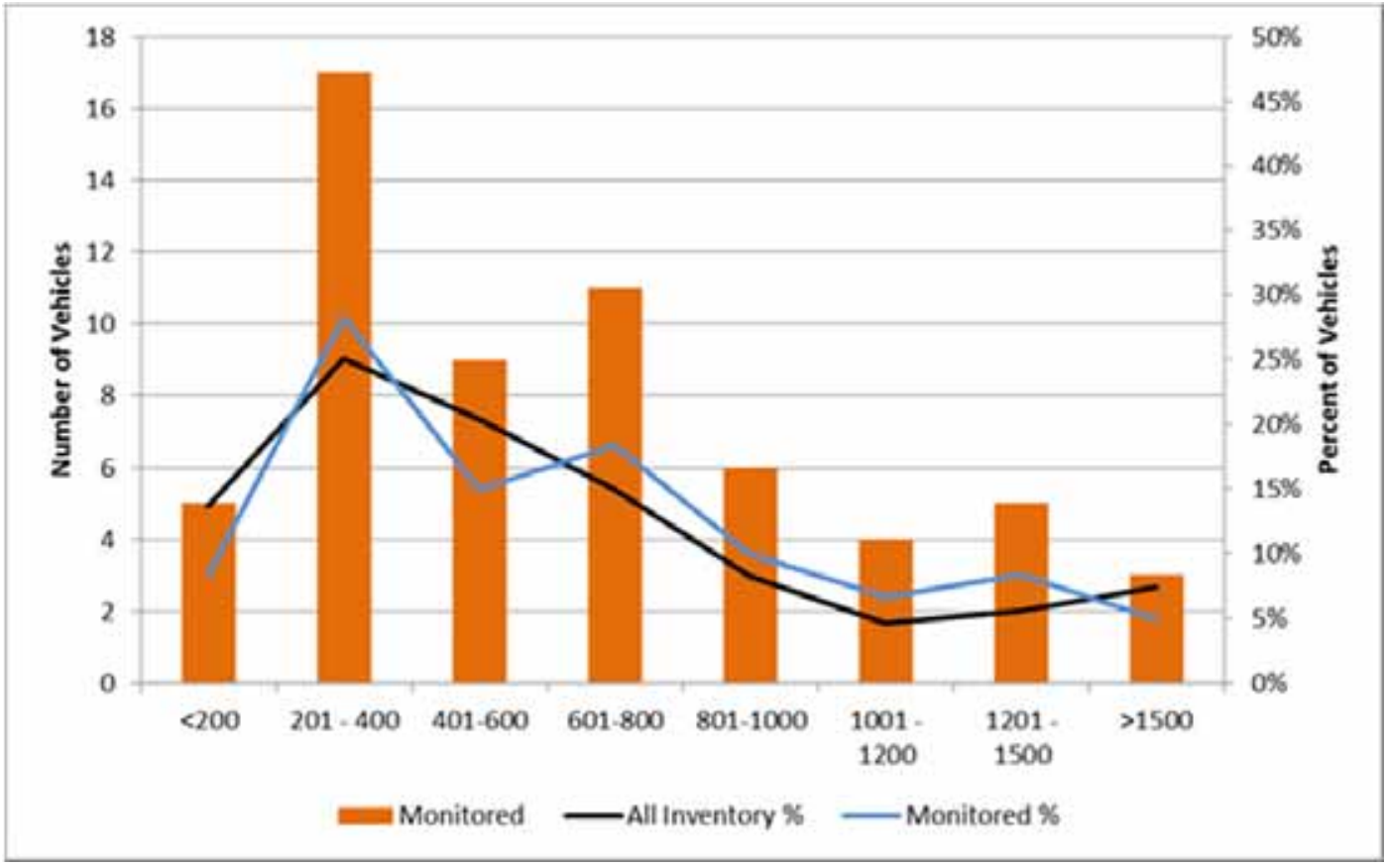

Figure 4. Monthly mileage for vehicles with data loggers. 


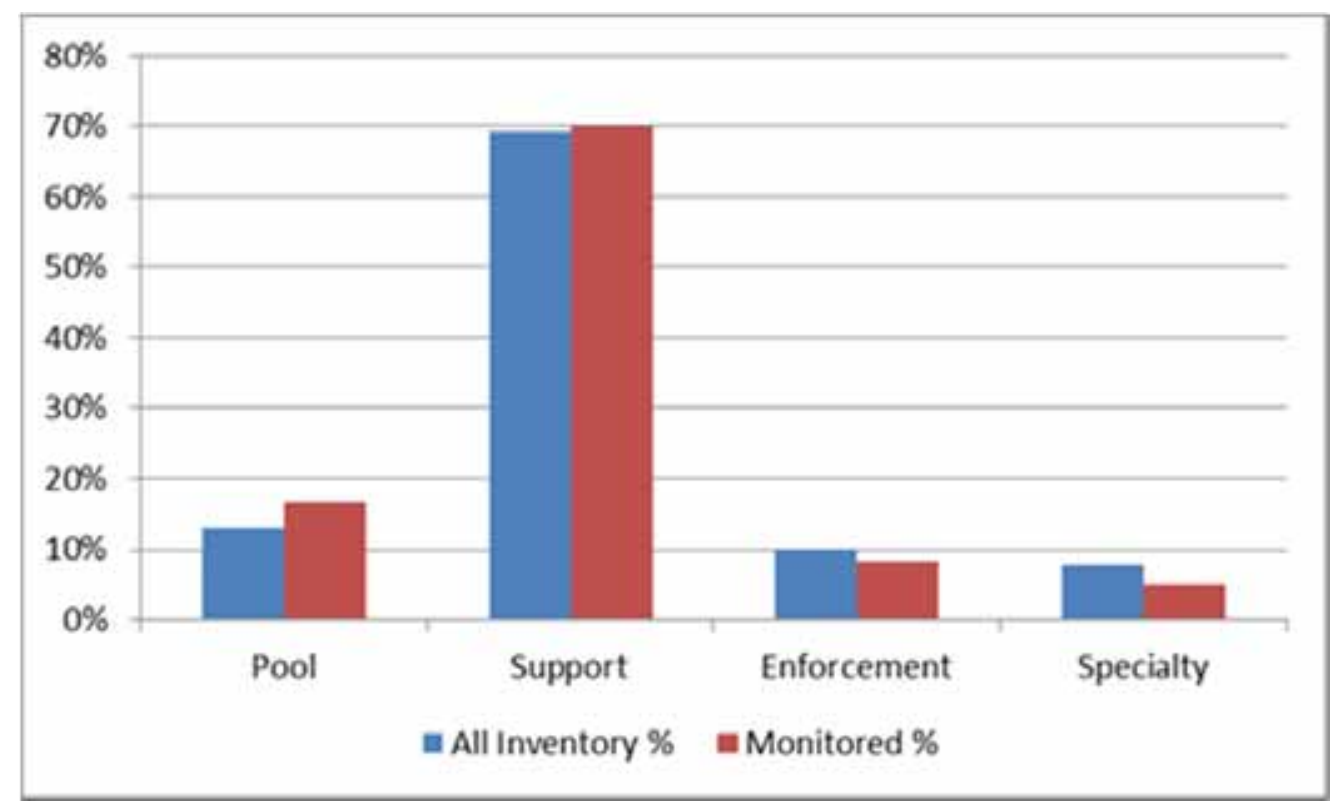

Figure 5. Vehicle mission for vehicles with data loggers.

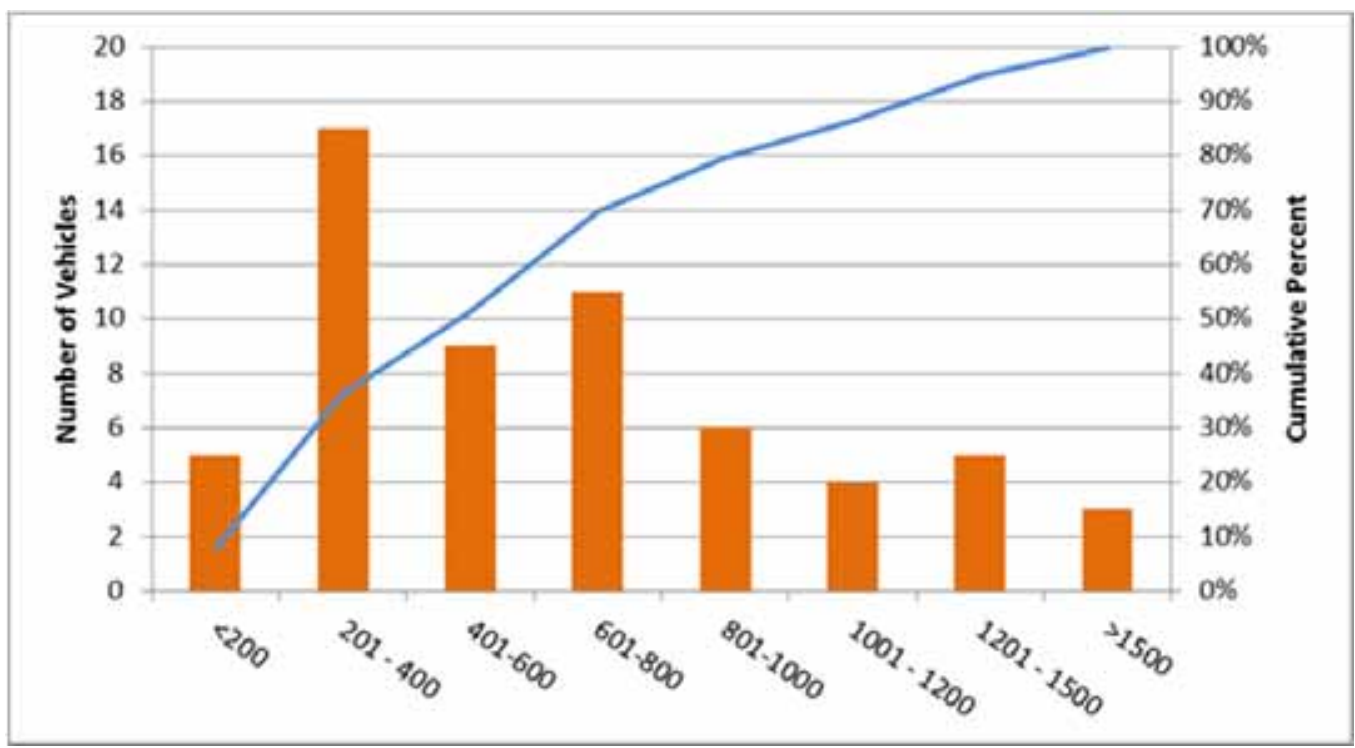

Figure 6. Distribution of monthly distance driven for vehicles with data loggers.

If one assumes a battery range of 70 miles for a BEV and 21 working days per month, then a vehicle that consistently travels the same distance each day would have to travel greater than approximately 1,500 miles per month to exceed the batter capacity. Fully $95 \%$ of the monitored vehicles average less than 1,500 miles per month in travel. This is the same percentage as the entire fleet inventory. Therefore, barring charging constraints associated with the timing of daily mission activities, payload requirements, and range issues associated with off-base trips, a significant number of vehicles should be eligible for replacement by BEVs.

MCBCL identified 784 fleet vehicles in its non-tactical, on-road fleet to be included in the study. Table 1 compares the monitored vehicles to the full fleet by mission type. (Note that Section 3 provides descriptions of the vehicle mission types.) 
Table 1. Fleet evaluation.

\begin{tabular}{lccc}
\multicolumn{1}{c}{ Vehicle Mission } & $\begin{array}{c}\text { Study } \\
\text { Vehicles }\end{array}$ & $\begin{array}{c}\text { Total Fleet } \\
\text { Reported }\end{array}$ & $\begin{array}{c}\text { Percentage } \\
\text { Studied }\end{array}$ \\
\hline Pool Vehicles & 10 & 98 & $10.2 \%$ \\
Support Vehicles & 43 & 548 & $7.8 \%$ \\
Enforcement Vehicles & 5 & 78 & $6.4 \%$ \\
Specialty Vehicles & 2 & 60 & $3.3 \%$ \\
Total Fleet Vehicles & 60 & 784 & $7.7 \%$ \\
\hline
\end{tabular}

Intertek coordinated with the MCBCL fleet management to identify the specific vehicles for inclusion in the study. The vehicle selections represent high-interest vehicles based on vehicle missions and vehicle type/class. Selection also favored a typical cross section of the full fleet. Because data loggers rely on the vehicle's battery power, non-use of the vehicle can result in the vehicle having a depleted battery. Intertek received no reports of depleted batteries during the study at MCBCL.

\subsection{Data Collection}

Individual privacy concerns existed when monitoring vehicle movement with data loggers. Data collection occurred through vehicle identification as identified by Intertek, data logger number, and agency-assigned vehicle number. Intertek received no information related to the vehicle operator and provided no raw data to the fleet managers. In this manner, Intertek did not collect, analyze, or report on individual driving habits.

\subsubsection{Data Logger}

Non-intrusive data loggers produced by InTouchMVC ${ }^{3}$ and depicted in Figure 7 were installed onto the vehicle's onboard diagnostic port to collect and transmit relevant data. Installation of the data logger and manual recording of information about the vehicle that tied the logger and vehicle together in the data typically took less than 5 minutes. Once installed and activated (during vehicle use), the data loggers transmitted vehicle information every minute during vehicle operation by cellular communication to the data center.

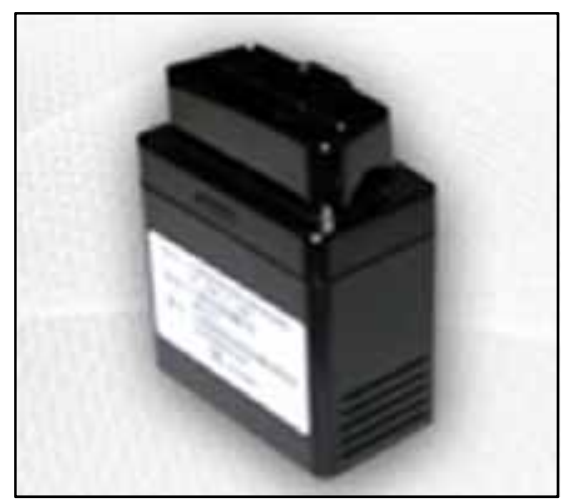

Figure 7. InTouchMVC data logger. ${ }^{4}$

Intertek maintained the data logger's connectivity and verified data transmission weekly. Missing data (reported as "null" values) were frequently the result of lost global positioning system reception, logger device removal, or extended periods in regions with insufficient cellular reception. Intertek filtered

${ }^{3}$ www.intouchmvc.com [accessed July 30, 2014].

${ }^{4}$ ibid. 
the vehicle and data logger information if these null values presented a significant impact on the data collected and no resolution was possible. This report also identified the statistics on this validation process.

MCBCL requested and installed 60 data loggers into their fleet. MCBCL removed and shipped the data loggers to Intertek at the conclusion of the data collection period.

\subsubsection{Data Captured}

Data consisted of key-on events, key-off events, and position updates logged every minute while the vehicle was keyed-on. InTouchMVC fleet reporting converted these data points into records of trip events, stop events, and idle events.

From these data points, the following information was available for evaluation:

- Trip start and stop time and location

- Trip distance and duration

- Idle start time, location, and duration

- Stop start time, location, and duration.

\subsection{Data Analysis}

\subsubsection{Definitions}

Figure 8 illustrates a vehicle outing, which is comprised of trips, stops, and idle events, that may occur over one day or several days. The following list provides a definition of these terms:

1. Outing: An outing is the combination of trips and stops that begin at the home base and includes all travel until the vehicle returns home.

2. Trip: A trip begins with a key-on event and ends with the next key-off event.

3. Vehicle stop: A vehicle stop includes a key-off/key-on event pair.

4. Idle time: Idle time is the amount of time a vehicle spends stationary after a key-on event when the vehicle is not moving for a period of 3 minutes or longer.

5. Trip travel time: Trip travel time is the amount of time required to complete a trip, excluding stops but including idle time.

Definitions of additional analysis and survey terms are as follows:

1. Operating shift: Fleet manager-defined period worked

2. Study days: Days during which the data loggers are connected

3. Vehicle days: Study days during which a vehicle is used

4. Null values: Data record unusable for analysis for various reasons.

\subsubsection{Data Evaluation}

Processing the data involved removal of null values and aggregation by different spatial and temporal scales. Aggregation was by day, by trip, and by outing to produce figures showing the patterns of use. Aggregation by vehicle mission followed to characterize use for the agency fleet. Section 4 presents these results. Data were extrapolated to provide overall fleet usage and benefit analysis when fleet information was provided. Section 5 presents these benefits. Intertek observations are included in Section 6. 


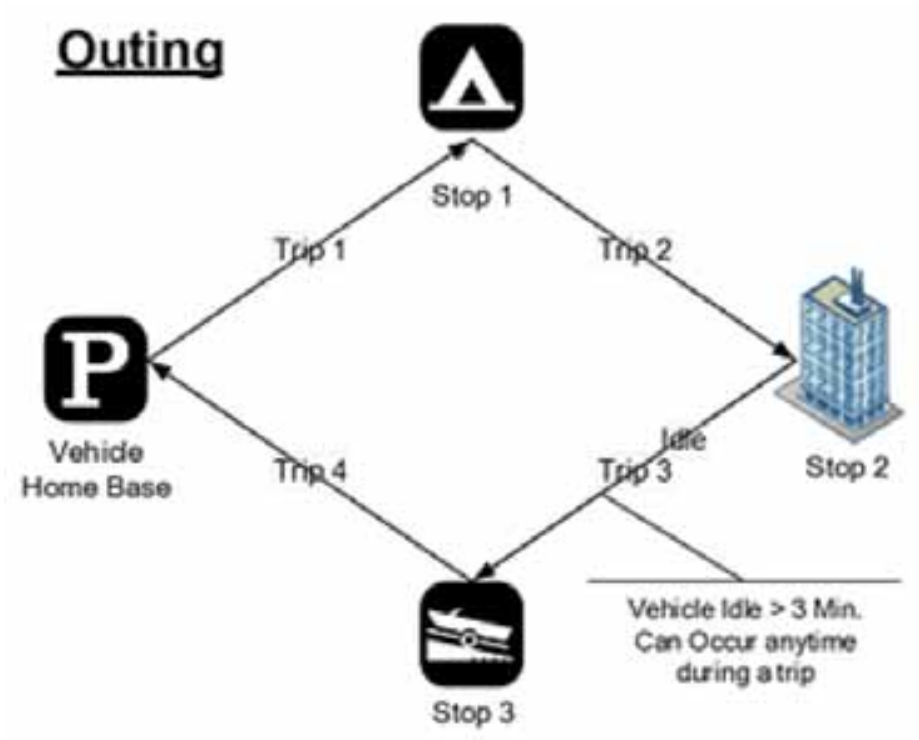

Figure 8. Example vehicle outing.

Statistical data analysis used Microsoft ${ }^{\circledR}$ Excel and Tableau ${ }^{\circledR}$ software. Frequency distributions summarized the travel behavior of each vehicle and vehicle mission during the study period. Rounding of the tables and figures were to three significant digits.

\section{VEHICLES}

\subsection{Vehicle Missions}

Vehicle mission was an important characteristic in the fleet study. Information used to define the vehicle mission included the vehicle's configuration, vehicle use, classification per 40 CFR Part 600.315-82 and the U.S. Environmental Protection Agency (EPA), the participating agency use, and generally understood vehicle uses. Based on fleet information gathered, Intertek established the following seven mission/vehicle categories for analysis, which are depicted in Figure 9:

1. Pool vehicles: A pool vehicle is any automobile (other than the low-speed vehicles identified below) manufactured primarily for use in passenger transportation, with not more than 10 passengers.

2. Enforcement vehicles: Vehicles specifically approved in an agency's appropriation act for use in apprehension, surveillance, police, or other law enforcement work. This category also includes site security vehicles, parking enforcement, and general use, but the vehicles are capable of requirements to support enforcement activities. Appendix A provides further definition.

3. Support vehicles: Vehicles assigned to a specific work function or group to support the mission of that group. Vehicles are generally passenger vehicles or light-duty pickup trucks and may contain after-market modifications to support the mission.

5. Transport vehicles: Light, medium, or heavy-duty trucks used to transport an operator and tools or equipment of a non-specific design or nature. The vehicle's uses include repair, maintenance, or delivery.

6. Specialty vehicles: Vehicles designed to accommodate a specific purpose or mission (such as ambulances, mobile cranes, and handicap access assistance).

7. Shuttles/buses: Vehicles designed to carry more than 12 passengers and further outlined in 49 CFR 532.2. 
8. Low-speed vehicles: Vehicles that are legally limited to roads with posted speed limits up to 35 or $45 \mathrm{mph}$ (depending on state law) and that have a limited load-carrying capability.

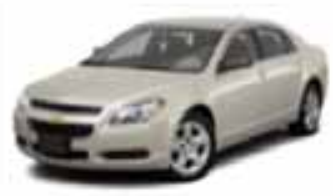

Pool Vehicle

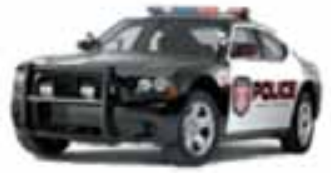

Enforcement Vehicle

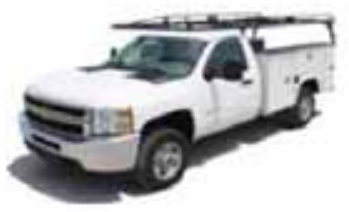

Support Vehicle

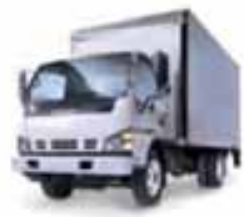

Transport Vehicle

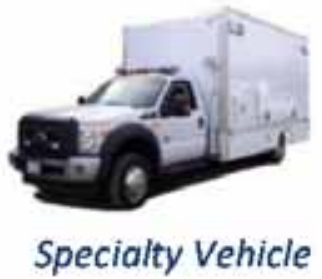

Specialty Vehicle

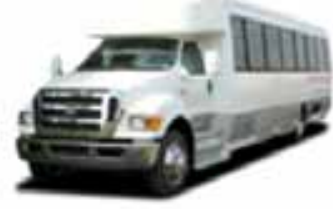

Shuttle / Bus

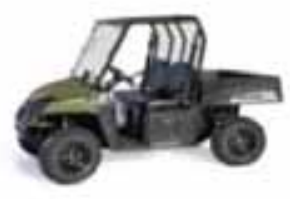

Low Speed

Figure 9. Vehicle missions.

\subsection{Alternative Fuel Vehicles}

As the operating agency, MCBCL has a unique opportunity to plan for adoption of BEVs and PHEVs, along with planning for supporting infrastructure. The adoption of PHEVs and BEVs is a primary goal of General Services Administration (GSA) and supports many directives in this area.

As GSA increases its certification of PHEVs and BEVs, agencies can plan for vehicle replacement through the GSA for passenger vehicles and trucks. Table 2 presents the replacement requirements for fleet vehicles. Note that both the age and mileage requirements need to be met in order for the vehicle to qualify for replacement, except where noted as "or."

Table 2. GSA vehicle replacement requirements.

\begin{tabular}{|l|c|c|c|}
\hline \multirow{3}{*}{ GSA Vehicle Replacement Requirements } \\
& Fuel Type & Years & Miles \\
\hline Passenger vehicles & Gasoline or & 3 & 36,000 \\
& alternative fuel & 4 & 24,000 \\
& vehicle & 5 & Any mileage \\
& & Any age & 75,000 \\
& Hybrid & 5 & Any mileage \\
& Low-speed BEV & 6 & Any mileage \\
\hline Light trucks 4 x 2 & Non-diesel & 7 or & 65,000 \\
& Diesel & 8 or & 150,000 \\
& Hybrid & 7 & Any mileage \\
\hline
\end{tabular}

\footnotetext{
${ }^{5}$ http://www.gsa.gov/graphics/fas/VehicleReplacementStandardsJune2011Redux.pdf [accessed January 10, 2014].
} 


\begin{tabular}{|l|c|c|c|}
\hline \multirow{4}{*}{ GSA Vehicle Replacement Requirements } \\
& Fuel Type & Years & Miles \\
\hline Light trucks 4 x 4 & Non-diesel & 7 or & 60,000 \\
& Diesel & 8 or & 150,000 \\
& Hybrid & 7 & Any mileage \\
\hline Medium trucks & Non-diesel & 10 or & 100,000 \\
& Diesel & 10 or & 150,000 \\
\hline Heavy Trucks & Non-diesel & 12 or & 100,000 \\
& Diesel & 12 or & 250,000 \\
\hline
\end{tabular}

\subsection{Battery Electric Vehicle and Plug-In Hybrid Electric Vehicle Benefits/Challenges}

BEVs are powered completely by the battery energy storage system onboard the vehicle. The Nissan Leaf is an example of a BEV. Because the BEV has no other energy source for propulsion, the range, power requirements, and mission of the needed vehicle factor greatly in purchasing decisions.

Maximizing BEV capabilities typically requires batteries more than an order of magnitude larger than the batteries in hybrid electric vehicles.

PHEVs obtain their power from two energy sources. The typical PHEV configuration uses a battery and an ICE and is powered by either gasoline or diesel. PHEV designs differ between manufacturers. All PHEVs have a charge-depleting (CD) mode, where the battery discharges its stored energy to propel the vehicle, and a charge-sustaining (CS) mode (or extended-range mode) that is entered after CD mode is complete, where the battery and ICE work together to provide propulsion and the state of charge of the battery is maintained between set limits. Some CD modes are purely electric, while other vehicle designers employ the engine to supplement the battery power during the initial battery depletion to a set state of charge (usually below 50\%).

\subsubsection{Battery Electric Vehicle Benefits/Challenges}

EPA identifies the following benefits and challenges of BEVs: ${ }^{6}$

- Energy efficient: Electric vehicles convert about 59 to $62 \%$ of electrical energy from the grid to power at the wheels, whereas conventional gasoline vehicles only convert about 17 to $21 \%$ of the energy stored in gasoline to power at the wheels.

- Environmentally friendly: PEVs emit no tailpipe pollutants, although the power plant producing the electricity may emit them. Electricity from nuclear, hydro, solar, or wind-powered plants causes no air pollutants.

- Performance benefits: Electric motors provide quiet, smooth operation and exhibit maximum torque at zero and low speeds, while also requiring less maintenance than ICEs.

- Reduce energy dependence: Electricity is a domestic energy source.

EPA also identifies challenges associated with BEVs, including the following:

- Driving range: Most BEVs can only travel about 100 to 200 miles (or less) before recharging, whereas gasoline vehicles can often travel over 300 miles before refueling and some much further.

- Recharge time: Fully recharging the battery pack can take 4 to 8 hours. Even a "fast charge" to $80 \%$ capacity can take 30 minutes.

${ }^{6}$ http://www.fueleconomy.gov/feg/evtech.shtml [accessed December 27, 2013]. 
- Battery cost: The large battery packs are expensive and may need to be replaced one or more times.

- Bulk and weight: Battery packs are heavy and take up considerable vehicle space.

\subsubsection{Plug-In Hybrid Electric Vehicle Benefits/Challenges}

EPA identifies the following benefits and challenges of PHEVs: ${ }^{7}$

- Less petroleum use: PHEVs are expected to use about 40 to $60 \%$ less petroleum than conventional vehicles. Because electricity is produced primarily from domestic resources, PHEVs reduce dependence on oil.

- Fewer GHG emissions: PHEVs are expected to emit fewer GHG emissions than conventional vehicles, but, as with BEVs, the difference depends largely on the type of power plant supplying the electricity.

- Higher vehicle costs, lower fuel costs: PHEVs will likely cost $\$ 1,000$ to $\$ 7,000$ more than comparable non-PHEVs. Fuel will cost less because electricity is much cheaper than gasoline, but the fuel savings depends on how much of the driving is done with off-board electrical energy.

- Recharging takes time: Recharging the battery typically takes several hours. However, PHEVs do not have to be plugged in to be driven. They can be fueled solely with gasoline, but will not achieve maximum range, fuel economy, or fuel savings without charging.

- Measuring fuel economy: Because a PHEV can operate on electricity alone, gasoline alone, or a mixture of the two, EPA provides a fuel economy estimate for gasoline-only operation (CS mode), electric-only operation (all-electric CD mode), or combined gasoline and electric operation (blended CD mode).

In most cases, the PEV's retail cost is higher than a non-PEV model. This incremental purchase cost may be a fleet budget challenge; however, many original equipment manufacturers (OEMs) have offered incentives to encourage the use and adoption of BEVs and PHEVs. Some OEMs have recently reduced the vehicle cost, while also increasing vehicle range. Additionally, federal and state incentives have increased the attractiveness of purchasing a PEV. A common assumption is that increasing PEV sales will result in a reduction in this incremental purchase cost and a positive feedback loop will ensue.

\subsection{Plug-In Electric Vehicle Availability}

GSA provides a summary of the light and medium-duty passenger vehicles that are available for lease or purchase through the GSA portal, ${ }^{8}$ although not all BEVs and PHEVs currently on the market are 'certified' to be GSA replacements. Vehicles not on the GSA list of 'certified' vehicles require an agency to self-certify a functional need or alternative measures for exemptions. Tables 3 and 4 summarize the vehicles that may be suitable replacements and are certified replacements through GSA. Note that the "CD/CS" column provides the EPA fuel economy values for CD and CS modes. The fuel economy of CD mode is provided in units of miles-per-gallon-of-gasoline-equivalent (MPGe). This metric allows for electricity consumption during CD mode to be compared with fuel consumption during CS mode (or against conventional vehicles). The Nissan Leaf and Mitsubishi i-MiEV are not included in the alternative fuel guide for 2015, but they have appeared in previous guides.

Replacement is dependent on vehicle configuration characteristics and vehicle mission. Further evaluation related to vehicle purpose, mission, and need should be completed.

\footnotetext{
${ }^{7}$ http://www.fueleconomy.gov/feg/phevtech.shtml [accessed July 19, 2013].

${ }^{8}$ http://www.gsa.gov/portal/content/104211 [accessed August 1, 2014].
} 
Table 3. GSA-certified PHEVs for 2014.

\begin{tabular}{lcccc}
\multicolumn{1}{c}{ Make/Model } & GSA Class & Type & CD/CS & GSA Incremental Price \\
\hline Chevrolet Volt* & Sedan, Subcompact & PHEV & $98 \mathrm{MPGe} / 37 \mathrm{mpg}$ & $\$ 17,692.17$ \\
Ford C-MAX Energi & Sedan, Subcompact & PHEV & $88 / 38 \mathrm{mpg}$ & $\$ 14,062.23$ \\
Ford Fusion Energi & Sedan, Compact & PHEV & $88 / 38 \mathrm{mpg}$ & $\$ 13,640.05$ \\
\hline
\end{tabular}

* The Chevrolet Volt has an all-electric CD mode rated for 38 miles. The Ford vehicles have blended CD modes rated for 20 miles.

Table 4. GSA-certified BEVs.

\begin{tabular}{lcccc}
\multicolumn{1}{c}{ Make/Model } & GSA Class & Type & City/Highway & GSA Incremental Price \\
\hline Ford Focus Electric & Sedan, Subcompact & BEV & $110 / 99 \mathrm{MPGe}$ & $\$ 11,351.15$ \\
Smart Fortwo ED & Sedan, Microcompact & BEV & $123 / 93 \mathrm{MPGe}$ & $\$ 7,277.05$ \\
\hline
\end{tabular}

OEMs provide information related to a vehicle's range in CD mode and EPA provides test results. However, actual results may vary depending on several factors other than travel that may also deplete a vehicle's battery. These factors include changes in the battery's capacity over time, area topography, weather conditions (e.g., cabin cooling/heating), and payload. This report will identify a BEV's "safe range" as 70 miles because this is typically less than the advertised range of most BEV OEMs. PHEV's advertised ranges vary from 6 miles to 72 miles. The average range of PHEVs currently available is about 33 miles. This report will identify the PHEV safe range in CD mode as 30 miles.

Tables 5 through 8 provide summaries of PHEVs and BEVs either currently available or near commercialization in both passenger cars and pickup trucks, but that do not appear on the GSA 'certified' vehicle list. These vehicles may qualify for use by the agency through demonstrating a functional need.

Note that EPA differs in vehicle class. EPA identifies the Volt as a compact, the C-MAX Energi as a midsize, the Fusion Energi as a midsize, and the Focus as a compact. ${ }^{9}$

Table 5. OEM PHEV cars and availability.

\begin{tabular}{lccc}
\multicolumn{1}{c}{ Make } & EPA Class & Model & $\begin{array}{c}\text { Initial Model Year/Estimated } \\
\text { Year for Commercialization }\end{array}$ \\
\hline Chevrolet & Compact & Volt & 2011 \\
Ford & Midsize & C-MAX Energi & 2013 \\
Ford & Midsize & Fusion Energi & 2013 \\
Toyota & Midsize & Prius PHEV & 2012 \\
Honda & Midsize & Accord PHEV* & 2014 \\
Cadillac & Subcompact & ELR & 2014 \\
Porsche & Large & Panamera S E-Hybrid & 2014 \\
BMW & Subcompact & i3 REx & 2014 \\
BMW & Subcompact & i8 & 2014 \\
Hyundai & Midsize & Sonata PHEV & 2015 (estimate) \\
Audi & Compact & A3 e-tron & 2016 (estimate) \\
Mercedes & Subcompact & C350 PHEV & 2016 (estimate) \\
Mercedes & Large & S550 PHEV & 2016 (estimate) \\
\hline
\end{tabular}

* Honda did not release an MY2015 Accord PHEV; the return of this vehicle model is uncertain.

\footnotetext{
${ }^{9}$ http://www.fueleconomy.gov/feg/Find.do?action=sbs\&id=34130 [accessed August 1, 2014].
} 
Table 6. OEM BEV cars and availability.

\begin{tabular}{lccc}
\multicolumn{1}{c}{ Make } & EPA Class & Model & $\begin{array}{c}\text { Initial Model Year/Estimated } \\
\text { Year for Commercialization }\end{array}$ \\
\hline Nissan & Midsize & Leaf & 2011 \\
Ford & Compact & Focus Electric & 2012 \\
Tesla & Large & Model S & 2012 \\
Mitsubishi & Subcompact & i-MiEV* & 2012 \\
Fiat & Mini & $500 \mathrm{e}$ & 2013 \\
Honda & Small Station Wagon & Fit EV & 2013 \\
smart & Two Seater & Fortwo ED & 2013 \\
BMW & Subcompact & i3 & 2014 \\
Chevrolet & Subcompact & Spark EV & 2014 \\
Kia & Small Station Wagon & Soul EV & 2014 \\
Volkswagen & Compact & e-Golf & 2015 \\
Mercedes-Benz & Midsize & B-Class Electric Drive & 2015 \\
\hline
\end{tabular}

* Mitsubishi did not manufacture an MY15 i-MiEV; the vehicle returned in the $2016 \mathrm{MY}$.

Table 7. OEM PHEV trucks, vans, and availability.

\begin{tabular}{|c|c|c|c|}
\hline Make & EPA Class & Model & $\begin{array}{l}\text { Initial Model Year/Estimated } \\
\text { Year for Commercialization }\end{array}$ \\
\hline Via & Standard Pickup Truck & VTRUX VR300 & 2013 \\
\hline Via & Special Purpose Vehicle & VTRUX Cargo Van & 2013 \\
\hline Via & Vans, Cargo Type & VTRUX Pass Van & 2013 \\
\hline Mitsubishi & Small SUV & Outlander PHEV & 2016 (estimate) \\
\hline
\end{tabular}

Table 8. OEM BEV trucks, vans, and availability.

\begin{tabular}{cccc} 
& & & Initial Model Year/Estimated \\
Make & EPA Class & Model & Year for Commercialization \\
\hline Tesla & Standard SUV & Model X & 2015 (estimate) \\
Nissan & Van & e-NV200 & 2016 (estimate) \\
\hline
\end{tabular}

As further indication of the expanding market for PEVs, companies are offering after-market vehicle upgrades involving the addition of plug-in capabilities to OEM vehicles. For example, Echo Automotive headquartered in Scottsdale, Arizona offers a "...low-cost, bolt-on, plug-in hybrid system that can quickly be installed on new or existing fleet vehicles to increase fuel efficiency and decrease operating costs - all without affecting the OEM power train or requiring costly infrastructure." ${ }^{\prime 10}$ EVAOS conducts conversions of Ford F-series pickup trucks to PHEV models and has delivered vehicles to the U.S. Air Force. ${ }^{11}$ Options such as this company's conversions might be of benefit to the passenger vans identified in the MCBCL fleet, but for which no replacement PEV is currently available.

${ }^{10} \mathrm{http}: / /$ www.echoautomotive.com/index.php?option=com content\&view=article\&id=8 [accessed July 14, 2014].

${ }^{11} \mathrm{http} / / / w w w . e v a o s . c o m ~[a c c e s s e d ~ N o v e m b e r ~ 20,2014]$. 


\subsection{Plug-In Electric Specialty Vehicles}

Section 3 identifies specialty vehicles as those vehicles designed to accommodate a specific purpose or mission (such as ambulances, mobile cranes, and handicap access assistance). Many specialty vehicles involve heavy-duty truck frames with high power requirements. For MCBCL, specialty vehicles included fire trucks (e.g., ladder trucks and pumpers), rescue vehicles, tankers, mobile cranes, and bucket trucks. MCBCL specifically requested monitoring of some specialty vehicles; a bucket truck and a refrigeration truck were selected. The refrigeration truck recorded no usage during the study period.

Some specialty vehicle manufacturers and some offering after-market modifications provide battery-powered operation of the tools and accessories. For this study, only those specialty vehicles whose motive power is provided at least partly by electric drive are considered.

Recently, Pacific Gas and Electric Company displayed a new plug-in hybrid Class 5 Ford F-550 bucket truck. ${ }^{12}$ This vehicle's hybrid system was designed and built by Efficient Drivetrains Inc. The 20,000-pound vehicle is reported to provide more than 35 miles of all-electric driving range at a highway speed of over 65 miles per hour and is capable of exporting $120 \mathrm{~kW}$ of AC power. For illustration, this specialty vehicle is included for analysis in Sections 4 and 5. Figure 10 shows specialty trucks converted to PHEVs by Efficient Drivetrains Inc.

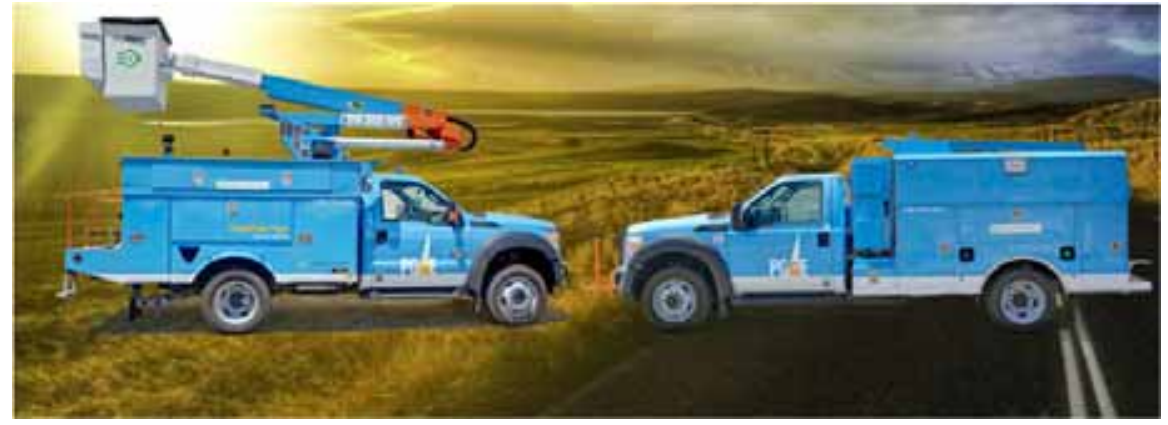

Figure 10. Specialty vehicles with electric drive. ${ }^{13}$

\subsection{Plug-In Electric Vehicle Charging}

Refueling electric vehicles presents some challenges and some opportunities not encountered when refueling petroleum-fueled vehicles. Recharging the battery of a PHEV follows the same methodology as that for BEVs. This section provides basic information on recharging PEVs.

\subsubsection{Electric Vehicle Supply Equipment Design}

3.6.1.1 Charging Components. Electric vehicle supply equipment (EVSE) stations deliver electric power from the utility to the applicable charge port on the vehicle. Figure 11 illustrates the primary components of a typical alternating current (AC) Level 2 EVSE.

The electric utility delivers AC current to the charging location. The conversion from AC to the direct current (DC) electricity necessary for battery charging can occur either on or off board the vehicle. Section 3.5.1.2 provides further explanation of the different EVSE configurations. For onboard conversion, AC current flows through the PEV inlet to the onboard charger. The charger converts AC to the DC current required to charge the battery. A connector attached to the EVSE inserts into a PEV inlet to establish an electrical connection to the PEV for charging and information/data exchange. Off-board

\footnotetext{
${ }^{12}$ Powerful Plug-Ins, Charged Electric Vehicle Magazine, March/April 2015, pp.60.

${ }^{13}$ www.efficientpowertrains.com [accessed August 1, 2015].
} 
conversion, also known as DC charging, proceeds in a similar manner except that the AC to DC conversion occurs in a charger that is off board the vehicle and, thus, bypasses any onboard charger. For both AC and DC charging, the PEV's battery management system on board the vehicle controls the battery rate of charge, among other functions. All current PEVs have an onboard charger; some BEVs (but no PHEVs currently available in the United States) accommodate DC charging.

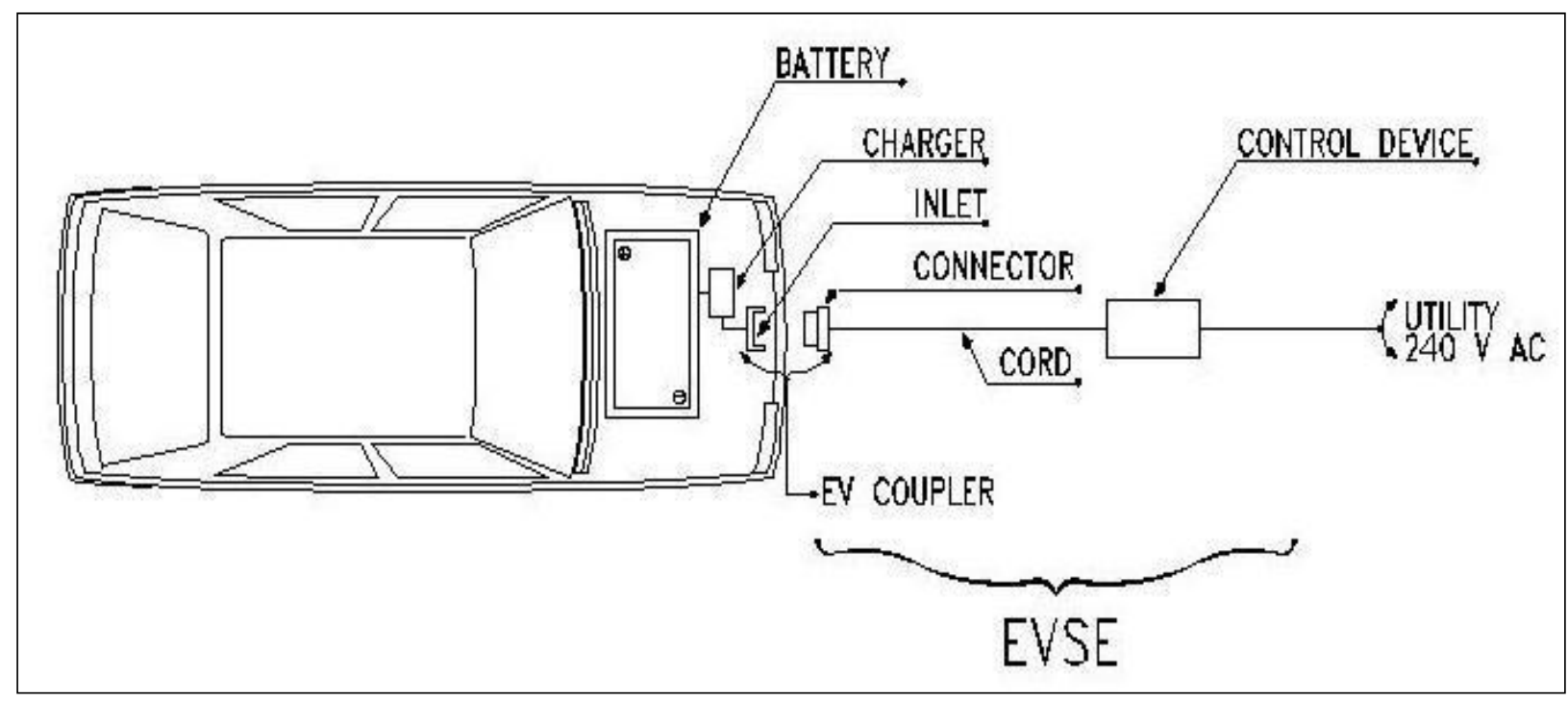

Figure 11. AC Level 2 charging diagram. ${ }^{14}$

3.6.1.2 Charging Configurations and Ratings. The Society of Automotive Engineers (SAE) standardized the requirements, configurations, and equipment followed by most PEV suppliers in the United States in the $\mathrm{J} 1772^{\mathrm{TM}}$ Standard. Figure 112 summarizes these attributes and the estimated recharge times. Actual recharge times depend on the onboard equipment, including the charger, battery, and battery management system.

PEVs are typically sold with an AC Level 1 cordset included. This cordset is generally intended to be used when a 120-volt electrical outlet is available (and a slower charge rate is acceptable) or in emergencies when the vehicle is away from installed AC Level 2 EVSE. A typical cordset is shown in Figure 13.

$\mathrm{AC}$ recharging capabilities found in the public arena more typically are AC Level 2. Figure 14 depicts a typical J1772-compliant inlet and connector for both AC Levels 1 and 2.

The J1772 standard also identifies requirements for DC charging. For PEVs that accept both AC and DC inputs, the SAE approved a single connector and inlet design, known as the combined charging system. Figure 115 shows this connector, which is colloquially known as the J1772 "combo connector."

Some BEVs delivered in the United States prior to the approval of the J1772 standard for DC charging employed the CHAdeMO (designed in Japan) standard for connector and inlet design. Figure 16 shows this connector. DC EVSE units that are either J1772-compliant or CHAdeMO-compliant are both known as DC fast chargers (DCFCs). Tesla Motors has installed proprietary EVSE units for their vehicles because these vehicles do not meet either DCFC standard; however, Tesla offers adapters for their vehicles that allow for charging at J1772 AC Level 2 and CHAdeMO EVSE.

\footnotetext{
${ }^{14}$ http://www.theevproject.com/downloads/documents/Electric\%20Vehicle\%20Charging\%20Infrastructure\%20Deployment $\% 20$
} Guidelines\%20for\%20the\%20Greater\%20Phoenix\%20Area\%20Ver\%203.2.pdf [accessed January 15, 2014]. 


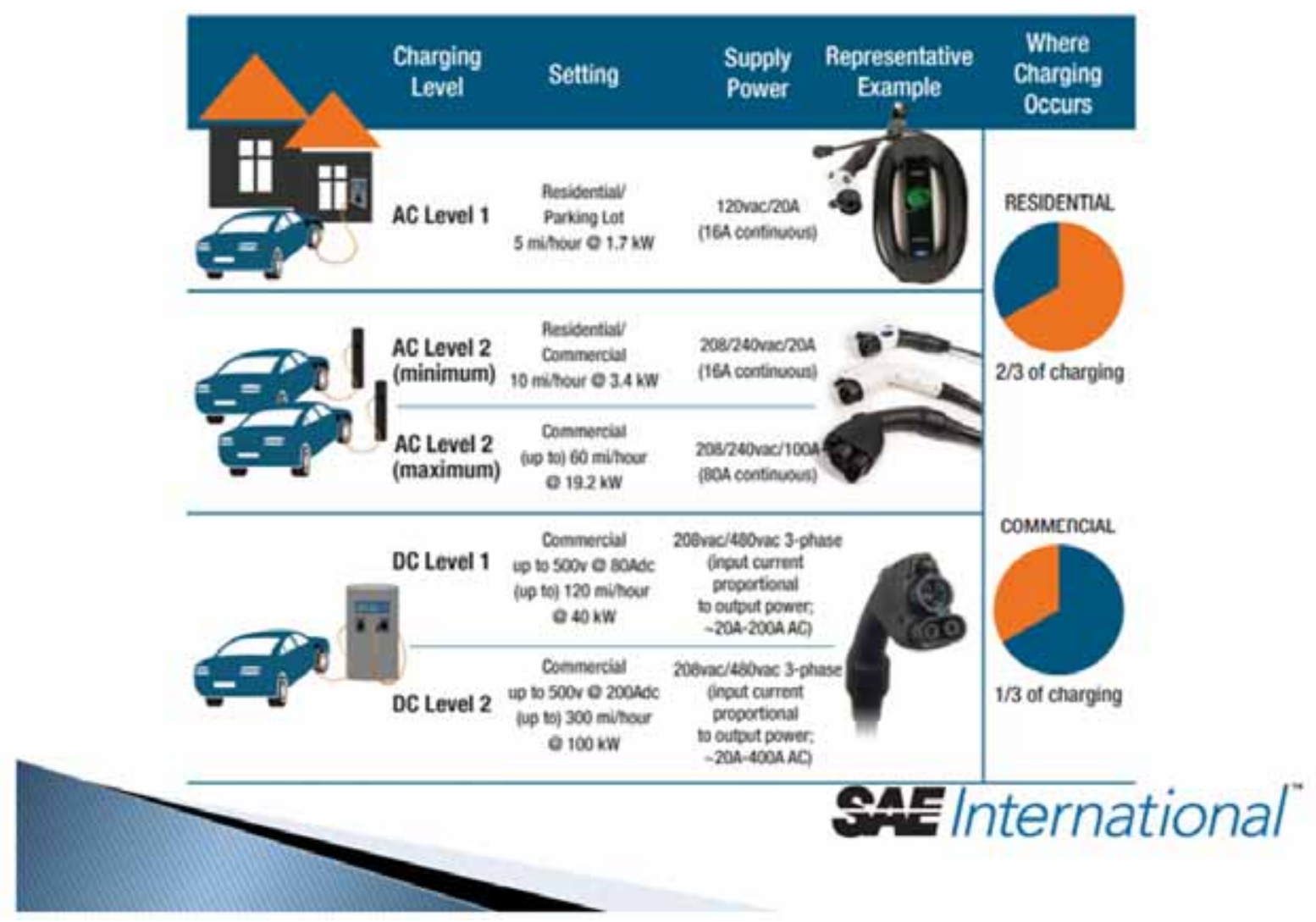

Figure 12. SAE charging configurations and ratings terminology. ${ }^{15}$

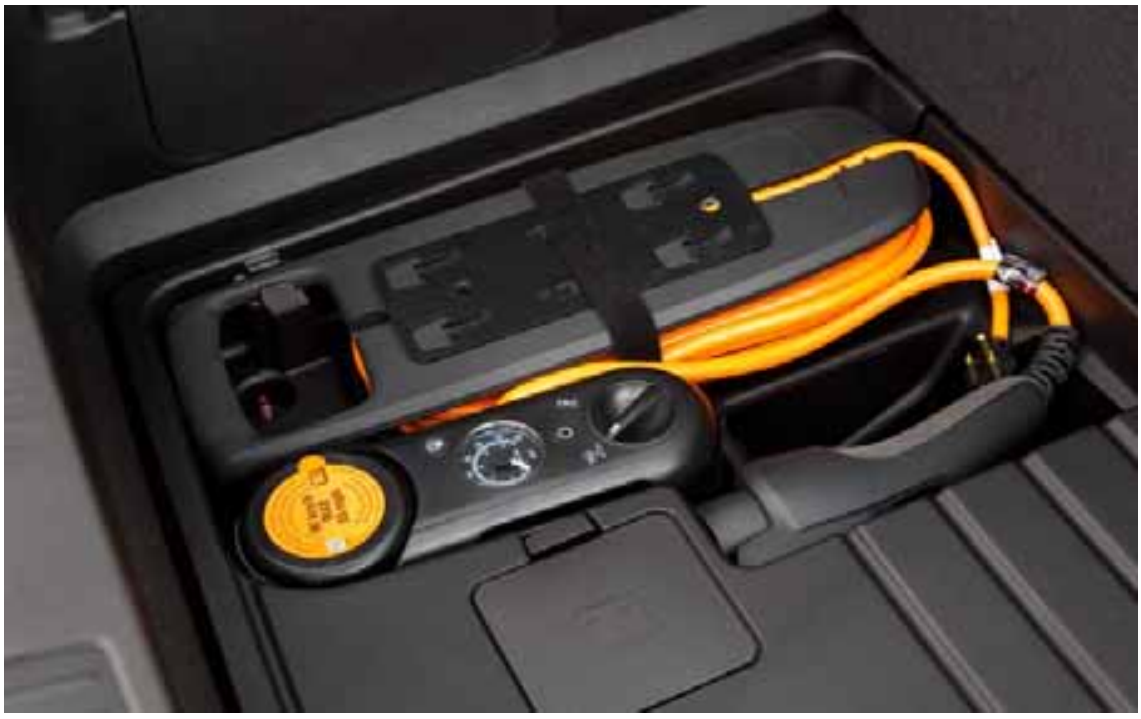

Figure 13. Chevrolet Volt AC Level 1 cordset. ${ }^{16}$

\footnotetext{
${ }^{15}$ http://www.sae.org/events/gim/presentations/2013/pev charging_standards status.pdf [accessed June 25, 2015].

${ }^{16}$ www.pluginamerica.org.
} 


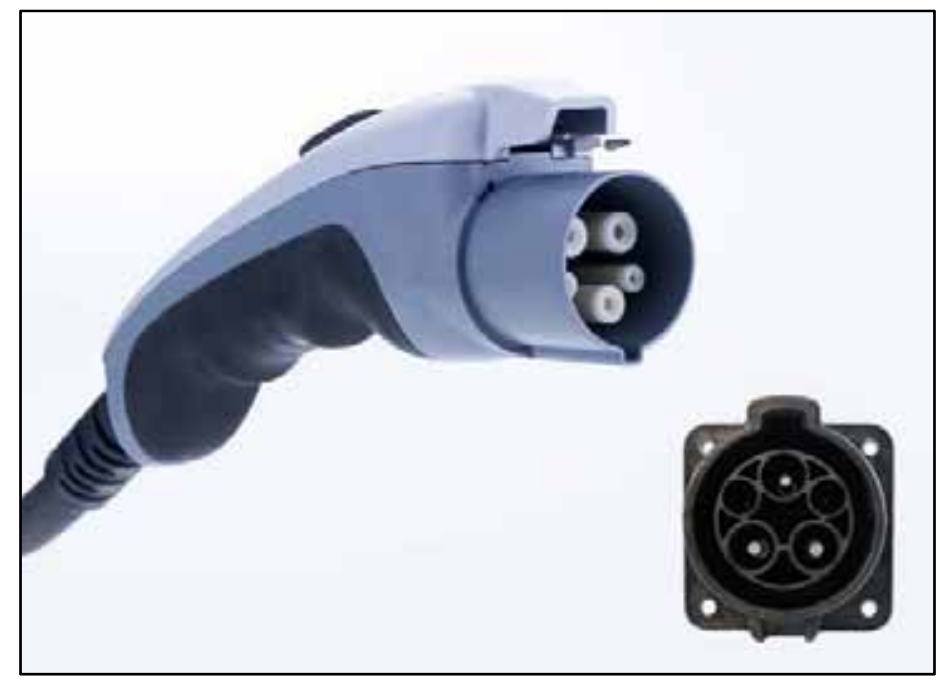

Figure 14. J1772 connector and inlet. ${ }^{17}$
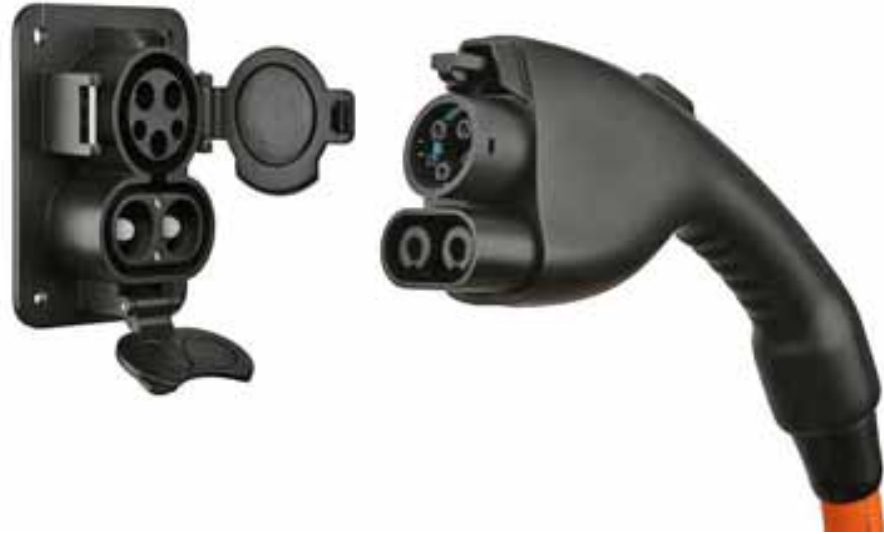

Figure 15. J1772-compliant combo connector. ${ }^{18}$

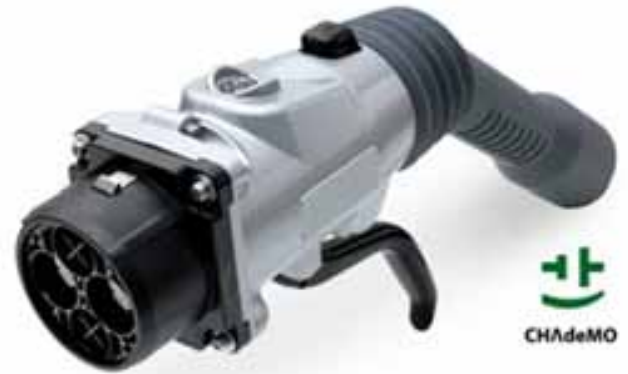

Figure 16. CHAdeMO-compliant connector. ${ }^{19}$

\footnotetext{
${ }^{17}$ http://carstations.com/types/j09 [accessed January 15, 2014].

${ }^{18}$ http://www.zemotoring.com/news/2012/10/sae-standardizes-j1772-fast-dc-charging-up-to-100-kw [accessed January 15, 2014].
} 
The presence of three separate standards for DC charging presents challenges for vehicle owners to ensure the EVSE that is accessed provides the appropriate connector for their vehicle inlet. Not all PEV suppliers include DC charging options. BEV suppliers have provided DC inlets where PHEV suppliers have not, because the rapid recharging provides opportunities for expanded vehicle range with minimal operator wait times. PHEV operators can rely on the gasoline drive in the event they deplete the vehicle's battery (and for comparison to the energy transfer of the charge rate, the energy being added by the gasoline pump is about $10 \mathrm{MW}$ ). At present, no PHEV on the market or near commercialization has DC charging capability (although the upcoming Mitsubishi Outlander PHEV may offer DC charging capability as an option).

Because the battery of a BEV is typically much larger than that of a PHEV, recharge times are longer (see Figure 12). BEVs that see daily mileage near the limits of the advertised range do better when recharged using AC Level 2 EVSE or DCFC, because AC Level 1 recharge times are usually extensive. PHEVs, on the other hand, generally can use AC Level 1 EVSE for overnight charging to ensure a fully charged battery at the start of daily use. AC Level 2 EVSE units provide greater range in the shortest amount of time when intermediate or opportunity charging. DCFC provides the fastest recharge capability for those vehicles equipped with DCFC inlets.

\subsubsection{Electric Vehicle Supply Equipment Stations}

AC Level 2 charging is the predominant rating of publicly accessible EVSE because of its wide acceptance by auto manufacturers and faster recharge times than AC Level 1. Purchase and installation costs are more manageable than DCFCs and less space is required. There are several manufacturers of AC Level 2 equipment and the agency should review brands for comparison purposes. Figure 17 provides an example of a public AC Level 2 EVSE unit. ${ }^{20}$

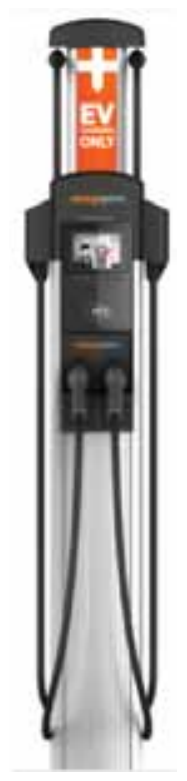

Figure 17. Public AC Level 2 unit.

\footnotetext{
${ }^{19}$ https://radio.azpm.org/p/azspot/2012/5/10/1632-electric-cars/ [accessed January 15, 2014].

${ }^{20} \mathrm{http}: / /$ www.chargepoint.com/files/73-001061-01-2_BR-CT4000-01.pdf [accessed March 7, 2015].
} 
DCFCs also are available from several manufacturers. Figure 18 illustrates one such charger. ${ }^{21}$ This particular unit uses the CHAdeMO connector standard.

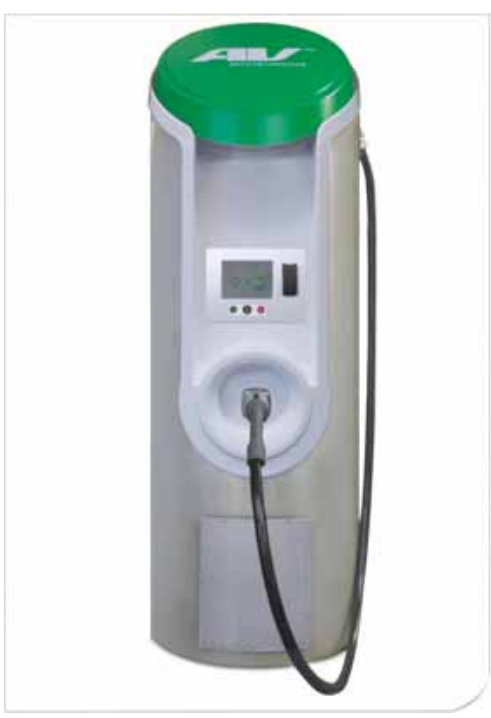

Figure 18. Public DCFC unit.

In general, installation costs are higher for DCFC because of the higher voltage requirements and the inclusion of the $\mathrm{AC}$ to DC converter and other safety and design features. Costs for both types are highly dependent on site characteristics such as distance to the nearest power source, asphalt or concrete cutting and repair, conduit requirements, and payment systems, if any.

Payment and equipment control systems included by some suppliers provide the potential for use by privately owned vehicles for a fee, but allow agency fleet vehicle use without direct payment. These systems allow for accurate record keeping of vehicle charging requirements.

\section{MARINE CORPS BASE CAMP LEJEUNE ANALYSIS}

Sixty vehicles belonging to the tenant commands (i.e., Commands) group and the Marine Corps Installations East (MCIE) group were included in the study at MCBCL. Analysis by user was conducted first and was followed by aggregating across all users and vehicles. The Commands and MCIE groups used the fleet vehicles for a variety of purposes. The Commands group includes II Marine Expeditionary Force, 2nd Marine Division, 2nd Marine Logistics Group, and the naval hospital to name a few. MCIE owns all real estate, hosts entry level and career-level formal schools, and provides support and training for tenant commands.

\subsection{Analysis Results - Commands}

This section summarizes and aggregates data collection for the Commands group. The details of each vehicle monitored are included in Appendix B.

The Commands group operates 249 of the fleet vehicles, with 18 of those vehicles included as the monitored vehicles. Table 9 provides a summary of all vehicles in this fleet by mission type and vehicle type. The monitored vehicles included two minivans, three SUVs, six passenger vans, and seven pickup trucks. All of these monitored vehicles served the support mission category.

\footnotetext{
${ }^{21} \mathrm{http}: / /$ evsolutions.avinc.com/products/public_charging/public_charging_b [Accessed April 16, 2014].
} 
Table 9. Commands total fleet summary.

\begin{tabular}{lcccccccccc}
\hline & $\begin{array}{c}\text { Sedan }- \\
\text { Compact }\end{array}$ & $\begin{array}{c}\text { Sedan }- \\
\text { Midsize }\end{array}$ & $\begin{array}{c}\text { Sedan }- \\
\text { Large }\end{array}$ & Minivan & SUV & $\begin{array}{c}\text { Van } \\
\text { Cargo }\end{array}$ & $\begin{array}{c}\text { Van } \\
\text { Pass }\end{array}$ & Pickup & Specialty & Total \\
\hline Support & 1 & 7 & 5 & 30 & 20 & 12 & 66 & 108 & - & 249 \\
\hline
\end{tabular}

\subsubsection{Commands Support Vehicles Evaluation}

Grouping the vehicles by mission creates an aggregated view of mission requirements to provide observations related to PEV replacement. All vehicles assigned to the Commands are support vehicles.

Support vehicles provide a specific work function, facilitating the mission of a particular group. The vehicles are generally passenger or light-duty pickup trucks and may contain after-market modifications to support the mission. While assigned to maintenance and service areas, missions may vary depending on agency needs. Incorporation of BEVs and/or PHEVs into the support mission is a definite possibility. Support vehicles used for shorter trips or outings qualify for BEV or PHEV replacement, while other support vehicle activities that are associated with longer trips may require PHEV capabilities.

4.1.1.1 Summary for Commands Support Vehicles. Appendix B provides the vehicle data sheets for each of the support vehicles monitored and Appendix D provides the detailed analysis that is summarized in this section. Table 10 summarizes support travel during the study period for those days in which the vehicle was driven. Vehicle use occurred primarily between 0500 and 1500 hours daily. The monitored vehicles traveled 15,512 miles, logged 785 hours, and idled for 245 hours during the 31-day study period.

Table 10. Command support vehicles travel summary.

\begin{tabular}{lcccc} 
& Support Vehicles Travel Summary & & \\
& $\begin{array}{c}\text { Per Day } \\
\text { Average/Peak }\end{array}$ & $\begin{array}{c}\text { Per Outing } \\
\text { Average/Peak }\end{array}$ & $\begin{array}{c}\text { Per Trip } \\
\text { Average/Peak }\end{array}$ & Total \\
\hline Travel Distance (Miles) & $46.4 / 405.0$ & $18.6 / 1,012.4$ & $7.9 / 208.1$ & 15,512 \\
Travel Time (Minutes) & $133.4 / 836.0$ & $51.7 / 1,008.4$ & $22.6 / 315.0$ & 47,097 \\
Idle Time (Minutes) & $2.2 / \mathrm{NA}$ & $16.7 / \mathrm{NA}$ & $7.3 / \mathrm{NA}$ & 14,687 \\
\hline
\end{tabular}

The distance a PEV can travel in CD mode between charge opportunities is the most important factor in considering vehicle replacement. The two most significant factors in vehicle analysis include the vehicle daily travel and vehicle outings. Section 2.3 provides the definitions of these terms. In both graphs of daily travel and outings, the distance axis is divided into 10-mile segments, with green bars indicating all travel less than 20 miles. Thirty miles is the assumed typical PHEV range in CD mode. The blue bars indicate travel between 30 and 70 miles. Seventy miles is considered to be within the BEV safe range (blue and green bars). That is, while BEV range can vary based on several factors, most BEVs provide at least 70 miles of vehicle range on a single battery charge. All travel greater than 70 miles is shown by the gray bars and indicate travel beyond the capability of a BEV. Figure 19 shows the daily travel summary for the monitored vehicles. For example, Figure 19 shows that almost $30 \%$ of daily travel was less than 10 miles per day.

The average travel distance per day, when driven, for support vehicles was 46.4 miles. On $79 \%$ of these vehicle days, the daily travel was less than the 70 miles and within the BEV safe range. Meanwhile, $21 \%$ percent of support daily travel was greater than 70 miles, with $53 \%$ of vehicle travel days less than 30 miles. A very basic look might suggest that considering only daily travel, a fleet consisting of $79 \%$ BEVs and 21\% PHEVs would meet vehicle travel needs. However, other considerations will apply. 


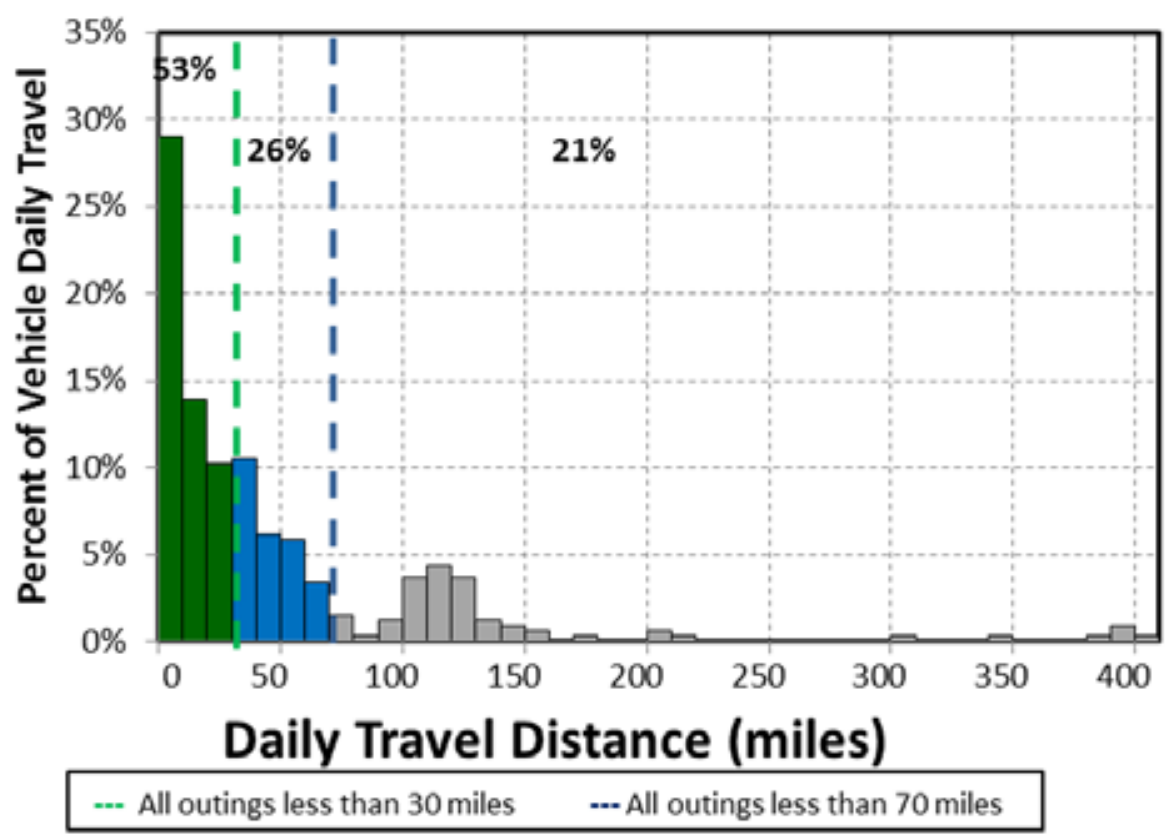

Figure 19. Command support vehicle daily travel miles (all vehicles).

Figure 20 shows the outings for all vehicles. The figure notes that $75 \%$ of all vehicle outings travel was less than 10 miles.

The average travel outing when driven for support vehicles was 18.6 miles. On $94 \%$ of these vehicle outings, the distance traveled was less than 70 miles and considered to be within the BEV safe range. Meanwhile, only $6 \%$ of support outing travel was greater than 70 miles, with $88 \%$ of vehicle travel outings less than the 30 miles considered to be within the CD range of a PHEV.

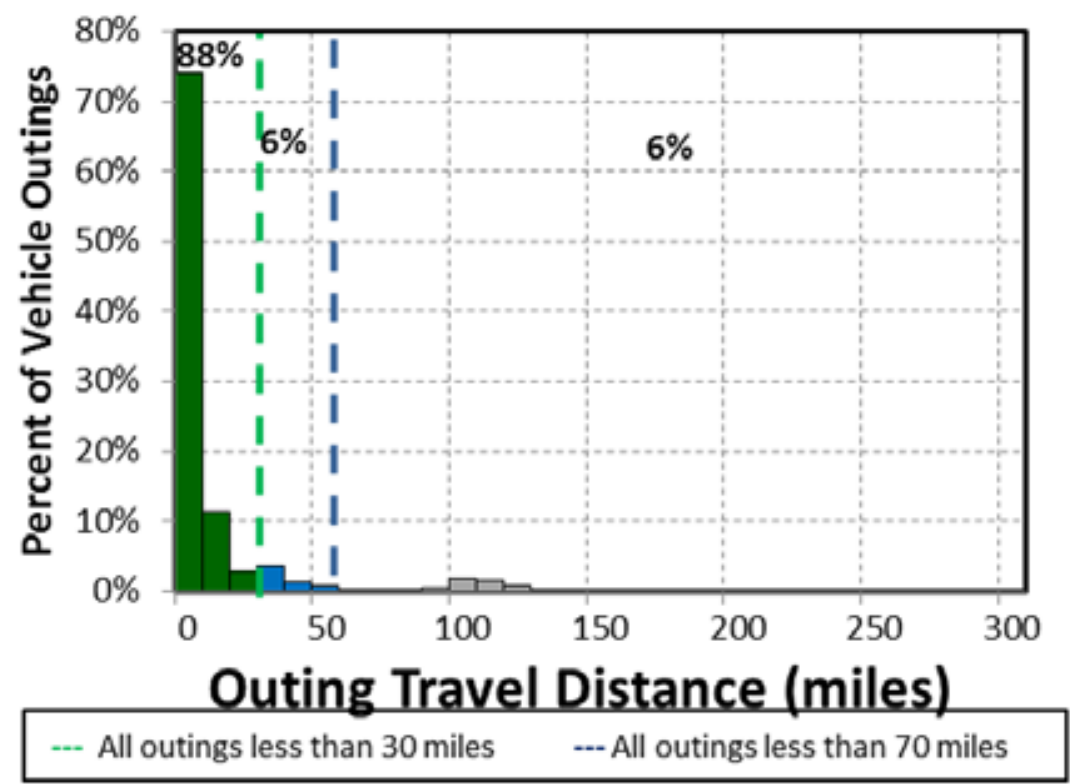

Figure 20. Command support vehicle combined outings. Note that the three longest outings of $1,012,788$, and 785 miles are not for clarity of scale. 
4.1.1.2 Commands Support Vehicle Observations/Summary. In summary, the vast majority of daily travel and outings were short and well within the capabilities of BEVs. This was consistent with the optimum goal of incorporating as many BEVs as possible to realize the advantages of reduced petroleum usage and reduced emissions of GHGs. A review of the specific vehicles monitored in this study show they were assigned to different groups and not easily shared (i.e., while two vehicles may have only one extended outing each, it may not be possible to have all extended outings on the one vehicle). A conservative approach to vehicle usage suggests eight BEVs and 10 PHEVs would meet the needs of the support vehicles.

Considering a full complement of 249 support vehicles in the Commands fleet, Intertek suggests that a mixed fleet may be possible. Assuming the balance of vehicles are operated similarly to those monitored and considering the average annual (and, thus, monthly) mileage, replacement PEVs are suggested as identified in Table 11. Note that a higher percentage of BEVs is possible because command fleets may have several vehicles to share the longer distance travels. This will be explored in detail in the Task 4 adoption approach. Intertek suggests that a fleet of 143 BEVs and 106 PHEVs (57\% BEV/43\% PHEV) conservatively meets vehicle travel requirements.

Table 11. Commands PEV potential replacements.

\begin{tabular}{lcccccccccc}
\hline & $\begin{array}{c}\text { Sedan }- \\
\text { Compact }\end{array}$ & $\begin{array}{c}\text { Sedan }- \\
\text { Midsize }\end{array}$ & $\begin{array}{c}\text { Sedan }- \\
\text { Large }\end{array}$ & Minivan & SUV & $\begin{array}{c}\text { Van } \\
\text { Cargo }\end{array}$ & $\begin{array}{c}\text { Van } \\
\text { Pass }\end{array}$ & Pickup & Specialty & Total \\
\hline BEV & 1 & 2 & 3 & 11 & 7 & 11 & 30 & 78 & - & 143 \\
PHEV & - & 5 & 2 & 19 & 13 & 1 & 36 & 30 & - & 106 \\
Total & 1 & 7 & 5 & 30 & 20 & 12 & 66 & 108 & - & 249 \\
\hline
\end{tabular}

4.1.1.3 Commands Support Vehicle Charging Needs. As noted previously, AC Level 2 (240-VAC) overnight charging of BEVs is typical, whereas overnight charging of PHEVs can usually be accomplished with AC Level 1 (110-VAC) charging. Intertek's experience suggests that each vehicle should have an assigned charging location at its home base. Assigned stations require less management attention to ensure completion of overnight charging. BEVs and PHEVs not assigned to these locations also benefit during visits to the location as part of their normal operation. For the entire fleet of Commands support vehicles, eight BEVs require eight AC Level 2 EVSE units for overnight charging and 10 PHEVs require $10 \mathrm{AC}$ Level 1 outlets for home base charging. Intertek recommends a minimum of two EVSE at each location to maximize charge capability without a significant increase in installation costs. PHEVs can utilize AC Level 2 EVSE at the home base during the day to increase the amount of vehicle miles traveled in $C D$ mode.

At times, fleet vehicles obtain benefit from using public charging infrastructure. Figure 21 displays the availability of public charging at the time of this writing for the MCBCL area. The green-colored sites are AC sites, indicating AC Level 1 and Level 2 public locations.

There is significant development in public charging infrastructure in the Raleigh-Durham area of North Carolina due to great public interest in PEV adoption. However, that infrastructure density does not extend to the MCBCL area.

One station is located at the local Nissan dealership and the other at a hotel. Both are AC Level 2 EVSE.

The Task 3 report on infrastructure provides details about infrastructure planning. 


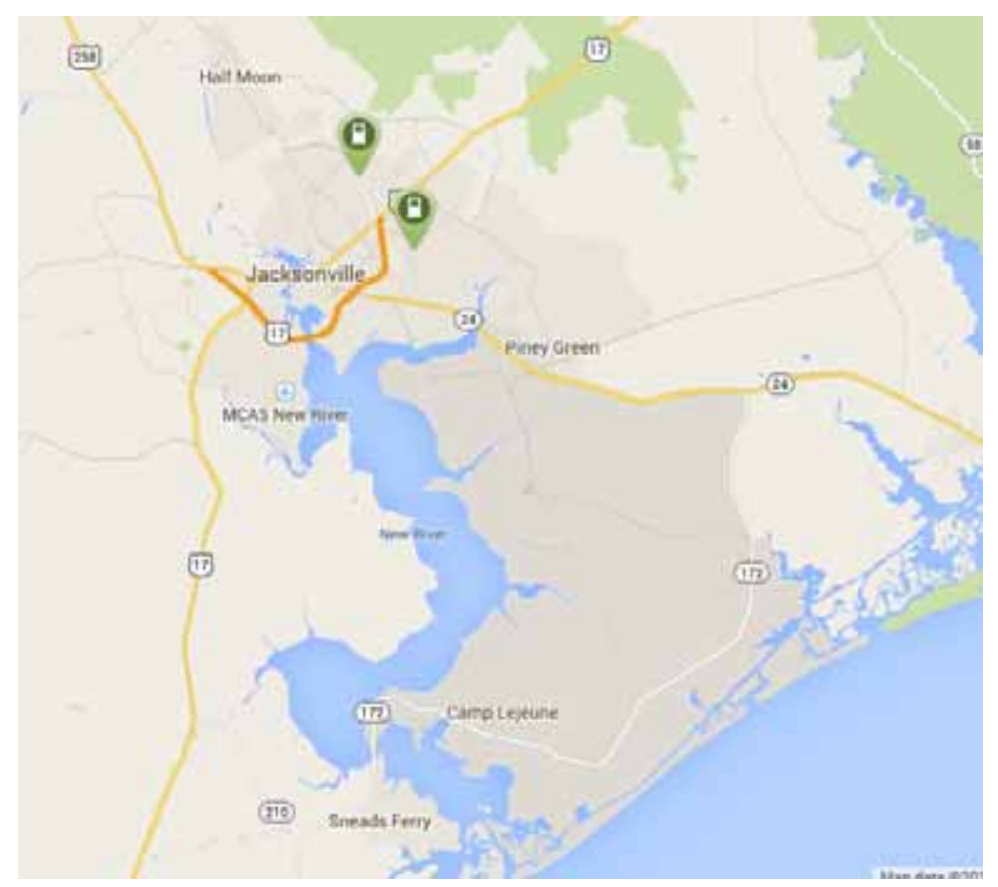

Figure 21. Public EVSE in MCBCL region. ${ }^{22}$

\subsubsection{Commands Fleet Vehicles Mileage}

The vehicle's annual miles are factored into calculations for replacement of vehicles as noted in Section 5 and Appendix D. The actual miles measured during the study were extrapolated to identify calculated annual miles in the study. This was compared to the mileage provided by MCBCL. The MCBCL figures were used in the calculations. However, there were significant differences between the usage of the vehicle during the study and the average annual usage as noted in Table 12.

Table 12. Commands group monitored vehicle mileage.

\begin{tabular}{ccccc} 
Logger & Vehicle ID & Vehicle Class & $\begin{array}{c}\text { Study Extrapolated } \\
\text { Annual Mileage }\end{array}$ & $\begin{array}{c}\text { MCBCL Reported } \\
\text { Annual Mileage }\end{array}$ \\
\hline 88 & 291073 & Van - Pass & 2,686 & 2,935 \\
17 & 301321 & Pickup & 1,012 & 3,669 \\
95 & G41-0762M & Minivan & 15,510 & 20,099 \\
86 & G41-1846K & Minivan & 12,460 & 12,317 \\
83 & G41-2399K & Pickup & 3,906 & 10,754 \\
90 & G42-0216F & Van - Pass & 18,336 & 2,189 \\
92 & G42-0883M & Van - Pass & 21,806 & 16,827 \\
84 & G42-0898M & Van - Pass & 15,305 & 16,246 \\
18 & G43-0326H & Pickup & 763 & 4,863 \\
103 & G43-1453G & Van - Pass & 5,050 & 15,539 \\
19 & G43-1855P & Pickup & 7,733 & 4,800 \\
20 & G43-2025K & Pickup & 2,944 & 3,755 \\
\hline
\end{tabular}

${ }^{22}$ http://www.plugshare.com/ [accessed February 10, 2015]. 


\begin{tabular}{ccccc}
\hline 110 & G43-4073F & Van - Pass & 3,592 & 4,712 \\
87 & G61-0594L & SUV & 13,887 & 10,657 \\
94 & G61-2644P & SUV & 25,651 & 24,000 \\
91 & G62-0791H & SUV & 9,940 & 9,273 \\
99 & G63-0309R & Pickup & 8,623 & 2,469 \\
120 & G63-0934G & Pickup & 15,505 & 7,502 \\
\hline
\end{tabular}

For the entire Commands group fleet, the average monthly miles traveled as provided by MCBCL are 707 miles for an average annual travel total of 8,484 miles. On an average basis, this reflects positively on the use of BEVs in the fleet.

\subsubsection{Commands Fleet Summary}

This study provides observations for both the vehicles monitored and for the entire non-tactical fleet of vehicles identified with the Commands group. The study indicates that PEVs offer alternatives to vehicles in the existing fleet if any specific cargo requirements are met by the PEV. In general, a mixed fleet of BEVs and PHEVs is suggested.

The fleet of Commands support vehicles in this study included two minivans, three SUVs, six passenger vans, and seven pickup trucks. Section 3.4 provides information on PEVs currently or soon to

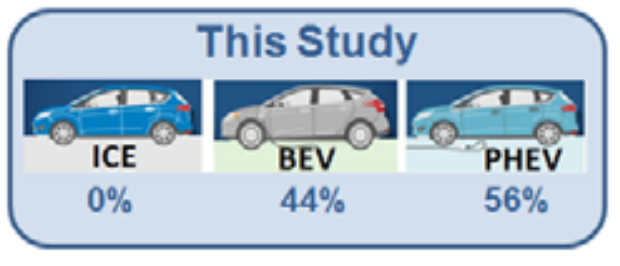
be available in the automotive market. Without consideration of specific cargo requirements, replacement PEVs currently exist for all of these vehicles. Appendix D provides details about the observations and summary and, based on these travel data, Intertek suggests that replacing these 18 vehicles with eight BEVs and 10 PHEVs would meet current mission requirements.

The vehicles studied were utilized on 58\% of the study days and averaged 2.2 hours of use per day. While daily usage was quite low, the vehicles were used often enough that eliminating a vehicle is not recommended.

Considering a full complement of 249 support vehicles assigned to the Commands group, Intertek suggests that a mixed fleet may be possible. These remaining vehicles were not monitored, but using the data collected for those that were, Intertek suggests that a fleet of 143 BEVs and 106 PHEVs

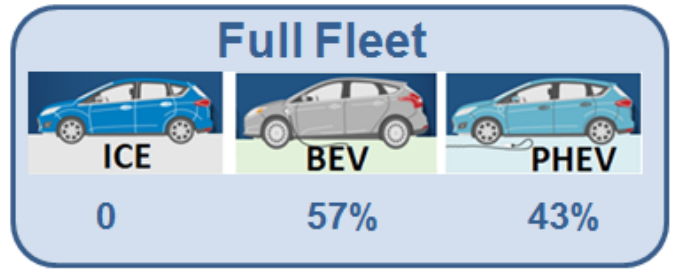
conservatively meets vehicle travel requirements.

With potential replacement by PEVs established, Section 5 and Appendix D provide further evaluation of the benefits of such replacements. This will be factored into further observations and suggestions related to the PEV adoption approach and schedule for any replacements for the Commands group. Those observations will be addressed in Task 4 of this project.

\subsection{Analysis Results - Marine Corps Installations East Fleet}

The MCIE fleet operates 535 vehicles. Table 13 identifies these vehicles by vehicle type according to site records. The mission assignments identified in Table 13 are based on agency records and general assumptions. Forty-two vehicles were monitored as part of this study, including four sedans, three minivans, seven SUVS, four cargo vans, two passenger vans, 21 pickup trucks, and one specialty vehicle. This section summarizes and aggregates data collection for the MCIE fleet. The details of each vehicle 
monitored are included in Appendix C. Appendix E presents the full detailed analysis for the vehicles monitored and for the group as a whole.

Table 13. MCIE total fleet characterization.

\begin{tabular}{lcccccccccc}
\hline & $\begin{array}{c}\text { Sedan }- \\
\text { Compact }\end{array}$ & $\begin{array}{c}\text { Sedan - } \\
\text { Midsize }\end{array}$ & $\begin{array}{c}\text { Sedan- } \\
\text { Large }\end{array}$ & Minivan & SUV & $\begin{array}{c}\text { Van } \\
\text { Cargo }\end{array}$ & $\begin{array}{c}\text { Van } \\
\text { Pass }\end{array}$ & Pickup & Specialty & Total \\
\hline Pool & - & 3 & - & 11 & 11 & 4 & 32 & 41 & - & 102 \\
Support & 3 & 13 & 2 & 19 & 33 & 42 & 8 & 174 & - & 294 \\
Enforcement & 2 & - & 36 & 7 & 12 & 4 & 3 & 13 & 2 & 79 \\
Specialty & - & - & - & - & - & - & - & - & 60 & 60 \\
Total & 5 & 16 & 38 & 37 & 56 & 50 & 43 & 228 & 62 & 535 \\
\hline
\end{tabular}

Grouping the vehicles by mission creates an aggregated view of mission requirements to provide observations related to PEV replacement. Analysis by mission type is provided in the following subsections.

\subsubsection{Marine Corps Installations East Pool Vehicles Analysis}

Pool vehicles typically are light-duty motor vehicles for use in passenger transportation, with not more than 10 passengers. Pool missions can vary by agency, location, and jurisdiction. For the MCIE group, the pool vehicles include one sedan, two minivans, two SUVs, two passenger vans, one cargo van, and two pickups.

Incorporation of BEVs and/or PHEVs into the pool mission is a definite possibility. Pool vehicles used for shorter trips or outings qualify for BEV or PHEV replacement, while other pool vehicle activities that are associated with longer trips may require PHEV capabilities.

4.2.1.1 Summary for Marine Corps Installations East Pool Vehicles. Appendix C provides the vehicle data sheets for each of the pool vehicles monitored. This section aggregates data for all pool vehicles. Table 14 summarizes pool vehicle travel during the study period for those days when the vehicle was driven. Vehicle use occurred primarily between 0600 and 1500 hours daily. They traveled 6,672 miles, logged 446 hours, and idled for 155 hours during the 31-day study period.

Table 14. Pool vehicles travel summary.

\begin{tabular}{|c|c|c|c|c|}
\hline \multicolumn{5}{|c|}{ Pool Vehicles Travel Summary } \\
\hline & $\begin{array}{c}\text { Per Day } \\
\text { Average/Peak }\end{array}$ & $\begin{array}{c}\text { Per Outing } \\
\text { Average/Peak }\end{array}$ & $\begin{array}{c}\text { Per Trip } \\
\text { Average/Peak }\end{array}$ & Total \\
\hline Travel Distance (Miles) & $35.9 / 289.4$ & $8.9 / 537.2$ & $4.6 / 258.5$ & 6,672 \\
\hline Travel Time (Minutes) & $144.0 / 1,140.0$ & $35.9 / 875.0$ & $18.4 / 504.0$ & 26,781 \\
\hline Idle Time (Minutes) & $50.2 / \mathrm{NA}$ & $12.5 / \mathrm{NA}$ & $6.4 / \mathrm{NA}$ & 9,328 \\
\hline
\end{tabular}

The distance a PEV can travel in CD mode between charge opportunities is the most important factor when considering vehicle replacement. The two most significant factors in vehicle analysis include vehicle daily travel and vehicle outings. Section 2.3 provides the definitions of these terms. Figure 22 shows the travel summary for all monitored pool vehicles.

The average travel distance per day, when driven, for pool vehicles was 35.9 miles. On $87 \%$ of the vehicle travel days, the daily travel was less than the 70 miles considered to be within the BEV safe range (blue and green bars in Figure 22). Meanwhile, 58\% of vehicle travel days were less than the 30 miles considered to be within the CD range of a PHEV (green bars of Figure 22). This suggests a fleet of $87 \%$ BEVs and $13 \%$ PHEVs would meet travel needs without consideration of other factors. 


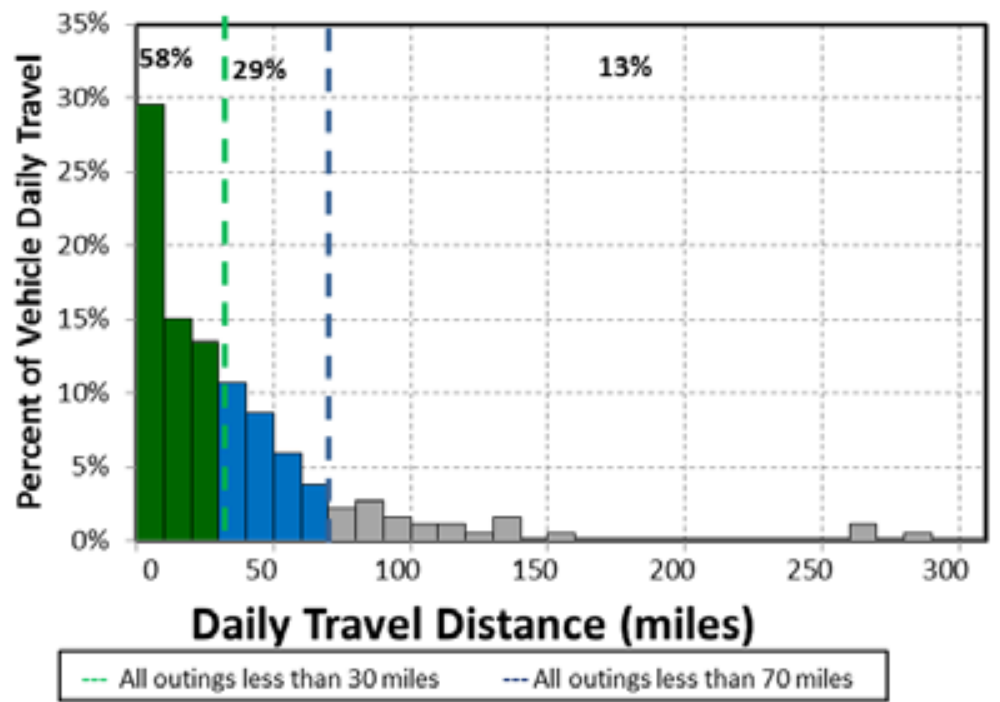

Figure 22. Pool vehicle daily travel miles (all vehicles).

The pool vehicles were used, on average, $58 \%$ of the study days. However, there were periods where each vehicle operated several days in a row and days that several vehicles were in use. Figure 23 shows the outings for all vehicles.

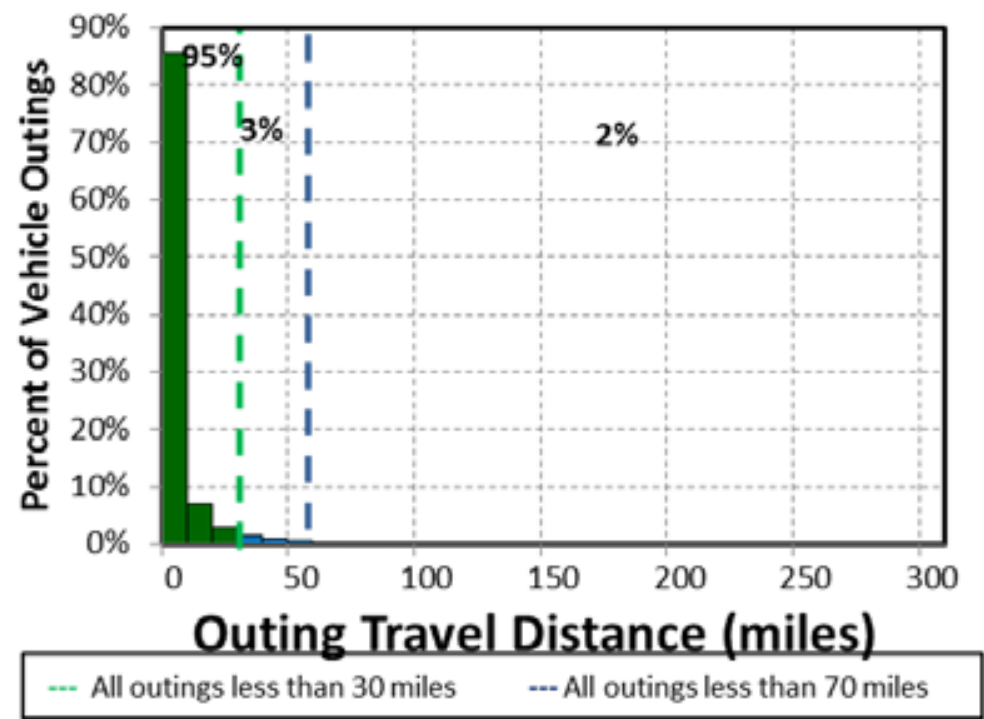

Figure 23. Pool vehicle combined outings. Note that the single longest outing of 537 miles was not shown for clarity of scale.

Appendix D provides the details of each of the pool vehicle's outings. The average travel outing when driven for pool vehicles was 8.9 miles. Further, $98 \%$ of the outings were less than the 70 miles considered to be within the BEV safe range and $95 \%$ t of pool outings were less than the 30 miles considered to be within the CD mode range of a PHEV.

4.2.1.2 Pool Vehicle Observations/Summary. The vast majority of daily travel and outings were short and well within the capabilities of BEVs. This is consistent with the optimum goal of incorporating as many BEVs as possible to realize the advantages of reduced petroleum usage and reduced emissions of GHG. 
The actual miles measured during the study were extrapolated to identify calculated annual miles in the study. This was compared to the mileage provided by MCBCL. The MCBCL figures were used in the calculations. However, there were significant differences between usage of the vehicle during the study and average annual usage as noted in Table 15.

Table 15. MCIE monitored pool vehicle mileage.

\begin{tabular}{ccccc} 
Logger & Vehicle ID & Vehicle Class & $\begin{array}{c}\text { Study Extrapolated Annual } \\
\text { Mileage }\end{array}$ & $\begin{array}{c}\text { MCBCL Reported } \\
\text { Annual Mileage }\end{array}$ \\
\hline 4 & 290597 & Van - Cargo & 2,394 & 957 \\
5 & G10-3327L & Sedan - Midsize & 5,225 & 7,085 \\
7 & G41-0379H & Minivan & 4,855 & 5,614 \\
8 & G41-0754M & Minivan & 10,173 & 5,183 \\
9 & G42-0644M & Van - Pass & 2,264 & 22,209 \\
10 & G42-0911L & Pickup & 17,658 & 7,978 \\
13 & G43-0310H & Van - Pass & 7,096 & 7,232 \\
14 & G43-4075P & Pickup & 13,963 & 12,000 \\
15 & G61-1508D & SUV & 3,485 & 1,051 \\
16 & G61-1509D & SUV & 5,252 & 3,292 \\
\hline
\end{tabular}

The fleet of pool vehicles in this study included one sedan, two minivans, two SUVs, two passenger vans, one cargo van, and two pickups. Intertek would suggest that five BEVs and five PHEVs could meet mission requirements. Section 3.4 provides information on PEVs currently or soon to be available in the automotive market and Section 5 provides details on the suggestions.

Considering a full complement of 102 pool vehicles in the entire MCIE group fleet, Intertek suggests that in extrapolating the collected data to the entire fleet, a mixed fleet of 69 BEVs and 33 PHEVs $(67 \%$ $\mathrm{BEV} / 33 \% \mathrm{PHEV}$ ) may be possible.

The vehicle summary shows sufficient time for charging at the base location during the course of the day and additional opportunities at intermediate charging stations. These stations also provide charging opportunities for the visiting public, whose fees may assist in offsetting operating costs.

4.2.1.3 Pool Vehicle Charging Needs. Upon review of these data, Intertek suggests replacement of the MCIE pool fleet with 69 BEVs and 33 PHEVs. As noted previously, AC Level 2 overnight charging of BEVs is typical, whereas overnight charging of PHEVs can be accomplished with AC Level 1 charging.

Intertek's experience suggests that each vehicle have an assigned charging location at their home base. Assigned stations require less management attention to ensure completion of overnight charging. BEVs and PHEVs not assigned to these locations also benefit during visits to the location as part of their normal operation. Intertek recommends a minimum of two EVSE at each location to maximize charge capability without a significant increase in installation costs. The PHEVs can utilize AC Level 2 EVSE at the home base during the day to increase the amount of vehicle miles traveled in CD mode.

At times, fleet vehicles obtain benefit from using public charging infrastructure. Figure 21 displays the availability of public charging for the MCBCL area at the time of this writing. Little public infrastructure is available or needed.

\subsubsection{Marine Corps Installations East Support Vehicles Analysis}

Support vehicles provide a specific work function, facilitating the mission of a particular group. The vehicles are generally passenger or light-duty pickup trucks and may contain after-market modifications 
to support the mission. While assigned to maintenance and service areas, missions may vary depending on agency needs.

As shown above, MCIE support vehicles that were monitored included three sedans, one minivan, two SUVs, three cargo vans, and 16 pickup trucks.

4.2.2.1 Summary for Marine Corps Installations East Support Vehicles. Appendix D provides the vehicle data sheets for each of the 25 MCIE support vehicles monitored. This section aggregates the data for those support vehicles.

Table 16 summarizes support vehicle travel during the study period. Vehicle use occurred primarily between 0600 and 1500 hours daily. The 25 support vehicles traveled 844 miles, logged 38 hours, and idled for 8 hours during the study period.

Table 16. Support vehicle travel summary.

\begin{tabular}{lcccc}
\hline \multicolumn{4}{c}{ Support Vehicle Travel Summary } & \\
& Per Day & Per Outing & Per Trip & \\
& Average/Peak & Average/Peak & Average/Peak & Total \\
\hline Travel Distance (Miles) & $43.7 / 154.0$ & $22.8 / 151.8$ & $6.9 / 76.8$ & 844 \\
Travel Time (Minutes) & $119.1 / 456.0$ & $60.2 / 456.0$ & $18.6 / 362.0$ & 2,304 \\
Idle Time (Minutes) & $23.6 / \mathrm{NA}$ & $11.5 / \mathrm{NA}$ & $3.9 / \mathrm{NA}$ & 466 \\
\hline
\end{tabular}

The distance a PEV can travel in CD mode between charge opportunities is the most important factor in considering vehicle replacement. The two most significant factors in vehicle analysis include the vehicle daily travel and vehicle outings. Section 2.3 provides the definitions of these terms. Figure 24 shows the travel summary for the support vehicles monitored.

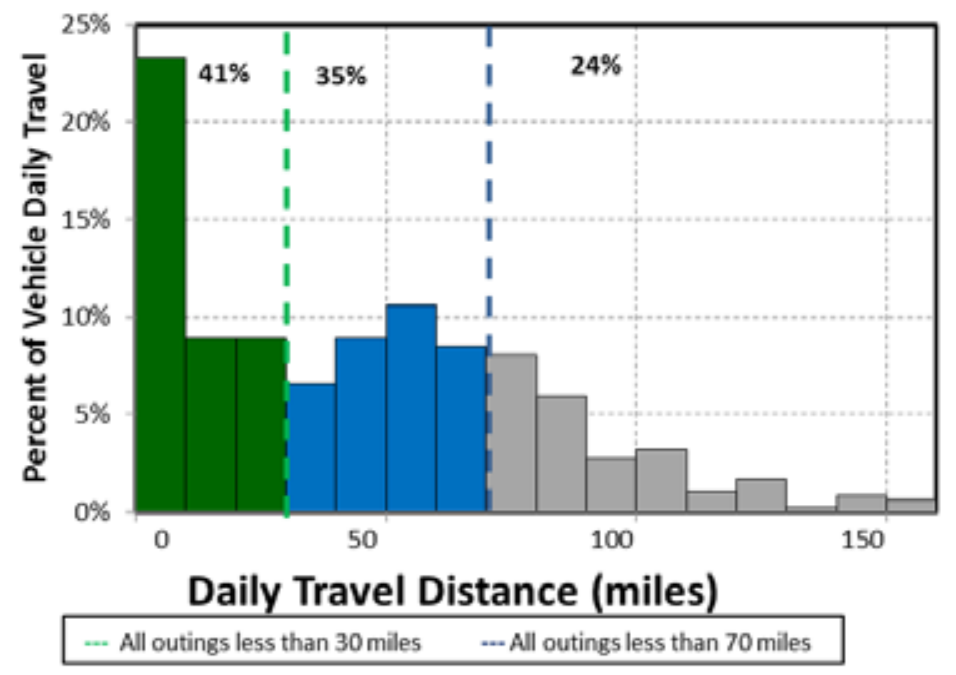

Figure 24. Support vehicle daily travel miles and usage time (all vehicles).

The average travel distance per day, when driven, for support vehicles was 43.7 miles. On $76 \%$ of these vehicle days, the daily travel was less than the 70 miles considered to be within the BEV safe range. Meanwhile, $24 \%$ percent of support vehicle daily travel was greater than 70 miles. Furthermore, $41 \%$ of vehicle travel days were less than the 30 miles considered to be within the CD mode range of a PHEV. Figure 25 shows the outings for all support vehicles combined. 
Appendix D provides the details of each of the support vehicle's daily travel. Without consideration of other vehicle requirements, this would suggest a support fleet could consist of approximately $76 \%$ BEVs and 24\% PHEVs. Figure 25 shows the outings for all vehicles.

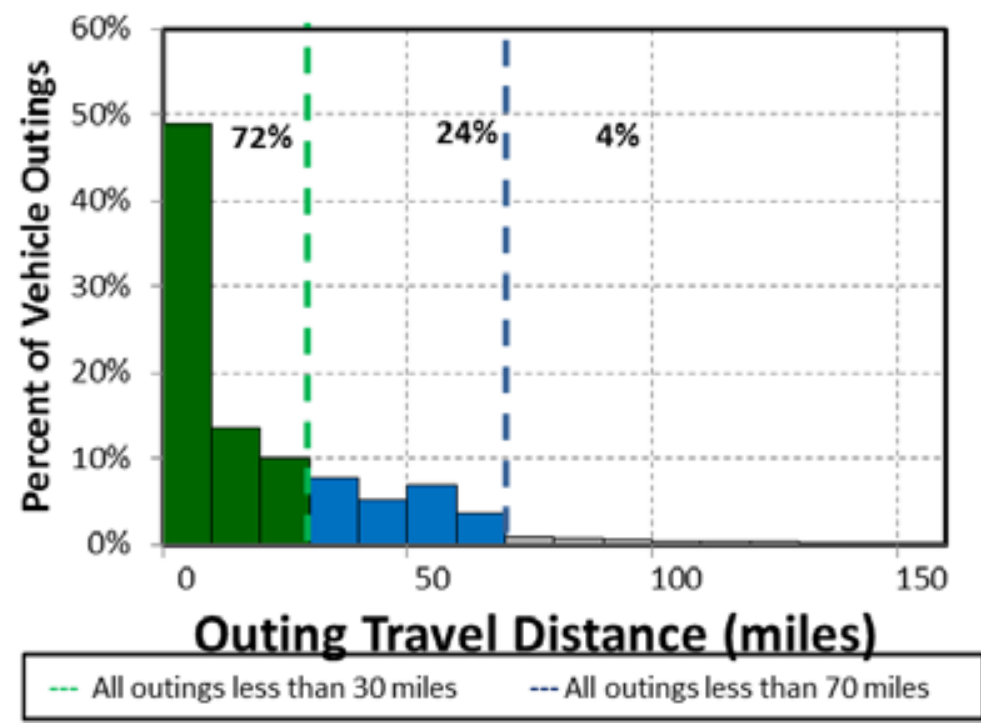

Figure 25. Support vehicle combined outings.

The average travel outing, when driven, for support vehicles was 22.8 miles. On $96 \%$ of these vehicle outings, the distance traveled was less than the 70 miles considered to be within the BEV safe range. Furthermore, $72 \%$ of vehicle travel outings were less than the 30 miles considered to be within the CD mode range of a PHEV.

\subsubsection{Marine Corps Installations East Support Vehicle Observations/Summary. A} significant amount of daily travel and outings were within the capabilities of BEVs. This is consistent with the optimum goal of incorporating as many BEVs as possible to realize the advantages of reduced petroleum usage and reduced emissions of GHG.

The actual miles measured during the study were extrapolated to identify calculated annual miles in the study. This was compared to the mileage provided by MCBCL. The MCBCL figures were used in the calculations. However, there were significant differences between usage of the vehicle during the study and average annual usage as noted in Table 17.

Table 17. MCIE monitored support vehicle mileage.

\begin{tabular}{ccccc} 
Logger & Vehicle ID & Vehicle Class & $\begin{array}{c}\text { Study Extrapolated } \\
\text { Annual Mileage }\end{array}$ & $\begin{array}{c}\text { MCBCL Reported } \\
\text { Annual Mileage }\end{array}$ \\
\hline 35 & 294285 & Sedan - Midsize & 10,765 & 3,795 \\
42 & 294315 & Pickup & 6,808 & 3,208 \\
54 & 294324 & SUV & 14,382 & 8,195 \\
55 & 302039 & Pickup & 14,511 & 6,424 \\
56 & 302040 & Pickup & 13,725 & 10,937 \\
79 & 302334 & Pickup & 2,076 & 1,200 \\
41 & G13-0325K & Sedan - Compact & 2,149 & 1,037 \\
39 & G13-7974P & Sedan - Compact & 12,533 & 12,000 \\
40 & G41-0391H & Pickup & 8,938 & 7,507 \\
57 & G41-0806P & Minivan & 19,692 & 12,552 \\
58 & G41-1689L & Pickup & 5,334 & 5,649 \\
59 & G41-3297K & Pickup & 7,997 & 5,368 \\
\hline
\end{tabular}




\begin{tabular}{ccccc}
\hline Logger & Vehicle ID & Vehicle Class & $\begin{array}{c}\text { Study Extrapolated } \\
\text { Annual Mileage }\end{array}$ & $\begin{array}{c}\text { MCBCL Reported } \\
\text { Annual Mileage }\end{array}$ \\
\hline 61 & G41-3301K & Pickup & 5,813 & 7,306 \\
68 & G42-0667P & Pickup & 13,116 & 9,600 \\
69 & G42-0671P & Pickup & 25,172 & 7,678 \\
75 & G42-0915M & Pickup & 4,217 & 7,072 \\
71 & G43-0323H & Van - Cargo & 13,656 & 12,155 \\
74 & G43-0324H & Van - Cargo & 269 & 5,969 \\
36 & G43-1182M & Van - Cargo & 8,006 & 12,279 \\
77 & G61-0161H & Pickup & 19,471 & 14,979 \\
78 & G61-0174H & SUV & 10,154 & 8,683 \\
82 & G62-1583G & Pickup & 9,935 & 10,816 \\
46 & G62-4085L & Pickup & 7,374 & 10,608 \\
98 & G63-0163H & Pickup & 5,620 & 9,018 \\
47 & G63-2885L & Pickup & 5,528 & 4,112 \\
\hline
\end{tabular}

The fleet of support vehicles in this study included three sedans, one minivan, two SUVs, three cargo vans, and 16 pickup trucks. Intertek would suggest that 10 BEVs and 115 PHEVs could meet mission requirements. This is a lesser percentage than identified above because the vehicles are dispersed among several different groups. Section 3.4 provides information on PEVs currently or soon to be available in the automotive market and Section 5 provides details on the suggestions.

Considering a full complement of 294 support vehicles in the entire MCIE group support fleet, Intertek suggests that in extrapolating the collected data to the entire fleet, a mixed fleet of $189 \mathrm{BEVs}$ and 105 PHEVs may be possible.

The vehicle summary shows sufficient time for charging at the base location during the course of the day and additional opportunities at intermediate charging stations. These stations also provide charging opportunities for the visiting public, whose fees may assist in offsetting operating costs.

4.2.2.3 Marine Corps Installations East Support Vehicle Charging Needs. As noted above, AC Level 2 overnight charging of BEVs is typical, whereas overnight charging of PHEVs can be accomplished with AC Level 1 charging. Opportunity charging at intermediate stops obtains greater benefits from AC Level 2 EVSE. Most vehicles returned to their home base daily, with the exception of long trips lasting several days.

Greater management attention provides the possibility of reducing the overall number of AC Level 2 EVSE units. A ratio of two AC Level 2 charging stations to three vehicles typically sustains a normal fleet operation. Fleet managers rotate vehicles on the charger to complete charging of all vehicles in the allotted time. This analysis does assume a fully recharged battery at the start of each day. MCBCL will gain experience in this management as the PEV fleet grows.

\subsubsection{Marine Corps Installations Enforcement Vehicles Analysis}

Enforcement vehicles are typically light-duty motor vehicles specifically approved in an agency's appropriation act for use in apprehension, surveillance, police, or other law enforcement work. Enforcement missions can vary by agency, location, and jurisdiction; however, they typically utilize sedans, minivans, vans, or small pickup trucks and typically do not carry specific cargo or equipment.

As shown above, MCIE enforcement vehicles that were monitored included two SUVs and three pickup trucks. 


\subsubsection{Summary for Marine Corps Installations East Enforcement Vehicles.}

Appendix D provides the vehicle data sheets for each of the five enforcement vehicles monitored. This section aggregates the data for all enforcement vehicles.

Table 18 summarizes enforcement vehicle travel during the study period. Vehicle use occurred primarily between 0400 and 1700 hours daily, although many were used at all hours. The five enforcement vehicles traveled 6,106 miles, logged 520 hours, and idled for 295 hours during the study period.

Table 18. Enforcement vehicle travel summary.

\begin{tabular}{lcccc}
\hline & Enforcement Vehicle Travel Summary & & \\
& Per Day & Per Outing & Per Trip & \\
& Average/Peak & Average/Peak & Average/Peak & Total \\
\hline Travel Distance (Miles) & $51.3 / 208.1$ & $20.6 / 167.6$ & $6.8 / 99.7$ & 6,106 \\
Travel Time (Minutes) & $262.4 / 1,464.0$ & $105.5 / 1,209.0$ & $35.0 / 752.0$ & 31,228 \\
Idle Time (Minutes) & $149.7 / \mathrm{NA}$ & $60.2 / \mathrm{NA}$ & $20.0 / \mathrm{NA}$ & 17,726 \\
\hline
\end{tabular}

The distance a PEV can travel in CD mode between charge opportunities is the most important factor when considering vehicle replacement. The two most significant factors in vehicle analysis include the vehicle daily travel and vehicle outings. Section 2.3 provides the definitions of these terms. Figure 226 shows the daily travel summary for the enforcement vehicles monitored. Appendix D provides the details of each of the enforcement vehicle's daily travel.

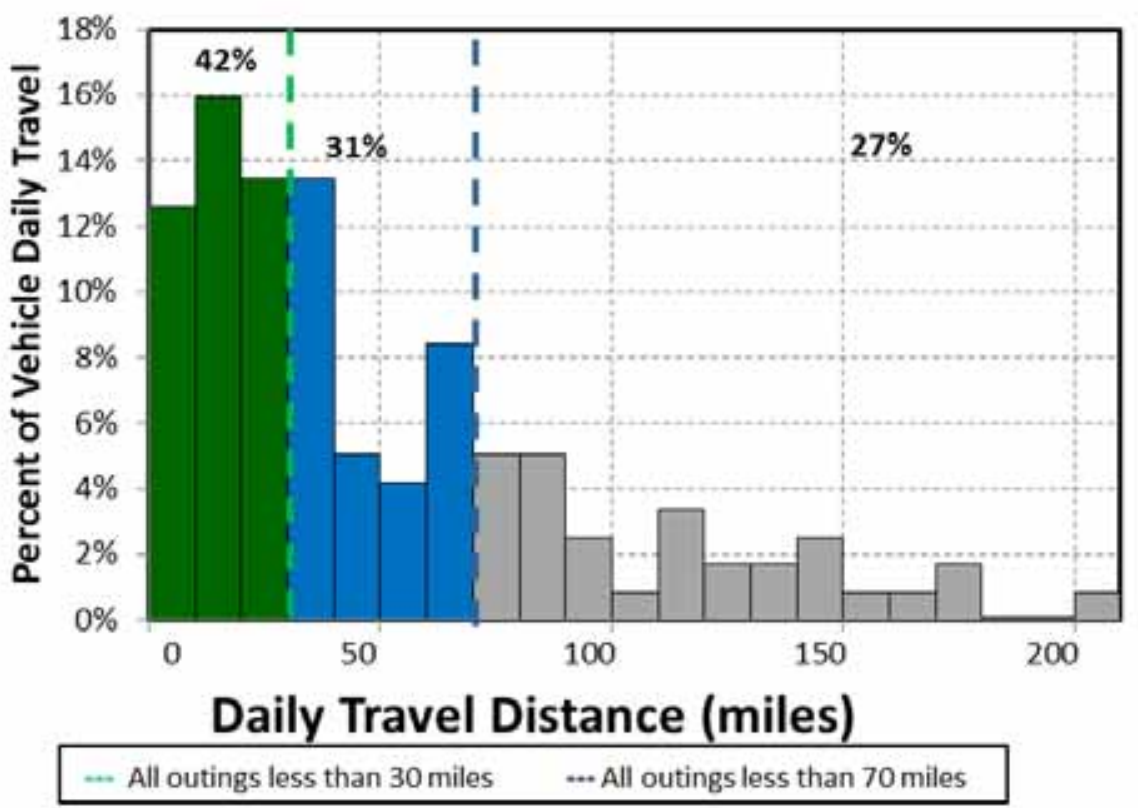

Figure 26. Enforcement vehicle daily travel miles and usage time (all vehicles).

The average travel distance per day, when driven, for enforcement vehicles was 51.3 miles. On $73 \%$ of these vehicle days, the daily travel was less than the 70 miles considered to be within the BEV safe range. Meanwhile, $27 \%$ percent of enforcement vehicle daily travel was greater than 70 miles.

Furthermore, $42 \%$ of vehicle travel days were less than the 30 miles considered to be within the CD mode range of a PHEV. Without any other considerations, this would suggest the fleet could be composed of $73 \%$ BEVs and $27 \%$ PHEVs. However, most enforcement fleet managers prefer vehicles with no range 
limitations. Thus, the composition would shift more toward the PHEV preference. Figure 27 shows the outings for all enforcement vehicles combined.

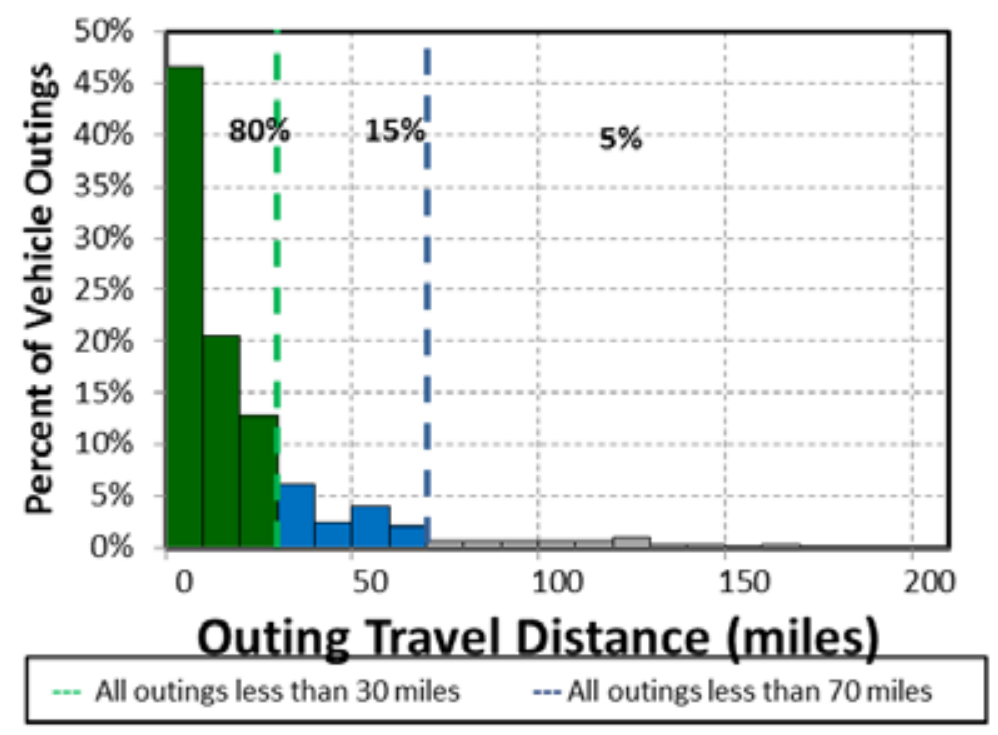

Figure 27. Enforcement vehicle combined outings.

The average travel outing when driven for enforcement vehicles was 20.6 miles. On $95 \%$ of these vehicle outings, the distance traveled was less than the 70 miles considered to be within the BEV safe range. Furthermore, $80 \%$ of vehicle travel outings were less than the 30 miles considered to be within the $\mathrm{CD}$ mode range of a PHEV.

\subsubsection{Marine Corps Installations East Enforcement Vehicle Observations/Summary.} The vast majority of daily travel and outings were short and well within the capabilities of BEVs. This is consistent with the optimum goal to incorporate as many BEVs as possible to realize the advantages of reduced petroleum usage and reduced emissions of GHG.

The actual miles measured during the study were extrapolated to identify calculated annual miles in the study. This was compared to the mileage provided by MCBCL. The MCBCL figures were used in the calculations. However, there were significant differences between usage of the vehicle during the study and average annual usage as noted in Table 19.

Table 19. MCIE monitored enforcement vehicle mileage.

\begin{tabular}{ccccc} 
Logger & Vehicle ID & Vehicle Class & $\begin{array}{c}\text { Study Extrapolated } \\
\text { Annual Mileage }\end{array}$ & $\begin{array}{c}\text { MCBCL Reported } \\
\text { Annual Mileage }\end{array}$ \\
\hline 48 & 294293 & SUV & 4,839 & 4,214 \\
49 & G41-3300K & Pickup & 26,944 & 15,644 \\
50 & G42-2985H & Pickup & 22,331 & 20,146 \\
51 & G61-0879P & SUV & 12,235 & 4,232 \\
52 & G63-2888L & Pickup & 6,272 & 4,480 \\
\hline
\end{tabular}

The fleet of pool vehicles in this study included two SUVs and three pickup trucks. Intertek would suggest that two BEVs and three PHEVs could meet mission requirements. Section 3.4 provides information on PEVs currently or soon to be available in the automotive market and Section 5 provides details on the suggestions. 
Considering a full complement of 79 pool vehicles in the entire MCIE group enforcement fleet, Intertek suggests that in extrapolating the collected data to the entire fleet, a mixed fleet consisting of 17 BEVs, 60 PHEVs, and two conventional specialty brig trucks should meet the mission objectives.

The vehicle summary shows sufficient time for charging at the base location during the course of the day and additional opportunities at intermediate charging stations. These stations also provide charging opportunities for the visiting public, whose fees may assist in offsetting operating costs.

4.2.3.3 Marine Corps Installations East Enforcement Vehicle Charging Needs. As noted above, AC Level 2 overnight charging of BEVs is typical, whereas overnight charging of PHEVs can be accomplished with AC Level 1 charging. Opportunity charging at intermediate stops obtains the greater benefits from AC Level 2 EVSE. Most vehicles returned to their home base daily.

Greater management attention provides the possibility of reducing the overall number of AC Level 2 EVSE units. A ratio of two AC Level 2 charging stations to three vehicles typically sustains a normal fleet operation. Fleet managers rotate vehicles on the charger to complete charging of all vehicles in the allotted time. This analysis does assume a fully recharged battery at the start of each day. MCBCL will gain experience in this management as the PEV fleet grows.

\subsubsection{Marine Corps Installations East Specialty Vehicles Analysis}

Two specialty vehicles were selected for monitoring as part of the study: one bucket truck and one refrigeration truck. The refrigeration truck was a pool vehicle available through Motor Transport and was not used during the study. The operations details of the other specialty truck 300672 are included in Appendix C. The bucket truck identified in Section 3.5 would appear to be a suitable PHEV replacement. Conversion of a refrigeration vehicle may be more difficult because energy would be required for the refrigeration service. A PHEV conversion may be possible, but range in CD mode may be limited. The remaining 60 specialty vehicles were not monitored. Insufficient experience of prototypes for potential conversion of these types of vehicles to PEVs exists to suggest any further replacement. The entire fleet of specialty vehicles contains eight bucket trucks: three of which are on the Ford F550 frame. These eight vehicles have this potential PHEV replacement.

\subsubsection{Marine Corps Installations East Group Vehicles Mileage}

The vehicle's annual miles factor into the calculations for replacement of the vehicle, as noted in Section 5 and Appendix E. The actual miles measured during the study were extrapolated to identify the calculated annual miles in the study. MCBCL has also provided vehicle information that identified the average monthly miles and vehicle mileage for December 2014.

For the entire MCIE group fleet, the average monthly miles traveled were 667 miles for an average annual travel of 8,000 miles. This is relatively low mileage and, on an average basis, this reflects positively on the use of BEVs in the fleet.

\subsubsection{Marine Corps Installations East Group Summary}

This study provides observations for both the vehicles monitored and for the entire non-tactical fleet of vehicles identified in the MCIE Group. The study indicates that PEVs offer alternatives to existing vehicles provided that any specific cargo requirements are met by the PEV. In general, a mixed fleet of BEVs and PHEVs is suggested.

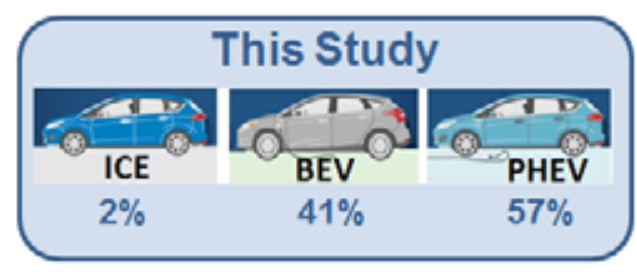

The vehicles monitored in this study included four sedans, three minivans, six SUVs, two passenger vans, four cargo vans, 21 pickup trucks, and two specialty trucks. Based on the travel data, Intertek suggests that retaining the refrigeration truck and replacing the remaining vehicles with $17 \mathrm{BEVs}$ and 24 PHEVs would meet current mission requirements. 
Section 5 identifies potential replacement PEVs and Appendix E provides specific recommendations.

The vehicles studied were utilized on $59 \%$ of the study days and averaged 2.2 hours of use per day. While daily usage was quite low, the vehicles were used often enough that eliminating any of these vehicles is not recommended.

The MCIE Group's full fleet of vehicles contains 535 vehicles. Intertek suggests retaining most of the conventional specialty vehicles and suggests a fleet of 275 BEVs and 207 PHEVs could meet the balance of vehicle travel requirements.

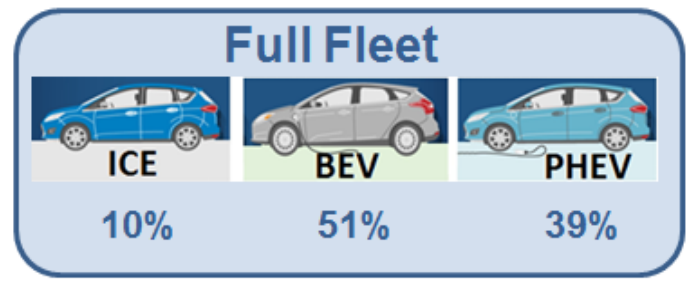

With the potential replacement by PEVs established, Section 5 and Appendix E provide further evaluation of the benefits of such replacements. This will be factored into further observations and suggestions related to the business case and schedule for any replacements for the MCIE group. Those observations will be addressed in Task 4 of this project.

\subsection{Analysis Results - Combined Groups}

The full fleet in the study contains 784 vehicles, not including the low-speed vehicles and non-powered trailer type vehicles. Table 20 identifies these vehicles by vehicle type according to site records. The mission assignments identified in Table 20 are based on survey responses received and extrapolated to the entire fleet.

Table 1 . All fleet vehicles by type and mission.

\begin{tabular}{|c|c|c|c|c|c|c|c|c|c|c|}
\hline & $\begin{array}{l}\text { Sedan - } \\
\text { Compact }\end{array}$ & $\begin{array}{l}\text { Sedan - } \\
\text { Midsize }\end{array}$ & $\begin{array}{l}\text { Sedan - } \\
\text { Large }\end{array}$ & Minivan & SUV & $\begin{array}{l}\text { Van } \\
\text { Cargo }\end{array}$ & $\begin{array}{l}\text { Van } \\
\text { Pass }\end{array}$ & Pickup & Specialty & Total \\
\hline Pool & - & 3 & - & 11 & 11 & 4 & 32 & 37 & - & 98 \\
\hline Support & 4 & 20 & 7 & 49 & 53 & 55 & 74 & 286 & - & 548 \\
\hline Enforcement & 2 & - & 36 & 7 & 12 & 3 & 3 & 13 & 2 & 78 \\
\hline Specialty & - & - & - & - & - & - & - & - & 60 & 60 \\
\hline Total & 6 & 23 & 43 & 67 & 76 & 62 & 109 & 336 & 62 & 784 \\
\hline
\end{tabular}

Grouping the vehicles by mission creates an aggregated view of mission requirements to provide observations related to PEV replacement. Analysis by mission type is provided in the following subsections.

\subsubsection{All Pool Vehicles Analysis}

All pool vehicles were assigned to the MCIE Group and analyzed in detail in Section 4.2.1.

\subsubsection{All Support Vehicles Analysis}

Support vehicles assigned to the Commands group are analyzed in Section 4.1.1 and those assigned to the MCIE group are analyzed in Section 4.2.2. This section combines this analysis for all support vehicles.

4.3.2.1 Summary for All Support Vehicles. Appendices B and C provides the vehicle data sheets for each of the 43 support vehicles monitored. This section aggregates the data for all support vehicles.

Table 21 summarizes support vehicle travel during the study period. Vehicle use may occur at any hour, but primarily occurred between 0600 and 1600 hours daily. Support vehicles traveled 36,601 miles, logged 1,745 hours, and idled for 439 hours during the study period. 
Table 21. Support vehicle travel summary.

\begin{tabular}{lcccc}
\hline \multicolumn{4}{c}{ Support Vehicle Travel Summary } & \\
& Per Day & Per Outing & Per Trip & \\
& Average/Peak & Average/Peak & Average/Peak & Total \\
\hline Travel Distance (Miles) & $46.0 / 405.0$ & $18.1 / 1,012.4$ & $6.8 / 208.1$ & 36,601 \\
Travel Time (Minutes) & $131.5 / 836.0$ & $51.7 / 1,443.0$ & $19.4 / 362.0$ & 104,690 \\
Idle Time (Minutes) & $33.1 / \mathrm{NA}$ & $13.0 / \mathrm{NA}$ & $4.9 / \mathrm{NA}$ & 26,336 \\
\hline
\end{tabular}

The distance a PEV can travel in CD mode between charge opportunities is the most important factor when considering vehicle replacement. The two most significant factors in vehicle analysis include the vehicle daily travel and vehicle outings. Figure 28 shows the travel summary for support vehicles by vehicle.

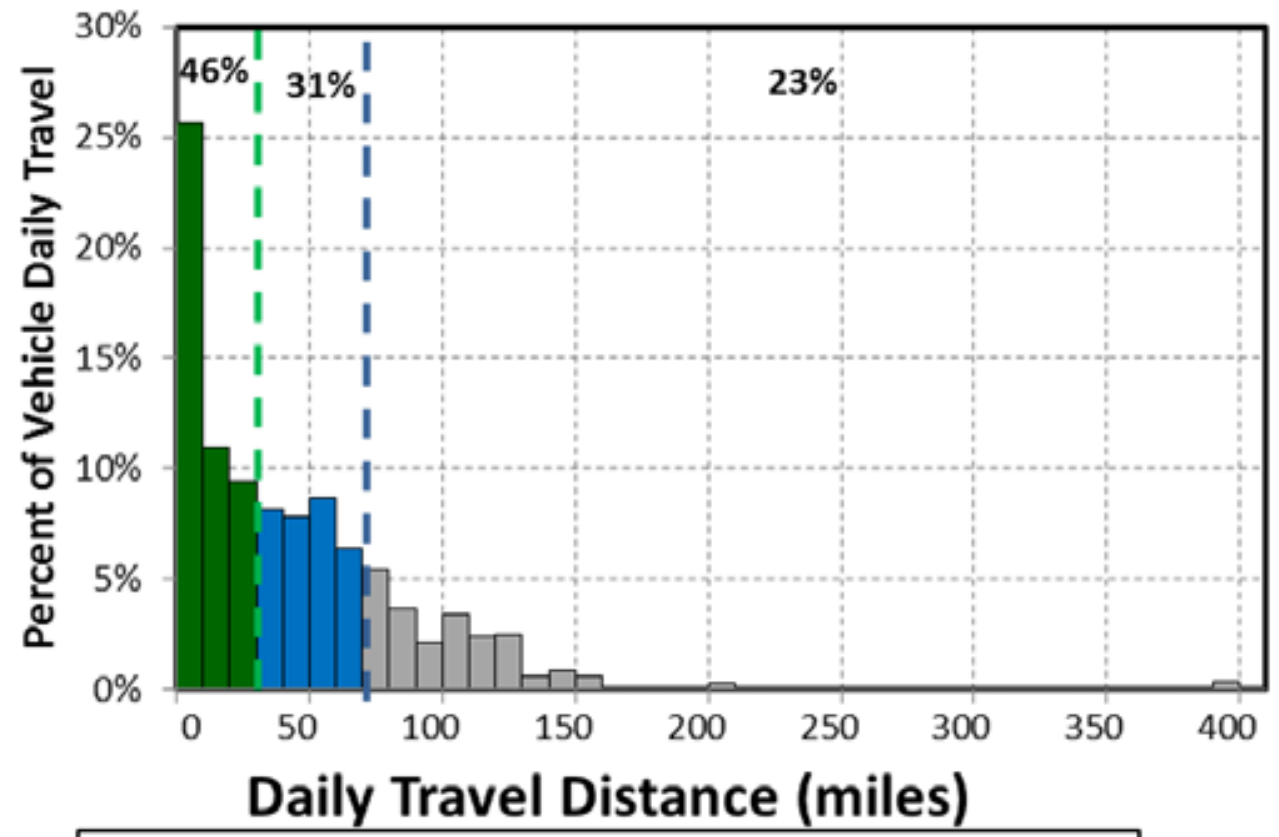

\section{--- All outings less than 30 miles $\quad$---All outings less than 70 miles}

Figure 28. Support vehicle daily travel miles (all vehicles).

The average travel distance per day, when driven, for support vehicles was 46.0 miles. On $77 \%$ of these vehicle days, the daily travel was less than the 70 miles considered to be within the BEV safe range. Meanwhile, $23 \%$ percent of support vehicle daily travel was greater than 70 miles. Furthermore, $46 \%$ of vehicle travel days were less than the 30 miles considered to be within the CD range of a PHEV. Figure 29 shows the outings for all support vehicles combined.

The average travel outing when driven for support vehicles was 18.1 miles. On $95 \%$ of these vehicle outings, the distance traveled was less than the 70 miles considered to be within the BEV safe range. Meanwhile, $5 \%$ of support outing travel was greater than 70 miles. Furthermore, $80 \%$ of vehicle travel outings were less than the 30 miles considered to be within the CD range of a PHEV. 


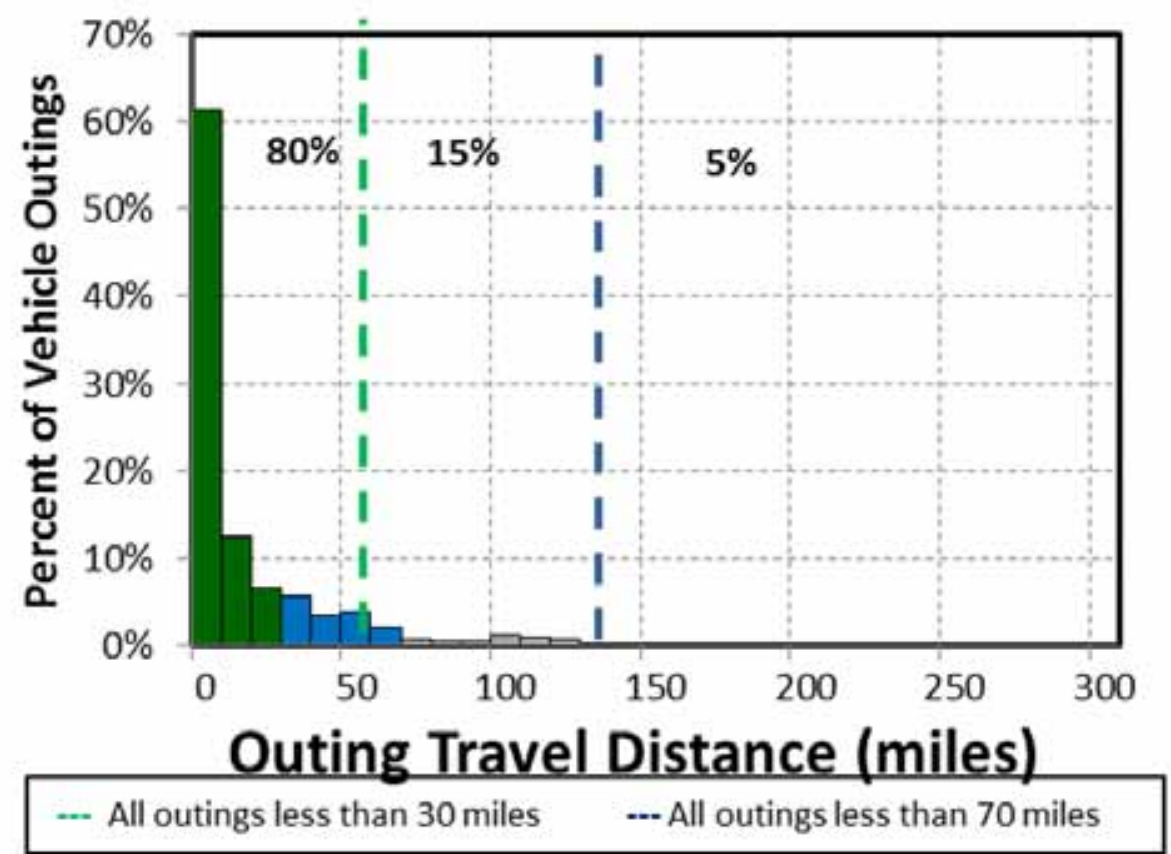

Figure 29. Support vehicle combined outings for all vehicles. Note that the longest outings of 1,012, 788, and 785 miles are not shown in the figure for clarity.

4.3.2.2 All Support Vehicle Observations/Summary. The all support vehicle daily travel miles and outings graphs are similar to those of the Commands group and MCIE group analyses, except that MCIE support vehicles tend toward longer distances each day and longer outings as well. The balance of the observations is included in the fleet analysis sections.

\subsubsection{All Enforcement Vehicles Analysis}

All enforcement vehicles were assigned to the MCIE group and analyzed in detail in Section 4.2.3.

\subsubsection{All Specialty Vehicle Analysis}

All specialty vehicles were assigned to the MCIE group and analyzed in detail in Section 4.2.4.

\subsubsection{All Vehicles Mileage}

The vehicle's annual miles factor into the calculations for replacement of vehicles, as noted in Section 5. The actual miles measured during the study were extrapolated to identify calculated annual miles in the study. MCBCL has also provided vehicle information that identified the average monthly miles and vehicle mileage in April 2012.

For all fleet vehicles, the average monthly miles traveled were 668 miles, for an average annual travel of 8,016 miles and typical workday travel of 334 miles. Overall, this average mileage is relatively low and reflects positively on the use of BEVs in the fleet.

\subsubsection{All Vehicles Summary}

This study provides observations for both the vehicles monitored and extrapolates that for the entire non-tactical fleet of vehicles. The study indicates that PEVs offer alternatives to vehicles in the existing fleet, provided any specific cargo requirements are met by the PEV. In general, a mixed fleet of BEVs and PHEVs is suggested. 


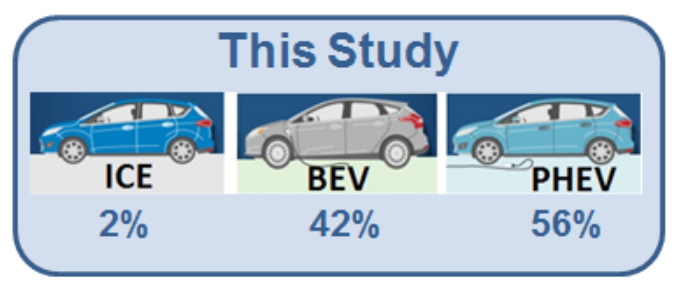

The vehicles monitored in this study included four sedans, five minivans, nine SUVs, four cargo vans, eight passenger vans, 28 pickup trucks, and two heavy-duty specialty trucks. Based on the travel data, Intertek suggests that retaining one specialty heavy-duty truck and replacing the remaining vehicles with $25 \mathrm{BEVs}$ and 34 PHEVs would meet current mission requirements. Section 5 identifies potential replacement PEVs, while Appendices D and E provide specific recommendations.

The studied vehicles were utilized on $60 \%$ of the study days and averaged 2.2 hours of use per day. Daily usage was quite low, although most vehicles showed frequent use.

The all vehicles full fleet of vehicles contains 784 vehicles. Intertek suggests that after retaining 53 conventional specialty vehicles, a fleet of $418 \mathrm{BEVs}$ and 313 PHEVs could meet the vehicle travel requirements.

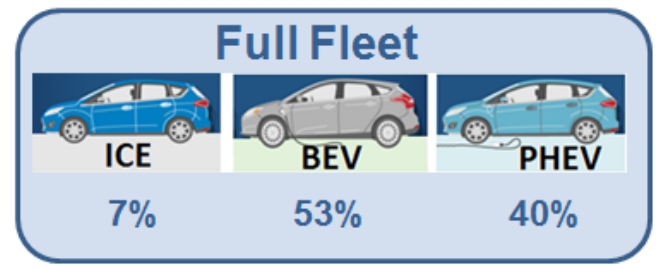

With potential replacement by PEVs established, Section 5 and Appendices D and E provide further evaluation of the benefits of such replacements. This will be factored into further observations and suggestions related to the replacements adoption approach. Those observations will be addressed in Task 4 of this project.

\section{GREENHOUSE GAS EMISSIONS AVOIDED AND FUEL COST REDUCTION ANALYSIS}

\subsection{Background and Methods}

PEV substitution for an existing conventional vehicle avoids GHG emissions and reduces fuel costs. The GHG emissions avoided occur due to the difference in emissions associated with power plant electricity generation versus fuel combustion that occurs in the engine of a conventional vehicle. This analysis does not account for life-cycle emissions that occur outside of electricity generation and fuel combustion phases (i.e., materials and resource extraction, production supply chains, and decommissioning are not accounted for). These phases are beyond the scope of this report due to the significant effort required to conduct an accurate environmental life-cycle assessment for a transportation system in a very specific setting. The analysis used is known as a "tank-to-wheel" analysis, rather than a "well-to-wheel" analysis that would include the aforementioned phases. Cost reduction also occurs because the cost of electricity is much less than the cost of gasoline and PEVs are more efficient than conventional ICE vehicles. Because fuel logs were not kept, the mileage accumulated by each vehicle during the study is compared to the average miles reported by MCBCL. The MCBCL report provides the source of fuel consumption estimates for the study vehicles.

Several PEV types are available for potential replacement in the MCBCL fleets as shown in Section 3. For this analysis, Table 22 provides the vehicles suggested as replacement vehicles for those identified in the analysis of Section 4. In some cases, the vehicles suggested for replacement may not meet specific cargo or other vehicle requirements. In addition, these are intended to be examples of potential replacement. PEVs are being added each year and, when MCBCL is ready to replace an ICE with a PEV, other PEV options may be available. In most cases, the EPA class of the replacement PEV is the same or similar to the current vehicle class. The energy consumption values for each PEV are displayed with the vehicle; note that for PHEVs, the energy consumption is only for CD mode. 
Table 22. PEV substitutions for current vehicles.

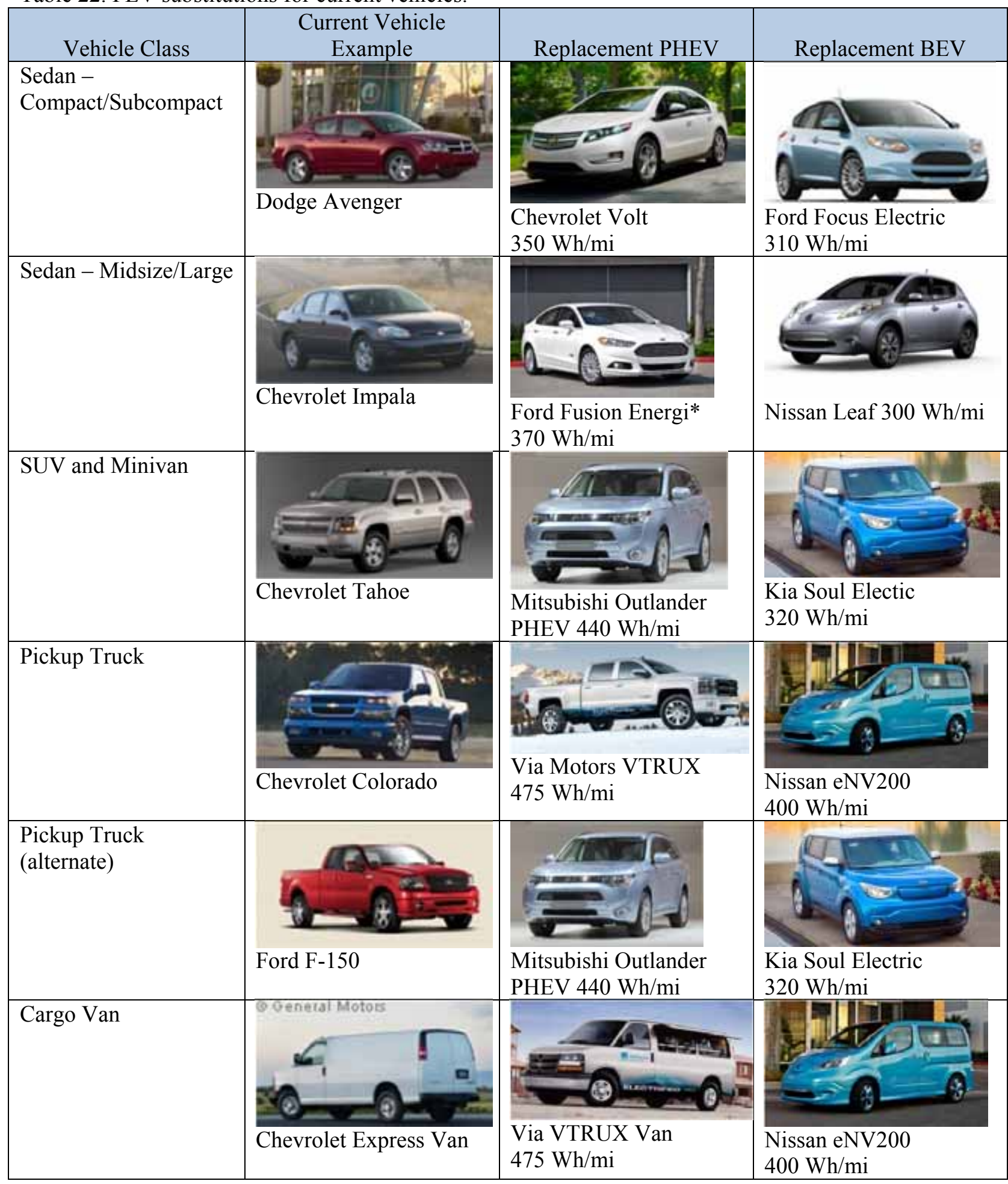




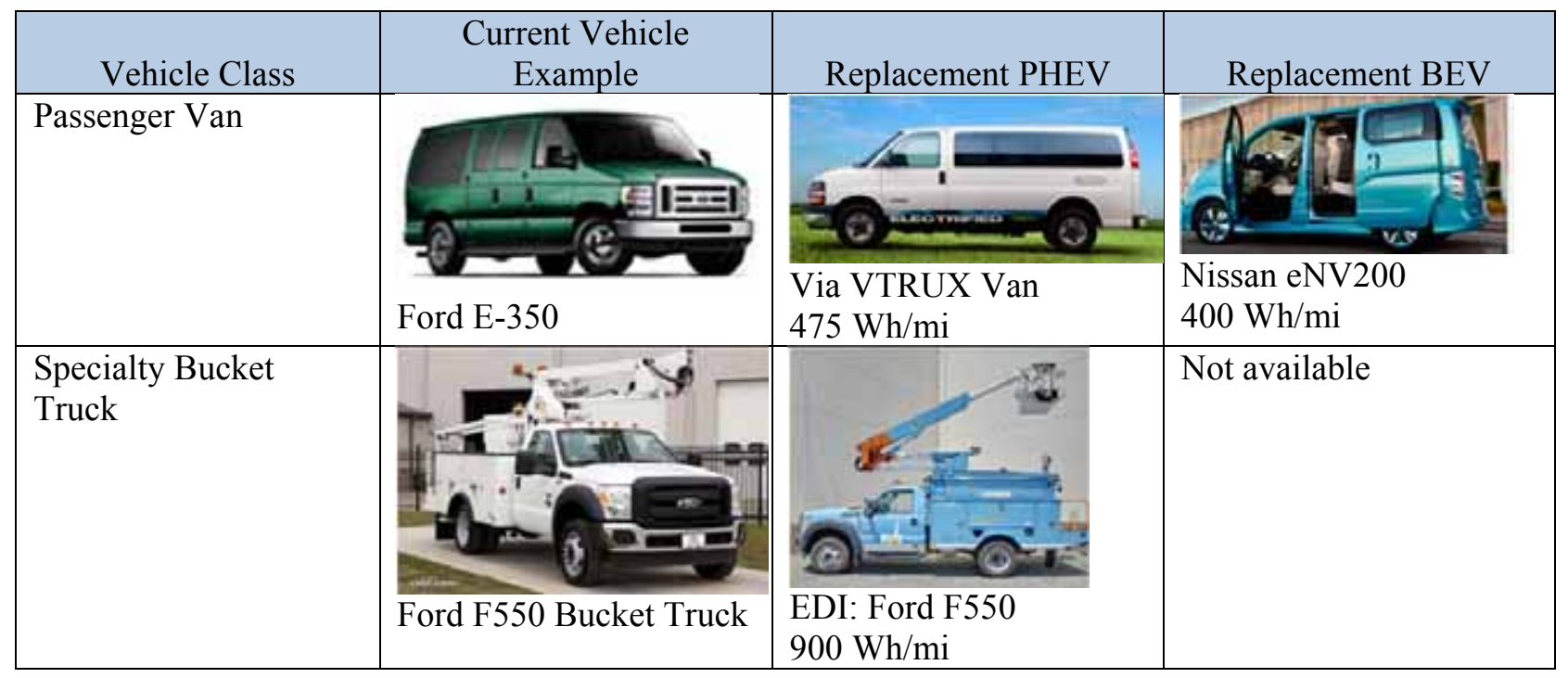

Calculations provided for GHG emissions and fuel savings include both a total U.S. perspective and a perspective for the local area. The electricity generation mix of power plants for the total United States is different from the local mix of generation in the MCBCL area. Likewise, the national average cost for petroleum fuel is different from the local cost for fuel. This analysis includes both approaches in order to allow for local evaluation and to provide potential benefit for fleet vehicles in other locations of the United States that may be of interest.

For the GHG emissions avoided portion of the analysis, the GHG emissions (in pounds of carbon dioxide equivalent, which accounts for other GHGs such as methane and nitrous oxide, $1 \mathrm{~b}-\mathrm{CO}_{2} \mathrm{e}$ ) from combustion of gasoline or E85 is the product of the EPA fuel economy and tailpipe emissions converted to $\mathrm{lb}-\mathrm{CO}_{2} \mathrm{e} /$ gallon and is approximately $20.1 \mathrm{lb}-\mathrm{CO}_{2} \mathrm{e} /$ gallon. ${ }^{23}$ The EPA does not provide emissions information for individual heavy-duty diesel trucks because of the highly varied use. However, the EPA provides guidance for estimates based on modeling. The emission factor for $\mathrm{N}_{2} \mathrm{O}$ and $\mathrm{CH}_{4}$ are very low compared to $\mathrm{CO}_{2}$. The emissions of $10.21 \mathrm{~kg} \mathrm{CO}_{2}$ per gallon diesel in this report are based on those estimates. ${ }^{24}$ In a like manner, EPA provides fuel economy estimates for heavy-duty trucks. ${ }^{25}$ These factors are used to calculate emissions for diesel vehicles. The United States' average for GHG emissions for the production of electricity is $1.53 \mathrm{lb}-\mathrm{CO}_{2} \mathrm{e} / \mathrm{kWh}^{26}$

MCBCL reported receiving base power from Duke Energy through Duke Energy Progress (formerly Progress Energy). EPA reports GHG emissions from the production of electricity. The annual report is available in the Emissions and Generation Resource Integrated Database. The most recent publication is for $2010 .{ }^{27}$ Using the generation mix reported by Duke Energy in 2014 and the Emissions and Generation Resource Integrated Database plant reports, emissions for 2010 for the production of electricity were $1.134 \mathrm{lb}-\mathrm{CO}_{2} \mathrm{e} / \mathrm{kWh}$. This emissions rate reflects the higher-than-average reliance on nuclear and hydroelectric as the generation source and, thus, emissions are lower than the national average.

\footnotetext{
${ }^{23} \mathrm{http}$ ://avt.inl.gov/pdf/EVProj/106077-891082.ghg.pdf for the methodology for gasoline [accessed 7 July 2015].

${ }^{24}$ Emission Factors for Greenhouse Gas Inventories, 4 April 2014, http://www.epa.gov/climateleadership/documents/emissionfactors.pdf [accessed 7 July 2015].

${ }^{25}$ Update Heavy-Duty Engine Emission Conversion Factors for MOBILE6, http://www.epa.gov/otaq/models/mobile6/r02005.pdf [accessed 7 July 2015].

${ }^{26}$ op.cit EVProj/106077.

${ }^{27}$ http://www.epa.gov/cleanenergy/energy-resources/egrid/ [accessed 30 June 2015].
} 
GHG emissions avoided are the annual GHGs emitted by the current vehicle (total annual gallons gasoline $\times$ GHG emissions/gallon) minus the annual GHG emitted by the replacement PEV (total annual $\mathrm{kWh} \times \mathrm{GHG}$ emissions $/ \mathrm{kWh}$ ). For PHEVs, only the percentages of travel less than 30 miles are counted for the annual miles saved in CD mode.

For the cost-avoided piece of the analysis, EPA provides information on current fuel prices. At the time of this report, fuel costs for regular gasoline and diesel fuel were \$2.801/gallon and \$2.843/gallon, respectively, for the United States and \$2.650/gallon and \$2.823/gallon, respectively, for the lower Atlantic region. ${ }^{28}$ E85 prices were \$2.13/gallon for the United States and \$2.17/gallon for the Lower Atlantic region. ${ }^{29}$ Electrical cost assumptions were $0.1032 \$ / \mathrm{kWh}^{30}$ for the United States and $0.05566 \$ / \mathrm{kWh}$ energy charge for industrial customers on Schedule LGS-32 (Large General Service) in the Duke Energy Progress service territory. ${ }^{31}$ Therefore, fuel costs savings are the current vehicle's calculated annual gasoline cost (total annual gallons gasoline $\times$ cost/gallon) minus the electricity cost (total annual $\mathrm{kWh} \times \operatorname{cost} / \mathrm{kWh}$ ) of the replacement PEV traveling the same distance.

The miles calculated above for CD mode yield estimates for yearly GHG emissions avoided and fuel cost reductions. Appendices D and E provide the details of the results of these analyses for each of the fleets studied. While the appendices provide both national and local figures, only the local North Carolina area figures are reported here for clarity.

\subsection{Monitored Vehicles Fuel Cost Reduction}

Tables 23 provides a summary of the potential fuel cost reductions with the replacement of monitored vehicles with PEVs in the missions identified as noted in Appendices D and E. Only the local North Carolina fuel costs are considered in these tables. Comparison to national averages occurs in the appendices.

Table 23. Fuel cost reduction of monitored vehicles with PEV replacements.

\begin{tabular}{cccccccccc}
\hline & & $\begin{array}{c}\text { Number } \\
\text { of }\end{array}$ & $\begin{array}{c}\text { Average } \\
\% \text { Travel } \\
\text { CD }\end{array}$ & $\begin{array}{c}\text { Annual } \\
\text { Miles } \\
\text { CD }\end{array}$ & $\begin{array}{c}\text { Gallons } \\
\text { Fuel }\end{array}$ & $\begin{array}{c}\text { Local } \\
\text { Fuel }\end{array}$ & $\begin{array}{c}\text { Local } \\
\text { Elect. }\end{array}$ & $\begin{array}{c}\text { Local } \\
\text { Fnnual } \\
\text { Fuel }\end{array}$ & $\begin{array}{c}\text { Local Fuel } \\
\text { Cost }\end{array}$ \\
Fleet & Mission & Vehicles & Mode & Mode & Saved & Cost & Cost & Savings & Reduction \\
\hline MCIE & Pool & 10 & $76 \%$ & 59,160 & 4,807 & $\$ 10,552$ & $\$ 1,289$ & $\$ 9,264$ & $88 \%$ \\
MCIE & Support & 25 & $70 \%$ & 125,260 & 8,542 & $\$ 20,311$ & $\$ 2,961$ & $\$ 17,350$ & $85 \%$ \\
Comman & Support & 18 & $65 \%$ & 100,478 & 6,859 & $\$ 16,071$ & $\$ 2,322$ & $\$ 13,749$ & $86 \%$ \\
ds & & & & & & & & & \\
MCIE & Enforce & 5 & $65 \%$ & 24,213 & 1,398 & $\$ 3,367$ & $\$ 561$ & $\$ 2,806$ & $83 \%$ \\
MCIE & Specialty & 1 & $68 \%$ & 2,402 & 240 & $\$ 678$ & $\$ 120$ & $\$ 558$ & $82 \%$ \\
Total & & 59 & $69 \%$ & 311,513 & 21,846 & $\$ 50,979$ & $\$ 7,283$ & $\$ 43,727$ & $85 \%$ \\
\hline
\end{tabular}

In summary, if all possible monitored vehicles were replaced with PEVs, nearly 22,000 gallons of fuel would be avoided each year. This would save over $\$ 43,000$ in fuel costs, while only using about $\$ 7,200$ of electricity. This is an average of over $\$ 700$ of savings in fuel cost per vehicle annually when replaced by a PEV.

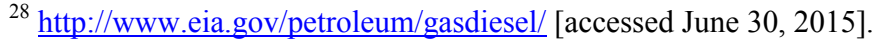

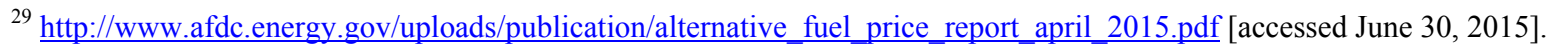

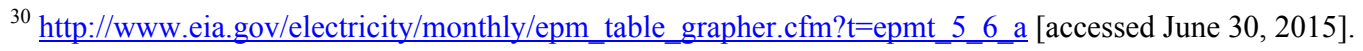

${ }^{31} \mathrm{http}: / /$ www.duke-energy.com/pdfs/G9-NC-Schedule-LGS-dep.pdf [accessed June 30, 2015].
} 


\subsection{Monitored Vehicles Greenhouse Gas Emissions Reduction}

Table 24 provides the summary of potential GHG emissions reduction with replacement of monitored vehicles with PEVs in the missions identified in Appendices D and E. Again, no replacements are suggested for most of the specialty heavy-duty vehicles. Only the local North Carolina GHG reductions are considered in these tables. Electrical emissions are significantly lower than petroleum-based fuel emissions. Table 24 provides a total of all vehicles monitored.

Table 24. GHG emissions reduction of monitored vehicles with PEV replacements.

\begin{tabular}{|c|c|c|c|c|c|c|c|}
\hline Fleet & Mission & $\begin{array}{c}\text { Annual } \\
\text { Miles } \\
\text { CD } \\
\text { Mode }\end{array}$ & $\begin{array}{c}\text { Gallons } \\
\text { Fuel } \\
\text { Saved }\end{array}$ & $\begin{array}{l}\text { Annual GHG } \\
\text { Emissions } \\
\text { ICE } \mathrm{lb}-\mathrm{CO}_{2} \mathrm{e}\end{array}$ & $\begin{array}{c}\text { Annual PEV } \\
\text { GHG Local } \\
\text { lb- } \mathrm{CO}_{2} \mathrm{e}\end{array}$ & $\begin{array}{c}\text { Annual } \\
\text { GHG } \\
\text { Savings } \\
\text { lb- } \mathrm{CO}_{2} \mathrm{e}\end{array}$ & $\begin{array}{c}\text { Annual } \\
\text { GHG } \\
\text { Reduction \% }\end{array}$ \\
\hline MCIE & Pool & 59,160 & 4,807 & 67,204 & 26,254 & 40.950 & $61 \%$ \\
\hline MCIE & Support & 125,260 & 8,542 & 142,186 & 60,324 & 81,861 & $58 \%$ \\
\hline Command & Support & 100,478 & 6,859 & 116,215 & 47,306 & 68,908 & $59 \%$ \\
\hline MCIE & Enforce & 24,213 & 1,398 & 23,279 & 11,431 & 11,848 & $51 \%$ \\
\hline MCIE & Specialty & 2,402 & 240 & 5,406 & 2,451 & 2,955 & $55 \%$ \\
\hline Total & & 311,513 & 21,846 & 354,289 & 147,767 & 206,522 & $58 \%$ \\
\hline
\end{tabular}

In summary, if all possible monitored conventional vehicles are replaced with PEVs, GHG emissions are reduced over $200,000 \mathrm{lb}-\mathrm{CO}_{2}$ e per year. On average, each vehicle replaced results in an over 3,500 $\mathrm{lb}-\mathrm{CO}_{2} \mathrm{e}$ reduction in $\mathrm{GHG}$ emissions per year.

\subsection{Full Fleet Fuel Cost and Greenhouse Gas Reductions}

The appendices identify the potential full cost and GHG reductions if all appropriate vehicles in these fleets are replaced by PEVs using the averages identified during the monitoring process (Table 25).

Table 25. Projected fuel costs and GHG reduction potential for all vehicles in monitored fleets.

\begin{tabular}{|c|c|c|c|c|c|c|c|c|}
\hline $\begin{array}{c}\text { Annual } \\
\text { Miles CD } \\
\text { Mode }\end{array}$ & $\begin{array}{c}\text { Annual } \\
\text { Fuel Cost }\end{array}$ & $\begin{array}{l}\text { Annual } \\
\text { Elect. } \\
\text { Fuel Cost }\end{array}$ & $\begin{array}{l}\text { Annual } \\
\text { Fuel } \\
\text { Savings }\end{array}$ & $\begin{array}{c}\text { Annual } \\
\text { Fuel } \\
\text { Savings } \\
\%\end{array}$ & $\begin{array}{c}\text { Annual } \\
\text { GHG } \\
\text { Emissions } \\
\text { ICE } \mathrm{lb}_{-} \mathrm{CO}_{2} \mathrm{e}\end{array}$ & $\begin{array}{c}\text { Annual } \\
\text { PEV GHG } \\
\text { Local } \\
\text { lb- } \mathrm{CO}_{2} \mathrm{e}\end{array}$ & $\begin{array}{l}\text { Annual } \\
\text { GHG } \\
\text { Savings } \\
\text { lb- } \mathrm{CO}_{2} \mathrm{e}\end{array}$ & $\begin{array}{c}\text { Annual } \\
\text { GHG } \\
\text { Reduction } \\
\%\end{array}$ \\
\hline $4,455,269$ & $\$ 745,106$ & $\$ 99,852$ & $\$ 645,255$ & $87 \%$ & $5,174,703$ & $2,034,349$ & $3,140,354$ & $61 \%$ \\
\hline
\end{tabular}

For the vehicles represented by the full fleet at MCBCL, the annual potential fuel savings are over $\$ 645,000$ and the potential annual GHG reduction is over 1,570 tons- $\mathrm{CO}_{2} \mathrm{e}$.

\section{OBSERVATIONS}

Intertek appreciates the opportunity to present the results of this evaluation. The following observations provide input to the next phases of this study:

- Suggested PEV replacements lead to identification of charging infrastructure needs and locations to be reported separately as part of Task 3 .

- Suggested PEV replacements can be considered with vehicle age to prepare a replacement approach as part of Task 4.

- The replacement schedule will identify the charging infrastructure deployment schedule.

- Vehicle and EVSE schedules can factor into budget considerations for implementing vehicle replacements. 
- Vehicle and EVSE schedules can factor into base objectives in fuel cost reductions and GHG emissions reductions.

The analysis of Section 5 shows that the average vehicle travels approximately 8,000 miles per year. This is an average of 667 miles per month or 153 miles per week. This may reflect the opportunity to increase the percentage of BEVs over that analyzed in Section 5.

Intertek suggests that MCBCL may wish to move forward in the near future to replace pool, support, and transport vehicles with PEVs as current budget and vehicle replacement schedules allow. Certainly, the vehicle types studied in this report may be candidates for immediate replacement. 


\section{Appendix A Definitions}

Alternative fuel

City fuel economy (MPG)

Conventional fuel

Daily travel

Diesel fuel

E85

Electric vehicle

Ethanol-fueled vehicle

Federal vehicle standards

Government motor vehicle

Gross vehicle weight rating

GSA fleet
An alternative fuel means any fuel other than gasoline and diesel fuels, such as methanol, ethanol, and gaseous fuels (40 CFR 86.1803-01). A fuel type other than petroleum-based gasoline or diesel as defined by the Energy Policy Act (examples include ethanol, methanol, compressed natural gas, propane, and electrical energy).

City fuel economy means the city fuel economy determined by operating a vehicle (or vehicles) over the driving schedule in the federal emission test procedure or determined according to the vehicle-specific 5-cycle or derived 5-cycle procedures (40 CFR 600.001).

A petroleum-based fuel (examples include gasoline and diesel fuel).

The sum of daily trips and stops in one day.

Diesel means a type of engine with operating characteristics significantly similar to the theoretical diesel combustion cycle. The non-use of a throttle during normal operation is indicative of a diesel engine (49 CFR 86-1803).

Ethanol fuel blend of up to $85 \%$ denatured ethanol fuel and gasoline or other hydrocarbons by volume.

Electric vehicle means a motor vehicle that is powered solely by an electric motor drawing current from a rechargeable energy storage system, such as from storage batteries or other portable electrical energy storage devices, including hydrogen fuel cells, provided that

(1) The vehicle is capable of drawing recharge energy from a source off the vehicle, such as residential electric service

(2) The vehicle must be certified to the emission standards of Bin \#1 of Table S04-1 in § 86.1811-09(c)(6)

(3) The vehicle does not have an onboard combustion engine/generator system as a means of providing electrical energy (40 CFR 86-1803).

Ethanol-fueled vehicle-means any motor vehicle or motor vehicle engine that is engineered and designed to be operated using ethanol fuel (i.e., a fuel that contains at least $50 \%$ ethanol $\left(\mathrm{C}_{2} \mathrm{H}_{5} \mathrm{OH}\right)$ by volume) as fuel (40 CFR 86.1803-01).

The document that establishes classifications for various types and sizes of vehicles, general requirements, and equipment options. It is issued annually by the GSA Vehicle Acquisition and Leasing Service's Automotive Division.

Any motor vehicle that the government owns or leases. This includes motor vehicles obtained through purchase, excess, forfeiture, commercial lease, or GSA fleet lease.

Gross vehicle weight rating (GVWR) means the value specified by the vehicle manufacturer as the maximum design loaded weight of a single vehicle (e.g., vocational vehicle) (US Government Printing Office 2009)

GSA fleet lease means obtaining a motor vehicle from the General Services Administration fleet (GSA fleet) (41 CFR 102-34). 
Heavy light-duty truck

Highway fuel economy (Hwy MPG)

Hybrid electric vehicle

Idle time

Law enforcement

Light-duty motor vehicle Light-duty truck
Heavy light-duty truck means any light-duty truck rated greater than 6,000 lb GVWR. The light-duty truck 3 (LDT3) and LDT4 classifications comprise the heavy light-duty truck category (40 CFR 86.1803-01).

Highway fuel economy means the highway fuel economy determined either by operating a vehicle (or vehicles) over the driving schedule in the federal highway fuel economy test procedure or determined according to either the vehicle-specific, 5-cycle equation, or the derived 5-cycle equation for highway fuel economy (40 CFR 600.001).

Hybrid electric vehicle means a motor vehicle that draws propulsion energy from onboard sources of stored energy that are both an internal combustion engine or heat engine using consumable fuel and a rechargeable energy storage system (such as a battery, capacitor, hydraulic accumulator, or flywheel), where recharge energy for the energy storage system comes solely from sources on board the vehicle.

Idle time is logged whenever a vehicle idles with the engine running for 3 minutes or longer.

Law enforcement motor vehicle means a light-duty motor vehicle that is specifically approved in an agency-s appropriation act for use in apprehension, surveillance, police, or other law enforcement work or specifically designed for use in law enforcement. If not identified in an agency's appropriation language, a motor vehicle qualifies as a law enforcement motor vehicle only in the following cases:

(1) A passenger automobile having heavy-duty components for electrical, cooling, and suspension systems and at least the next higher cubic inch displacement or more powerful engine than is standard for the automobile concerned

(2) A light truck having emergency warning lights and identified with markings such as "police"

(3) An unmarked motor vehicle certified by the agency head as essential for the safe and efficient performance of intelligence, counterintelligence, protective, or other law enforcement duties

(4) A forfeited motor vehicle seized by a federal agency that subsequently is used for performing law enforcement activities (41 CFR Part 102-34.35).

Any motor vehicle with a GVWR of 8,500 pounds or less (41 CFR 102-34). Light-duty truck means any motor vehicle rated at 8,500 pounds GVWR or less, which has a curb weight of 6,000 pounds or less and, which has a basic vehicle frontal area of 45 square feet or less, which is as follows:

(1) Designed primarily for purposes of transportation of property or is a derivation of such a vehicle

(2) Designed primarily for transportation of persons and has a capacity of more than 12 persons

(3) Available with special features, enabling off-street or off-highway operation and use.

LDT1 means any light light-duty truck up through 3,750-lb loaded vehicle weight.

LDT2 means any light light-duty truck greater than 3,750-lb loaded vehicle weight. 


\section{Light-duty vehicle \\ Low-speed vehicle \\ Light-duty vehicle means a passenger car or passenger car derivative capable of seating 12 passengers or less. \\ Low-speed vehicle means a motor vehicle \\ (1) That is 4-wheeled \\ (2) Whose speed attainable in $1.6 \mathrm{~km}$ (1 mile) is more than 32 kilometers per hour (20 miles per hour) and not more than 40 kilometers per hour (25 miles per hour) on a paved level surface \\ (3) Whose GVWR is less than 1,361 kilograms (3,000 pounds) (49 CFR 571.3 - Definitions).}

Medium-duty passenger vehicle

Model year

$M P G$

$M P G e$

Non-passenger automobile
LDT3 means any heavy light-duty truck up through 5,750-lb adjusted loaded vehicle weight.

LDT4 means any heavy light-duty truck greater than 5,750-lb adjusted loaded vehicle weight (US Government Printing Office 2009)

Medium-duty passenger vehicle means any heavy-duty vehicle (as defined in this subpart) with a GVWR of less than 10,000 pounds that is designed primarily for transportation of persons. The medium-duty passenger vehicle definition does not include any vehicle which

(1) Is an "incomplete truck" as defined in this subpart

(2) Has a seating capacity of more than 12 persons

(3) Is designed for more than 9 persons in seating rearward of the driver's seat

(4) Is equipped with an open cargo area (for example, a pick-up truck box or bed) of 72.0 inches in interior length or more. A covered box not readily accessible from the passenger compartment will be considered an open cargo area for purposes of this definition (US Government Printing Office 2009)

Model year means the manufacturer's annual production period (as determined by the administrator), which includes January 1 of such calendar year; provided that if the manufacturer has no annual production period, the term "model year" shall mean the calendar year (40 CFR 86-1803.01).

"MPG" or "mpg" means miles per gallon. This generally may be used to describe fuel economy as a quantity or it may be used as the units associated with a particular value.

MPGe means miles per gallon equivalent. This generally is used to quantify a fuel economy value for vehicles that use a fuel other than gasoline. The value represents miles the vehicle can drive with the energy equivalent of one gallon of gasoline:

(c) SCF means standard cubic feet

(d) SUV means sport utility vehicle

(e) CREE means carbon-related exhaust emissions [76 FR 39527, July 6, 2011].

A non-passenger automobile means an automobile that is not a passenger automobile or a work truck and includes vehicles described in paragraphs (a) and (b) of 49 CFR 523.5. 
Owning agency

Passenger automobile

Pickup truck

Plug-in hybrid electric vehicle

Vehicle class

Vehicle configuration

Vehicle days

Vehicle home base

Vehicle study period
Owning agency means the executive agency that holds the vehicle title, manufacturer's Certificate of Origin or is the lessee of a commercial lease. This term does not apply to agencies that lease motor vehicles from the GSA fleet (41 CFR Part 102-34.35).

A passenger automobile is any automobile (other than an automobile capable of off-highway operation) manufactured primarily for use in the transportation of not more than 10 individuals (49 CFR 523.4 - Passenger automobile). A sedan or station wagon designed primarily to transport people (41 CFR 102-34).

Pickup truck means a non-passenger automobile, which has a passenger compartment and an open cargo bed (49 CFR 523.2).

PHEV means a hybrid electric vehicle that has the capability to charge the battery from an off-vehicle electric source, such that the off-vehicle source cannot be connected to the vehicle while the vehicle is in motion (40 CFR 86.1803).

The designation of motor vehicle types that include sedans, station wagons, ambulances, buses, and trucks, or different categories of vehicles according to Federal vehicle standards and further defined in 49 CFR 600.315-82.

Vehicle configuration means a unique combination of basic engine, engine code, inertia weight class, transmission configuration, and axle ratio.

The number of days a vehicle was driven or utilized during the (vehicle) study period.

The primary assigned outing beginning and ending parking location for the vehicle.

The time period the vehicle, within the study, has been equipped with a data logger. 


\section{Appendix B \\ Marine Corps Base Camp Lejeune Commands Group Vehicle Data Sheets}

Table B-1. MCBCL Commands Group vehicle index.

\begin{tabular}{cccccccc}
\hline \multicolumn{7}{c}{ Fleet } & \multicolumn{5}{c}{ Vehicle Index } \\
Sheet & Log & Vehicle Id & Make & Model & Year & EPA Class & Mission \\
\hline 1 & 88 & 291073 & Ford & E250 & 2007 & Van - Pass & Support \\
2 & 17 & 301321 & Ford & F350 & 2012 & Pickup & Support \\
3 & 95 & G41-0762M & Dodge & Grand Caravan & 2012 & Minivan & Support \\
4 & 86 & G41-1846K & Dodge & Grand Caravan & 2011 & Minivan & Support \\
5 & 83 & G41-2399K & Dodge & Dakota & 2010 & Pickup & Support \\
6 & 90 & G42-0216F & Ford & E150 & 2008 & Van - Pass & Support \\
7 & 92 & G42-0883M & Ford & E150 & 2012 & Van - Pass & Support \\
8 & 84 & G42-0898M & Ford & E150 & 2012 & Van - Pass & Support \\
9 & 18 & G43-0326H & Chevrolet & $2500 H D$ & 2009 & Pickup & Support \\
10 & 103 & G43-1453G & Chevrolet & G2300 & 2008 & Van - Pass & Support \\
11 & 19 & G43-1855P & Ford & F350 & 2015 & Pickup & Support \\
12 & 20 & G43-2025K & Ford & F250 & 2010 & Pickup & Support \\
13 & 110 & G43-4073F & Chevrolet & G2300 & 2008 & Van - Pass & Support \\
14 & 87 & G61-0594L & Jeep & Patriot & 2011 & SUV & Support \\
15 & 94 & G61-2644P & Jeep & Patriot & 2015 & SUV & Support \\
16 & 91 & G62-0791H & Ford & Expedition & 2009 & SUV & Support \\
17 & 99 & G63-0309R & Ford & F350 & 2015 & Pickup & Support \\
18 & 120 & G63-0934G & Chevrolet & K3500 & 2008 & Pickup & Support \\
\hline
\end{tabular}


Sheet 1: Vehicle 291073

\begin{tabular}{|l|l|c|}
\hline \multirow{4}{*}{} & Make/Model/Year & Ford E250 - 2007 \\
\cline { 2 - 3 } & EPA Class Size & Van - Passenger \\
\cline { 2 - 3 } & Mission & Support \\
\cline { 2 - 3 } & Contact & Marine Headquarters \\
\cline { 2 - 3 } & Parking Location & Building PP2 \\
\cline { 2 - 3 } & Fleet Vehicle ID & 291073 \\
\cline { 2 - 3 } & Fuel Type & Gas \\
\cline { 2 - 3 } & EPA Label/MPG (City/Hwy/Combined)* & $14 / 19 / 16$ \\
\cline { 2 - 3 } & EPA GHG Emissions (Grams CO $/$ /Mi)* & 555 \\
\cline { 2 - 3 } & Study Logger ID & 88 \\
\cline { 2 - 3 } & Total Vehicle Days/Total Study Days & $14 / 33$ \\
\hline
\end{tabular}

\begin{tabular}{|l|c|c|c|c|}
\hline \multicolumn{5}{|c|}{ Vehicle 291073 Travel Summary } \\
\hline & $\begin{array}{c}\text { Per Day } \\
\text { Average/Peak }\end{array}$ & $\begin{array}{c}\text { Per Outing } \\
\text { Average/Peak }\end{array}$ & $\begin{array}{c}\text { Per Trip } \\
\text { Average/Peak }\end{array}$ & Total \\
\hline Travel Distance (Miles) & $17.3 / 45.8$ & $7.1 / 25.6$ & $4.1 / 21.8$ & 243 \\
\hline Travel Time (Minutes) & $89.0 / 272.0$ & $36.7 / 152.0$ & $20.8 / 130.0$ & 1,249 \\
\hline Idle Time (Minutes) & $36.6 / \mathrm{NA}$ & $15.1 / \mathrm{NA}$ & $8.6 / \mathrm{NA}$ & 513 \\
\hline
\end{tabular}

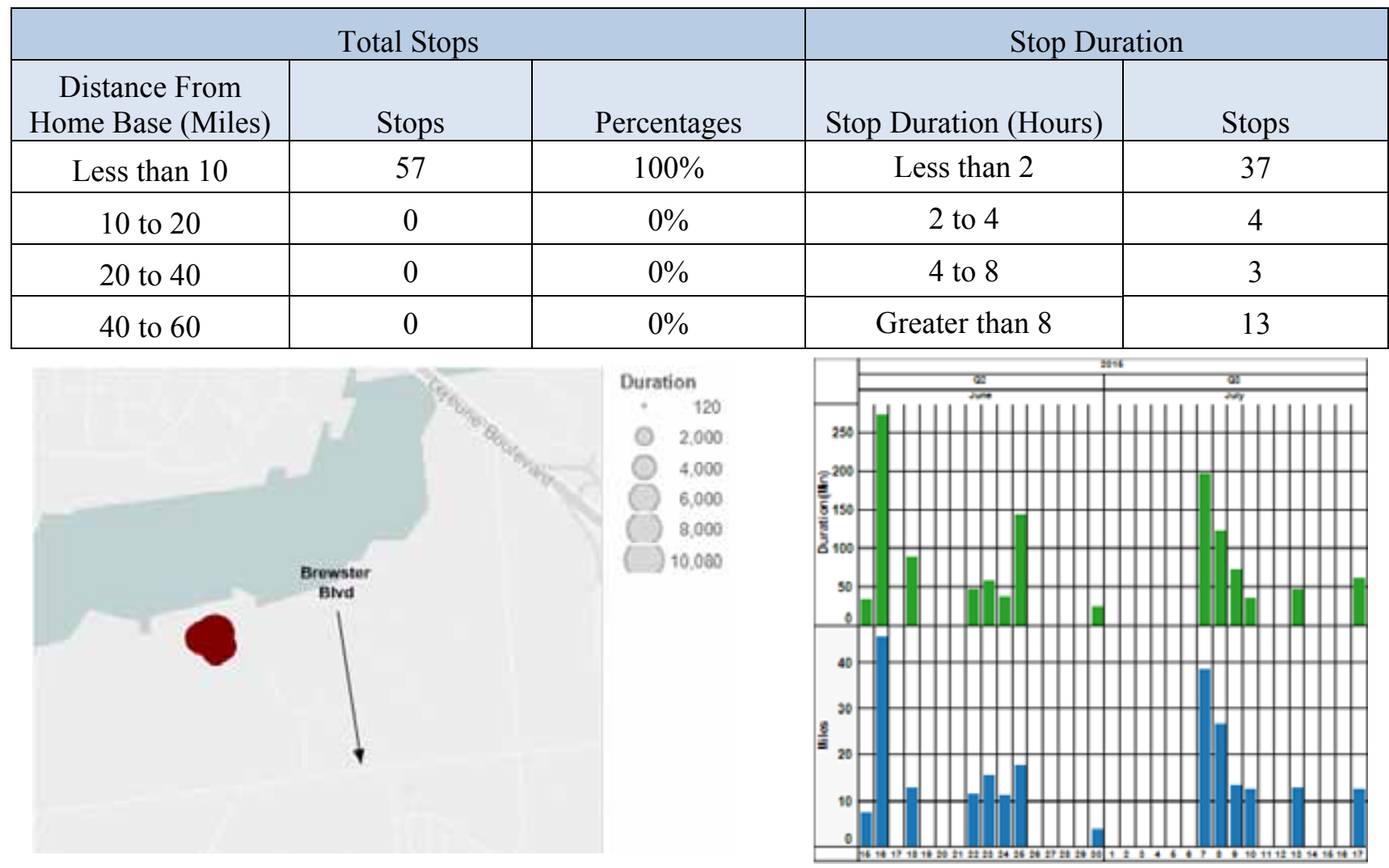

Figure B-1. Vehicle 291073 stops.

Figure B-2. Vehicle 291073 history.

*EPA economy is not available for E250. Economy used is for F150. 

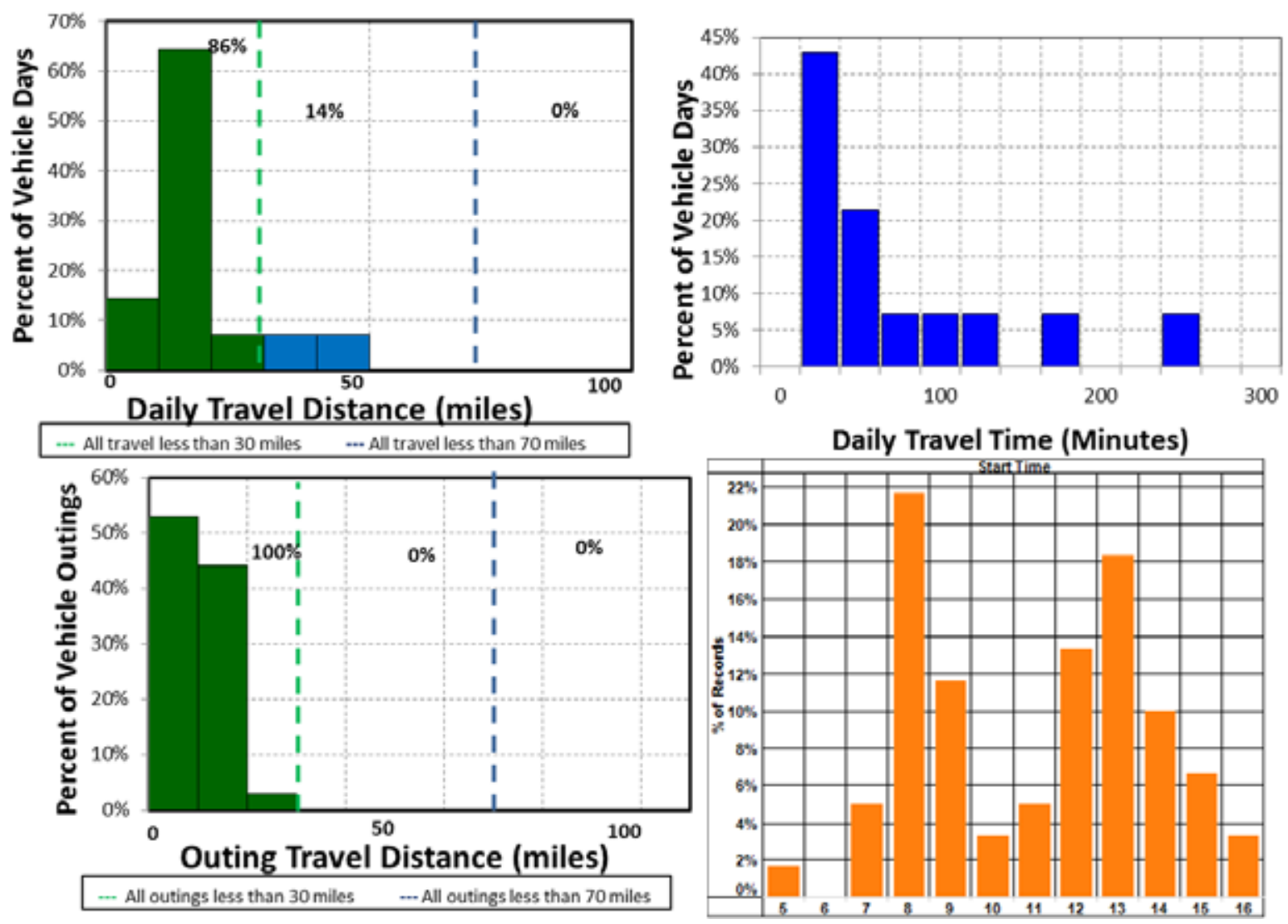

Figure B-3. Vehicle 291073 travel graphs.

\section{Vehicle 291073 Observations}

Logger 88 collected data on this vehicle for a period of 14 days of the 33-day study period. Validation occurred on $97.6 \%$ of the input data. Data indicate that this vehicle has a support mission for the Marine Headquarters Group. This vehicle's data indicate it parks near Building PP2 on Hospital Corps Boulevard as shown in the Google Earth figure to the right.

MCBCL reports a recent odometer reading of 45,547 miles and an average annual mileage of 2,935 miles. The vehicle was used on $42 \%$ of the available days, with an average daily usage of 1.5 hours and a peak daily usage of 4.5 hours on the days it was used. The vehicle was used primarily during day shift hours.

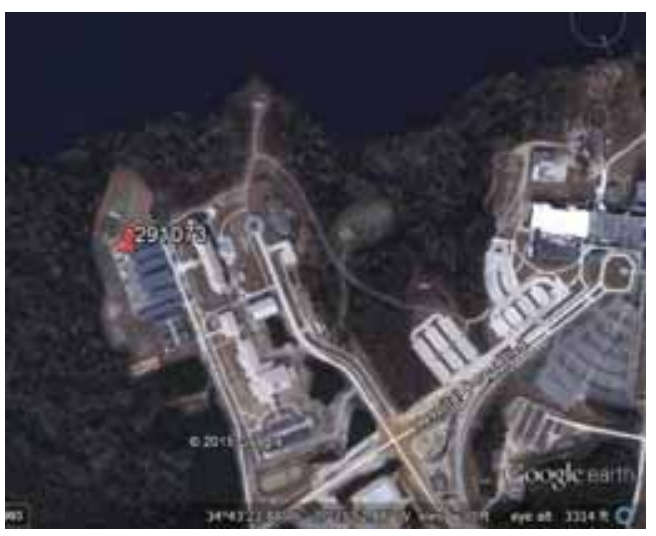

Figure B-3 shows that all daily travel was within the typically advertised range of a BEV of approximately 70 miles. All outings were also within this range. Further, $86 \%$ of daily travel and all outings were within the typically advertised CD mode of 30 miles for PHEVs.

A BEV could meet all daily travel without additional charging opportunities, assuming the vehicle was assigned a home base. 
Sheet 2: Vehicle 301321

\begin{tabular}{|c|c|c|}
\hline $3 x y=$ & Make/Model/Year & Ford F350 - 2012 \\
\hline 18 & EPA Class Size & Pickup \\
\hline 189 & Mission & Support \\
\hline Ext- in & Contact & School of Infantry \\
\hline & Parking Location & Building G644 \\
\hline & Fleet Vehicle ID & 301321 \\
\hline & Fuel Type & E85 \\
\hline & EPA Label/MPG (City/Hwy/Combined)* & $9 / 12 / 10$ \\
\hline & EPA GHG Emissions $\left(\mathrm{Grams} \mathrm{CO}_{2} / \mathrm{Mi}\right)^{*}$ & 620 \\
\hline & Study Logger ID & 17 \\
\hline & Total Vehicle Days/Total Study Days & $9 / 40$ \\
\hline
\end{tabular}

\begin{tabular}{|l|c|c|c|c|}
\hline \multicolumn{5}{|c|}{ Vehicle 301321Travel Summary } \\
\hline & $\begin{array}{c}\text { Per Day } \\
\text { Average/Peak }\end{array}$ & $\begin{array}{c}\text { Per Outing } \\
\text { Average/Peak }\end{array}$ & $\begin{array}{c}\text { Per Trip } \\
\text { Average/Peak }\end{array}$ & Total \\
\hline Travel Distance (Miles) & $12.3 / 31.7$ & $8.5 / 31.7$ & $3.6 / 28.3$ & 111 \\
\hline Travel Time (Minutes) & $60.7 / 137.0$ & $42.0 / 217.0$ & $17.6 / 78.0$ & 546 \\
\hline Idle Time (Minutes) & $28.7 / \mathrm{NA}$ & $19.8 / \mathrm{NA}$ & $8.3 / \mathrm{NA}$ & 258 \\
\hline
\end{tabular}

\begin{tabular}{|c|c|c|c|c|}
\hline \multicolumn{3}{|c|}{ Total Stops } & \multicolumn{2}{c|}{ Stop Duration } \\
\hline $\begin{array}{c}\text { Distance From } \\
\text { Home Base (Miles) }\end{array}$ & Stops & Percentages & Stop Duration (Hours) & Stops \\
\hline Less than 10 & 27 & $100 \%$ & Less than 2 & 17 \\
\hline 10 to 20 & 0 & 0 & 2 to 4 & 2 \\
\hline 20 to 40 & 0 & 0 & 4 to 8 & \\
\hline 40 to 60 & 0 & 0 & Greater than 8 & \\
\hline
\end{tabular}

Figure B-4. Vehicle 301321 stops.

*Fuel Economy for F350 is not available. Figures used are for E350.

Figure B-5. Vehicle 301321 history. 


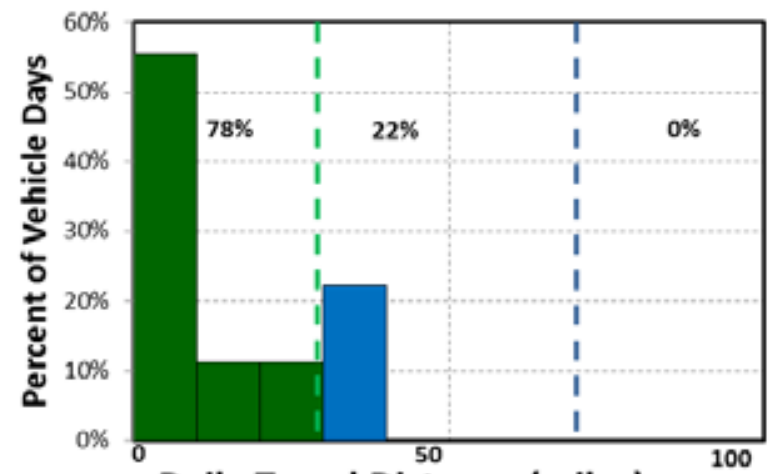

Daily Travel Distance (miles)

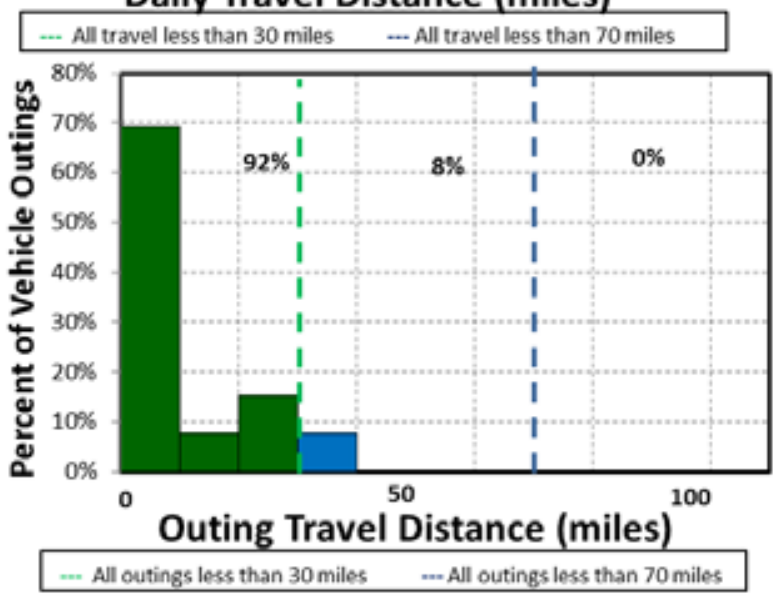

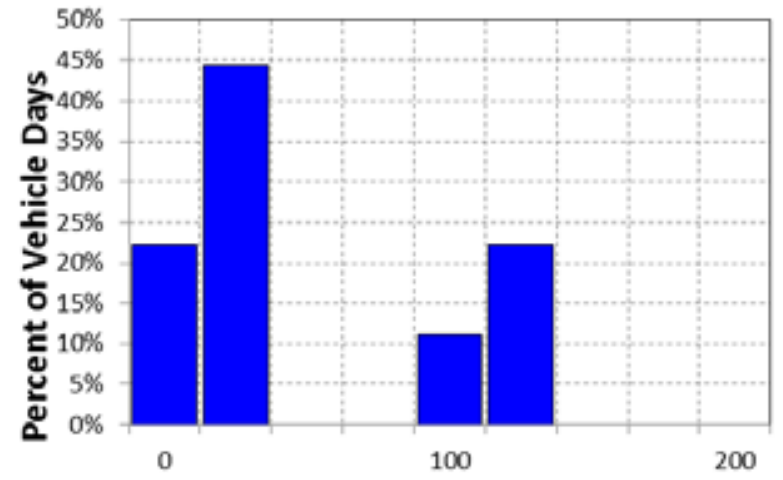

Daily Travel Time (Minutes)

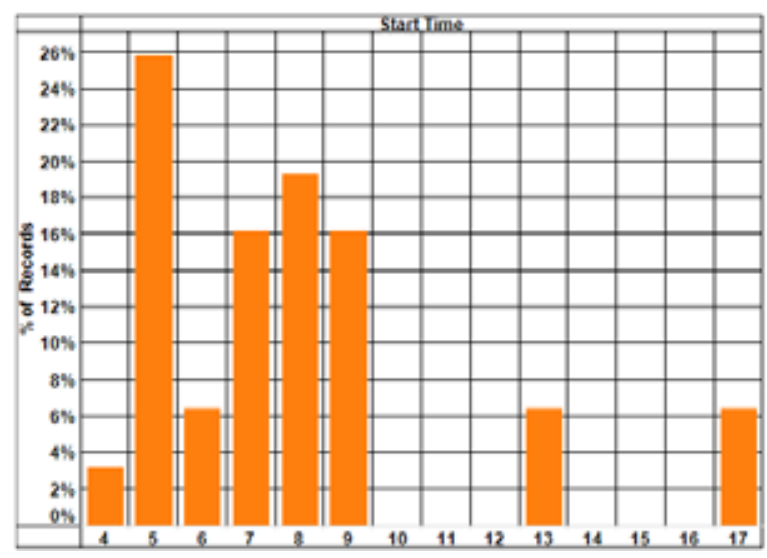

Figure B-6. Vehicle 301321 travel graphs.

\section{Vehicle 301321 Observations}

Logger 17 collected data on this vehicle for a period of 9 days of the 40-day study period. Validation occurred on $100 \%$ of the input data. Data indicate that this vehicle has a support mission for the School of Infantry. This vehicle's data indicate it parks near Building TC771 on G Street as shown in the Google Earth figure to the right.

MCBCL reports that the vehicle odometer indicated a recent odometer reading of 11,849 miles at the start of this study and an average annual mileage of 3,669 miles. The vehicle was used on $23 \%$ of the available days, with an average daily usage of 1.0 hours and a peak daily usage of 2.3 hours on the days it was used. The vehicle was used during all hours of the day.

Figure B-6 shows all daily travel was within the typically

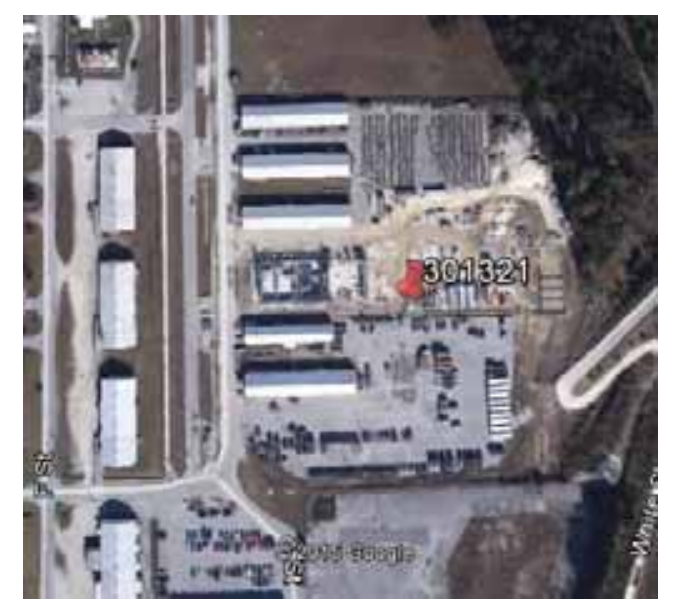
advertised range of a BEV of approximately 70 miles. All outings were also within this range. Further, $78 \%$ of daily travel and $92 \%$ of outings were within the typically advertised CD mode of 30 miles for PHEVs.

A BEV could meet all daily travel without additional charging opportunities, assuming the vehicle was assigned a home base. 


\begin{tabular}{|c|c|c|}
\hline$h$ hescaresy & Make/Model/Year & Dodge Grand Caravan - 2012 \\
\hline $2 \times 10$ & EPA Class Size & Minivan \\
\hline$x-5=$ & Mission & Support \\
\hline 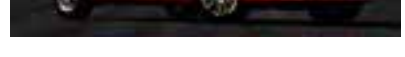 & Contact & Marine Aircraft Group 26 \\
\hline & Parking Location & Building AS217 \\
\hline & Fleet Vehicle ID & G41-0762M \\
\hline & Fuel Type & E85 \\
\hline & EPA Label/MPG (City/Hwy/Combined) & $12 / 18 / 14$ \\
\hline & EPA GHG Emissions (Grams $\left.\mathrm{CO}_{2} / \mathrm{Mi}\right)$ & 443 \\
\hline & Study Logger ID & 95 \\
\hline & Total Vehicle Days/Total Study Days & $22 / 33$ \\
\hline
\end{tabular}

\begin{tabular}{|l|c|c|c|c|}
\hline \multicolumn{5}{|c|}{ Vehicle G41-0762M Travel Summary } \\
\hline & $\begin{array}{c}\text { Per Day } \\
\text { Average/Peak }\end{array}$ & $\begin{array}{c}\text { Per Outing } \\
\text { Average/Peak }\end{array}$ & $\begin{array}{c}\text { Per Trip } \\
\text { Average/Peak }\end{array}$ & Total \\
\hline Travel Distance (Miles) & $63.7 / 140.8$ & $27.0 / 125.4$ & $11.7 / 59.6$ & 1,402 \\
\hline Travel Time (Minutes) & $154.7 / 411.0$ & $65.5 / 318.0$ & $28.4 / 128.0$ & 3,404 \\
\hline Idle Time (Minutes) & $37.2 / \mathrm{NA}$ & $15.8 / \mathrm{NA}$ & $6.8 / \mathrm{NA}$ & 819 \\
\hline
\end{tabular}

\begin{tabular}{|c|c|c|c|c|}
\hline \multicolumn{2}{|c|}{ Total Stops } & \multicolumn{2}{c|}{ Stop Duration } \\
\hline $\begin{array}{c}\text { Distance From } \\
\text { Home Base (Miles) }\end{array}$ & Stops & Percentages & Stop Duration (Hours) & Stops \\
\hline Less than 10 & 86 & $78.9 \%$ & Less than 2 & 70 \\
\hline 10 to 20 & 0 & 0 & 2 to 4 & 13 \\
\hline 20 to 40 & 23 & $21.1 \%$ & 4 to 8 & 19 \\
\hline 40 to 60 & 0 & 0 & Greater than 8 & \\
\hline 4 & & & & \\
\hline
\end{tabular}

Figure B-7. Vehicle G41-0762M stops.

Figure B-8. Vehicle G41-0762M history. 

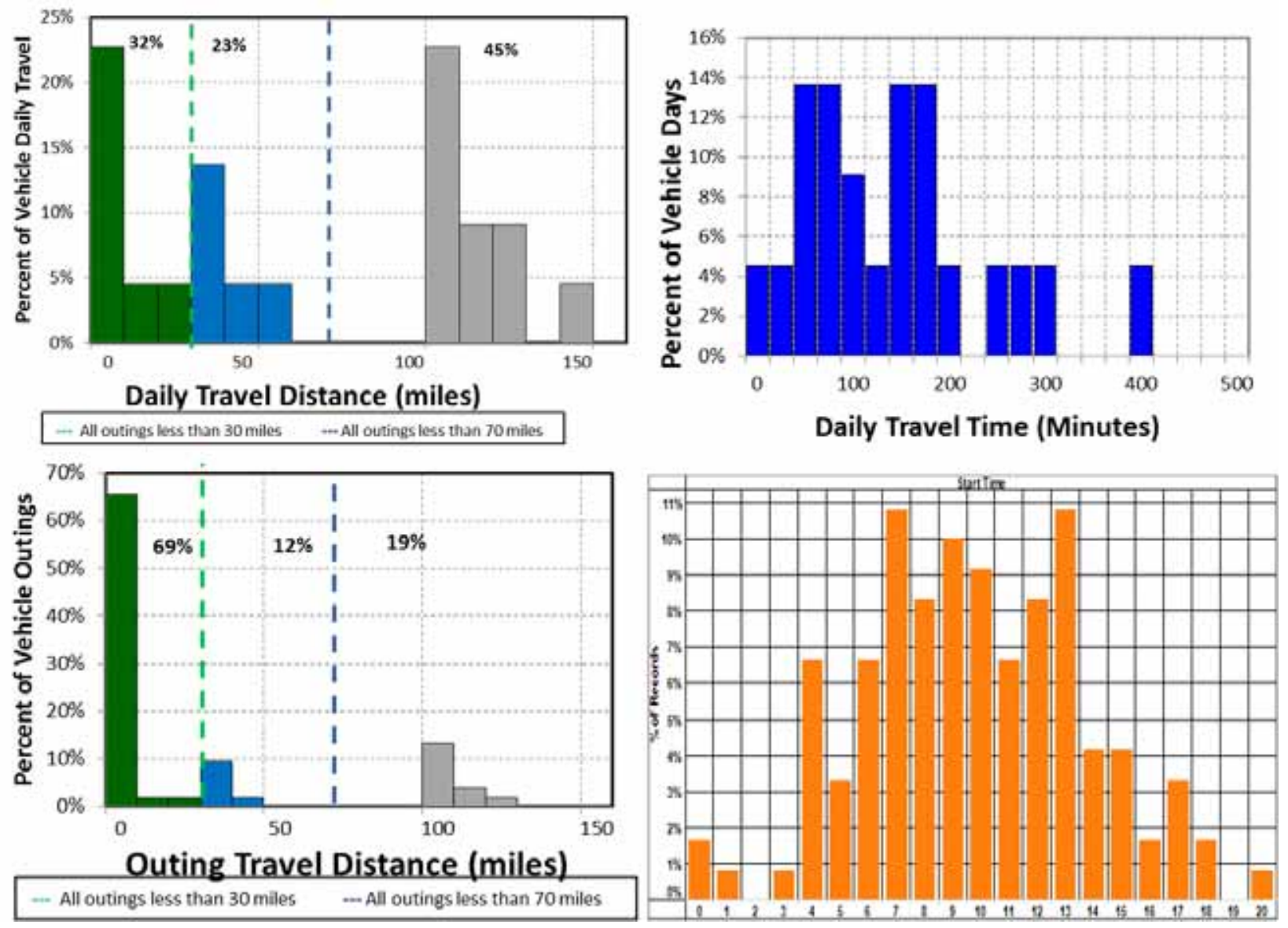

Figure B-9. Vehicle G41-0762M travel graphs.

\section{Vehicle G41-0762M Observations}

Logger 95 collected data on this vehicle for a period of 22 days of the 33-day study period. Validation occurred on $99.4 \%$ of the input data. Data indicate that this vehicle has a support mission for MAG26. This vehicle's data indicate it parks near Building AS217 on Campbell Street as shown in the Google Earth figure to the right.

MCBCL reports that a recent odometer indicated 24,992 miles and an average annual mileage of 20,099 miles. The vehicle was used on $67 \%$ of the available days, with an average daily usage of 2.6 hours and a peak daily usage of 6.9 hours on the days it was used. The vehicle was used primarily during extended day shift hours.

Figure B-9 shows that $55 \%$ of daily travel was within the

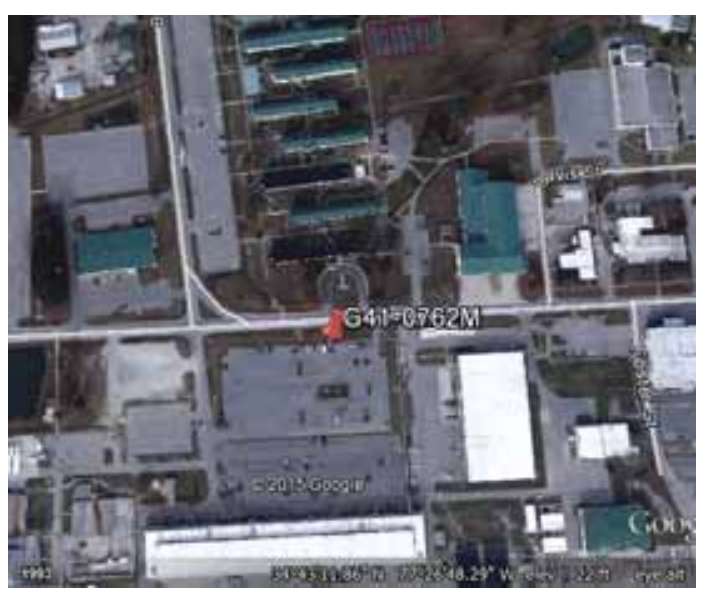
typically advertised range of a BEV of approximately 70 miles and $81 \%$ of outings were also within this range. Further, $32 \%$ of daily travel and $69 \%$ of outings were within the typically advertised CD mode of 30 miles for PHEVs.

A BEV could not meet all daily travel without additional charging opportunities, assuming the vehicle was assigned a home base. However, because several outings also exceeded the BEV range, a PHEV would be recommended. 
Sheet 4: Vehicle G41-1846K

\begin{tabular}{|l|l|c|}
\hline & Make/Model/Year & Dodge Grand Caravan - 2011 \\
\cline { 2 - 3 } & EPA Class Size & Sinivan \\
\cline { 2 - 3 } & Mission & Special Operation Training \\
\cline { 2 - 3 } & Contact & Building BA134 \\
\cline { 2 - 3 } & Parking Location & G41-1846K \\
\hline Fleet Vehicle ID & E85 \\
\cline { 2 - 3 } & Fuel Type & $12 / 18 / 14$ \\
\hline & EPA Label/MPG (City/Hwy/Combined) & 443 \\
\cline { 2 - 3 } & EPA GHG Emissions (Grams CO $/$ Mi) & 86 \\
\cline { 2 - 3 } & Study Logger ID & $11 / 30$ \\
\hline & Total Vehicle Days/Total Study Days & \\
\hline
\end{tabular}

\begin{tabular}{|l|c|c|c|c|}
\hline \multicolumn{5}{|c|}{ Vehicle G41-1846K Travel Summary } \\
\hline & $\begin{array}{c}\text { Per Day } \\
\text { Average/Peak }\end{array}$ & $\begin{array}{c}\text { Per Outing } \\
\text { Average/Peak }\end{array}$ & $\begin{array}{c}\text { Per Trip } \\
\text { Average/Peak }\end{array}$ & Total \\
\hline Travel Distance (Miles) & $93.1 / 405.0$ & $42.7 / 788.0$ & $15.5 / 208.1$ & 1,024 \\
\hline Travel Time (Minutes) & $147.6 / 510.0$ & $67.7 / 911.0$ & $24.6 / 179.0$ & 1,624 \\
\hline Idle Time (Minutes) & $37.0 / \mathrm{NA}$ & $17.0 / \mathrm{NA}$ & $6.2 / \mathrm{NA}$ & 407 \\
\hline
\end{tabular}

\begin{tabular}{|c|c|c|c|c|c|}
\hline \multicolumn{2}{|c|}{ Total Stops } & \multicolumn{3}{c|}{ Stop Duration } \\
\hline $\begin{array}{c}\text { Distance From } \\
\text { Home Base (Miles) }\end{array}$ & Stops & Percentages & Stop Duration (Hours) & Stops \\
\hline Less than 10 & 39 & $81.3 \%$ & Less than 2 & 32 \\
\hline 10 to 20 & 0 & 0 & 2 to 4 & 5 \\
\hline 20 to 40 & 0 & 0 & & 4 to 8 & 2 \\
\hline Greater than 40 & 9 & $18.7 \%$ & & Greater than 8 & \\
\hline
\end{tabular}

Figure B-10. Vehicle G41-1846K stops.

Figure B-11. Vehicle G41-1846K history. 


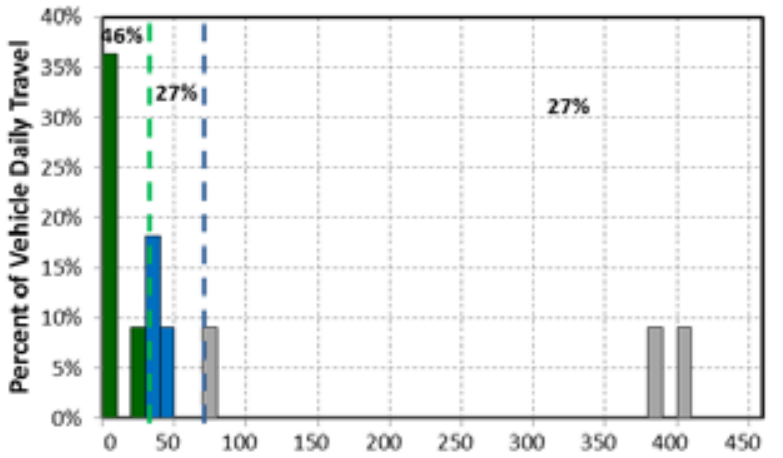

Daily Travel Distance (miles)

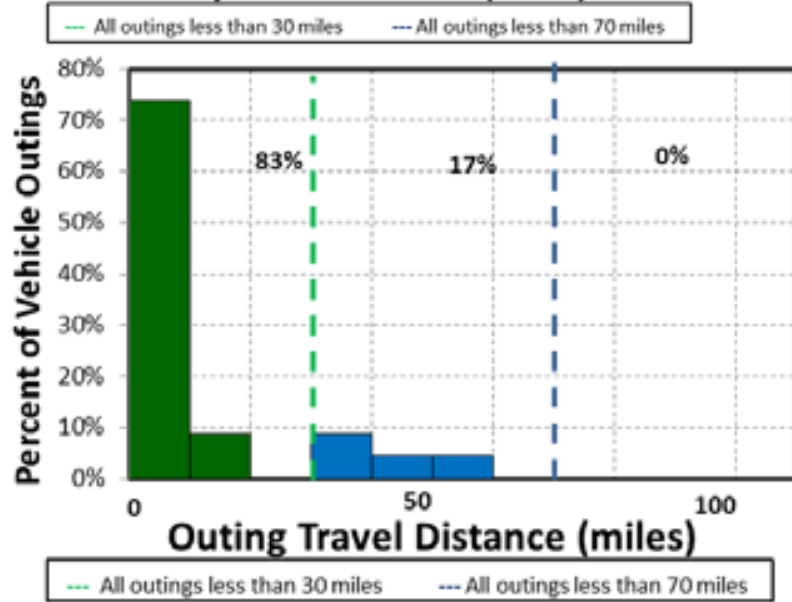

All outings less than 30 miles $\quad$.... All outings less than 70 miles

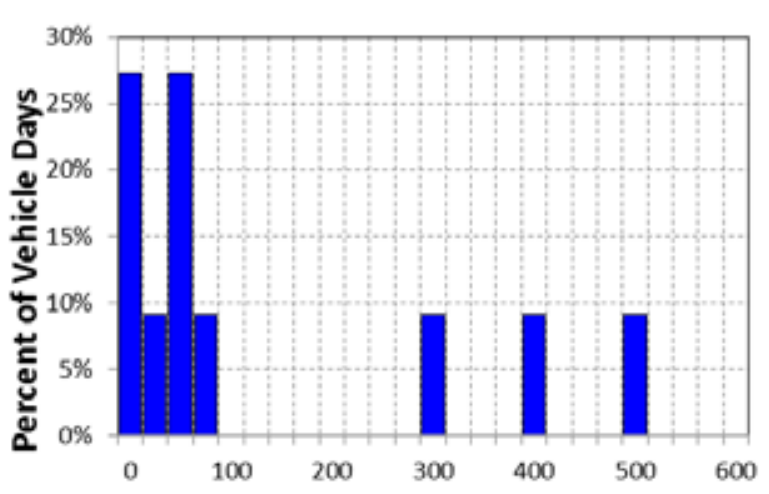

Daily Travel Time (Minutes)

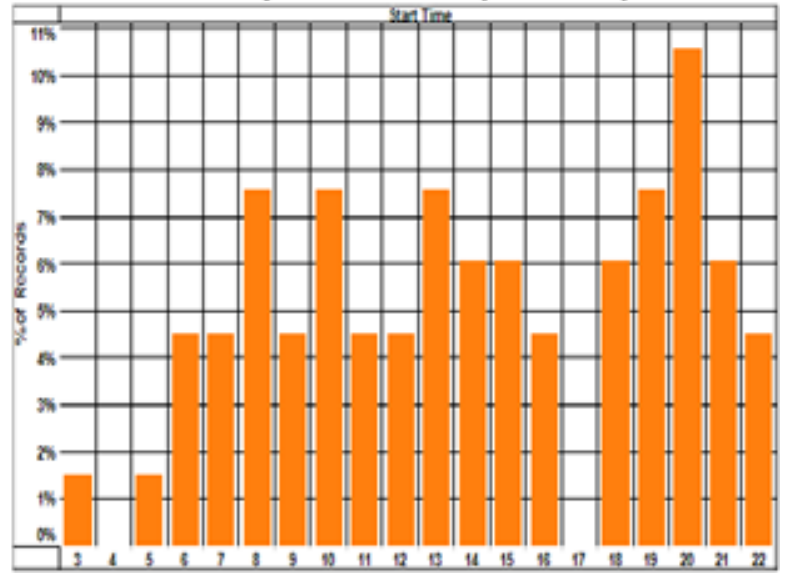

Figure B-12. Vehicle G41-1846K travel graphs. Note that the maximum outing of 788 miles is not shown for clarity of scale.

\section{Vehicle G41-1846K Observations}

Logger 86 collected data on this vehicle for a period of 11 days of the 30-day study period. Validation occurred on $100 \%$ of the input data. Data indicate that this vehicle has a support mission for Special Operations Training. This vehicle's data indicate it parks overnight at several different locations, including near Dr G W Carver Street but mostly near Building BA134 on Ocean Drive as shown in the Google Earth figure to the right.

MCBCL reports that a recent vehicle odometer indicated 43,151 miles and an average annual mileage of 12,317 miles. The vehicle was used on $37 \%$ of the available days, with an average daily

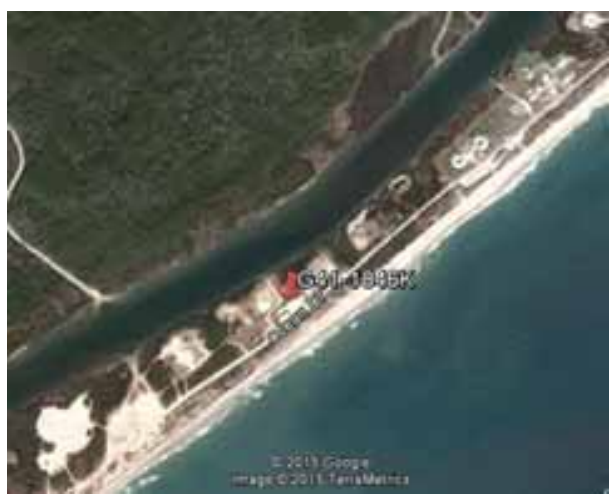
usage of 2.5 hours and a peak daily usage of 8.5 hours on the days it was used. The vehicle was used during all hours of the day.

Figure B-12 shows that $73 \%$ of daily travel was within the typically advertised range of a BEV of approximately 70 miles. Nearly $100 \%$ of outings were also within this range. Further, $46 \%$ of daily travel and $83 \%$ of outings were within the typically advertised CD mode of 30 miles for PHEVs. The peak outing of 788 miles occurred over a several day period on an excursion to Hindsville, Georgia and Florence, South Carolina.

A BEV could not meet all daily travel without additional charging opportunities, assuming the vehicle was assigned a home base. In addition, the long excursion exceeded the BEV range, even with additional charge opportunities. A PHEV would be suggested. 
Sheet 5: Vehicle G41-2399K

\begin{tabular}{|l|l|c|}
\hline & Make/Model/Year & Dodge Dakota -2010 \\
\cline { 2 - 3 } & EPA Class Size & Pickup \\
\cline { 2 - 3 } & Mission & Support \\
\cline { 2 - 3 } & Contact & $2^{\text {nd }}$ Marine Division \\
\cline { 2 - 3 } & Parking Location & Building 1707 \\
\cline { 2 - 3 } & Fleet Vehicle ID & G41-2399K \\
\cline { 2 - 3 } & Fuel Type & E85 \\
\cline { 2 - 3 } & EPA Label/MPG (City/Hwy/Combined) & $9 / 13 / 10$ \\
\cline { 2 - 3 } & EPA GHG Emissions (Grams CO $/$ Mi) & 620 \\
\cline { 2 - 3 } & Study Logger ID & 83 \\
\cline { 2 - 3 } & Total Vehicle Days/Total Study Days & $11 / 32$ \\
\hline
\end{tabular}

\begin{tabular}{|l|c|c|c|c|}
\hline \multicolumn{5}{|c|}{ Vehicle G41-2399K Travel Summary } \\
\hline & $\begin{array}{c}\text { Per Day } \\
\text { Average/Peak }\end{array}$ & $\begin{array}{c}\text { Per Outing } \\
\text { Average/Peak }\end{array}$ & $\begin{array}{c}\text { Per Trip } \\
\text { Average/Peak }\end{array}$ & Total \\
\hline Travel Distance (Miles) & $31.1 / 100.8$ & $14.3 / 60.0$ & $7.6 / 59.7$ & 342 \\
\hline Travel Time (Minutes) & $110.6 / 317.0$ & $50.7 / 181.0$ & $27.0 / 165.0$ & 1,217 \\
\hline Idle Time (Minutes) & $37.8 / \mathrm{NA}$ & $17.3 / \mathrm{NA}$ & $9.2 / \mathrm{NA}$ & 416 \\
\hline
\end{tabular}

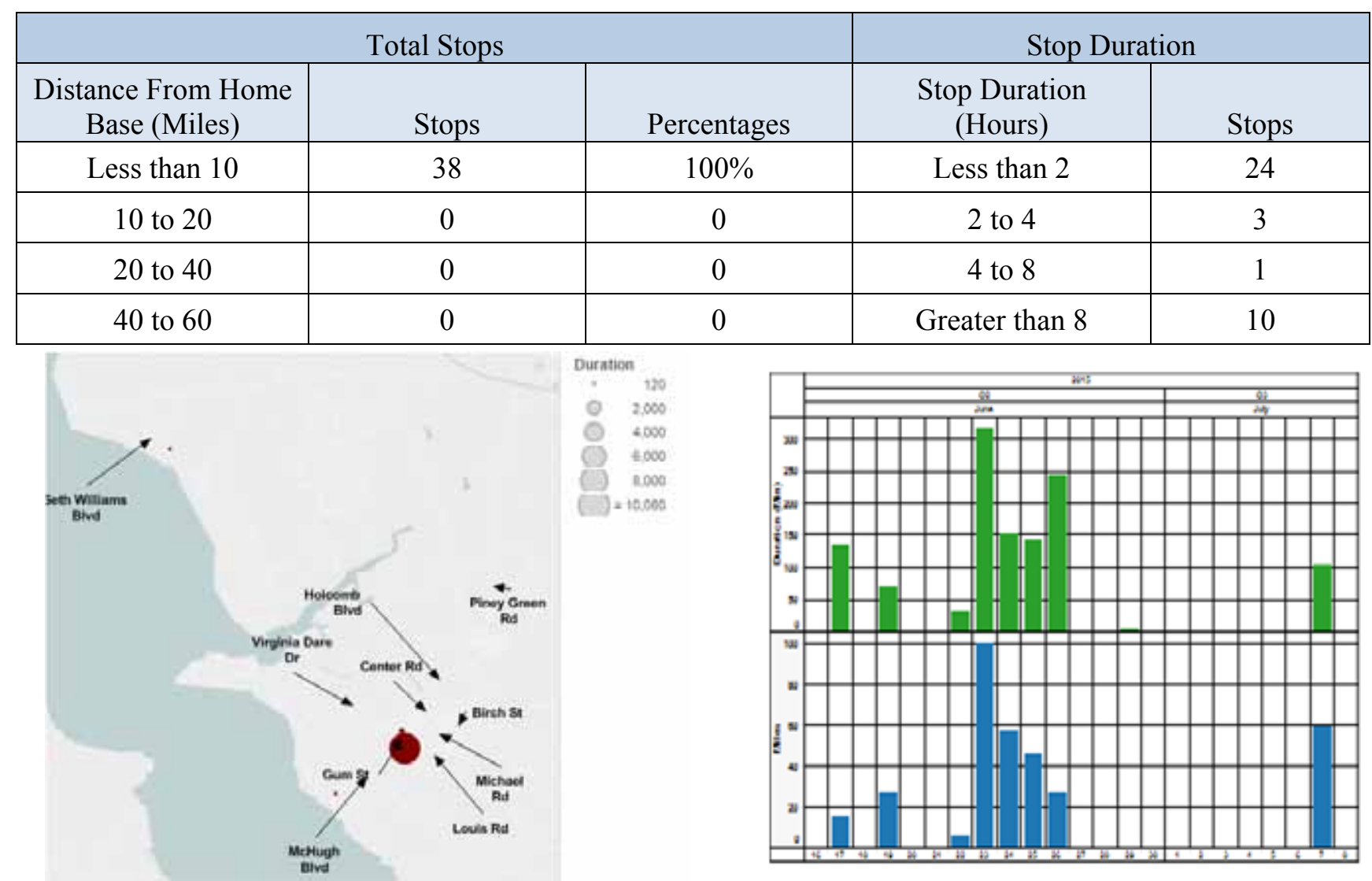

Figure B-13. Vehicle G41-2399K stops.

Figure B-14. Vehicle G41-2399K history. 


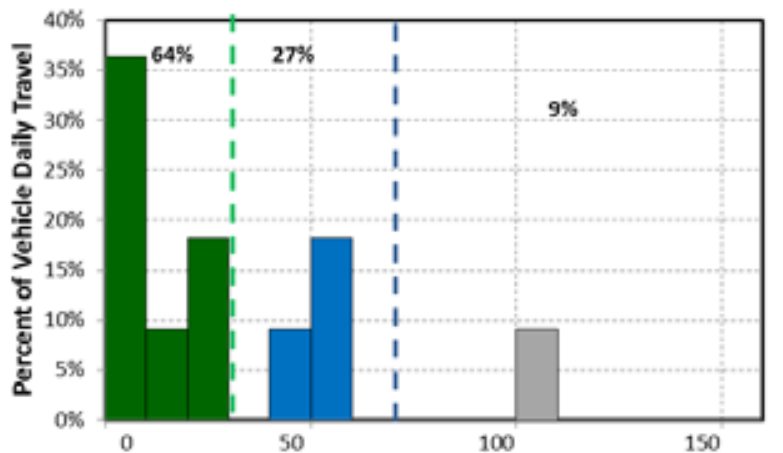

Daily Travel Distance (miles)

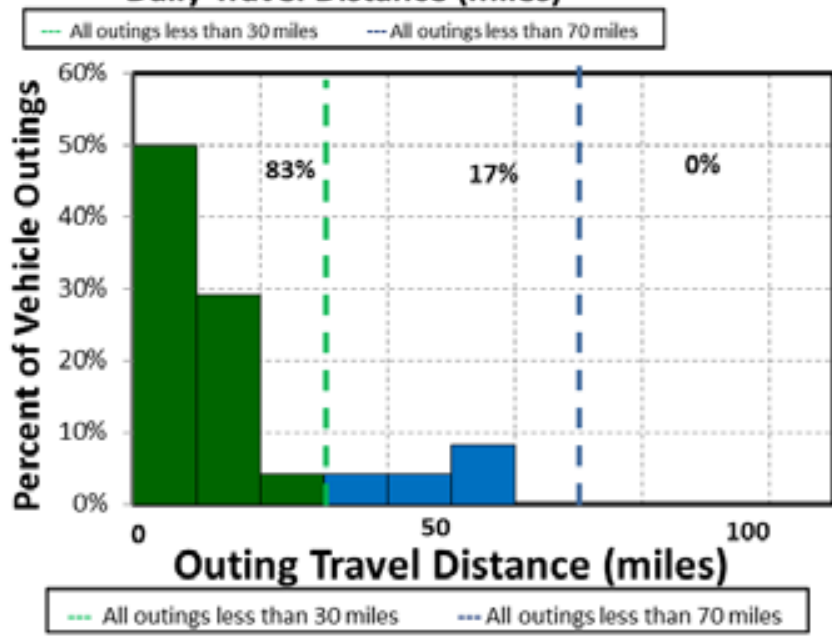

Figure B-15. Vehicle G41-2399K travel graphs.

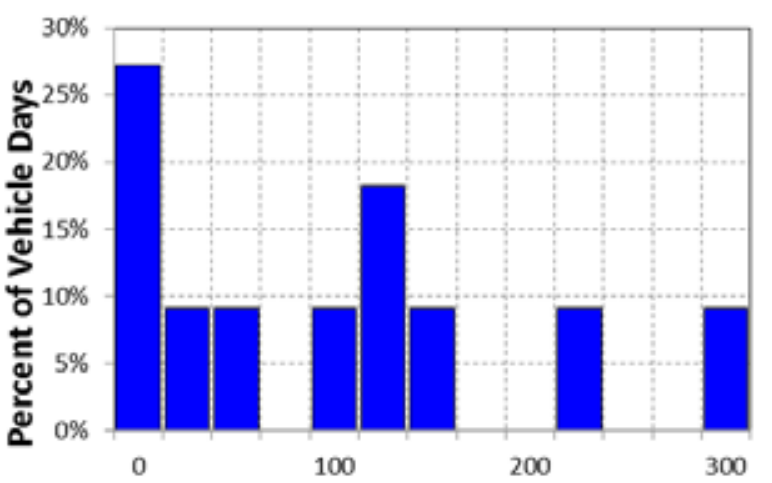

Daily Travel Time (Minutes)

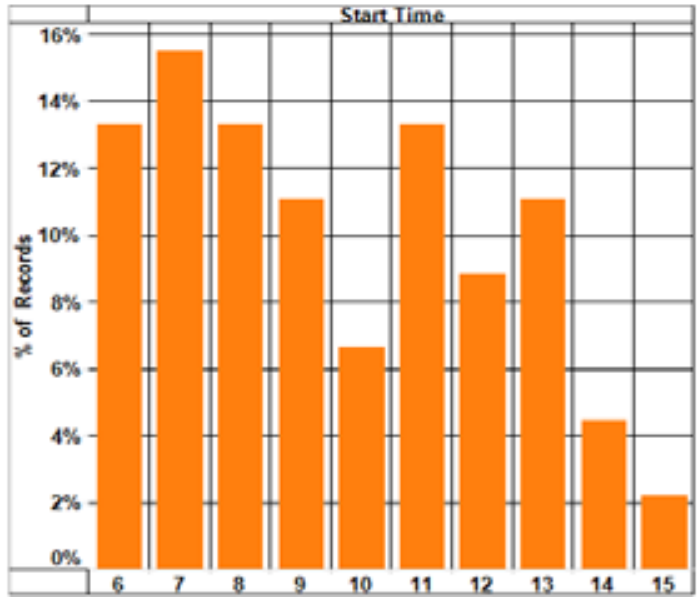

\section{Vehicle G41-2399K Observations}

Logger 83 collected data on this vehicle for a period of 11 days of the 32-day study period. Validation occurred on $100 \%$ of the input data. Data indicate that this vehicle has a support mission for the 2nd Marine Division. This vehicle's data indicate it parks near Building 1707 on Gum Street as shown in the Google Earth figure to the right.

MCBCL reports that a recent vehicle odometer indicated 32,811 miles and an average annual mileage of 10,754 miles. The vehicle was used on $34 \%$ of the available days, with an average daily usage of 1.8 hours and a peak daily usage of 5.3 hours on the days it was used. The vehicle was used during typical day shift hours.

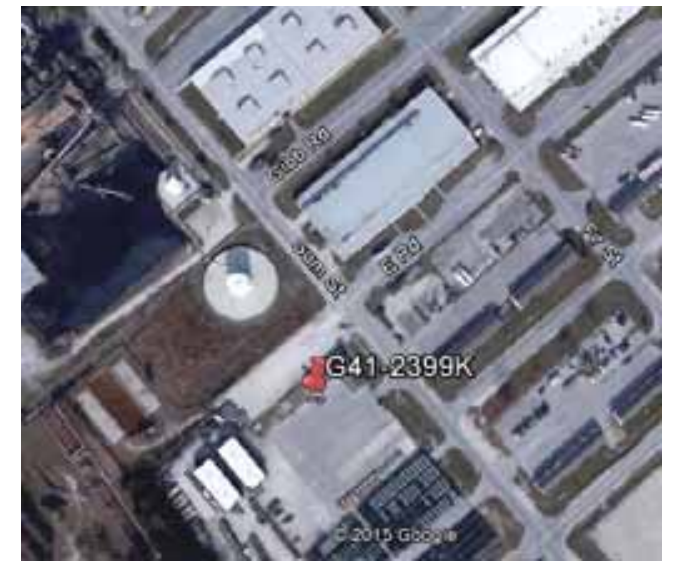

Figure B-15 shows that $91 \%$ of daily travel was within the typically advertised range of a BEV of approximately 70 miles. All outings were also within this range. Further, $64 \%$ of daily travel and $83 \%$ of outings were within the typically advertised CD mode of 30 miles for PHEVs.

A BEV could not meet all daily travel without additional charging opportunities, assuming the vehicle was assigned a home base. Time does exist each day for additional charging. Thus, a fleet of support vehicles would likely contain a mix of BEVs and PHEVs. 
Sheet 6: Vehicle G42-0216F

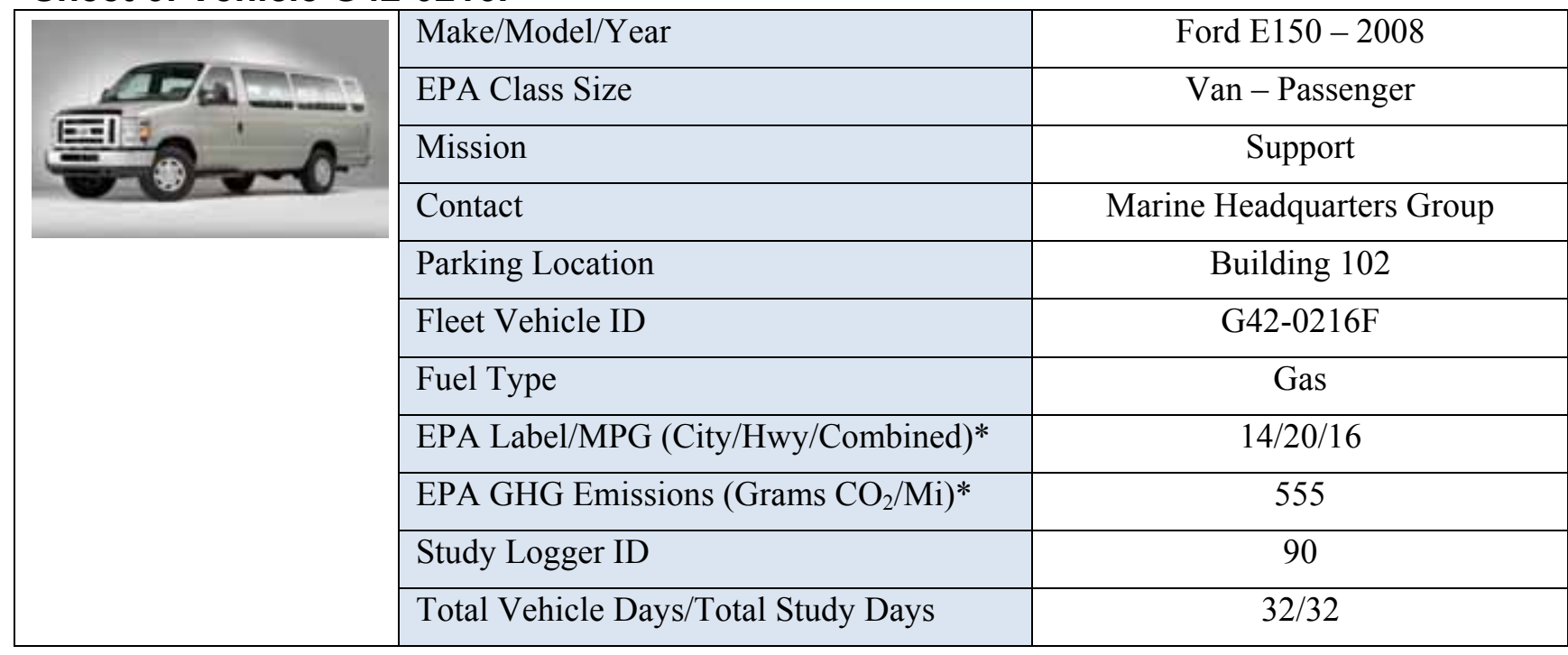

\begin{tabular}{|l|c|c|c|c|}
\hline \multicolumn{5}{|c|}{ Vehicle G42-0216F Travel Summary } \\
\hline & $\begin{array}{c}\text { Per Day } \\
\text { Average/Peak }\end{array}$ & $\begin{array}{c}\text { Per Outing } \\
\text { Average/Peak }\end{array}$ & $\begin{array}{c}\text { Per Trip } \\
\text { Average/Peak }\end{array}$ & Total \\
\hline Travel Distance (Miles) & $50.2 / 140.1$ & $11.7 / 97.6$ & $4.3 / 46.1$ & 1,608 \\
\hline Travel Time (Minutes) & $167.4 / 477.0$ & $39.1 / 243.0$ & $14.5 / 116.0$ & 5,356 \\
\hline Idle Time (Minutes) & $27.7 / \mathrm{NA}$ & $6.5 / \mathrm{NA}$ & $2.4 / \mathrm{NA}$ & 885 \\
\hline
\end{tabular}

\begin{tabular}{|c|c|c|c|c|}
\hline \multicolumn{2}{|c|}{ Total Stops } & \multicolumn{2}{c|}{ Stop Duration } \\
\hline $\begin{array}{c}\text { Distance From } \\
\text { Home Base (Miles) }\end{array}$ & Stops & Percentages & Stop Duration (Hours) & Stops \\
\hline Less than 10 & 348 & $99.1 \%$ & Less than 2 & 245 \\
\hline 10 to 20 & 2 & $0.6 \%$ & 2 to 4 & 44 \\
\hline 20 to 40 & 1 & $0.3 \%$ & 4 to 8 & \\
\hline 40 to 60 & 0 & 0 & & \\
\hline
\end{tabular}

Figure B-16. Vehicle G42-0216F stops.

*Fuel economy for E150 is not available. Economy used is for F150.

Figure B-17. Vehicle G42-0216F history. 

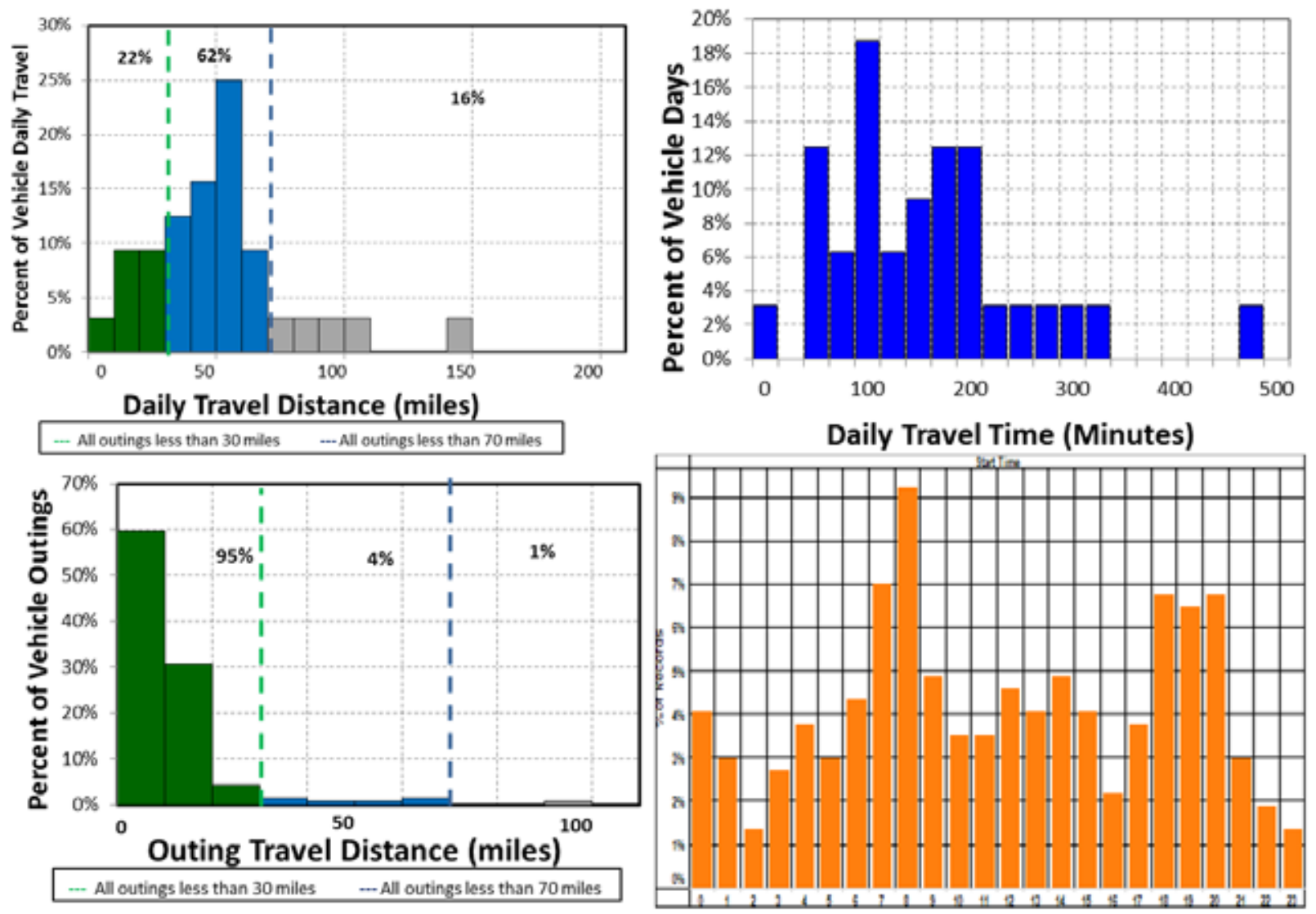

Figure B-18. Vehicle G42-0216F travel graphs.

\section{Vehicle G42-0216F Observations}

Logger 90 collected data on this vehicle for a period of 32 days of the 32-day study period. Validation occurred on $100 \%$ of the input data. Data indicate that this vehicle has a support mission for the Marine Headquarters Group. This vehicle's data indicate it parks near Building 102 on A Street as shown in the Google Earth figure to the right.

MCBCL reports that a recent vehicle odometer indicated 16,356 miles and an average annual mileage of 2,189 miles. The vehicle was used on $100 \%$ of the available days, with an average daily usage of 2.8 hours and a peak daily usage of 8.0 hours on the days it was used. The vehicle was used during all hours of the day.

Figure B-18 shows that $84 \%$ of daily travel was within

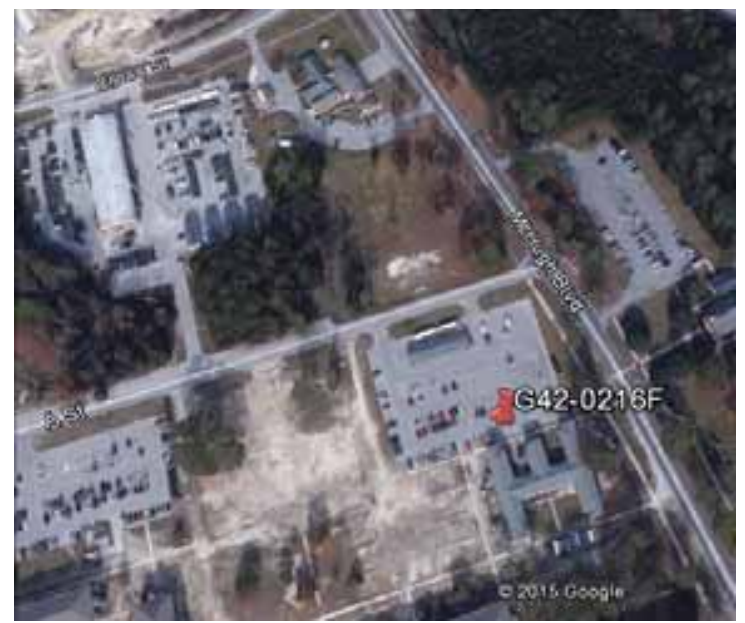
the typically advertised range of a BEV of approximately 70 miles and $99 \%$ of the outings were also within this range. Further, $22 \%$ of daily travel and $95 \%$ of outings were within the typically advertised CD mode of 30 miles for PHEVs.

A BEV could not meet all daily travel without additional charging opportunities, assuming the vehicle was assigned a home base. However, most of the daily travel was within the BEV's capability. Thus, a fleet of support passenger vehicles would likely contain a mix of BEVs and PHEVs. 
Sheet 7: Vehicle G42-0883M

\begin{tabular}{|l|l|c|}
\hline & Make/Model/Year & Ford E150 - 2012 \\
\cline { 2 - 3 } & EPA Class Size & Van - Passenger \\
\cline { 2 - 3 } & Mission & Support \\
\cline { 2 - 3 } & Contact & Building AS4108 Aircraft Group 29 \\
\cline { 2 - 3 } & Parking Location & G42-0883M \\
\hline & Fleet Vehicle ID & E85 \\
\cline { 2 - 3 } & Fuel Type & $9 / 12 / 10$ \\
\cline { 2 - 3 } & EPA Label/MPG (City/Hwy/Combined) & 620 \\
\cline { 2 - 3 } & EPA GHG Emissions $\left(\mathrm{Grams} \mathrm{CO}_{2} / \mathrm{Mi}\right)$ & 92 \\
\cline { 2 - 3 } & Study Logger ID & $23 / 33$ \\
\cline { 2 - 3 } & Total Vehicle Days/Total Study Days & \\
\hline
\end{tabular}

\begin{tabular}{|l|c|c|c|c|}
\hline \multicolumn{5}{|c|}{ Vehicle G42-0883M Travel Summary } \\
\hline & $\begin{array}{c}\text { Per Day } \\
\text { Average/Peak }\end{array}$ & $\begin{array}{c}\text { Per Outing } \\
\text { Average/Peak }\end{array}$ & $\begin{array}{c}\text { Per Trip } \\
\text { Average/Peak }\end{array}$ & Total \\
\hline Travel Distance (Miles) & $85.7 / 214.5$ & $38.7 / 126.8$ & $14.1 / 94.8$ & 1,972 \\
\hline Travel Time (Minutes) & $176.0 / 363.0$ & $79.4 / 307.0$ & $28.9 / 163.0$ & 4,048 \\
\hline Idle Time (Minutes) & $27.7 / \mathrm{NA}$ & $12.5 / \mathrm{NA}$ & $4.6 / \mathrm{NA}$ & 637 \\
\hline
\end{tabular}

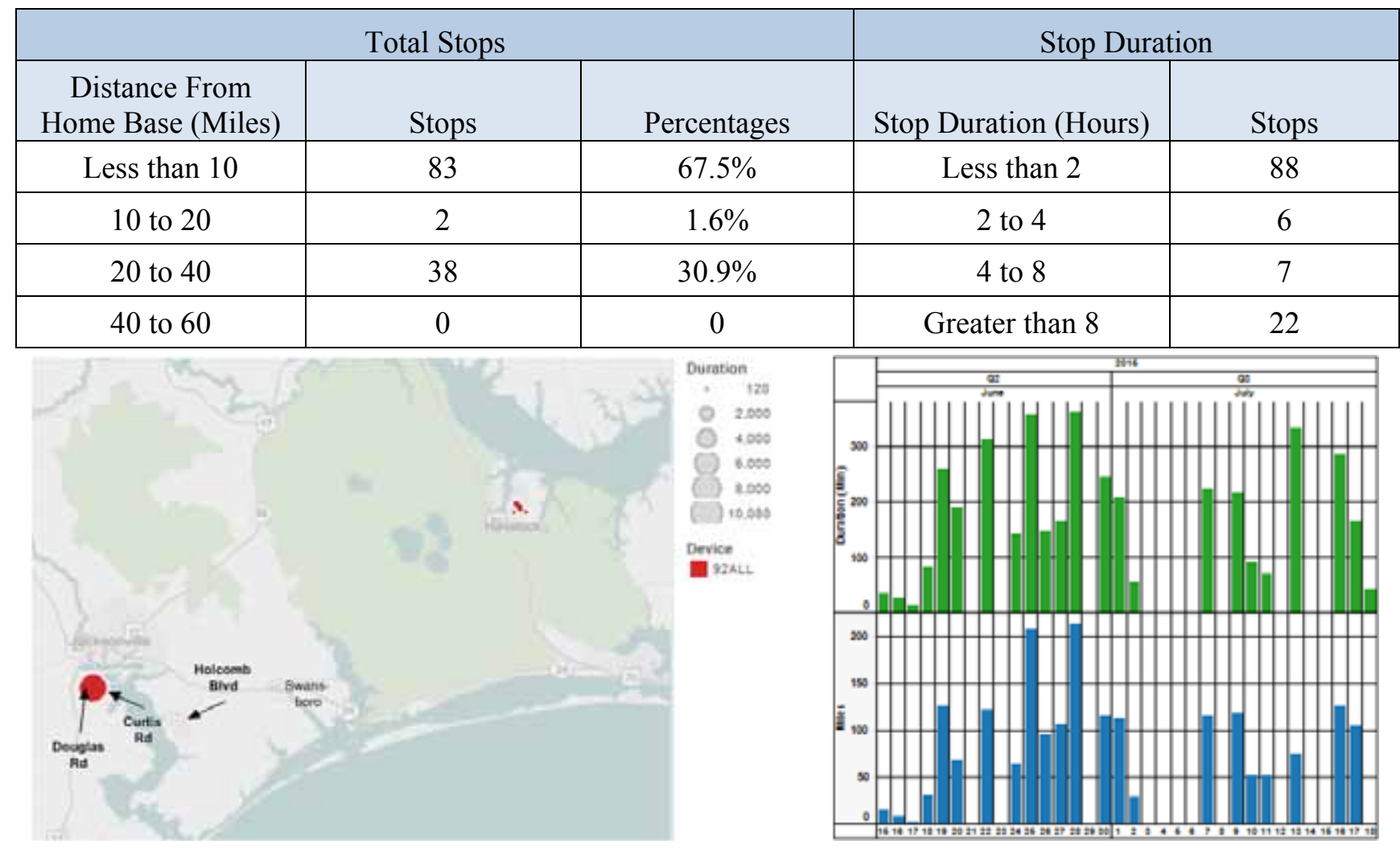

Figure B-19. Vehicle G42-0883M stops.

Figure B-20. Vehicle G42-0883M history. 

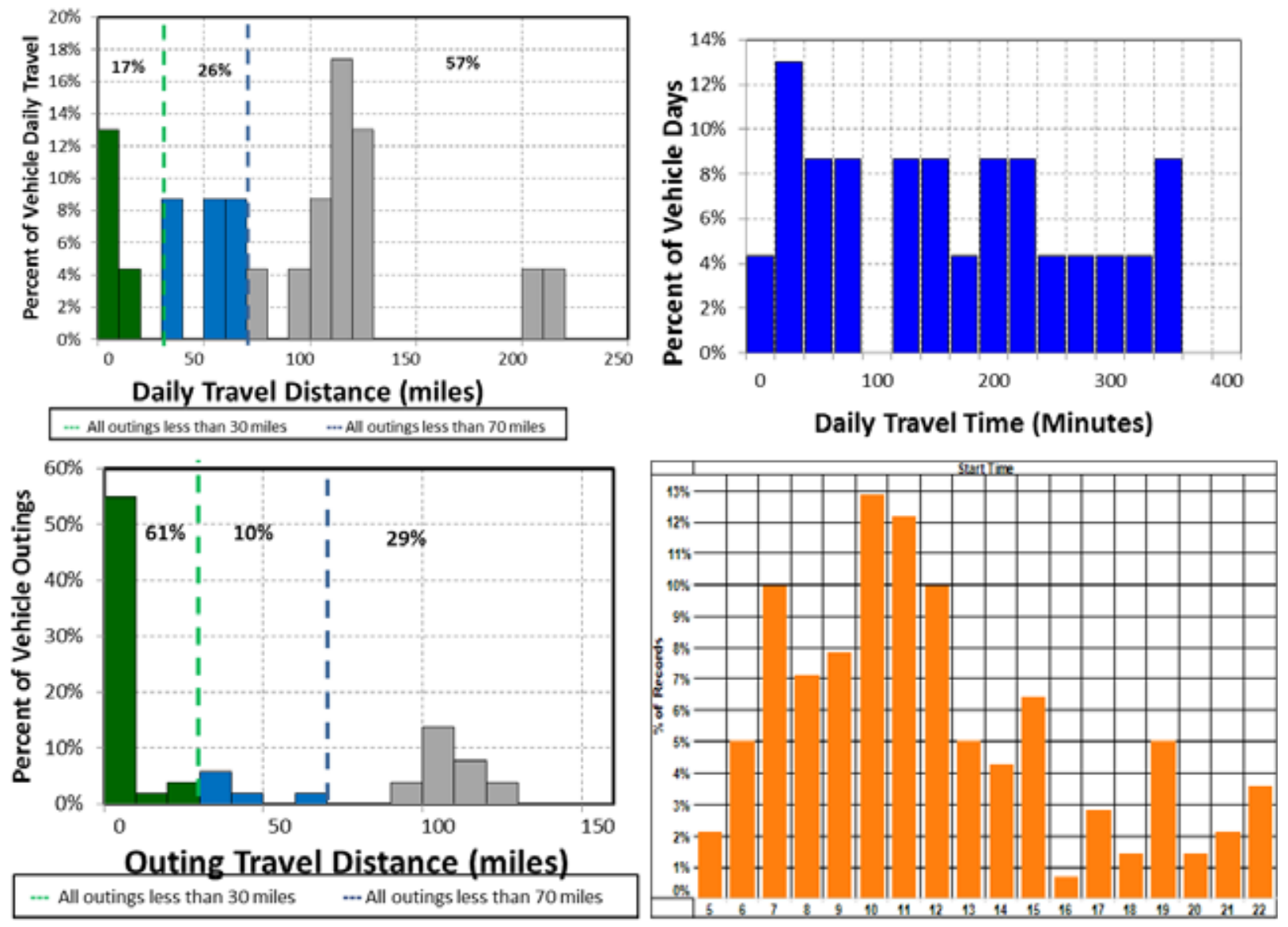

Figure B-21. Vehicle G42-0883M travel graphs.

\section{Vehicle G42-0883M Observations}

Logger 92 collected data on this vehicle for a period of 23 days of the 33-day study period. Validation occurred on $100 \%$ of the input data. Data indicate that this vehicle has a support mission for Marine Aircraft Group 29. This vehicle's data indicate it parked overnight equally near Schmidt Street and near Building AS4108 on White Street as shown in the Google Earth figure to the right.

MCBCL reports that a recent vehicle odometer indicated 42,763 miles and an average annual mileage is 16,827 miles. The vehicle was used on $70 \%$ of the available days, with an average daily usage of 2.9 hours and a peak daily usage of 6.1 hours on the days it was used. The vehicle was used during

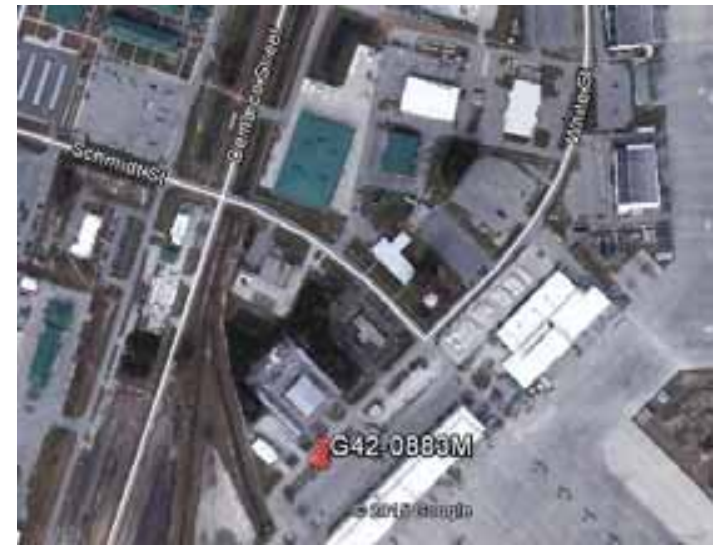
day and evening hours.

Figure B-21 shows that $43 \%$ of daily travel was within the typically advertised range of a BEV of approximately 70 miles and $71 \%$ of the outings were also within this range. Further, $17 \%$ of daily travel and $61 \%$ of outings were within the typically advertised CD mode of 30 miles for PHEVs.

A BEV could not meet all daily travel. A PHEV would be suggested to replace this vehicle. Thus, a fleet of enforcement vehicles would likely contain a mix of BEVs and PHEVs. 
Sheet 8: Vehicle G42-0898M

\begin{tabular}{|l|l|c|}
\hline & Make/Model/Year & Ford E150-2012 \\
\cline { 2 - 3 } & EPA Class Size & Van - Passenger \\
\cline { 2 - 3 } & Mission & Support \\
\cline { 2 - 3 } & Contact & 2 \\
\cline { 2 - 3 } & Parking Location & Building FC400 \\
\hline & Fleet Vehicle ID & G42-0898M \\
\cline { 2 - 3 } & Fuel Type & E85 \\
\cline { 2 - 3 } & EPA Label/MPG (City/Hwy/Combined) & $9 / 12 / 10$ \\
\cline { 2 - 3 } & EPA GHG Emissions (Grams $\left.\mathrm{CO}_{2} / \mathrm{Mi}\right)$ & 620 \\
\cline { 2 - 3 } & Study Logger ID & 84 \\
\cline { 2 - 3 } & Total Vehicle Days/Total Study Days & $32 / 32$ \\
\hline
\end{tabular}

\begin{tabular}{|c|c|c|c|c|}
\hline \multicolumn{5}{|c|}{ Vehicle G42-0898M Travel Summary } \\
\hline & $\begin{array}{c}\text { Per Day } \\
\text { Average/Peak }\end{array}$ & $\begin{array}{c}\text { Per Outing } \\
\text { Average/Peak }\end{array}$ & $\begin{array}{c}\text { Per Trip } \\
\text { Average/Peak }\end{array}$ & Total \\
\hline Travel Distance (Miles) & $40.7 / 201.8$ & $6.2 / 143.8$ & $4.4 / 68.1$ & 1,342 \\
\hline Travel Time (Minutes) & $231.6 / 549.0$ & $35.1 / 269.0$ & $24.9 / 269$ & 7,644 \\
\hline Idle Time (Minutes) & $87.6 / \mathrm{NA}$ & $13.3 / \mathrm{NA}$ & $9.4 / \mathrm{NA}$ & 2,891 \\
\hline
\end{tabular}

\begin{tabular}{|c|c|c|c|c|}
\hline \multicolumn{2}{|c|}{ Total Stops } & \multicolumn{2}{c|}{ Stop Duration } \\
\hline $\begin{array}{c}\text { Distance From } \\
\text { Home Base (Miles) }\end{array}$ & Stops & Percentages & Stop Duration (Hours) & Stops \\
\hline Less than 10 & 275 & $98.9 \%$ & Less than 2 & 176 \\
\hline 10 to 20 & 0 & 0 & 2 to 4 & 41 \\
\hline 20 to 40 & 2 & $0.7 \%$ & & 4 to 8 \\
\hline 40 to 60 & 1 & $0.4 \%$ & & \\
\hline
\end{tabular}

Figure B-22. Vehicle G42-0898M stops.

Figure B-23. Vehicle G42-0898M history. 

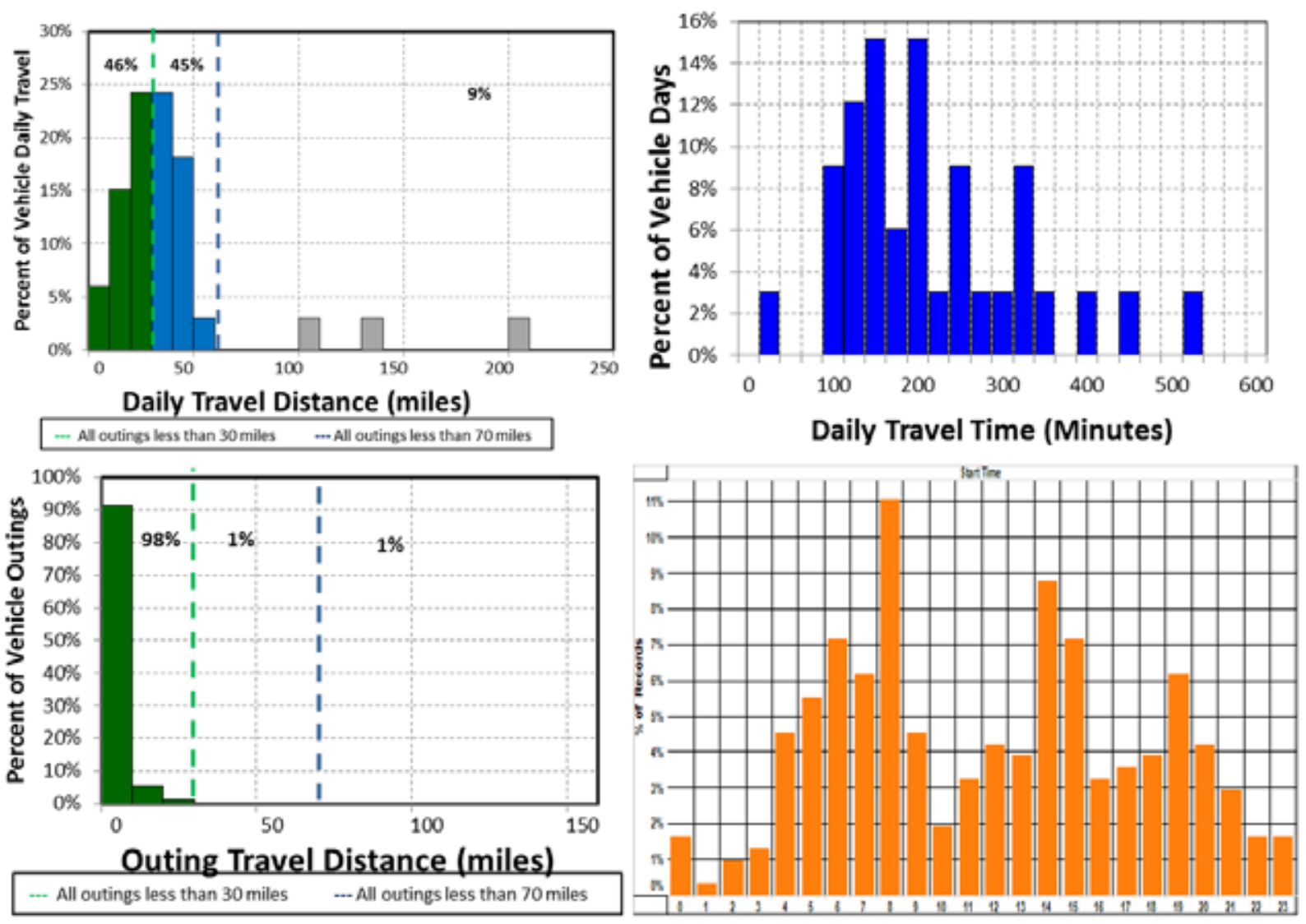

Figure B-24. Vehicle G42-0898M travel graphs. The maximum outing of 143.8 miles is not clearly visible on the above graph because of scale.

\section{Vehicle G42-0898M Observations}

Logger 84 collected data on this vehicle for a period of 32 days of the 32-day study period. Validation occurred on $99.7 \%$ of the input data. Data indicate that this vehicle has a support mission for the 2nd Marine Logistics Group. This vehicle's data indicate it parks near Building FC400 on H M Smith Boulevard as shown in the Google Earth figure to the right.

MCBCL reports that a recent vehicle odometer indicated 36,465 miles at the start of this study and an average annual mileage of 16,246 miles. The vehicle was used on $100 \%$ of the available days, with an average daily usage of 3.9 hours and a peak daily usage of 9.2 hours on the days it was used. The vehicle was used during all hours of the day.

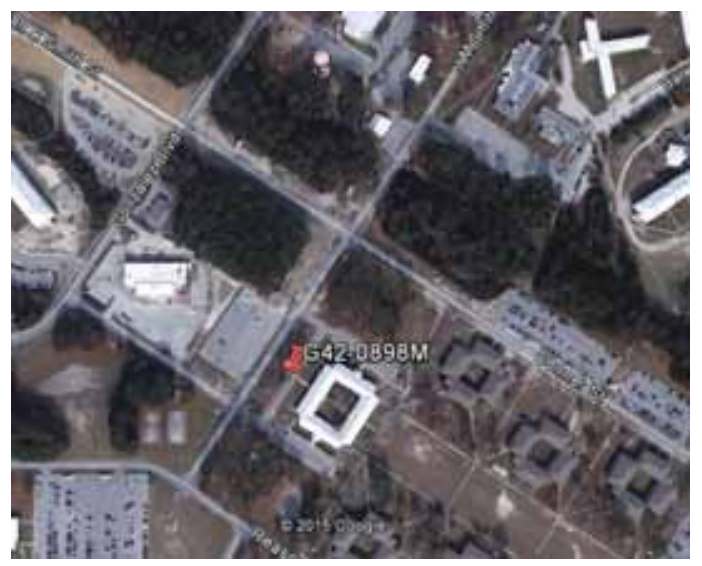

Figure B-24 shows that $91 \%$ of daily travel was within the typically advertised range of a BEV of approximately 70 miles and $99 \%$ of outings were also within this range. Further, $46 \%$ of daily travel and $98 \%$ of outings were within the typically advertised CD mode of 30 miles for PHEVs.

A BEV could not meet all daily travel because of the frequent longer travel days. However, because $91 \%$ of daily travel as within the range of a BEV, a fleet of vehicles would likely contain a mix of BEVs and PHEVs. 
Sheet 9: Vehicle G43-0326H

\begin{tabular}{|l|l|c|}
\hline \multirow{5}{*}{} & Make/Model/Year & Chevrolet 2500HD - 2009 \\
\cline { 2 - 3 } & EPA Class Size & Pickup \\
\cline { 2 - 3 } & Mission & Support \\
\cline { 2 - 3 } & Contact & School of Infantry \\
\cline { 2 - 3 } & Parking Location & Building G554 \\
\cline { 2 - 3 } & Fleet Vehicle ID & Gas \\
\hline & Fuel Type & $15 / 20 / 17$ \\
\cline { 2 - 3 } & EPA Label/MPG (City/Hwy/Combined)* \\
\cline { 2 - 3 } & EPA GHG Emissions (Grams $\left.\mathrm{CO}_{2} / \mathrm{Mi}\right)^{*}$ & 592 \\
\cline { 2 - 3 } & Study Logger ID & 18 \\
\hline & Total Vehicle Days/Total Study Days & $22 / 31$ \\
\hline
\end{tabular}

\begin{tabular}{|l|c|c|c|c|}
\hline \multicolumn{5}{|c|}{ Vehicle G43-0326H Travel Summary } \\
\hline & $\begin{array}{c}\text { Per Day } \\
\text { Average/Peak }\end{array}$ & $\begin{array}{c}\text { Per Outing } \\
\text { Average/Peak }\end{array}$ & $\begin{array}{c}\text { Per Trip } \\
\text { Average/Peak }\end{array}$ & Total \\
\hline Travel Distance (Miles) & $2.9 / 21.4$ & $1.1 / 28.8$ & $0.6 / 14.9$ & 65 \\
\hline Travel Time (Minutes) & $31.5 / 153.0$ & $12.2 / 298.0$ & $5.9 / 92.0$ & 693 \\
\hline Idle Time (Minutes) & $14.5 / \mathrm{NA}$ & $5.6 / \mathrm{NA}$ & $2.7 / \mathrm{NA}$ & 320 \\
\hline
\end{tabular}

\begin{tabular}{|c|c|c|c|c|c|}
\hline \multicolumn{2}{|c|}{ Total Stops } & \multicolumn{2}{c|}{ Stop Duration } \\
\hline $\begin{array}{c}\text { Distance From } \\
\text { Home Base (Miles) }\end{array}$ & Stops & Percentages & Stop Duration (Hours) & Stops \\
\hline Less than 10 & 105 & $100 \%$ & Less than 2 & 60 \\
\hline 10 to 20 & 0 & 0 & 2 to 4 & 9 \\
\hline 20 to 40 & 0 & 0 & 4 to 8 & & 22 \\
\hline 40 to 60 & 0 & 0 & Greater than 8 & & \\
\hline
\end{tabular}

Figure B-25. Vehicle G43-0326H stops.

Figure B-26. Vehicle G43-0326H history.

*Fuel economy for 2500HD is not available. Economy used is for Van 1500. 


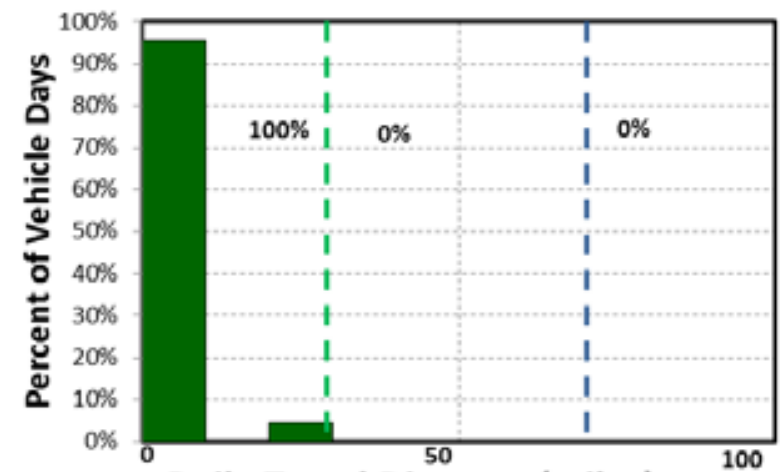

Daily Travel Distance (miles)

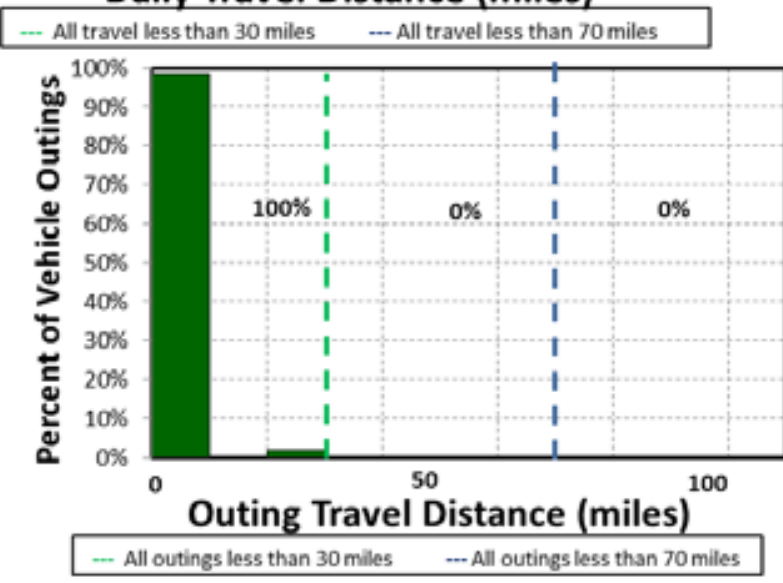

Figure B-27. Vehicle G43-0326H travel graphs.

\section{Vehicle G43-0326H Observations}

Logger 18 collected data on this vehicle for a period of 22 days of the31-day study period. Validation occurred on $100 \%$ of the input data. Data indicate that this vehicle has a support mission for the School of Infantry. This vehicle's data indicate it parks near Building G554 on 4th Street as shown in the Google Earth figure to the right.

MCBCL reports that a recent vehicle odometer indicated 39,522 miles and an average annual mileage of 4,863 miles. The vehicle was used on $71 \%$ of the available days, with an average daily usage of 0.5 hours and a peak daily usage of 2.6 hours on the days it was used. The vehicle was used during all hours of the day.

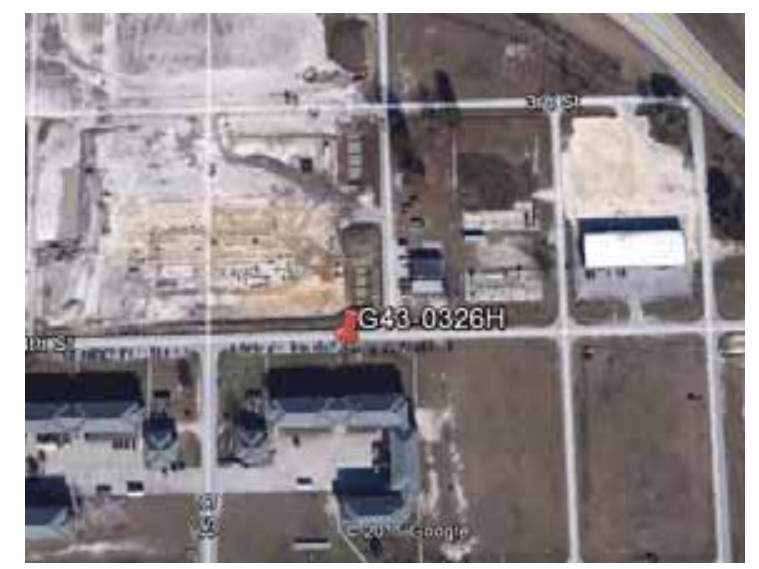

Figure B-27 shows all daily travel was within the typically advertised range of a BEV of approximately 70 miles. All outings were also within this range. Further, all daily travel and all outings were within the typically advertised CD mode of 30 miles for PHEVs.

A BEV could meet all daily travel without additional charging opportunities, assuming the vehicle was assigned a home base. Thus, a fleet of pickups would likely contain some PHEVs. 
Sheet 10: Vehicle G43-1453G

\begin{tabular}{|c|c|c|}
\hline $\cos ^{2}$ & Make/Model/Year & Chevrolet G2300-2008 \\
\hline & EPA Class Size & Van - Passenger \\
\hline & Mission & Support \\
\hline & Contact & MARSOC \\
\hline & Parking Location & Building FC306 near Anderson Street \\
\hline & Fleet Vehicle ID & G43-1453G \\
\hline & Fuel Type & Gas \\
\hline & EPA Label/MPG (City/Hwy/Combined) & $15 / 20 / 17$ \\
\hline & EPA GHG Emissions (Grams $\left.\mathrm{CO}_{2} / \mathrm{Mi}\right)$ & 523 \\
\hline & Study Logger ID & 103 \\
\hline & Total Vehicle Days/Total Study Days & $14 / 23$ \\
\hline
\end{tabular}

\begin{tabular}{|l|c|c|c|c|}
\hline \multicolumn{5}{|c|}{ Vehicle G43-1453G Travel Summary } \\
\hline & $\begin{array}{c}\text { Per Day } \\
\text { Average/Peak }\end{array}$ & $\begin{array}{c}\text { Per Outing } \\
\text { Average/Peak }\end{array}$ & $\begin{array}{c}\text { Per Trip } \\
\text { Average/Peak }\end{array}$ & Total \\
\hline Travel Distance (Miles) & $22.7 / 113.2$ & $12.2 / 113.2$ & $4.6 / 57.1$ & 318 \\
\hline Travel Time (Minutes) & $71.6 / 255.0$ & $38.5 / 255.0$ & $14.3 / 143.0$ & 1,002 \\
\hline Idle Time (Minutes) & $16.1 / \mathrm{NA}$ & $8.7 / \mathrm{NA}$ & $3.2 / \mathrm{NA}$ & 226 \\
\hline
\end{tabular}

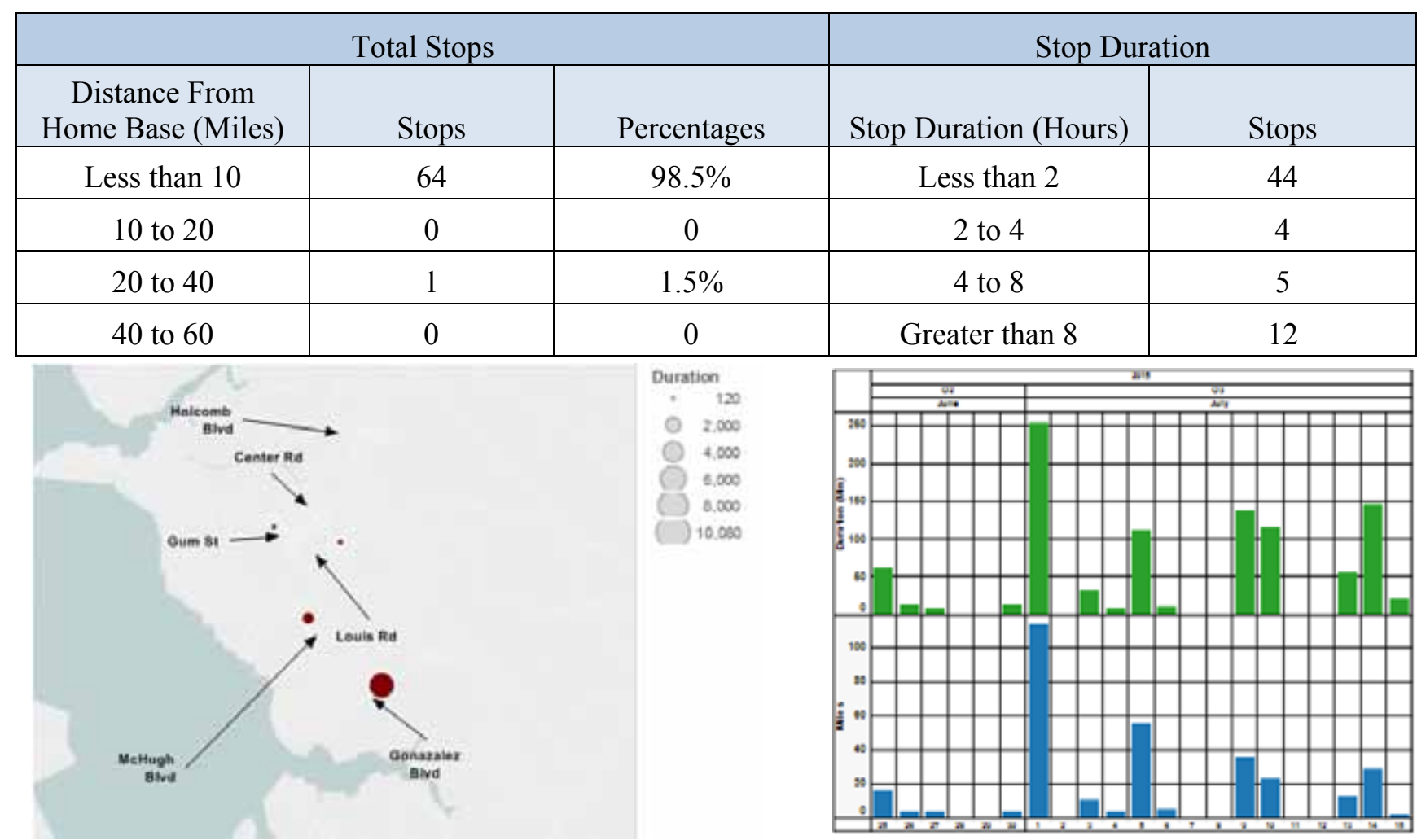

Figure B-28. Vehicle G43-1453G stops.

Figure B-29. Vehicle G43-1453G history. 


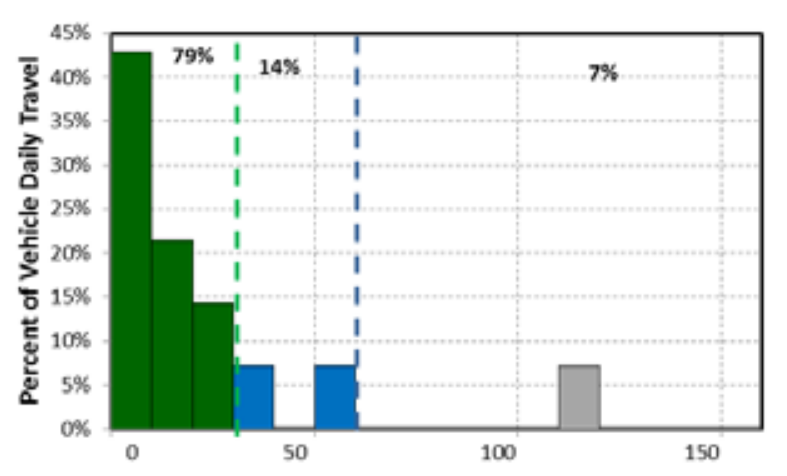

Daily Travel Distance (miles)

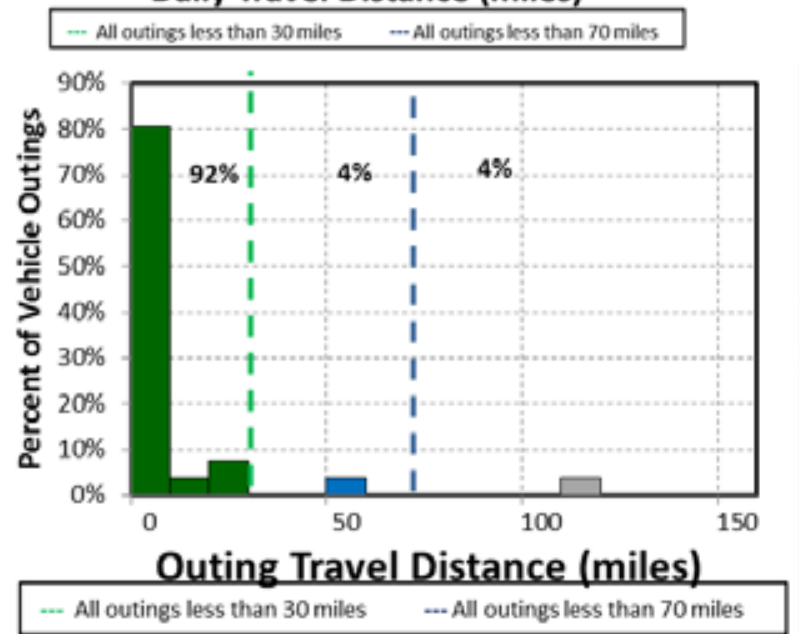

Figure B-30. Vehicle G43-1453G travel graphs.

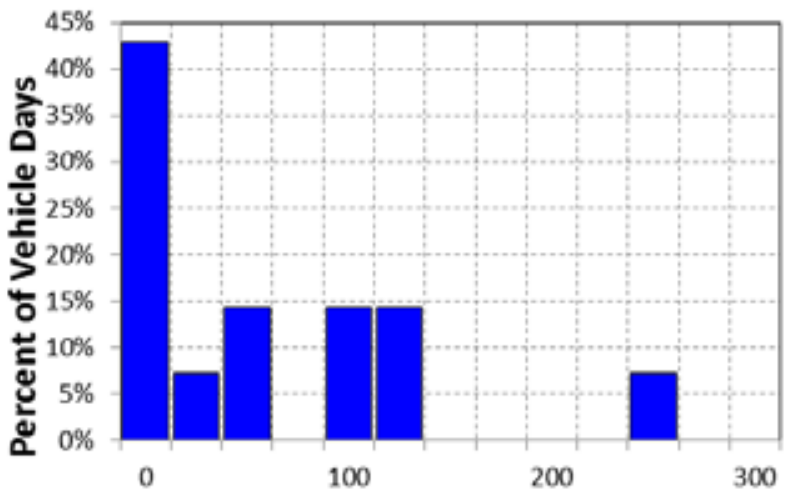

Daily Travel Time (Minutes)

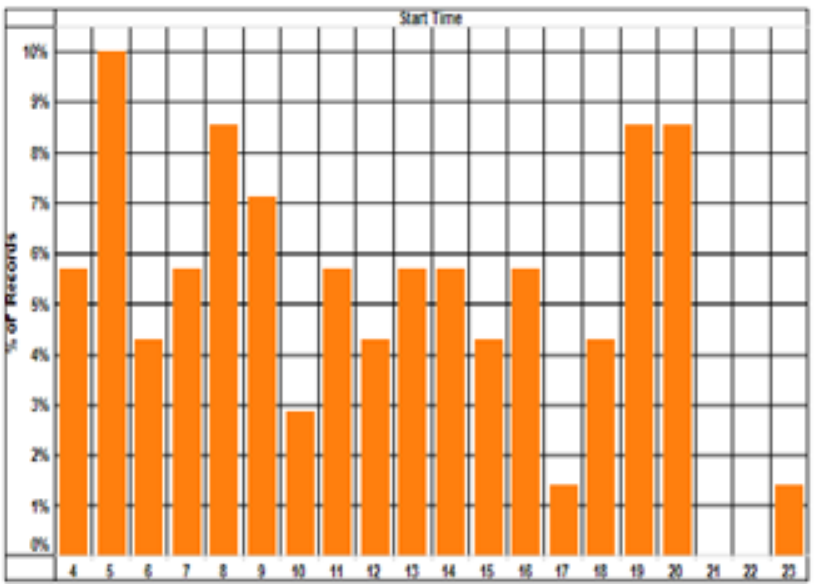

\section{Vehicle G43-1453G Observations}

Logger 103 collected data on this vehicle for a period of 14 days of the 23-day study period. Validation occurred on $100 \%$ of the input data. Data indicate that this vehicle has a support mission for Marine Corps Forces Special Operations Command. This vehicle's data indicate it parks near Building FC306 near Anderson Street as shown in the Google Earth figure to the right.

MCBCL reports that a recent vehicle odometer indicated 64,529 miles and an average annual mileage of 15,539 miles. The vehicle was used on $61 \%$ of the available days, with an average daily usage of 1.2 hours and a peak daily usage of 4.3 hours on the days it was used. The vehicle was used during all hours of the day.

Figure B-30 shows that $93 \%$ of daily travel was within the typically advertised range of a BEV of approximately 70 miles and $96 \%$ of the outings were also within this range. Further, $79 \%$ of daily travel and $92 \%$ of outings were within the typically advertised CD mode of 30 miles for PHEVs.

A BEV could not meet all daily travel without additional charging opportunities, assuming the vehicle was assigned a home base. However, a significant amount of daily travel was within the range of a BEV and there is sufficient time each day for recharging. Thus, a fleet of passenger vans would likely contain a mix of BEVs and PHEVs. 
Sheet 11: Vehicle G43-1855P

\begin{tabular}{|l|l|c|}
\hline & Make/Model/Year & Ford F350-2015 \\
\cline { 2 - 3 } & EPA Class Size & Pickup \\
\cline { 2 - 3 } & Mission & Support \\
\cline { 2 - 3 } & Contact & Building G702 on B St \\
\cline { 2 - 3 } & Parking Location & G43-1855P \\
\cline { 2 - 3 } & Fleet Vehicle ID & E85 \\
\cline { 2 - 3 } & Fuel Type & $13 / 18 / 15$ \\
\hline & EPA Label/MPG (City/Hwy/Combined)* & 419 \\
\cline { 2 - 3 } & EPA GHG Emissions (Grams CO $2 / \mathrm{Mi})^{*}$ & 19 \\
\cline { 2 - 3 } & Study Logger ID & $18 / 31$ \\
\cline { 2 - 3 } & Total Vehicle Days/Total Study Days & \\
\hline
\end{tabular}

\begin{tabular}{|l|c|c|c|c|}
\hline \multicolumn{5}{|c|}{ Vehicle G43-1855P Travel Summary } \\
\hline & $\begin{array}{c}\text { Per Day } \\
\text { Average/Peak }\end{array}$ & $\begin{array}{c}\text { Per Outing } \\
\text { Average/Peak }\end{array}$ & $\begin{array}{c}\text { Per Trip } \\
\text { Average/Peak }\end{array}$ & Total \\
\hline Travel Distance (Miles) & $36.5 / 141.6$ & $11.9 / 99.0$ & $5.6 / 60.3$ & 657 \\
\hline Travel Time (Minutes) & $137.7 / 393.0$ & $45.1 / 217.0$ & $21.0 / 177.0$ & 2,479 \\
\hline Idle Time (Minutes) & $58.4 / \mathrm{NA}$ & $19.1 / \mathrm{NA}$ & $8.9 / \mathrm{NA}$ & 1,051 \\
\hline
\end{tabular}

\begin{tabular}{|c|c|c|c|c|}
\hline \multicolumn{2}{|c|}{ Total Stops } & \multicolumn{2}{c|}{ Stop Duration } \\
\hline $\begin{array}{c}\text { Distance From } \\
\text { Home Base (Miles) }\end{array}$ & Stops & Percentages & Stop Duration (Hours) & Stops \\
\hline Less than 10 & 86 & $82.7 \%$ & Less than 2 & 70 \\
\hline 10 to 20 & 18 & $17.3 \%$ & 2 to 4 & \\
\hline 20 to 40 & 0 & 0 & 4 to 8 & \\
\hline 40 to 60 & 0 & 0 & & \\
\hline
\end{tabular}

Figure B-31. Vehicle G43-1855P stops.

*Fuel economy for F350 is not available. Economy used is for F150.

Figure B-32. Vehicle G43-1855P history. 

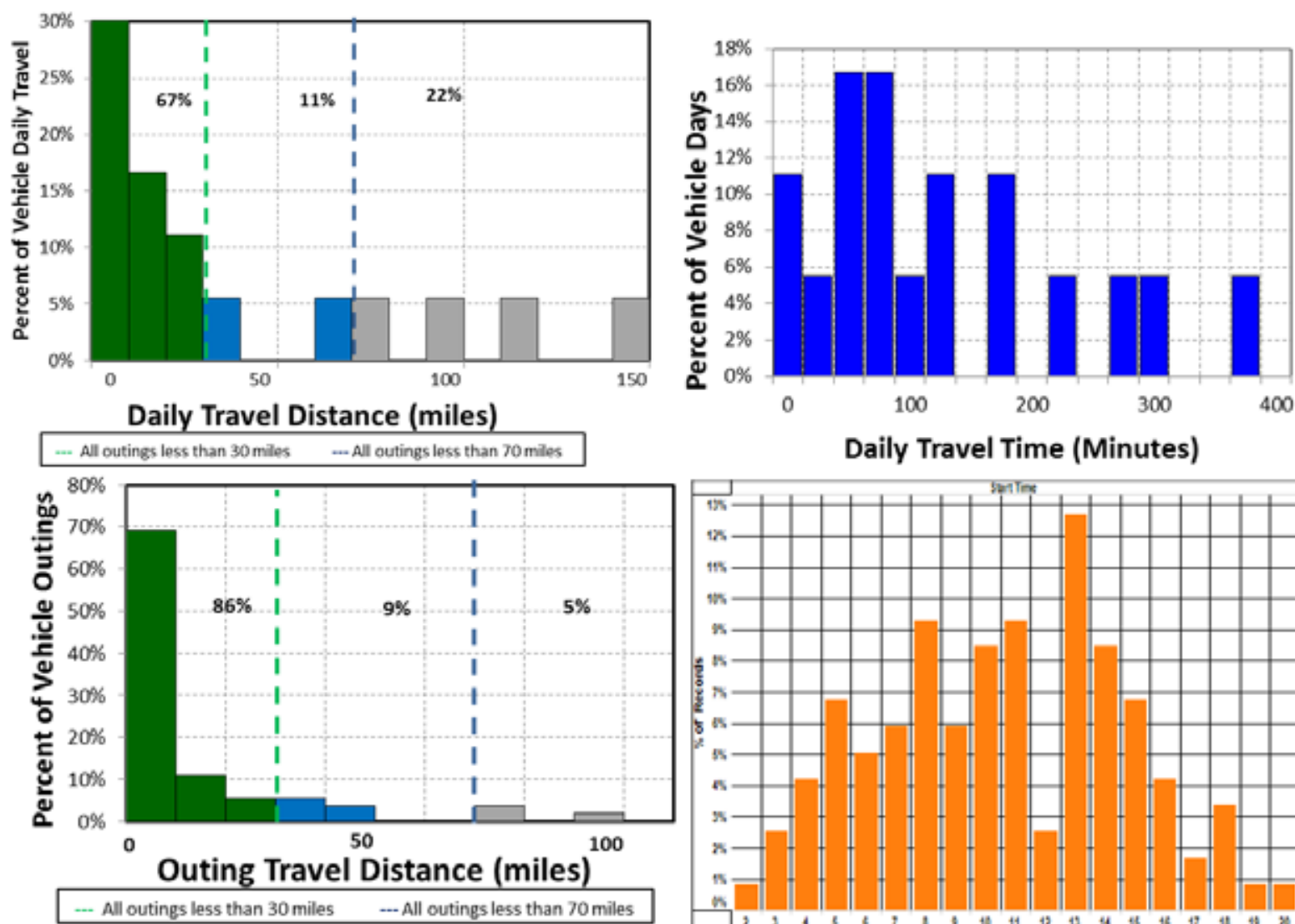

Daily Travel Time (Minutes)

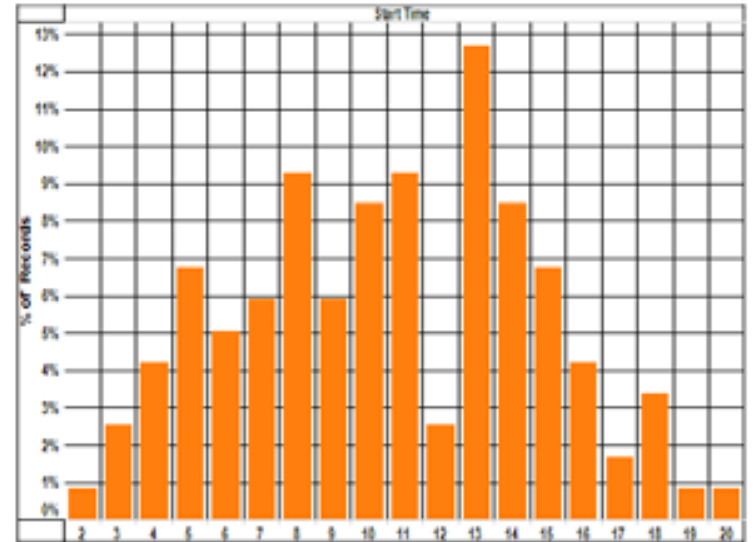

Figure B-33. Vehicle G43-1855P travel graphs.

\section{Vehicle G43-1855P Observations}

Logger 19 collected data on this vehicle for a period of 18 days of the 31-day study period. Validation occurred on $100 \%$ of the input data. Data indicate that this vehicle has a support mission for the School of Infantry. This vehicle's data indicate it parked overnight in several different locations but primarily near Building G702 on B Street as shown in the Google Earth figure to the right.

MCBCL reports that a recent vehicle odometer indicated 2,522 miles and an average annual mileage of 4,800 miles. The vehicle was used on $58 \%$ of the available days, with an average daily usage of 2.3 hours

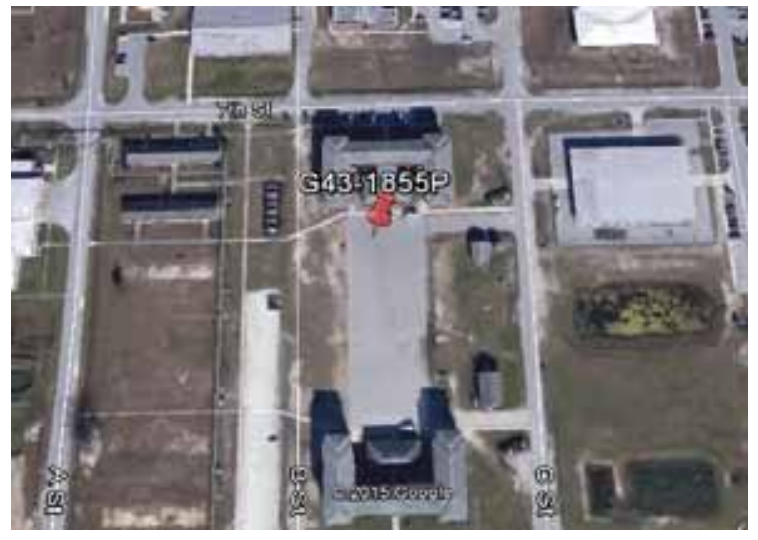
and a peak daily usage of 6.6 hours on the days it was used. The vehicle was used primarily during day and evening shifts.

Figure B-33 shows that $88 \%$ of daily travel was within the typically advertised range of a BEV of approximately 70 miles and $95 \%$ of outings were also within this range. Further, $67 \%$ of daily travel and $86 \%$ of outings were within the typically advertised CD mode of 30 miles for PHEVs.

A BEV could not meet all daily travel without additional charging opportunities, assuming the vehicle was assigned a home base. However, a significant amount of daily travel was within the BEV range; therefore, a fleet of vehicles would likely contain a mix of BEVs and PHEVs. 


\begin{tabular}{|c|c|c|}
\hline 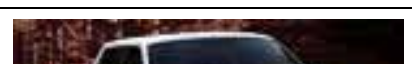 & Make/Model/Year & Ford F250-2010 \\
\hline & EPA Class Size & Pickup \\
\hline Aी & Mission & Support \\
\hline L & Contact & School of Infantry \\
\hline & Parking Location & Building TC846 \\
\hline & Fleet Vehicle ID & G43-2025K \\
\hline & Fuel Type & Gas \\
\hline & EPA Label/MPG (City/Hwy/Combined)* & $15 / 21 / 17$ \\
\hline & EPA GHG Emissions (Grams $\left.\mathrm{CO}_{2} / \mathrm{Mi}\right)^{*}$ & 523 \\
\hline & Study Logger ID & 20 \\
\hline & Total Vehicle Days/Total Study Days & $20 / 31$ \\
\hline
\end{tabular}

\begin{tabular}{|l|c|c|c|c|}
\hline \multicolumn{5}{|c|}{ Vehicle G43-2025K Travel Summary } \\
\hline & $\begin{array}{c}\text { Per Day } \\
\text { Average/Peak }\end{array}$ & $\begin{array}{c}\text { Per Outing } \\
\text { Average/Peak }\end{array}$ & $\begin{array}{c}\text { Per Trip } \\
\text { Average/Peak }\end{array}$ & Total \\
\hline Travel Distance (Miles) & $12.5 / 36.4$ & $4.0 / 56.4$ & $1.5 / 36.4$ & 250 \\
\hline Travel Time (Minutes) & $88.0 / 273.0$ & $28.4 / 263.0$ & $10.5 / 172.0$ & 1,760 \\
\hline Idle Time (Minutes) & $44.5 / \mathrm{NA}$ & $14.4 / \mathrm{NA}$ & $5.3 / \mathrm{NA}$ & 890 \\
\hline
\end{tabular}

\begin{tabular}{|c|c|c|c|c|}
\hline \multicolumn{2}{|c|}{ Total Stops } & \multicolumn{3}{c|}{ Stop Duration } \\
\hline $\begin{array}{c}\text { Distance From Home } \\
\text { Base (Miles) }\end{array}$ & Stops & Percentages & Stop Duration (Hours) & Stops \\
\hline Less than 10 & 162 & $97.6 \%$ & Less than 2 & 115 \\
\hline 10 to 20 & 4 & $2.4 \%$ & 2 to 4 & 22 \\
\hline 20 to 40 & 0 & 0 & 4 to 8 & 12 \\
\hline 40 to 60 & 0 & 0 & Greater than 8 & 17 \\
\hline
\end{tabular}

Figure B-34. Vehicle G43-2025K stops.

Figure B-35. Vehicle G43-2025K history.

*Fuel economy for F250 is not available. Economy used is for F150. 


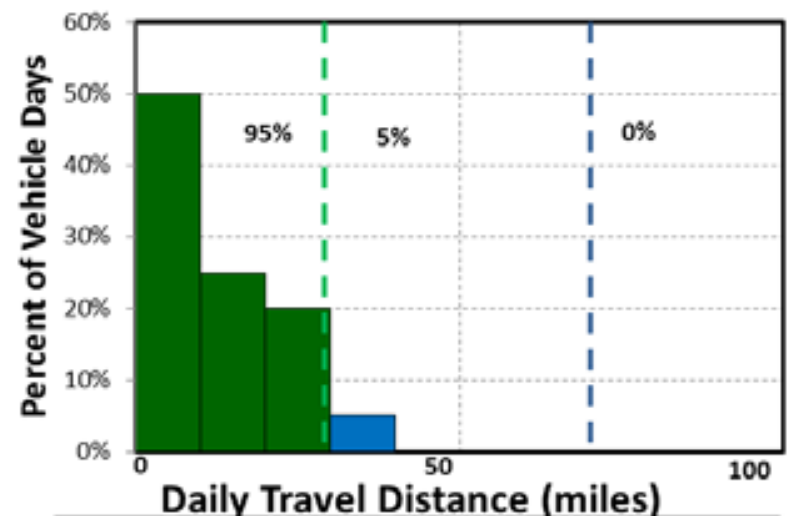

Daily Travel Distance (miles)

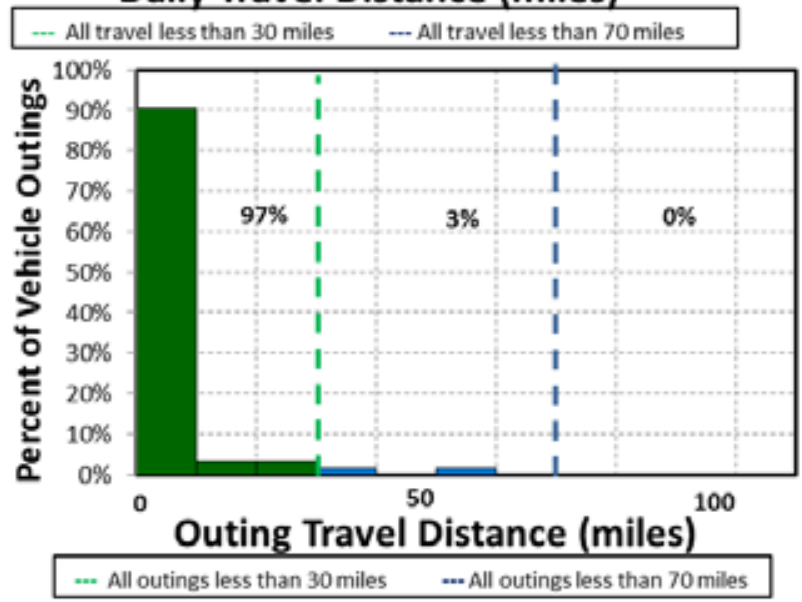

Figure B-36. Vehicle G43-2025K travel graphs.

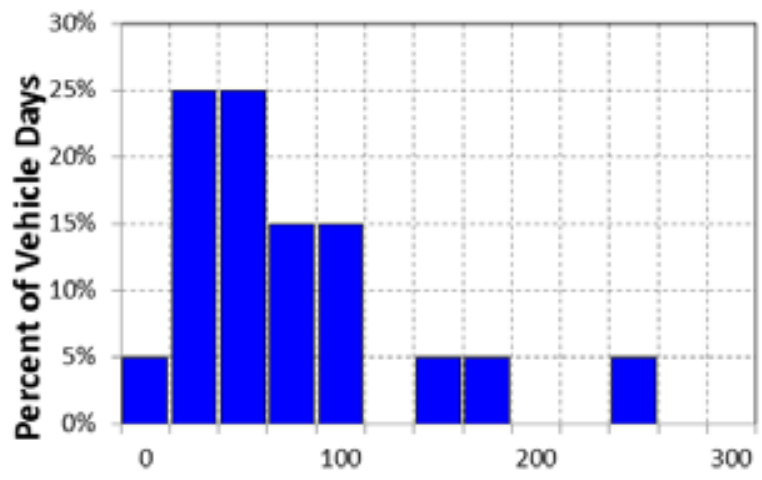

Daily Travel Time (Minutes)

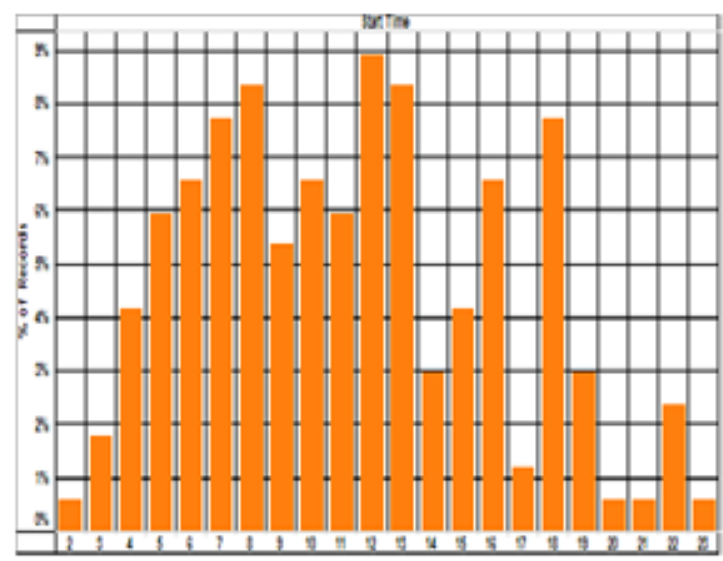

\section{Vehicle G43-2025K Observations}

Logger 20 collected data on this vehicle for a period of 20 days of the 31-day study period. Validation occurred on $100 \%$ of the input data. Data indicate that this vehicle has a support mission for the School of Infantry. This vehicle's data indicate it parked overnight in several different locations but primarily near Building TC846 on E Street as shown in the Google Earth figure to the right.

MCBCL reports that a recent vehicle odometer indicated 12,867 miles and an average annual mileage of 3,755 miles. The vehicle was used on $65 \%$ of the available days, with an average daily usage of 1.5 hours

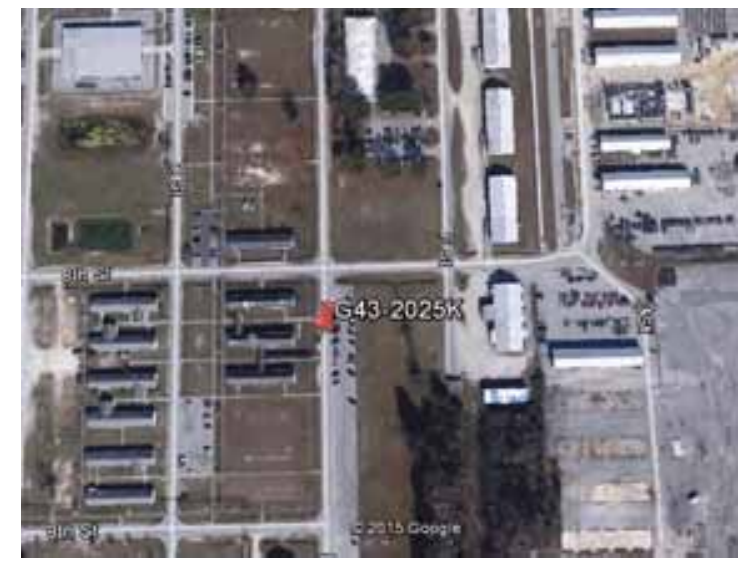
and a peak daily usage of 4.6 hours on the days it was used. The vehicle was used primarily overnight and during day shift hours.

Figure B-36 shows that all daily travel was within the typically advertised range of a BEV of approximately 70 miles. All outings were also within this range. Further, $95 \%$ of daily travel and $97 \%$ of outings were within the typically advertised CD mode of 30 miles for PHEVs.

A BEV could meet all daily travel without additional charging opportunities, assuming the vehicle was assigned a home base. Thus, a fleet of pickup vehicles would likely contain a mix of BEVs and PHEVs. 
Sheet 13: Vehicle G43-4073F

\begin{tabular}{|c|c|c|}
\hline 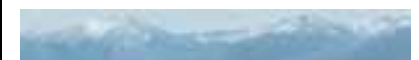 & Make/Model/Year & Chevrolet G2300 - 2008 \\
\hline 10 & EPA Class Size & Van - Passenger \\
\hline$\sqrt{6}$ & Mission & Support \\
\hline & Contact & MARSOC \\
\hline & Parking Location & Building RR272 on Range Road \\
\hline & Fleet Vehicle ID & G43-4073F \\
\hline & Fuel Type & Gas \\
\hline & EPA Label/MPG (City/Hwy/Combined)* & $15 / 20 / 17$ \\
\hline & EPA GHG Emissions (Grams $\left.\mathrm{CO}_{2} / \mathrm{Mi}\right)^{*}$ & 523 \\
\hline & Study Logger ID & 110 \\
\hline & Total Vehicle Days/Total Study Days & $11 / 17$ \\
\hline
\end{tabular}

\begin{tabular}{|l|c|c|c|c|}
\hline \multicolumn{5}{|c|}{ Vehicle G43-4073F Travel Summary } \\
\hline & $\begin{array}{c}\text { Per Day } \\
\text { Average/Peak }\end{array}$ & $\begin{array}{c}\text { Per Outing } \\
\text { Average/Peak }\end{array}$ & $\begin{array}{c}\text { Per Trip } \\
\text { Average/Peak }\end{array}$ & Total \\
\hline Travel Distance (Miles) & $15.2 / 52.8$ & $5.4 / 45.3$ & $3.6 / 45.3$ & 167 \\
\hline Travel Time (Minutes) & $53.5 / 132.0$ & $19.0 / 127.0$ & $12.5 / 106.0$ & 589 \\
\hline Idle Time (Minutes) & $15.6 / \mathrm{NA}$ & $5.5 / \mathrm{NA}$ & $3.7 / \mathrm{NA}$ & 172 \\
\hline
\end{tabular}

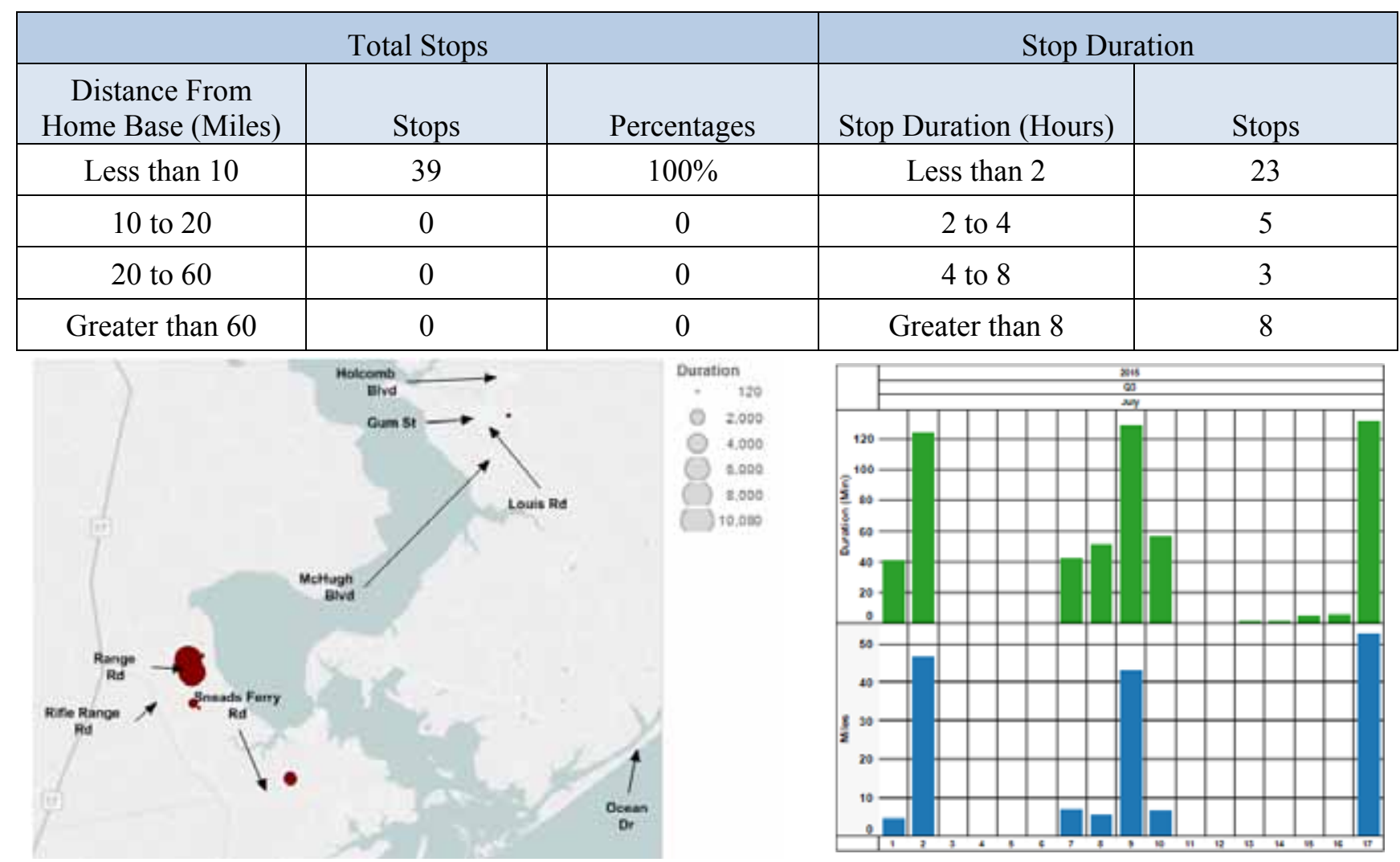

Figure B-37. Vehicle G43-4073F stops.

Figure B-38. Vehicle G43-4073F history.

*Fuel economy for G2300 is not available. Economy used is for 1500/2500 Van. 


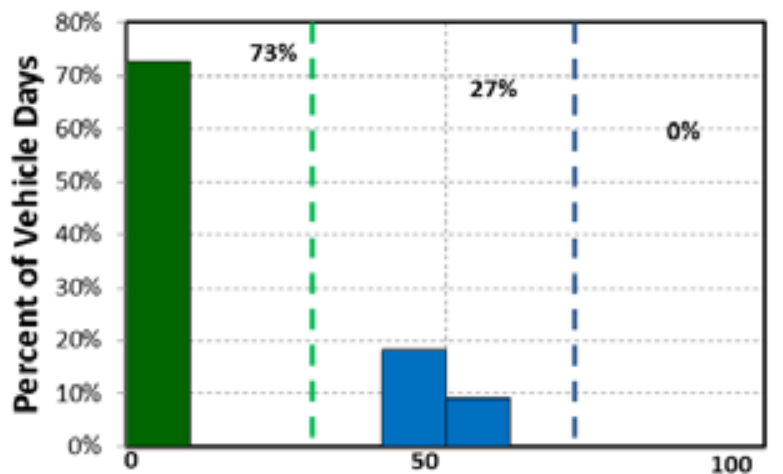

Daily Travel Distance (miles)

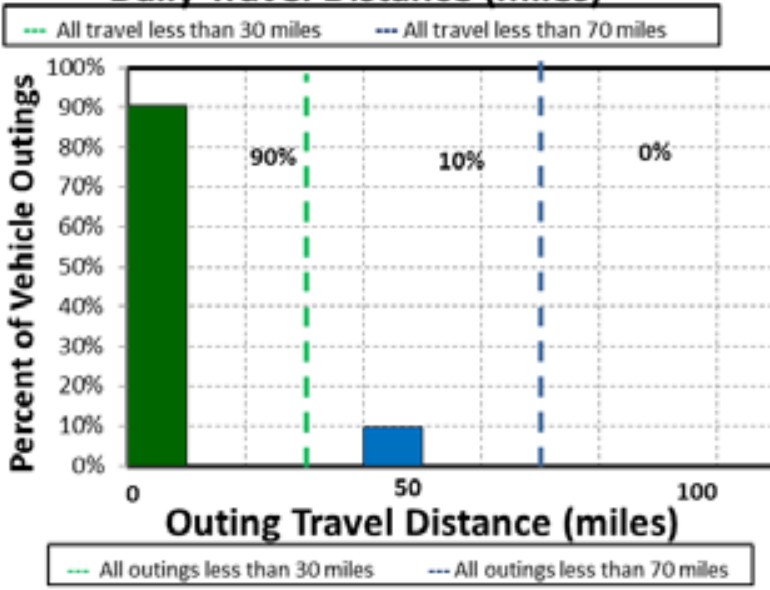

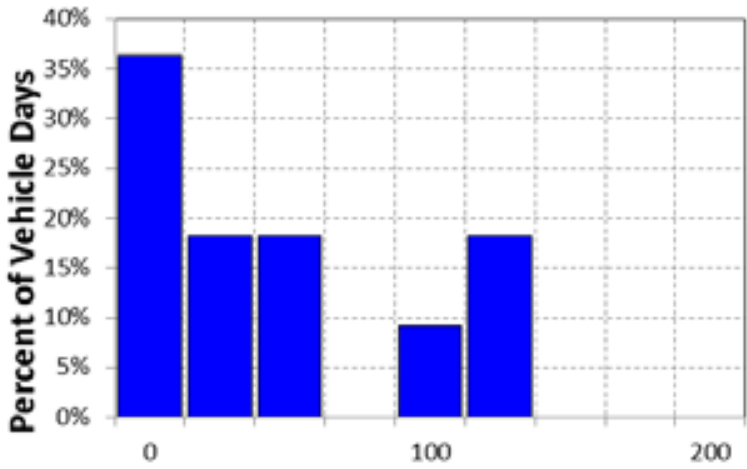

100

200

Daily Travel Time (Minutes)

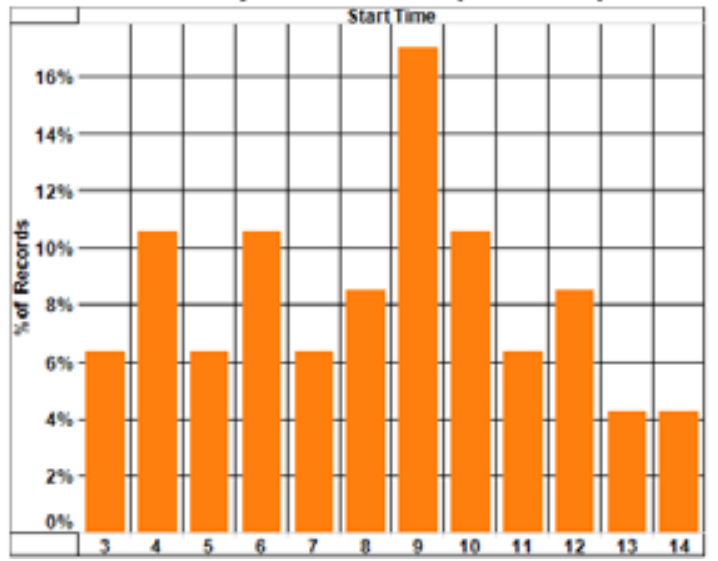

Figure B-39. Vehicle G43-4073F travel graphs.

\section{Vehicle G43-4073F Observations}

Logger 110 collected data on this vehicle for a period of 11 days of the 17-day study period. Validation occurred on $100 \%$ of the input data. Data indicate that this vehicle has a support mission for Marine Corps Forces Special Operations Command. This vehicle's data indicate it parks near Building RR272 on Range Road as shown in the Google Earth figure to the right.

MCBCL reports that a recent vehicle odometer indicated 51,238 miles and an average annual mileage of 4,712 miles. The vehicle was used on $65 \%$ of the available days, with an average daily usage of 0.9 hours and a

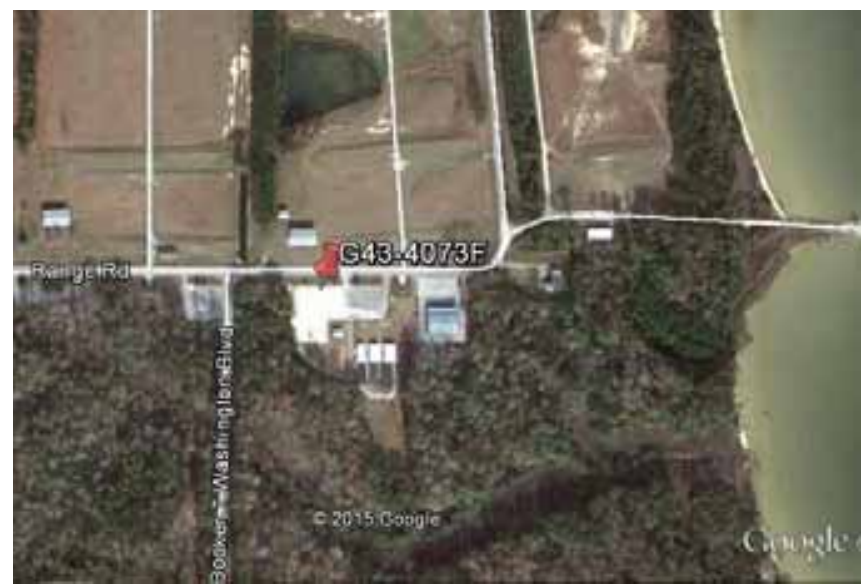
peak daily usage of 2.2 hours on the days it was used. The vehicle was used during day shift hours.

Figure B-39 shows that all daily travel was within the typically advertised range of a BEV of approximately 70 miles. All outings were also within this range. Further, $73 \%$ of daily travel and $90 \%$ of outings were within the typically advertised CD mode of 30 miles for PHEVs.

A BEV could meet all daily travel without additional charging opportunities, assuming the vehicle was assigned a home base. However, fleet managers typically prefer options without range limitations. Thus, a fleet of passenger van vehicles would likely contain a mix of BEVs and PHEVs. 
Sheet 14: Vehicle G61-0594L

\begin{tabular}{|l|l|c|}
\hline \multirow{2}{*}{} & Make/Model/Year & Jeep Patriot -2011 \\
\hline & EPA Class Size & SUV \\
\hline Mission & Support \\
\hline & Contact & Special Operation Training \\
\hline & Parking Location & Building 518 near N Street \\
\hline & Fleet Vehicle ID & G61-0594L \\
\cline { 2 - 3 } & Fuel Type & Gas \\
\cline { 2 - 3 } & EPA Label/MPG (City/Hwy/Combined) & $23 / 29 / 25$ \\
\cline { 2 - 3 } & EPA GHG Emissions (Grams $\left.\mathrm{CO}_{2} / \mathrm{Mi}\right)$ & 355 \\
\cline { 2 - 3 } & Study Logger ID & 87 \\
\cline { 2 - 3 } & Total Vehicle Days/Total Study Days & $15 / 30$ \\
\hline
\end{tabular}

\begin{tabular}{|l|c|c|c|c|}
\hline \multicolumn{5}{|c|}{ Vehicle G61-0594L Travel Summary } \\
\hline & $\begin{array}{c}\text { Per Day } \\
\text { Average/Peak }\end{array}$ & $\begin{array}{c}\text { Per Outing } \\
\text { Average/Peak }\end{array}$ & $\begin{array}{c}\text { Per Trip } \\
\text { Average/Peak }\end{array}$ & Total \\
\hline Travel Distance (Miles) & $76.1 / 393.1$ & $47.6 / 785.1$ & $16.1 / 185.6$ & 1,141 \\
\hline Travel Time (Minutes) & $168.4 / 836.0$ & $105.3 / 1,392.0$ & $35.6 / 250$ & 2,526 \\
\hline Idle Time (Minutes) & $60.7 / \mathrm{NA}$ & $38.0 / \mathrm{NA}$ & $12.8 / \mathrm{NA}$ & 911 \\
\hline
\end{tabular}

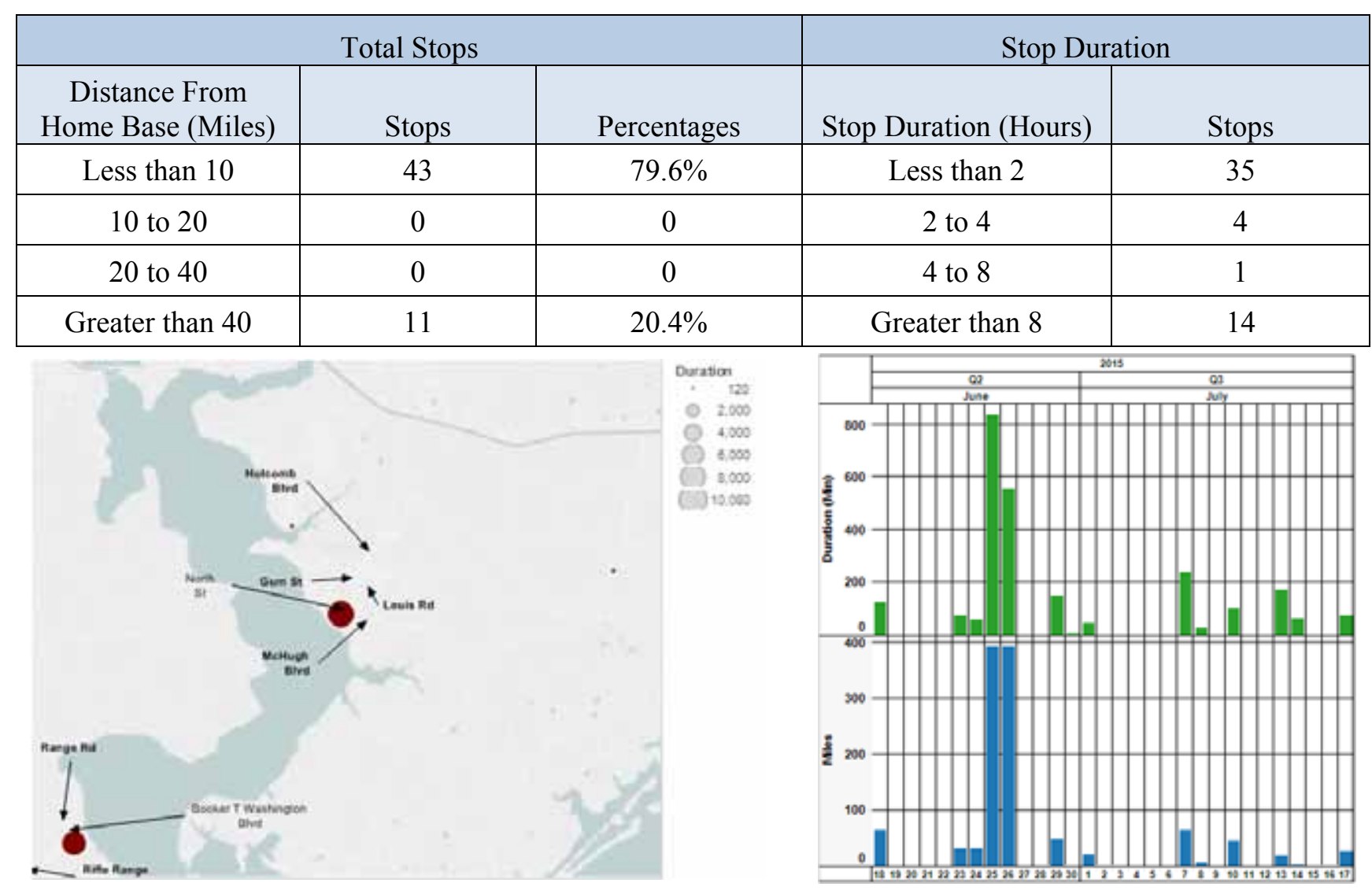

Figure B-40. Vehicle G61-0594L stops.

Figure B-41. Vehicle G61-0594L history. 


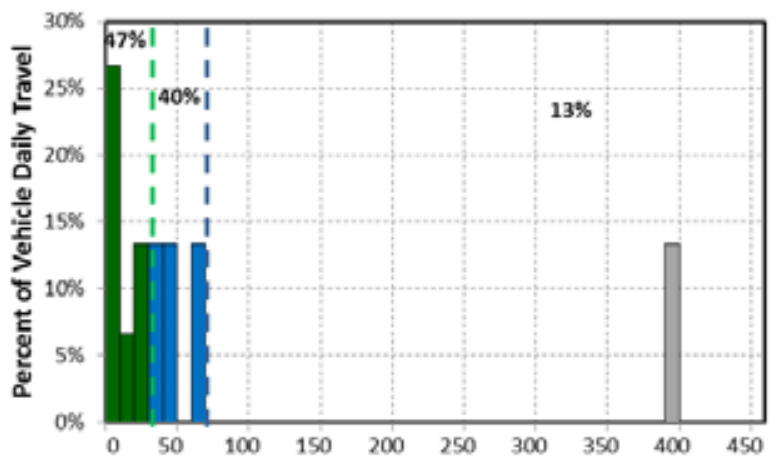

Daily Travel Distance (miles)

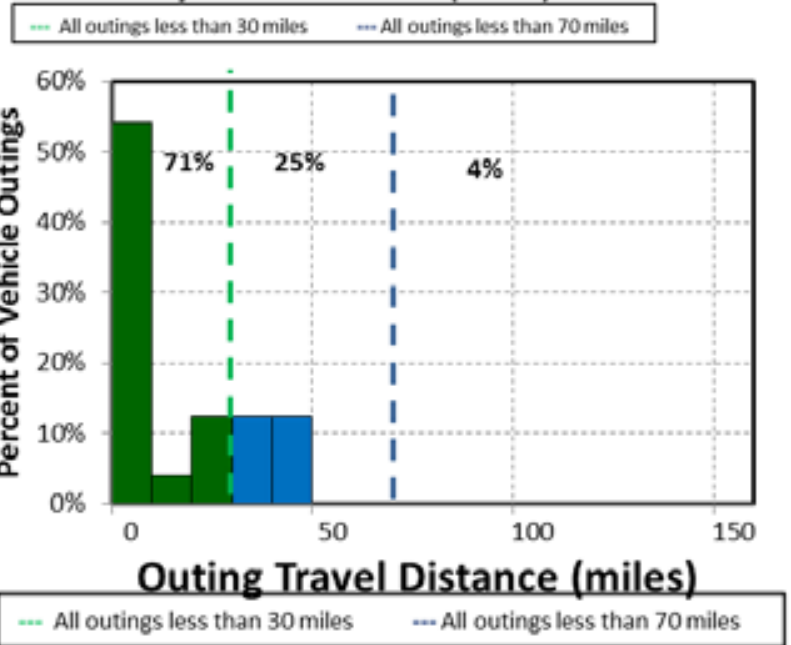

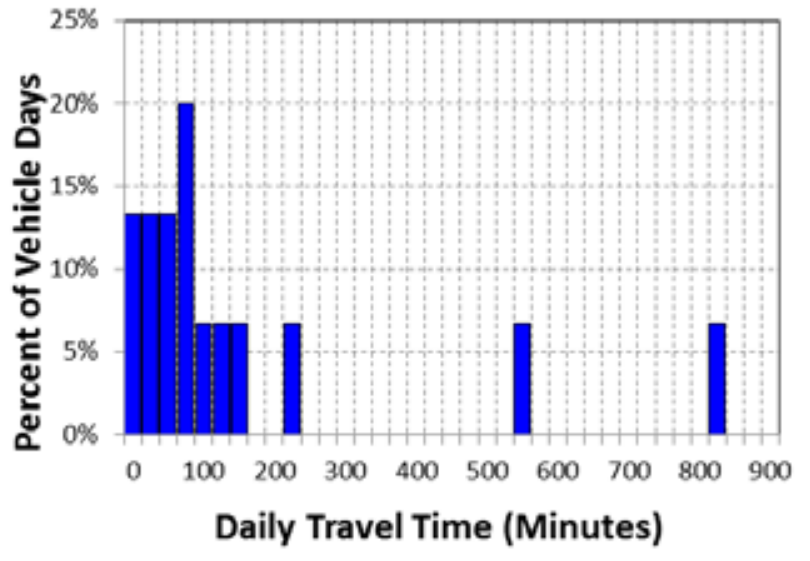

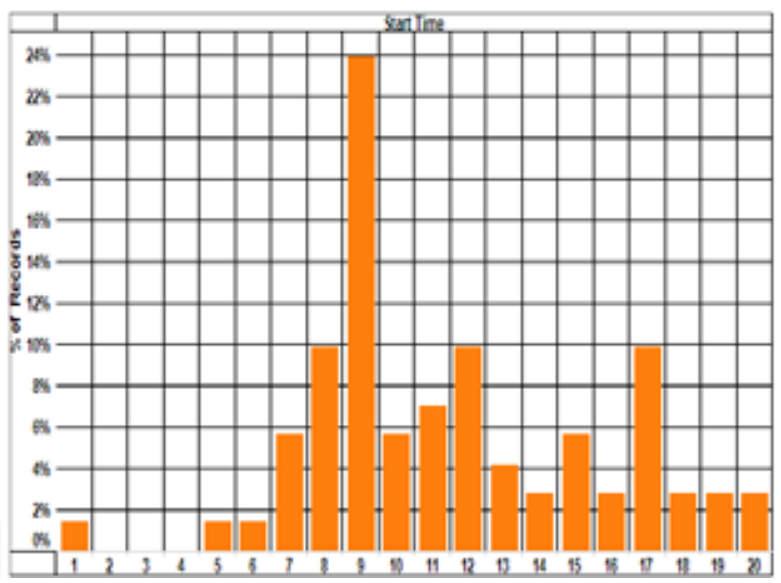

Figure B-42. Vehicle G61-0594L travel graphs. Note that the outing graph does not show the single outing of 785 miles.

\section{Vehicle G61-0594L Observations}

Logger 87 collected data on this vehicle for a period of 15 days of the 30-day study period. Validation occurred on $100 \%$ of the input data. Data indicate that this vehicle has a support mission for Special Operation Training. This vehicle's data indicate it parks overnight near Building 518 on N Street (North Street) as shown in the Google Earth figure to the right.

MCBCL reports that a recent vehicle odometer indicated 26,107 miles at the start of this study and an average annual mileage of 10,657 miles. The vehicle was used on $50 \%$ of the available days, with an average daily usage of 2.8 hours and a peak daily usage of 13.9 hours on the days it was used. The vehicle was used primarily during day shift hours.

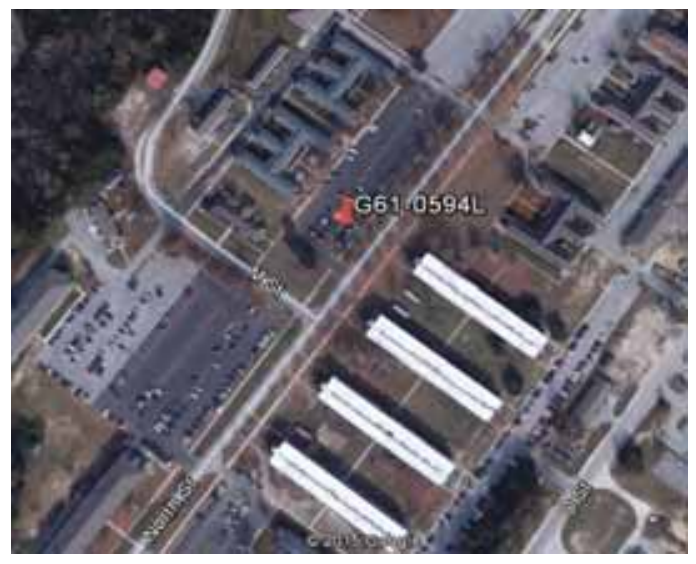

Figure B-42 shows that $87 \%$ of daily travel was within the typically advertised range of a BEV of approximately 70 miles and $96 \%$ of outings were also within this range. Further, $47 \%$ of daily travel and $71 \%$ of outings were within the typically advertised CD mode of 30 miles for PHEVs. The peak outing of 785 miles occurred over a several day period on an extended excursion to South Carolina and Georgia.

A BEV could not meet all daily travel because of the long excursion. However, a significant amount of daily travel was within a BEV's capability. Thus, a fleet of SUVs would likely contain a mix of BEVs and PHEVs. 
Sheet 15: Vehicle G61-2644P

\begin{tabular}{|l|l|c|}
\hline & Make/Model/Year & Jeep Patriot - 2015 \\
\hline & EPA Class Size & SUV \\
\hline & Mission & Support \\
\hline Contact & Marine Aircraft Group 29 \\
\cline { 2 - 3 } & Parking Location & Building AS4122 \\
\cline { 2 - 3 } & Fleet Vehicle ID & G61-2644P \\
\hline & Fuel Type & Gas \\
\hline & EPA Label/MPG (City/Hwy/Combined) & $22 / 27 / 24$ \\
\cline { 2 - 3 } & EPA GHG Emissions (Grams CO $/$ Mi) & 367 \\
\cline { 2 - 3 } & Study Logger ID & 94 \\
\hline & Total Vehicle Days/Total Study Days & $21 / 33$ \\
\hline
\end{tabular}

\begin{tabular}{|l|c|c|c|c|}
\hline \multicolumn{5}{|c|}{ Vehicle G61-2644P Travel Summary } \\
\hline & $\begin{array}{c}\text { Per Day } \\
\text { Average/Peak }\end{array}$ & $\begin{array}{c}\text { Per Outing } \\
\text { Average/Peak }\end{array}$ & $\begin{array}{c}\text { Per Trip } \\
\text { Average/Peak }\end{array}$ & Total \\
\hline Travel Distance (Miles) & $110.4 / 157.6$ & $40.0 / 131.4$ & $17.4 / 126.2$ & 2,319 \\
\hline Travel Time (Minutes) & $279.2 / 432.0$ & $101.1 / 432.0$ & $44.1 / 315.0$ & 5,863 \\
\hline Idle Time (Minutes) & $91.0 / \mathrm{NA}$ & $33.0 / \mathrm{NA}$ & $14.4 / \mathrm{NA}$ & 1,912 \\
\hline
\end{tabular}

\begin{tabular}{|c|c|c|c|c|}
\hline \multicolumn{2}{|c|}{ Total Stops } & \multicolumn{2}{c|}{ Stop Duration } \\
\hline $\begin{array}{c}\text { Distance From } \\
\text { Home Base (Miles) }\end{array}$ & Stops & Percentages & Stop Duration (Hours) & Stops \\
\hline Less than 10 & 83 & $69.2 \%$ & Less than 2 & 28 \\
\hline 10 to 20 & 1 & $0.8 \%$ & 2 to 4 & 0 \\
\hline 20 to 40 & 33 & $27.5 \%$ & 4 to 8 & 20 \\
\hline 40 to 60 & 3 & $2.5 \%$ & \\
\hline
\end{tabular}

Figure B-43. Vehicle G61-2644P stops.

Figure B-44. Vehicle G61-2644P history. 

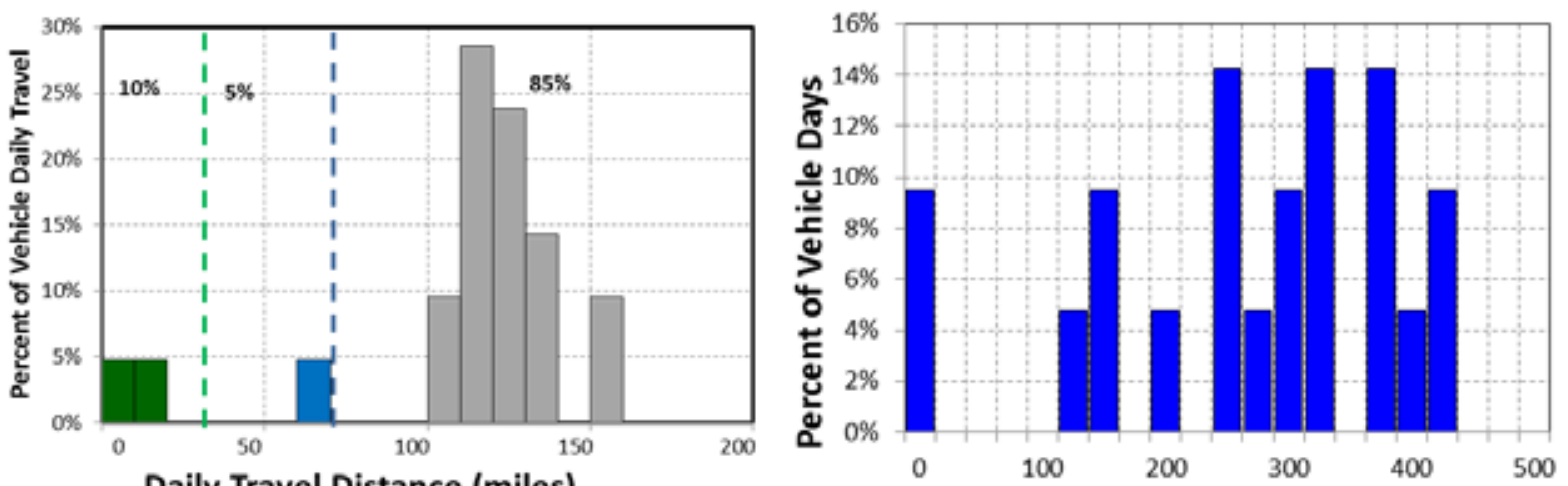

Daily Travel Distance (miles)
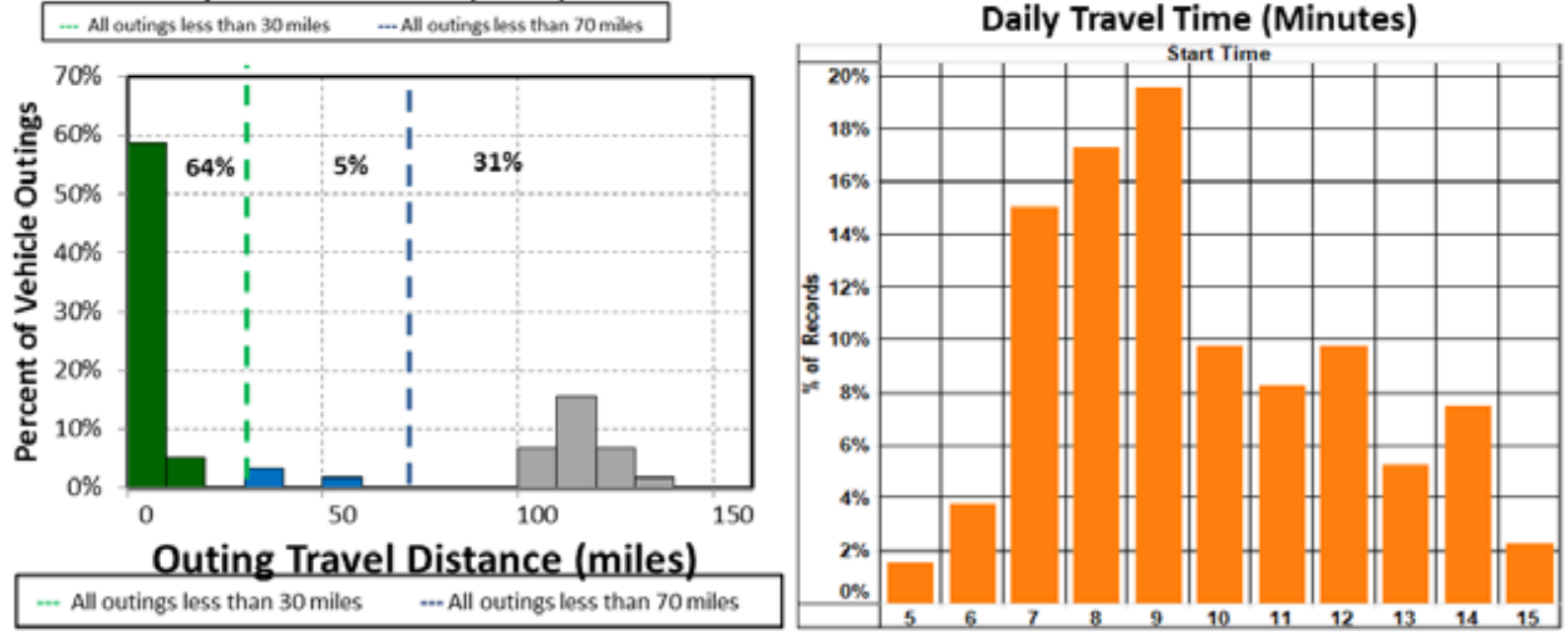

Figure B-45. Vehicle G61-2644P travel graphs.

\section{Vehicle G61-2644P Observations}

Logger 94 collected data on this vehicle for a period of 21 days of the 33-day study period. Validation occurred on $100 \%$ of the input data. Data indicate that this vehicle has a support mission for Marine Aircraft Group 29. This vehicle's data indicate it parks near Building AS4122 on White Street as shown in the Google Earth figure to the right.

MCBCL reports that a recent vehicle odometer indicated 10 miles and an average annual mileage of 3,600 miles. The vehicle was used on $64 \%$ of the available days, with an average daily usage of 4.7 hours and a peak daily usage of 7.2 hours on the days it was used. The vehicle was used during day shift hours.

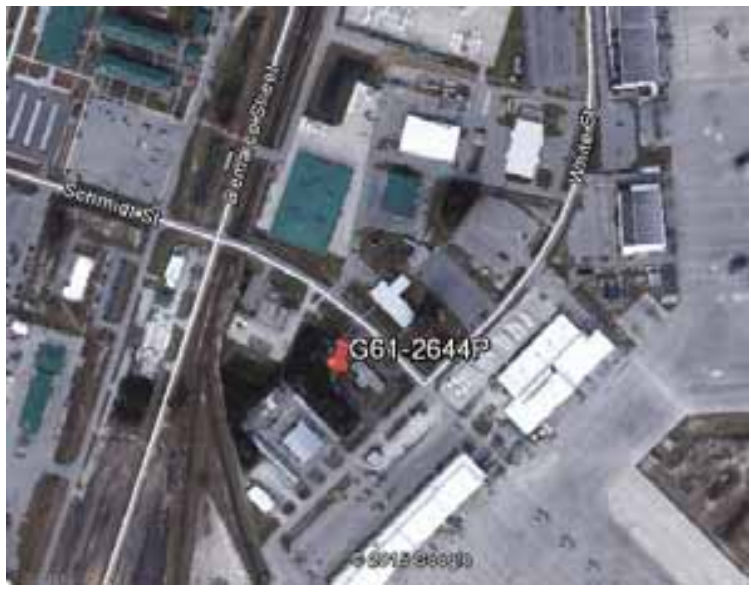

Figure B-45 shows that $15 \%$ of daily travel was within the typically advertised range of a BEV of approximately 70 miles and $69 \%$ of the outings were also within this range. Further, $10 \%$ of daily travel and $64 \%$ of outings were within the typically advertised CD mode of 30 miles for PHEVs.

A BEV could not meet all daily travel due to the consistent long distance trips. A PHEV would be recommended as a replacement. 
Sheet 16: Vehicle G62-0791H

\begin{tabular}{|c|c|c|}
\hline 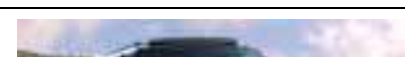 & Make/Model/Year & Ford Expedition - 2009 \\
\hline & EPA Class Size & SUV - K9 \\
\hline & Mission & Support \\
\hline & Contact & Marine Headquarters Group \\
\hline & Parking Location & Building SAW353 \\
\hline & Fleet Vehicle ID & G62-0791H \\
\hline & Fuel Type & E85 \\
\hline & EPA Label/MPG (City/Hwy/Combined) & $10 / 14 / 11$ \\
\hline & EPA GHG Emissions (Grams $\left.\mathrm{CO}_{2} / \mathrm{Mi}\right)$ & 564 \\
\hline & Study Logger ID & 91 \\
\hline & Total Vehicle Days/Total Study Days & $21 / 33$ \\
\hline
\end{tabular}

\begin{tabular}{|l|c|c|c|c|}
\hline \multicolumn{5}{|c|}{ Vehicle G62-0791H Travel Summary } \\
\hline & $\begin{array}{c}\text { Per Day } \\
\text { Average/Peak }\end{array}$ & $\begin{array}{c}\text { Per Outing } \\
\text { Average/Peak }\end{array}$ & $\begin{array}{c}\text { Per Trip } \\
\text { Average/Peak }\end{array}$ & Total \\
\hline Travel Distance (Miles) & $42.8 / 305.9$ & $24.3 / 298.3$ & $9.6 / 138.3$ & 899 \\
\hline Travel Time (Minutes) & $167.6 / 552.0$ & $95.1 / 477.0$ & $37.4 / 248.0$ & 3,519 \\
\hline Idle Time (Minutes) & $83.4 / \mathrm{NA}$ & $47.4 / \mathrm{NA}$ & $18.6 / \mathrm{NA}$ & 1,752 \\
\hline
\end{tabular}

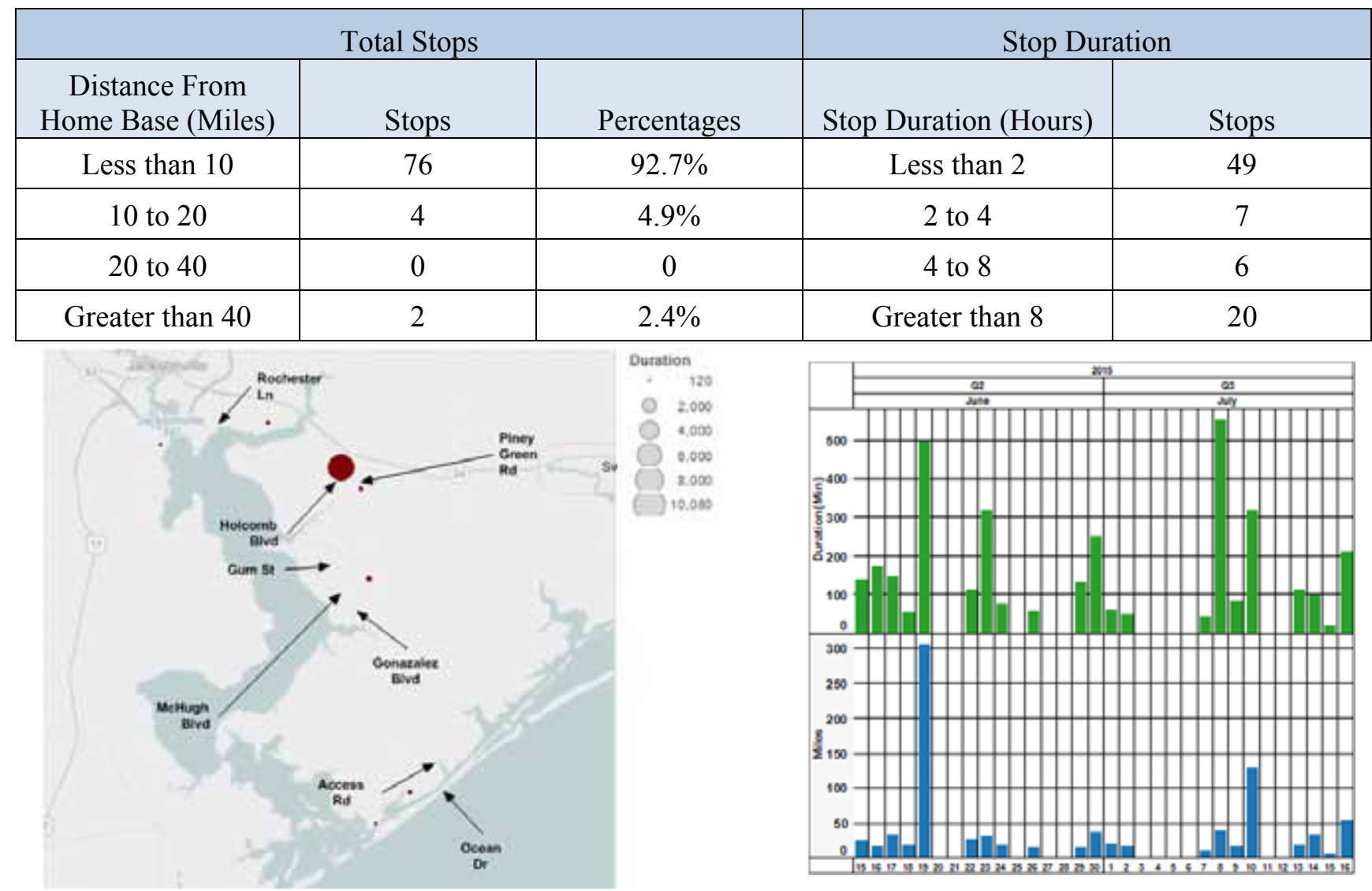

Figure B-46. Vehicle G62-0791H stops.

Figure B-47. Vehicle G62-0791H history. 

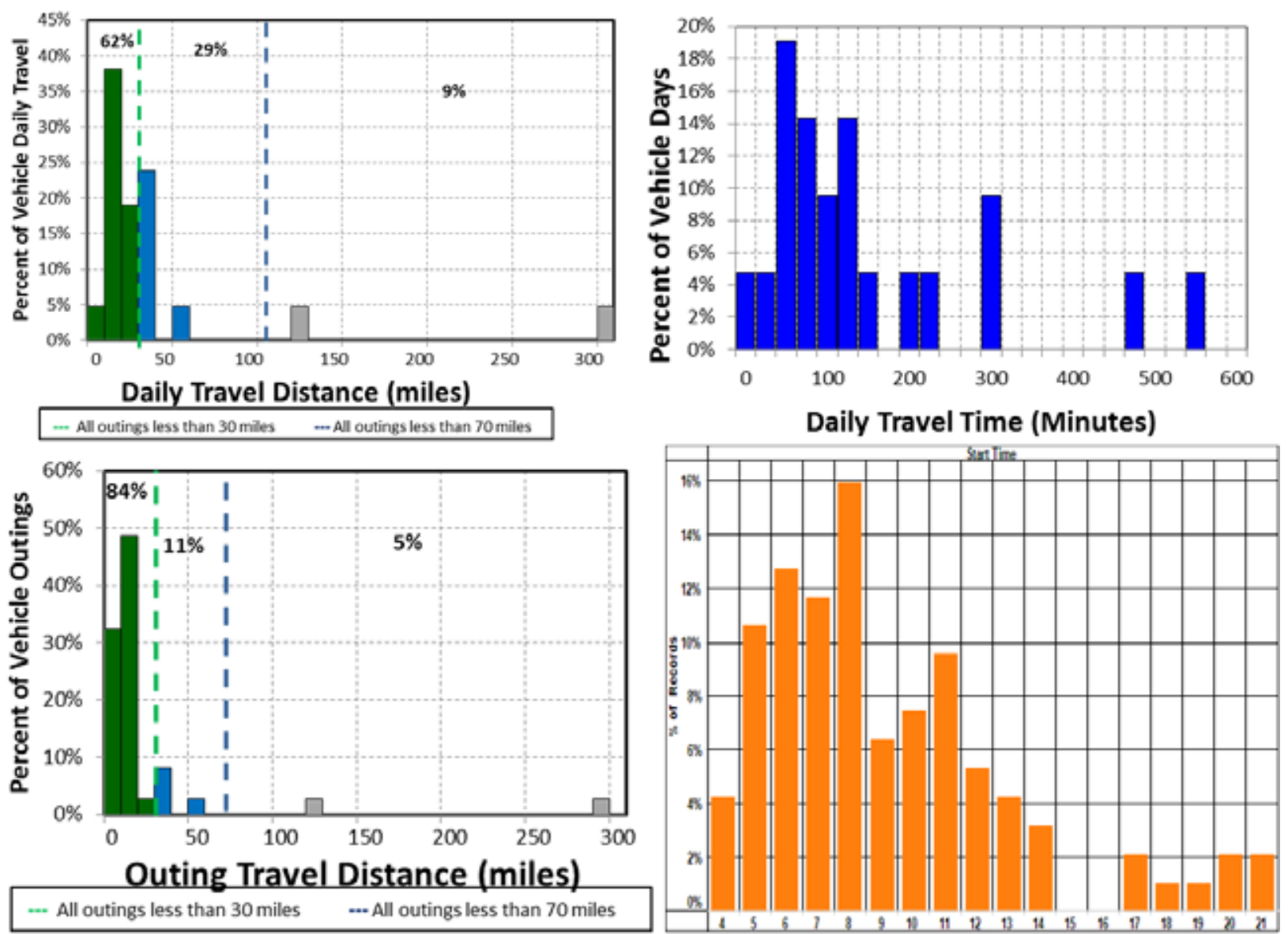

Figure B-48. Vehicle G62-0791H travel graphs.

\section{Vehicle G62-0791H Observations}

Logger 91 collected data on this vehicle for a period of 21 days of the 33-day study period. Validation occurred on $100 \%$ of the input data. Data indicate that this vehicle has a support mission for the Marine Headquarters Group. This vehicle's data indicate it parks near Building SAW353 on Sawmill Road as shown in the Google Earth figure to the right.

MCBCL reports that a recent vehicle odometer indicated 45,614 miles at the start of this study and an average annual mileage of 9,273 miles. The vehicle was used on $64 \%$ of the available days, with an average daily usage of 2.8 hours and a peak daily usage of 9.2 hours on the days it was used. The vehicle was used

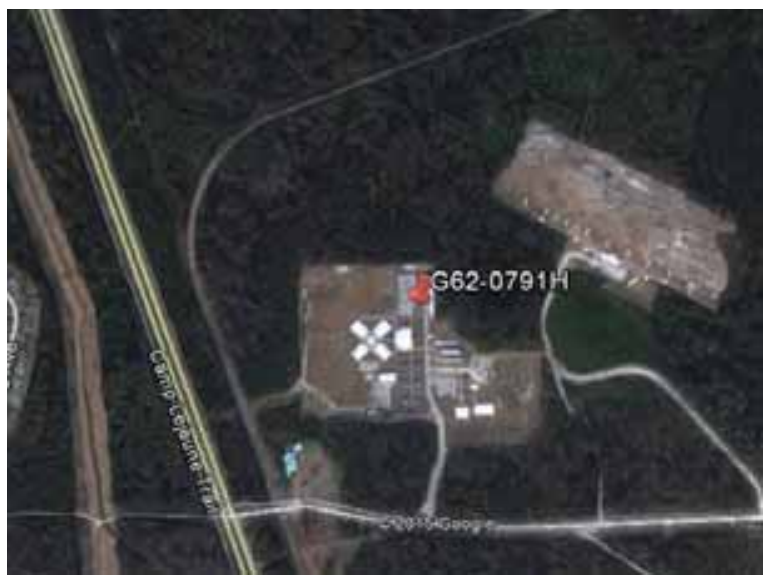
primarily during day shift hours and some evening hours.

Figure B-48 shows that $91 \%$ of daily travel was within the typically advertised range of a BEV of approximately 70 miles and $95 \%$ of outings were also within this range. Further, $62 \%$ of daily travel and $84 \%$ of outings were within the typically advertised CD mode of 30 miles for PHEVs.

A BEV could not meet not all daily travel because of frequent trips greater than 70 miles. However, a significant amount of daily travel was within the range of a BEV; therefore, a fleet of SUVs would likely contain a mix of BEVs and PHEVs. 
Sheet 17: Vehicle G63-0309R

\begin{tabular}{|c|c|c|}
\hline & Make/Model/Year & Ford F350-2015 \\
\hline & EPA Class Size & Pickup \\
\hline$\frac{1}{2}$ & Mission & Support \\
\hline$\Rightarrow \cdot \theta$ ल & Contact & Marine Wing SS 272 \\
\hline & Parking Location & Building AS4158 \\
\hline & Fleet Vehicle ID & G63-0309R \\
\hline & Fuel Type & E85 \\
\hline & EPA Label/MPG (City/Hwy/Combined)* & $13 / 18 / 15$ \\
\hline & EPA GHG Emissions (Grams $\left.\mathrm{CO}_{2} / \mathrm{Mi}\right)^{*}$ & 419 \\
\hline & Study Logger ID & 99 \\
\hline & Total Vehicle Days/Total Study Days & $13 / 25$ \\
\hline
\end{tabular}

\begin{tabular}{|l|c|c|c|c|}
\hline \multicolumn{5}{|c|}{ Vehicle G63-0309R Travel Summary } \\
\hline & $\begin{array}{c}\text { Per Day } \\
\text { Average/Peak }\end{array}$ & $\begin{array}{c}\text { Per Outing } \\
\text { Average/Peak }\end{array}$ & $\begin{array}{c}\text { Per Trip } \\
\text { Average/Peak }\end{array}$ & Total \\
\hline Travel Distance (Miles) & $45.4 / 171.3$ & $10.4 / 129.2$ & $6.7 / 74.2$ & 591 \\
\hline Travel Time (Minutes) & $141.9 / 378.0$ & $32.4 / 231.0$ & $21.0 / 132.0$ & 1,845 \\
\hline Idle Time (Minutes) & $31.7 / \mathrm{NA}$ & $7.2 / \mathrm{NA}$ & $4.7 / \mathrm{NA}$ & 412 \\
\hline
\end{tabular}

\begin{tabular}{|c|c|c|c|c|}
\hline \multicolumn{2}{|c|}{ Total Stops } & \multicolumn{2}{c|}{ Stop Duration } \\
\hline $\begin{array}{c}\text { Distance From } \\
\text { Home Base (Miles) }\end{array}$ & Stops & Percentages & Stop Duration (Hours) & Stops \\
\hline Less than 10 & 109 & $98.2 \%$ & Less than 2 & 88 \\
\hline 10 to 20 & 0 & 0 & 2 to 4 & 6 \\
\hline 20 to 40 & 2 & $1.8 \%$ & 4 to 8 & \\
\hline 40 to 60 & 0 & 0 & Greater than 8 & 13 \\
\hline
\end{tabular}

Figure B-49. Vehicle G63-0309R stops.

Figure B-50. Vehicle G63-0309R history.

*Fuel economy for F350 is unavailable. Information is for F150. 


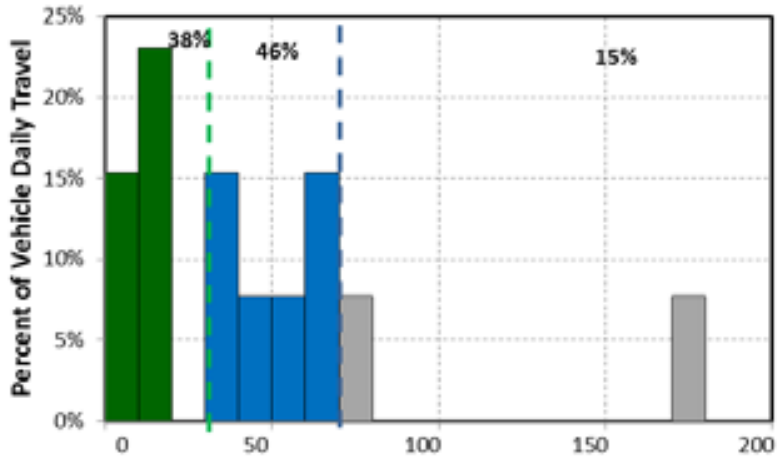

Daily Travel Distance (miles)

-.- All outings less than 30 miles ....All outings less than 70 miles

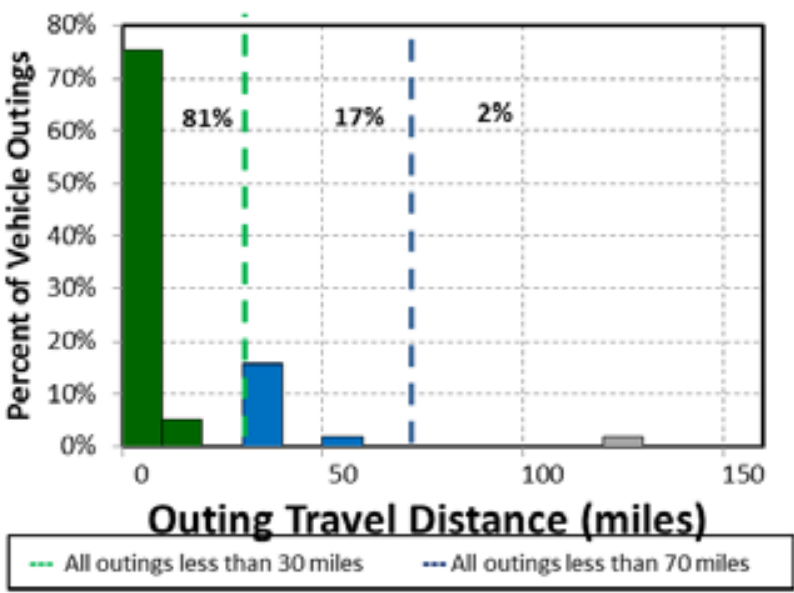

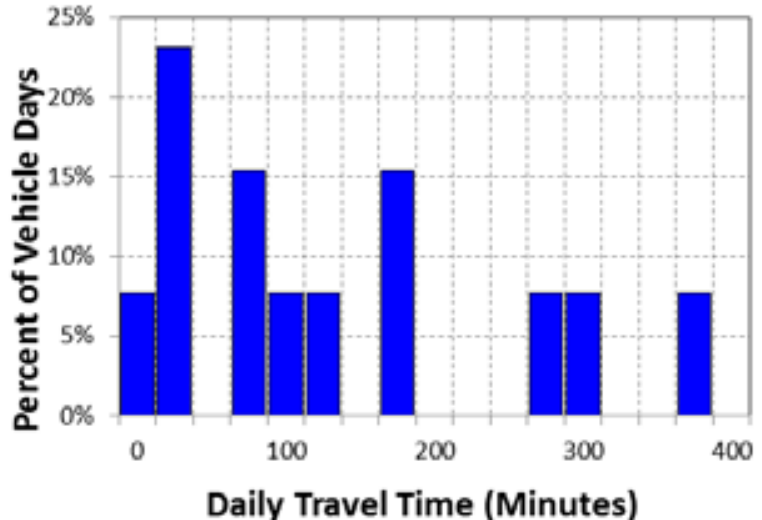

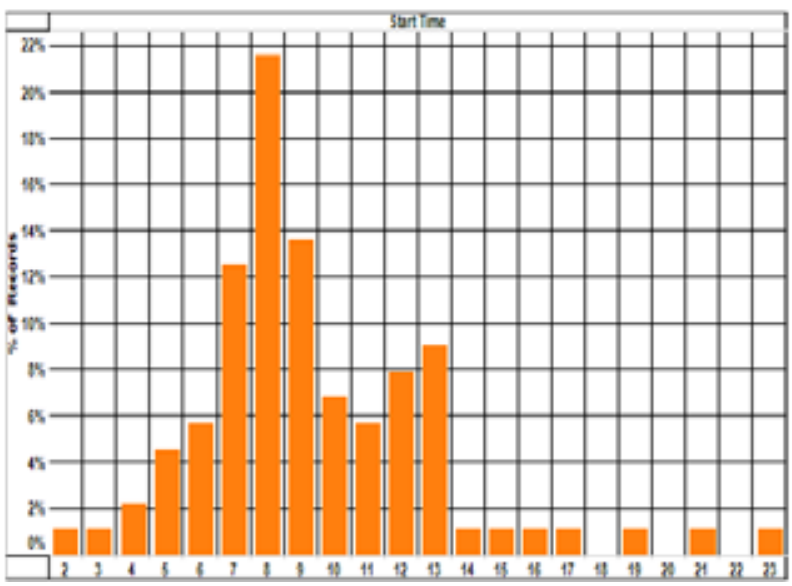

Figure B-51. Vehicle G63-0309R travel graphs.

\section{Vehicle G63-0309R Observations}

Logger 99 collected data on this vehicle for a period of 13 days of the 25-day study period. Validation occurred on $100 \%$ of the input data. Data indicate that this vehicle has a support mission for Marine Wing SS 272. This vehicle's data indicate it parks near Building AS4158 near Demarco and Schmidt Street as shown in the Google Earth figure to the right.

MCBCL reports that the vehicle odometer indicated 0 miles for this new vehicle and its average annual mileage is estimated to be 2,469 miles. The vehicle was used on $52 \%$ of the available days, with an average daily usage of 2.4 hours and a peak daily usage of 6.3 hours on the days it was used. The vehicle was used during all hours of the day.

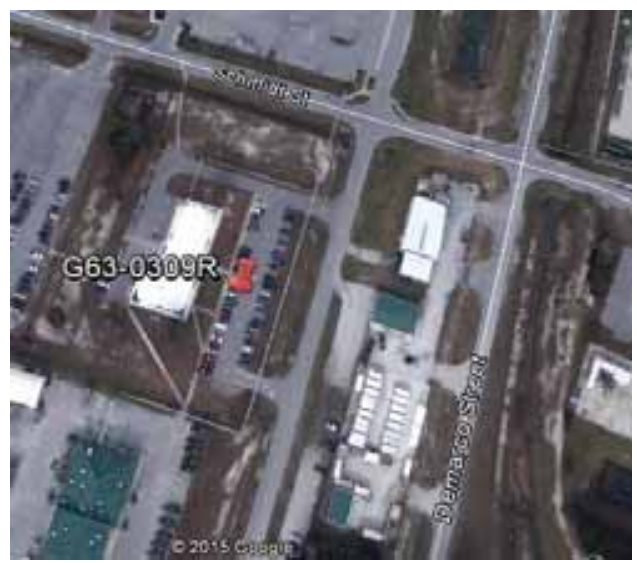

Figure B-51 shows that $85 \%$ of daily travel was within the typically advertised range of a BEV of approximately 70 miles and $98 \%$ of outings were also within this range. Further, $38 \%$ of daily travel and $81 \%$ of outings were within the typically advertised CD mode of 30 miles for PHEVs.

A BEV could not meet all daily travel without additional charging opportunities because of the single daily trip. However, a significant amount of daily travel was within the range of the BEV. Thus, a fleet of pickups would likely contain a mix of BEVs and PHEVs. 
Sheet 18: Vehicle G63-0934G

\begin{tabular}{|c|c|c|}
\hline & Make/Model/Year & Chevrolet K3500-2008 \\
\hline & EPA Class Size & Pickup \\
\hline & Mission & Support \\
\hline $20-9=$ & Contact & MARSOC \\
\hline & Parking Location & Building RR450 near Range Road \\
\hline & Fleet Vehicle ID & G63-0934G \\
\hline & Fuel Type & Gas \\
\hline & EPA Label/MPG (City/Hwy/Combined)* & $15 / 20 / 17$ \\
\hline & EPA GHG Emissions $\left(\mathrm{Grams} \mathrm{CO}_{2} / \mathrm{Mi}\right)^{*}$ & 523 \\
\hline & Study Logger ID & 120 \\
\hline & Total Vehicle Days/Total Study Days & $14 / 25$ \\
\hline
\end{tabular}

\begin{tabular}{|l|c|c|c|c|}
\hline \multicolumn{5}{|c|}{ Vehicle G63-0934G Travel Summary } \\
\hline & $\begin{array}{c}\text { Per Day } \\
\text { Average/Peak }\end{array}$ & $\begin{array}{c}\text { Per Outing } \\
\text { Average/Peak }\end{array}$ & $\begin{array}{c}\text { Per Trip } \\
\text { Average/10.0/Peak }\end{array}$ & Total \\
\hline Travel Distance (Miles) & $75.9 / 396.5$ & $22.6 / 1,012.4$ & $10.8 / 202.9$ & 1,062 \\
\hline Travel Time (Minutes) & $123.8 / 485.0$ & $36.9 / 1,443.0$ & $17.7 / 218.0$ & 1,733 \\
\hline Idle Time (Minutes) & $15.4 / \mathrm{NA}$ & $4.6 / \mathrm{NA}$ & $2.2 / \mathrm{NA}$ & 215 \\
\hline
\end{tabular}

\begin{tabular}{|c|c|c|}
\hline \multicolumn{3}{|c|}{ Total Stops } \\
\hline $\begin{array}{c}\text { Distance From } \\
\text { Home Base } \\
\text { (Miles) }\end{array}$ & Stops & Percentages \\
\hline Less than 10 & 51 & $57.3 \%$ \\
\hline 10 to 20 & 0 & 0 \\
\hline 20 to 40 & 0 & 0 \\
\hline$>40$ & 38 & $42.7 \%$ \\
\hline & & \\
\hline & & \\
\hline & & \\
\hline
\end{tabular}

Figure B-52. Vehicle G63-0934G stops.

\begin{tabular}{|c|c|}
\hline \multicolumn{2}{|c|}{ Stop Duration } \\
\hline Stop Duration (Hours) & Stops \\
\hline Less than 2 & 71 \\
\hline 2 to 4 & 3 \\
\hline 4 to 8 & 2 \\
\hline Greater than 8 & 13 \\
\hline & \\
\hline & \\
\hline 200 & \\
\hline & \\
\hline & \\
\hline$\frac{9}{400}=$ & \\
\hline 300 & \\
\hline & \\
\hline & \\
\hline
\end{tabular}

Figure B-53. Vehicle G63-0934G history.

*Fuel economy for K3500 is not available. Economy used is for 1500/2500. 

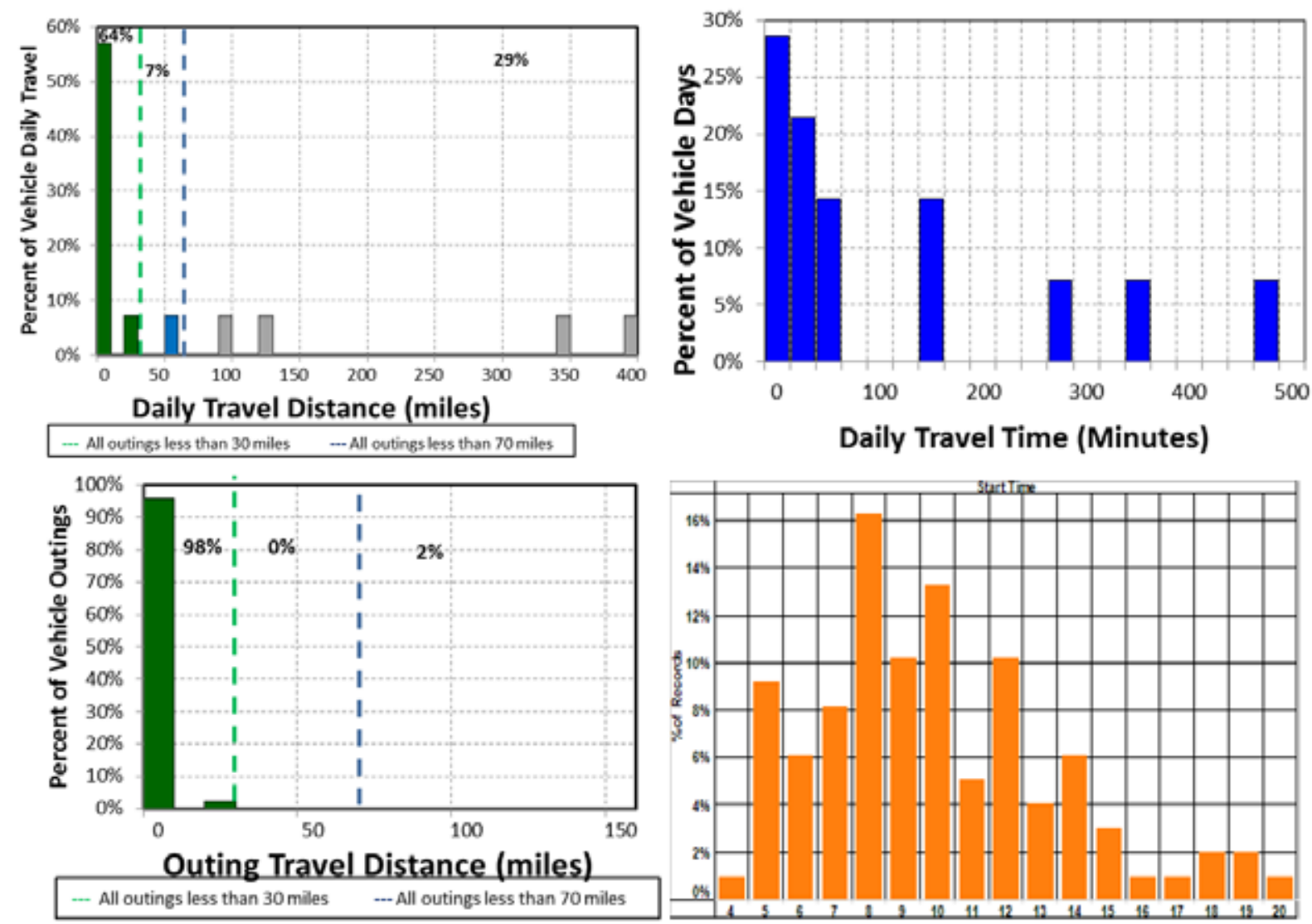

Figure B-54. Vehicle G63-0934G travel graphs. Note that the outing graph does not show the single extended excursion of 1,012 miles.

\section{Vehicle G63-0934G Observations}

Logger 120 collected data on this vehicle for a period of 14 days of the 25-day study period. Validation occurred on $100 \%$ of the input data. Data indicate that this vehicle has a support mission for Marine Corps Forces Special Operations Command. This vehicle's data indicate it parks near Building RR450 near Range Road as shown in the Google Earth figure to the right.

MCBCL reports that a recent vehicle odometer indicated 49,385 miles and an average annual mileage of 7,502 miles. The vehicle was used on $56 \%$ of the available days, with an average daily usage of 2.1 hours and a peak daily usage of 8.1 hours on the days it was used. The vehicle was used during all hours of the day.

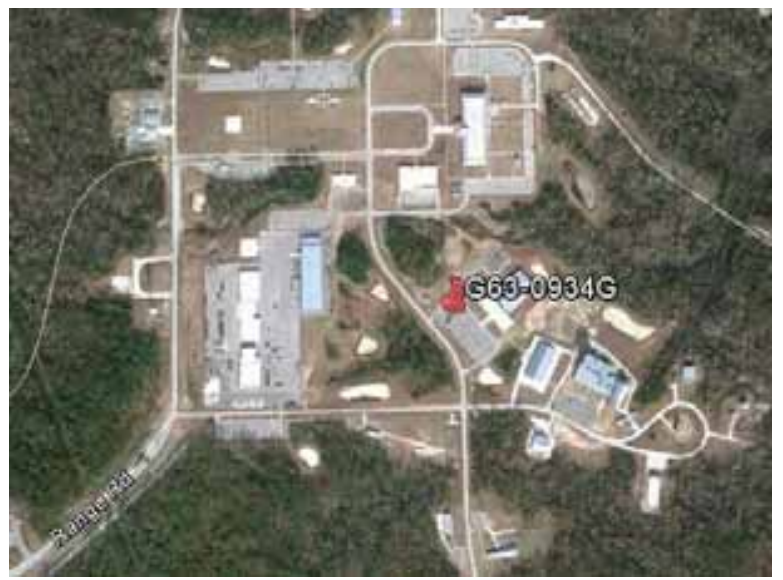

Figure B-54 shows that $71 \%$ of daily travel was within the typically advertised range of a BEV of approximately 70 miles and $98 \%$ of the outings were also within this range. Further, $64 \%$ of daily travel and $98 \%$ of outings were within the typically advertised CD mode of 30 miles for PHEVs. The peak outing of 1,012 miles occurred over a several day period during an extended excursion to various locations in North Carolina.

A BEV could not meet all daily travel because of the frequent daily travel exceeding the BEV range. However, a significant amount of daily travel was within a BEV range; therefore, a fleet of pickup trucks would likely contain a mix of BEVs and PHEVs. 


\section{Appendix C \\ Marine Corps Installations East Vehicle Data Sheets}

Table C-1. MCBCL MCIE vehicle index.

\begin{tabular}{|c|c|c|c|c|c|c|c|}
\hline \multicolumn{8}{|c|}{ Vehicle Index } \\
\hline Sheet & Log & $\begin{array}{c}\text { Fleet } \\
\text { Vehicle Id }\end{array}$ & Make & Model & Year & EPA Class & Mission \\
\hline 19 & 4 & 290597 & Ford & E350 & 1997 & Van - Cargo & Pool \\
\hline 20 & 37 & 291007 & Ford & F550 & 2004 & SP & Specialty \\
\hline 21 & 35 & 294285 & Chevrolet & Malibu & 2009 & Sedan - Midsize & Support \\
\hline 22 & 48 & 294293 & Chevrolet & HHR & 2009 & SUV & Enforcement \\
\hline 23 & 42 & 294315 & Chevrolet & 3500 & 2009 & Pickup & Support \\
\hline 24 & 54 & 294324 & Chevrolet & HHR & 2009 & SUV & Support \\
\hline 25 & 53 & 300672 & Ford & F550 & 2011 & SP & Specialty \\
\hline 26 & 55 & 302039 & Ford & F250XL & 2014 & Pickup & Support \\
\hline 27 & 56 & 302040 & Ford & F250XL & 2014 & Pickup & Support \\
\hline 28 & 79 & 302334 & Ford & F350 Stake & 2015 & Pickup & Support \\
\hline 29 & 5 & G10-3327L & Chevrolet & Malibu & 2012 & Sedan - Midsize & Pool \\
\hline 30 & 41 & G13-0325K & Ford & Focus & 2012 & Sedan - Compact & Support \\
\hline 31 & 39 & G13-7974P & Ford & Focus & 2015 & Sedan - Compact & Support \\
\hline 32 & 7 & G41-0379H & Dodge & Grand Caravan & 2009 & Minivan & Pool \\
\hline 33 & 40 & G41-0391H & Dodge & Dakota & 2009 & Pickup & Support \\
\hline 34 & 8 & G41-0754M & Dodge & Grand Caravan & 2012 & Minivan & Pool \\
\hline 35 & 57 & G41-0806P & Dodge & Caravan & 2014 & Minivan & Support \\
\hline 36 & 58 & G41-1689L & Ford & Ranger & 2011 & Pickup & Support \\
\hline 37 & 59 & G41-3297K & Ford & Ranger & 2011 & Pickup & Support \\
\hline 38 & 49 & G41-3300K & Ford & Ranger & 2011 & Pickup & Enforcement \\
\hline 39 & 61 & G41-3301K & Ford & Ranger & 2011 & Pickup & Support \\
\hline 40 & 9 & G42-0644M & Ford & E150 & 2012 & Van - Pass & Pool \\
\hline 41 & 68 & G42-0667P & Ford & F150 & 2014 & Pickup & Support \\
\hline 42 & 69 & G42-0671P & Ford & F150 & 2014 & Pickup & Support \\
\hline 43 & 10 & G42-0911L & Chevrolet & C1500 & 2012 & Pickup & Pool \\
\hline 44 & 75 & G42-0915M & Ford & F150 & 2012 & Pickup & Support \\
\hline 45 & 50 & G42-2985H & Chevrolet & $\mathrm{C} 1500$ & 2010 & Pickup & Enforcement \\
\hline 46 & 13 & G43-0310H & Ford & E350 & 2009 & Van - Pass & Pool \\
\hline 47 & 71 & G43-0323H & Ford & E350 & 2009 & Van - Cargo & Support \\
\hline 48 & 74 & G43-0324H & Ford & E350 & 2009 & Van - Cargo & Support \\
\hline 49 & 36 & G43-1182M & Chevrolet & CG3300 & 2012 & Van - Cargo & Support \\
\hline 50 & 14 & G43-4075P & Ford & $\mathrm{F} 250$ & 2015 & Pickup & Pool \\
\hline 51 & 77 & G61-0161H & Dodge & Dakota & 2009 & Pickup & Support \\
\hline 52 & 78 & G61-0174H & Jeep & Liberty & 2009 & SUV & Support \\
\hline 53 & 51 & G61-0879P & Chevrolet & Equinox & 2014 & SUV & Enforcement \\
\hline 54 & 15 & G61-1508D & Jeep & Liberty & 2008 & SUV & Pool \\
\hline 55 & 16 & G61-1509D & Jeep & Liberty & 2008 & SUV & Pool \\
\hline 56 & 82 & G62-1583G & Chevrolet & K1500 & 2008 & Pickup & Support \\
\hline 57 & 46 & G62-4085L & Dodge & 1500 & 2012 & Pickup & Support \\
\hline 58 & 98 & G63-0163H & Chevrolet & $\mathrm{K} 2500 \mathrm{HD}$ & 2009 & Pickup & Support \\
\hline
\end{tabular}




\begin{tabular}{|c|c|c|c|c|c|c|c|}
\hline \multirow[b]{2}{*}{ Sheet } & \multicolumn{7}{|c|}{ Vehicle Index } \\
\hline & Log & $\begin{array}{c}\text { Fleet } \\
\text { Vehicle Id }\end{array}$ & Make & Model & Year & EPA Class & Mission \\
\hline 59 & 47 & G63-2885L & Chevrolet & K2500HD & 2012 & Pickup & Support \\
\hline 60 & 52 & G63-2888L & Chevrolet & $\mathrm{K} 2500 \mathrm{HD}$ & 2012 & Pickup & Enforcement \\
\hline
\end{tabular}


Sheet 19: Vehicle 290597

\begin{tabular}{|c|c|c|}
\hline 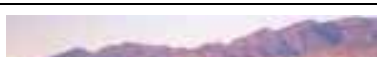 & Make/Model/Year & Ford E350 - 1997 \\
\hline & EPA Class Size & Van - Cargo \\
\hline A & Mission & Pool \\
\hline$\pi$ & Contact & Motor Transport C-Pool \\
\hline & Parking Location & Building 11407 on Michael Road \\
\hline & Fleet Vehicle ID & 290597 \\
\hline & Fuel Type & Gas \\
\hline & EPA Label/MPG (City/Hwy/Combined)* & $12 / 17 / 14$ \\
\hline & EPA GHG Emissions (Grams $\left.\mathrm{CO}_{2} / \mathrm{Mi}\right)^{*}$ & 635 \\
\hline & Study Logger ID & 4 \\
\hline & Total Vehicle Days/Total Study Days & $18 / 34$ \\
\hline
\end{tabular}

\begin{tabular}{|l|c|c|c|c|}
\hline \multicolumn{5}{|c|}{ Vehicle 290597Travel Summary } \\
\hline & $\begin{array}{c}\text { Per Day } \\
\text { Average/Peak }\end{array}$ & $\begin{array}{c}\text { Per Outing } \\
\text { Average/Peak }\end{array}$ & $\begin{array}{c}\text { Per Trip } \\
\text { Average/Peak }\end{array}$ & Total \\
\hline Travel Distance (Miles) & $12.4 / 100.7$ & $12.4 / 145.4$ & $3.1 / 52.1$ & 223 \\
\hline Travel Time (Minutes) & $47.9 / 192.0$ & $47.9 / 342.0$ & $12.0 / 124.0$ & 863 \\
\hline Idle Time (Minutes) & $15.4 / \mathrm{NA}$ & $15.4 / \mathrm{NA}$ & $3.8 / \mathrm{NA}$ & 277 \\
\hline
\end{tabular}

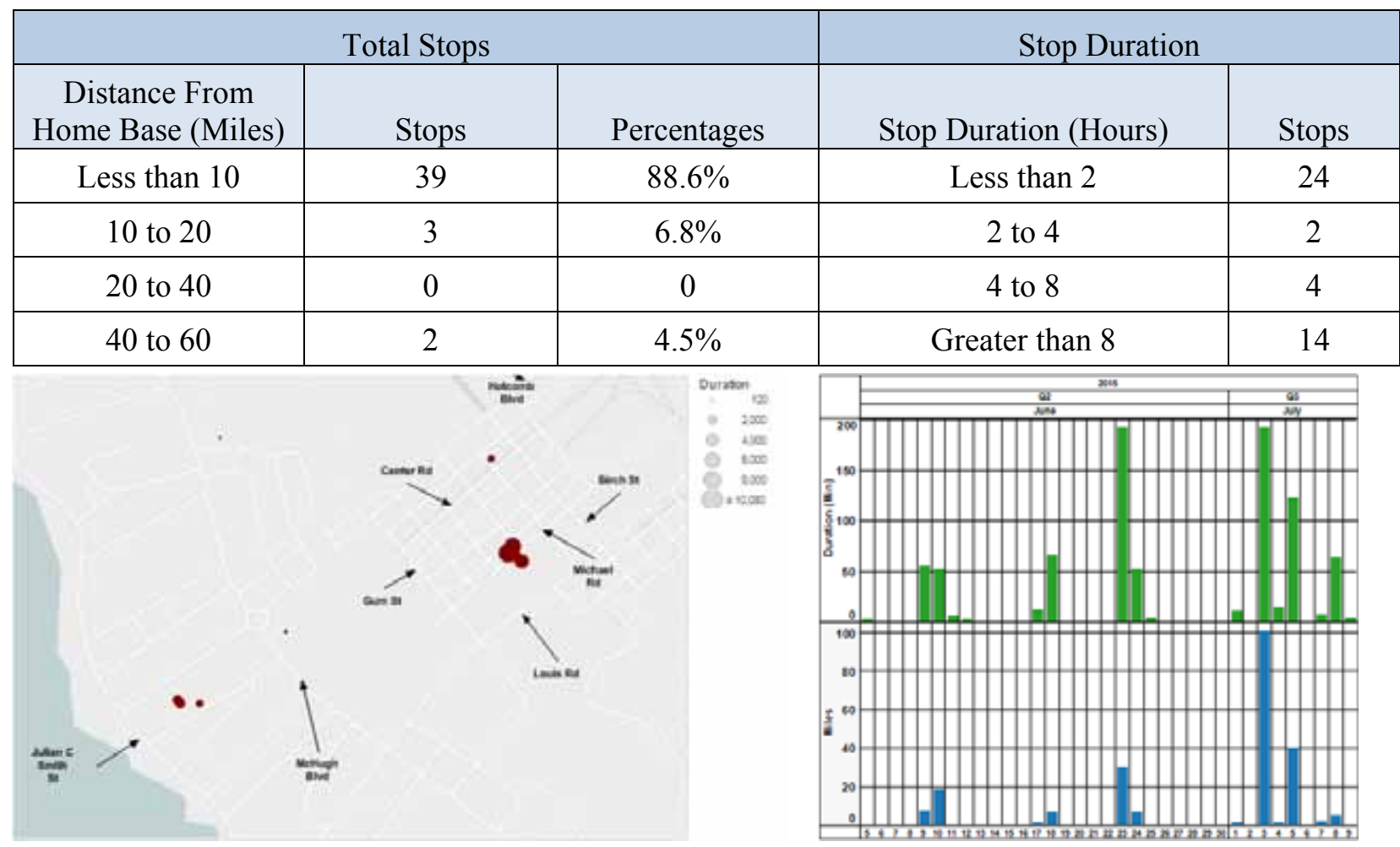

Figure C-1. Vehicle 290597 stops.

Figure C-2. Vehicle 290597 history.

*Fuel economy for E350 is not available. Economy used is for E250. 


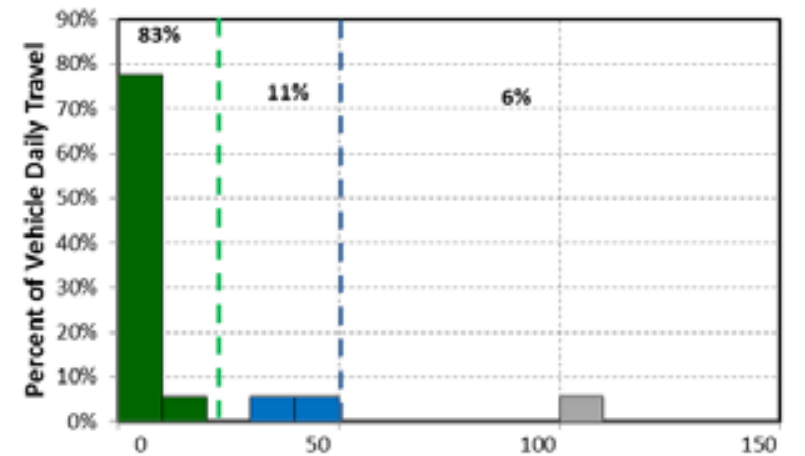

Daily Travel Distance (miles)

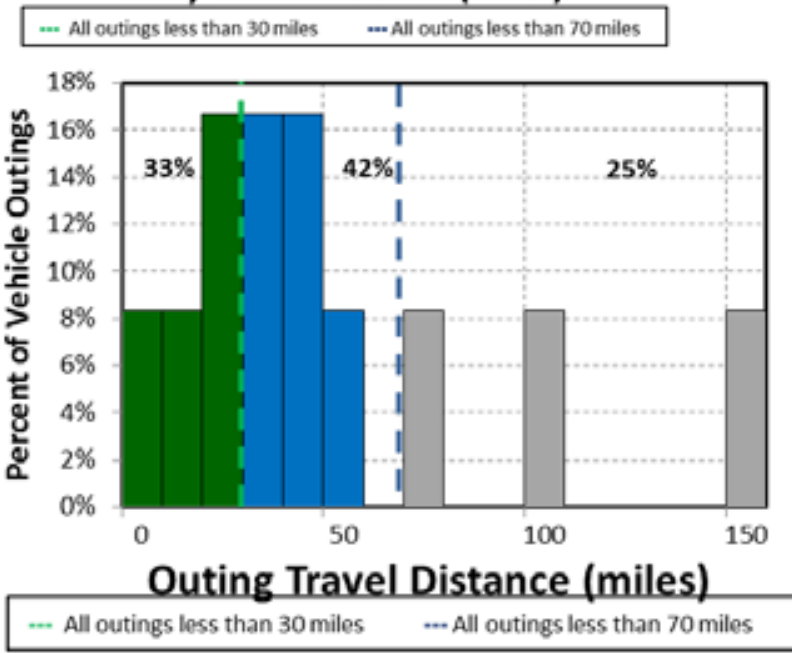

Figure C-3. Vehicle 290597 travel graphs.

\section{Vehicle 290597 Observations}

Logger 4 collected data on this vehicle for a period of 18 days of the 34-day study period. Validation occurred on $100 \%$ of the input data. Data indicate that this vehicle has a pool mission for Motor Transport C-Pool. This vehicle's data indicate it parks near Building 1407 near Michael Road as shown in the Google Earth figure to the right.

MCBCL reports that a recent vehicle odometer indicated 27,949 miles and an average annual mileage of 957 miles. The vehicle was used on $53 \%$ of the available days, with an average daily usage of 0.8 hours and a peak daily usage of 3.2 hours on the days it was used. The vehicle was used during day and evening hours.

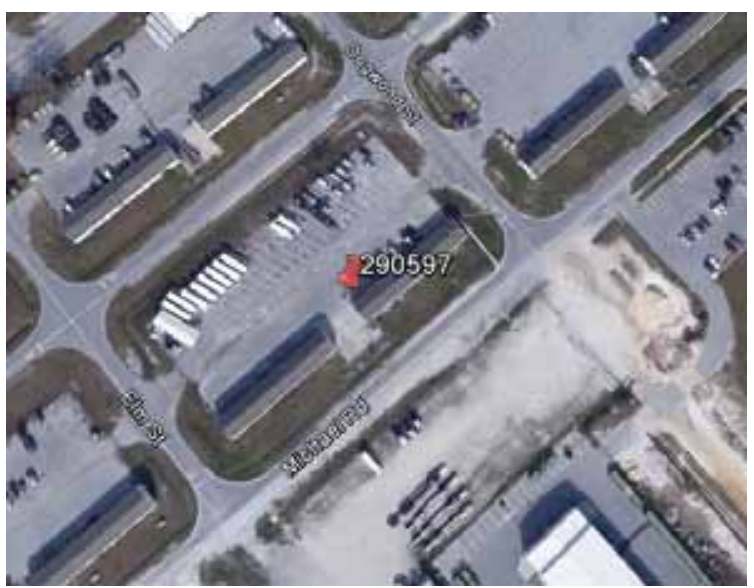

Figure C-3 shows that $94 \%$ of daily travel was within the typically advertised range of a BEV of approximately 70 miles and $75 \%$ of outings were also within this range. Further, $83 \%$ of daily travel and $33 \%$ of outings were within the typically advertised CD mode of 30 miles for PHEVs. The peak outing of 145 miles occurred over a several day period when the vehicle traveled to several locations in North Carolina and back to Camp Lejeune, but did not return to Michael Road and parked in several other locations at the main campus.

A BEV could not meet all daily travel. However, a significant amount of daily travel is within the BEV range; therefore, a fleet of vehicles would likely contain a mix of BEVs and PHEVs. 


\begin{tabular}{|c|c|c|}
\hline- & Make/Model/Year & Ford F560 - 2004 \\
\hline 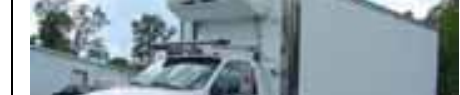 & EPA Class Size & $\begin{array}{c}\text { Specialty - Refrigeration } \\
\text { Truck }\end{array}$ \\
\hline & Mission & Specialty \\
\hline$A$ & Contact & MTO \\
\hline & Parking Location & Building 327 near H Street \\
\hline & Fleet Vehicle ID & 291007 \\
\hline & Fuel Type & Diesel \\
\hline & EPA Label/MPG (City/Hwy/Combined)* & 10 \\
\hline & EPA GHG Emissions (Grams $\left.\mathrm{CO}_{2} / \mathrm{Mi}\right)^{*}$ & 1021 \\
\hline & Study Logger ID & 37 \\
\hline & Total Vehicle Days/Total Study Days & Insufficient Data \\
\hline
\end{tabular}

\begin{tabular}{|l|c|c|c|c|}
\hline \multicolumn{5}{|c|}{ Vehicle 291007 Travel Summary } \\
\hline & $\begin{array}{c}\text { Per Day } \\
\text { Average/Peak }\end{array}$ & $\begin{array}{c}\text { Per Outing } \\
\text { Average/Peak }\end{array}$ & $\begin{array}{c}\text { Per Trip } \\
\text { Average/Peak }\end{array}$ & Total \\
\hline Travel Distance (Miles) & Insufficient Data & Insufficient Data & Insufficient Data & Insufficient Data \\
\hline Travel Time (Minutes) & Insufficient Data & Insufficient Data & Insufficient Data & Insufficient Data \\
\hline Idle Time (Minutes) & Insufficient Data & Insufficient Data & Insufficient Data & Insufficient Data \\
\hline
\end{tabular}

\begin{tabular}{|c|c|c|c|c|}
\hline \multicolumn{2}{|c|}{ Total Stops } & \multicolumn{2}{c|}{ Stop Duration } \\
\hline $\begin{array}{c}\text { Distance From } \\
\text { Home Base (Miles) }\end{array}$ & Stops & Percentages & Stop Duration (Hours) & Stops \\
\hline Less than 10 & Insufficient Data & Insufficient Data & Less than 2 & Insufficient Data \\
\hline 10 to 20 & Insufficient Data & Insufficient Data & 2 to 4 & Insufficient Data \\
\hline 20 to 40 & Insufficient Data & Insufficient Data & 4 to 8 & Insufficient Data \\
\hline 40 to 60 & Insufficient Data & Insufficient Data & Greater than 8 & Insufficient Data \\
\hline
\end{tabular}

Insufficient Data

\section{Vehicle 291007 Observations}

Logger 37 was installed in this specialty vehicle that was used as a pool vehicle. However, no usage was obtained during the study period.

MCBCL reports that a recent vehicle odometer indicated 21,217 miles and an average annual mileage of 1,425 miles. 
Sheet 21: Vehicle 294285

\begin{tabular}{|c|c|c|}
\hline ter. & Make/Model/Year & Chevrolet Malibu - 2009 \\
\hline wiv $1 \mathrm{~T}$ & EPA Class Size & Sedan - Midsize \\
\hline 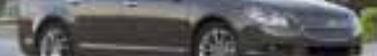 & Mission & Support \\
\hline & Contact & Postal \\
\hline & Parking Location & Building 1770 \\
\hline & Fleet Vehicle ID & 294285 \\
\hline & Fuel Type & Gas \\
\hline & EPA Label/MPG (City/Hwy/Combined) & $22 / 33 / 26$ \\
\hline & EPA GHG Emissions (Grams $\left.\mathrm{CO}_{2} / \mathrm{Mi}\right)$ & 342 \\
\hline & Study Logger ID & 35 \\
\hline & Total Vehicle Days/Total Study Days & $18 / 31$ \\
\hline
\end{tabular}

\begin{tabular}{|l|c|c|c|c|}
\hline \multicolumn{5}{|c|}{ Vehicle 294285 Travel Summary } \\
\hline & $\begin{array}{c}\text { Per Day } \\
\text { Average/Peak }\end{array}$ & $\begin{array}{c}\text { Per Outing } \\
\text { Average/Peak }\end{array}$ & $\begin{array}{c}\text { Per Trip } \\
\text { Average/Peak }\end{array}$ & Total \\
\hline Travel Distance (Miles) & $50.8 / 74.8$ & $31.5 / 64.0$ & $5.9 / 48.2$ & 914 \\
\hline Travel Time (Minutes) & $149.7 / 224.0$ & $92.9 / 207.0$ & $17.3 / 157.0$ & 2,695 \\
\hline Idle Time (Minutes) & $24.2 / \mathrm{NA}$ & $15.0 / \mathrm{NA}$ & $2.8 / \mathrm{NA}$ & 435 \\
\hline
\end{tabular}

\begin{tabular}{|c|c|c|c|c|}
\hline \multicolumn{2}{|c|}{ Total Stops } & \multicolumn{2}{c|}{ Stop Duration } \\
\hline $\begin{array}{c}\text { Distance From } \\
\text { Home Base (Miles) }\end{array}$ & Stops & Percentages & Stop Duration (Hours) & Stops \\
\hline Less than 10 & 93 & $100 \%$ & Less than 2 & 71 \\
\hline 10 to 20 & 0 & 0 & 2 to 4 & 2 \\
\hline 20 to 40 & 0 & 0 & 4 to 8 & 2 \\
\hline 40 to 60 & 0 & 0 & Greater than 8 & 18 \\
\hline
\end{tabular}

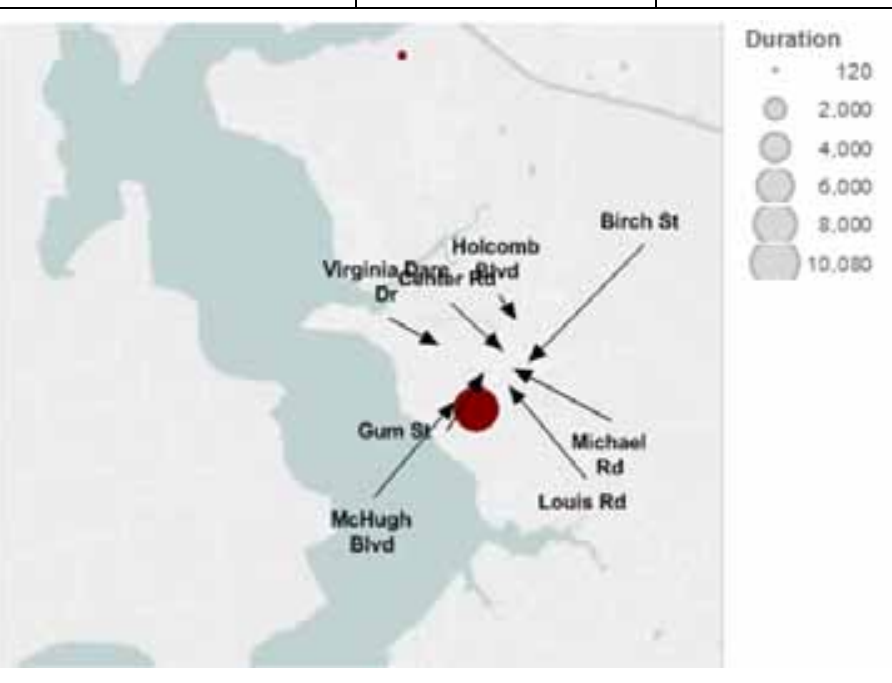

Figure C-4. Vehicle 294285 stops.

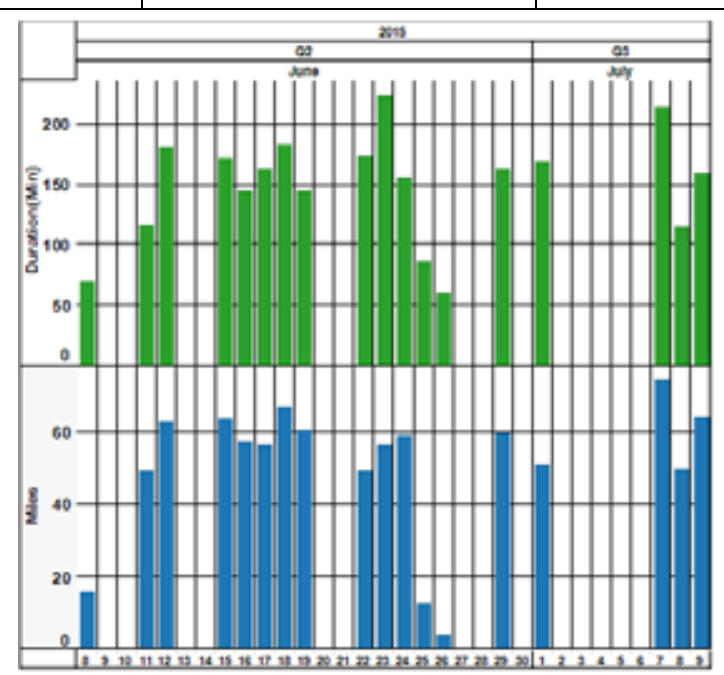

Figure C-5. Vehicle 294285 history. 


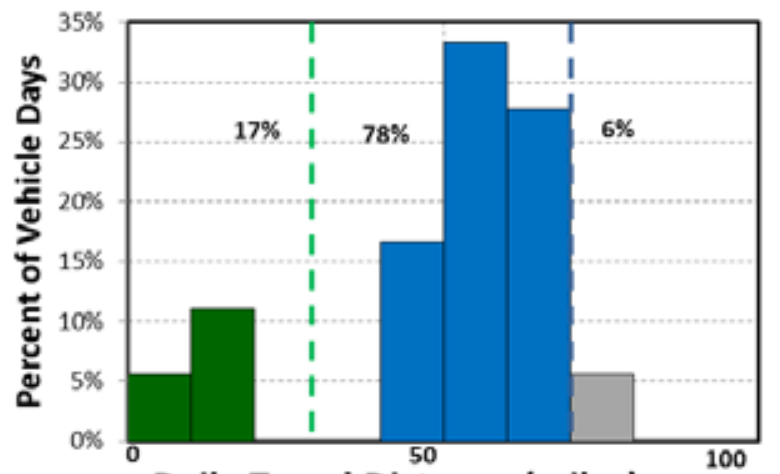

Daily Travel Distance (miles)
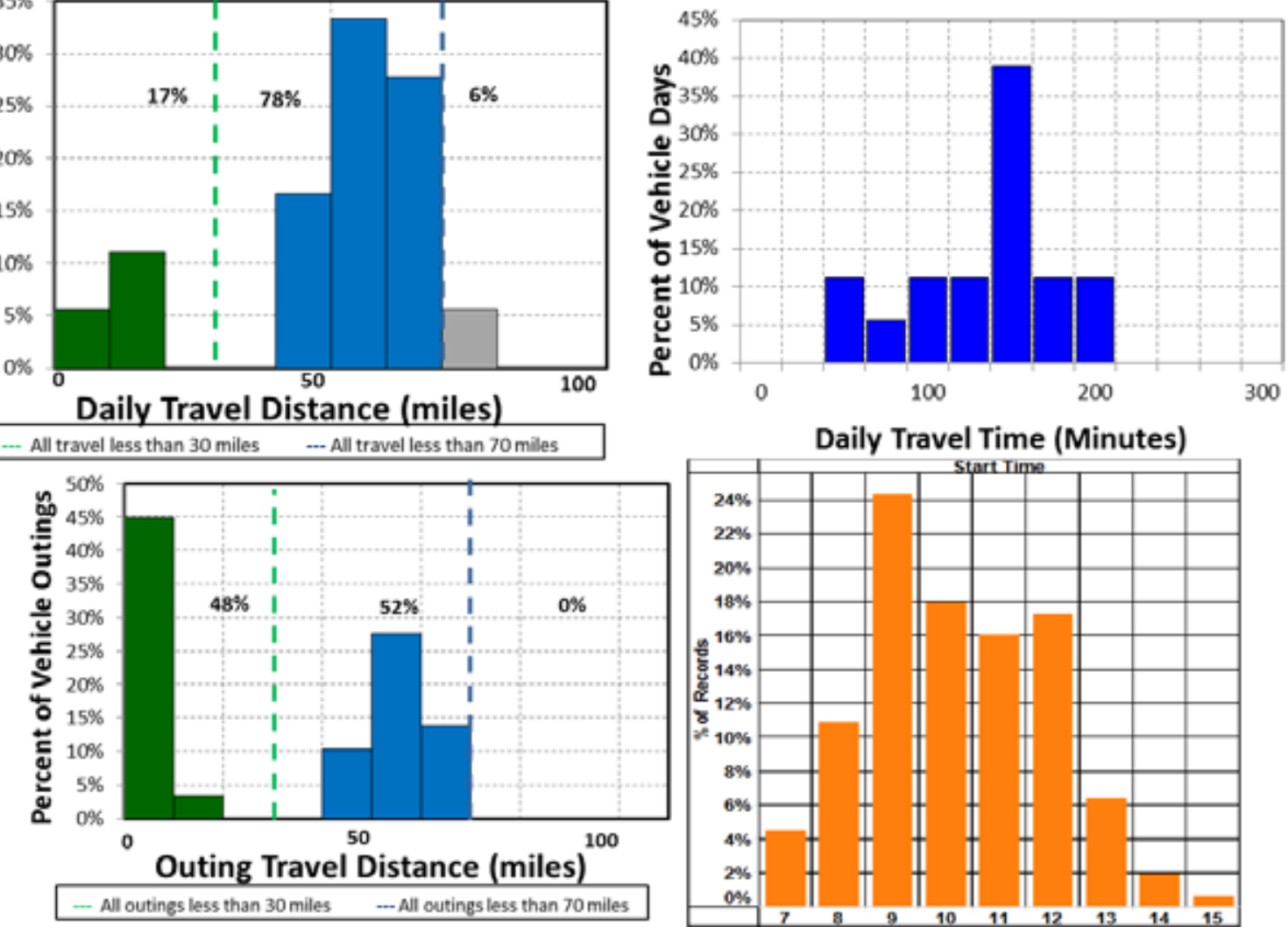

Daily Travel Time (Minutes)

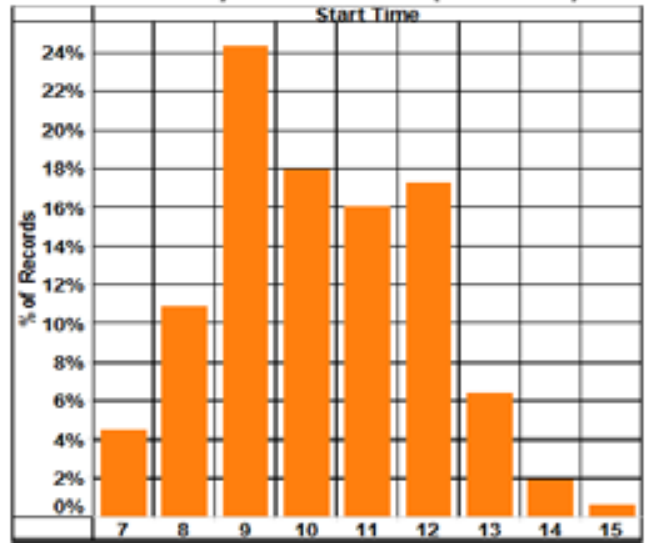

Figure C-6. Vehicle 294285 travel graphs.

\section{Vehicle 294285 Observations}

Logger 35 collected data on this vehicle for a period of 18 days of the 31-day study period.

Validation occurred on $100 \%$ of the input data. Data indicate that this vehicle has a support mission for the Post Office. This vehicle's data indicate it parks near Building 1770 on Louis Road as shown in the Google Earth figure to the right.

MCBCL reports that a recent vehicle odometer indicated 44,190 miles at the start of this study and an average annual mileage of 3,795 miles. The vehicle was used on $58 \%$ of the available days, with an average daily usage of 2.5 hours and a peak daily usage of 3.7 hours on the days it was used. The vehicle was used during day shift hours.

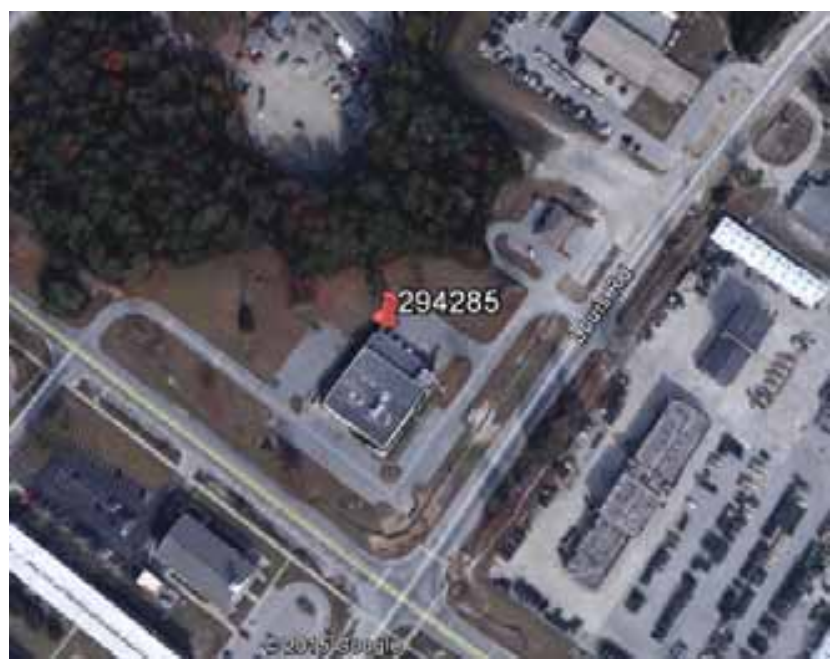

Figure C-6 shows that $94 \%$ of daily travel was within the typically advertised range of a BEV of approximately 70 miles. All outings were also within this range. Further, $17 \%$ of daily travel and $48 \%$ of outings were within the typically advertised CD mode of 30 miles for PHEVs.

A BEV could meet all daily travel with additional charging opportunities, assuming the vehicle was assigned a home base. Fleet managers typically prefer a vehicle that does not have range limitations. Thus, a fleet of vehicles would likely contain a mix of BEVs and PHEVs. 
Sheet 22: Vehicle 294293

\begin{tabular}{|c|c|c|c|c|}
\hline \multirow{11}{*}{ 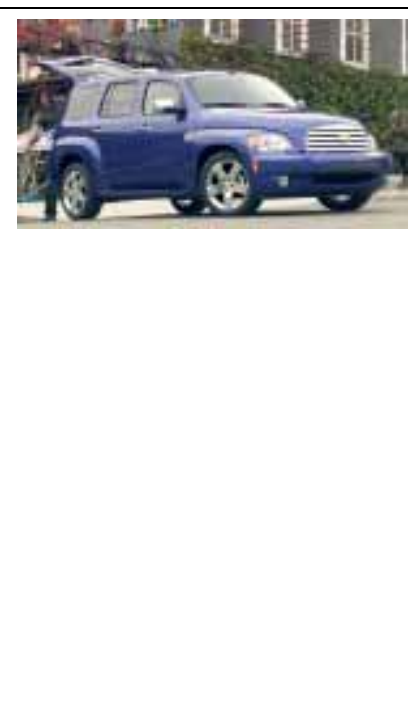 } & \multicolumn{2}{|l|}{ Make/Model/Year } & \multicolumn{2}{|c|}{ Chevrolet HHR - 2009} \\
\hline & \multicolumn{2}{|l|}{ EPA Class Size } & \multicolumn{2}{|c|}{ SUV } \\
\hline & \multicolumn{2}{|l|}{ Mission } & \multicolumn{2}{|c|}{ Enforcement } \\
\hline & \multicolumn{2}{|l|}{ Contact } & \multicolumn{2}{|c|}{ Provost Marshal's Office } \\
\hline & \multicolumn{2}{|l|}{ Parking Location } & \multicolumn{2}{|c|}{ Building AS302 } \\
\hline & \multicolumn{2}{|l|}{ Fleet Vehicle ID } & \multicolumn{2}{|c|}{294293} \\
\hline & \multicolumn{2}{|l|}{ Fuel Type } & \multicolumn{2}{|c|}{ E85 } \\
\hline & \multicolumn{2}{|c|}{ EPA Label/MPG (City/Hwy/Combined) } & \multicolumn{2}{|c|}{$16 / 22 / 18$} \\
\hline & \multicolumn{2}{|c|}{ EPA GHG Emissions (Grams $\mathrm{CO}_{2} / \mathrm{Mi}$ ) } & \multicolumn{2}{|c|}{345} \\
\hline & \multicolumn{2}{|l|}{ Study Logger ID } & \multicolumn{2}{|c|}{48} \\
\hline & \multicolumn{2}{|c|}{ Total Vehicle Days/Total Study Days } & \multicolumn{2}{|c|}{$16 / 31$} \\
\hline \multicolumn{5}{|c|}{ Vehicle 294293 Travel Summary } \\
\hline & $\begin{array}{c}\text { Per Day } \\
\text { Average/Peak }\end{array}$ & $\begin{array}{c}\text { Per Outing } \\
\text { Average/Peak }\end{array}$ & $\begin{array}{c}\text { Per Trip } \\
\text { Average/Peak }\end{array}$ & Total \\
\hline Travel Distance (Miles) & $25.7 / 39.9$ & $22.8 / 54.7$ & $7.3 / 16.0$ & 411 \\
\hline Travel Time (Minutes) & $52.6 / 117.0$ & $46.8 / 148.0$ & $15.0 / 31.0$ & 842 \\
\hline Idle Time (Minutes) & $0.8 / \mathrm{NA}$ & $0.7 / \mathrm{NA}$ & $0.2 / \mathrm{NA}$ & 13 \\
\hline
\end{tabular}

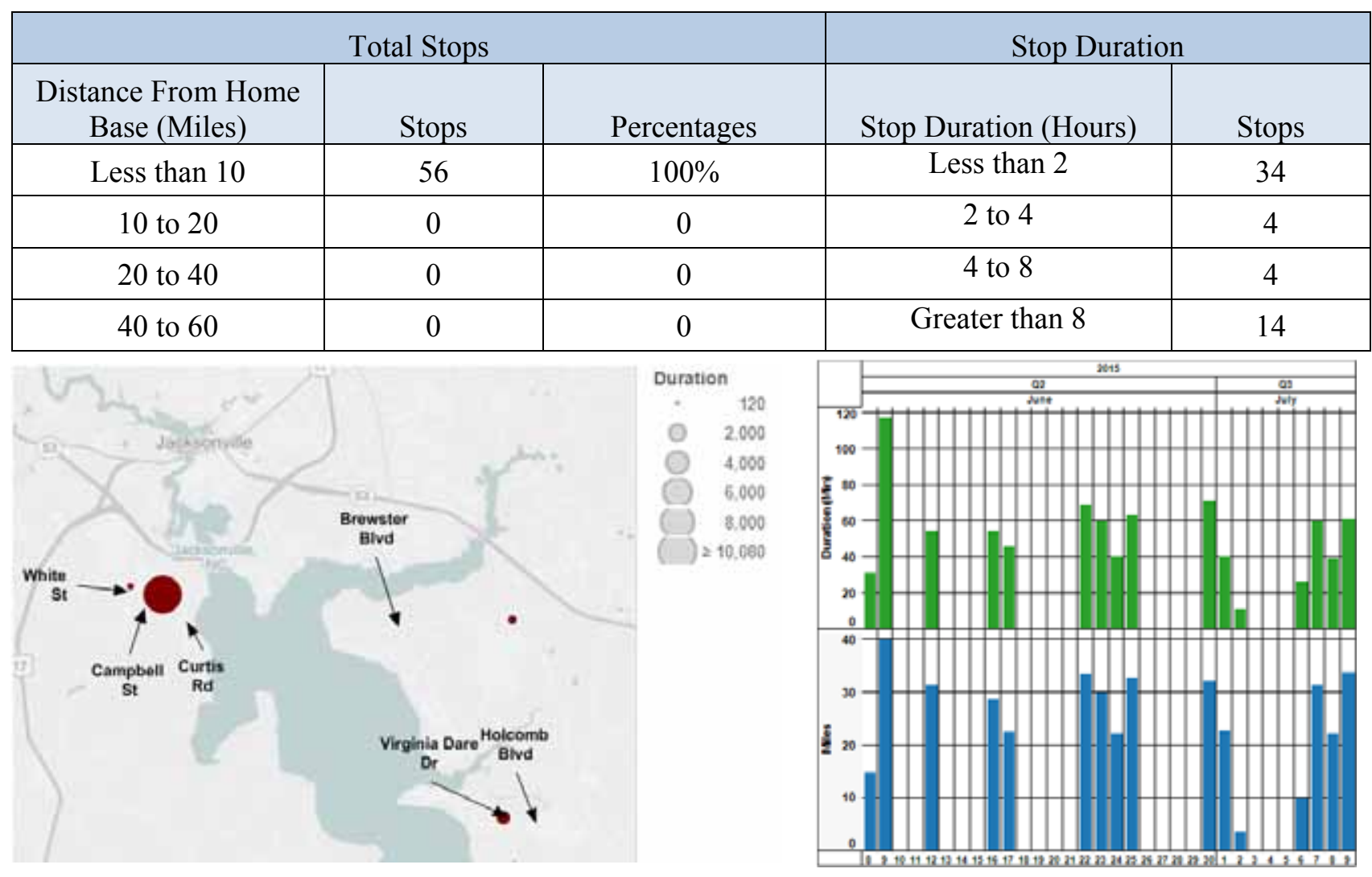

Figure C-7. Vehicle 294293 stops.

Figure C-8. Vehicle 294293 history. 

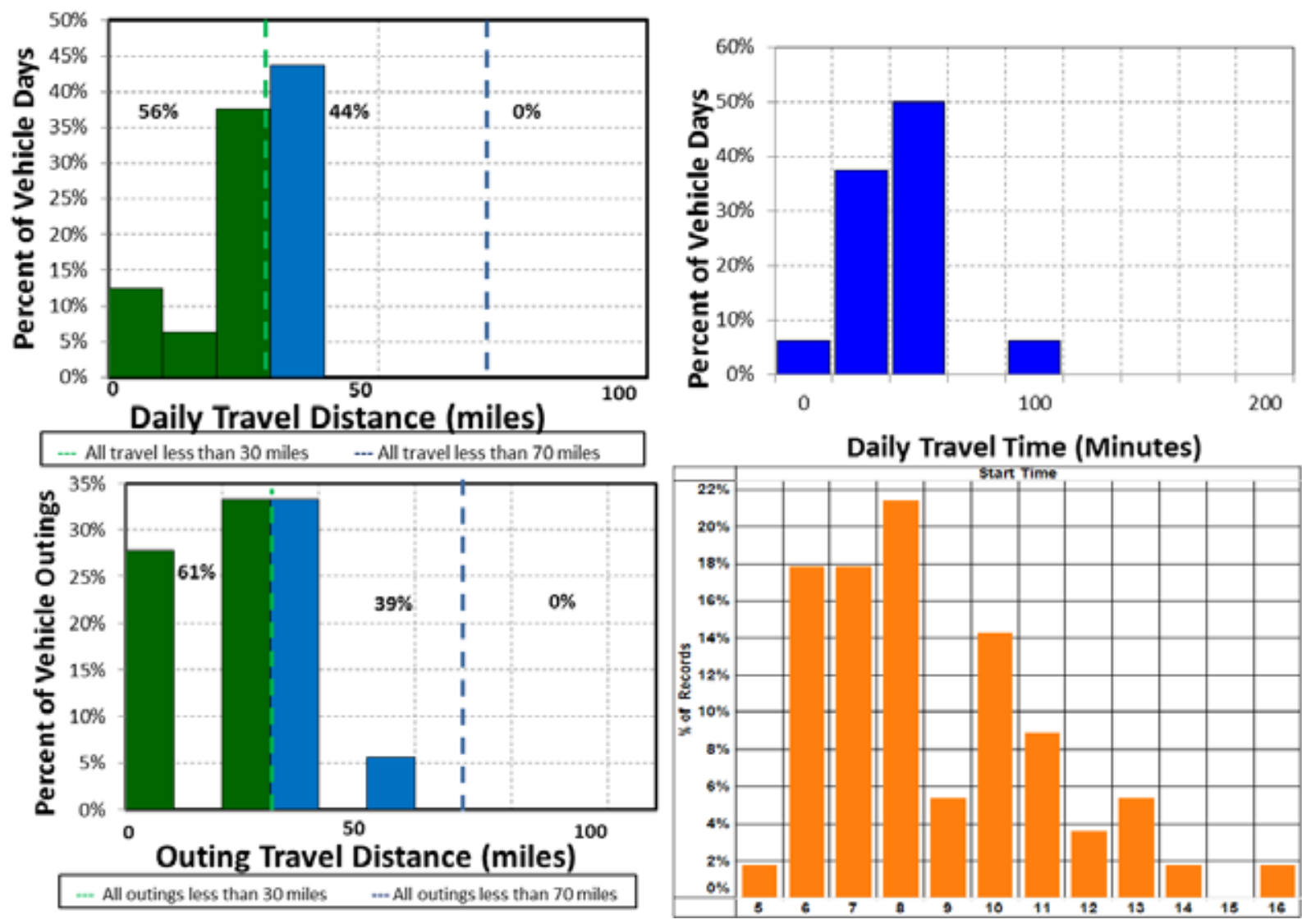

Figure C-9. Vehicle 294293 travel graphs.

\section{Vehicle 294293 Observations}

Logger 48 collected data on this vehicle for a period of 16 days of the 31-day study period. Validation occurred on $100 \%$ of the input data. Data indicate that this vehicle has an enforcement mission for the Provost Marshal's Office. This vehicle's data indicate it parks near Building AS 302 on McAvoy Street as shown in the Google Earth figure to the right.

MCBCL reports that a recent vehicle odometer indicated 53,870 miles at the start of this study and an average annual mileage of 4,214 miles. The vehicle was used on $52 \%$ of the available days, with an average daily usage of 0.9 hours and a peak daily usage of 2.0 hours on the days it was used. The vehicle was used during all hours of the day.

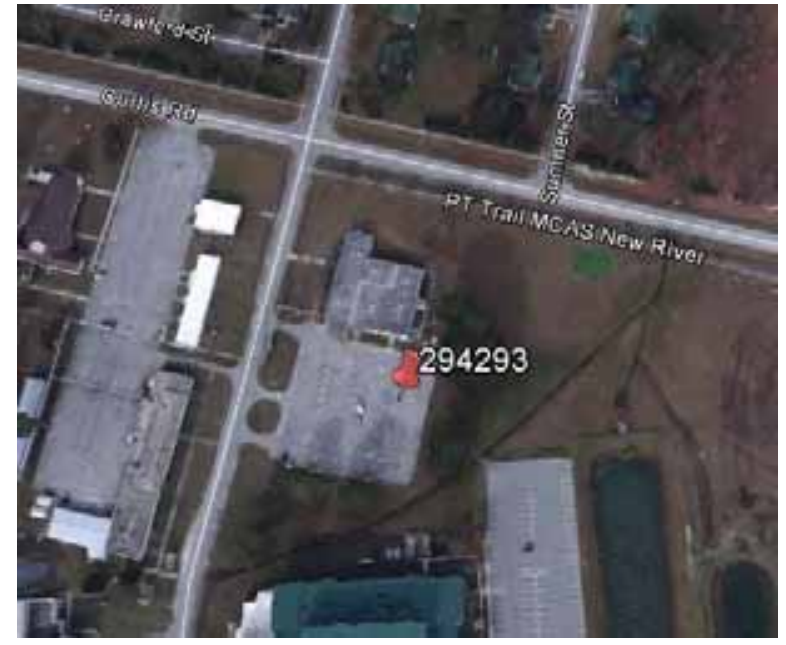

Figure C-9 shows that all daily travel was within the typically advertised range of a BEV of approximately 70 miles. All outings were also within this range. Further, $56 \%$ of daily travel and $61 \%$ of outings were within the typically advertised CD mode of 30 miles for PHEVs.

A BEV could meet all daily travel without additional charging opportunities, assuming the vehicle was assigned a home base. However, fleet managers typically do not prefer enforcement vehicles that contain range limitations. Thus, a fleet of enforcement vehicles would likely contain a mix of BEVs and PHEVs. 
Sheet 23: Vehicle 294315

\begin{tabular}{|c|c|c|}
\hline & Make/Model/Year & Chevrolet $3500-2009$ \\
\hline & EPA Class Size & Pickup \\
\hline & Mission & Support \\
\hline & Contact & Fire Department \\
\hline & Parking Location & Building TC701 \\
\hline & Fleet Vehicle ID & 294315 \\
\hline & Fuel Type & Diesel \\
\hline & EPA Label/MPG (City/Hwy/Combined)* & 14 \\
\hline & EPA GHG Emissions (Grams $\left.\mathrm{CO}_{2} / \mathrm{Mi}\right) *$ & 729 \\
\hline & Study Logger ID & 42 \\
\hline & Total Vehicle Days/Total Study Days & $24 / 31$ \\
\hline
\end{tabular}

\begin{tabular}{|l|c|c|c|c|}
\hline \multicolumn{5}{|c|}{ Vehicle 294315 Travel Summary } \\
\hline & $\begin{array}{c}\text { Per Day } \\
\text { Average/Peak }\end{array}$ & $\begin{array}{c}\text { Per Outing } \\
\text { Average/Peak }\end{array}$ & $\begin{array}{c}\text { Per Trip } \\
\text { Average/Peak }\end{array}$ & Total \\
\hline Travel Distance (Miles) & $24.1 / 83.2$ & $23.1 / 98.6$ & $7.1 / 31.4$ & 578 \\
\hline Travel Time (Minutes) & $67.4 / 243.0$ & $64.7 / 248.0$ & $20.0 / 135.0$ & 1,618 \\
\hline Idle Time (Minutes) & $23.8 / \mathrm{NA}$ & $22.8 / \mathrm{NA}$ & $7.0 / \mathrm{NA}$ & 570 \\
\hline
\end{tabular}

\begin{tabular}{|c|c|c|c|c|}
\hline \multicolumn{2}{|c|}{ Total Stops } & \multicolumn{2}{c|}{ Stop Duration } \\
\hline $\begin{array}{c}\text { Distance From } \\
\text { Home Base (Miles) }\end{array}$ & Stops & Percentages & Stop Duration (Hours) & Stops \\
\hline Less than 10 & 63 & $96.6 \%$ & Less than 2 & 39 \\
\hline 10 to 20 & 2 & $3.1 \%$ & 2 to 4 & 6 \\
\hline 20 to 40 & 0 & 0 & 4 to 8 & 1 \\
\hline 40 to 60 & 0 & 0 & Greater than 8 & 19 \\
\hline
\end{tabular}

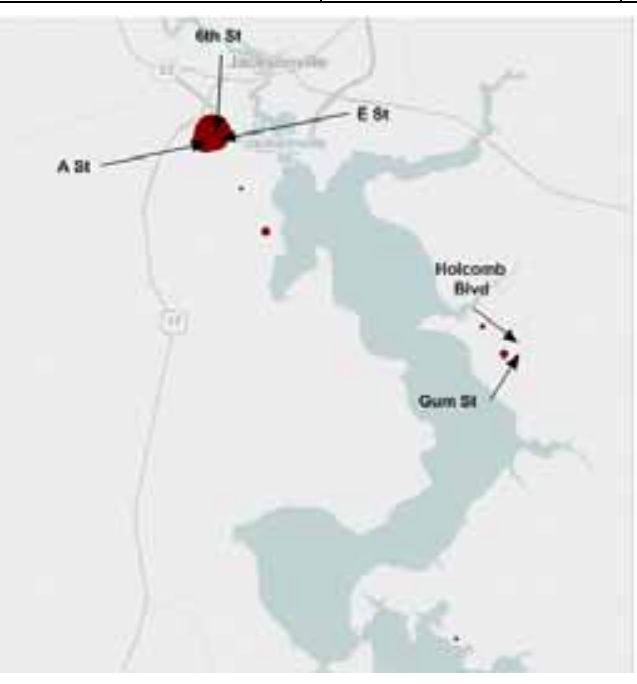

Figure C-10. Vehicle 294315 stops.

*EPA fuel economy is not available. Figures calculated for diesel per Section 5. 

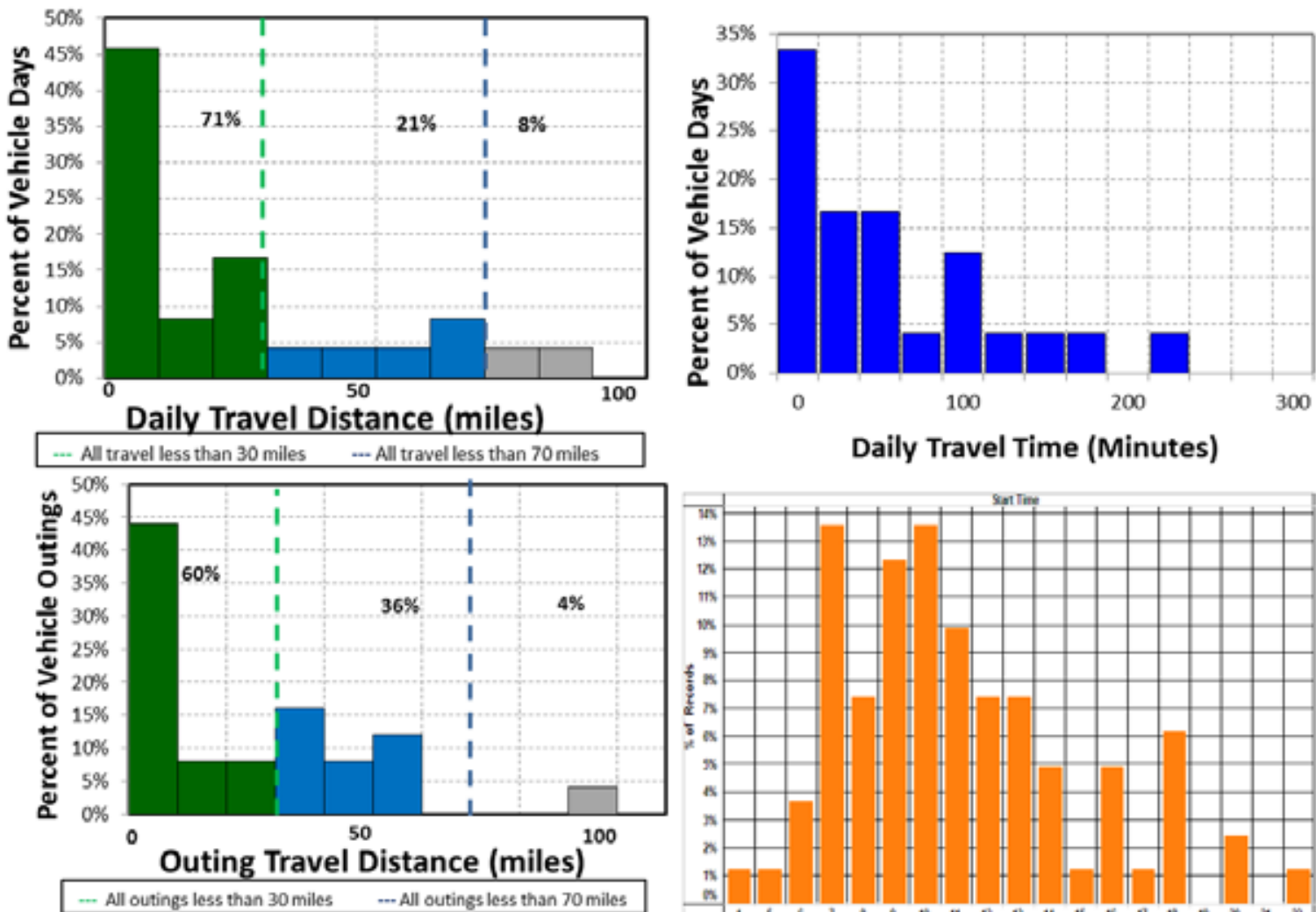

Daily Travel Time (Minutes)

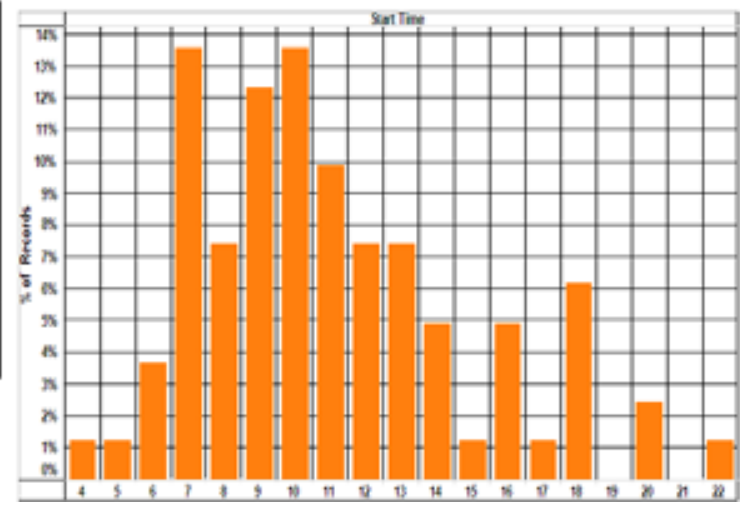

Figure C-12. Vehicle 294315 travel graphs.

\section{Vehicle 294315 Observations}

Logger 42 collected data on this vehicle for a period of 24 days of the 31-day study period. Validation occurred on $92.7 \%$ of the input data. Data indicate that this vehicle has a support mission for the fire department. This vehicle's data indicate it parks overnight in several different locations, but primarily near Building TC701 near $7^{\text {th }}$ Street as shown in the Google Earth figure to the right.

MCBCL reports that a recent vehicle odometer indicated 23,997 miles and an average annual mileage of 3,208 miles. The vehicle was used on $77 \%$ of the available days, with an average daily usage of 1.1 hours and a peak daily usage of 4.1 hours on the days it was used. The vehicle was used primarily during day shift hours.

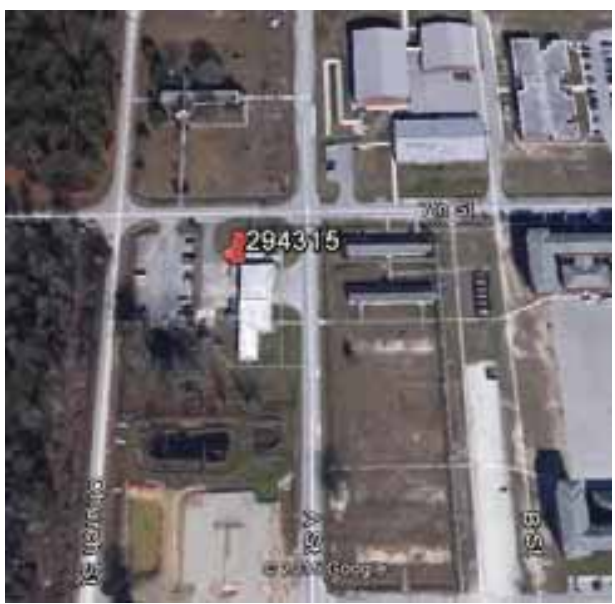

Figure C-12 shows that $92 \%$ of daily travel was within the typically advertised range of a BEV of approximately 70 miles and $96 \%$ of outings were also within this range. Further, $71 \%$ of daily travel and $60 \%$ of outings were within the typically advertised CD mode of 30 miles for PHEVs.

A BEV could not meet all daily travel without additional charging opportunities, assuming the vehicle was assigned a home base. However, a significant amount of daily travel was within the range of a BEV. Thus, a fleet of pickup trucks would likely contain a mix of BEVs and PHEVs. 


\begin{tabular}{|c|c|c|}
\hline 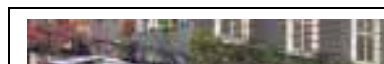 & Make/Model/Year & Chevrolet HHR - 2009 \\
\hline & EPA Class Size & SUV \\
\hline 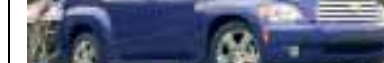 & Mission & Support \\
\hline & Contact & Public Works \\
\hline & Parking Location & Building 1005 \\
\hline & Fleet Vehicle ID & 294324 \\
\hline & Fuel Type & E85 \\
\hline & EPA Label/MPG (City/Hwy/Combined) & $22 / 32 / 26$ \\
\hline & EPA GHG Emissions (Grams $\mathrm{CO}_{2} / \mathrm{Mi}$ ) & 326 \\
\hline & Study Logger ID & 54 \\
\hline & Total Vehicle Days/Total Study Days & $22 / 1$ \\
\hline
\end{tabular}

\begin{tabular}{|l|c|c|c|c|}
\hline \multicolumn{5}{|c|}{ Vehicle 294324Travel Summary } \\
\hline & $\begin{array}{c}\text { Per Day } \\
\text { Average/Peak }\end{array}$ & $\begin{array}{c}\text { Per Outing } \\
\text { Average/Peak }\end{array}$ & $\begin{array}{c}\text { Per Trip } \\
\text { Average/Peak }\end{array}$ & Total \\
\hline Travel Distance (Miles) & $55.5 / 106.3$ & $30.5 / 60.0$ & $8.1 / 53.1$ & 1,222 \\
\hline Travel Time (Minutes) & $127.2 / 207.0$ & $70.0 / 119.0$ & $18.7 / 96.0$ & 2,798 \\
\hline Idle Time (Minutes) & $22.9 / \mathrm{NA}$ & $12.6 / \mathrm{NA}$ & $3.4 / \mathrm{NA}$ & 504 \\
\hline
\end{tabular}

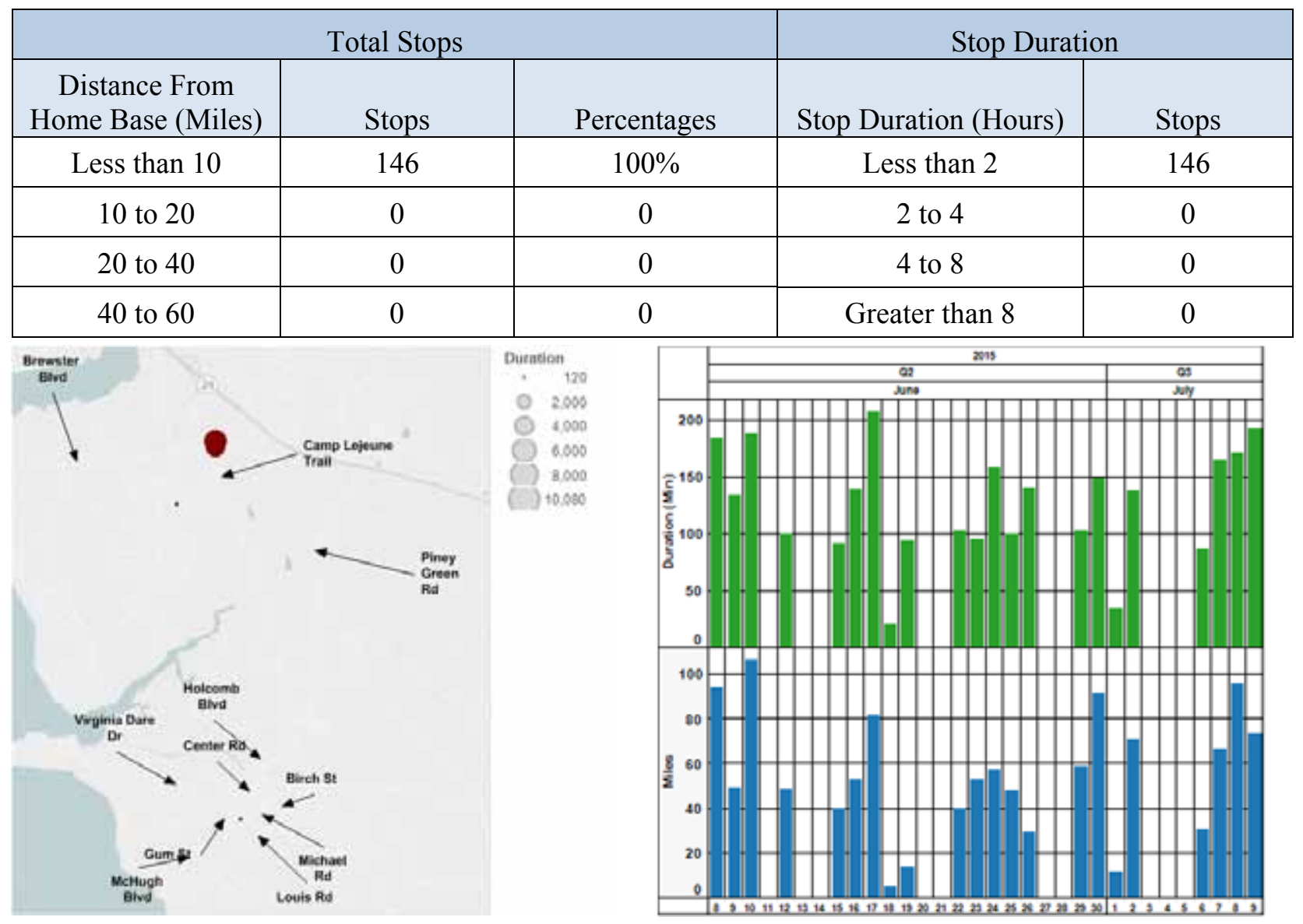

Figure C-13. Vehicle 294324 stops.

Figure C-14. Vehicle 294324 history. 

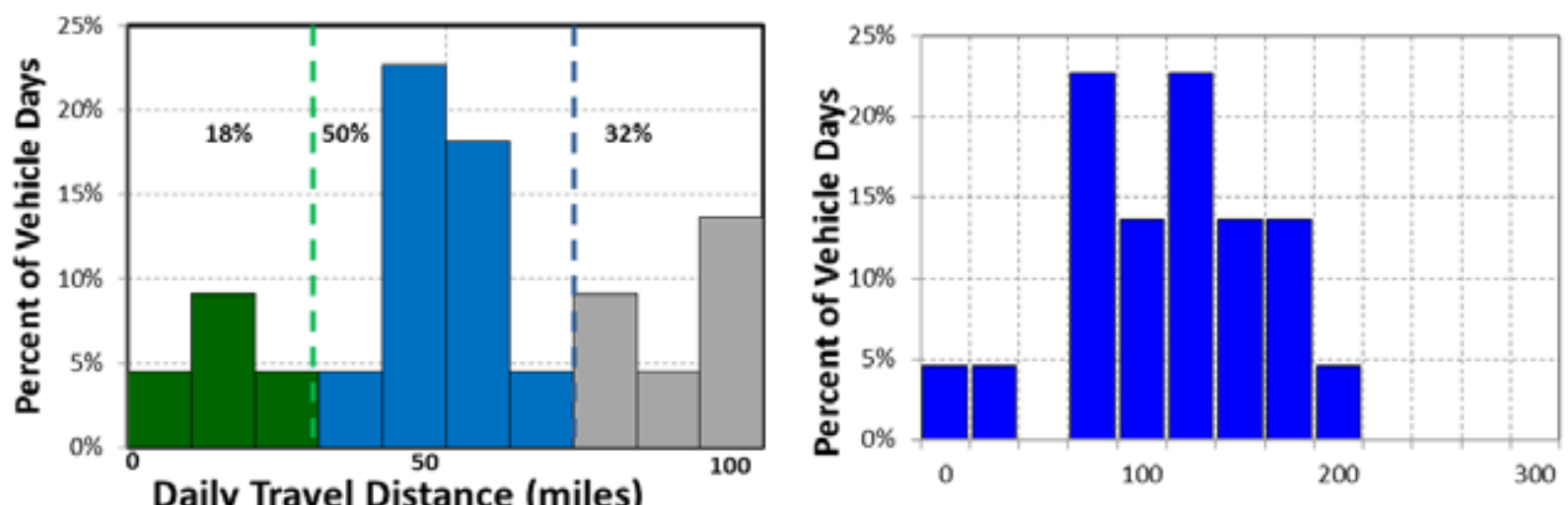

-.. All travel less than 30 miles _.. All travel less than 70 miles
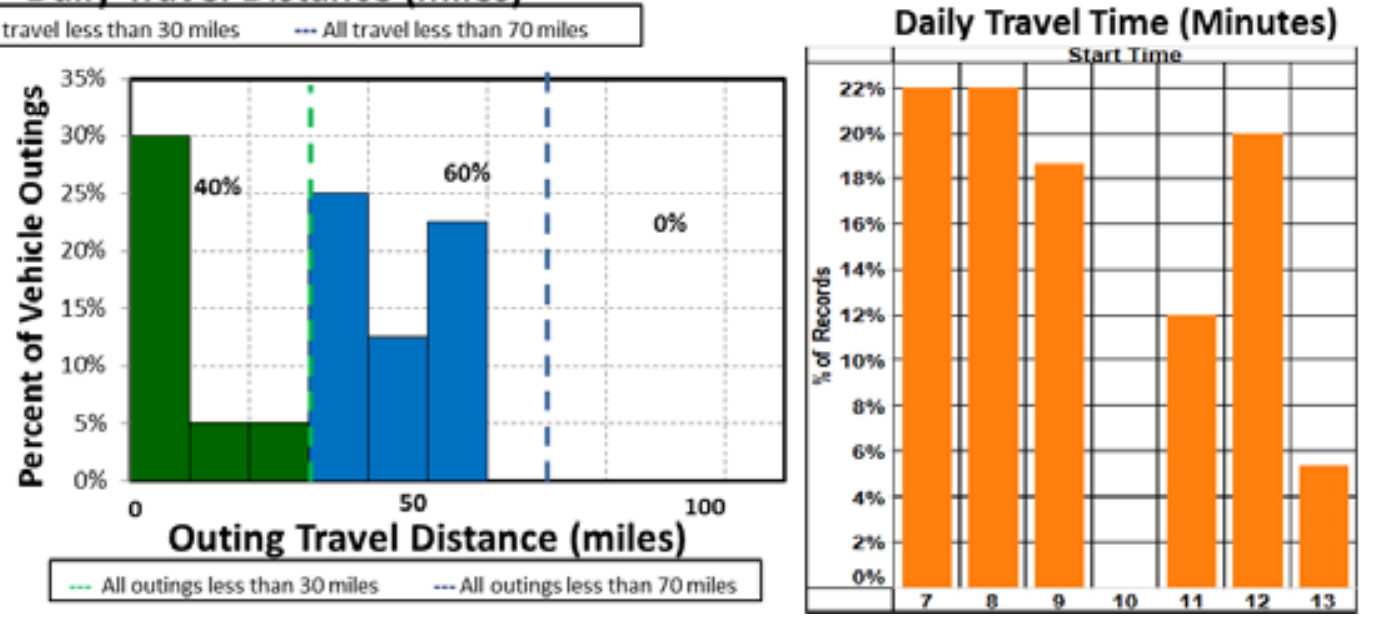

Figure C-15. Vehicle 294324 travel graphs.

\section{Vehicle 294324 Observations}

Logger 54 collected data on this vehicle for a period of 22 days of the 31-day study period. Validation occurred on $100 \%$ of the input data. Data indicate that this vehicle has a support mission for Public Works. This vehicle's data indicate it parks near Building 1005 near Ash Street as shown in the Google Earth figure to the right.

MCBCL reports that a recent vehicle odometer indicated 42,589 miles and an average annual mileage of 8,195 miles. The vehicle was used on $71 \%$ of the available days, with an average daily usage of 2.1 hours and a peak daily usage of 3.5 hours on the days it was used. The vehicle was used during all hours of the day.

Figure C- 15 shows that $68 \%$ of daily travel was within

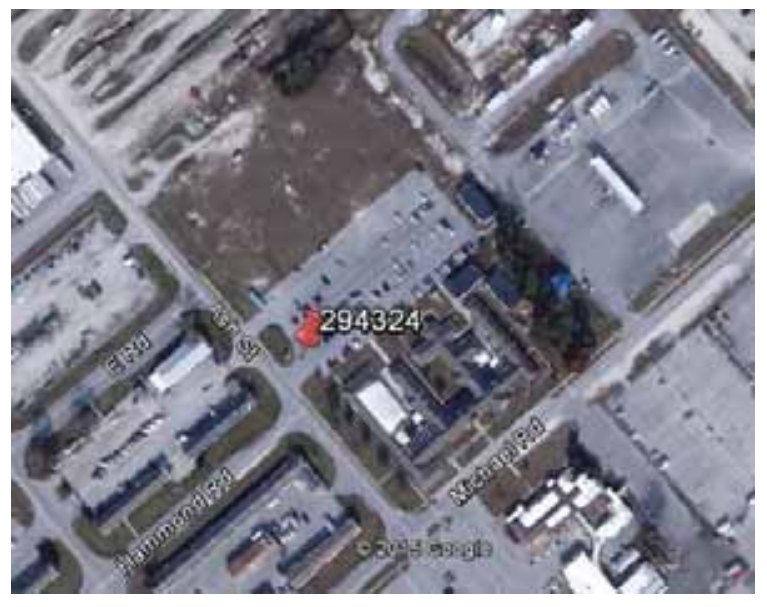
the typically advertised range of a BEV of approximately 70 miles. All outings were also within this range. Further, $18 \%$ of daily travel and $40 \%$ of outings were within the typically advertised CD mode of 30 miles for PHEVs.

A BEV could not meet all daily travel without additional charge opportunities because of the frequent daily travel exceeding its range. However, a significant amount of daily travel is within the BEV's capabilities. Thus, a fleet of vehicles would likely contain a mix of BEVs and PHEVs. 


\begin{tabular}{|c|c|c|}
\hline \multirow{11}{*}{ 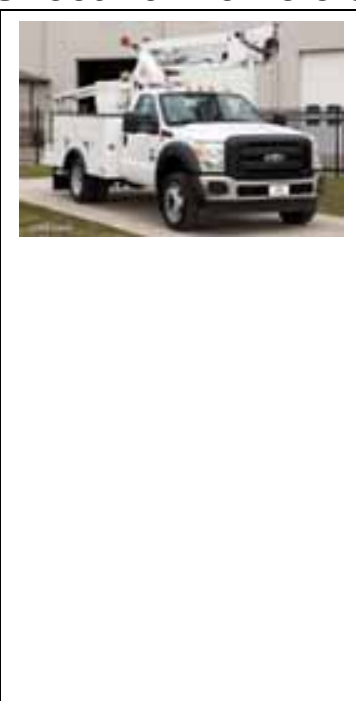 } & Make/Model/Year & Ford F550 - 2011 \\
\hline & EPA Class Size & Specialty - Bucket Truck \\
\hline & Mission & Specialty \\
\hline & Contact & Public Works \\
\hline & Parking Location & Building 1023 near Michael Road \\
\hline & Fleet Vehicle ID & 300672 \\
\hline & Fuel Type & Diesel \\
\hline & EPA Label/MPG (City/Hwy/Combined)* & 10 \\
\hline & EPA GHG Emissions (Grams $\left.\mathrm{CO}_{2} / \mathrm{Mi}\right)^{*}$ & 1021 \\
\hline & Study Logger ID & 53 \\
\hline & Total Vehicle Days/Total Study Days & $10 / 21$ \\
\hline
\end{tabular}

\begin{tabular}{|l|c|c|c|c|}
\hline \multicolumn{5}{|c|}{ Vehicle 300672 Travel Summary } \\
\hline & $\begin{array}{c}\text { Per Day } \\
\text { Average/Peak }\end{array}$ & $\begin{array}{c}\text { Per Outing } \\
\text { Average/Peak }\end{array}$ & $\begin{array}{c}\text { Per Trip } \\
\text { Average/Peak }\end{array}$ & Total \\
\hline Travel Distance (Miles) & $23.7 / 69.4$ & $8.5 / 39.0$ & $4.8 / 39.0$ & 237 \\
\hline Travel Time (Minutes) & $126.6 / 271.0$ & $45.2 / 171.0$ & $25.8 / 152.0$ & 1,266 \\
\hline Idle Time (Minutes) & $2.1 / \mathrm{NA}$ & $26.6 / \mathrm{NA}$ & $5.2 / \mathrm{NA}$ & 746 \\
\hline
\end{tabular}

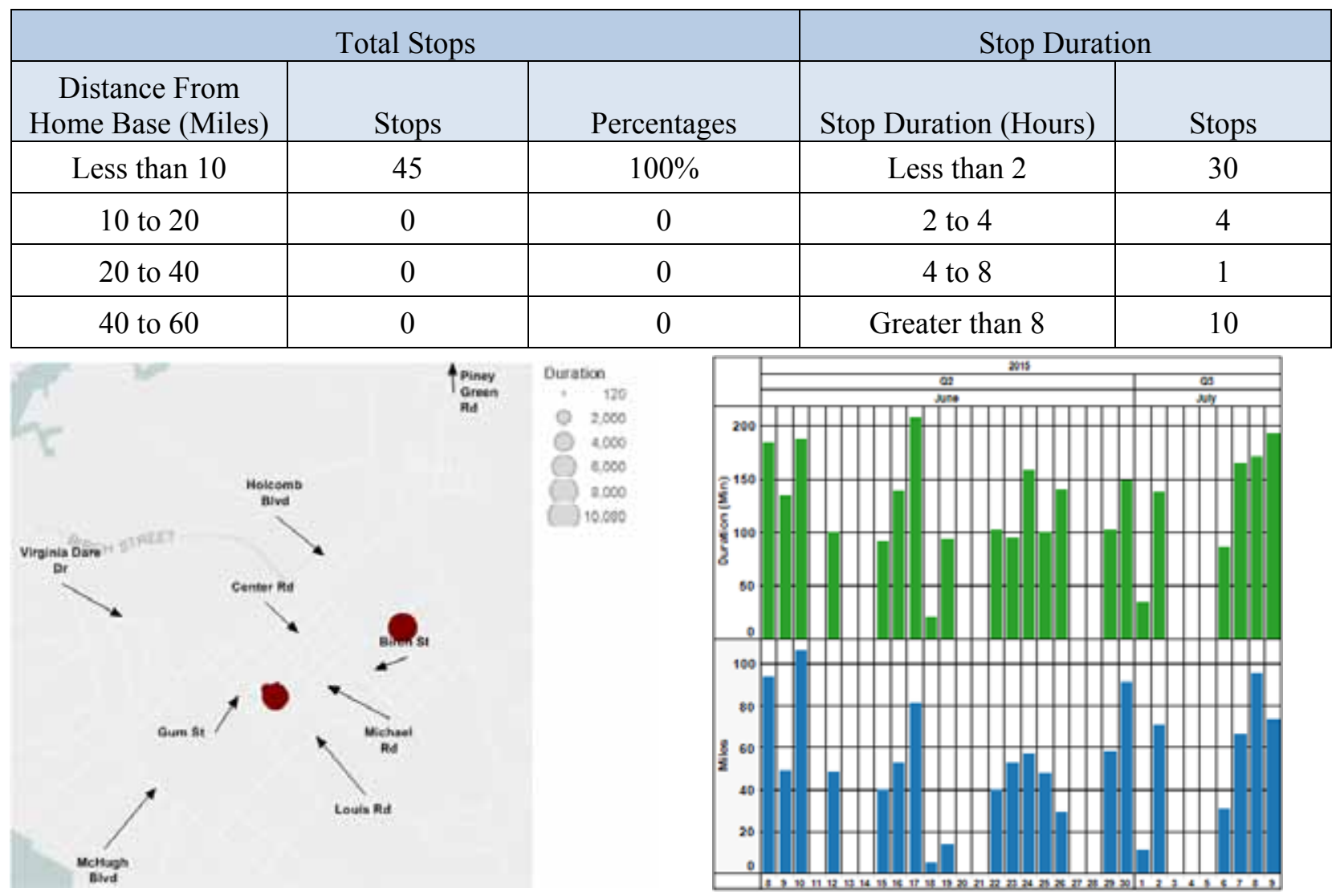

Figure C-16. Vehicle 300672 stops.

Figure C-17. Vehicle 300672 history.

*EPA fuel economy is not available. Figures calculated for diesel per Section 5. 

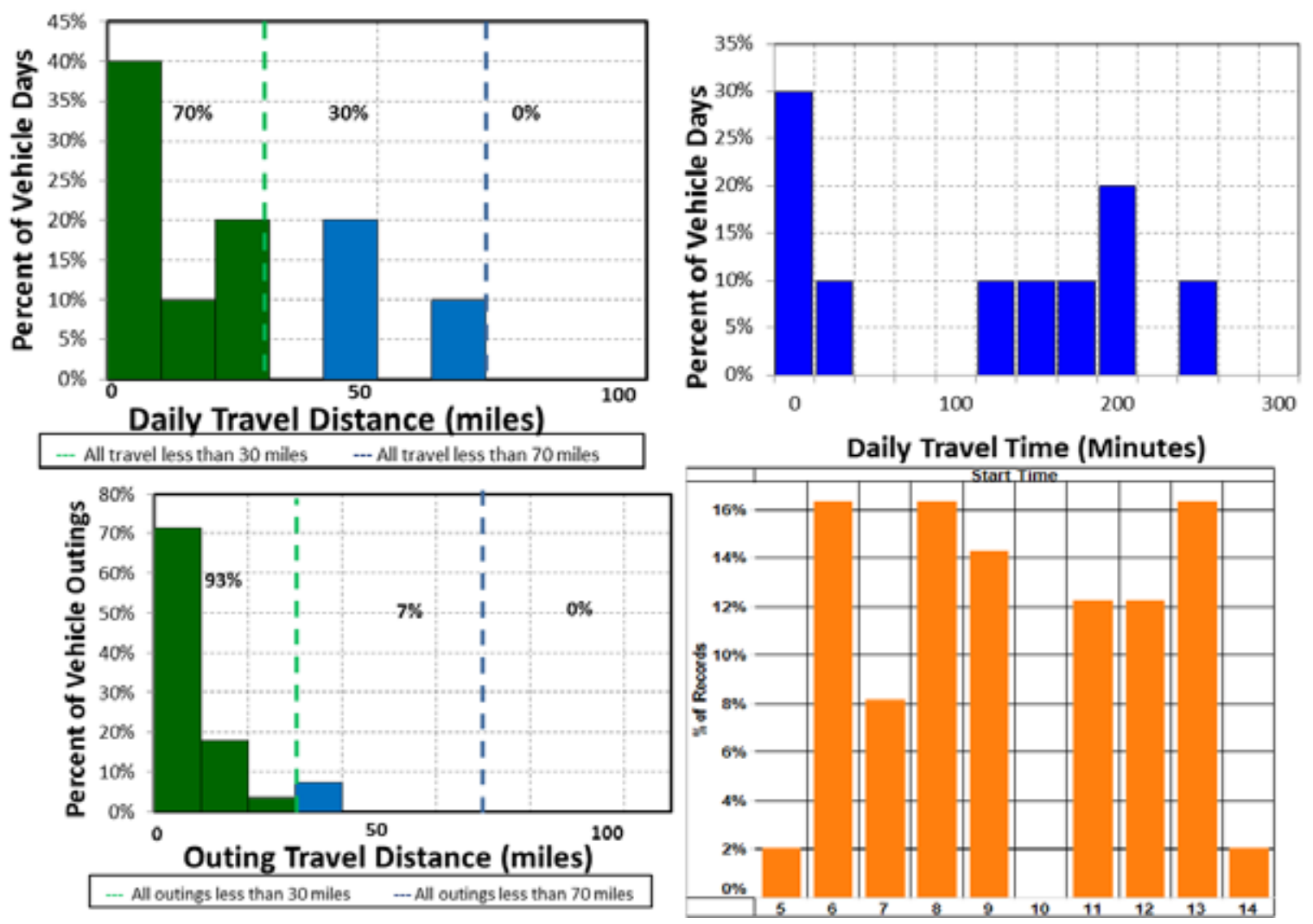

Figure C-18. Vehicle 300672 travel graphs.

\section{Vehicle 300672 Observations}

Logger 53 collected data on this vehicle for a period of 10 days of the 21-day study period. Validation occurred on $100 \%$ of the input data. Data indicate that this vehicle has a specialty mission for Public Works. This vehicle's data indicate it parks near Building 1023 on Michael Road as shown in the Google Earth figure to the right.

MCBCL reports that the vehicle odometer indicated 33,968 miles at the start of this study and an average annual mileage of 7,214 miles. The vehicle was used on $48 \%$ of the available days, with an average daily usage of 2.1 hours and a peak daily usage of 4.5 hours on the days it was used. The vehicle was used primarily during day shift

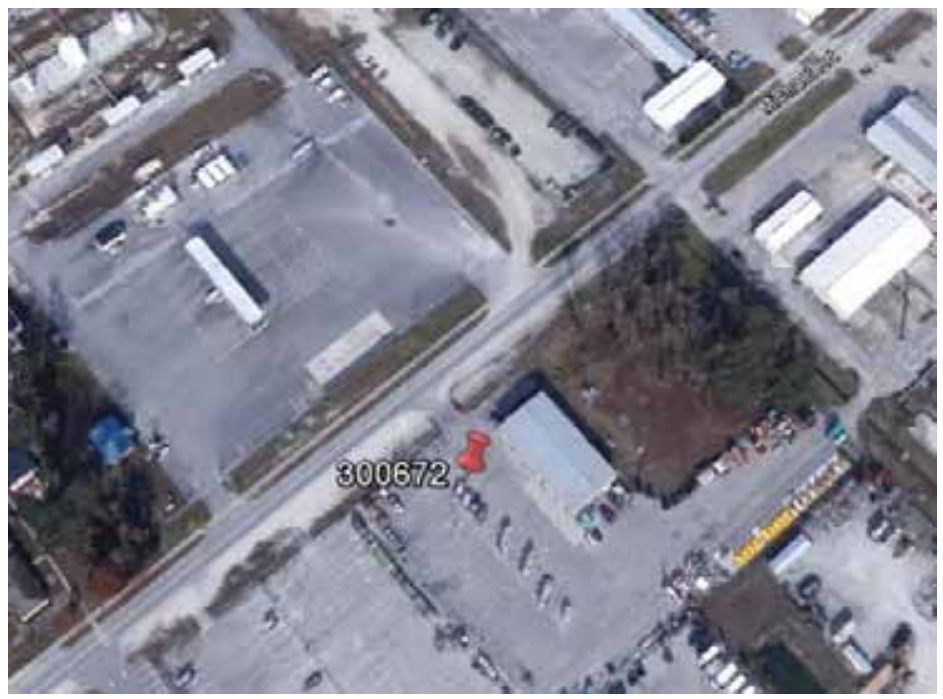
hours.

Figure $\mathrm{C}-18$ shows that all daily travel was within the typically advertised range of a BEV of approximately 70 miles. All outings were also within this range. Further, $70 \%$ of daily travel and $93 \%$ of outings were within the typically advertised CD mode of 30 miles for PHEVs.

A BEV could meet all daily travel without additional charging opportunities. However, bucket truck specialty vehicles are not currently being deployed as PHEVs. 
Sheet 26: Vehicle 302039

\begin{tabular}{|c|c|c|}
\hline (1) & Make/Model/Year & Ford F250XL - 201 \\
\hline & EPA Class Size & Pickup \\
\hline & Mission & Support \\
\hline . & Contact & Public Works \\
\hline & Parking Location & Building 670 \\
\hline & Fleet Vehicle ID & 302039 \\
\hline & Fuel Type & Diesel \\
\hline & EPA Label/MPG (City/Hwy/Combined)* & 14 \\
\hline & EPA GHG Emissions (Grams $\mathrm{CO}_{2} / \mathrm{Mi}$ ) & 729 \\
\hline & Study Logger ID & 55 \\
\hline & Total Vehicle Days/Total Study Days & $18 / 31$ \\
\hline
\end{tabular}

\begin{tabular}{|l|c|c|c|c|}
\hline \multicolumn{5}{|c|}{ Vehicle 302039 Travel Summary } \\
\hline & $\begin{array}{c}\text { Per Day } \\
\text { Average/Peak }\end{array}$ & $\begin{array}{c}\text { Per Outing } \\
\text { Average/Peak }\end{array}$ & $\begin{array}{c}\text { Per Trip } \\
\text { Average/Peak }\end{array}$ & Total \\
\hline Travel Distance (Miles) & $68.5 / 151.7$ & $20.5 / 82.2$ & $7.6 / 70.7$ & 1,232 \\
\hline Travel Time (Minutes) & $252.4 / 421.0$ & $75.7 / 251.0$ & $28.0 / 159.0$ & 4,543 \\
\hline Idle Time (Minutes) & $89.2 / \mathrm{NA}$ & $26.8 / \mathrm{NA}$ & $9.9 / \mathrm{NA}$ & 1,606 \\
\hline
\end{tabular}

\begin{tabular}{|c|c|c|c|c|c|}
\hline \multicolumn{3}{|c|}{ Total Stops } & \multicolumn{2}{c|}{ Stop Duration } \\
\hline $\begin{array}{c}\text { Distance From } \\
\text { Home Base (Miles) }\end{array}$ & Stops & Percentages & Stop Duration (Hours) & Stops \\
\hline Less than 10 & 131 & $97.0 \%$ & Less than 2 & 115 \\
\hline 10 to 20 & 4 & $3.0 \%$ & 2 to 4 & 16 \\
\hline 20 to 40 & 0 & 0 & 4 to 8 & Greater than 8 \\
\hline 40 to 60 & 0 & 0 & & \\
\hline
\end{tabular}

Figure C-19. Vehicle 302039 stops.

*EPA fuel economy is not available. Figures calculated for diesel per Section 5. 

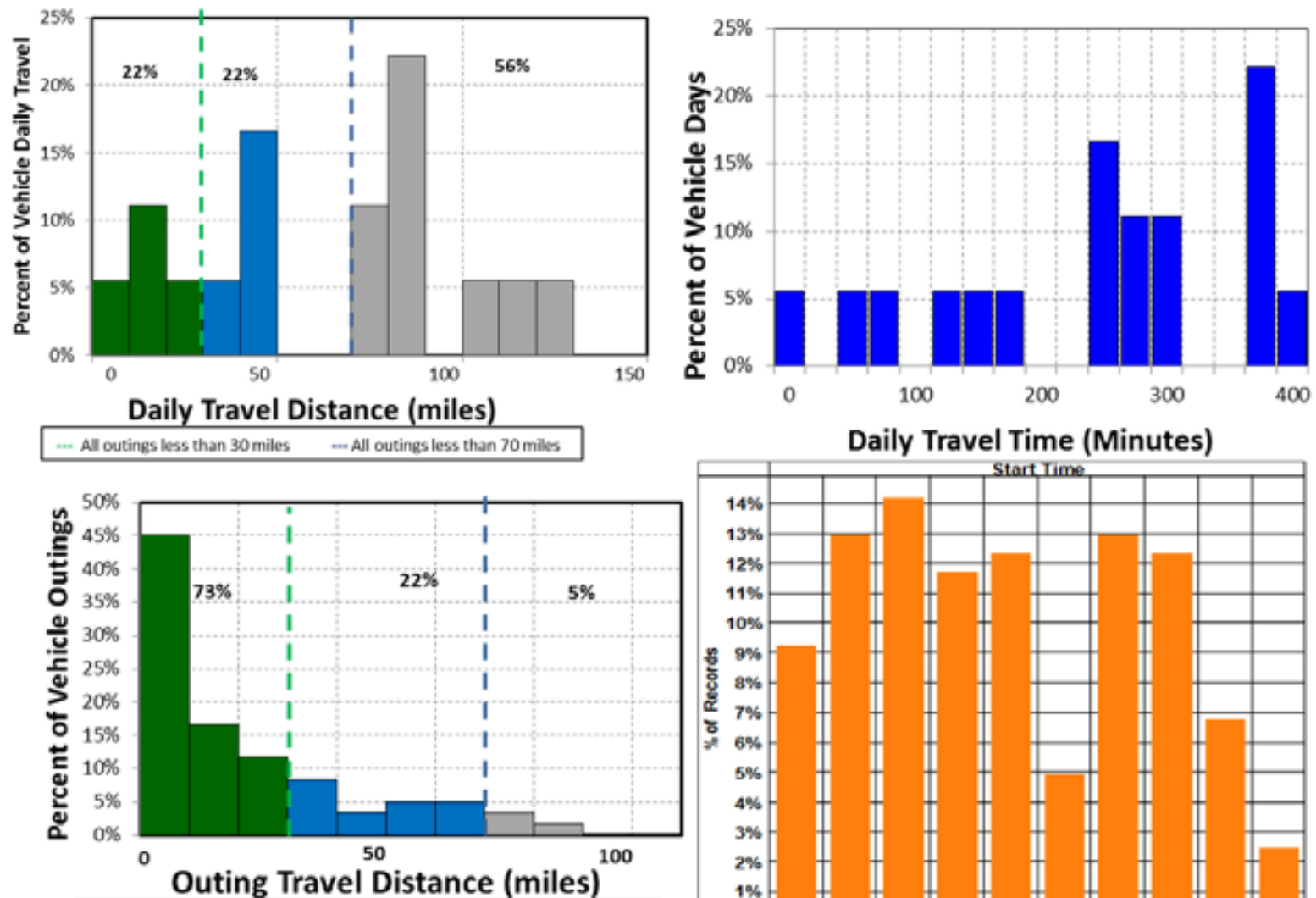

- All outings less than 30 miles

-.- All outings less than 70 miles

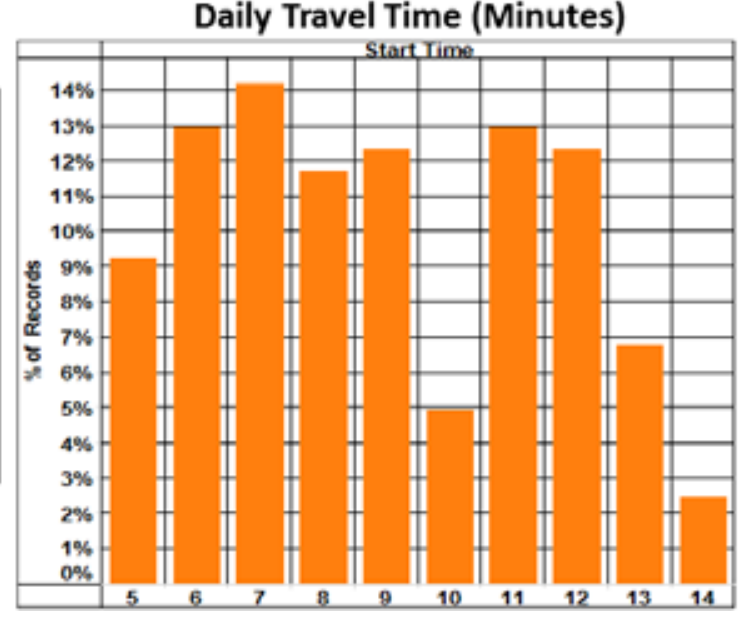

Figure C-21. Vehicle 302039 travel graphs.

\section{Vehicle 302039 Observations}

Logger 55 collected data on this vehicle for a period of 18 days of the 31-day study period. Validation occurred on $100 \%$ of the input data. Data indicate that this vehicle has a support mission for Public Works. This vehicle's data indicate it parks near Building 670 near Brewster and Holcomb Boulevard as shown in the Google Earth figure to the right.

MCBCL reports that a recent vehicle odometer indicated 6,871 miles and an average annual mileage of 6,424 miles. The vehicle was used on $58 \%$ of the available days, with an average daily usage of 4.2 hours and a peak daily usage of 7.0 hours on the days it was used. The vehicle was used during day

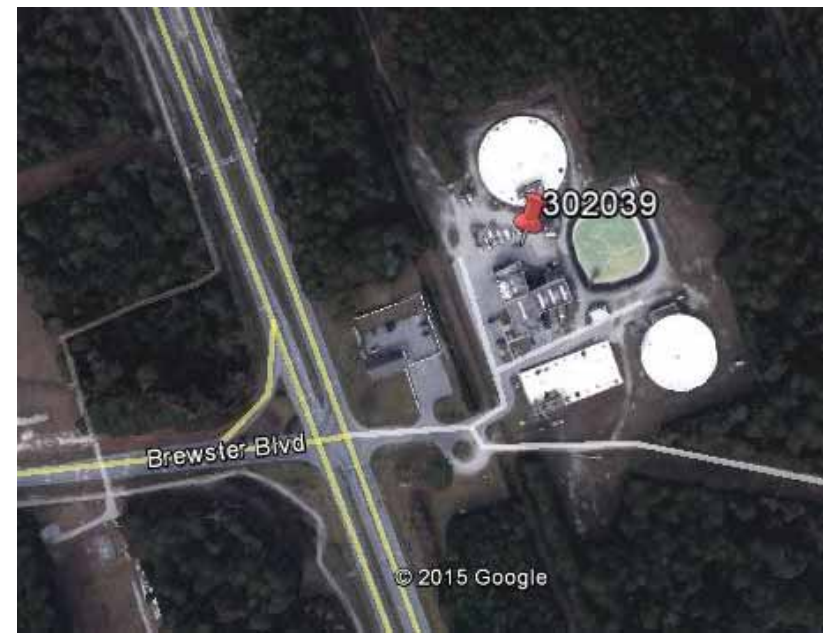
shift hours.

Figure C-21 shows that $44 \%$ of daily travel was within the typically advertised range of a BEV of approximately 70 miles and $95 \%$ of the outings were also within this range. Further, $22 \%$ of daily travel and $73 \%$ of outings were within the typically advertised CD mode of 30 miles for PHEVs.

A BEV could not meet all daily travel without additional charging opportunities due to the frequent days greater than the BEV range. Thus, a fleet of pickup trucks would likely contain a mix of BEVs and PHEVs. 


\begin{tabular}{|c|c|c|}
\hline Er & Make/Model/Year & Ford F250XL - 201 \\
\hline & EPA Class Size & Pickup \\
\hline ? & Mission & Support \\
\hline- & Contact & Public Works \\
\hline & Parking Location & Building FC436 \\
\hline & Fleet Vehicle ID & 302040 \\
\hline & Fuel Type & Diesel \\
\hline & EPA Label/MPG (City/Hwy/Combined)* & 14 \\
\hline & EPA GHG Emissions (Grams $\mathrm{CO}_{2} / \mathrm{Mi}$ )* & 729 \\
\hline & Study Logger ID & 56 \\
\hline & Total Vehicle Days/Total Study Days & $19 / 31$ \\
\hline
\end{tabular}

\begin{tabular}{|l|c|c|c|c|}
\hline \multicolumn{5}{|c|}{ Vehicle 302040 Travel Summary } \\
\hline & $\begin{array}{c}\text { Per Day } \\
\text { Average/Peak }\end{array}$ & $\begin{array}{c}\text { Per Outing } \\
\text { Average/Peak }\end{array}$ & $\begin{array}{c}\text { Per Trip } \\
\text { Average/Peak }\end{array}$ & Total \\
\hline Travel Distance (Miles) & $61.4 / 113.0$ & $26.5 / 112.8$ & $3.2 / 38.5$ & 1,166 \\
\hline Travel Time (Minutes) & $211.7 / 367.0$ & $91.4 / 367.0$ & $11.2 / 131.0$ & 4,022 \\
\hline Idle Time (Minutes) & $41.1 / \mathrm{NA}$ & $17.7 / \mathrm{NA}$ & $2.2 / \mathrm{NA}$ & 780 \\
\hline
\end{tabular}

\begin{tabular}{|c|c|c|c|c|c|}
\hline \multicolumn{2}{|c|}{ Total Stops } & \multicolumn{3}{c|}{ Stop Duration } \\
\hline $\begin{array}{c}\text { Distance From } \\
\text { Home Base (Miles) }\end{array}$ & Stops & Percentages & Stop Duration (Hours) & Stops \\
\hline Less than 10 & 340 & $100 \%$ & Less than 2 & 320 \\
\hline 10 to 20 & 0 & 0 & 2 to 4 & 0 \\
\hline 20 to 40 & 0 & 0 & 4 to 8 & 1 \\
\hline 40 to 60 & 0 & 0 & Greater than 8 & 19 \\
\hline
\end{tabular}

Figure C-22. Vehicle 302040 stops.

Figure C-23. Vehicle 302040 history.

*EPA fuel economy not available. Figures calculated for diesel per Section 5. 

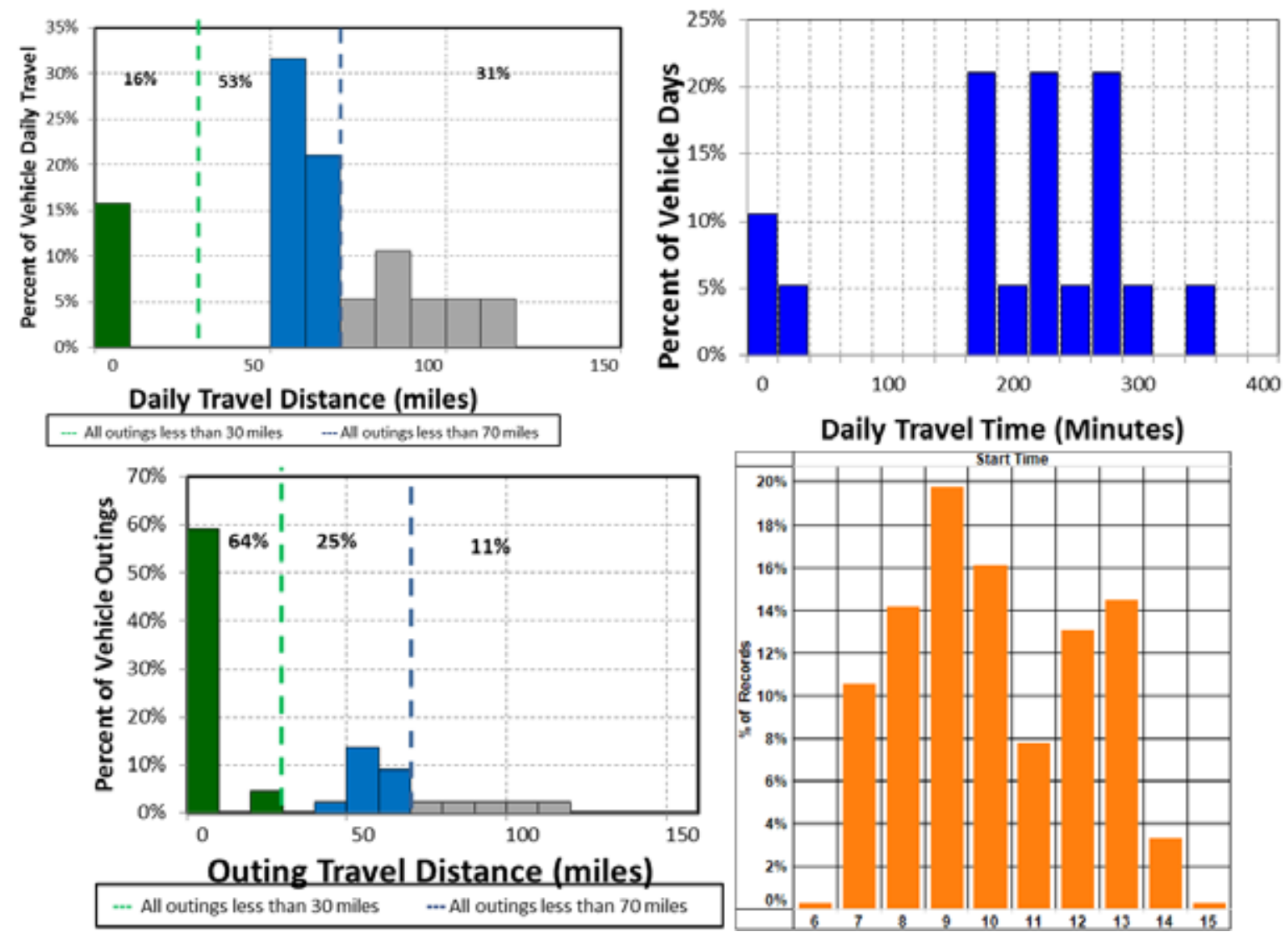

Figure C-24. Vehicle 302040 travel graphs.

\section{Vehicle 302040 Observations}

Logger 56 collected data on this vehicle for a period of 19 days of the 31-day study period. Validation occurred on $100 \%$ of the input data. Data indicate that this vehicle has a support mission for Public Works. This vehicle's data indicate it parks near Building FC436 near Gonzalez Boulevard as shown in the Google Earth figure to the right.

MCBCL reports that a recent vehicle odometer indicated 13,083 miles and an average annual mileage of 10,937 miles. The vehicle was used on $61 \%$ of the available days, with an average daily usage of 3.5 hours and a peak daily usage of 6.1 hours on the days it was used. The vehicle was used during all hours of the day.

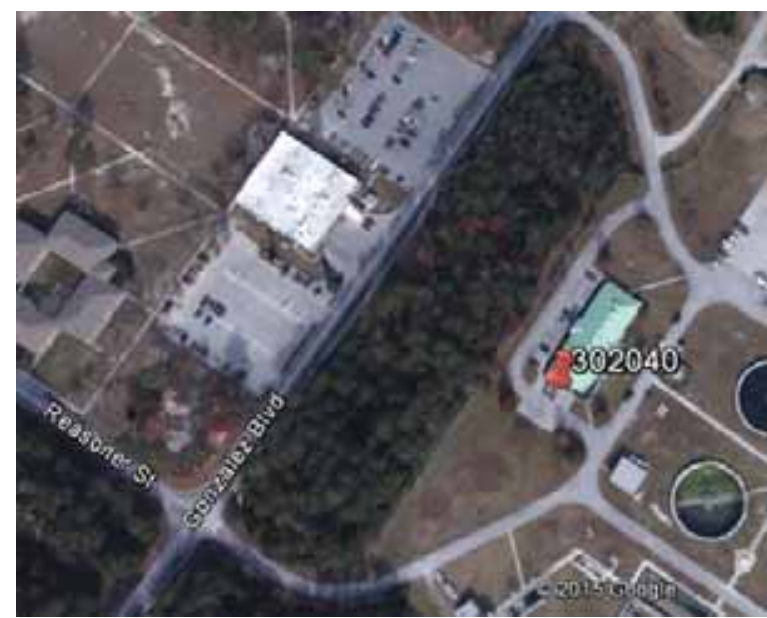

Figure C-24 shows that $69 \%$ of daily travel was within the typically advertised range of a BEV of approximately 70 miles and $89 \%$ of outings were also within this range. Further, $16 \%$ of daily travel and $64 \%$ of outings were within the typically advertised CD mode of 30 miles for PHEVs.

A BEV could not meet all daily travel because of the frequent days above the BEV range. However, a fleet of pickup trucks would likely contain a mix of BEVs and PHEVs. 
Sheet 28: Vehicle 302334

\begin{tabular}{|c|c|c|}
\hline \multirow{11}{*}{ 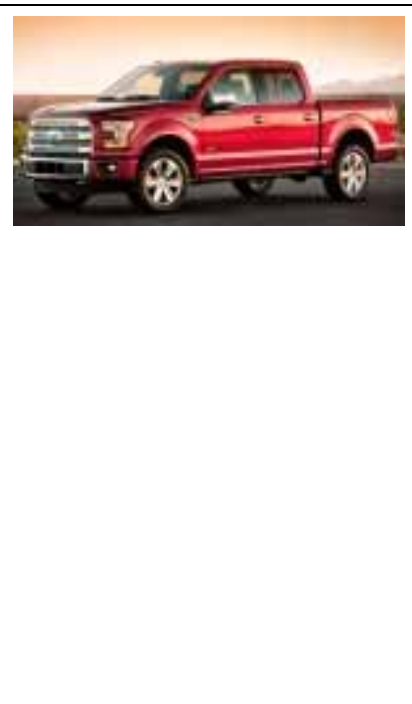 } & Make/Model/Year & Ford F350 Stake -2015 \\
\hline & EPA Class Size & Pickup \\
\hline & Mission & Support \\
\hline & Contact & G3 - Operations and Training \\
\hline & Parking Location & Building 56 \\
\hline & Fleet Vehicle ID & 302334 \\
\hline & Fuel Type & E85 \\
\hline & EPA Label/MPG (City/Hwy/Combined)* & $13 / 18 / 15$ \\
\hline & EPA GHG Emissions $\left(\text { Grams } \mathrm{CO}_{2} / \mathrm{Mi}\right)^{*}$ & 419 \\
\hline & Study Logger ID & 79 \\
\hline & Total Vehicle Days/Total Study Days & $18 / 34$ \\
\hline
\end{tabular}

\begin{tabular}{|l|c|c|c|c|}
\hline \multicolumn{5}{|c|}{ Vehicle 302334 Travel Summary } \\
\hline & $\begin{array}{c}\text { Per Day } \\
\text { Average/Peak }\end{array}$ & $\begin{array}{c}\text { Per Outing } \\
\text { Average/Peak }\end{array}$ & $\begin{array}{c}\text { Per Trip } \\
\text { Average/Peak }\end{array}$ & Total \\
\hline Travel Distance (Miles) & $10.7 / 54.6$ & $5.1 / 52.9$ & $2.0 / 22.1$ & 193 \\
\hline Travel Time (Minutes) & $34.9 / 99.0$ & $16.5 / 91.0$ & $6.3 / 38.0$ & 628 \\
\hline Idle Time (Minutes) & $1.6 / \mathrm{NA}$ & $0.7 / \mathrm{NA}$ & $0.3 / \mathrm{NA}$ & 28 \\
\hline
\end{tabular}

\begin{tabular}{|c|c|c|c|c|c|}
\hline \multicolumn{2}{|c|}{ Total Stops } & \multicolumn{3}{c|}{ Stop Duration } \\
\hline $\begin{array}{c}\text { Distance From } \\
\text { Home Base (Miles) }\end{array}$ & Stops & Percentages & Stop Duration (Hours) & Stops \\
\hline Less than 10 & 91 & $100 \%$ & Less than 2 & 70 \\
\hline 10 to 20 & 0 & 0 & 2 to 4 & 4 \\
\hline 20 to 40 & 0 & 0 & 4 to 8 & 16 \\
\hline 40 to 60 & 0 & 0 & Greater than 8 & \\
\hline
\end{tabular}

Figure C-25. Vehicle 302334 stops.

Figure C-26. Vehicle 302334 history.

*Fuel economy for F350 is not available. Economy used is for F150. 


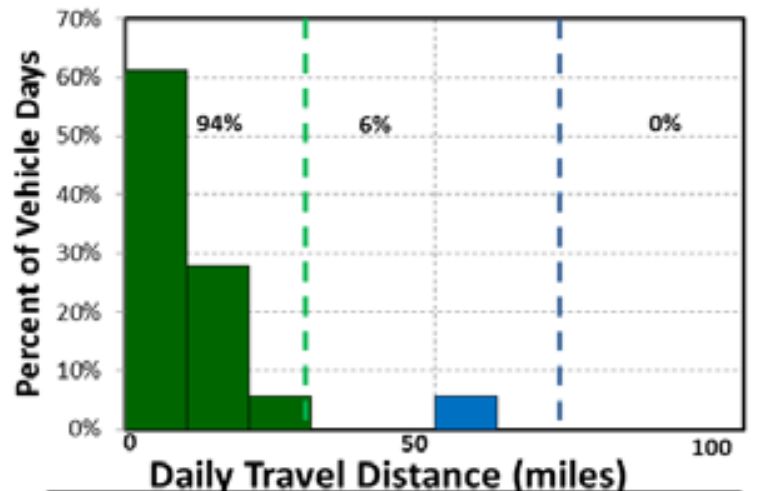

Daily Travel Distance (miles)
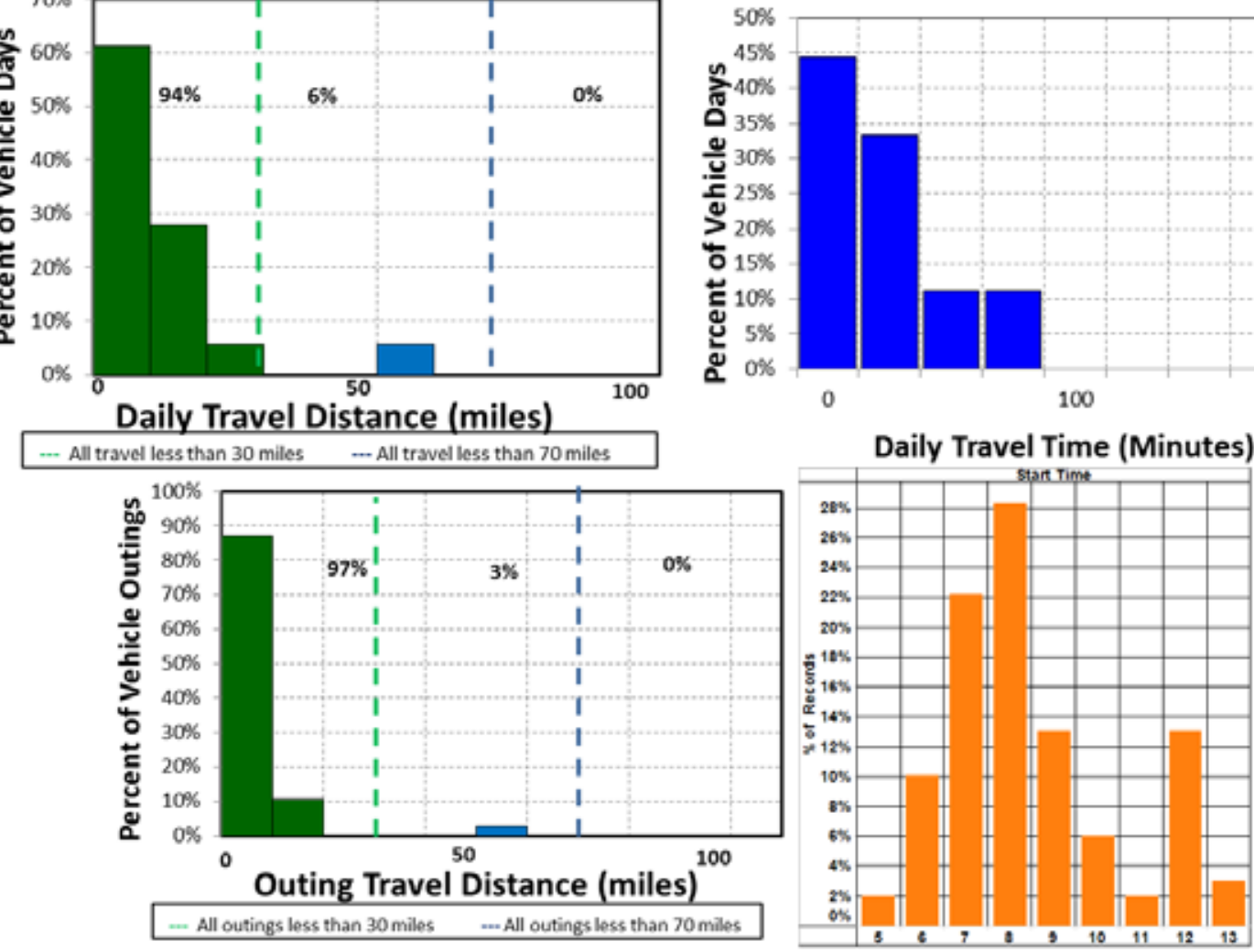

Figure C-27. Vehicle 302334 travel graphs.

\section{Vehicle 302334 Observations}

Logger 79 collected data on this vehicle for a period of 18 days of the 34-day study period. Validation occurred on $100 \%$ of the input data. Data indicate that this vehicle has a support mission for G3 - Operations and Training. This vehicle's data indicate it parks near Building 56 near Post Lane as shown in the Google Earth figure to the right.

MCBCL reports that the new vehicle odometer indicated 0 miles at the start of this study and an average annual mileage is estimated to be 1,200 miles. The vehicle was used on $53 \%$ of the available days, with an average daily usage of 0.6 hours and a peak daily usage of 1.7 hours on the days it was used. The vehicle was used during day shift hours.

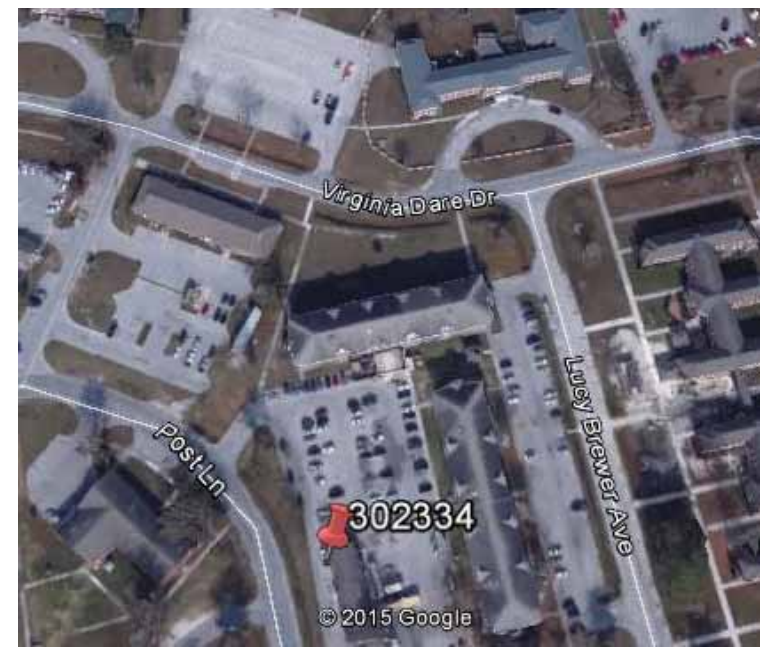

Figure C-27 shows that all daily travel was within the typically advertised range of a BEV of approximately 70 miles. All outings were also within this range. Further, $94 \%$ of daily travel and $97 \%$ of outings were within the typically advertised CD mode of 30 miles for PHEVs.

A BEV could meet all daily travel without additional charging opportunities. However, a suitable BEV replacement for a stake truck is not currently available. Thus, a PHEV Via Motors VTRUX pickup is suggested. 
Sheet 29: Vehicle G10-3327L

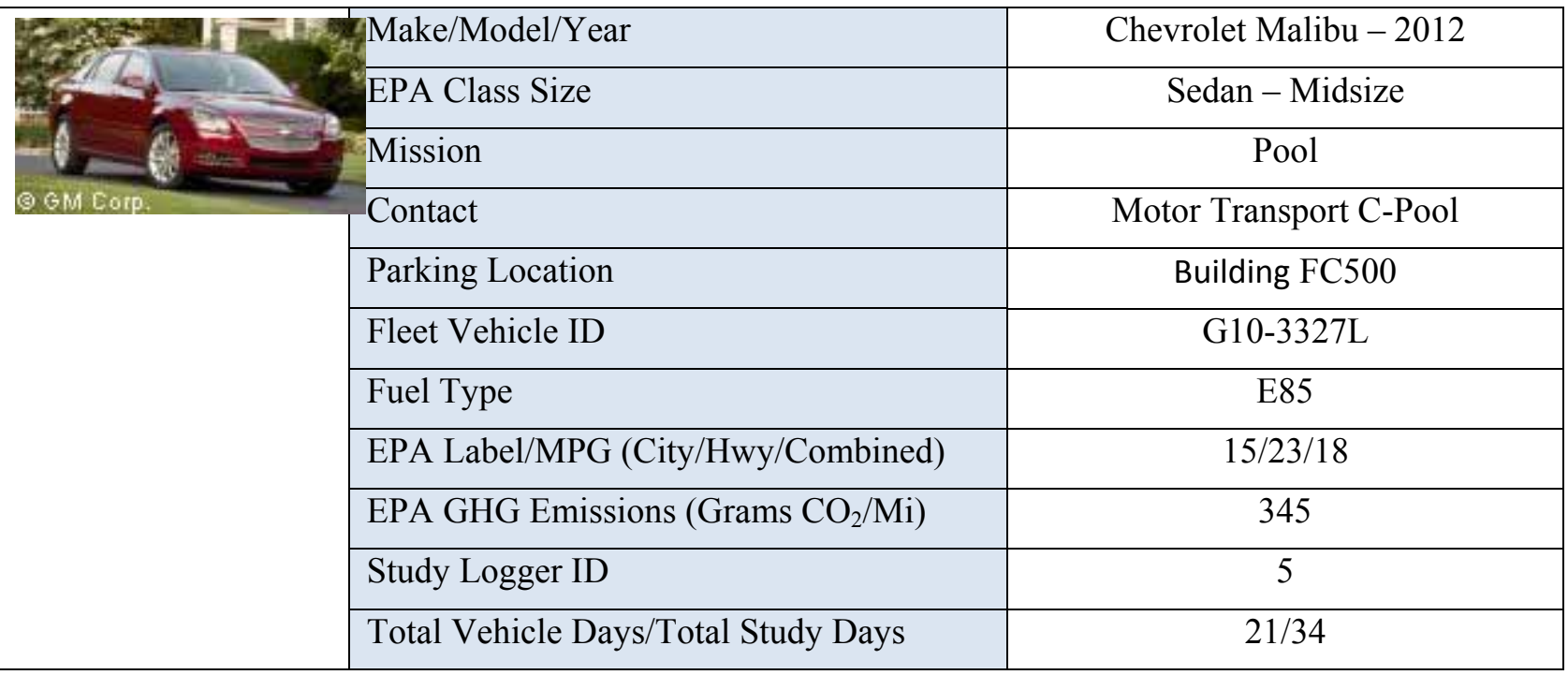

\begin{tabular}{|l|c|c|c|c|}
\hline \multicolumn{5}{|c|}{ Vehicle G10-3327L Travel Summary } \\
\hline & $\begin{array}{c}\text { Per Day } \\
\text { Average/Peak }\end{array}$ & $\begin{array}{c}\text { Per Outing } \\
\text { Average/Peak }\end{array}$ & $\begin{array}{c}\text { Per Trip } \\
\text { Average/Peak }\end{array}$ & Total \\
\hline Travel Distance (Miles) & $23.2 / 70.8$ & $6.0 / 51.0$ & $2.6 / 51.0$ & 487 \\
\hline Travel Time (Minutes) & $95.8 / 242.0$ & $24.8 / 159.0$ & $10.6 / 87.0$ & 2,012 \\
\hline Idle Time (Minutes) & $25.1 / \mathrm{NA}$ & $6.5 / \mathrm{NA}$ & $2.8 / \mathrm{NA}$ & 528 \\
\hline
\end{tabular}

\begin{tabular}{|c|c|c|c|c|}
\hline \multicolumn{2}{|c|}{ Total Stops } & \multicolumn{3}{c|}{ Stop Duration } \\
\hline $\begin{array}{c}\text { Distance From } \\
\text { Home Base (Miles) }\end{array}$ & Stops & Percentages & Stop Duration (Hours) & Stops \\
\hline Less than 10 & 178 & $99.4 \%$ & Less than 2 & 129 \\
\hline 10 to 20 & 1 & $0.6 \%$ & 2 to 4 & 16 \\
\hline 20 to 40 & 0 & 0 & 4 to 8 & 19 \\
\hline 40 to 60 & 0 & 0 & Greater than 8 & 14 \\
\hline
\end{tabular}

Figure C-28. Vehicle G10-3327L stops.

Figure C-29. Vehicle G10-3327L history. 


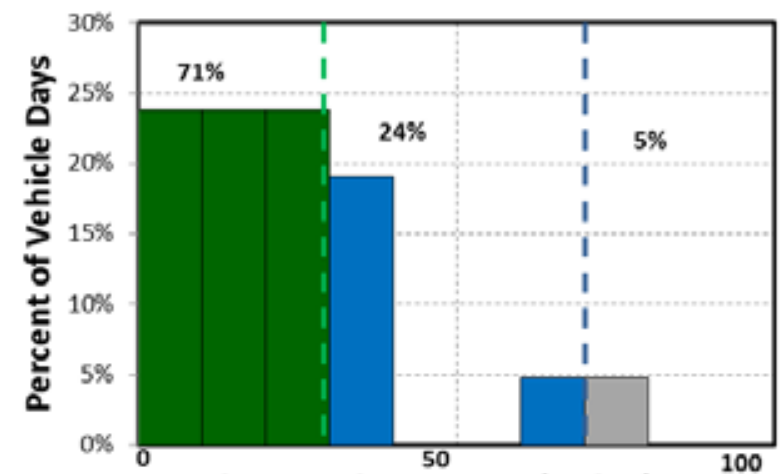

Daily Travel Distance (miles)

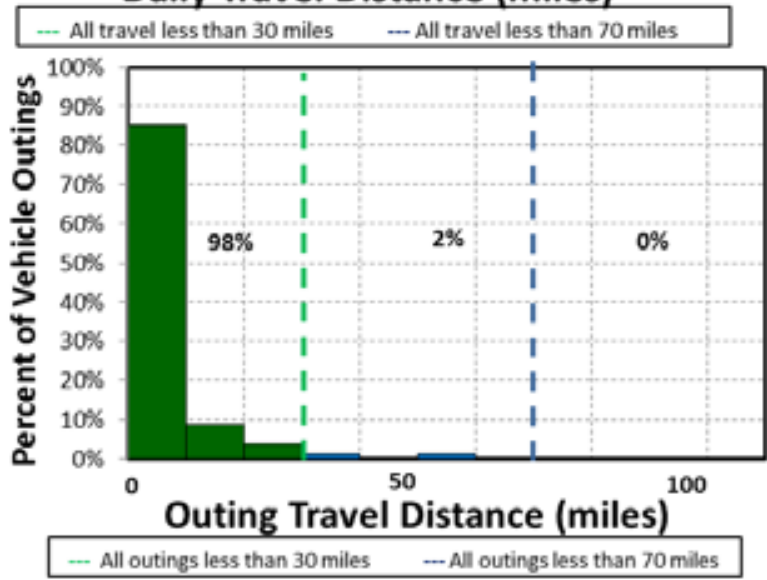

Figure C-30. Vehicle G10-3327L travel graphs.

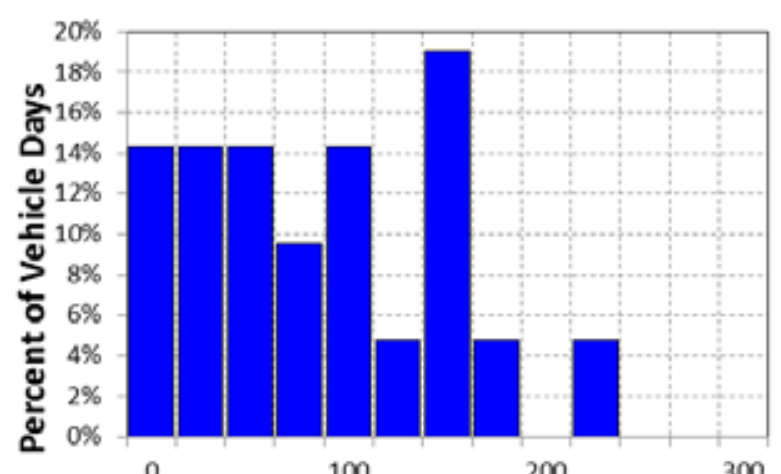

Daily Travel Time (Minutes)

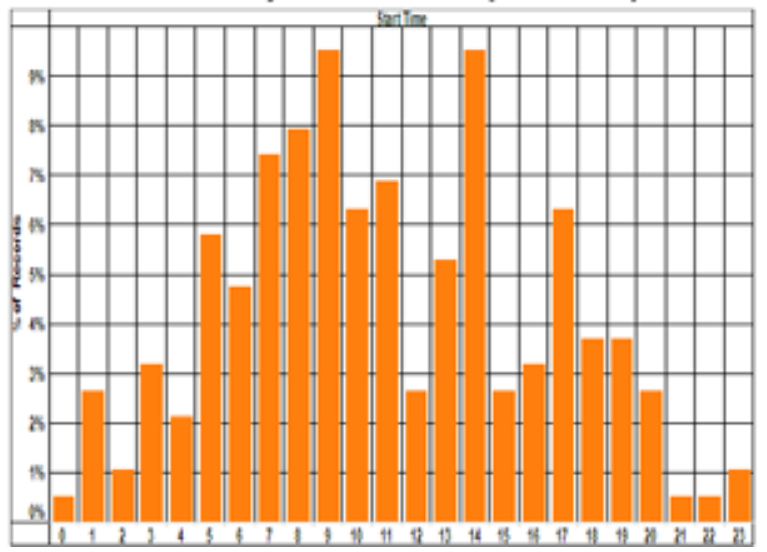

\section{Vehicle G10-3327L Observations}

Logger 5 collected data on this vehicle for a period of 21 days of the 34-day study period. Validation occurred on $100 \%$ of the input data. Data indicate that this vehicle has a pool mission for the Motor Transport C-Pool. This vehicle's data indicate it parked over night at several different locations during the study period: H M Smith Boulevard, Michael Road, F Street, and Flounder Road. The H M Smith location is shown in the Google Earth figure to the right.

MCBCL reports that a recent vehicle odometer indicated 17,359 miles at the start of this study and an average annual mileage of 7,085 miles. The vehicle was

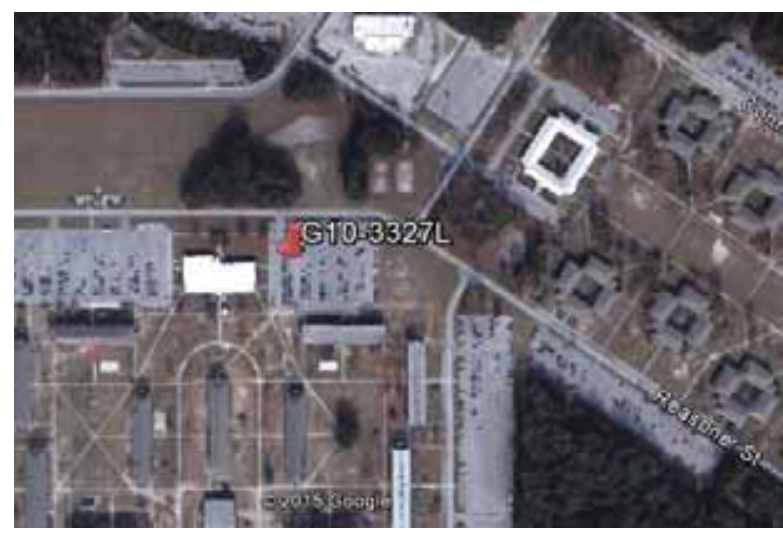
used on $62 \%$ of the available days, with an average daily usage of 1.6 hours and a peak daily usage of 4.0 hours on the days it was used. The vehicle was used during all hours of the day.

Figure C-30 shows that $95 \%$ of daily travel was within the typically advertised range of a BEV of approximately 70 miles. All outings were also within this range. Further, $71 \%$ of daily travel and $98 \%$ of outings were within the typically advertised CD mode of 30 miles for PHEVs.

A BEV could meet all daily travel with additional charging opportunities, assuming the vehicle was assigned a home base. A fleet of pool sedans would likely contain a mix of BEVs and PHEVs. 
Sheet 30: Vehicle G13-0325K

\begin{tabular}{|c|c|c|}
\hline$=$ & Make/Model/Year & Ford Focus -2012 \\
\hline & EPA Class Size & Sedan - Compact \\
\hline$\beta=A . \ldots,=A$ & Mission & Support \\
\hline 3 & Contact & Eastern Judicial Circuit \\
\hline & Parking Location & Building 67 \\
\hline & Fleet Vehicle ID & G13-0325K \\
\hline & Fuel Type & Gas \\
\hline & EPA Label/MPG (City/Hwy/Combined) & $28 / 38 / 31$ \\
\hline & EPA GHG Emissions (Grams $\mathrm{CO}_{2} / \mathrm{Mi}$ ) & 287 \\
\hline & Study Logger ID & 41 \\
\hline & Total Vehicle Days/Total Study Days & $13 / 40$ \\
\hline
\end{tabular}

\begin{tabular}{|l|c|c|c|c|}
\hline \multicolumn{5}{|c|}{ Vehicle G13-0325K Travel Summary } \\
\hline & $\begin{array}{c}\text { Per Day } \\
\text { Average/Peak }\end{array}$ & $\begin{array}{c}\text { Per Outing } \\
\text { Average/Peak }\end{array}$ & $\begin{array}{c}\text { Per Trip } \\
\text { Average/Peak }\end{array}$ & Total \\
\hline Travel Distance (Miles) & $18.1 / 94.6$ & $12.4 / 91.1$ & $5.4 / 45.7$ & 236 \\
\hline Travel Time (Minutes) & $40.8 / 149.0$ & $27.9 / 135.0$ & $12.0 / 71.0$ & 530 \\
\hline Idle Time (Minutes) & $1.5 / \mathrm{NA}$ & $1.0 / \mathrm{NA}$ & $0.4 / \mathrm{NA}$ & 19 \\
\hline
\end{tabular}

\begin{tabular}{|c|c|c|c|c|}
\hline \multicolumn{2}{|c|}{ Total Stops } & \multicolumn{2}{c|}{ Stop Duration } \\
\hline $\begin{array}{c}\text { Distance From } \\
\text { Home Base (Miles) }\end{array}$ & Stops & Percentages & Stop Duration (Hours) & Stops \\
\hline Less than 10 & 41 & $97.6 \%$ & Less than 2 & 27 \\
\hline 10 to 20 & 0 & 0 & 2 to 4 & 2 \\
\hline 20 to 40 & 1 & $2.4 \%$ & 4 to 8 & 1 \\
\hline 40 to 60 & 0 & 0 & Greater than 8 & 12 \\
\hline
\end{tabular}

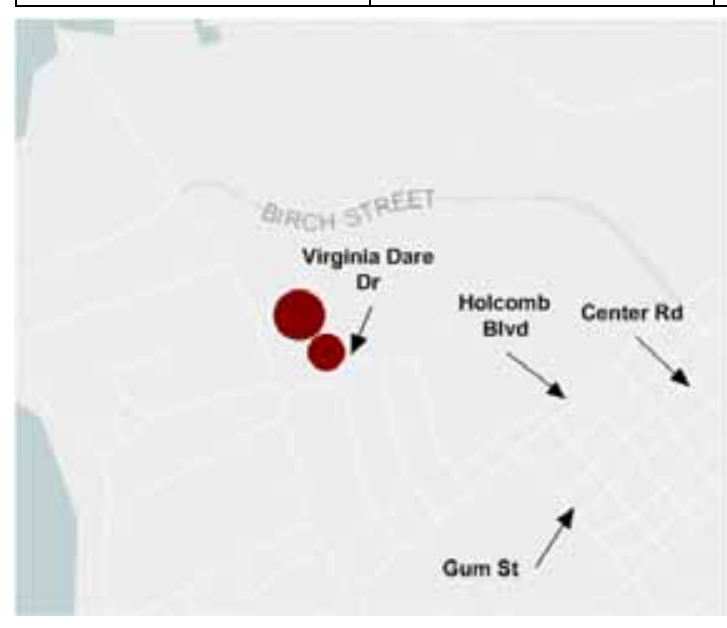

Figure C-31. Vehicle G13-0325K stops.

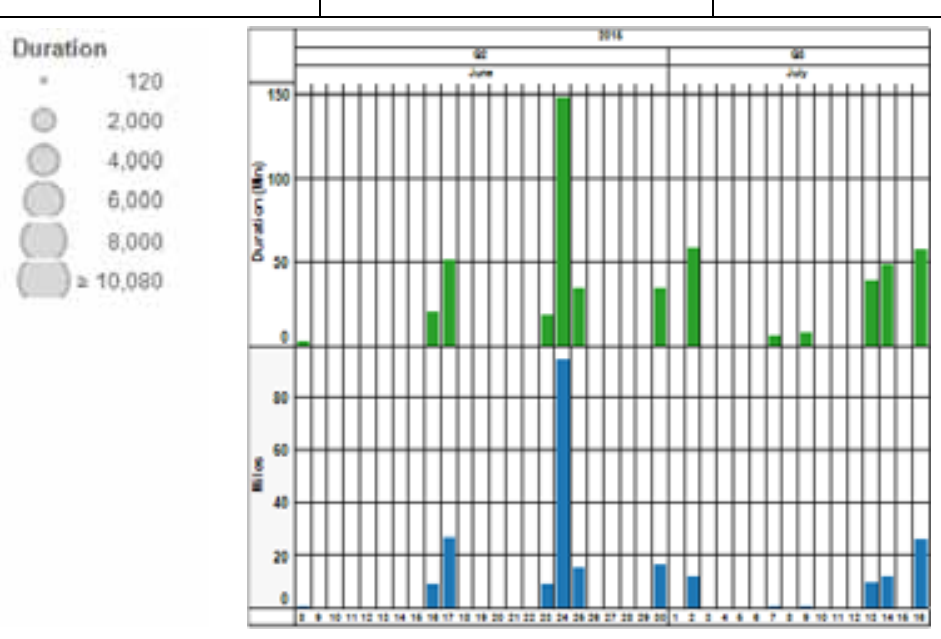

Figure C-32. Vehicle G13-0325K history. 

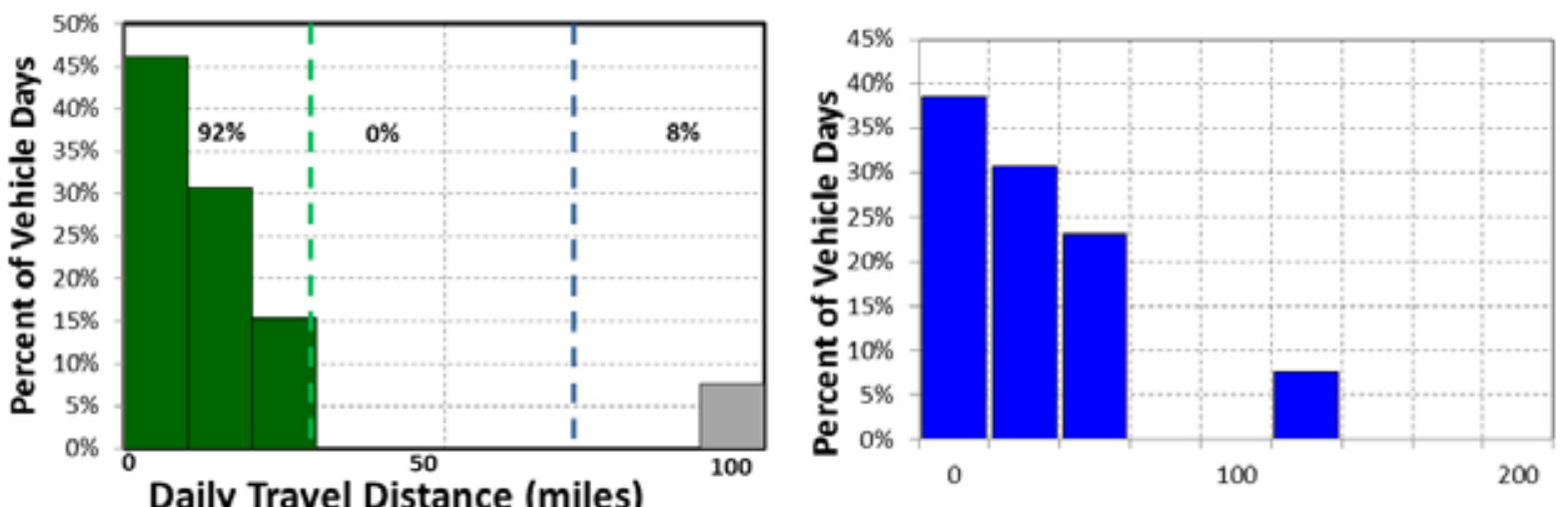

Daily Travel Distance (miles)

... All travel less than 30 miles _... All travel less than 70 miles

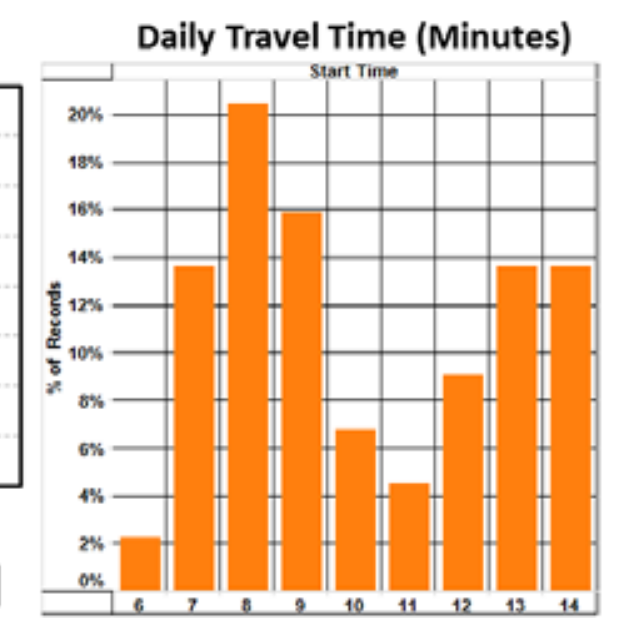

Figure C-33. Vehicle G13-0325K travel graphs.

\section{Vehicle G13-0325K Observations}

Logger 41 collected data on this vehicle for a period of 13 days of the 40-day study period. Validation occurred on $100 \%$ of the input data. Data indicate that this vehicle has a support mission for the Eastern Judicial Circuit. This vehicle's data indicate it parks near Building 67 near Virginia Dare Drive as shown in the Google Earth figure to the right.

MCBCL reports that a recent vehicle odometer indicated 6,380 miles at the start of this study and an average annual mileage of 1,037 miles. The vehicle was used on $33 \%$ of the available days, with an average daily usage of 0.7 hours and a peak daily usage of 2.5 hours

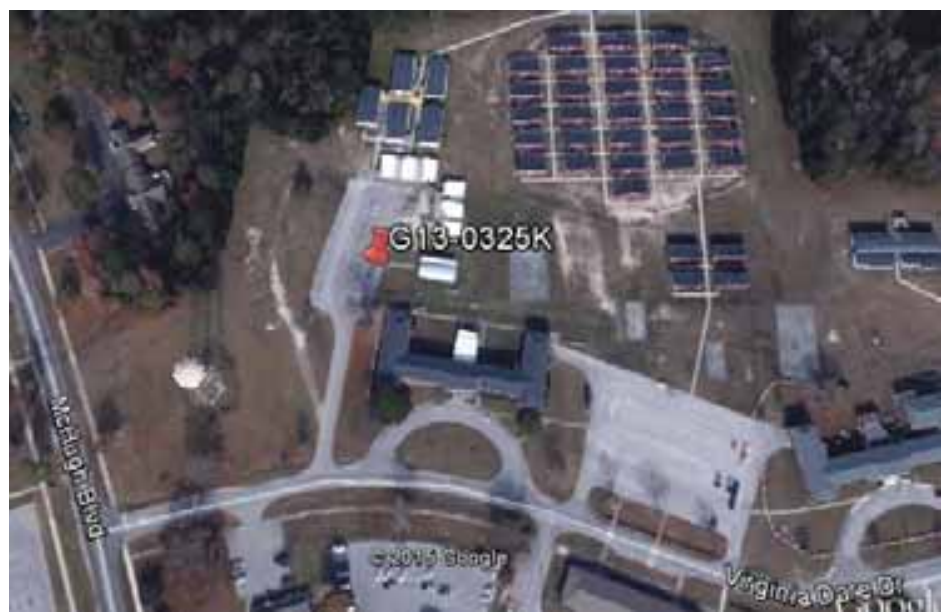
on the days it was used. The vehicle was used during day shift hours.

Figure C-33 shows that $92 \%$ of daily travel was within the typically advertised range of a BEV of approximately 70 mile and $95 \%$ of the outings were also within this range. Further, $92 \%$ of daily travel and $95 \%$ of outings were within the typically advertised CD mode of 30 miles for PHEVs.

A BEV could not meet all daily travel because one outing exceeded the BEV range. However, a significant amount of daily travel was less than the BEV range. Thus, a fleet of vehicles for the Eastern Judicial Circuit would likely contain a mix of BEVs and PHEVs. 
Sheet 31: Vehicle G13-7974P

\begin{tabular}{|l|l|c|}
\hline & Make/Model/Year & Ford Focus - 2015 \\
\cline { 2 - 3 } & EPA Class Size & Sedan - Compact \\
\cline { 2 - 3 } & Mission & Support \\
\cline { 2 - 3 } & Contact & Building 1117 \\
\cline { 2 - 3 } & Parking Location & G13-7974P \\
\hline Fleet Vehicle ID & E85 \\
\cline { 2 - 3 } & Fuel Type & $27 / 40 / 31$ \\
\cline { 2 - 3 } & EPA Label/MPG (City/Hwy/Combined) & 266 \\
\cline { 2 - 3 } & EPA GHG Emissions (Grams CO $/ \mathrm{Mi})$ & 39 \\
\cline { 2 - 3 } & Study Logger ID & $12 / 30$ \\
\cline { 2 - 3 } & Total Vehicle Days/Total Study Days & \\
\hline
\end{tabular}

\begin{tabular}{|l|c|c|c|c|}
\hline \multicolumn{5}{|c|}{ Vehicle G13-7974P Travel Summary } \\
\hline & $\begin{array}{c}\text { Per Day } \\
\text { Average/Peak }\end{array}$ & $\begin{array}{c}\text { Per Outing } \\
\text { Average/Peak }\end{array}$ & $\begin{array}{c}\text { Per Trip } \\
\text { Average/Peak }\end{array}$ & Total \\
\hline Travel Distance (Miles) & $85.8 / 152.1$ & $57.2 / 143.0$ & $6.8 / 54.5$ & 1,030 \\
\hline Travel Time (Minutes) & $172.6 / 292.0$ & $115.1 / 264.0$ & $13.7 / 73.0$ & 2,071 \\
\hline Idle Time (Minutes) & $10.4 / \mathrm{NA}$ & $6.9 / \mathrm{NA}$ & $0.8 / \mathrm{NA}$ & 125 \\
\hline
\end{tabular}

\begin{tabular}{|c|c|c|c|c|}
\hline \multicolumn{2}{|c|}{ Total Stops } & \multicolumn{2}{c|}{ Stop Duration } \\
\hline $\begin{array}{c}\text { Distance From } \\
\text { Home Base (Miles) }\end{array}$ & Stops & Percentages & Stop Duration (Hours) & Stops \\
\hline Less than 10 & 91 & $65.9 \%$ & Less than 2 & 125 \\
\hline 10 to 20 & 28 & $20.3 \%$ & 2 to 4 & 1 \\
\hline 20 to 40 & 14 & $10.1 \%$ & 4 to 8 & 1 \\
\hline 40 to 60 & 5 & $3.6 \%$ & Greater than 8 & 11 \\
\hline
\end{tabular}

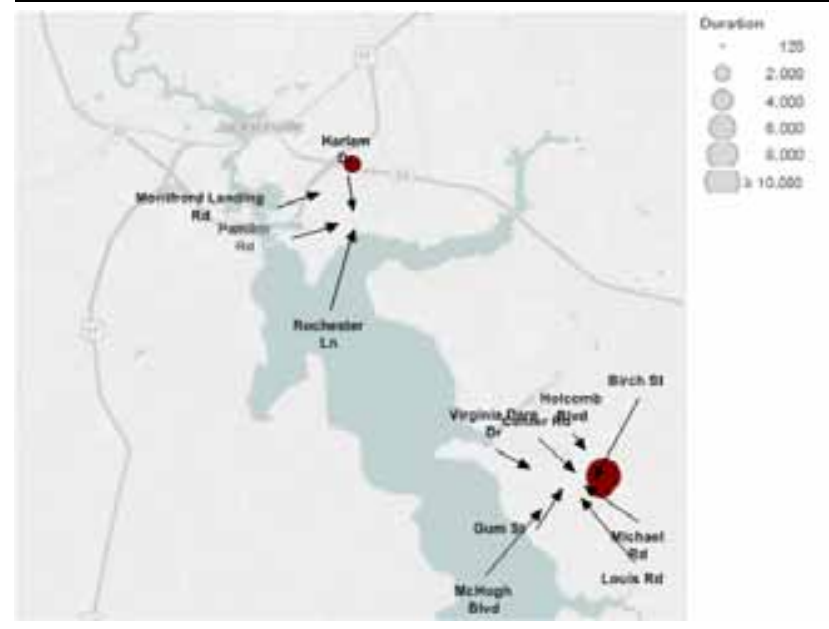

Figure C-34. Vehicle G13-7974P stops.

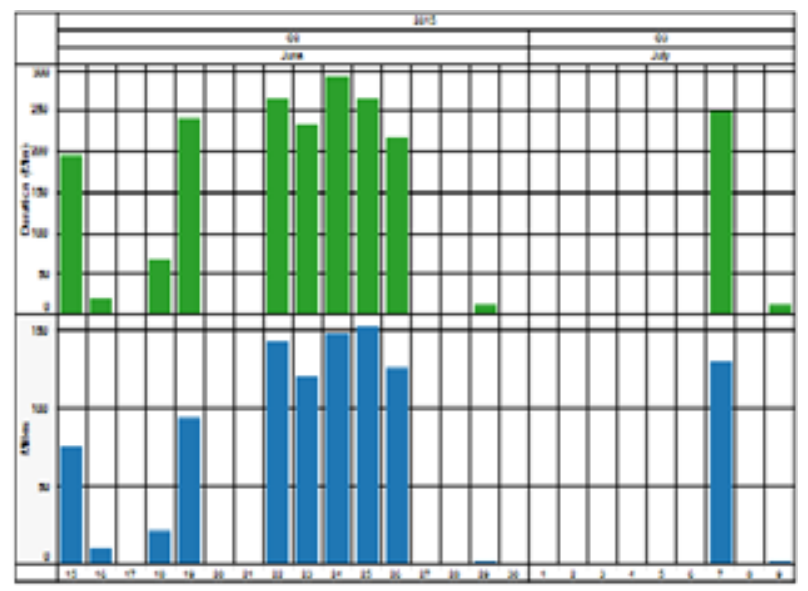

Figure C-35. Vehicle G13-7974P history. 

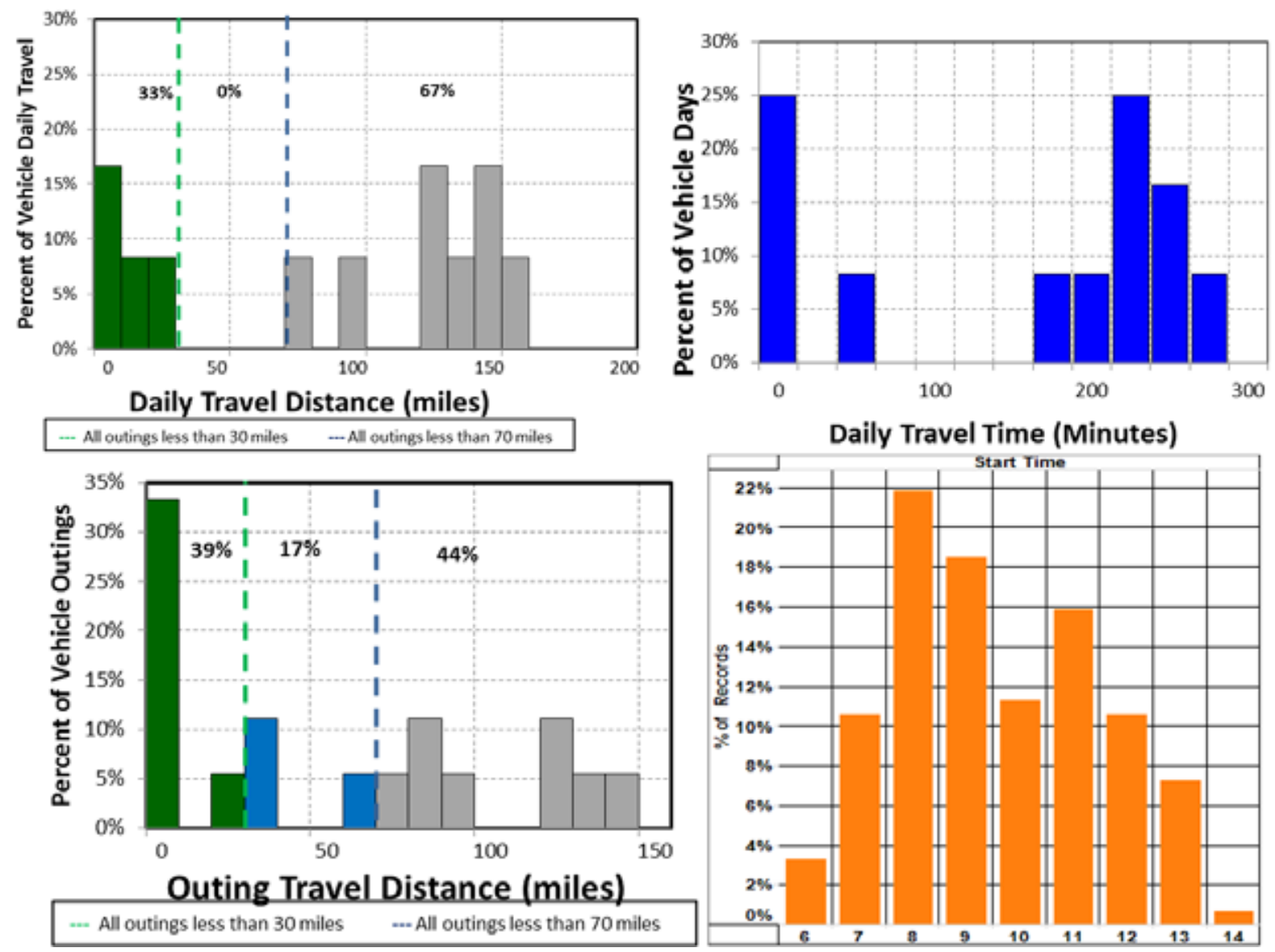

Figure C-36. Vehicle G13-7974P travel graphs.

\section{Vehicle G13-7974P Observations}

Logger 39 collected data on this vehicle for a period of 12 days of the 30-day study period. Validation occurred on $100 \%$ of the input data. Data indicate that this vehicle has a support mission for G4 - Logistics. This vehicle's data indicate it parked overnight in two separate locations at different time: initially near Building 1117 near Ash Street as shown in the Google Earth figure to the right and later on Franklin Street.

MCBCL reports that a recent vehicle odometer indicated 6,295 miles at the start of this study on this new vehicle and an average annual mileage of 12,000 miles. The vehicle was used on $40 \%$ of the available days, with an average daily usage of 2.9 hours and a peak daily usage of 4.9 hours on the days it was used. The vehicle was used during day shift hours.

Figure C-36 shows that $33 \%$ of daily travel was within the typically advertised range of a BEV of approximately 70 miles and $54 \%$ of the outings were also within this range. Further, $33 \%$ of daily travel and $39 \%$ of outings were within the typically advertised CD mode of 30 miles for PHEVs.

A BEV could not meet all daily travel due to the frequent days greater than the BEV range. 
Sheet 32: Vehicle G41-0379H

\begin{tabular}{|c|c|c|}
\hline & Make/Model/Year & Dodge Grand Caravan - 2009 \\
\hline $24=$ & EPA Class Size & Minivan \\
\hline$t=15$ & Mission & Pool \\
\hline$=2$ & Contact & Motor Transport-C-Pool \\
\hline & Parking Location & Building M305 \\
\hline & Fleet Vehicle ID & G41-0379H \\
\hline & Fuel Type & E85 \\
\hline & EPA Label/MPG (City/Hwy/Combined) & $11 / 16 / 13$ \\
\hline & EPA GHG Emissions (Grams $\left.\mathrm{CO}_{2} / \mathrm{Mi}\right)$ & 477 \\
\hline & Study Logger ID & 7 \\
\hline & Total Vehicle Days/Total Study Days & $16 / 35$ \\
\hline
\end{tabular}

\begin{tabular}{|l|c|c|c|c|}
\hline \multicolumn{5}{|c|}{ Vehicle G41-0379H Travel Summary } \\
\hline & $\begin{array}{c}\text { Per Day } \\
\text { Average/Peak }\end{array}$ & $\begin{array}{c}\text { Per Outing } \\
\text { Average/Peak }\end{array}$ & $\begin{array}{c}\text { Per Trip } \\
\text { Average/Peak }\end{array}$ & Total \\
\hline Travel Distance (Miles) & $29.1 / 289.4$ & $11.6 / 270.8$ & $6.2 / 136.5$ & 466 \\
\hline Travel Time (Minutes) & $62.6 / 409.0$ & $25.0 / 354.0$ & $13.3 / 186.0$ & 1,001 \\
\hline Idle Time (Minutes) & $11.5 / \mathrm{NA}$ & $4.6 / \mathrm{NA}$ & $2.5 / \mathrm{NA}$ & 184 \\
\hline
\end{tabular}

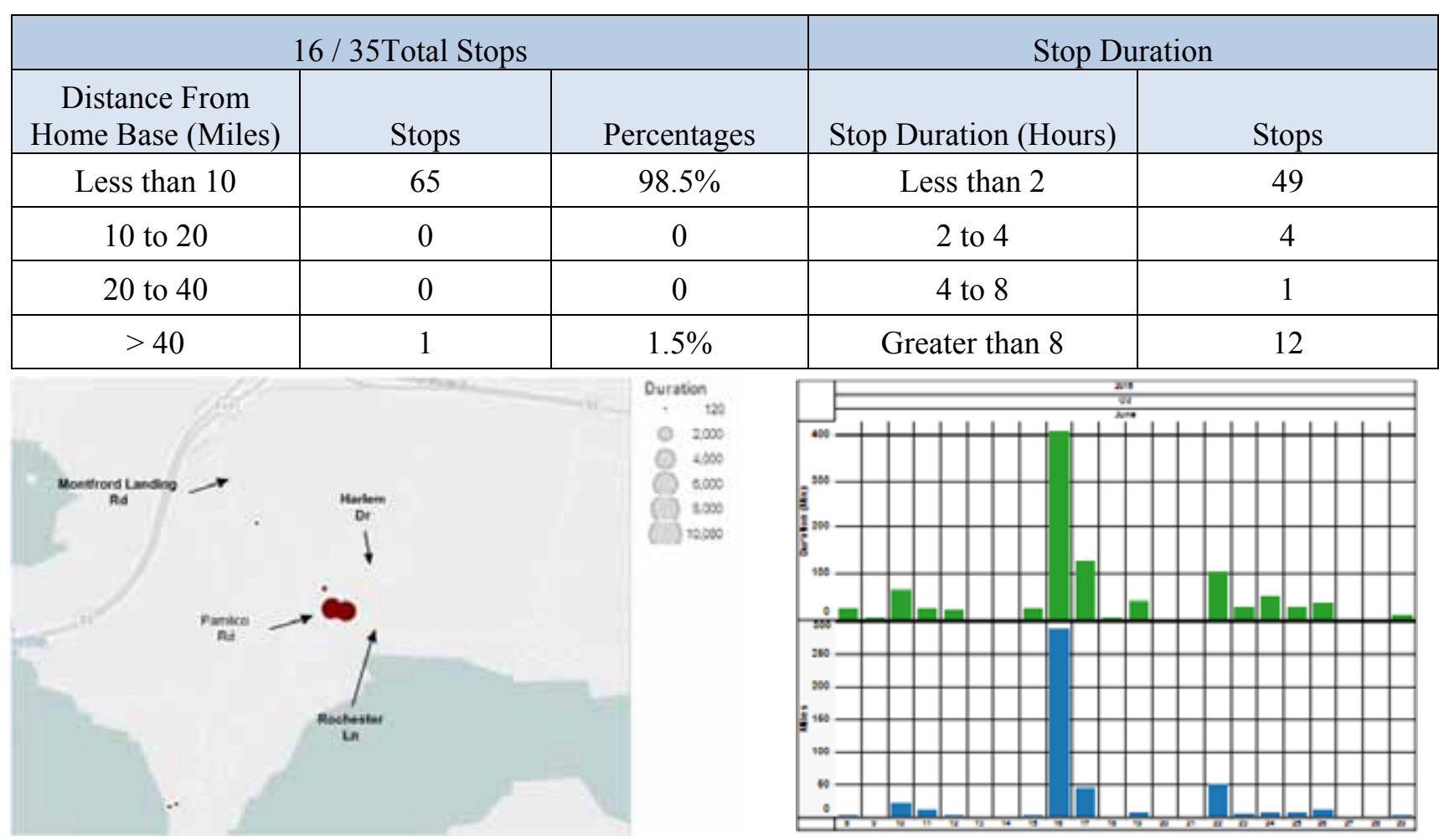

Figure C-37. Vehicle G41-0379H stops.

Figure C-38. Vehicle G41-0379H history. 

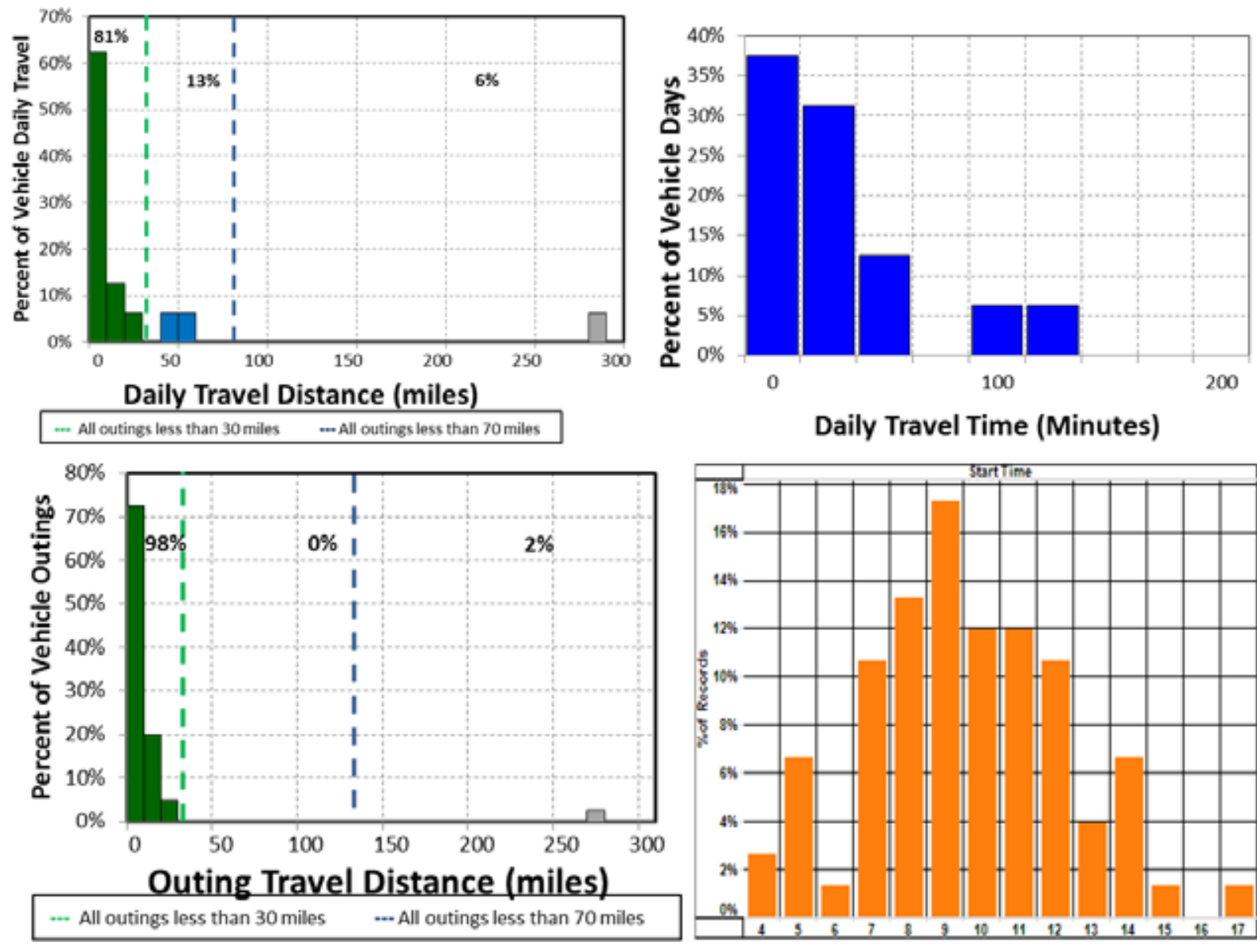

Daily Travel Time (Minutes)

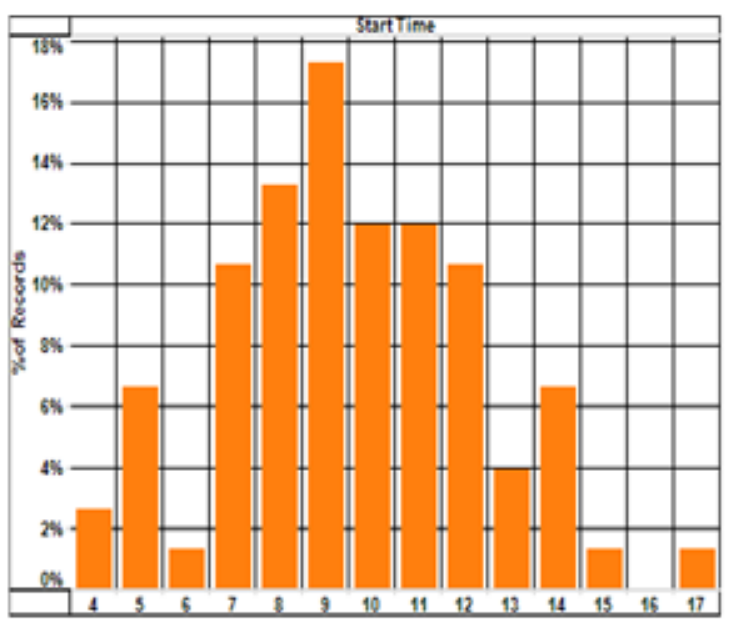

Figure C-39. Vehicle G41-0379H travel graphs.

\section{Vehicle G41-0379H Observations}

Logger 7 collected data on this vehicle for a period of 16 days of the 35-day study period. Validation occurred on $100 \%$ of the input data. Data indicate that this vehicle has a pool mission for Motor Transport C-Pool. This vehicle's data indicate it parks near Building M305 near Company Street B as shown in the Google Earth figure to the right.

MCBCL reports that a recent vehicle odometer indicated 25,874 miles at the start of this study and an average annual mileage of 5,614 miles. The vehicle was used on $46 \%$ of the available days, with an average daily usage of 1.0 hours and a peak daily usage of 6.8 hours

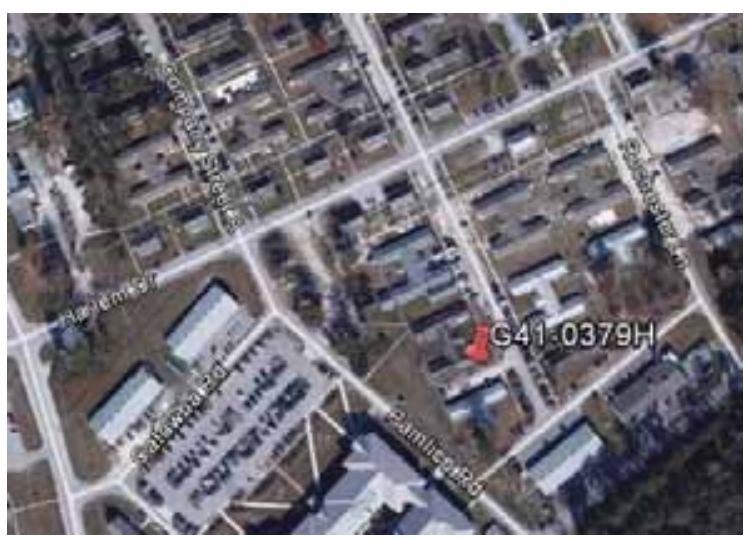
on the days it was used. The vehicle was used during day shift hours.

Figure C-39 shows that $94 \%$ of daily travel was within the typically advertised range of a BEV of approximately 70 miles and $98 \%$ of the outings were also within this range. Further, $81 \%$ of daily travel and $98 \%$ of outings were within the typically advertised CD mode of 30 miles for PHEVs. The peak outing of 271 miles occurred during a single outing to Cedar Fork, North Carolina.

A BEV could not meet all daily travel because of this single long outing. However, daily travel shows a significant number of days with travel within the BEV range. Thus, a fleet of pool vehicles would likely contain a mix of BEVs and PHEVs. 
Sheet 33: Vehicle G41-0391H

\begin{tabular}{|c|c|c|c|c|}
\hline & \multicolumn{2}{|l|}{ Make/Model/Year } & \multicolumn{2}{|c|}{ Dodge Dakota - 2009} \\
\hline 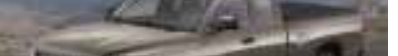 & \multicolumn{2}{|l|}{ EPA Class Size } & \multicolumn{2}{|c|}{ Pickup } \\
\hline$-4=0$ & \multicolumn{2}{|l|}{ Mission } & \multicolumn{2}{|c|}{ Support } \\
\hline mans & \multicolumn{2}{|l|}{ Contact } & \multicolumn{2}{|c|}{ G4- Logistics } \\
\hline & \multicolumn{2}{|l|}{ Parking Location } & \multicolumn{2}{|c|}{ Building 1117} \\
\hline & \multicolumn{2}{|l|}{ Fleet Vehicle ID } & \multicolumn{2}{|c|}{ G41-0391H } \\
\hline & \multicolumn{2}{|l|}{ Fuel Type } & \multicolumn{2}{|c|}{ E85 } \\
\hline & \multicolumn{2}{|c|}{ EPA Label/MPG (City/Hwy/Combined) } & \multicolumn{2}{|c|}{$9 / 13 / 10$} \\
\hline & \multicolumn{2}{|c|}{ EPA GHG Emissions (Grams $\mathrm{CO}_{2} / \mathrm{Mi}$ ) } & \multicolumn{2}{|c|}{620} \\
\hline & \multicolumn{2}{|l|}{ Study Logger ID } & \multicolumn{2}{|c|}{40} \\
\hline & \multicolumn{2}{|c|}{ Total Vehicle Days/Total Study Days } & \multicolumn{2}{|c|}{$13 / 30$} \\
\hline \multicolumn{5}{|c|}{ Vehicle G41-0391H Travel Summary } \\
\hline & $\begin{array}{c}\text { Per Day } \\
\text { Average/Peak }\end{array}$ & $\begin{array}{c}\text { Per Outing } \\
\text { Average/Peak }\end{array}$ & $\begin{array}{c}\text { Per Trip } \\
\text { Average/Peak }\end{array}$ & Total \\
\hline Travel Distance (Miles) & $56.5 / 140.5$ & $40.8 / 128.0$ & $6.6 / 43.8$ & 735 \\
\hline Travel Time (Minutes) & $157.4 / 329.0$ & $113.7 / 322.0$ & $18.3 / 102.0$ & 2,046 \\
\hline Idle Time (Minutes) & 29.9/NA & 21.6/NA & $3.5 / \mathrm{NA}$ & 389 \\
\hline
\end{tabular}

\begin{tabular}{|c|c|c|c|c|c|}
\hline \multicolumn{2}{|c|}{ Total Stops } & \multicolumn{3}{c|}{ Stop Duration } \\
\hline $\begin{array}{c}\text { Distance From } \\
\text { Home Base (Miles) }\end{array}$ & Stops & Percentages & Stop Duration (Hours) & Stops \\
\hline Less than 10 & 76 & $73.8 \%$ & Less than 2 & 28 \\
\hline 10 to 20 & 22 & $21.4 \%$ & 2 to 4 & 4 to 8 \\
\hline 20 to 40 & 5 & $4.9 \%$ & & \\
\hline 40 to 60 & 0 & 0 & \\
\hline
\end{tabular}

Figure C-40. Vehicle G41-0391H stops.

Figure C-41. Vehicle G41-0391H history. 

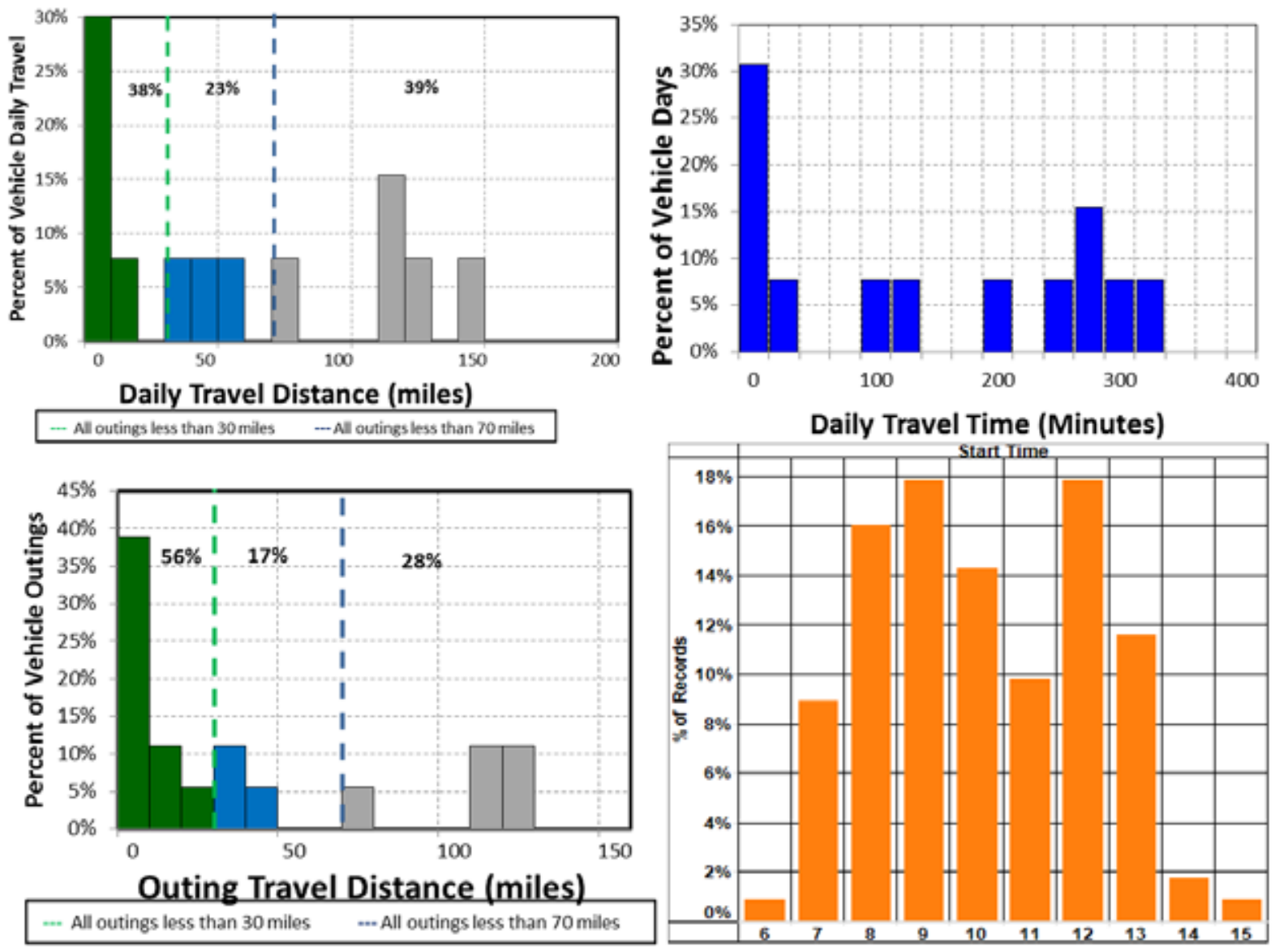

Figure C-42. Vehicle G41-0391H travel graphs.

\section{Vehicle G41-0391H Observations}

Logger 40 collected data on this vehicle for a period of 13 days of the 30-day study period. Validation occurred on $100 \%$ of the input data. Data indicate that this vehicle has a support mission for G4- Logistics. This vehicle's data indicate it parked overnight in several different locations, but primarily near Building 1117 on Franklin Street as shown in the Google Earth figure to the right.

MCBCL reports that a recent vehicle odometer indicated 27,140 miles at the start of this study and an average annual mileage of 7,507 miles. The vehicle was used on $43 \%$ of the available days, with an average daily usage of 2.6 hours and a peak daily usage of 5.5 hours on the days it was used. The

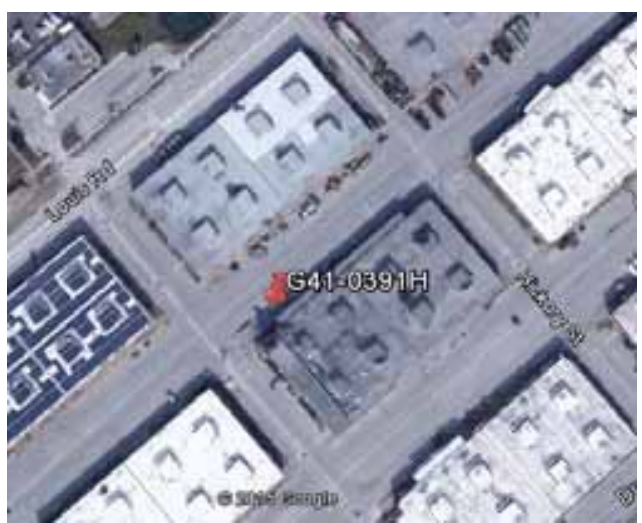
vehicle was used during day shift hours.

Figure C-42 shows that $61 \%$ of daily travel was within the typically advertised range of a BEV of approximately 70 miles and $72 \%$ of the outings were also within this range. Further, $38 \%$ of daily travel and $56 \%$ of outings were within the typically advertised CD mode of 30 miles for PHEVs.

A BEV could not meet all daily travel because of the frequent daily travel exceeding the BEV range. However, approximately half the daily travel is within the BEV range. Thus, a fleet of pickup trucks would likely contain a mix of BEVs and PHEVs. 


\begin{tabular}{|l|l|c|}
\hline & Make/Model/Year & Dodge Grand Caravan - 2012 \\
\cline { 2 - 3 } & EPA Class Size & Minivan \\
\cline { 2 - 3 } & Mission & Pool \\
\hline & Contact & Motor Transport - C-Pool \\
\cline { 2 - 3 } & Parking Location & G41-0754M \\
\cline { 2 - 3 } & Fleet Vehicle ID & E85 \\
\cline { 2 - 3 } & Fuel Type & $12 / 18 / 14$ \\
\cline { 2 - 3 } & EPA Label/MPG (City/Hwy/Combined) & 443 \\
\cline { 2 - 3 } & EPA GHG Emissions $\left(\mathrm{Grams} \mathrm{CO}_{2} / \mathrm{Mi}\right)$ & 8 \\
\cline { 2 - 3 } & Study Logger ID & $11 / 35$ \\
\cline { 2 - 3 } & Total Vehicle Days/Total Study Days & \\
\hline
\end{tabular}

\begin{tabular}{|l|c|c|c|c|}
\hline \multicolumn{5}{|c|}{ Vehicle G41-0754M travel Summary } \\
\hline & $\begin{array}{c}\text { Per Day } \\
\text { Average/Peak }\end{array}$ & $\begin{array}{c}\text { Per Outing } \\
\text { Average/Peak }\end{array}$ & $\begin{array}{c}\text { Per Trip } \\
\text { Average/Peak }\end{array}$ & Total \\
\hline Travel Distance (Miles) & $88.7 / 269.6$ & $48.8 / 537.2$ & $16.3 / 258.5$ & 976 \\
\hline Travel Time (Minutes) & $157.5 / 327.0$ & $86.7 / 680.0$ & $28.9 / 285.0$ & 1.733 \\
\hline Idle Time (Minutes) & $34.4 / \mathrm{NA}$ & $18.9 / \mathrm{NA}$ & $6.3 / \mathrm{NA}$ & 378 \\
\hline
\end{tabular}

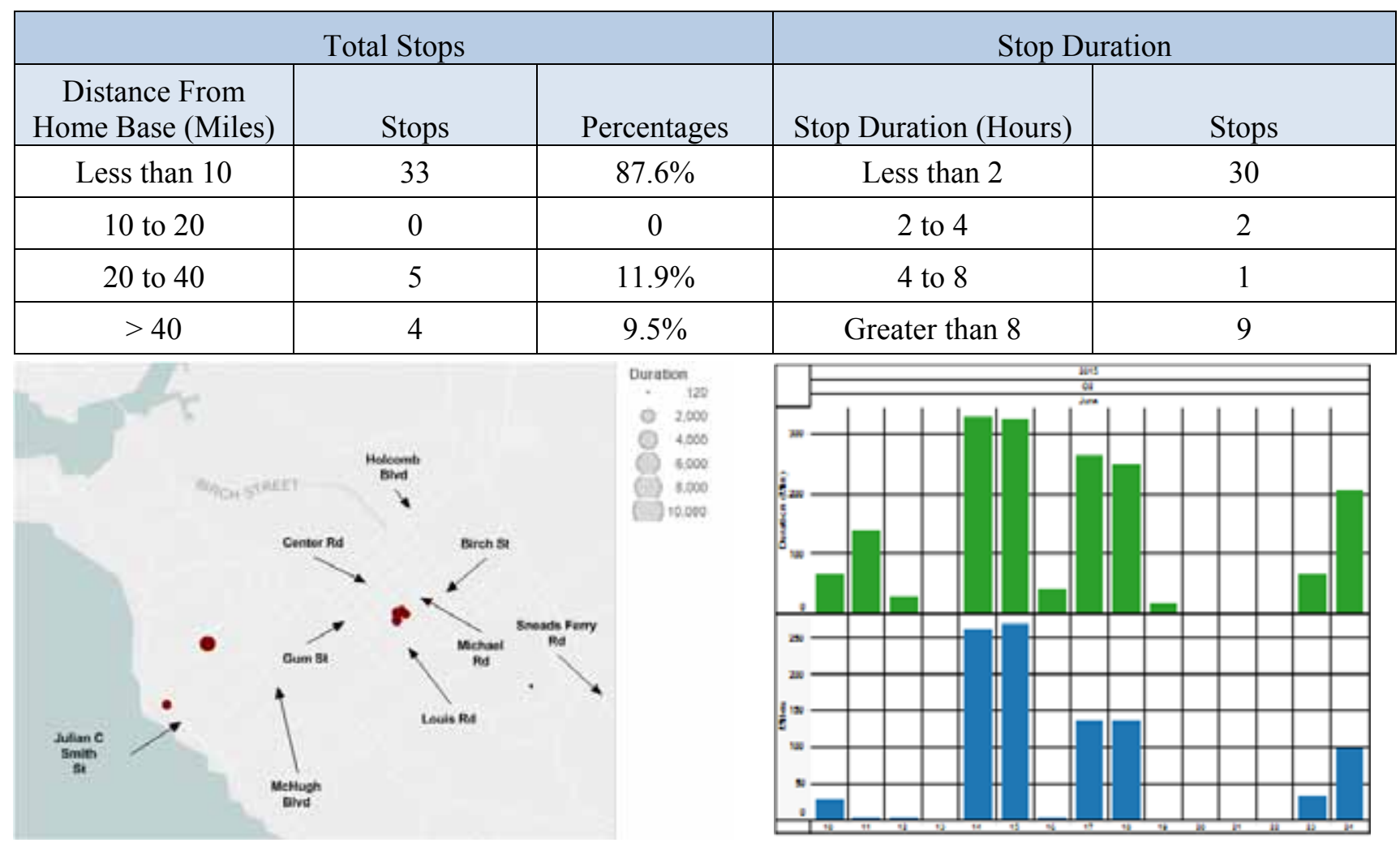

Figure C-43. Vehicle G41-0754M stops.

Figure C-44. Vehicle G41-0754M history. 

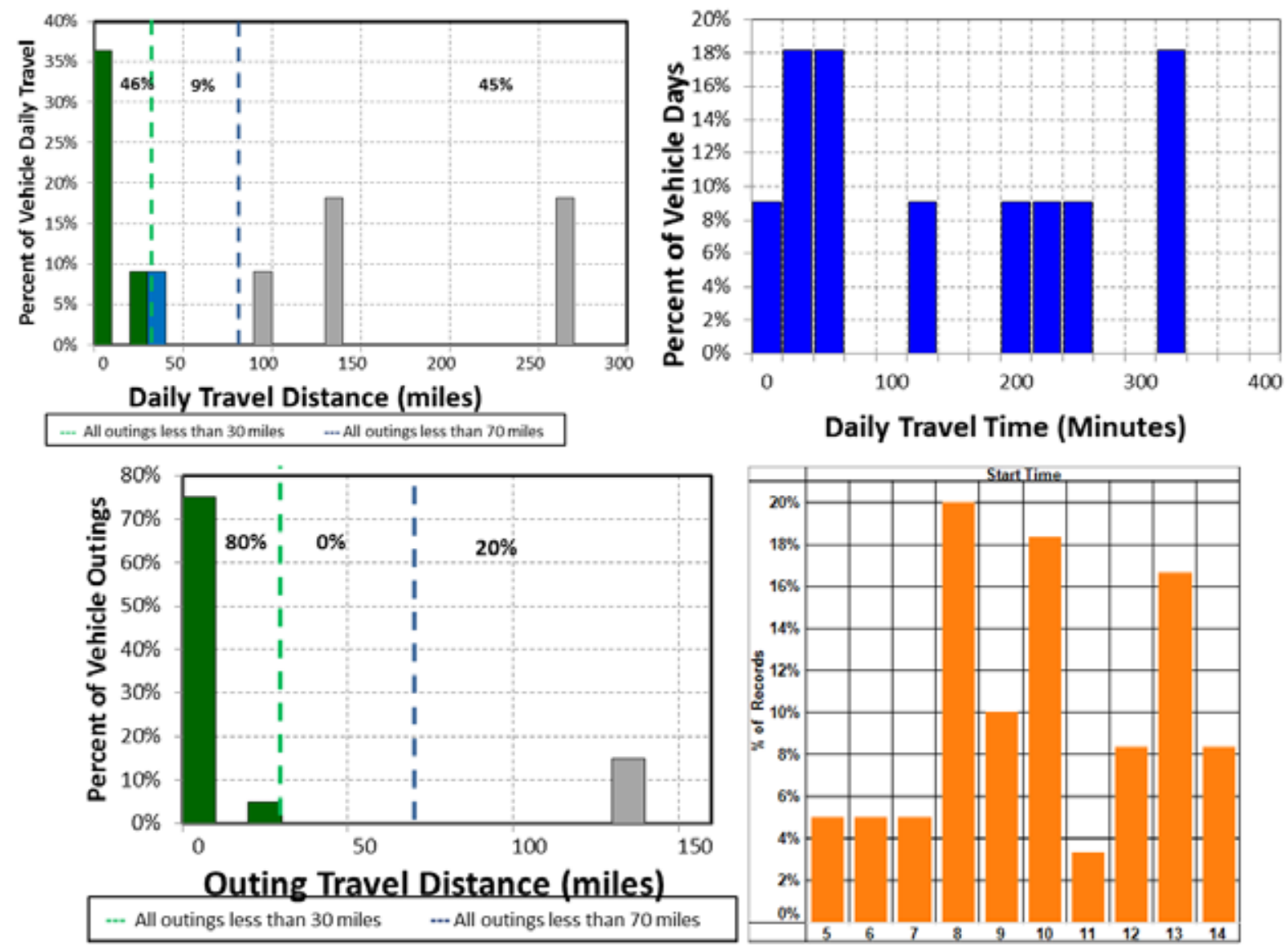

Figure C-45. Vehicle G41-0754M travel graphs. Note that the outing graph does not show the single outing of 537 miles.

\section{Vehicle G41-0754M Observations}

Logger 8 collected data on this vehicle for a period of 11 days of the 35-day study period. Validation occurred on $94.8 \%$ of the input data. Data indicate that this vehicle has a pool mission for Motor Transport - C-Pool. This vehicle's data indicate it parks near Building 1407 near Michael Road as shown in the Google Earth figure to the right.

MCBCL reports that a recent vehicle odometer indicated 10,918 miles at the start of this study and an average annual mileage of 5,183 miles. The vehicle was used on $43 \%$ of the available days, with an average daily usage of 2.6 hours and a peak daily usage of 5.5 hours on the days it was used. The vehicle was used during day shift hours.

Figure C-45 shows that $55 \%$ of daily travel was within the

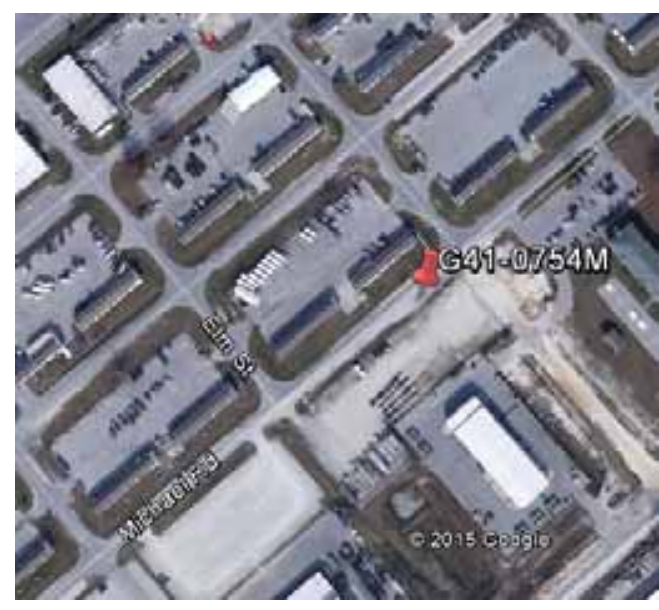
typically advertised range of a BEV of approximately 70 miles and $80 \%$ of the outings were also within this range. Further, $46 \%$ of daily travel and $80 \%$ of outings were within the typically advertised CD mode of 30 miles for PHEVs. The peak outing of 537 miles occurred over a several day period during an excursion to Whiteville and Charlotte.

A BEV could not meet all daily travel because of the extended excursion. However, significant daily travel is within the range of a BEV. Thus, a fleet of pool vehicles would likely contain a mix of BEVs and PHEVs. 
Sheet 35: Vehicle G41-0806P

\begin{tabular}{|c|c|c|}
\hline 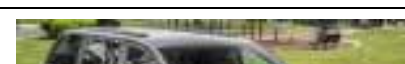 & Make/Model/Year & Dodge Caravan - 2014 \\
\hline & EPA Class Size & Minivan \\
\hline $20 x=3$ & Mission & Support \\
\hline " & Contact & Public Works \\
\hline & Parking Location & Building 1005 \\
\hline & Fleet Vehicle ID & G41-0806P \\
\hline & Fuel Type & E85 \\
\hline & EPA Label/MPG (City/Hwy/Combined) & $12 / 18 / 14$ \\
\hline & EPA GHG Emissions (Grams $\left.\mathrm{CO}_{2} / \mathrm{Mi}\right)$ & 434 \\
\hline & Study Logger ID & 57 \\
\hline & Total Vehicle Days/Total Study Days & $22 / 31$ \\
\hline
\end{tabular}

\begin{tabular}{|l|c|c|c|c|}
\hline \multicolumn{5}{|c|}{ Vehicle G41-0806P Travel Summary } \\
\hline & $\begin{array}{c}\text { Per Day } \\
\text { Average/Peak }\end{array}$ & $\begin{array}{c}\text { Per Outing } \\
\text { Average/Peak }\end{array}$ & $\begin{array}{c}\text { Per Trip } \\
\text { Average/Peak }\end{array}$ & Total \\
\hline Travel Distance (Miles) & $76.0 / 143.2$ & $40.8 / 74.1$ & $16.9 / 72.0$ & 1,673 \\
\hline Travel Time (Minutes) & $189.2 / 285.0$ & $101.5 / 183.0$ & $42.1 / 147.0$ & 4,163 \\
\hline Idle Time (Minutes) & $36.0 / \mathrm{NA}$ & $19.3 / \mathrm{NA}$ & $8.0 / \mathrm{NA}$ & 791 \\
\hline
\end{tabular}

\begin{tabular}{|c|c|c|c|c|}
\hline \multicolumn{2}{|c|}{ Total Stops } & \multicolumn{2}{c|}{ Stop Duration } \\
\hline $\begin{array}{c}\text { Distance From } \\
\text { Home Base (Miles) }\end{array}$ & Stops & Percentages & Stop Duration (Hours) & Stops \\
\hline Less than 10 & 100 & $100 \%$ & Less than 2 & 57 \\
\hline 10 to 20 & 0 & 0 & 2 to 4 & 19 \\
\hline 20 to 40 & 0 & 0 & 4 to 8 & 22 \\
\hline 40 to 60 & 0 & 0 & Greater than 8 & \\
\hline
\end{tabular}

Figure C-46. Vehicle G41-0806P stops.

Figure C-47. Vehicle G41-0806P history. 

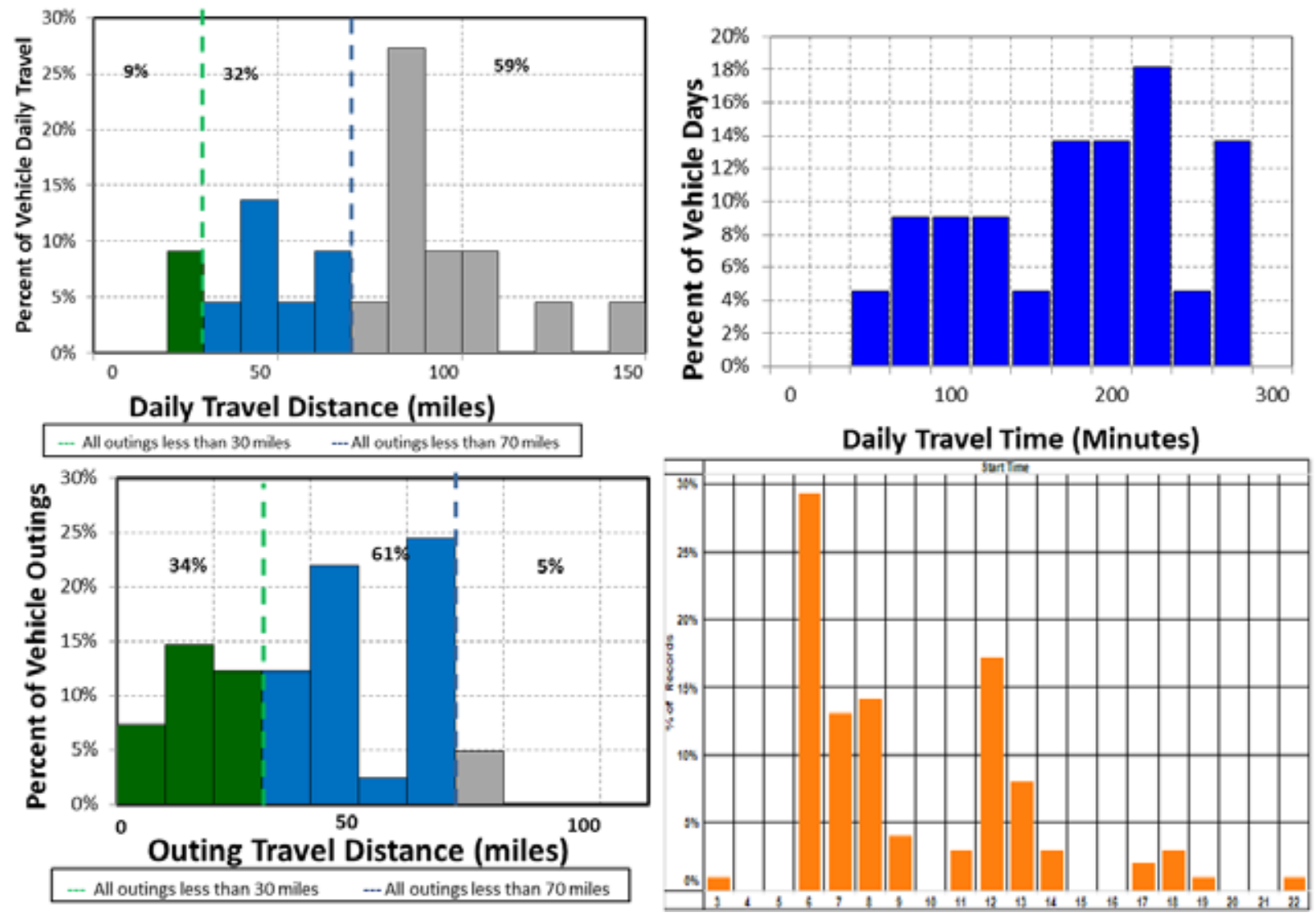

Figure C-48. Vehicle G41-0806P travel graphs.

\section{Vehicle G41-0806P Observations}

Logger 57 collected data on this vehicle for a period of 22 days of the 31-day study period. Validation occurred on $100 \%$ of the input data. Data indicate that this vehicle has a support mission for Public Works. This vehicle's data indicate it parks near Building 1005 near Ash Street as shown in the Google Earth figure to the right.

MCBCL reports that a recent vehicle odometer indicated 12,562 miles at the start of this study and an average annual mileage of 12,552 miles. The vehicle was used on $71 \%$ of the available days, with an average daily usage of 3.2 hours and a peak daily usage of 4.8 hours on the days it was used. The vehicle was used primarily during day shift hours.

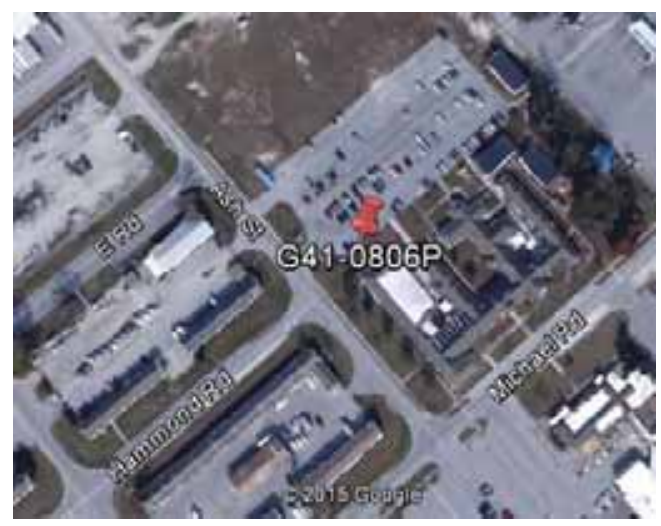

Figure C-48 shows that $41 \%$ of daily travel was within the typically advertised range of a BEV of approximately 70 miles and $95 \%$ of the outings were also within this range. Further, $9 \%$ of daily travel and $34 \%$ of outings were within the typically advertised CD mode of 30 miles for PHEVs.

A BEV could not meet all daily travel without additional charging opportunities, assuming the vehicle was assigned a home base. However, all travel is near the home base and there is sufficient charge opportunity during the day. Thus, a fleet of support vehicles would likely contain a mix of BEVs and PHEVs. 
Sheet 36: Vehicle G41-1689L

\begin{tabular}{|l|l|c|}
\hline & Make/Model/Year & Ford Ranger -2011 \\
\cline { 2 - 3 } & EPA Class Size & Pickup \\
\hline Mission & Support \\
\hline Contact & Public Works \\
\cline { 2 - 3 } & Parking Location & Building 1005 \\
\cline { 2 - 3 } & Fleet Vehicle ID & G41-1689L \\
\cline { 2 - 3 } & Fuel Type & Gas \\
\cline { 2 - 3 } & EPA Label/MPG (City/Hwy/Combined) & $22 / 27 / 24$ \\
\cline { 2 - 3 } & EPA GHG Emissions (Grams $\left.\mathrm{CO}_{2} / \mathrm{Mi}\right)$ & 370 \\
\cline { 2 - 3 } & Study Logger ID & 58 \\
\hline & Total Vehicle Days/Total Study Days & $16 / 31$ \\
\hline
\end{tabular}

\begin{tabular}{|l|c|c|c|c|}
\hline \multicolumn{5}{|c|}{ Vehicle G41-1689L Travel Summary } \\
\hline & $\begin{array}{c}\text { Per Day } \\
\text { Average/Peak }\end{array}$ & $\begin{array}{c}\text { Per Outing } \\
\text { Average/Peak }\end{array}$ & $\begin{array}{c}\text { Per Trip } \\
\text { Average/Peak }\end{array}$ & Total \\
\hline Travel Distance (Miles) & $28.3 / 81.6$ & $15.6 / 66.9$ & $6.6 / 36.3$ & 453 \\
\hline Travel Time (Minutes) & $71.6 / 163.0$ & $39.5 / 129.0$ & $16.6 / 60.6$ & 1,145 \\
\hline Idle Time (Minutes) & $15.4 / \mathrm{NA}$ & $8.5 / \mathrm{NA}$ & $3.6 / \mathrm{NA}$ & 247 \\
\hline
\end{tabular}

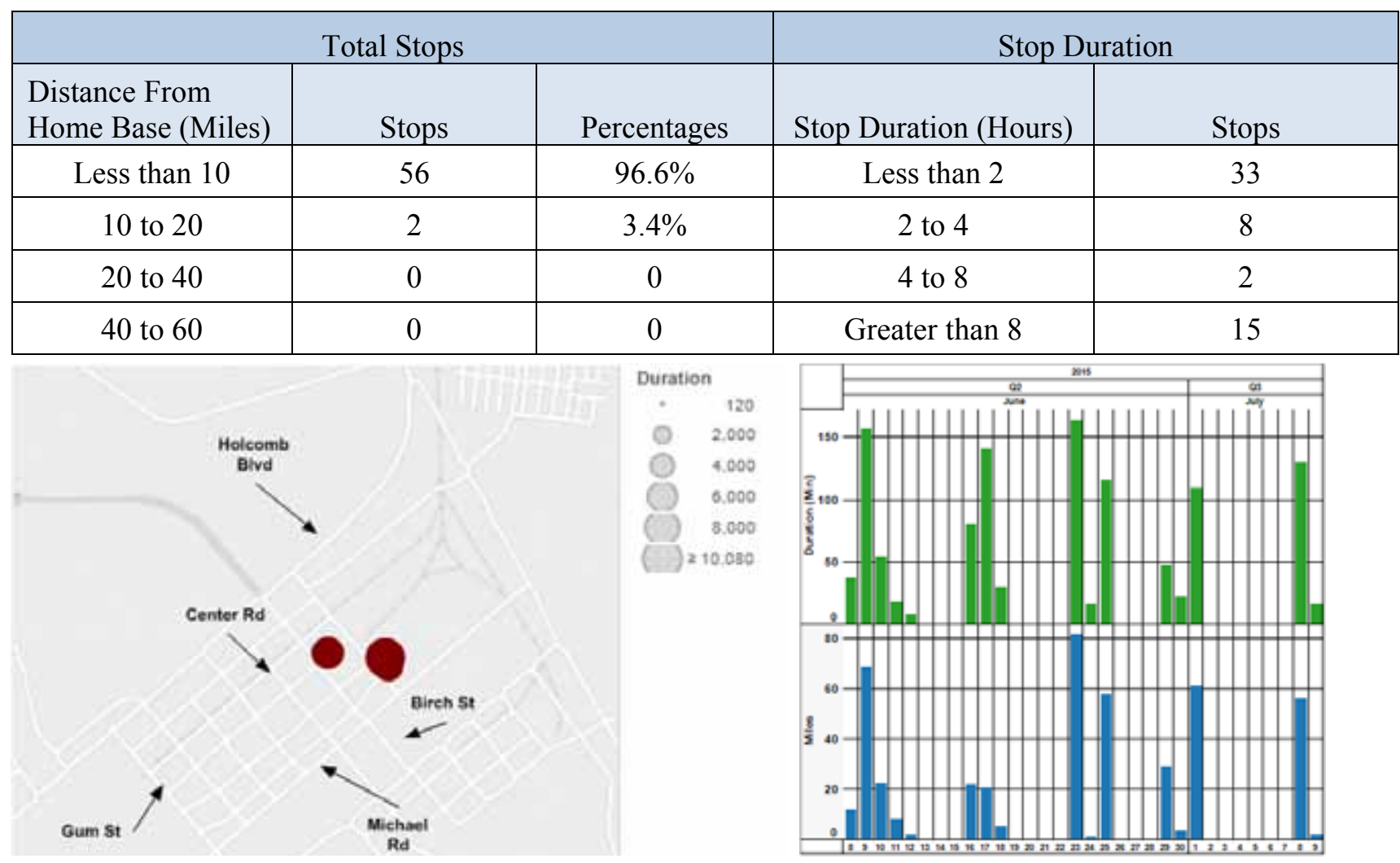

Figure C-49. Vehicle G41-1689L stops.

Figure C-50 Vehicle G41-1689L history. 

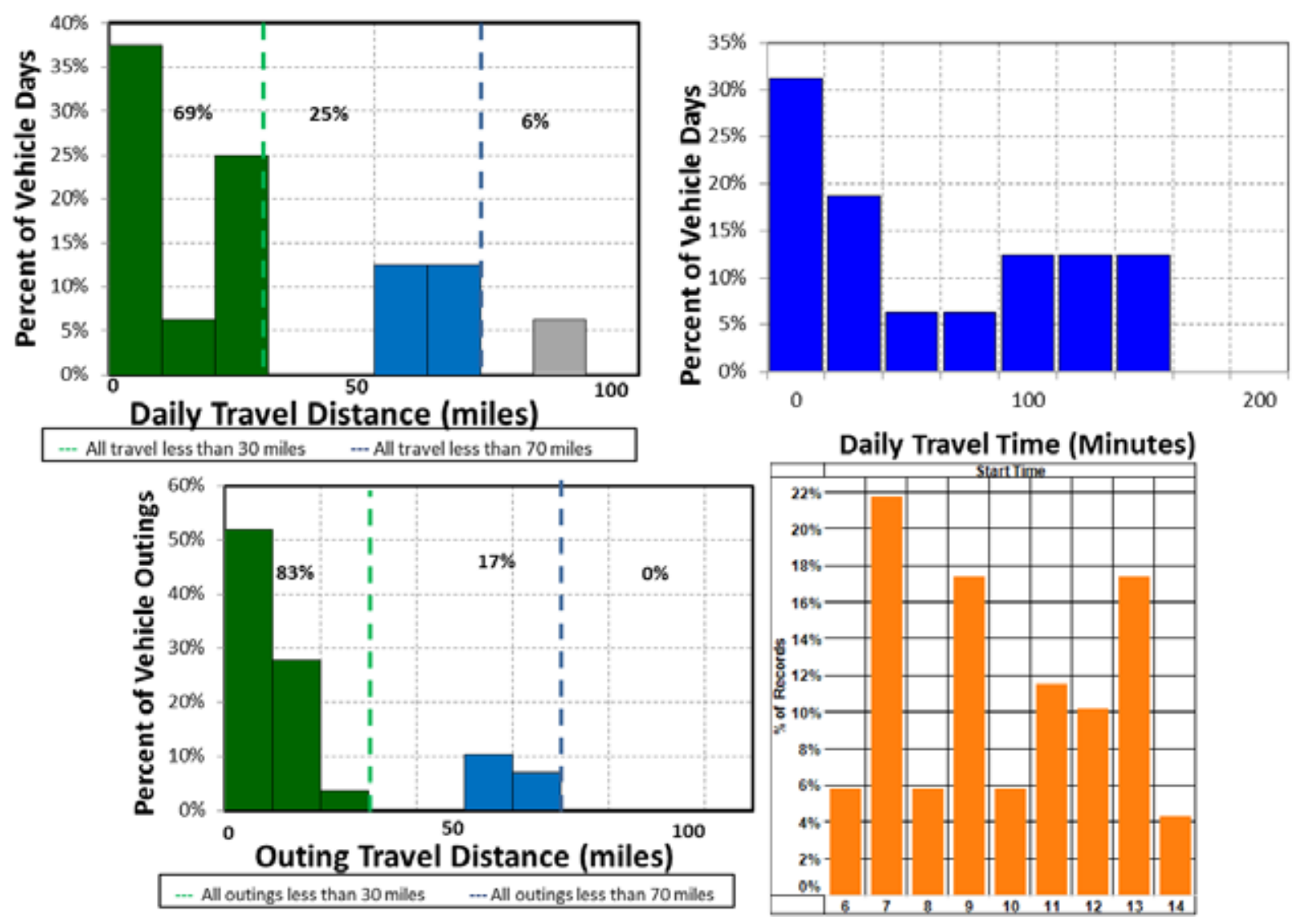

Figure C-51. Vehicle G41-1689L travel graphs.

\section{Vehicle G41-1689L Observations}

Logger 58 collected data on this vehicle for a period of 16 days of the 31-day study period. Validation occurred on $100 \%$ of the input data. Data indicate that this vehicle has a support mission for Public Works. This vehicle's data indicate it parks near Building 1005 near Ash Street as shown in the Google Earth figure to the right.

MCBCL reports that a recent vehicle odometer indicated 18,215 miles at the start of this study and an average annual mileage of 5,649 miles. The vehicle was used on $52 \%$ of the available days, with an average daily usage of 1.2 hours and a peak daily usage of 2.7 hours on the days it was used. The vehicle was used during day shift hours.

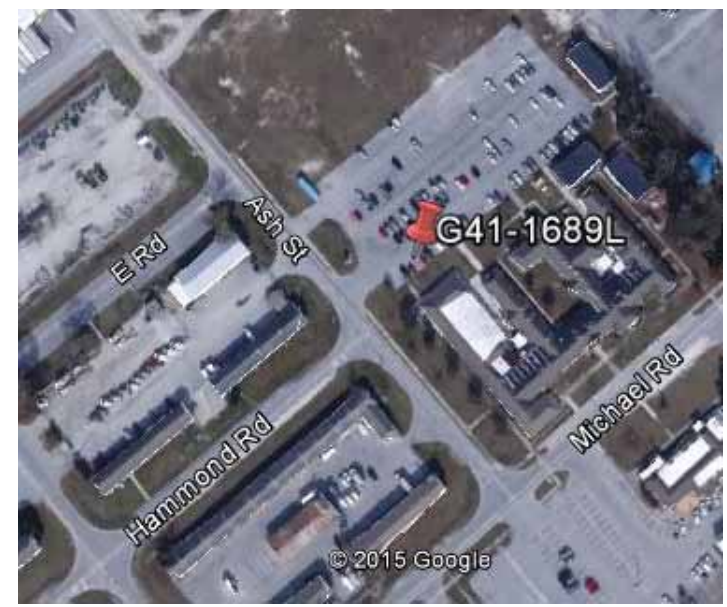

Figure C-51 shows that $94 \%$ of daily travel was within the typically advertised range of a BEV of approximately 70 miles. All outings were also within this range. Further, $69 \%$ of daily travel and $83 \%$ of outings were within the typically advertised CD mode of 30 miles for PHEVs.

A BEV could not meet all daily travel without additional charging opportunities that are possible because all stops are close to the home base and the vehicle has plenty of time each day for charging. However, fleet managers will typically prefer a mix of BEVs and PHEVs. 


\begin{tabular}{|l|l|c|}
\hline & Make/Model/Year & Ford Ranger -2011 \\
\hline & EPA Class Size & Pickup \\
\hline Mission & Support \\
\hline Contact & Public Works \\
\cline { 2 - 3 } & Parking Location & Building 1005 \\
\hline Fleet Vehicle ID & G41-3297K \\
\hline & Fuel Type & Gas \\
\cline { 2 - 3 } & EPA Label/MPG (City/Hwy/Combined) & $22 / 27 / 24$ \\
\cline { 2 - 3 } & EPA GHG Emissions (Grams $\left.\mathrm{CO}_{2} / \mathrm{Mi}\right)$ & 370 \\
\cline { 2 - 3 } & Study Logger ID & 59 \\
\cline { 2 - 3 } & Total Vehicle Days/Total Study Days & $19 / 31$ \\
\hline
\end{tabular}

\begin{tabular}{|l|c|c|c|c|}
\hline \multicolumn{5}{|c|}{ Vehicle G41-3297K Travel Summary } \\
\hline & $\begin{array}{c}\text { Per Day } \\
\text { Average/Peak }\end{array}$ & $\begin{array}{c}\text { Per Outing } \\
\text { Average/Peak }\end{array}$ & $\begin{array}{c}\text { Per Trip } \\
\text { Average/Peak }\end{array}$ & Total \\
\hline Travel Distance (Miles) & $35.7 / 101.6$ & $23.4 / 56.7$ & $9.1 / 50.1$ & 679 \\
\hline Travel Time (Minutes) & $73.8 / 159.0$ & $48.3 / 101.0$ & $18.7 / 90.0$ & 1,402 \\
\hline Idle Time (Minutes) & $8.5 / \mathrm{NA}$ & $5.6 / \mathrm{NA}$ & $2.2 / \mathrm{NA}$ & 162 \\
\hline
\end{tabular}

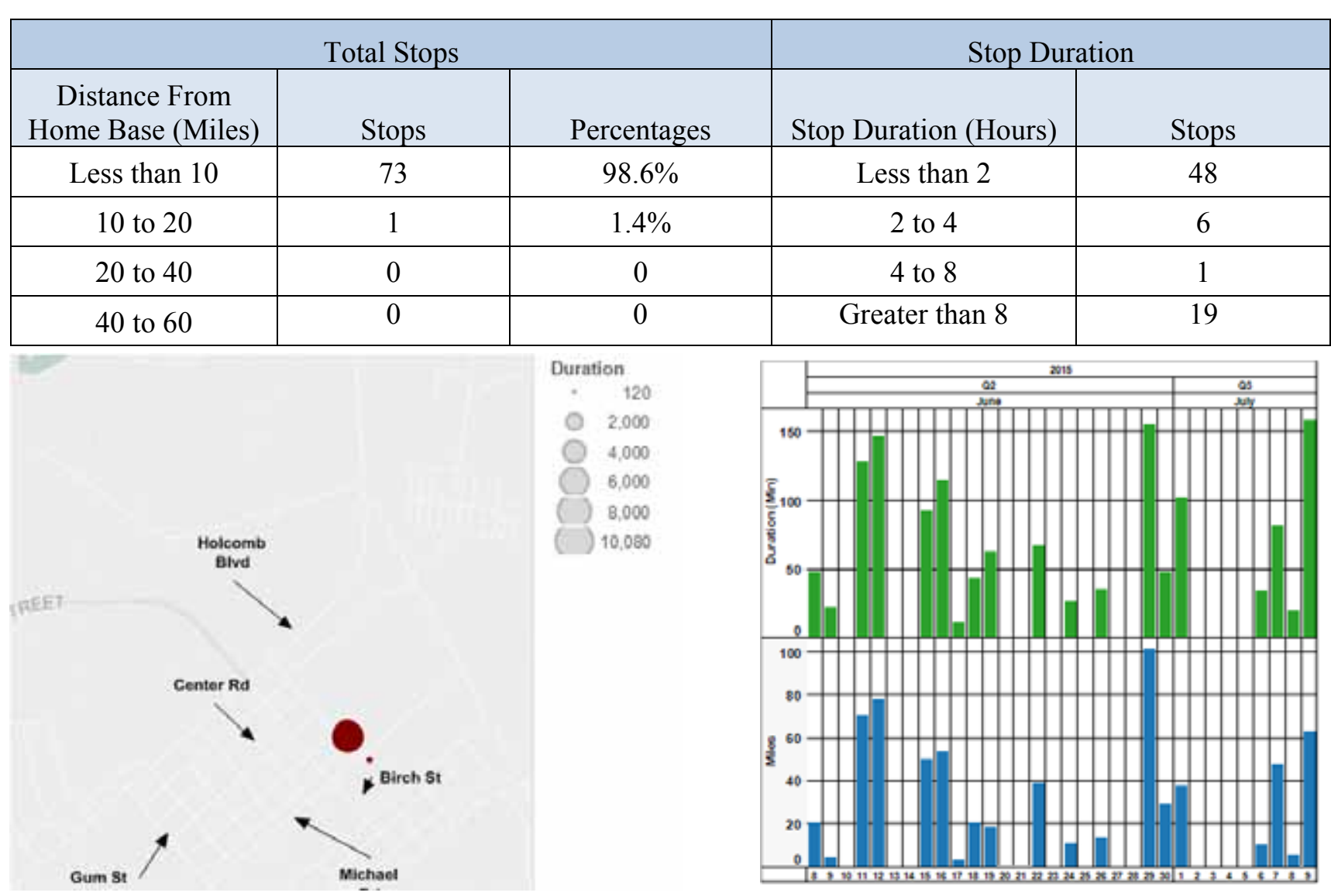

Figure C-52. Vehicle G41-3297K stops.

Figure C-53. Vehicle G41-3297K history. 


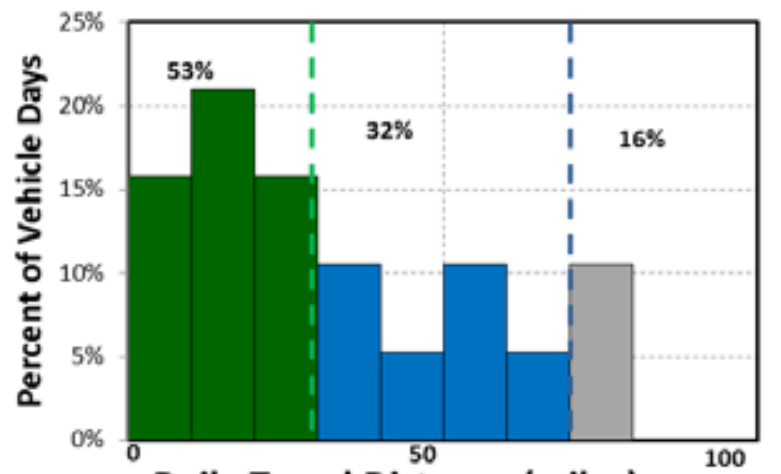

Daily Travel Distance (miles)

-.. All travel less than 30 miles $\quad$-. All travel less than 70 miles

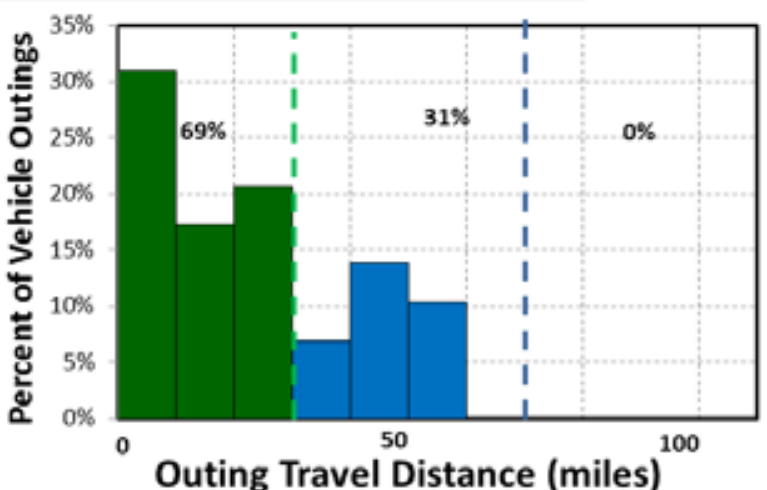

- All outings less than 30 miles .... All outings less than 70 miles

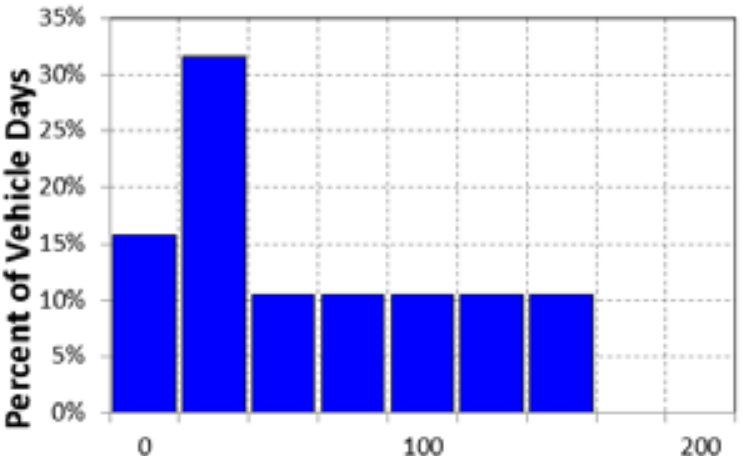

Daily Travel Time (Minutes)

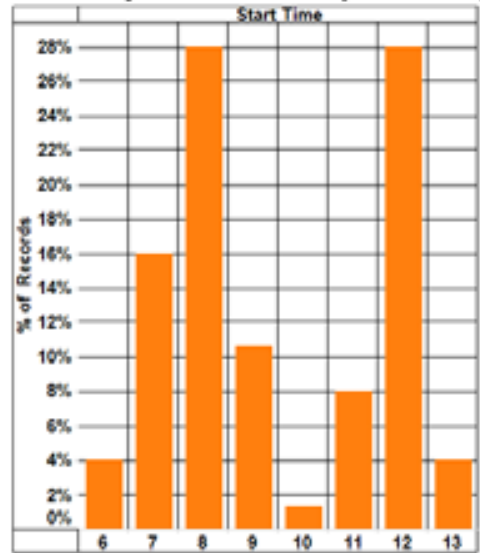

Figure C-54. Vehicle G41-3297K travel graphs.

\section{Vehicle G41-3297K Observations}

Logger 59 collected data on this vehicle for a period of 19 days of the 31-day study period. Validation occurred on $100 \%$ of the input data. Data indicate that this vehicle has a support mission for Public Works. This vehicle's data indicate it parks near Building 1005 near Ash Street as shown in the Google Earth figure to the right.

MCBCL reports that a recent vehicle odometer indicated 18,013 miles at the start of this study and an average annual mileage of 5,368 miles. The vehicle was used on $61 \%$ of the available days, with an average daily usage of 1.2 hours and a peak daily usage of 2.7 hours on the days it was used. The vehicle was used during day shift hours.

Figure C-54 shows that $84 \%$ of daily travel was within

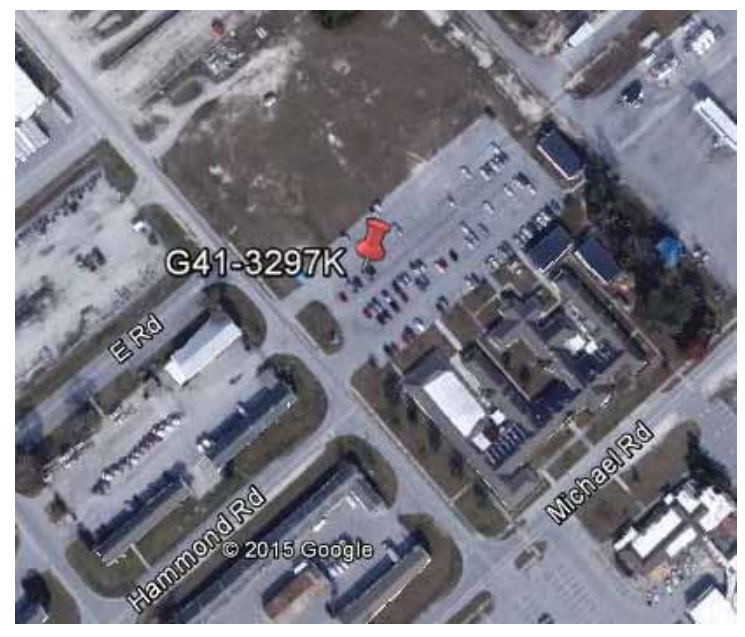
the typically advertised range of a BEV of approximately 70 miles. All outings were also within this range. Further, $53 \%$ of daily travel and $69 \%$ of outings were within the typically advertised CD mode of 30 miles for PHEVs.

A BEV could not meet all daily travel without additional charging opportunities, assuming the vehicle was assigned a home base. However, sufficient time does exist daily for recharging between outings and all outings are within the range of a BEV. Thus, a fleet of pickup trucks in Public Works would likely contain a mix of BEVs and PHEVs. 


\begin{tabular}{|l|l|c|}
\hline & Make/Model/Year & Ford Ranger - 2011 \\
\cline { 2 - 3 } & EPA Class Size & Pickup \\
\cline { 2 - 3 } & Mission & Enforcement \\
\cline { 2 - 3 } & Contact & Provost Marshal's Office \\
\cline { 2 - 3 } & Parking Location & Building 43 \\
\cline { 2 - 3 } & Fleet Vehicle ID & G41-3300K \\
\cline { 2 - 3 } & Fuel Type & Gas \\
\cline { 2 - 3 } & EPA Label/MPG (City/Hwy/Combined) & $22 / 27 / 24$ \\
\cline { 2 - 3 } & EPA GHG Emissions (Grams $\left.\mathrm{CO}_{2} / \mathrm{Mi}\right)$ & 370 \\
\cline { 2 - 3 } & Study Logger ID & 49 \\
\cline { 2 - 3 } & Total Vehicle Days/Total Study Days & $31 / 31$ \\
\hline
\end{tabular}

\begin{tabular}{|l|c|c|c|c|}
\hline \multicolumn{5}{|c|}{ Vehicle G41-3300K Travel Summary } \\
\hline & $\begin{array}{c}\text { Per Day } \\
\text { Average/Peak }\end{array}$ & $\begin{array}{c}\text { Per Outing } \\
\text { Average/Peak }\end{array}$ & $\begin{array}{c}\text { Per Trip } \\
\text { Average/Peak }\end{array}$ & Total \\
\hline Travel Distance (Miles) & $73.8 / 208.1$ & $15.9 / 144.6$ & $6.2 / 99.7$ & 2,288 \\
\hline Travel Time (Minutes) & $432.2 / 1,464.0$ & $93.0 / 1,209.0$ & $36.1 / 752.0$ & 13,397 \\
\hline Idle Time (Minutes) & $235.1 / \mathrm{NA}$ & $50.6 / \mathrm{NA}$ & $19.6 / \mathrm{NA}$ & 7,287 \\
\hline
\end{tabular}

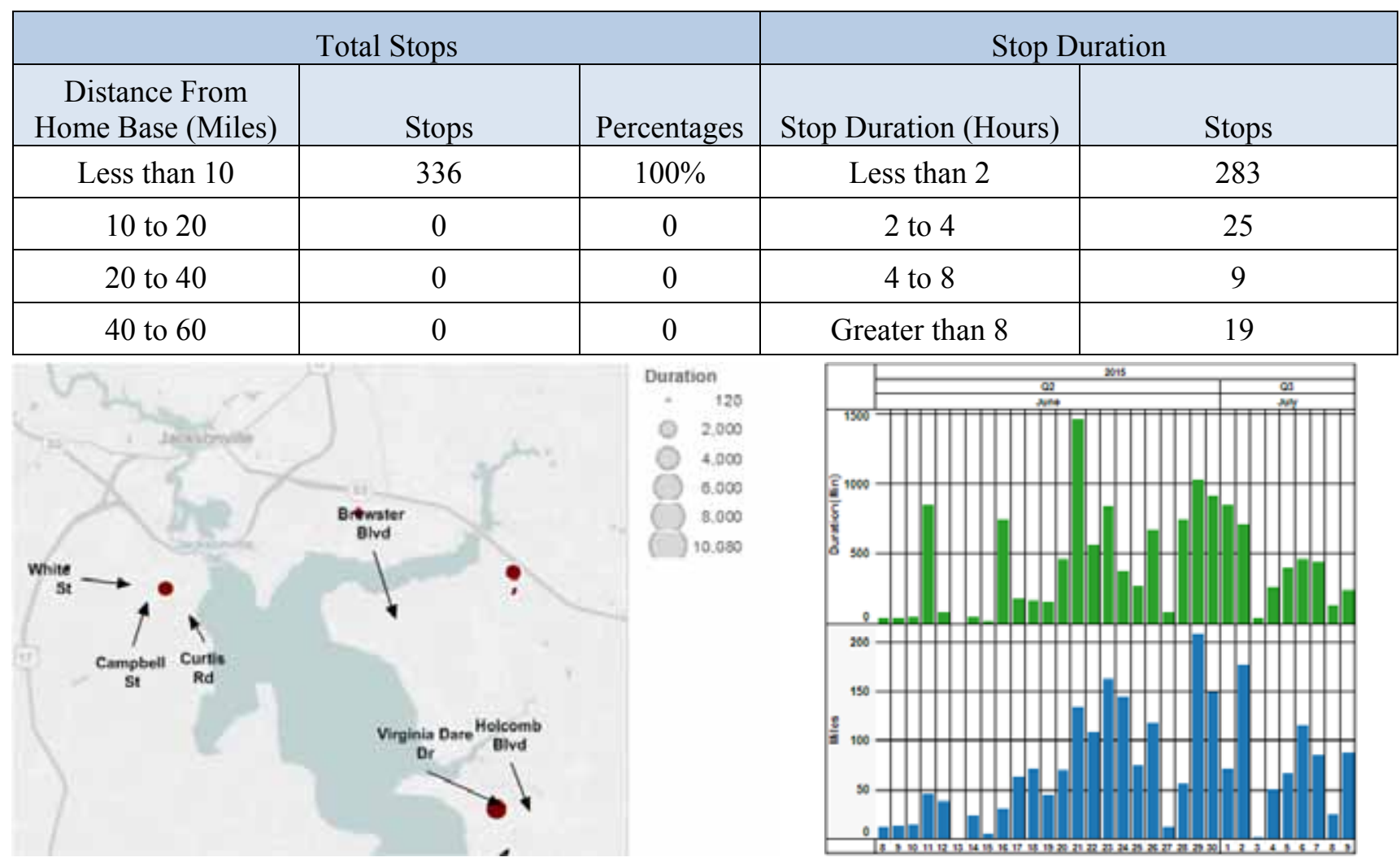

Figure C-55. Vehicle G41-3300K stops.

Figure C-56. Vehicle G41-3300K history. 


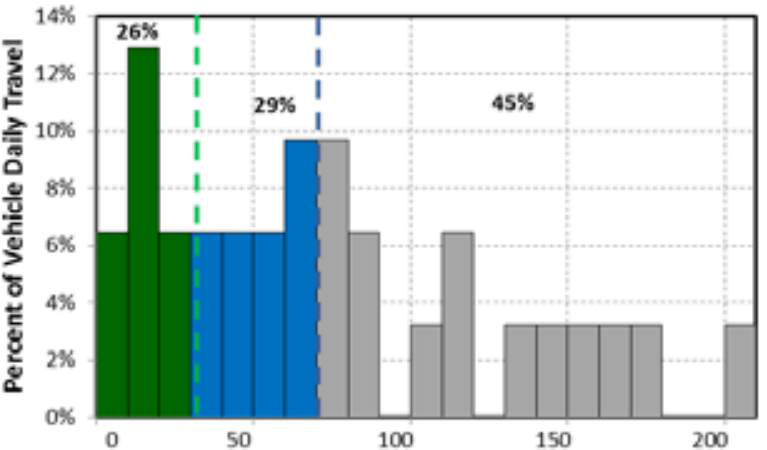

Daily Travel Distance (miles)

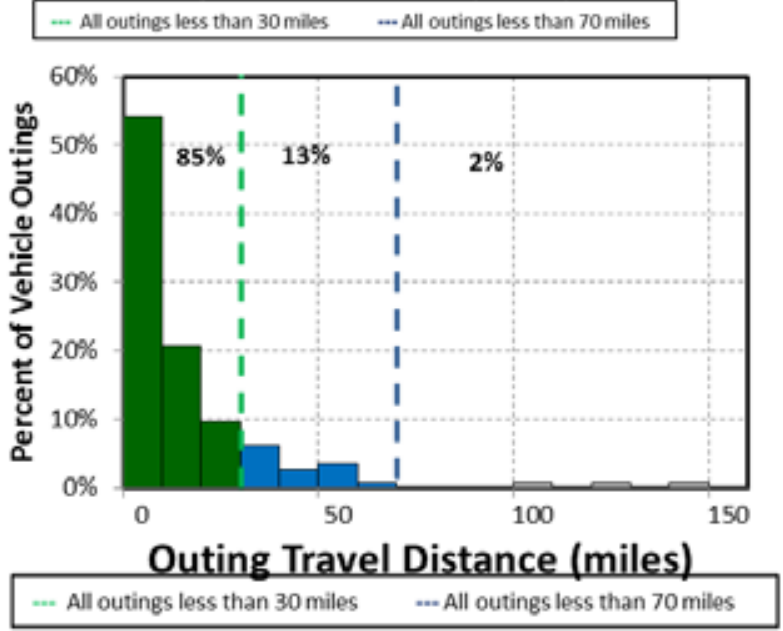

Figure C-57. Vehicle G41-3300K travel graphs.

\section{Vehicle G41-3300K Observations}

Logger 49 collected data on this vehicle for a period of 31 days of the 31-day study period. Validation occurred on $99.9 \%$ of the input data. Data indicate that this vehicle has an enforcement mission for the Provost Marshal's Office. This vehicle's data indicate it parked over night near Building 43 near Virginia Dare Drive as shown in the Google Earth figure to the right and later near McAvoy Street.

MCBCL reports that a recent vehicle odometer indicated 39,329 miles at the start of this study and an average annual mileage of 15,644 miles. The vehicle was used on $100 \%$ of the available days, with an average daily usage of 7.2 hours and a peak daily usage of 24 hours on the days it was used. The vehicle was used during all

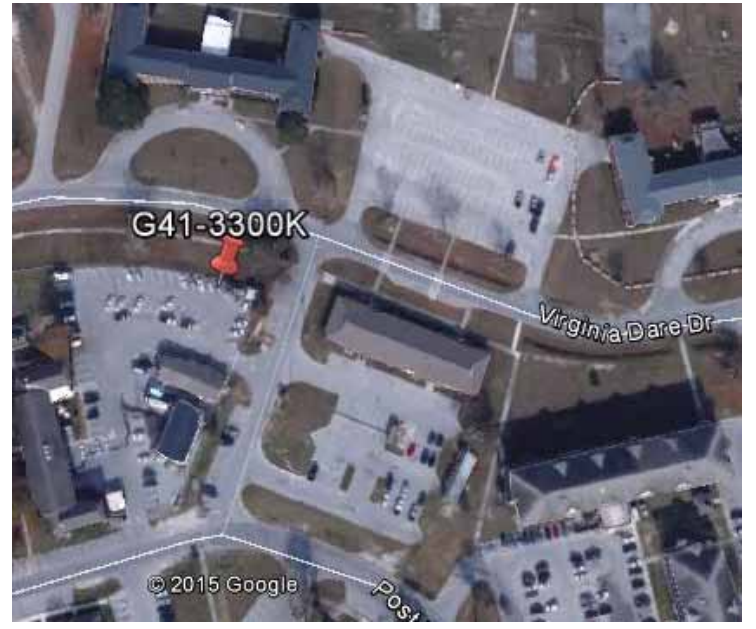
hours of the day.

Figure C- 57 shows that $55 \%$ of daily travel was within the typically advertised range of a BEV of approximately 70 miles and $98 \%$ of the outings were also within this range. Further, $26 \%$ of daily travel and $85 \%$ of outings were within the typically advertised CD mode of 30 miles for PHEVs.

A BEV could not meet all daily travel because of the frequent daily travel exceeding the BEV range and little time for recharging during the day. Fleet managers typically do not prefer enforcement vehicles that contain range limitations. Thus, a fleet of enforcement vehicles would likely contain a mix of BEVs and PHEVs, with preference for PHEVs. 


\begin{tabular}{|l|l|c|}
\hline & Make/Model/Year & Ford Ranger - 2011 \\
\cline { 2 - 3 } & EPA Class Size & Pickup \\
\cline { 2 - 3 } & Mission & Support \\
\hline Contact & Public Works \\
\cline { 2 - 3 } & Parking Location & Building 1005 \\
\hline Fleet Vehicle ID & G41-3301K \\
\cline { 2 - 3 } & Fuel Type & Gas \\
\cline { 2 - 3 } & EPA Label/MPG (City/Hwy/Combined) & $22 / 27 / 24$ \\
\cline { 2 - 3 } & EPA GHG Emissions (Grams $\left.\mathrm{CO}_{2} / \mathrm{Mi}\right)$ & 370 \\
\cline { 2 - 3 } & Study Logger ID & 61 \\
\cline { 2 - 3 } & Total Vehicle Days/Total Study Days & $15 / 31$ \\
\hline
\end{tabular}

\begin{tabular}{|l|c|c|c|c|}
\hline \multicolumn{5}{|c|}{ Vehicle G41-3301K Travel Summary } \\
\hline & $\begin{array}{c}\text { Per Day } \\
\text { Average/Peak }\end{array}$ & $\begin{array}{c}\text { Per Outing } \\
\text { Average/Peak }\end{array}$ & $\begin{array}{c}\text { Per Trip } \\
\text { Average/Peak }\end{array}$ & Total \\
\hline Travel Distance (Miles) & $32.9 / 58.2$ & $17.0 / 54.3$ & $6.7 / 32.2$ & 494 \\
\hline Travel Time (Minutes) & $77.3 / 126.0$ & $40.0 / 95.0$ & $15.7 / 61.0$ & 1,160 \\
\hline Idle Time (Minutes) & $4.3 / \mathrm{NA}$ & $2.2 / \mathrm{NA}$ & $0.9 / \mathrm{NA}$ & 64 \\
\hline
\end{tabular}

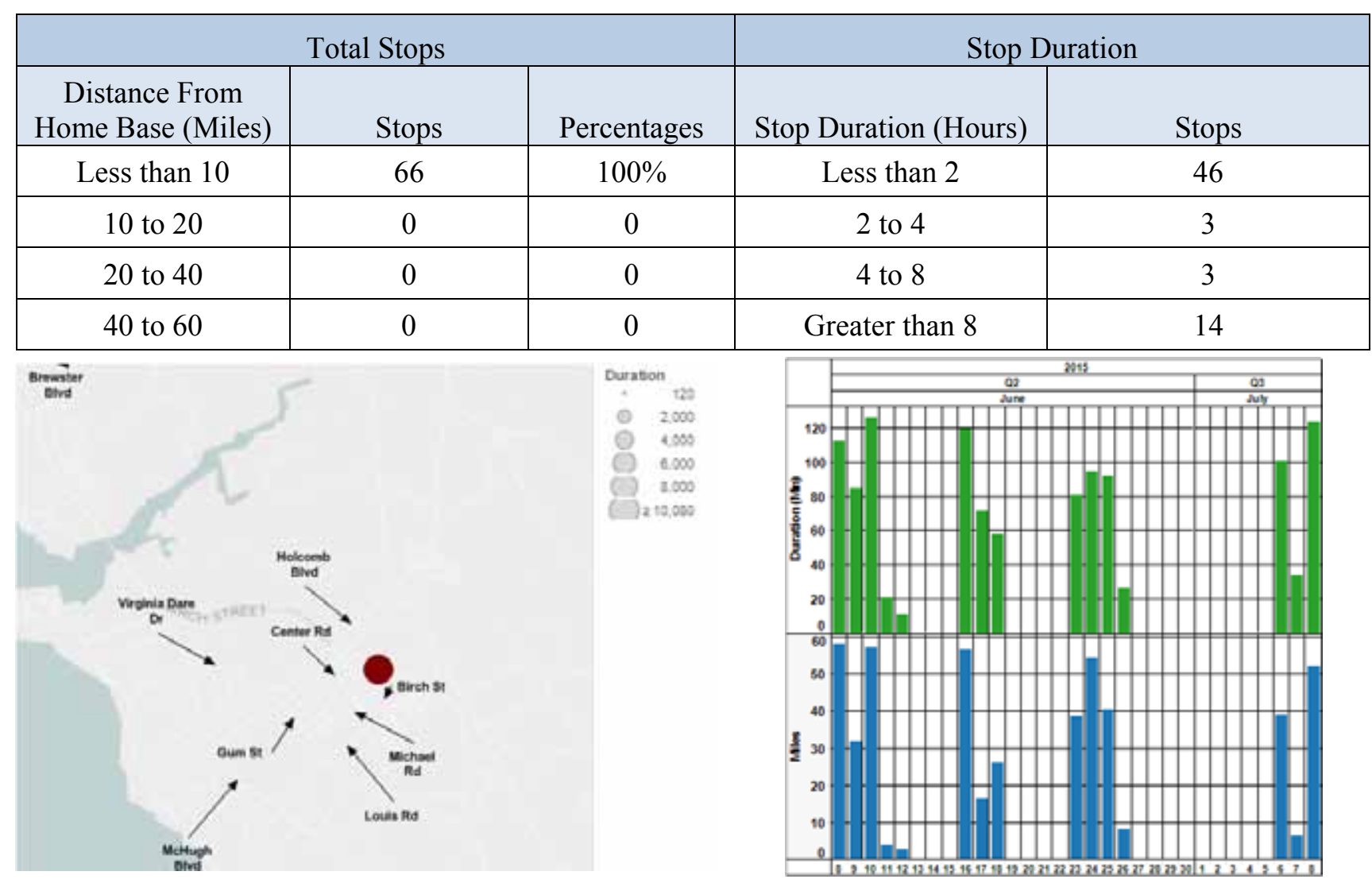

Figure C-58. Vehicle G41-3301K stops.

Figure C-59. Vehicle G41-3301K history. 

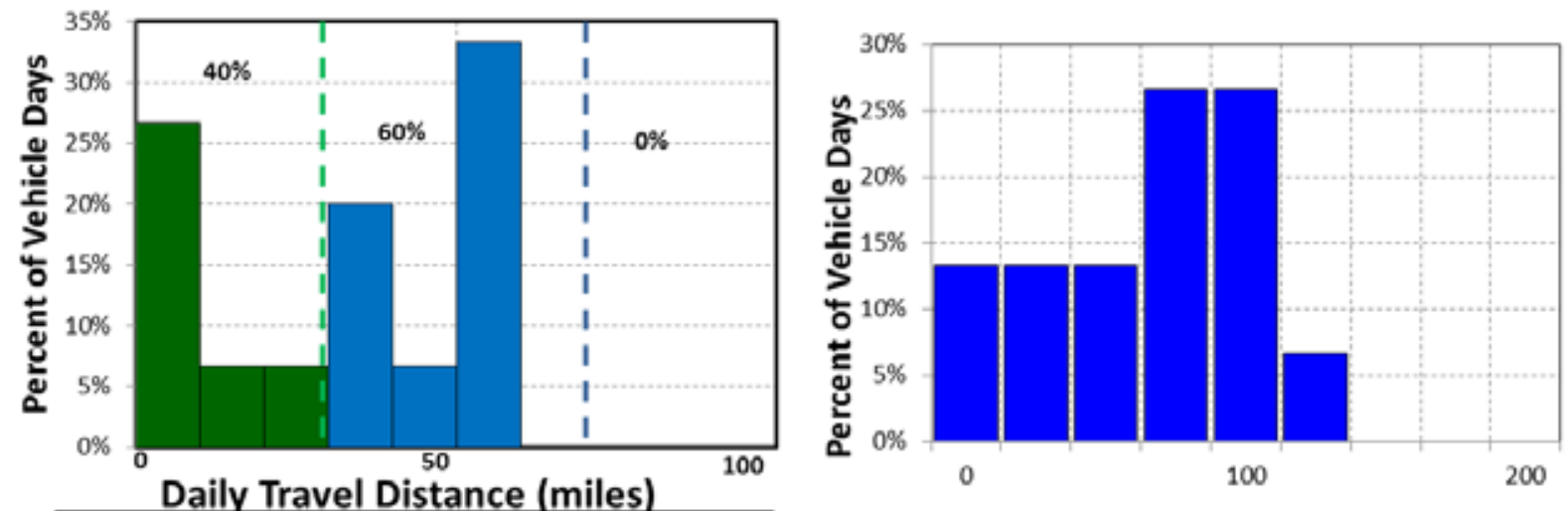

-.. All travel less than 30 miles _... All travel less than 70 miles

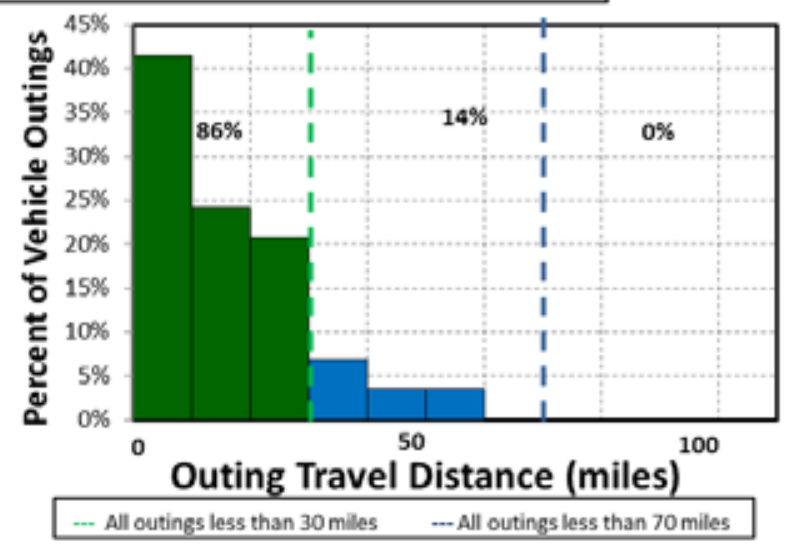

Daily Travel Time (Minutes)

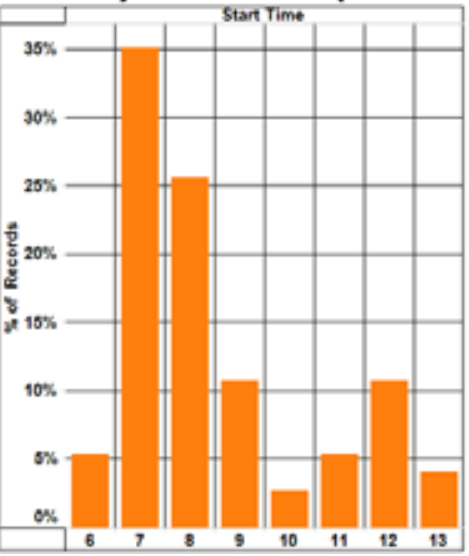

Figure C-60. Vehicle G41-3301K travel graphs.

\section{Vehicle G41-3301K Observations}

Logger 61 collected data on this vehicle for a period of 15 days of the 31-day study period.

Validation occurred on $100 \%$ of the input data. Data indicate that this vehicle has a support mission for Public Works. This vehicle's data indicate it parks near Building 1005 near Ash Street as shown in the Google Earth figure to the right.

MCBCL reports that a recent vehicle odometer indicated 21,645 miles at the start of this study and an average annual mileage of 7,306 miles. The vehicle was used on $48 \%$ of the available days, with an average daily usage of 1.3 hours and a peak daily usage of 2.1 hours on the days it was used. The vehicle

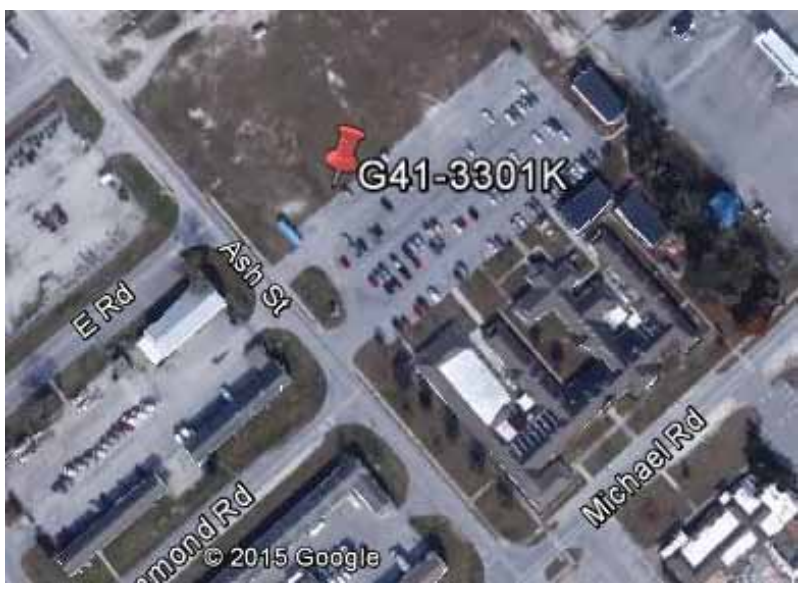
was used during day shift hours.

Figure C-60 shows that all of daily travel was within the typically advertised range of a BEV of approximately 70 miles. All outings were also within this range. Further, $40 \%$ of daily travel and $86 \%$ of outings were within the typically advertised CD mode of 30 miles for PHEVs.

A BEV could meet all daily travel without additional charging opportunities, assuming the vehicle was assigned a home base. However, fleet managers typically prefer vehicles that have no range limitations. Thus, a fleet of Public Works pickups would likely contain a mix of BEVs and PHEVs. 


\begin{tabular}{|l|l|c|}
\hline & Make/Model/Year & Ford E150 - 2012 \\
\cline { 2 - 3 } & EPA Class Size & Van - Passenger \\
\cline { 2 - 3 } & Mission & Pool \\
\hline & Contact & Building 58 \\
\cline { 2 - 3 } & Parking Location & G42-0644M \\
\cline { 2 - 3 } & Fleet Vehicle ID & E85 \\
\cline { 2 - 3 } & Fuel Type & $9 / 12 / 10$ \\
\cline { 2 - 3 } & EPA Label/MPG (City/Hwy/Combined) & 620 \\
\cline { 2 - 3 } & EPA GHG Emissions (Grams CO $/$ Mi) & 9 \\
\cline { 2 - 3 } & Study Logger ID & $10 / 31$ \\
\hline
\end{tabular}

\begin{tabular}{|l|c|c|c|c|}
\hline \multicolumn{5}{|c|}{ Vehicle G42-0644M Travel Summary } \\
\hline & $\begin{array}{c}\text { Per Day } \\
\text { Average/Peak }\end{array}$ & $\begin{array}{c}\text { Per Outing } \\
\text { Average/Peak }\end{array}$ & $\begin{array}{c}\text { Per Trip } \\
\text { Average/Peak }\end{array}$ & Total \\
\hline $\begin{array}{l}\text { Travel Distance } \\
\text { (Miles) }\end{array}$ & $19.2 / 57.3$ & $17.5 / 57.3$ & $4.6 / 22.2$ & 192 \\
\hline $\begin{array}{l}\text { Travel Time } \\
\text { (Minutes) }\end{array}$ & $64.2 / 147.0$ & $58.4 / 147.0$ & $15.3 / 64.0$ & 642 \\
\hline Idle Time (Minutes) & $12.8 / \mathrm{NA}$ & $11.6 / \mathrm{NA}$ & $3.0 / \mathrm{NA}$ & 128 \\
\hline
\end{tabular}

\begin{tabular}{|c|c|c|c|c|}
\hline \multicolumn{2}{|c|}{ Total Stops } & \multicolumn{3}{c|}{ Stop Duration } \\
\hline $\begin{array}{c}\text { Distance From } \\
\text { Home Base } \\
\text { (Miles) }\end{array}$ & Stops & Percentages & Stop Duration (Hours) & Stops \\
\hline Less than 10 & 39 & $100 \%$ & Less than 2 & 27 \\
\hline 10 to 20 & 0 & 0 & 2 to 4 & 2 \\
\hline 20 to 40 & 0 & 0 & 4 to 8 & 10 \\
\hline 40 to 60 & 0 & 0 & Greater than 8 & \\
\hline
\end{tabular}

Figure C-61. Vehicle G13-0325K stops.

Figure C-62. Vehicle G13-0325K history. 


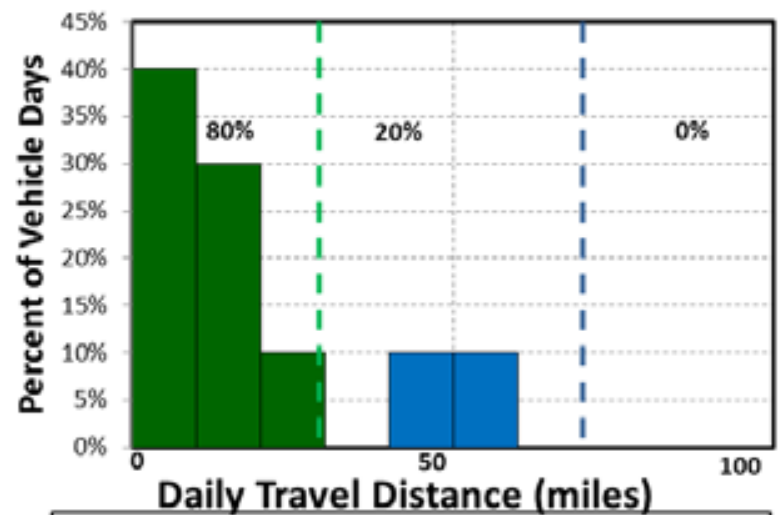

- All travel less than 30 miles _... All travel less than 70 miles

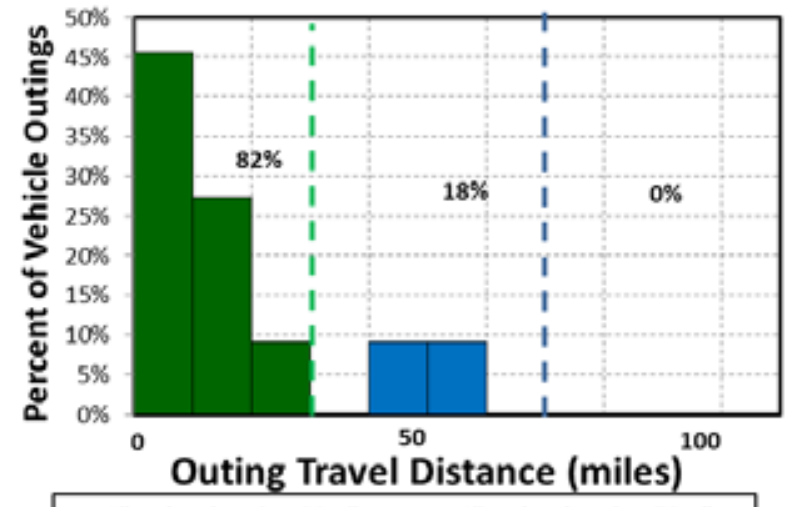

- All outings less than 30 miles _-All outings less than 70 miles

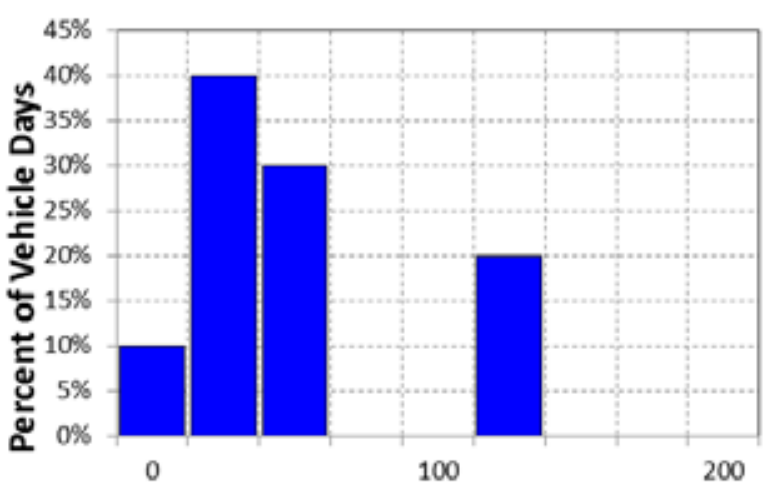

Daily Travel Time (Minutes)

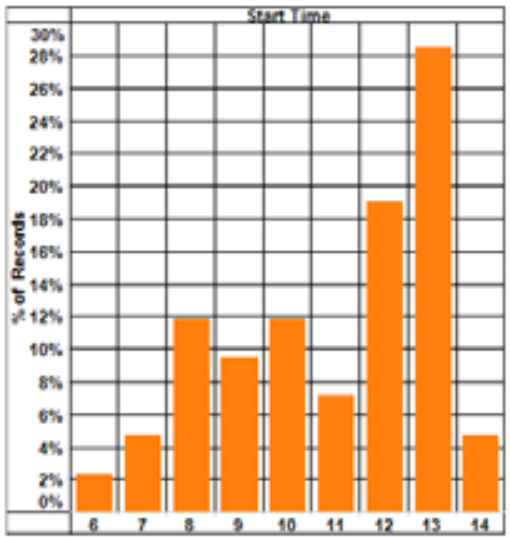

Figure C-63. Vehicle G42-0644M travel graphs.

\section{Vehicle G42-0644M Observations}

Logger 9 collected data on this vehicle for a period of 10 days of the 31-day study period. Validation occurred on $100 \%$ of the input data. Data indicate that this vehicle has a pool mission for the Motor Transport C-Pool. This vehicle's data indicate it parks near Building 58 near Virginia Dare Drive as shown in the Google Earth figure to the right.

MCBCL reports that a recent vehicle odometer indicated 42,887 miles at the start of this study and an average annual mileage of 22,209 miles. The vehicle was used on $32 \%$ of the available days, with an average daily usage of 1.1 hours and a peak daily usage of 2.5 hours on the days it was used. The vehicle was used during day shift hours.

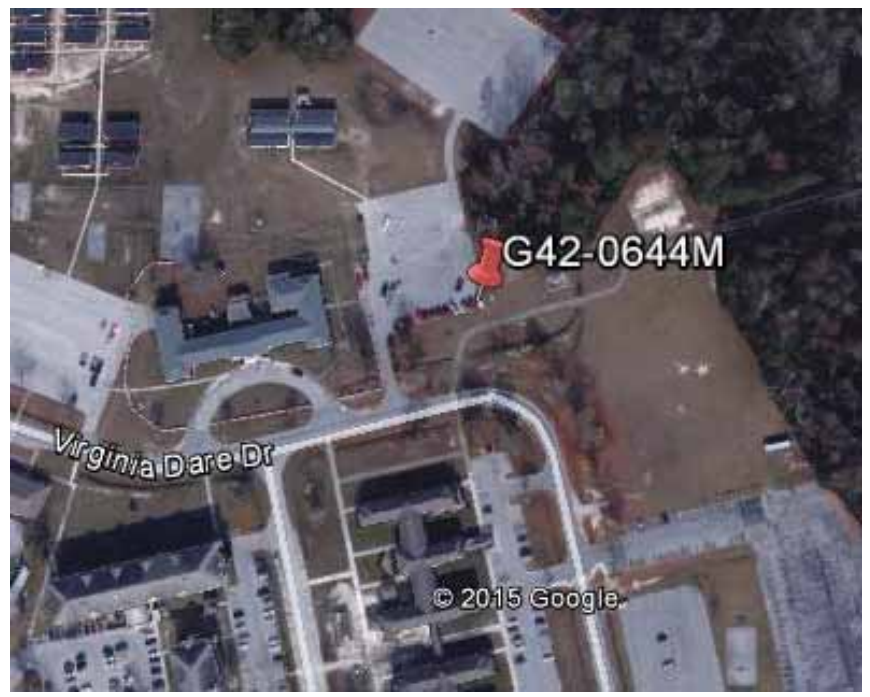

Figure C-63 shows that all daily travel was within the typically advertised range of a BEV of approximately 70 miles. All outings were also within this range. Further, $80 \%$ of daily travel and $82 \%$ of outings were within the typically advertised CD mode of 30 miles for PHEVs.

A BEV could meet all daily travel without additional charging opportunities, assuming the vehicle was assigned a home base. Thus, a fleet of passenger vans would likely contain a mix of BEVs and PHEVs. 
Sheet 41: Vehicle G42-0667P

\begin{tabular}{|l|l|c|}
\hline & Make/Model/Year & Ford F150- 2014 \\
\cline { 2 - 3 } & EPA Class Size & Support \\
\hline Mission & Public Works \\
\hline Contact & Building 1005 \\
\cline { 2 - 3 } & Parking Location & G42-0667P \\
\hline Fleet Vehicle ID & E85 \\
\cline { 2 - 3 } & Fuel Type & $12 / 17 / 14$ \\
\cline { 2 - 3 } & EPA Label/MPG (City/Hwy/Combined) & 442 \\
\cline { 2 - 3 } & EPA GHG Emissions (Grams CO $/ \mathrm{Mi})$ & 68 \\
\cline { 2 - 3 } & Study Logger ID & $17 / 31$ \\
\cline { 2 - 3 } & Total Vehicle Days/Total Study Days & \\
\hline
\end{tabular}

\begin{tabular}{|l|c|c|c|c|}
\hline \multicolumn{5}{|c|}{ Vehicle G42-0667P Travel Summary } \\
\hline & $\begin{array}{c}\text { Per Day } \\
\text { Average/Peak }\end{array}$ & $\begin{array}{c}\text { Per Outing } \\
\text { Average/Peak }\end{array}$ & $\begin{array}{c}\text { Per Trip } \\
\text { Average/Peak }\end{array}$ & Total \\
\hline Travel Distance (Miles) & $65.5 / 125.6$ & $33.8 / 75.0$ & $14.3 / 43.0$ & 1,114 \\
\hline Travel Time (Minutes) & $147.5 / 254.0$ & $76.0 / 166.0$ & $32.2 / 90.0$ & 2,508 \\
\hline Idle Time (Minutes) & $14.1 / \mathrm{NA}$ & $7.3 / \mathrm{NA}$ & $3.1 / \mathrm{NA}$ & 240 \\
\hline
\end{tabular}

\begin{tabular}{|c|c|c|c|c|c|}
\hline \multicolumn{2}{|c|}{ Total Stops } & \multicolumn{3}{c|}{ Stop Duration } \\
\hline $\begin{array}{c}\text { Distance From } \\
\text { Home Base (Miles) }\end{array}$ & Stops & Percentages & Stop Duration (Hours) & Stops \\
\hline Less than 10 & 77 & $100 \%$ & Less than 2 & 51 \\
\hline 10 to 20 & 0 & 0 & 2 to 4 & 10 \\
\hline 20 to 40 & 0 & 0 & & 4 to 8 & 16 \\
\hline 40 to 60 & 0 & 0 & Greater than 8 & \\
\hline
\end{tabular}

Figure C-64. Vehicle G42-0667P stops.

Figure C-65. Vehicle G42-0667P history. 

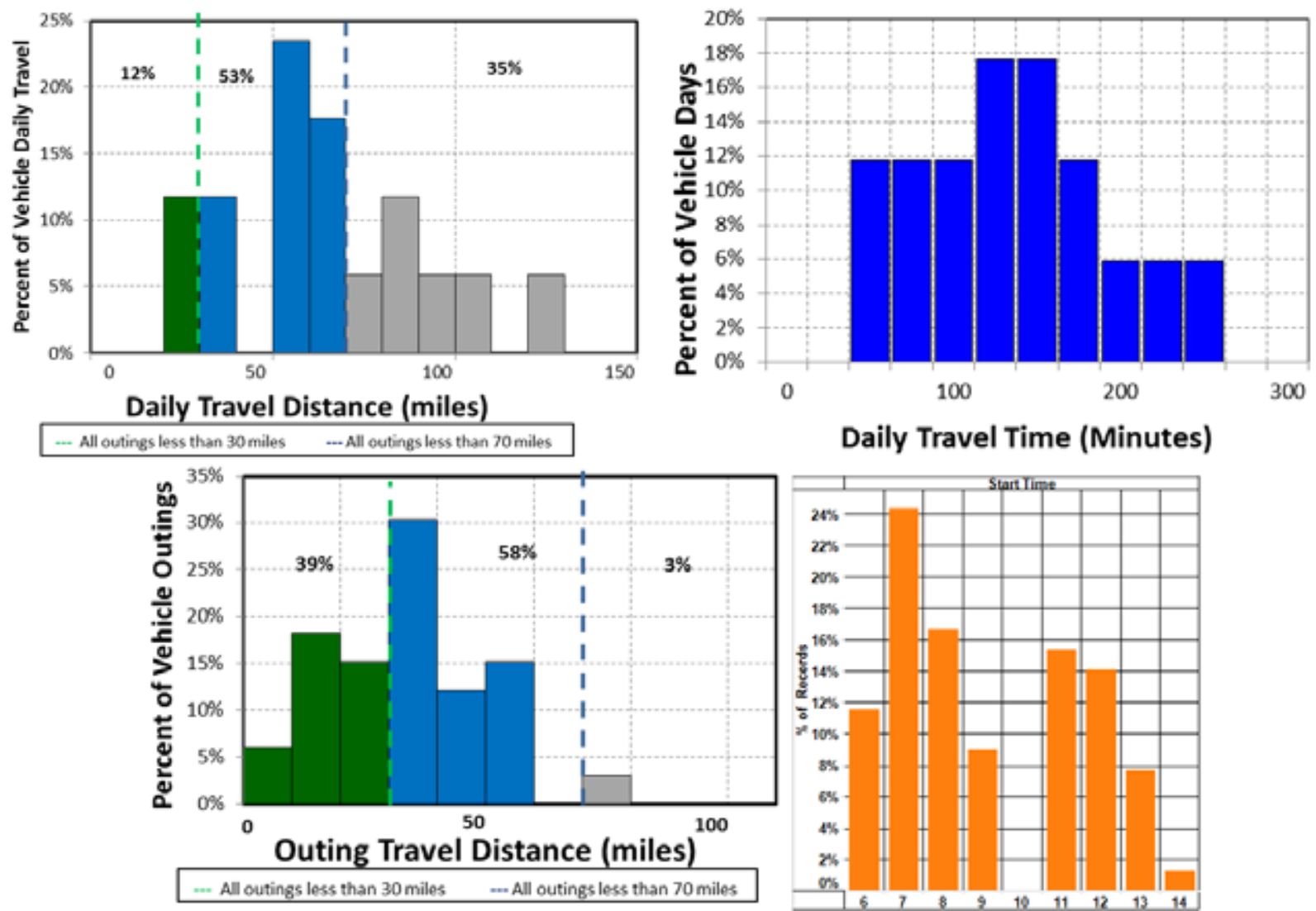

Figure C-66. Vehicle G42-0667P travel graphs.

\section{Vehicle G42-0667P Observations}

Logger 68 collected data on this vehicle for a period of 17 days of the 31-day study period. Validation occurred on $100 \%$ of the input data. Data indicate that this vehicle has a support mission for Public Works. This vehicle's data indicate it parks near Building 1005 near Ash Street as shown in the Google Earth figure to the right.

MCBCL reports that a recent vehicle odometer indicated 6,576 miles at the start of this study and an average annual mileage of 9,600 miles. The vehicle was used on $55 \%$ of the available days, with an average daily usage of 2.5 hours and a peak daily usage of 4.2 hours on the days it was used. The vehicle was used during day shift hours.

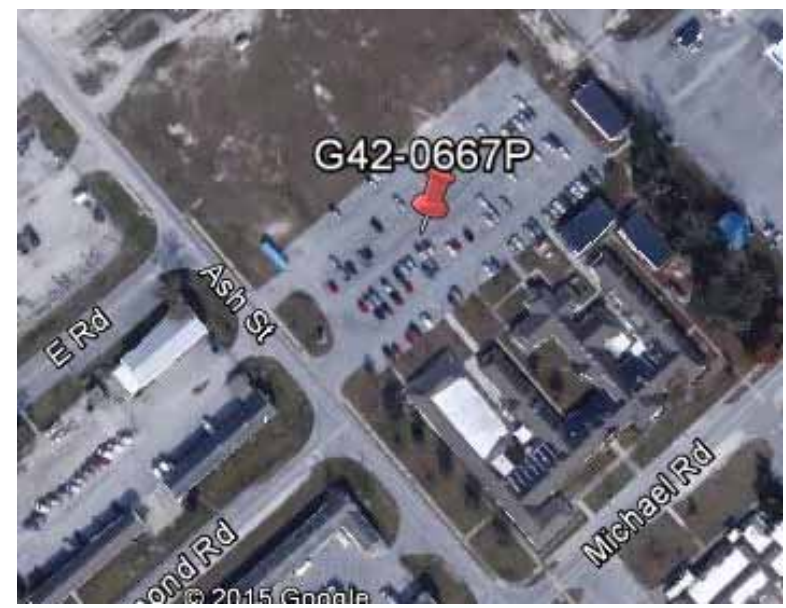

Figure C-66 shows that $65 \%$ of daily travel was within the typically advertised range of a BEV of approximately 70 miles and $97 \%$ of outings were also within this range. Further, $12 \%$ of daily travel and $39 \%$ of outings were within the typically advertised CD mode of 30 miles for PHEVs.

A BEV could not meet all daily travel because of the frequent travel beyond the BEV range. However, a significant percentage of travel was within the range of a BEV. Thus, a fleet of support vehicles would likely contain a mix of BEVs and PHEVs. 
Sheet 42: Vehicle G42-0671P

\begin{tabular}{|l|l|c|}
\hline & Make/Model/Year & Ford F150-2014 \\
\cline { 2 - 3 } & EPA Class Size & Pickup \\
\cline { 2 - 3 } & Mission & Support \\
\cline { 2 - 3 } & Contact & Public Works \\
\cline { 2 - 3 } & Parking Location & Building BA138 \\
\cline { 2 - 3 } & Fleet Vehicle ID & G42-0671P \\
\cline { 2 - 3 } & Fuel Type & E85 \\
\cline { 2 - 3 } & EPA Label/MPG (City/Hwy/Combined) & 12/17/14 \\
\cline { 2 - 3 } & EPA GHG Emissions (Grams CO $/$ Mi) & 642 \\
\cline { 2 - 3 } & Study Logger ID & $32 / 32$ \\
\hline
\end{tabular}

\begin{tabular}{|l|c|c|c|c|}
\hline \multicolumn{5}{|c|}{ Vehicle G42-0671P Travel Summary } \\
\hline & $\begin{array}{c}\text { Per Day } \\
\text { Average/Peak }\end{array}$ & $\begin{array}{c}\text { Per Outing } \\
\text { Average/Peak }\end{array}$ & $\begin{array}{c}\text { Per Trip } \\
\text { Average/Peak }\end{array}$ & Total \\
\hline Travel Distance (Miles) & $66.8 / 125.6$ & $17.8 / 75.0$ & $5.2 / 43.0$ & 2,138 \\
\hline Travel Time (Minutes) & $155.5 / 254.0$ & $41.5 / 166.0$ & $12.2 / 98.0$ & 4,975 \\
\hline Idle Time (Minutes) & $2.6 / \mathrm{NA}$ & $7.4 / \mathrm{NA}$ & $2.2 / \mathrm{NA}$ & 885 \\
\hline
\end{tabular}

\begin{tabular}{|c|c|c|c|c|}
\hline \multicolumn{2}{|c|}{ Total Stops } & \multicolumn{2}{c|}{ Stop Duration } \\
\hline $\begin{array}{c}\text { Distance From } \\
\text { Home Base (Miles) }\end{array}$ & Stops & Percentages & Stop Duration (Hours) & Stops \\
\hline Less than 10 & 370 & $94.9 \%$ & Less than 2 & 348 \\
\hline 10 to 20 & 20 & $5.1 \%$ & 2 to 4 & 0 \\
\hline 20 to 40 & 0 & 0 & & 4 to 8 \\
\hline 40 to 60 & 0 & 0 & \\
\hline
\end{tabular}

Figure C-67. Vehicle G42-0671P stops.

Figure C-68. Vehicle G42-0671P history. 


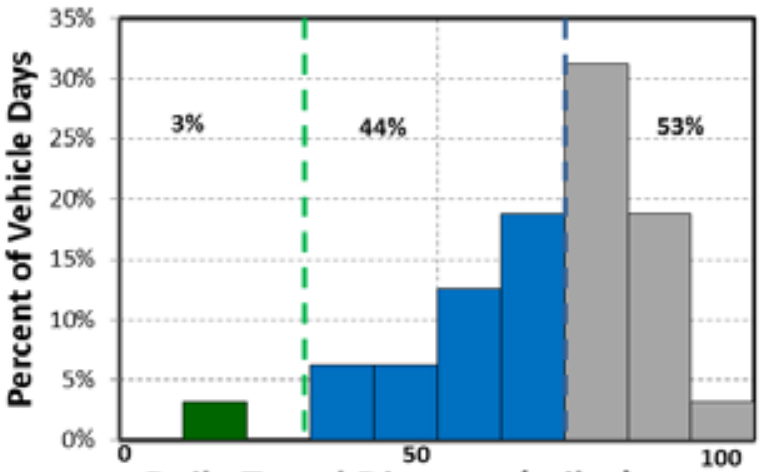

Daily Travel Distance (miles)

... All travel less than 30 miles .... All travel less than 70 miles

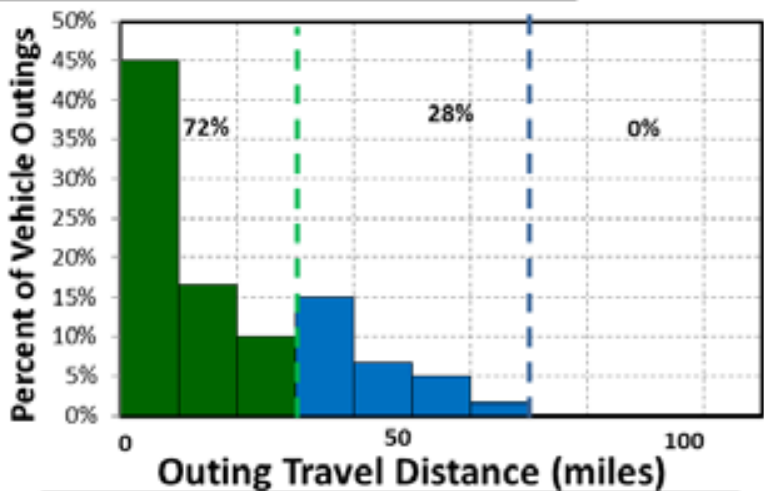

All outings less than 30 miles

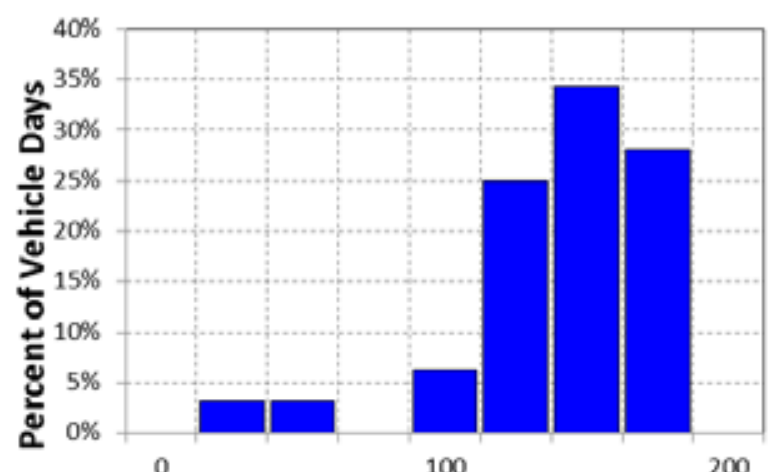

Daily Travel Time (Minutes)

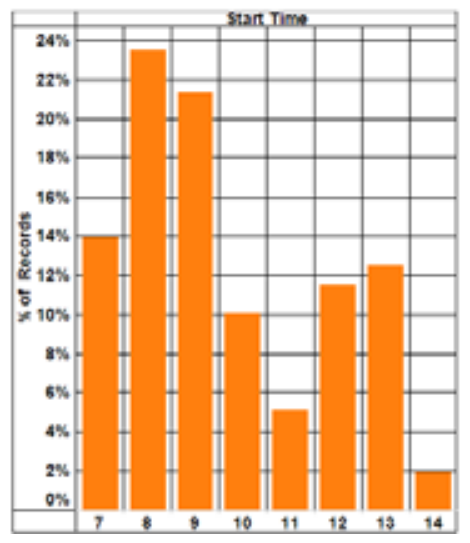

Figure C-69. Vehicle G42-0671P travel graphs.

\section{Vehicle G42-0671P Observations}

Logger 69 collected data on this vehicle for a period of 32 days of the 32-day study period. Validation occurred on $99.8 \%$ of the input data. Data indicate that this vehicle has a support mission for Public Works. This vehicle's data indicate it parks near Building BA138 near Access Road to Markup as shown in the Google Earth figure to the right.

MCBCL reports that a recent vehicle odometer indicated 7,688 miles at the start of this study and an average annual mileage of 7,678 miles. The vehicle was used on $100 \%$ of the available days, with an average daily usage of 2.6 hours and a peak daily usage of 4.2 hours on the days it was used. The vehicle was used during day shift hours.

Figure C-69 shows that $47 \%$ of daily travel was

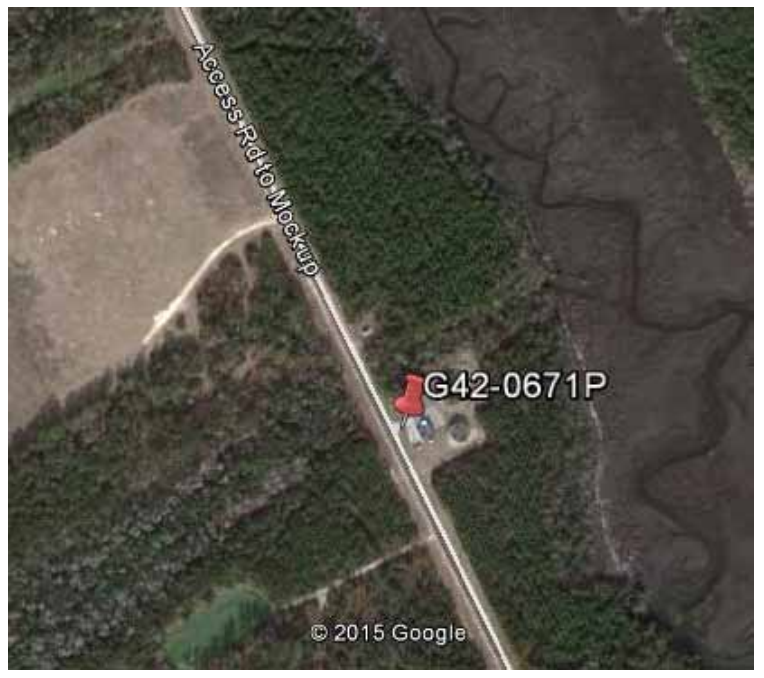
within the typically advertised range of a BEV of approximately 70 miles. All outings were also within this range. Further, $3 \%$ of daily travel and $72 \%$ of outings were within the typically advertised CD mode of 30 miles for PHEVs.

A BEV could not meet all daily travel without additional charging opportunities, assuming the vehicle was assigned a home base. However, there is sufficient time each day for recharging and all outings are within the BEV range. Thus, a fleet of Public Works pickup trucks would likely contain a mix of BEVs and PHEVs. 
Sheet 43: Vehicle G42-0911L

\begin{tabular}{|l|l|c|}
\hline & Make/Model/Year & Chevrolet C1500-2012 \\
\cline { 2 - 3 } & EPA Class Size & Pickup \\
\cline { 2 - 3 } & Mission & Pool \\
\cline { 2 - 3 } & Contact & Building 327 \\
\cline { 2 - 3 } & Parking Location & G42-0911L \\
\cline { 2 - 3 } & Fleet Vehicle ID & E85 \\
\hline & Fuel Type & $11 / 16 / 13$ \\
\cline { 2 - 3 } & EPA Label/MPG (City/Hwy/Combined) & 477 \\
\cline { 2 - 3 } & EPA GHG Emissions $\left(\right.$ Grams $\left.\mathrm{CO}_{2} / \mathrm{Mi}\right)$ & 10 \\
\cline { 2 - 3 } & Study Logger ID & $32 / 32$ \\
\cline { 2 - 3 } & Total Vehicle Days/Total Study Days & .Pool \\
\hline
\end{tabular}

\begin{tabular}{|l|c|c|c|c|}
\hline \multicolumn{5}{|c|}{ Vehicle G42-0911L Travel Summary } \\
\hline & $\begin{array}{c}\text { Per Day } \\
\text { Average/Peak }\end{array}$ & $\begin{array}{c}\text { Per Outing } \\
\text { Average/Peak }\end{array}$ & $\begin{array}{c}\text { Per Trip } \\
\text { Average/Peak }\end{array}$ & Total \\
\hline Travel Distance (Miles) & $51.4 / 114.6$ & $5.4 / 47.8$ & $3.9 / 46.1$ & 1,645 \\
\hline Travel Time (Minutes) & $363.4 / 1,140.0$ & $38.3 / 563.0$ & $27.9 / 504.0$ & 11,628 \\
\hline Idle Time (Minutes) & $185.1 / \mathrm{NA}$ & $19.5 / \mathrm{NA}$ & $14.3 / \mathrm{NA}$ & 5,924 \\
\hline
\end{tabular}

\begin{tabular}{|c|c|c|c|c|}
\hline \multicolumn{2}{|c|}{ Total Stops } & \multicolumn{2}{c|}{ Stop Duration } \\
\hline $\begin{array}{c}\text { Distance From } \\
\text { Home Base (Miles) }\end{array}$ & Stops & Percentages & Stop Duration (Hours) & Stops \\
\hline Less than 10 & 415 & $100 \%$ & Less than 2 & 315 \\
\hline 10 to 20 & 0 & 0 & 2 to 4 & 59 \\
\hline 20 to 40 & 0 & 0 & 4 to 8 & 34 \\
\hline 40 to 60 & 0 & 0 & \\
\hline
\end{tabular}

Figure C-70. Vehicle G42-0911L stops.

Figure C-71. Vehicle G42-0911L history. 


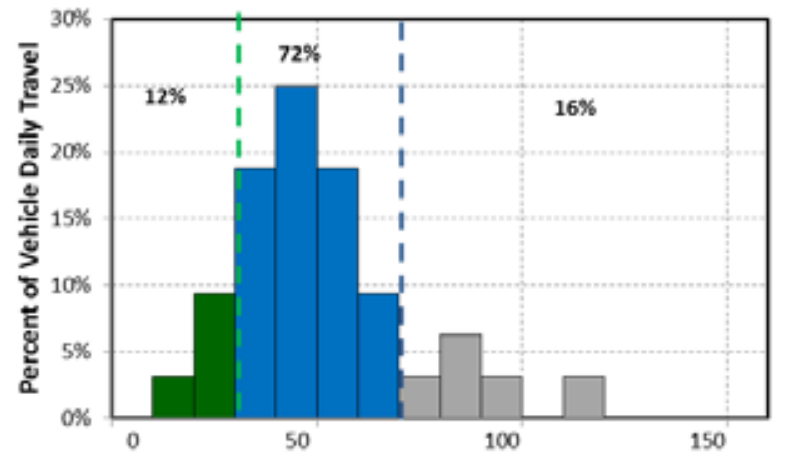

Daily Travel Distance (miles)

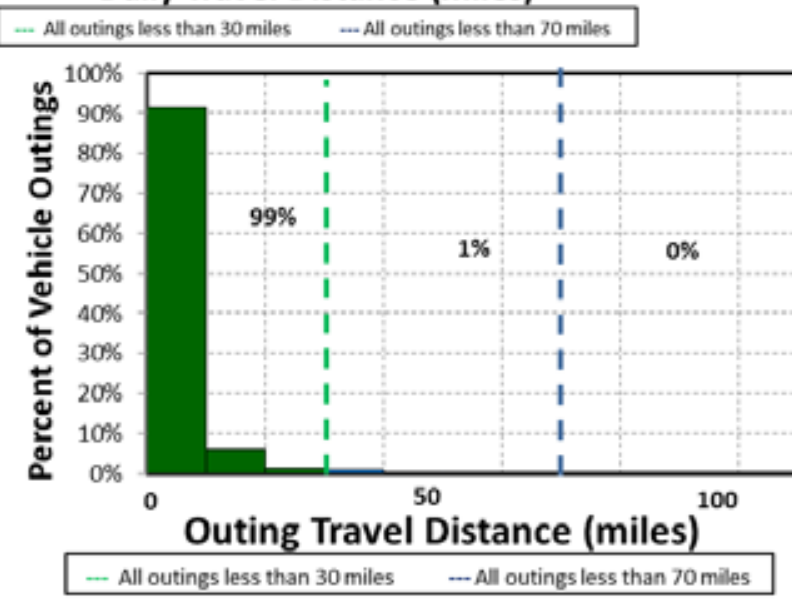

Figure C-72. Vehicle G42-0911L travel graphs. Daily travel time graph does not show maximum time of 1,140 minutes for clarity.

\section{Vehicle G42-0911L Observations}

Logger 10 collected data on this vehicle for a period of 32 days of the 32-day study period.

Validation occurred on $100 \%$ of the input data. Data indicate that this vehicle has a pool mission for the Motor Transport C-Pool. This vehicle's data indicate it parks near Building 327 near H Street as shown in the Google Earth figure to the right.

MCBCL reports that a recent vehicle odometer indicated 20,898 miles at the start of this study and average annual mileage of 7,978 miles. The vehicle was used on $100 \%$ of the available days, with an average daily usage of 6.1 hours and a peak daily usage of 19.0 hours on the days it was used. The vehicle was used during all hours of the day.

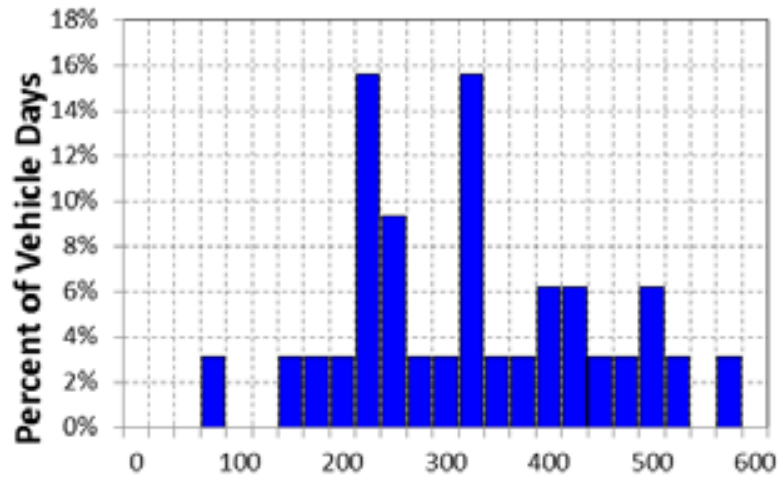

Daily Travel Time (Minutes)

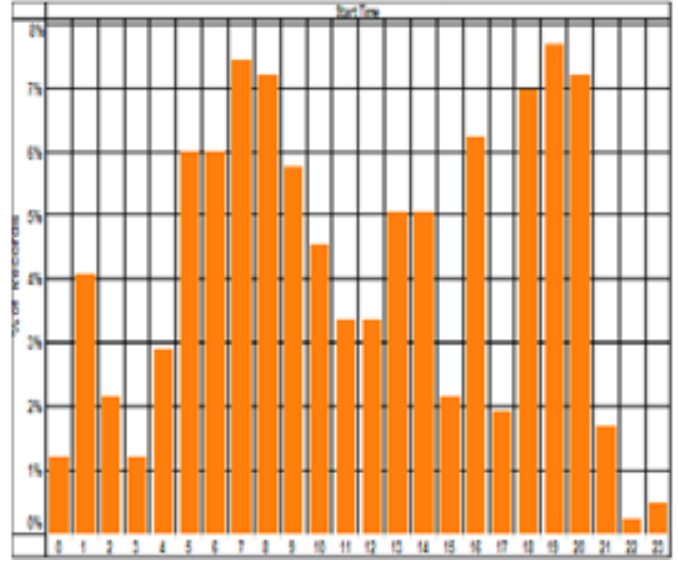

Figure C-72 shows that $84 \%$ of daily travel was within the typically advertised range of a BEV of approximately 70 miles. All outings were also within this range. Further, $12 \%$ of daily travel and $99 \%$ of outings were within the typically advertised CD mode of 30 miles for PHEVs.

A BEV could meet all daily travel with additional charging opportunities, assuming the vehicle was assigned a home base. However, the vehicle is highly utilized and charge time may not be available. While the pool fleet will likely contain a mix of BEVs and PHEVs, a PHEV is recommended for this vehicle. 


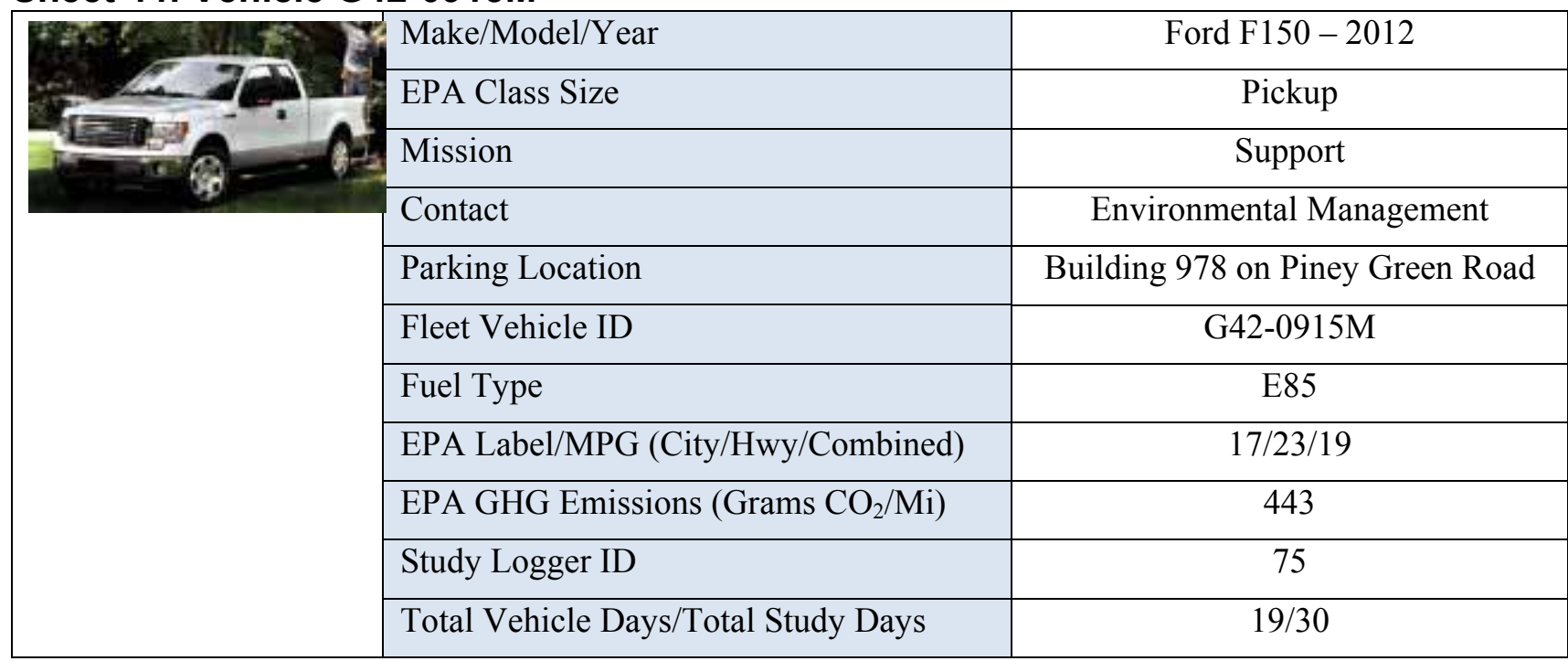

\begin{tabular}{|l|c|c|c|c|}
\hline \multicolumn{5}{|c|}{ Vehicle G42-0915M Travel Summary } \\
\hline & $\begin{array}{c}\text { Per Day } \\
\text { Average/Peak }\end{array}$ & $\begin{array}{c}\text { Per Outing } \\
\text { Average/Peak }\end{array}$ & $\begin{array}{c}\text { Per Trip } \\
\text { Average/Peak }\end{array}$ & Total \\
\hline Travel Distance (Miles) & $18.2 / 64.3$ & $10.8 / 61.3$ & $5.4 / 54.3$ & 347 \\
\hline Travel Time (Minutes) & $44.3 / 119.0$ & $26.3 / 112.0$ & $13.1 / 104.0$ & 841 \\
\hline Idle Time (Minutes) & $7.7 / \mathrm{NA}$ & $4.6 / \mathrm{NA}$ & $2.3 / \mathrm{NA}$ & 147 \\
\hline
\end{tabular}

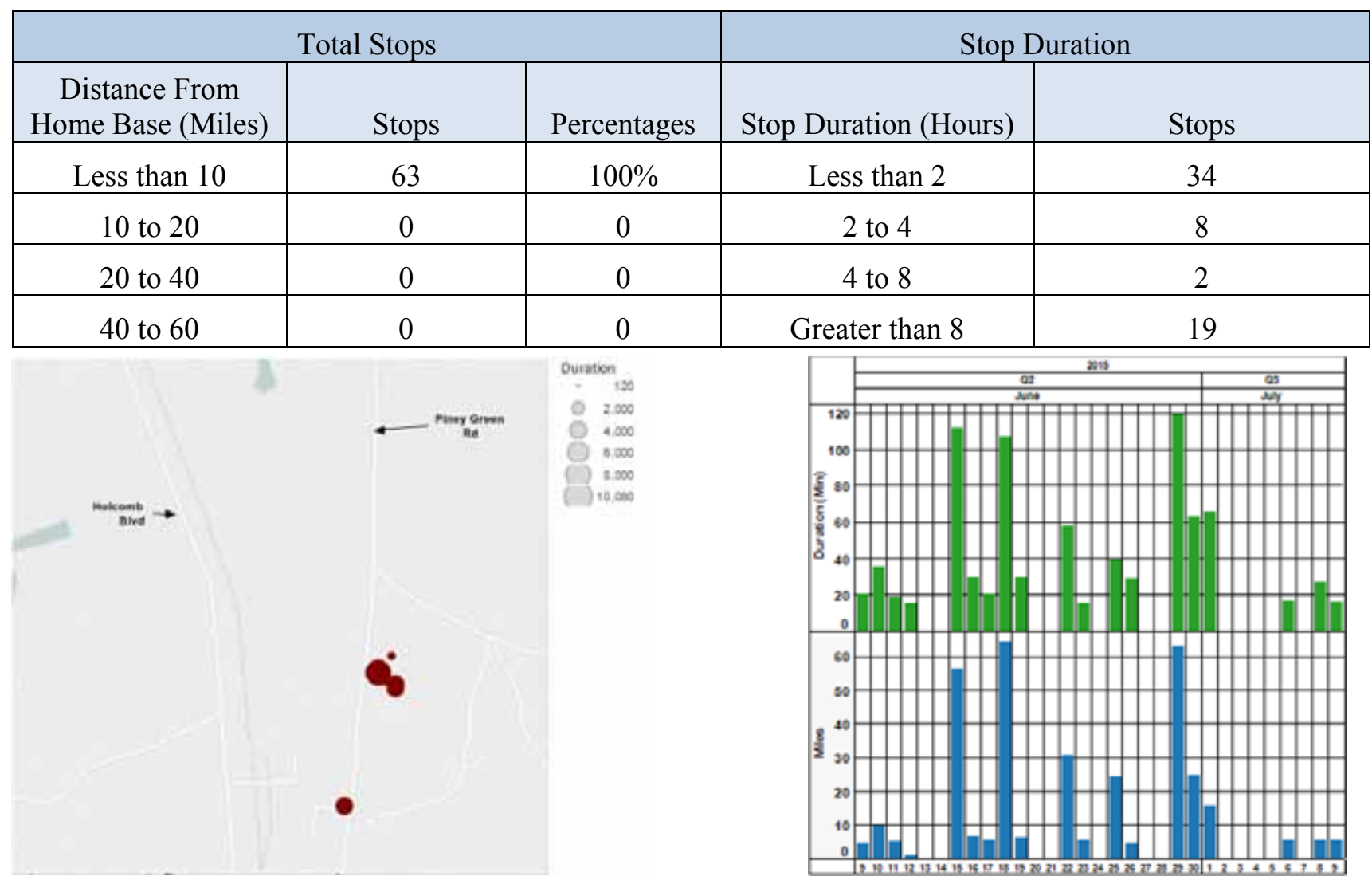

Figure C-73. Vehicle G42-0915M stops.

Figure C-74. Vehicle G42-0915M history. 


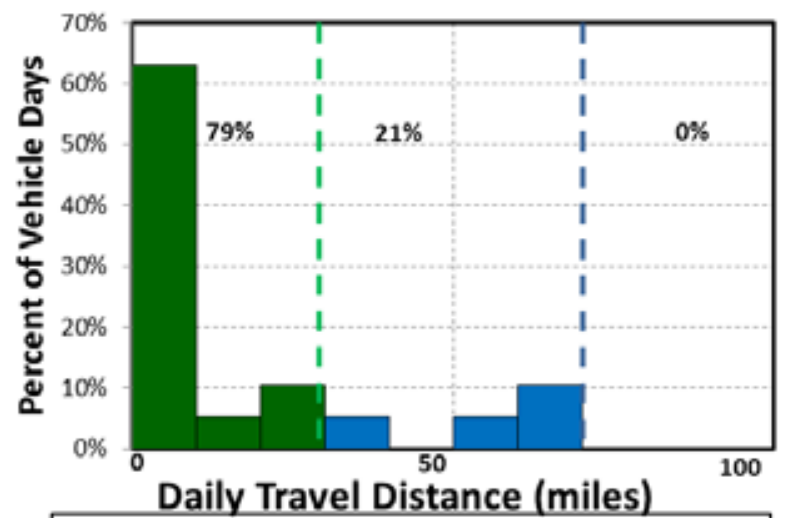

- All travel less than 30 miles _.-. All travel less than 70 miles

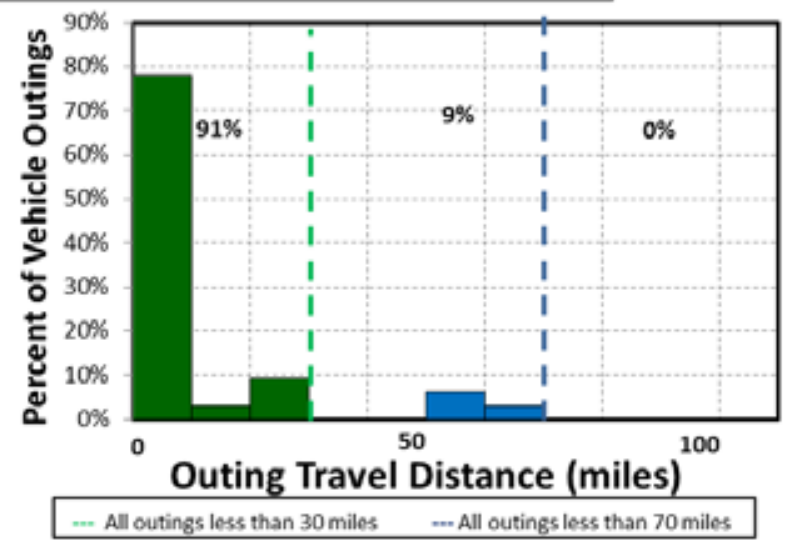

Figure C-75. Vehicle G42-0915M travel graphs.

\section{Vehicle G42-0915M Observations}

Logger 75 collected data on this vehicle for a period of 19 days of the 30-day study period. Validation occurred on $100 \%$ of the input data. Data indicate that this vehicle has a support mission for Environmental Management. This vehicle's data indicate it parks near Building 978 near Piney Green Road as shown in the Google Earth figure to the right.

MCBCL reports that a recent vehicle odometer indicated 16,287 miles at the start of this study and an average annual mileage of 7,072 miles. The vehicle was used on $63 \%$ of the available days with an average daily usage of 0.7 hours and a peak daily usage of 2.0 hours on the days it was used. The vehicle was used during day shift hours.

Figure $\mathrm{C}-75$ shows that all daily travel was within the typically advertised range of a BEV of approximately 70 miles. All outings were also within this range. Further, $79 \%$ of daily travel and $91 \%$ of outings were within the typically advertised CD mode of 30 miles for PHEVs.

A BEV could meet all daily travel without additional charging opportunities, assuming the vehicle was assigned a home base. Based on travel alone, a BEV could be a suitable replacement.

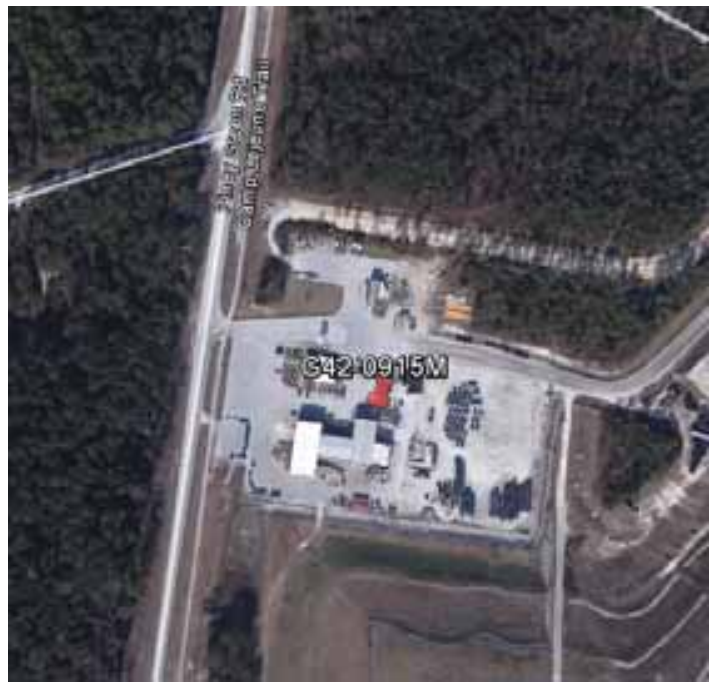

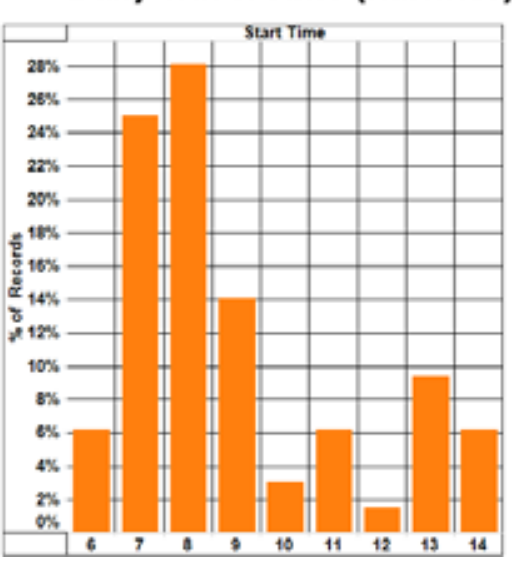

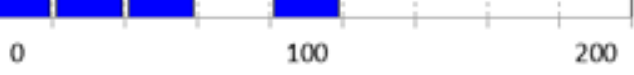

Daily Travel Time (Minutes) 
Sheet 45: Vehicle G42-2985H

\begin{tabular}{|c|c|c|}
\hline & Make/Model/Year & Chevrolet C1500 - 2010 \\
\hline-12 & EPA Class Size & Pickup \\
\hline 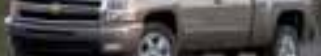 & Mission & Enforcement \\
\hline & Contact & Provost Marshal's Office \\
\hline & Parking Location & Building 43 \\
\hline & Fleet Vehicle ID & G42-2985H \\
\hline & Fuel Type & Gas \\
\hline & EPA Label/MPG (City/Hwy/Combined) & $15 / 21 / 17$ \\
\hline & EPA GHG Emissions (Grams $\left.\mathrm{CO}_{2} / \mathrm{Mi}\right)$ & 523 \\
\hline & Study Logger ID & 50 \\
\hline & Total Vehicle Days/Total Study Days & $30 / 30$ \\
\hline
\end{tabular}

\begin{tabular}{|l|c|c|c|c|}
\hline \multicolumn{5}{|c|}{ Vehicle G42-2985H Travel Summary } \\
\hline & $\begin{array}{c}\text { Per Day } \\
\text { Average/Peak }\end{array}$ & $\begin{array}{c}\text { Per Outing } \\
\text { Average/Peak }\end{array}$ & $\begin{array}{c}\text { Per Trip } \\
\text { Average/Peak }\end{array}$ & Total \\
\hline Travel Distance (Miles) & $61.2 / 179.1$ & $29.1 / 167.6$ & $7.5 / 79.5$ & 1,835 \\
\hline Travel Time (Minutes) & $406.1 / 1,338.0$ & $193.4 / 793.0$ & $49.5 / 716.0$ & 12,184 \\
\hline Idle Time (Minutes) & $304.3 / \mathrm{NA}$ & $144.9 / \mathrm{NA}$ & $37.1 / \mathrm{NA}$ & 9,128 \\
\hline
\end{tabular}

\begin{tabular}{|c|c|c|c|c|}
\hline \multicolumn{3}{|c|}{ Total Stops } & \multicolumn{2}{c|}{ Stop Duration } \\
\hline $\begin{array}{c}\text { Distance From } \\
\text { Home Base (Miles) }\end{array}$ & Stops & Percentages & Stop Duration (Hours) & Stops \\
\hline Less than 10 & 213 & $100 \%$ & Less than 2 & 166 \\
\hline 10 to 20 & 0 & 0 & 2 to 4 & 11 \\
\hline 20 to 40 & 0 & 0 & 4 to 8 & \\
\hline 40 to 60 & 0 & 0 & Greater than 8 & \\
\hline
\end{tabular}

Figure C-76. Vehicle G42-2985H stops.

Figure C-77. Vehicle G42-2985H history. 


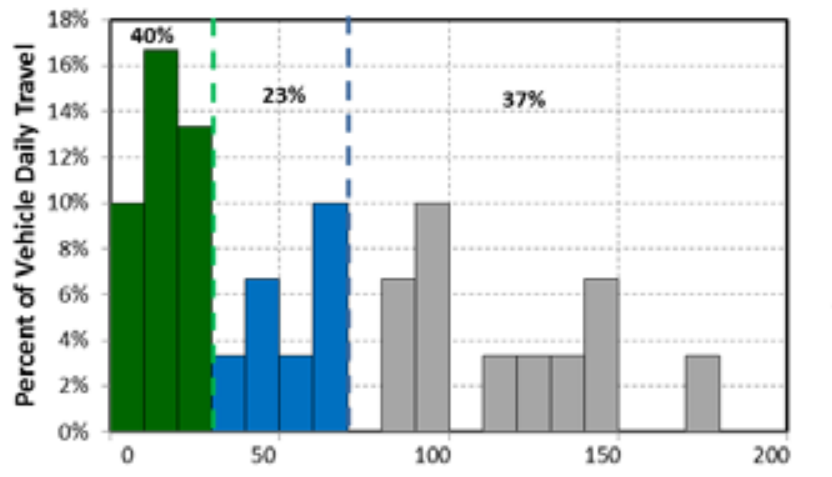

Daily Travel Distance (miles)

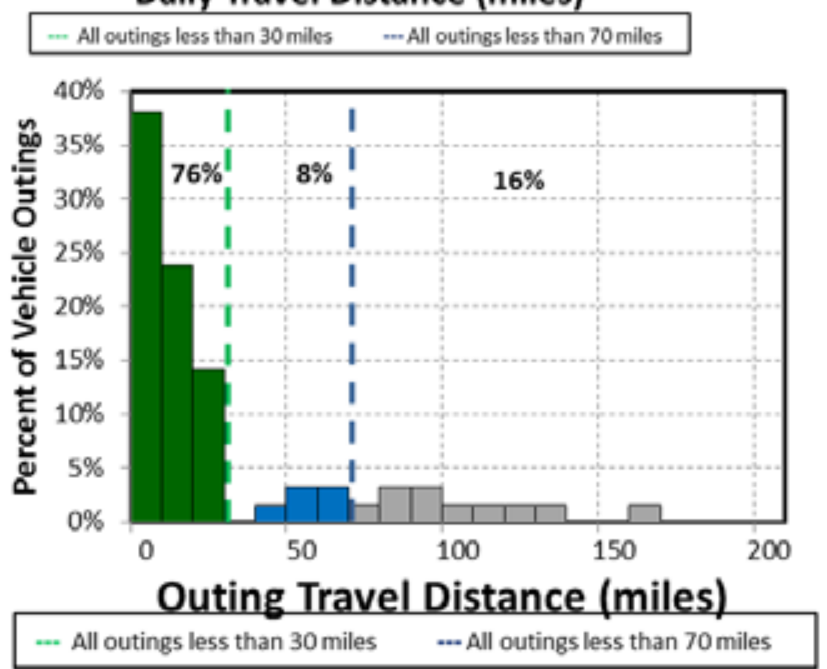

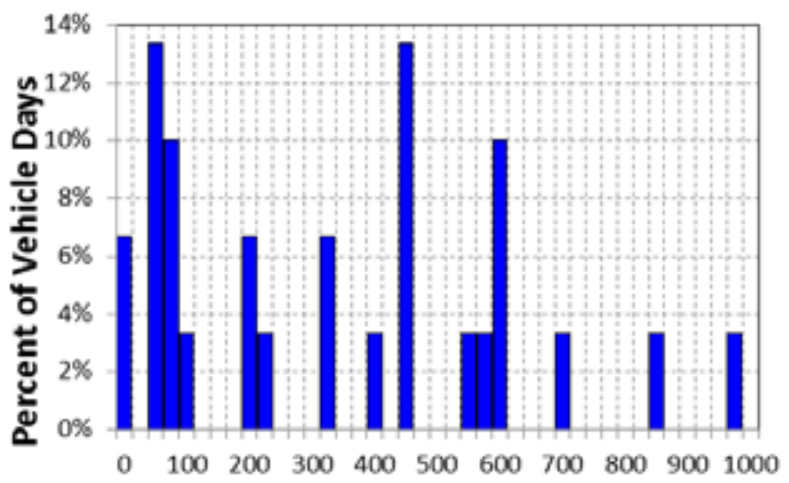

Daily Travel Time (Minutes)

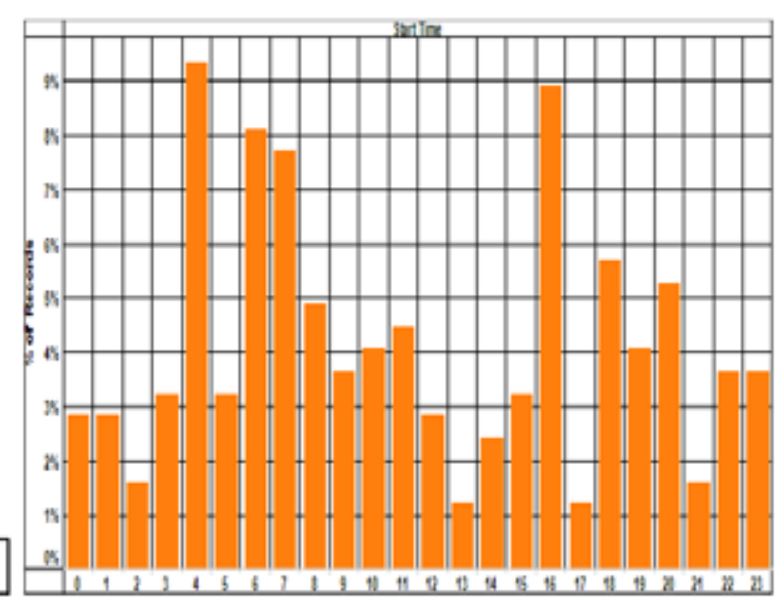

Figure C-78. Vehicle G42-2985H travel graphs. Note that the daily travel time graph does not show the maximums of 1,053 and 1,338 miles for clarity of scale.

\section{Vehicle G42-2985H Observations}

Logger 50 collected data on this vehicle for a period of 30 days of the 30-day study period. Validation occurred on $100 \%$ of the input data. Data indicate that this vehicle has a support mission for the Provost Marshal's Office. This vehicle's data indicate it parks frequently in several places but most frequently near Building 43 near Virginia Dare Drive as shown in the Google Earth figure to the right.

MCBCL reports that a recent vehicle odometer indicated 63,594 miles at the start of this study and an average annual mileage of 20,146 miles. The vehicle was used on $100 \%$ of the available days, with an average daily usage of 6.8 hours and a peak daily usage of 22.3 hours on the days it was used. The

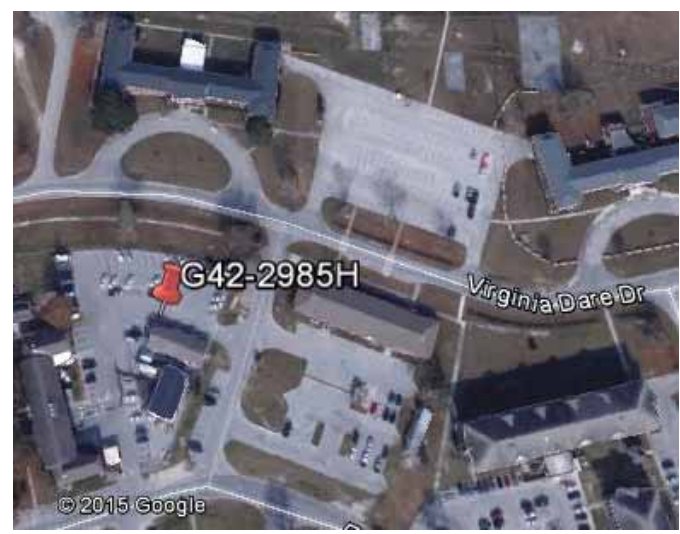
vehicle was used during all hours of the day.

Figure C-78 shows that $63 \%$ of daily travel was within the typically advertised range of a BEV of approximately 70 miles and $84 \%$ of outings were also within this range. Further, $40 \%$ of daily travel and $76 \%$ of outings were within the typically advertised CD mode of 30 miles for PHEVs.

A BEV could not meet all daily travel because of the high usage and lack of recharge time. In addition, fleet managers typically do not prefer enforcement vehicles that contain range limitations. Thus, a fleet of enforcement vehicles would likely contain a mix of BEVs and PHEVs. For this vehicle, a PHEV is suggested. 
Sheet 46: Vehicle G43-0310H

\begin{tabular}{|c|c|c|}
\hline 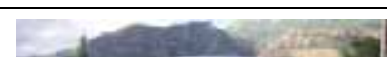 & Make/Model/Year & Ford E350 - 2009 \\
\hline & EPA Class Size & Van - Passenger \\
\hline & Mission & Pool \\
\hline & Contact & Motor Transport - C-Pool \\
\hline & Parking Location & Building 1407 near Michael Rd \\
\hline & Fleet Vehicle ID & G43-0310H \\
\hline & Fuel Type & E85 \\
\hline & EPA Label/MPG (City/Hwy/Combined)* & $10 / 13 / 11$ \\
\hline & EPA GHG Emissions $\left(\mathrm{Grams} \mathrm{CO}_{2} / \mathrm{Mi}\right)^{*}$ & 564 \\
\hline & Study Logger ID & 13 \\
\hline & Total Vehicle Days/Total Study Days & $13 / 31$ \\
\hline
\end{tabular}

\begin{tabular}{|l|c|c|c|c|}
\hline \multicolumn{5}{|c|}{ Vehicle G43-0310H Travel Summary } \\
\hline & $\begin{array}{c}\text { Per Day } \\
\text { Average/Peak }\end{array}$ & $\begin{array}{c}\text { Per Outing } \\
\text { Average/Peak }\end{array}$ & $\begin{array}{c}\text { Per Trip } \\
\text { Average/Peak }\end{array}$ & Total \\
\hline Travel Distance (Miles) & $46.4 / 136.4$ & $50.2 / 205.9$ & $7.5 / 47.1$ & 603 \\
\hline Travel Time (Minutes) & $171.9 / 577.0$ & $186.3 / 875.0$ & $27.9 / 213.0$ & 2,235 \\
\hline Idle Time (Minutes) & $75.5 / \mathrm{NA}$ & $81.8 / \mathrm{NA}$ & $12.3 / \mathrm{NA}$ & 982 \\
\hline
\end{tabular}

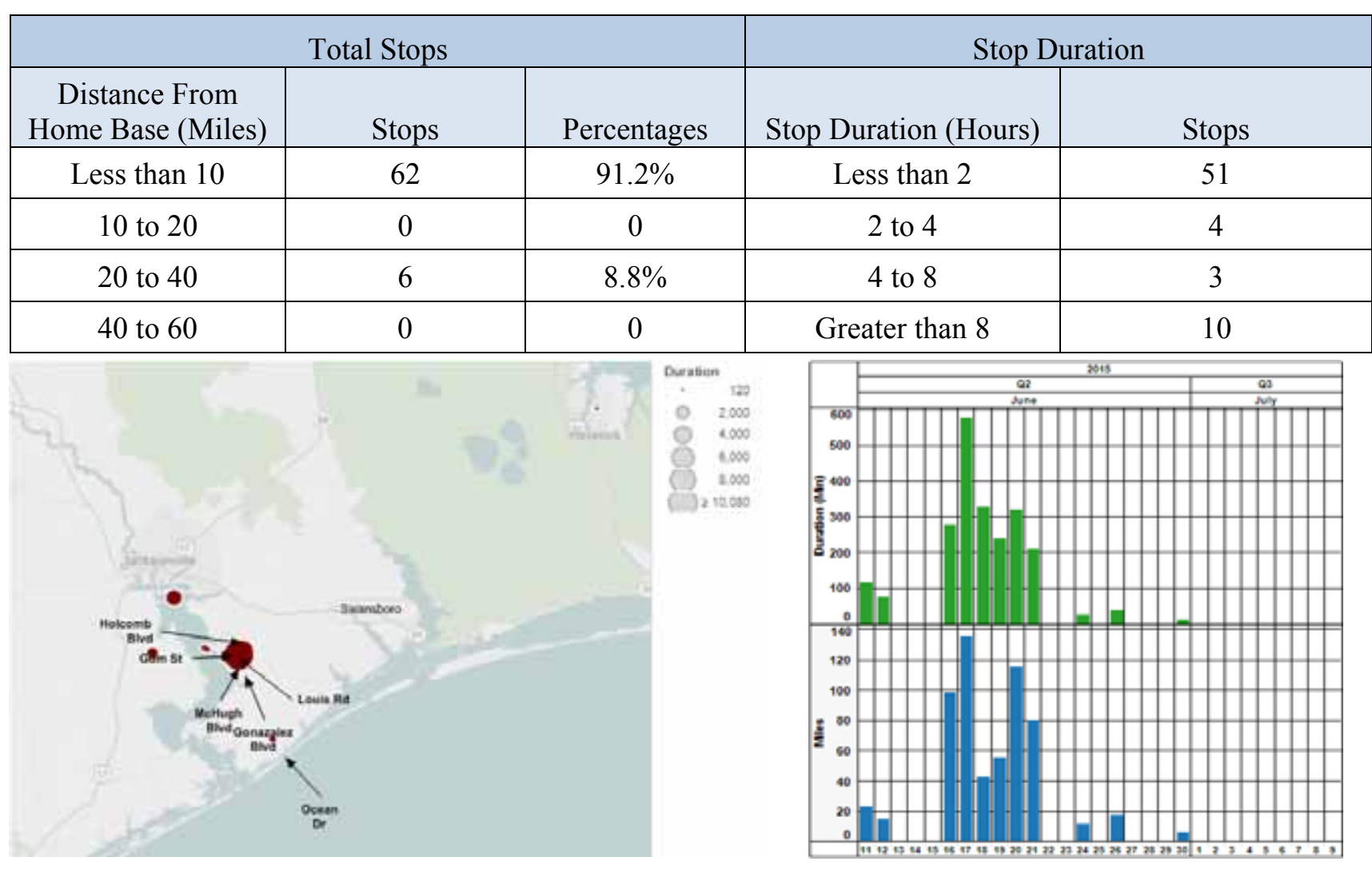

Figure C-79. Vehicle G43-0310H stops.

Figure C-80. Vehicle G43-0310H history.

*Fuel economy for E350 is unavailable. Economy for F150 is used. 


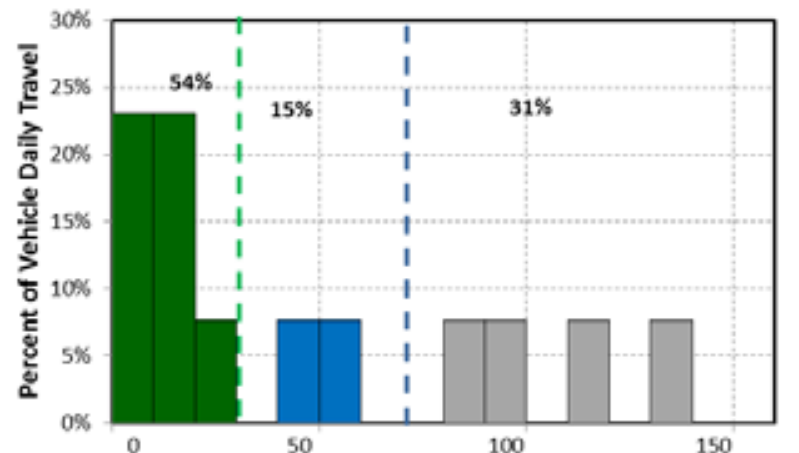

Daily Travel Distance (miles)

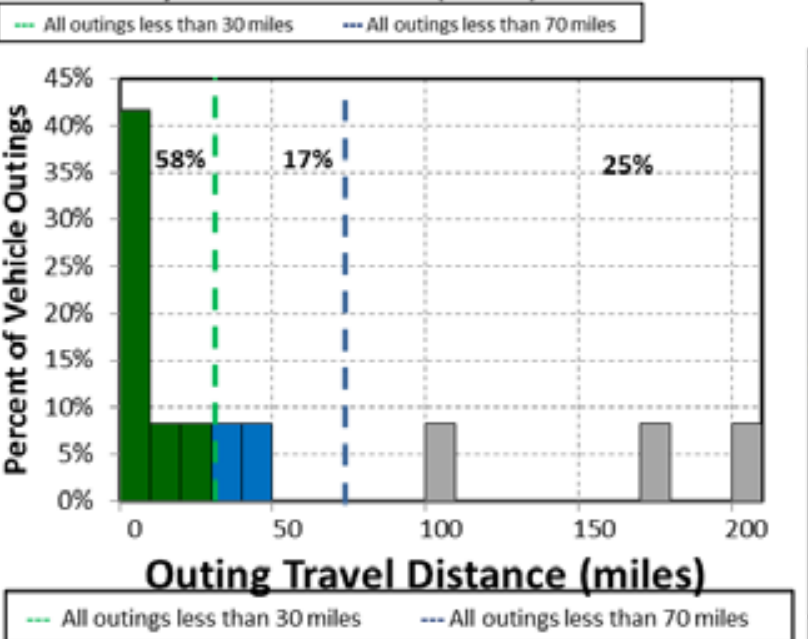

Figure C-81. Vehicle G43-0310H travel graphs.

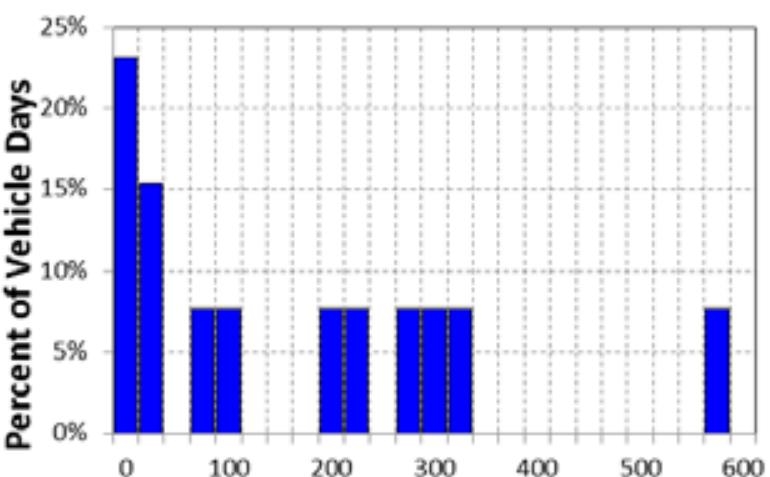

Daily Travel Time (Minutes)

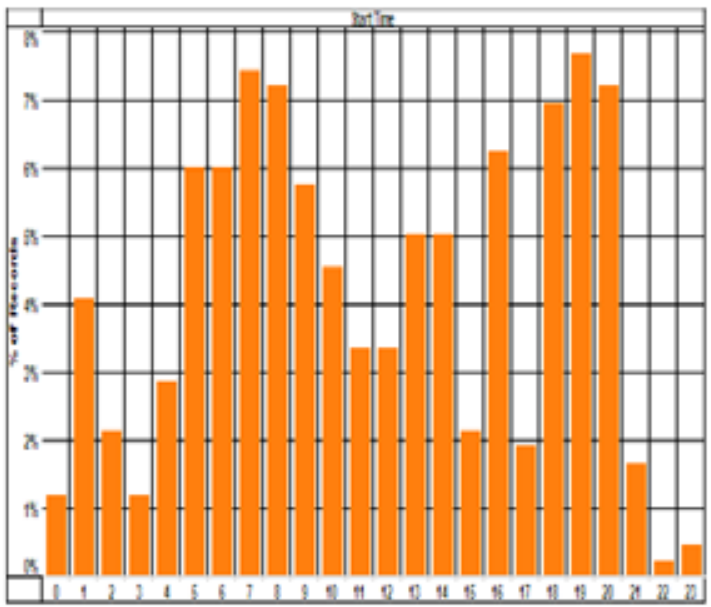

\section{Vehicle G43-0310H Observations}

Logger 13 collected data on this vehicle for a period of 13 days of the 31-day study period. Validation occurred on $100 \%$ of the input data. Data indicate that this vehicle has a pool mission for Motor Transport. This vehicle's data indicate it parked overnight in several different locations, but primarily near Building 1407 on Michael Road as shown in the Google Earth figure to the right.

MCBCL reports that a recent vehicle odometer indicated 55,280 miles at the start of this study and an average annual mileage of 7,232 miles. The vehicle was used on $42 \%$ of the available days, with an average daily usage of 2.9 hours and a peak daily usage of 9.6 hours on the days it was used. The

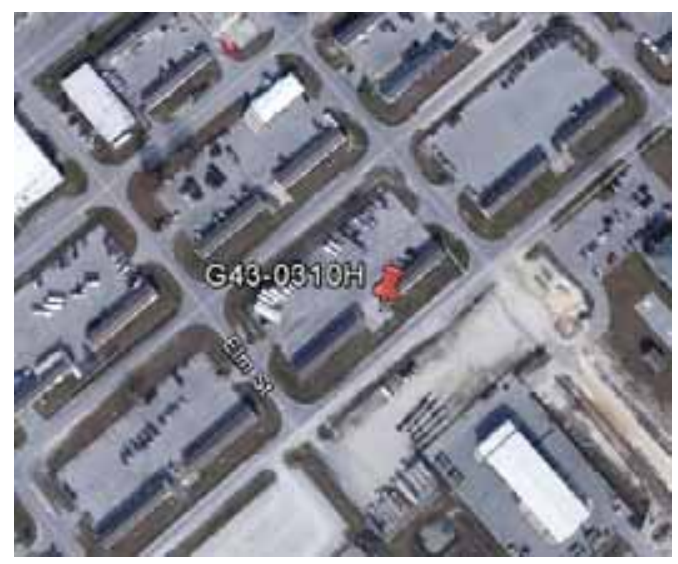
vehicle was used during all hours of the day.

Figure C- 81 shows that $69 \%$ of daily travel was within the typically advertised range of a BEV of approximately 70 miles and $75 \%$ of outings were also within this range. Further, $54 \%$ of daily travel and $58 \%$ of outings were within the typically advertised CD mode of 30 miles for PHEVs. The peak outing of 206 miles occurred over a several day period when the vehicle did not return to Michael Road, but parked in several other locations on base.

A BEV could not meet all daily travel because of significant outing distances. However, a fleet of passenger vans would likely contain a mix of BEVs and PHEVs. 
Sheet 47: Vehicle G43-0323H

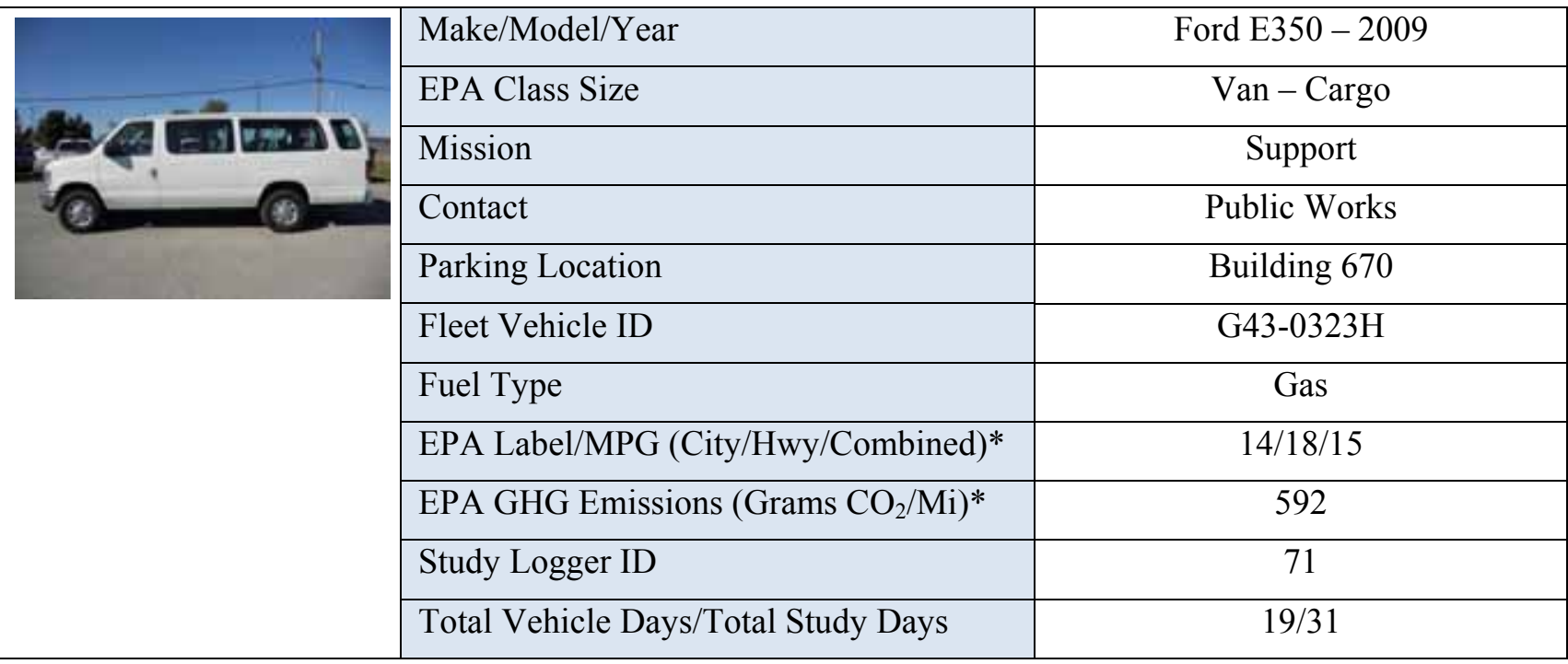

\begin{tabular}{|l|c|c|c|c|}
\hline \multicolumn{5}{|c|}{ Vehicle G43-0323H Travel Summary } \\
\hline & $\begin{array}{c}\text { Per Day } \\
\text { Average/Peak }\end{array}$ & $\begin{array}{c}\text { Per Outing } \\
\text { Average/Peak }\end{array}$ & $\begin{array}{c}\text { Per Trip } \\
\text { Average/Peak }\end{array}$ & Total \\
\hline Travel Distance (Miles) & $61.0 / 116.9$ & $28.3 / 116.9$ & $11.7 / 76.8$ & 1,160 \\
\hline Travel Time (Minutes) & $226.9 / 456.0$ & $105.1 / 456.0$ & $43.5 / 362.0$ & 4,311 \\
\hline Idle Time (Minutes) & $97.1 / \mathrm{NA}$ & $45.0 / \mathrm{NA}$ & $18.6 / \mathrm{NA}$ & 1,845 \\
\hline
\end{tabular}

\begin{tabular}{|c|c|c|c|c|}
\hline \multicolumn{2}{|c|}{ Total Stops } & \multicolumn{3}{c|}{ Stop Duration } \\
\hline $\begin{array}{c}\text { Distance From } \\
\text { Home Base (Miles) }\end{array}$ & Stops & Percentages & Stop Duration (Hours) & Stops \\
\hline Less than 10 & 82 & $93.2 \%$ & Less than 2 & 66 \\
\hline 10 to 20 & 6 & $6.8 \%$ & 2 to 4 & 5 \\
\hline 20 to 40 & 0 & 0 & & 4 to 8 \\
\hline 40 to 60 & 0 & 0 & Greater than 8 & \\
\hline
\end{tabular}

Figure C-82. Vehicle G43-0323H stops.

Figure C-83. Vehicle G43-0323H history.

*Fuel economy for E350 is not available. Economy used is for F-150. 

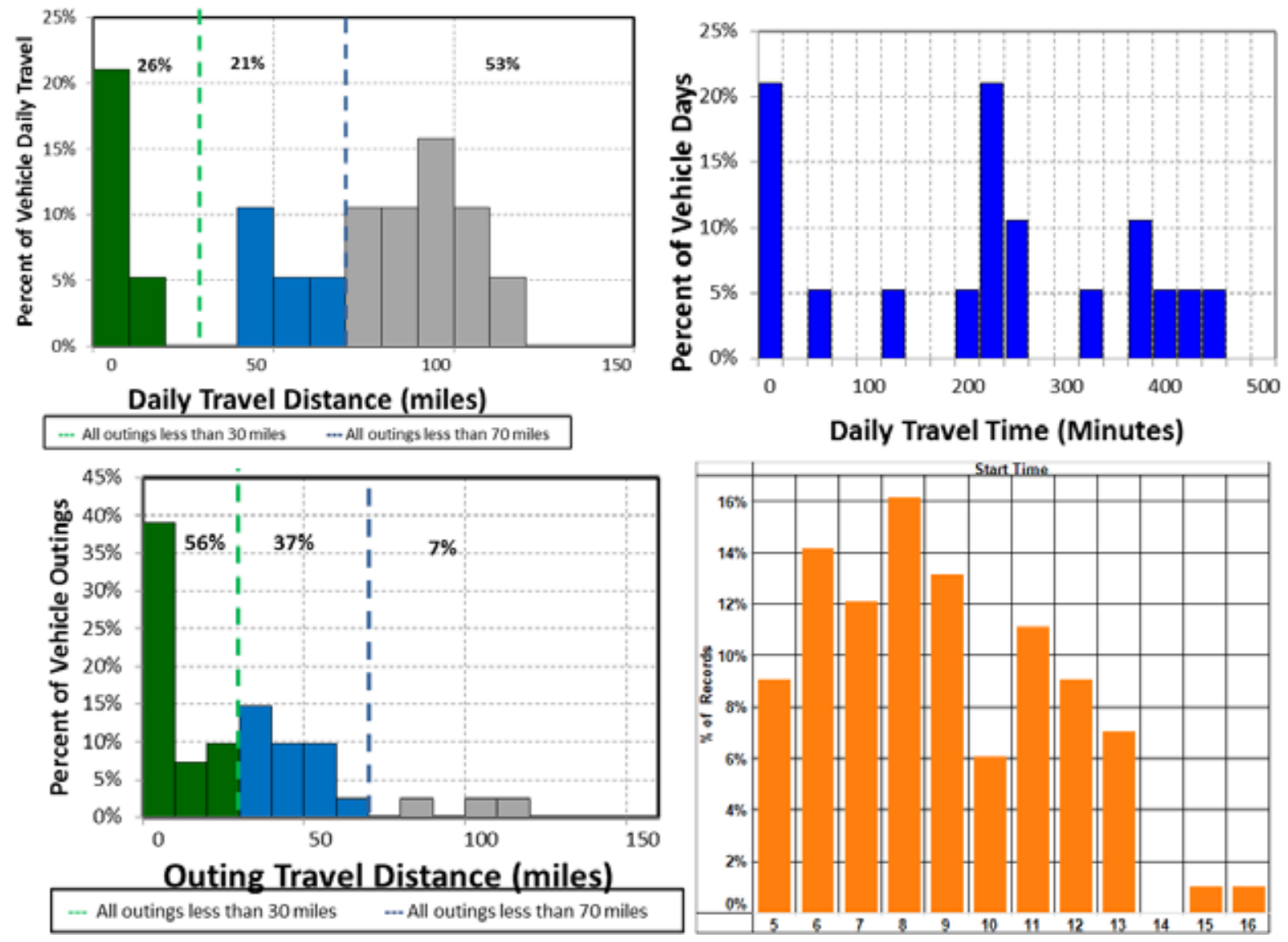

Figure C-84. Vehicle G43-0323H travel graphs.

\section{Vehicle G43-0323H Observations}

Logger 71 collected data on this vehicle for a period of 19 days of the 31-day study period. Validation occurred on $98.7 \%$ of the input data. Data indicate that this vehicle has a support mission for Public Works. This vehicle's data indicate it parks near Building 670 near Holcomb and Brewster Boulevard as shown in the Google Earth figure to the right.

MCBCL reports that a recent vehicle odometer indicated 67,585 miles at the start of this study and an average annual mileage of 12,155 miles. The vehicle was used on $61 \%$ of the available days, with an average daily usage of 3.8 hours and a peak daily usage of 7.6 hours on the days it was used. The vehicle was used during day shift hours.

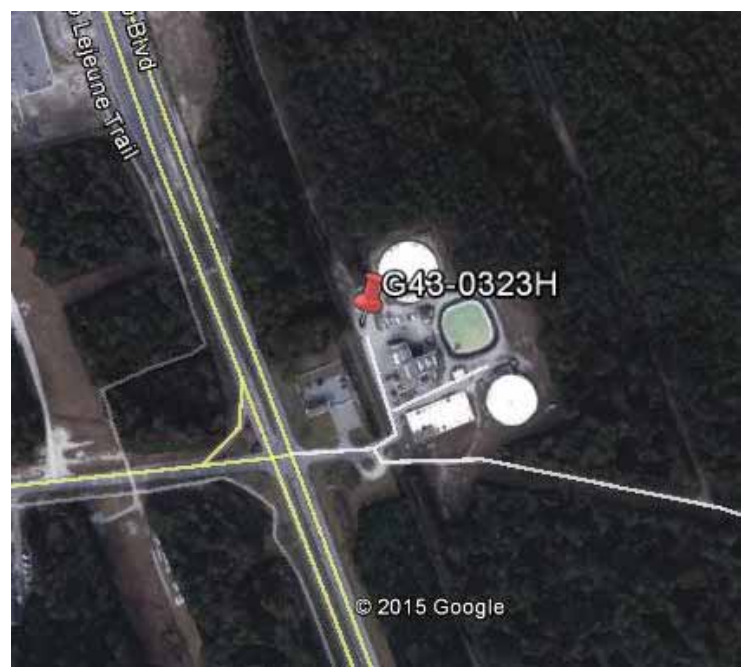

Figure C-84 shows that $47 \%$ of daily travel was within the typically advertised range of a BEV of approximately 70 miles and $93 \%$ of outings were also within this range. Further, $26 \%$ of daily travel and $56 \%$ of outings were within the typically advertised CD mode of 30 miles for PHEVs.

A BEV could not meet all daily travel without additional charging opportunities and sufficient recharge time may not be available. A fleet of cargo vans would likely contain a mix of BEVs and PHEVs. 


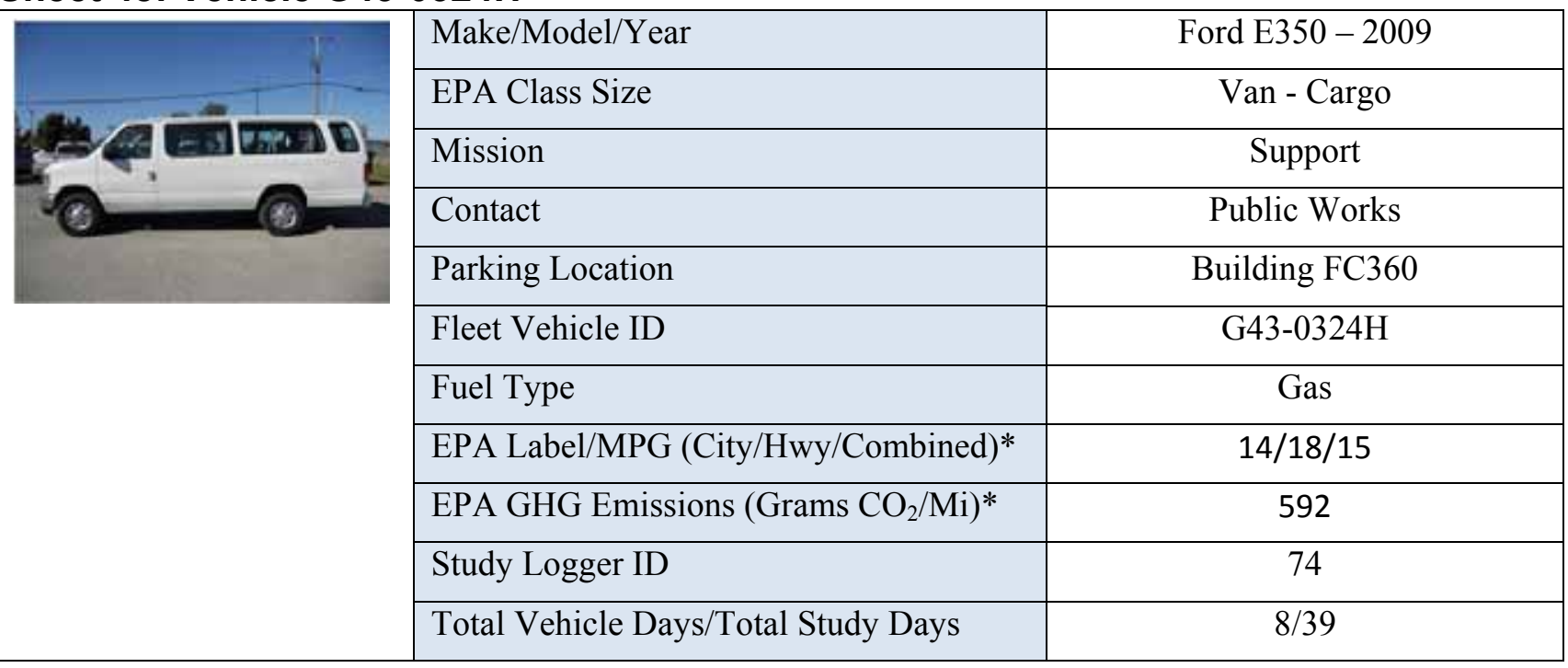

\begin{tabular}{|l|c|c|c|c|}
\hline \multicolumn{5}{|c|}{ Vehicle G43-0324H Travel Summary } \\
\hline & $\begin{array}{c}\text { Per Day } \\
\text { Average/Peak }\end{array}$ & $\begin{array}{c}\text { Per Outing } \\
\text { Average/Peak }\end{array}$ & $\begin{array}{c}\text { Per Trip } \\
\text { Average/Peak }\end{array}$ & Total \\
\hline Travel Distance (Miles) & $3.6 / 12.0$ & $2.9 / 16.6$ & $1.4 / 11.7$ & 29 \\
\hline Travel Time (Minutes) & $18.6 / 56.0$ & $14.9 / 76.0$ & $7.5 / 36.0$ & 149 \\
\hline Idle Time (Minutes) & $9.8 / \mathrm{NA}$ & $7.8 / \mathrm{NA}$ & $3.9 / \mathrm{NA}$ & 78 \\
\hline
\end{tabular}

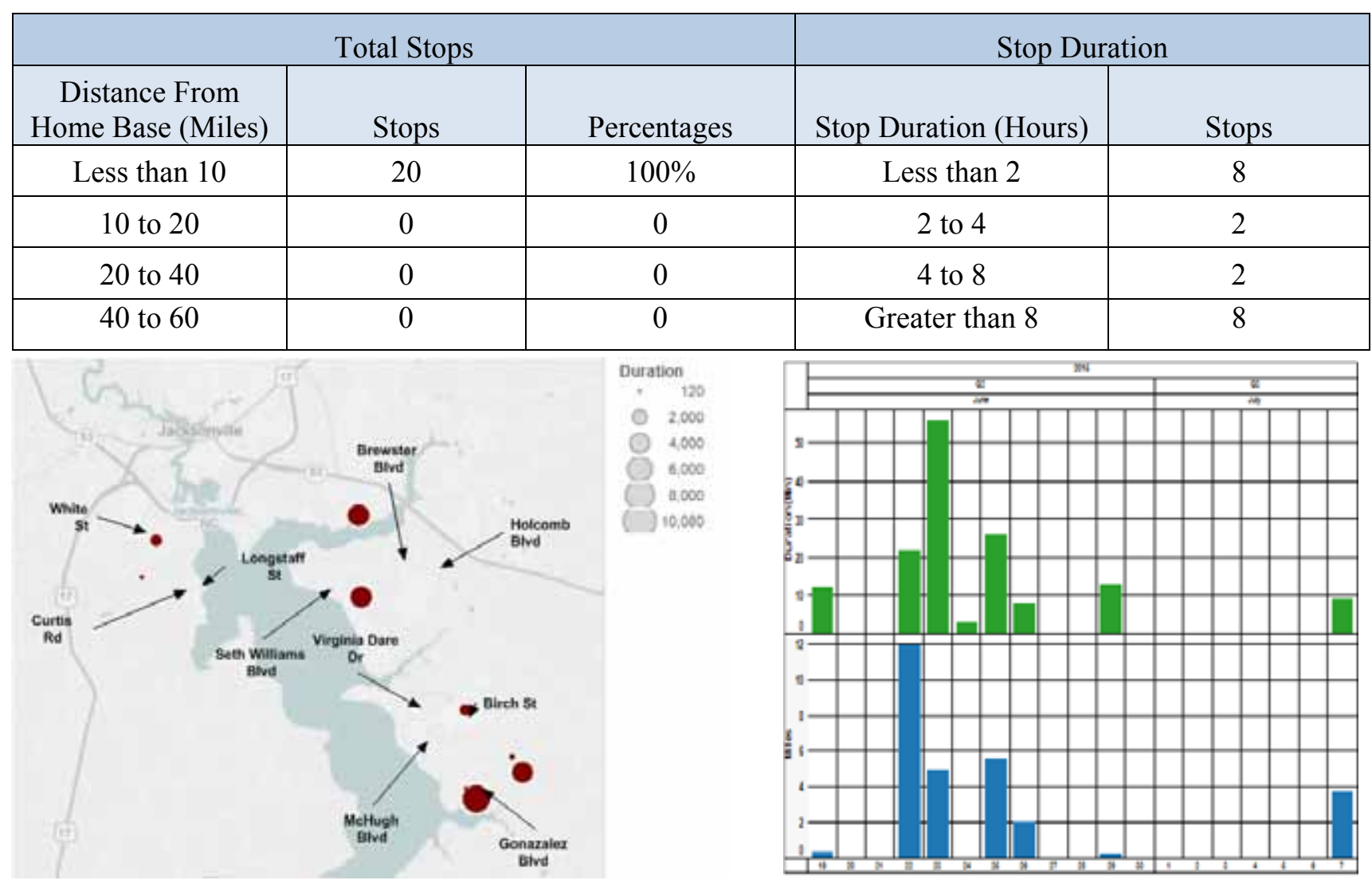

Figure C-85. Vehicle G43-0324H stops.

Figure C-86. Vehicle G43-0324H history.

*Fuel economy for E350 is not available. Economy used is for Ford F150. 


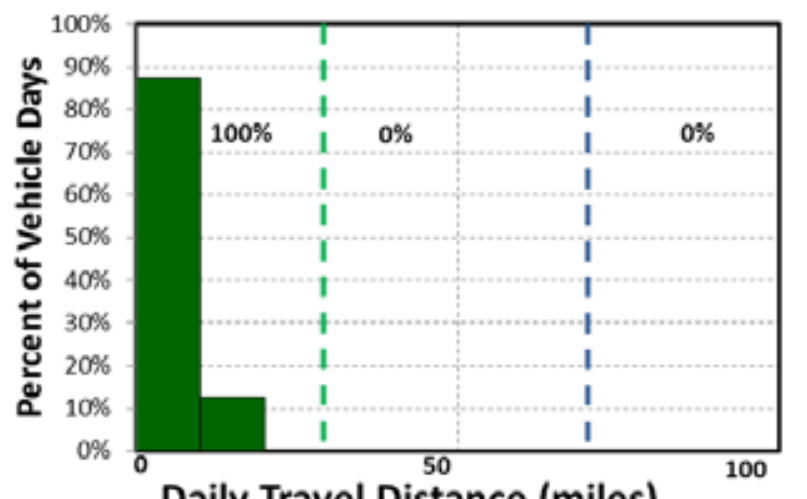

Daily Travel Distance (miles)

... All travel less than 30 miles $\quad \ldots$ All travel less than 70 miles

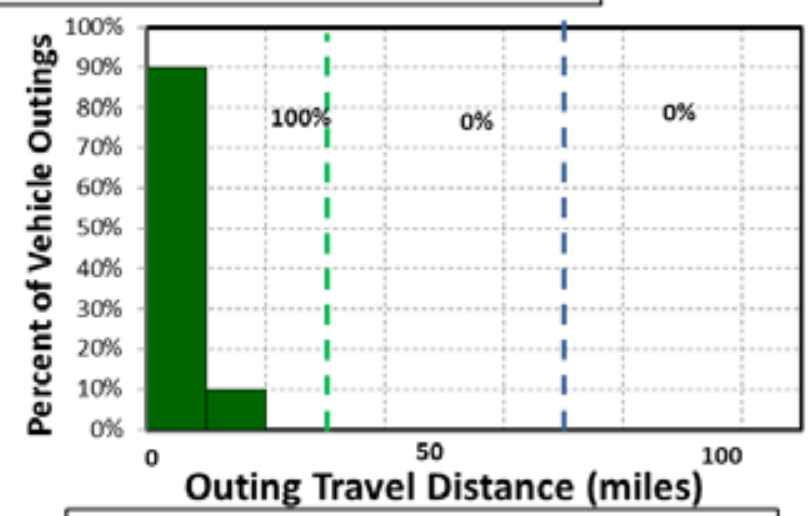

All outings less than 30 miles _- All outings less than 70 miles

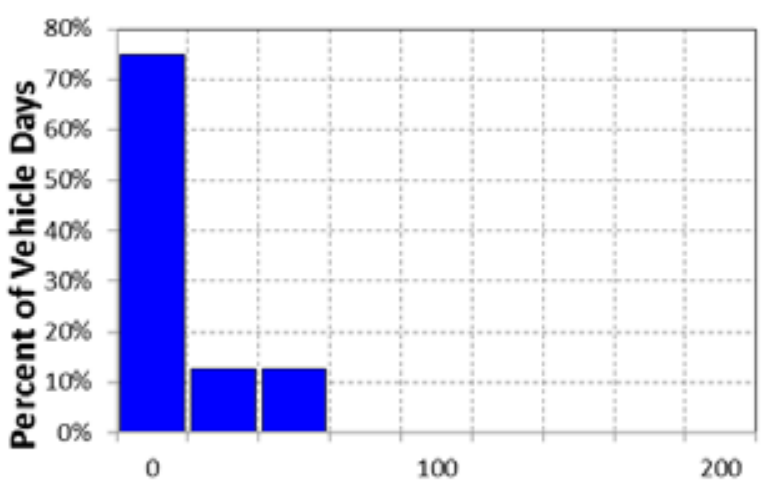

Daily Travel Time (Minutes)

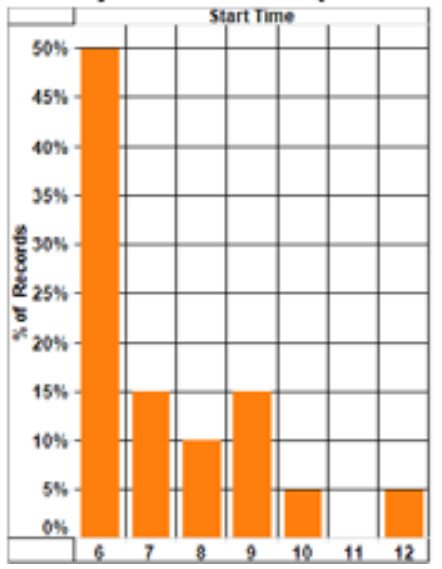

Figure C-87. Vehicle G43-0324H travel graphs.

\section{Vehicle G43-0324H Observations}

Logger 74 collected data on this vehicle for a period of 8 days of the 39-day study period. Validation occurred on $97.9 \%$ of the input data. Data indicate that this vehicle has a support mission for Public Works. This vehicle's data indicate it parks near Building FC360 near Gonzalez Boulevard as shown in the Google Earth figure to the right.

MCBCL reports that a recent vehicle odometer indicated 32,035 miles at the start of this study and an average annual mileage of 5,969 miles. The vehicle was used on $21 \%$ of the available days, with an average daily usage of 0.3 hours and a peak daily usage of 0.9 hours on the days it was used. The vehicle was used during day shift hours.

Figure $\mathrm{C}-87$ shows that all daily travel was within the

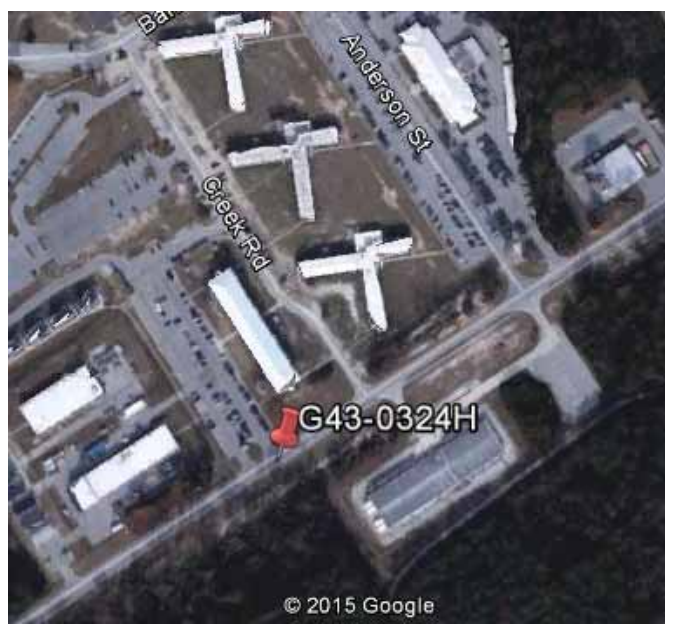
typically advertised range of a BEV of approximately 70 miles. All outings were also within this range. Further, all daily travel and all of outings were within the typically advertised CD mode of 30 miles for PHEVs.

A BEV could meet all daily travel without additional charging opportunities, assuming the vehicle was assigned a home base. 
Sheet 49: Vehicle G43-1182M

\begin{tabular}{|l|l|c|}
\hline & Make/Model/Year & Chevrolet CG3300-2012 \\
\cline { 2 - 3 } & EPA Class Size & Van - Cargo \\
\cline { 2 - 3 } & Mission & Pupport \\
\hline Contact & Puilding 1770 \\
\cline { 2 - 3 } & Parking Location & G43-1182M \\
\cline { 2 - 3 } & Fleet Vehicle ID & E85 \\
\cline { 2 - 3 } & Fuel Type & $7 / 11 / 9$ \\
\hline & EPA Label/MPG (City/Hwy/Combined) & 689 \\
\cline { 2 - 3 } & EPA GHG Emissions (Grams CO $/$ /Mi) & 36 \\
\cline { 2 - 3 } & Study Logger ID & $19 / 31$ \\
\cline { 2 - 3 } & Total Vehicle Days/Total Study Days & \\
\hline
\end{tabular}

\begin{tabular}{|l|c|c|c|c|}
\hline \multicolumn{5}{|c|}{ Vehicle G43-1182M Travel Summary } \\
\hline & $\begin{array}{c}\text { Per Day } \\
\text { Average/Peak }\end{array}$ & $\begin{array}{c}\text { Per Outing } \\
\text { Average/Peak }\end{array}$ & $\begin{array}{c}\text { Per Trip } \\
\text { Average/Peak }\end{array}$ & Total \\
\hline Travel Distance (Miles) & $35.8 / 44.5$ & $15.5 / 24.1$ & $4.7 / 12.5$ & 680 \\
\hline Travel Time (Minutes) & $97.6 / 200.0$ & $41.2 / 148.0$ & $12.7 / 81.0$ & 1,854 \\
\hline Idle Time (Minutes) & $18.3 / \mathrm{NA}$ & $7.7 / \mathrm{NA}$ & $2.4 / \mathrm{NA}$ & 347 \\
\hline
\end{tabular}

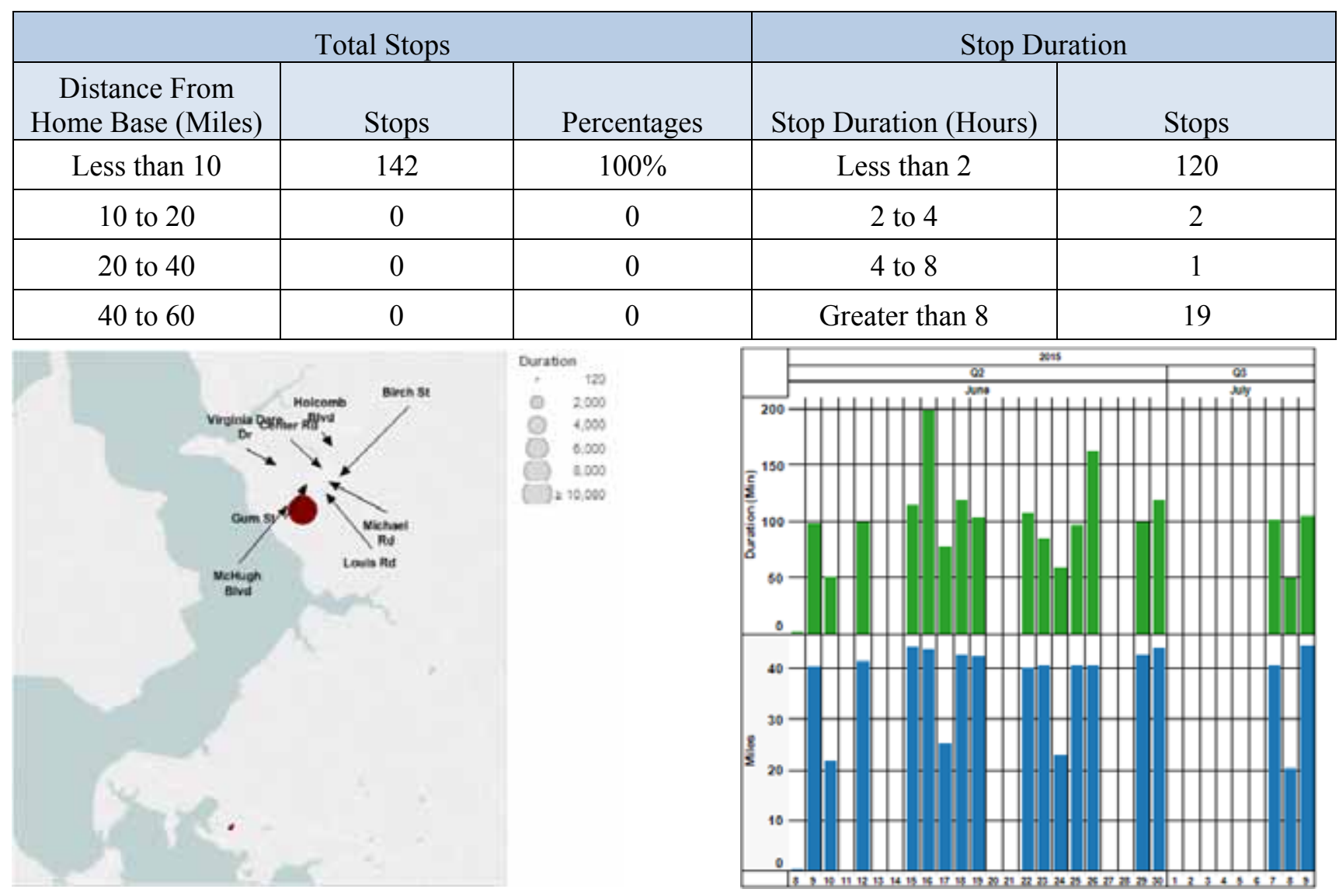

Figure C-88. Vehicle G43-1182M stops.

Figure C-89. Vehicle G43-1182M history. 

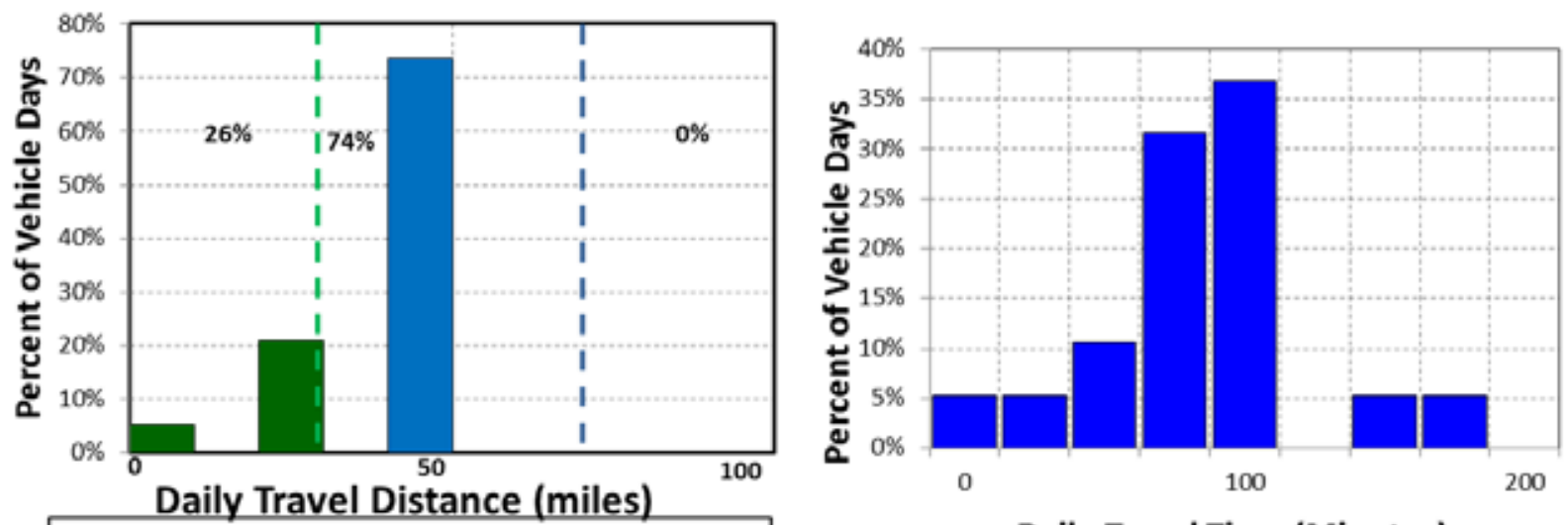

- All travel less than 30 miles _.. All travel less than 70 miles

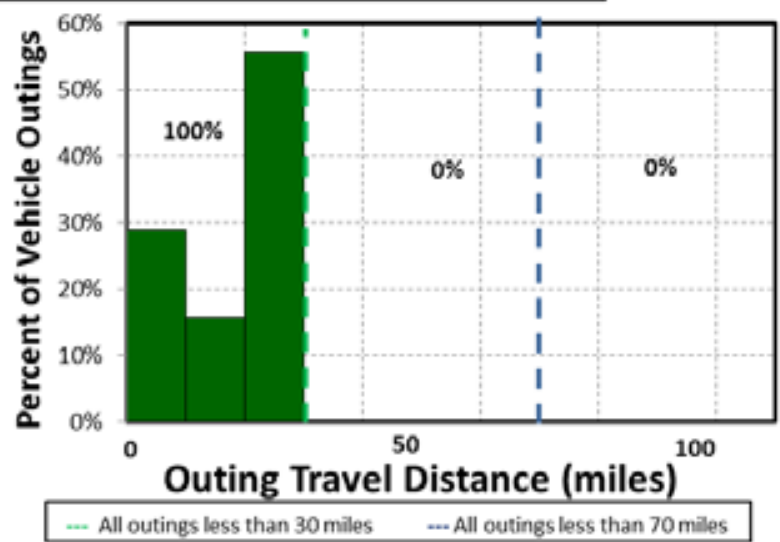

Daily Travel Time (Minutes)

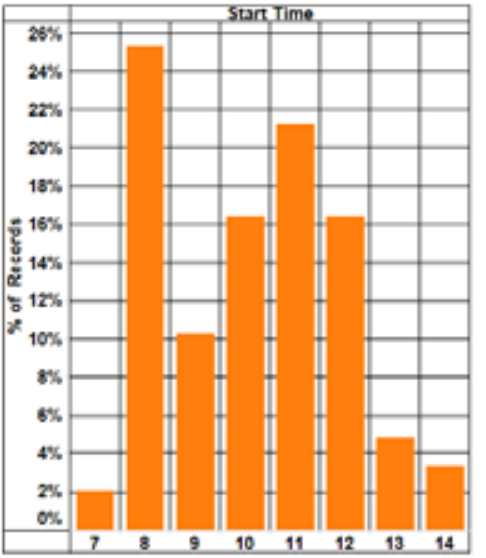

Figure C-90. Vehicle G43-1182M travel graphs.

\section{Vehicle G43-1182M Observations}

Logger 36 collected data on this vehicle for a period of 19 days of the 31-day study period. Validation occurred on $100 \%$ of the input data. Data indicate that this vehicle has a support mission for the Post Office. This vehicle's data indicate it parks near Building 1770 near Louis Road as shown in the Google Earth figure to the right.

MCBCL reports that a recent vehicle odometer indicated 28,376 miles at the start of this study and an average annual mileage of 12,279 miles. The vehicle was used on $61 \%$ of the available days, with an average daily usage of 1.6 hours and a peak daily usage of 3.3 hours on the days it was used. The vehicle was used during day shift hours.

Figure C-90 shows that all daily travel was within the

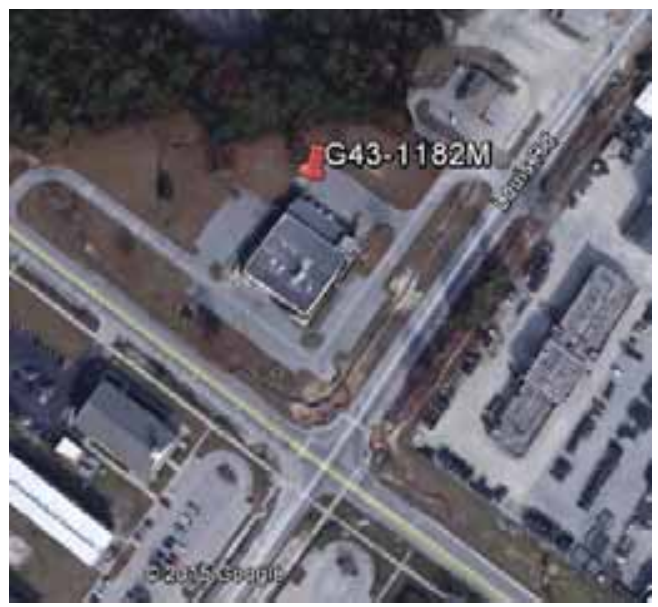
typically advertised range of a BEV of approximately 70 miles. All outings are also within this range. Further, $26 \%$ of daily travel and all outings were within the typically advertised CD mode of 30 miles for PHEVs.

A BEV could meet all daily travel without additional charging opportunities, assuming the vehicle was assigned a home base. 
Sheet 50: Vehicle G43-4075P

\begin{tabular}{|c|c|c|}
\hline \multirow{11}{*}{$\frac{1830}{830}$} & Make/Model/Year & Ford F250-2015 \\
\hline & EPA Class Size & Pickup \\
\hline & Mission & Pool \\
\hline & Contact & Motor Transport - C-Pool \\
\hline & Parking Location & Building 316 \\
\hline & Fleet Vehicle ID & G43-4075P \\
\hline & Fuel Type & E85 \\
\hline & EPA Label/MPG (City/Hwy/Combined)* & $13 / 17 / 14$ \\
\hline & EPA GHG Emissions (Grams $\left.\mathrm{CO}_{2} / \mathrm{Mi}\right)^{*}$ & 442 \\
\hline & Study Logger ID & 14 \\
\hline & Total Vehicle Days/Total Study Days & $34 / 34$ \\
\hline
\end{tabular}

\begin{tabular}{|l|c|c|c|c|}
\hline \multicolumn{5}{|c|}{ Vehicle G43-4075P Travel Summary } \\
\hline & $\begin{array}{c}\text { Per Day } \\
\text { Average/Peak }\end{array}$ & $\begin{array}{c}\text { Per Outing } \\
\text { Average/Peak }\end{array}$ & $\begin{array}{c}\text { Per Trip } \\
\text { Average/Peak }\end{array}$ & Total \\
\hline Travel Distance (Miles) & $38.3 / 151.4$ & $6.2 / 82.8$ & $3.4 / 56.1$ & 1,301 \\
\hline Travel Time (Minutes) & $140.6 / 456.0$ & $22.9 / 191.0$ & $12.5 / 120.0$ & 4,781 \\
\hline Idle Time (Minutes) & $24.3 / \mathrm{NA}$ & $4.0 / \mathrm{NA}$ & $2.2 / \mathrm{NA}$ & 826 \\
\hline
\end{tabular}

\begin{tabular}{|c|c|c|c|c|}
\hline \multicolumn{2}{|c|}{ Total Stops } & \multicolumn{3}{c|}{ Stop Duration } \\
\hline $\begin{array}{c}\text { Distance From } \\
\text { Home Base (Miles) }\end{array}$ & Stops & Percentages & Stop Duration (Hours) & Stops \\
\hline Less than 10 & 374 & $99.7 \%$ & Less than 2 & 274 \\
\hline 10 to 20 & 1 & $0.3 \%$ & 2 to 4 & 34 \\
\hline 20 to 40 & 0 & 0 & & \\
\hline Greater than 40 & 0 & 0 & Greater than 8 & 34 \\
\hline
\end{tabular}

Figure C-91. Vehicle G43-4075P stops.

Figure C-92. Vehicle G43-4075P history.

*Fuel Economy for F250 is unavailable. Economy for F150 is used. 


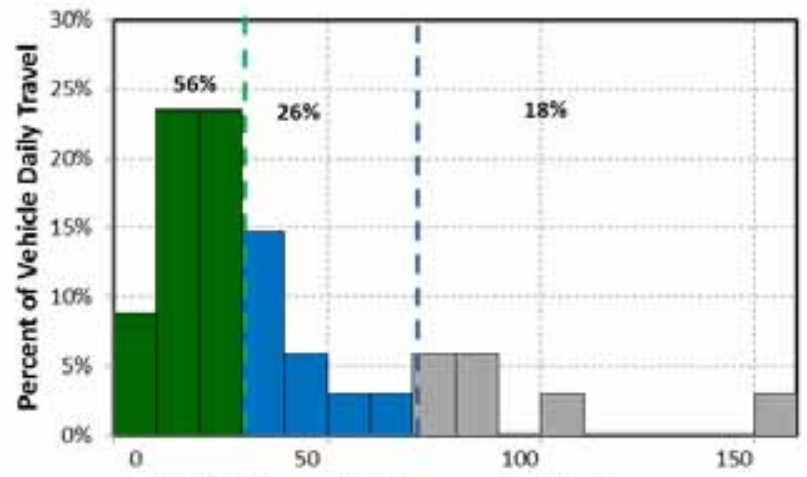

Daily Travel Distance (miles)

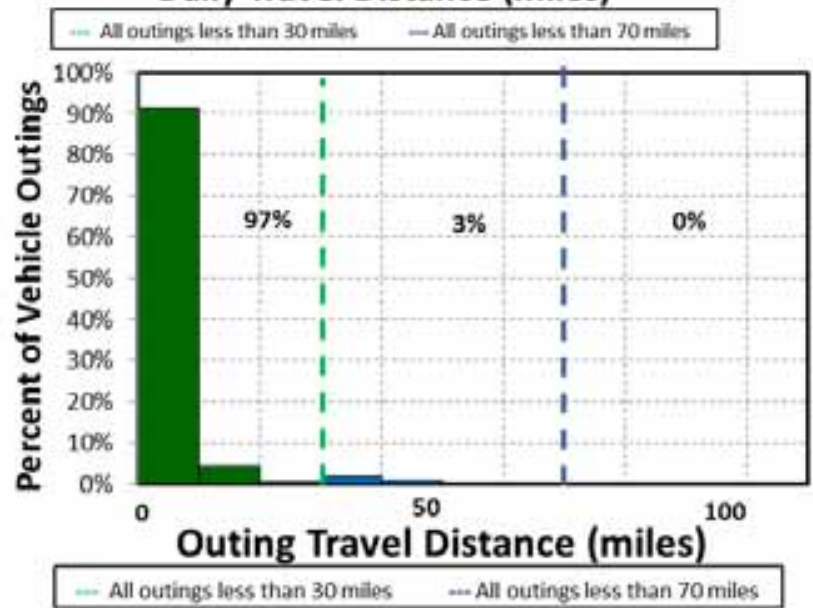

All outings less than 30 miles
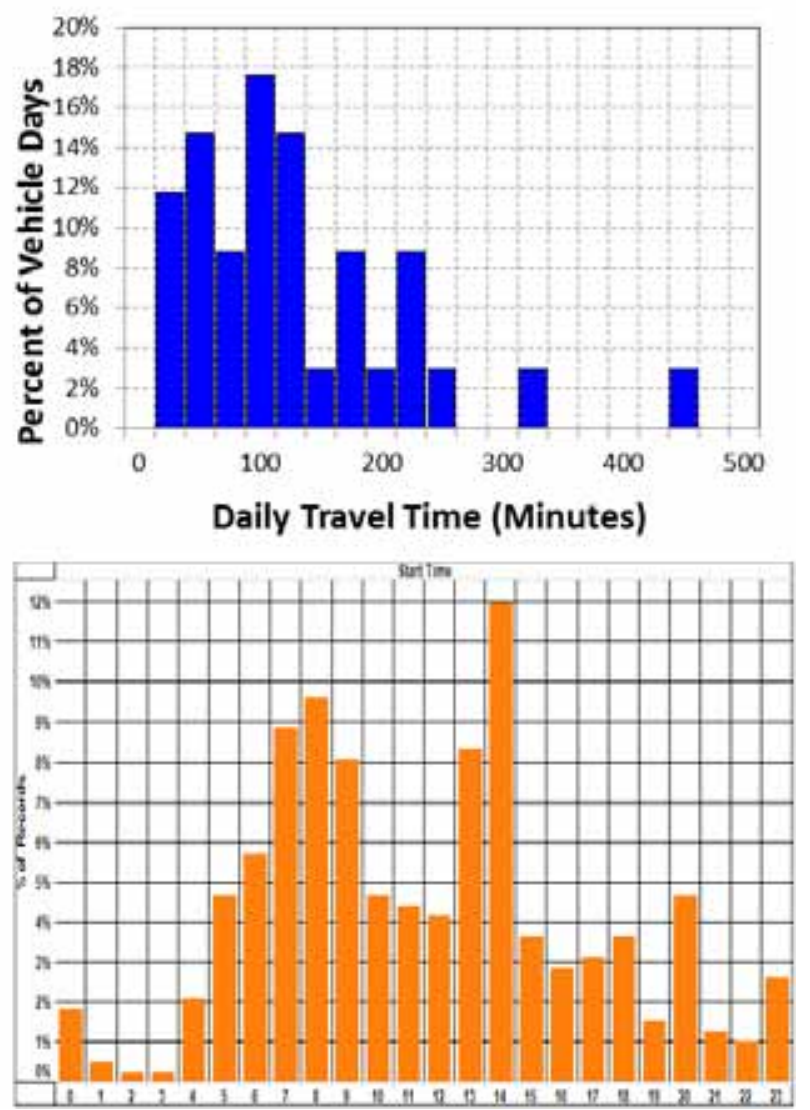

Figure C-93. Vehicle G43-4075P travel graphs.

\section{Vehicle G43-4075P Observations}

Logger 14 collected data on this vehicle for a period of 34 days of the 34-day study period. Validation occurred on $100 \%$ of the input data. Data indicate that this vehicle has a pool mission for the Motor Transport - C-Pool. This vehicle's data indicate it parks near Building 316 near G Street as shown in the Google Earth figure to the right.

MCBCL reports that a recent vehicle odometer indicated 464 miles on this new vehicle at the start of this study and an average annual mileage of 3,600 miles. The vehicle was used on $100 \%$ of the available days, with an average daily usage of 2.3 hours and a peak daily usage of 7.6 hours on the days it was used. The vehicle was used primarily during day and evening hours of the day.

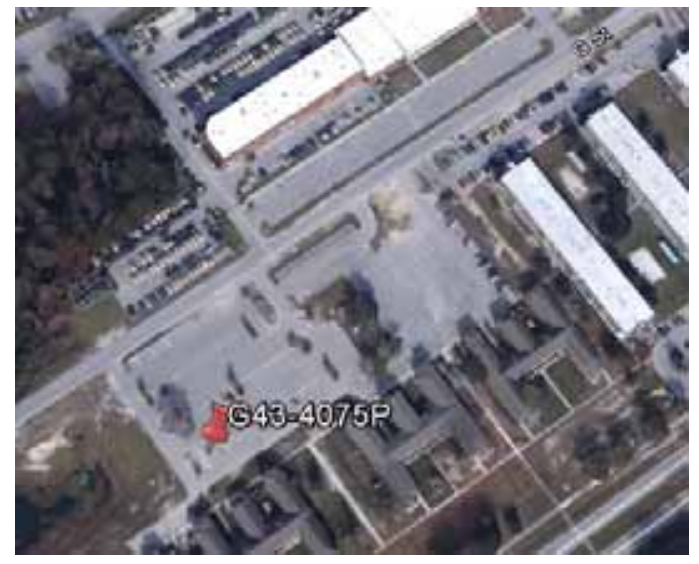

Figure C-93 shows $82 \%$ of daily travel was within the typically advertised range of a BEV of approximately 70 miles. All outings were also within this range. Further, $56 \%$ of daily travel and $97 \%$ of outings were within the typically advertised CD mode of 30 miles for PHEVs.

A BEV could not meet all daily travel without additional charging opportunities, but sufficient time during the day may not be available. A significant number of travel days are within the range of a BEV. Thus, a fleet of pickup trucks would likely contain a mix of BEVs and PHEVs. 
Sheet 51: Vehicle G61-0161H

\begin{tabular}{|c|c|c|}
\hline \multirow{11}{*}{ 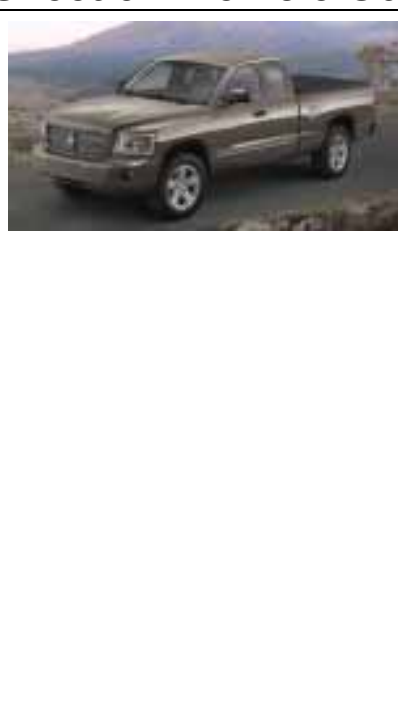 } & Make/Model/Year & Dodge Dakota - 2009 \\
\hline & EPA Class Size & Pickup \\
\hline & Mission & Support \\
\hline & Contact & Environmental Management \\
\hline & Parking Location & Building TP464 \\
\hline & Fleet Vehicle ID & G61-0161H \\
\hline & Fuel Type & E85 \\
\hline & EPA Label/MPG (City/Hwy/Combined) & $9 / 13 / 10$ \\
\hline & EPA GHG Emissions (Grams $\left.\mathrm{CO}_{2} / \mathrm{Mi}\right)$ & 620 \\
\hline & Study Logger ID & 77 \\
\hline & Total Vehicle Days/Total Study Days & $26 / 31$ \\
\hline
\end{tabular}

\begin{tabular}{|l|c|c|c|c|}
\hline \multicolumn{5}{|c|}{ Vehicle G61-0161H Travel Summary } \\
\hline & $\begin{array}{c}\text { Per Day } \\
\text { Average/Peak }\end{array}$ & $\begin{array}{c}\text { Per Outing } \\
\text { Average/Peak }\end{array}$ & $\begin{array}{c}\text { Per Trip } \\
\text { Average/Peak }\end{array}$ & Total \\
\hline Travel Distance (Miles) & $63.6 / 154.0$ & $20.9 / 93.0$ & $9.2 / 48.6$ & 1,654 \\
\hline Travel Time (Minutes) & $176.2 / 343.0$ & $58.0 / 350.0$ & $25.5 / 113.0$ & 4,582 \\
\hline Idle Time (Minutes) & $21.2 / \mathrm{NA}$ & $7.0 / \mathrm{NA}$ & $3.1 / \mathrm{NA}$ & 552 \\
\hline
\end{tabular}

\begin{tabular}{|c|c|c|c|c|}
\hline \multicolumn{2}{|c|}{ Total Stops } & \multicolumn{2}{c|}{ Stop Duration } \\
\hline $\begin{array}{c}\text { Distance From } \\
\text { Home Base (Miles) }\end{array}$ & Stops & Percentages & Stop Duration (Hours) & Stops \\
\hline Less than 10 & 166 & $98.2 \%$ & Less than 2 & 141 \\
\hline 10 to 20 & 2 & $1.2 \%$ & 2 to 4 & 2 \\
\hline 20 to 40 & 1 & $0.6 \%$ & 4 to 8 & 1 \\
\hline Greater than 40 & 0 & 0 & Greater than 8 & 25 \\
\hline
\end{tabular}

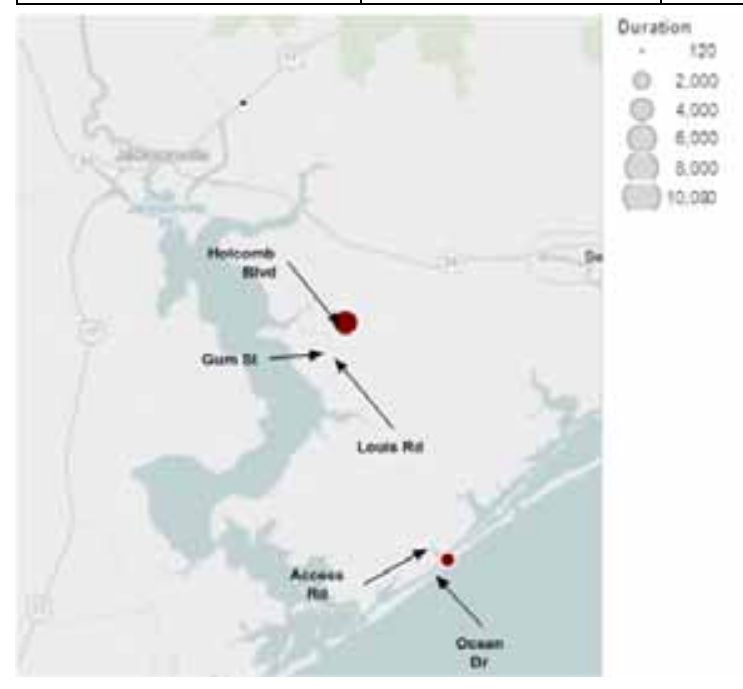

Figure C-94. Vehicle G61-0161H stops.

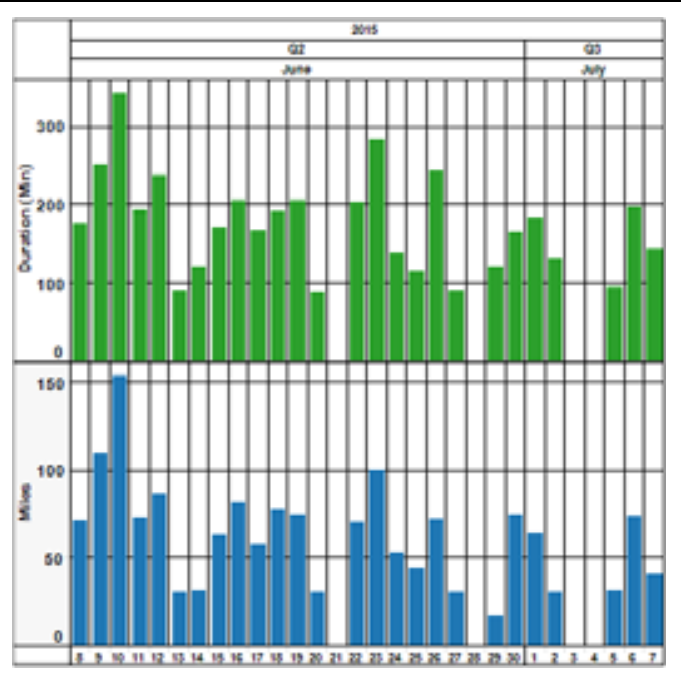

Figure C-95. Vehicle G61-0161H history. 

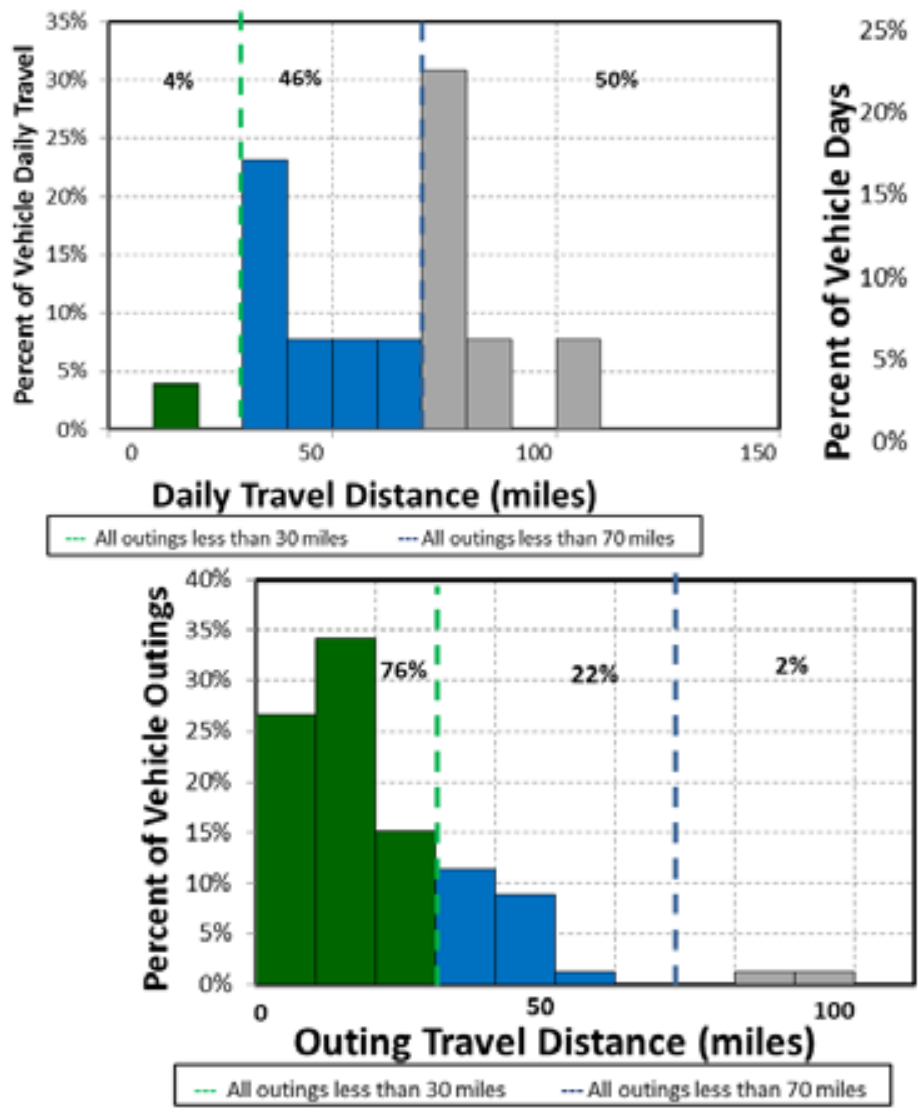

Figure C-96. Vehicle G61-0161H travel graphs.

\section{Vehicle G61-0161H Observations}

Logger 77 collected data on this vehicle for a period of 26 days of the 31-day study period. Validation occurred on $100 \%$ of the input data. Data indicate that this vehicle has a support mission for Environmental Management. This vehicle's data indicate it parks near Building TP464 near Piney Green Road as shown in the Google Earth figure to the right.

MCBCL reports that a recent vehicle odometer indicated 46,893 miles at the start of this study and an average annual mileage of 14,979 miles. The vehicle was used on $84 \%$ of the available days, with an average daily usage

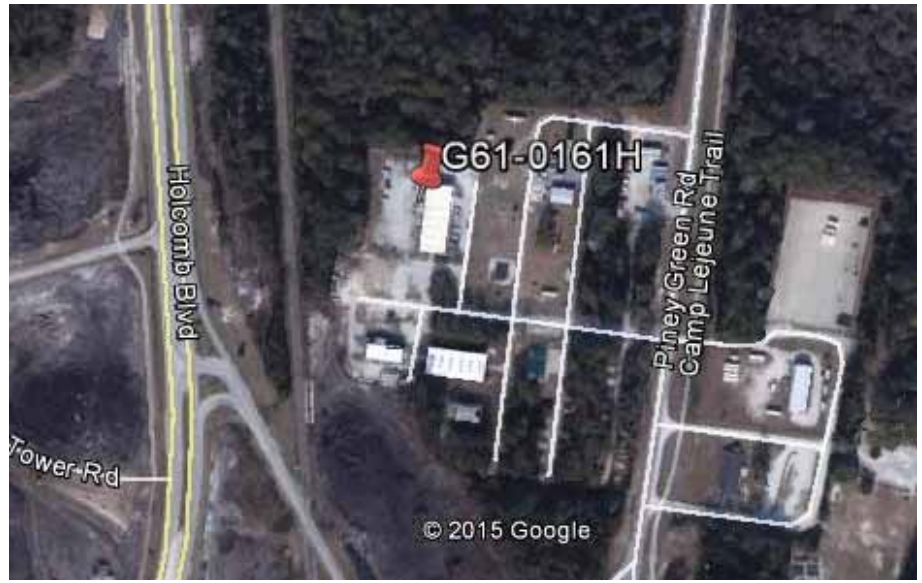
of 2.9 hours and a peak daily usage of 5.7 hours on the days it was used. The vehicle was used during day shift hours.

Figure C-96 shows that $50 \%$ of daily travel was within the typically advertised range of a BEV of approximately 70 miles and $98 \%$ of outings were also within this range. Further, $4 \%$ of daily travel and $76 \%$ of outings were within the typically advertised CD mode of 30 miles for PHEVs.

A BEV could not meet all daily travel because of consistent daily travel exceeding the BEV range. However, approximately half of daily travel was within the BEV range. Thus, a fleet of environmental vehicles could likely contain a mix of BEVs and PHEVs. 
Sheet 52: Vehicle G61-0174H

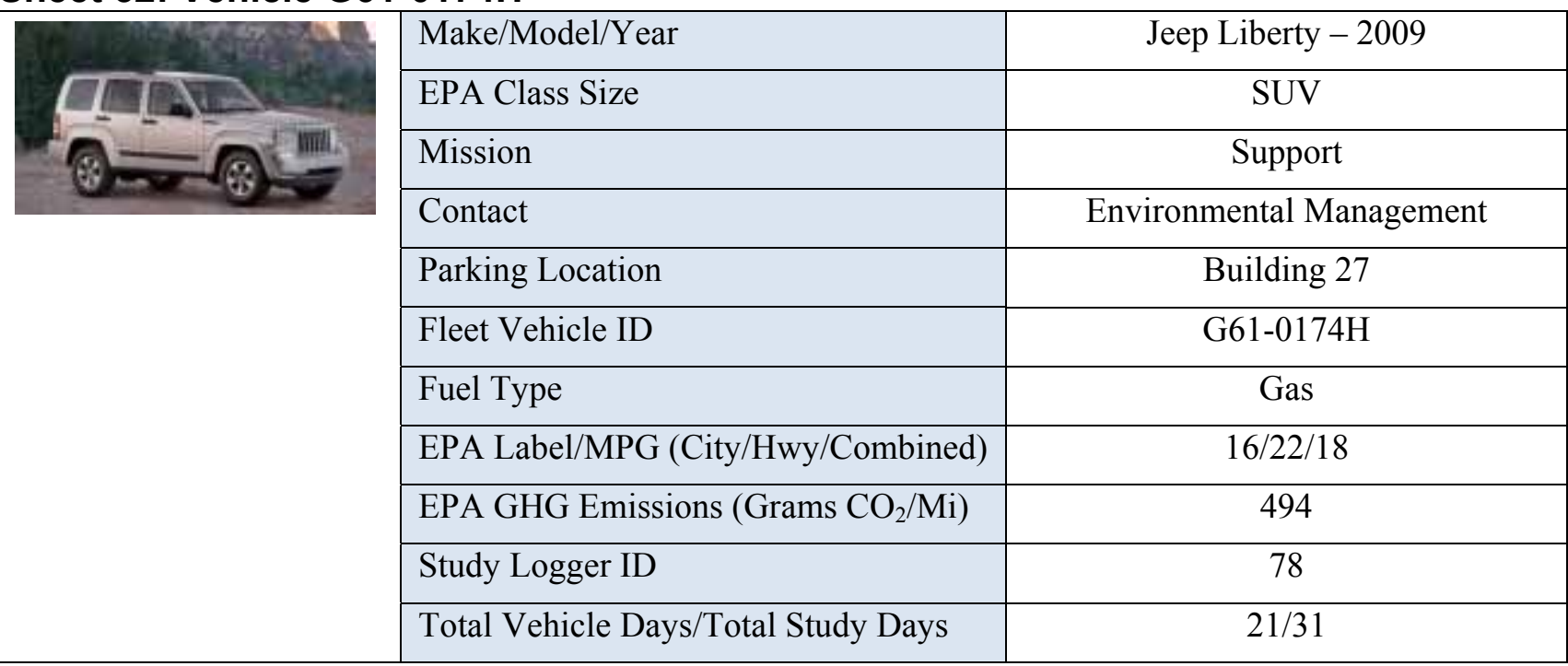

\begin{tabular}{|l|c|c|c|c|}
\hline \multicolumn{5}{|c|}{ Vehicle G61-0174H Travel Summary } \\
\hline & $\begin{array}{c}\text { Per Day } \\
\text { Average/Peak }\end{array}$ & $\begin{array}{c}\text { Per Outing } \\
\text { Average/Peak }\end{array}$ & $\begin{array}{c}\text { Per Trip } \\
\text { Average/Peak }\end{array}$ & Total \\
\hline Travel Distance (Miles) & $41.1 / 128.6$ & $23.3 / 151.8$ & $6.6 / 59.1$ & 862 \\
\hline Travel Time (Minutes) & $100.3 / 239.0$ & $56.9 / 292.0$ & $16.2 / 98.0$ & 2,107 \\
\hline Idle Time (Minutes) & $9.4 / \mathrm{NA}$ & $5.4 / \mathrm{NA}$ & $1.5 / \mathrm{NA}$ & 198 \\
\hline
\end{tabular}

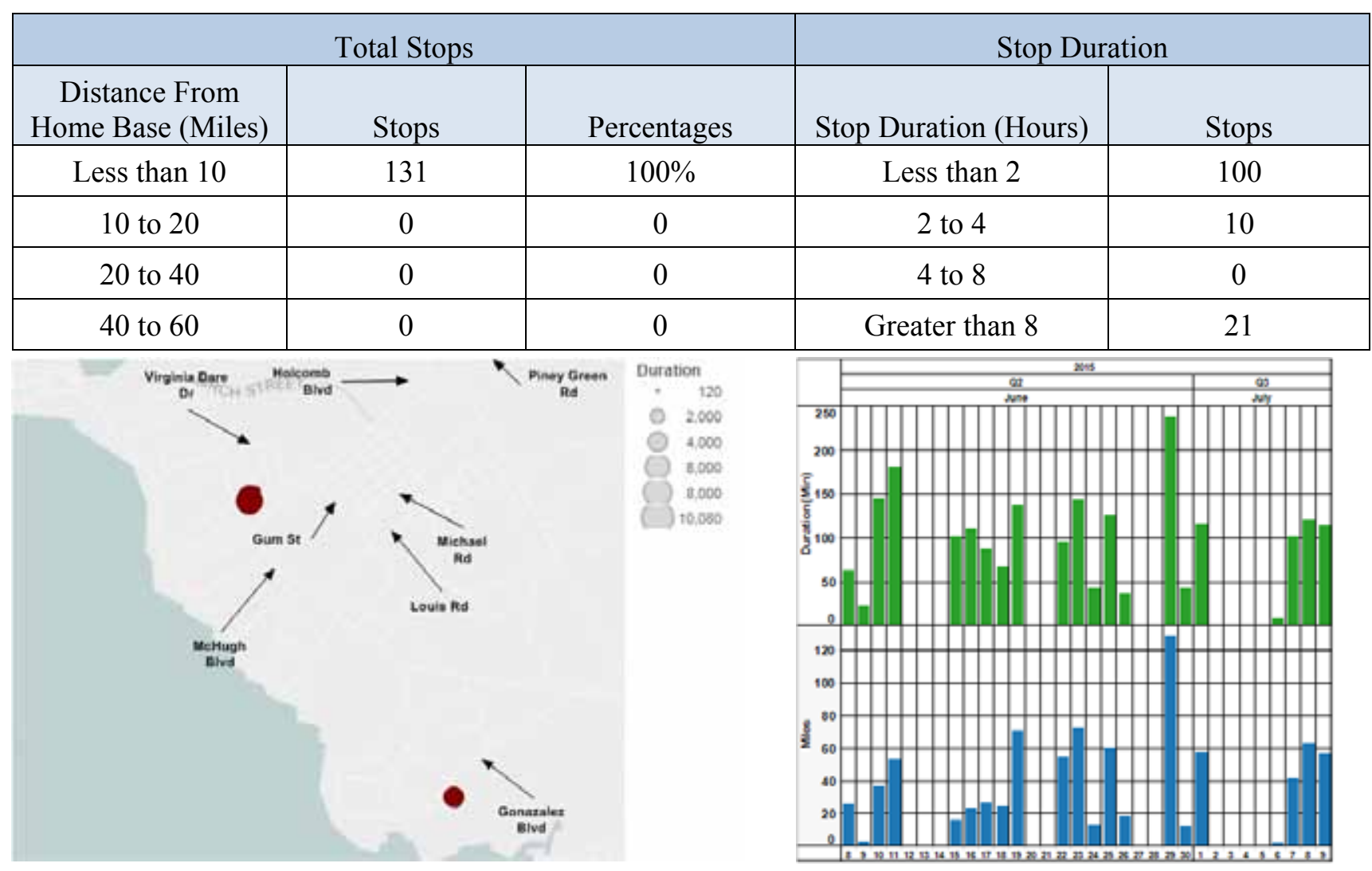

Figure C-97. Vehicle G61-0174H stops.

Figure C-98. Vehicle G61-0174H history. 

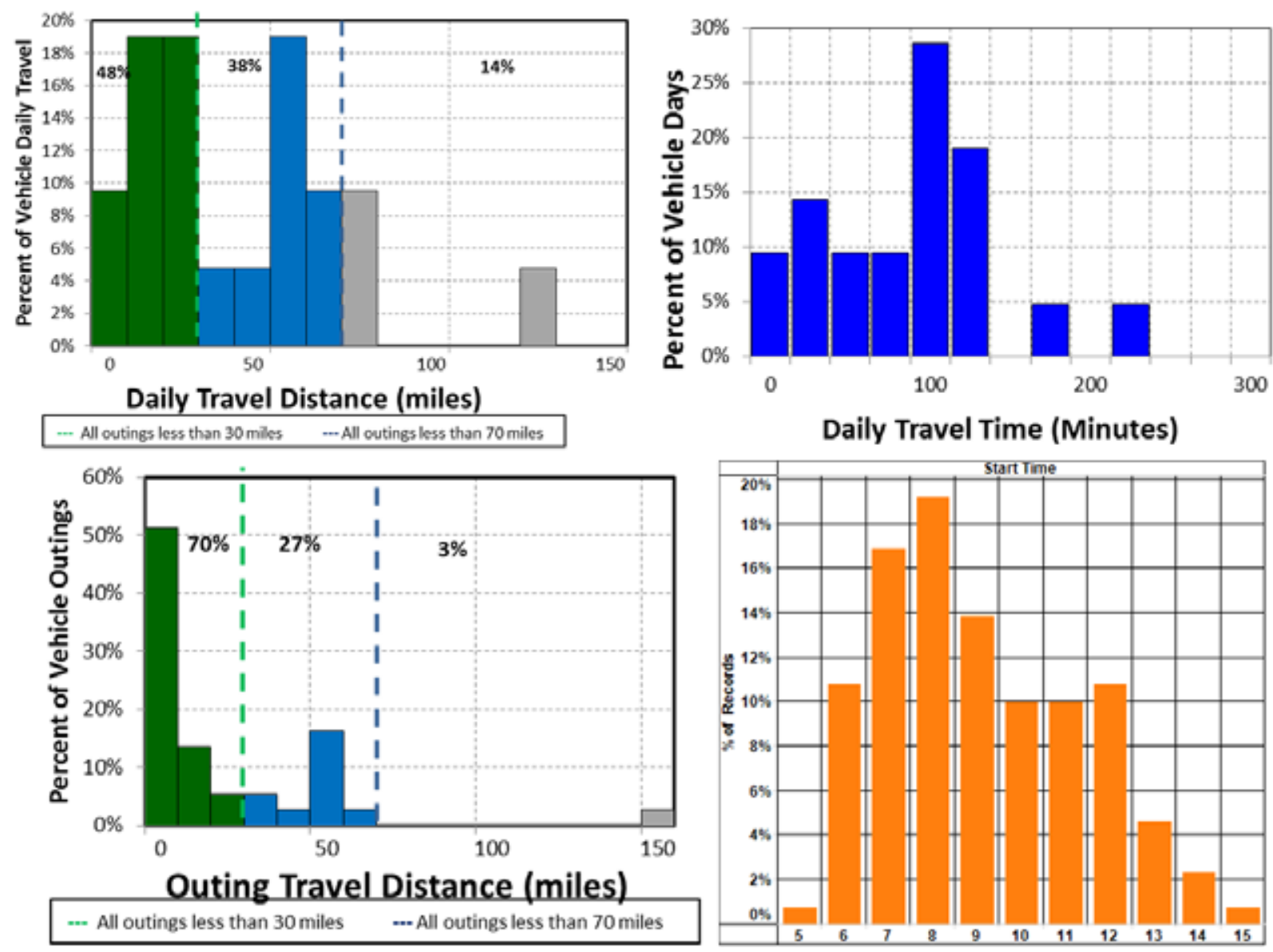

Figure C-99. Vehicle G61-0174H travel graphs.

\section{Vehicle G61-0174H Observations}

Logger 78 collected data on this vehicle for a period of 21 days of the 31-day study period. Validation occurred on $100 \%$ of the input data. Data indicate that this vehicle has a support mission for Environmental Management. This vehicle's data indicate it parks near Building 27 near Post Lane as shown in the Google Earth figure to the right.

MCBCL reports a recent vehicle odometer indicated 38,149 miles at the start of this study and an average annual mileage of 8,683 miles. The vehicle was used on $68 \%$ of the available days, with an average daily usage of 1.7 hours and a peak daily usage of 4.0 hours on the days it was used. The vehicle was used during day shift hours.

Figure C-99 shows that $86 \%$ of daily travel was within

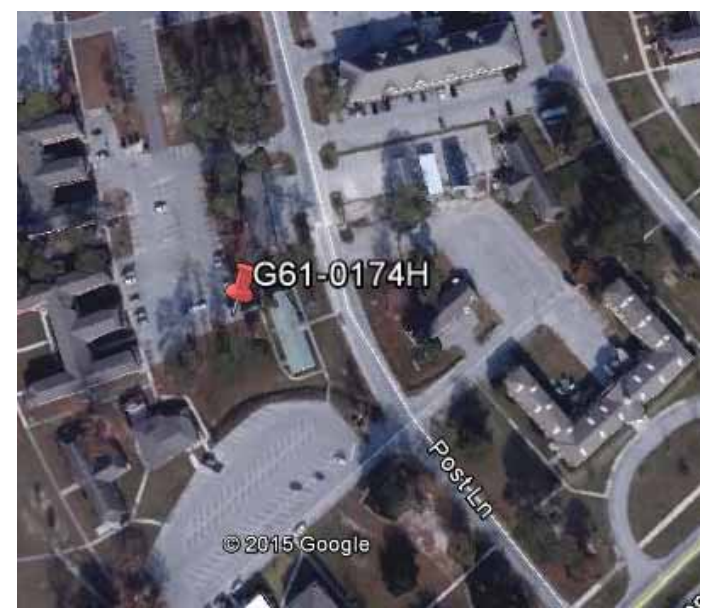
the typically advertised range of a BEV of approximately 70 miles and $97 \%$ of outings were also within this range. Further, $48 \%$ of daily travel and $70 \%$ of outings were within the typically advertised CD mode of 30 miles for PHEVs. The peak outing of 152 miles occurred over a several day period when the vehicle did not return to Post Lane but parked in several other locations on the base.

A BEV could not meet all daily travel without additional charging opportunities and the vehicle returning to its home base daily. However, a significant amount of daily travel was within the range of a BEV. Thus, a fleet of Environmental Management vehicles would likely contain a mix of BEVs and PHEVs. 
Sheet 53: Vehicle G61-0879P

\begin{tabular}{|c|c|c|}
\hline \multirow[t]{11}{*}{ General Motors } & Make/Model/Year & Chevrolet Equinox - 2014 \\
\hline & EPA Class Size & SUV \\
\hline & Mission & Enforcement \\
\hline & Contact & Provost Marshal's Office \\
\hline & Parking Location & Building 979 \\
\hline & Fleet Vehicle ID & G61-0879P \\
\hline & Fuel Type & E85 \\
\hline & EPA Label/MPG (City/Hwy/Combined) & $14 / 20 / 17$ \\
\hline & EPA GHG Emissions (Grams $\mathrm{CO}_{2} / \mathrm{Mi}$ ) & 375 \\
\hline & Study Logger ID & 51 \\
\hline & Total Vehicle Days/Total Study Days & $20 / 31$ \\
\hline
\end{tabular}

\begin{tabular}{|l|c|c|c|c|}
\hline \multicolumn{5}{|c|}{ Vehicle G61-0879P Travel Summary } \\
\hline & $\begin{array}{c}\text { Per Day } \\
\text { Average/Peak }\end{array}$ & $\begin{array}{c}\text { Per Outing } \\
\text { Average/Peak }\end{array}$ & $\begin{array}{c}\text { Per Trip } \\
\text { Average/Peak }\end{array}$ & Total \\
\hline Travel Distance (Miles) & $52.0 / 121.4$ & $28.1 / 121.4$ & $7.9 / 70.1$ & 1,039 \\
\hline Travel Time (Minutes) & $134.2 / 349.0$ & $72.5 / 337.0$ & $20.3 / 175.0$ & 2,683 \\
\hline Idle Time (Minutes) & $25.8 / \mathrm{NA}$ & $13.9 / \mathrm{NA}$ & $3.9 / \mathrm{NA}$ & 515 \\
\hline
\end{tabular}

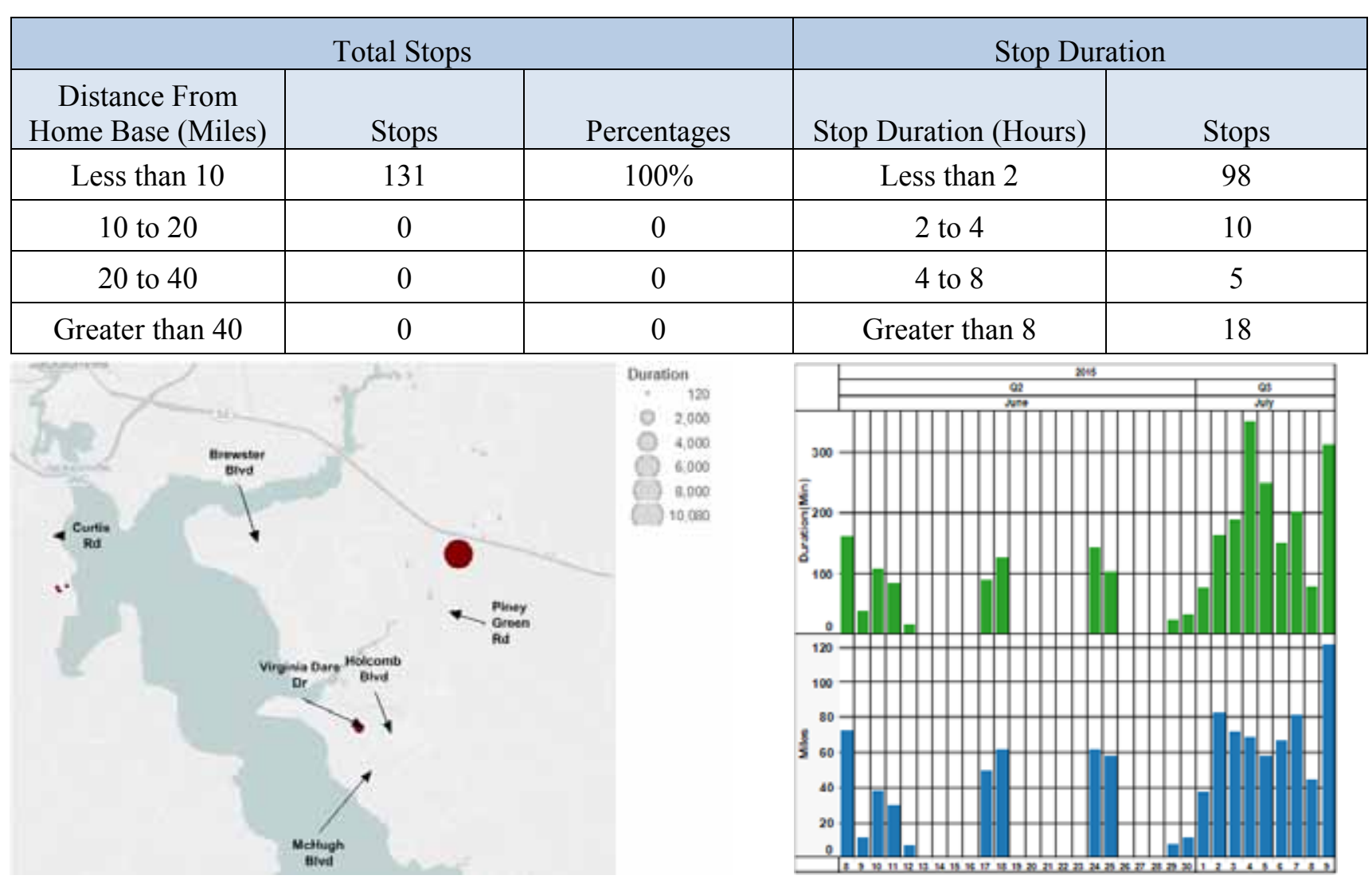

Figure C-100. Vehicle G61-0879P stops.

Figure C-101. Vehicle G61-0879P history. 

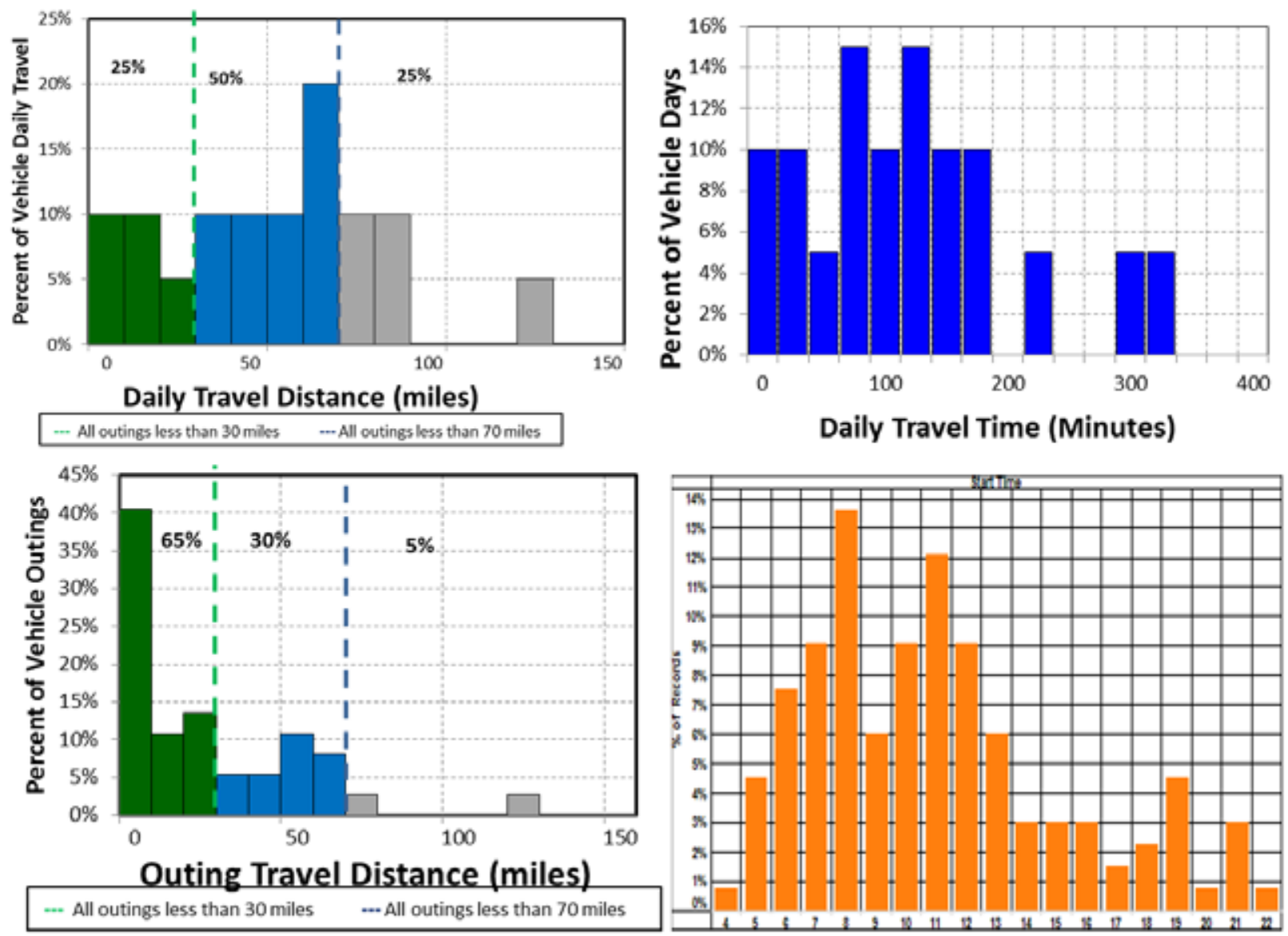

Figure C-102. Vehicle G61-0879P travel graphs.

\section{Vehicle G61-0879P Observations}

Logger 51 collected data on this vehicle for a period of 20 days of the 31-day study period. Validation occurred on $100 \%$ of the input data. Data indicate that this vehicle has an enforcement mission for Provost Marshal's Office. This vehicle's data indicate it parks frequently near Virginia Dare Drive but most often near Building 979 on Piney Green Road as shown in the Google Earth figure to the right.

MCBCL reports that a recent vehicle odometer indicated 4,434 miles at the start of this study and an average annual mileage of 4,232 miles. The vehicle was used on $65 \%$ of the available days, with an average daily usage of 2.2 hours and a

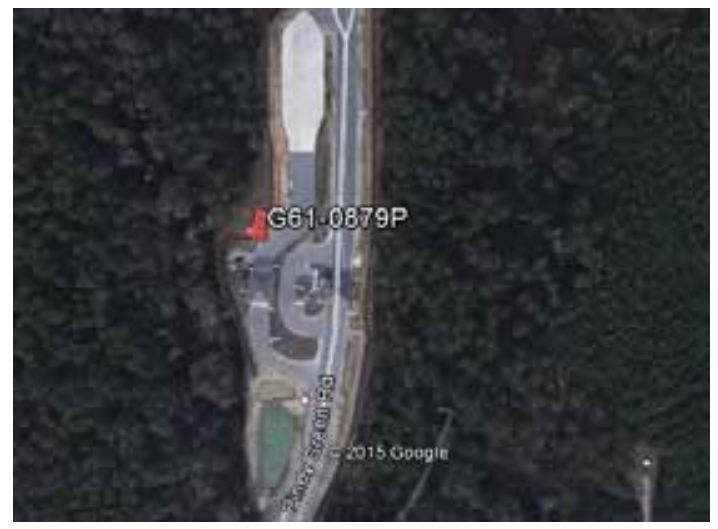
peak daily usage of 5.8 hours on the days it was used. The vehicle was used primarily during day and evening hours.

Figure C-102 shows that $75 \%$ of daily travel was within the typically advertised range of a BEV of approximately 70 miles and $95 \%$ of outings were also within this range. Further, $25 \%$ of daily travel and $65 \%$ of outings were within the typically advertised CD mode of 30 miles for PHEVs.

A BEV could not meet all daily travel without additional charging opportunities, assuming the vehicle was assigned a home base. While there is sufficient time each day for additional charges, fleet managers typically do not prefer enforcement vehicles that contain range limitations. Thus, a fleet of enforcement vehicles would likely contain a mix of BEVs and PHEVs, with preference toward PHEVs. 
Sheet 54: Vehicle G61-1508D

\begin{tabular}{|c|c|c|}
\hline 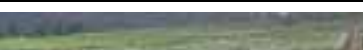 & Make/Model/Year & Jeep Liberty - 2008 \\
\hline DEs & EPA Class Size & SUV \\
\hline$\sqrt{a}=\sqrt{a}$ & Mission & Pool \\
\hline a & Contact & Motor Transport - C-Pool \\
\hline & Parking Location & Building 58 \\
\hline & Fleet Vehicle ID & G61-1508D \\
\hline & Fuel Type & Gas \\
\hline & EPA Label/MPG (City/Hwy/Combined) & $16 / 22 / 19$ \\
\hline & EPA GHG Emissions (Grams $\left.\mathrm{CO}_{2} / \mathrm{Mi}\right)$ & 468 \\
\hline & Study Logger ID & 15 \\
\hline & Total Vehicle Days/Total Study Days & $13 / 35$ \\
\hline
\end{tabular}

\begin{tabular}{|c|c|c|c|c|}
\hline \multicolumn{5}{|c|}{ Vehicle G61-1508D Travel Summary } \\
\hline & $\begin{array}{c}\text { Per Day } \\
\text { Average/Peak }\end{array}$ & $\begin{array}{c}\text { Per Outing } \\
\text { Average/Peak }\end{array}$ & $\begin{array}{c}\text { Per Trip } \\
\text { Average/Peak }\end{array}$ & Total \\
\hline Travel Distance (Miles) & $25.7 / 128.9$ & $13.9 / 98.9$ & $5.0 / 53.5$ & 334 \\
\hline Travel Time (Minutes) & $64.6 / 207.0$ & $35.0 / 156.0$ & $12.5 / 83.0$ & 840 \\
\hline Idle Time (Minutes) & 4.4/NA & $2.4 / \mathrm{NA}$ & $0.9 / \mathrm{NA}$ & 57 \\
\hline
\end{tabular}

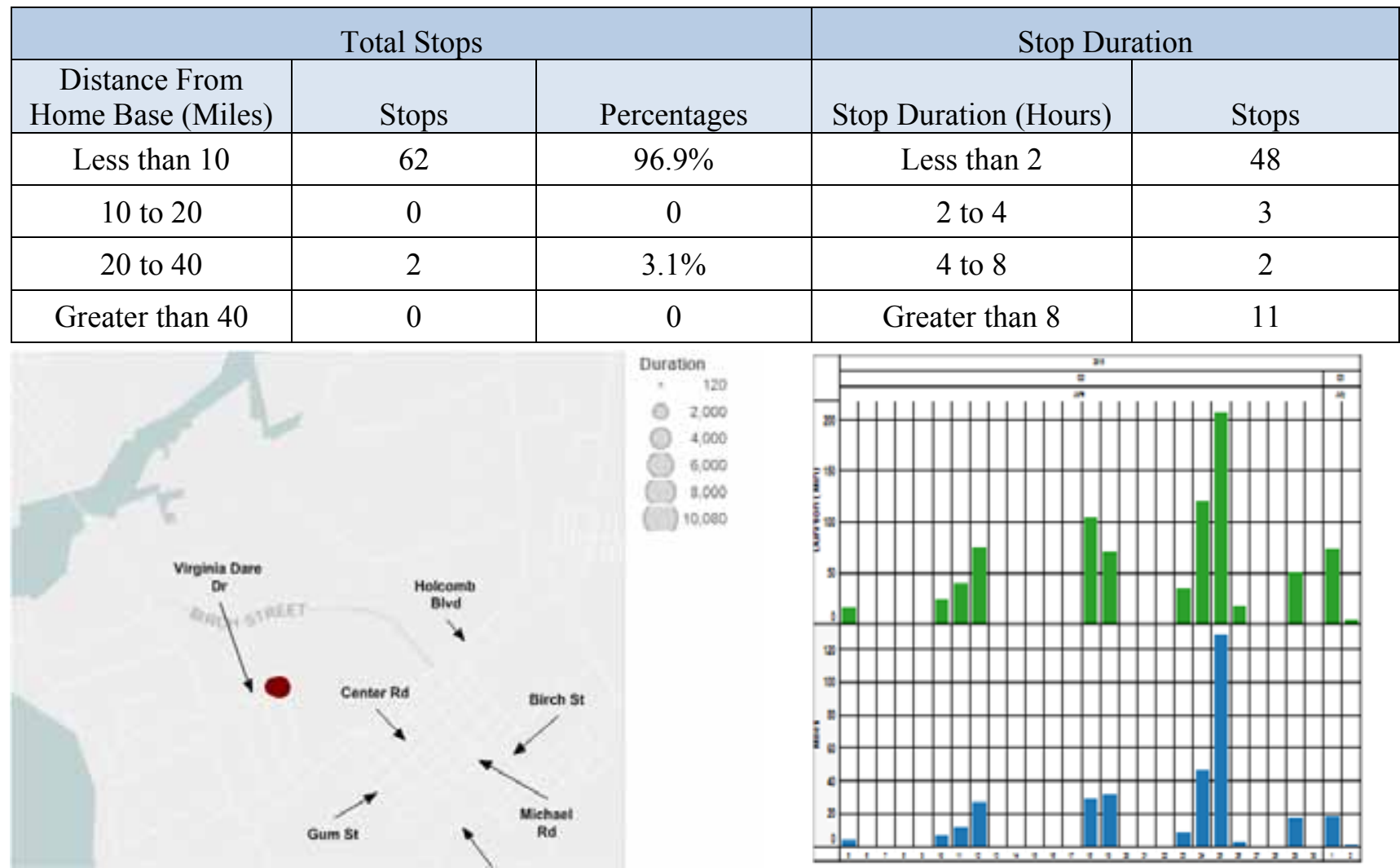

Figure C-103. Vehicle G61-1508D stops.

Figure C-104. Vehicle G61-1508D history. 

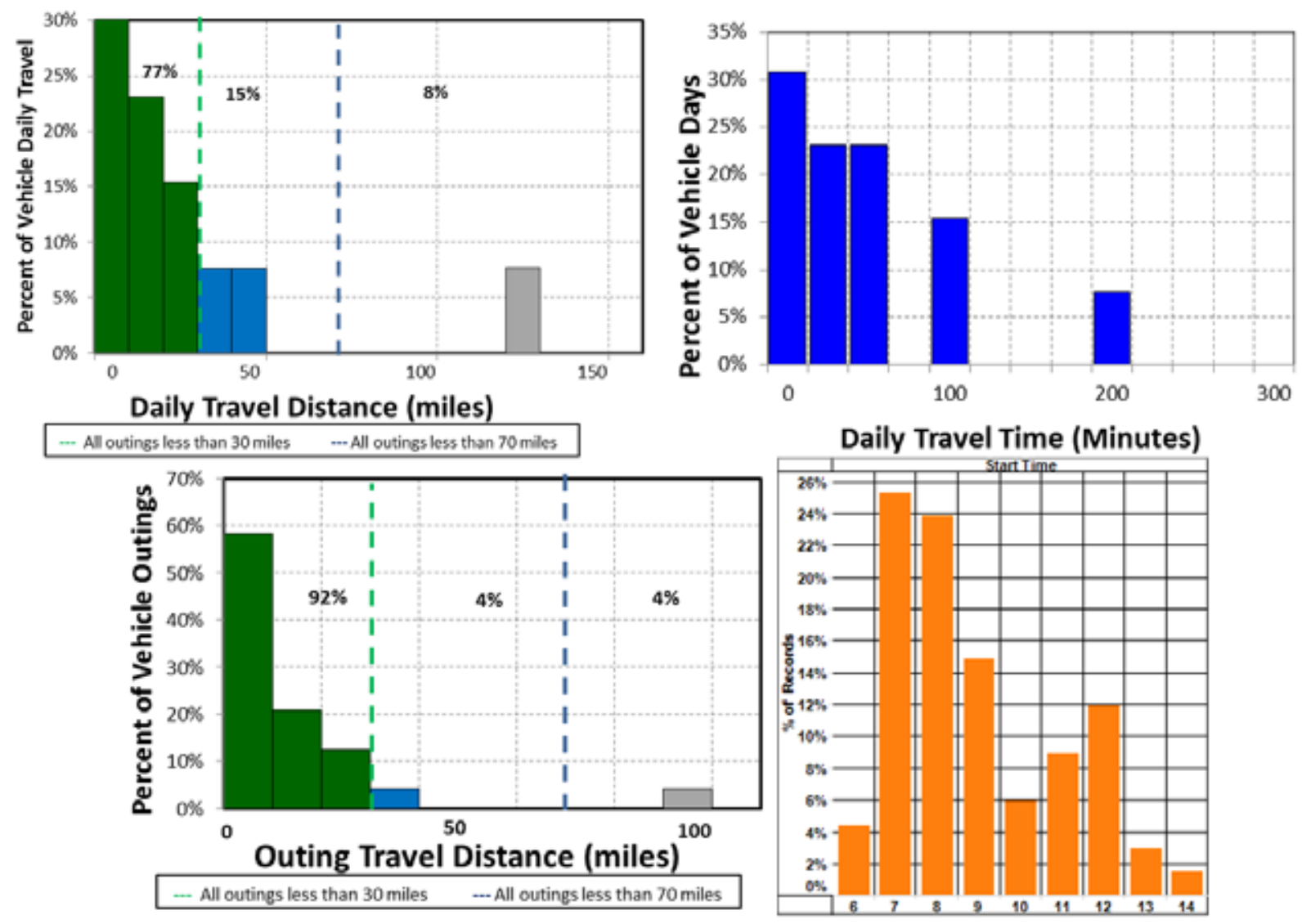

Figure C-105. Vehicle G61-1508D travel graphs.

\section{Vehicle G61-1508D Observations}

Logger 15 collected data on this vehicle for a period of 13 days of the 35-day study period. Validation occurred on $100 \%$ of the input data. Data indicate that this vehicle has a pool mission for Motor Transport - C-Pool. This vehicle's data indicate it parks near Building 58 near Virginia Dare Drive as shown in the Google Earth figure to the right.

MCBCL reports that a recent vehicle odometer indicated 31,152 miles at the start of this study and an average annual mileage of 1,051 miles. The vehicle was used on $37 \%$ of the available days, with an average daily usage of 1.1 hours and a peak daily usage of 3.5 hours on the days it was used. The vehicle was used during day shift hours.

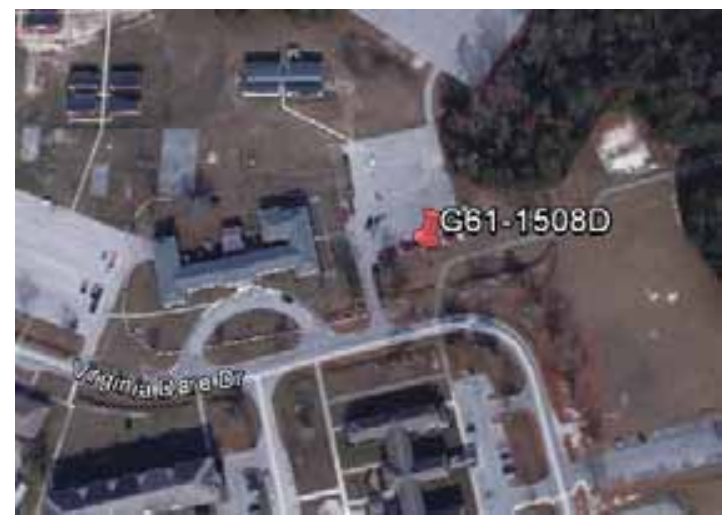

Figure C-105 shows that $92 \%$ of daily travel was within the typically advertised range of a BEV of approximately 70 miles and $96 \%$ of the outings were also within this range. Further, $77 \%$ of daily travel and $92 \%$ of outings were within the typically advertised CD mode of 30 miles for PHEVs.

A BEV could not meet all daily travel without additional charging opportunities and it appears there is sufficient time for recharge during the day. However, one outing exceeded the BEV range; therefore, a fleet of pool vehicles would likely contain a mix of BEVs and PHEVs. 
Sheet 55: Vehicle G61-1509D

\begin{tabular}{|c|c|c|}
\hline 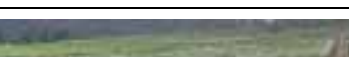 & Make/Model/Year & Jeep Liberty - 2008 \\
\hline Cas & EPA Class Size & SUV \\
\hline$\sqrt{a}-\sqrt{n}$ & Mission & Pool \\
\hline & Contact & Motor Transport - C-Pool \\
\hline & Parking Location & Building 28211 \\
\hline & Fleet Vehicle ID & G61-1509D \\
\hline & Fuel Type & Gas \\
\hline & EPA Label/MPG (City/Hwy/Combined) & $16 / 22 / 19$ \\
\hline & EPA GHG Emissions (Grams $\left.\mathrm{CO}_{2} / \mathrm{Mi}\right)$ & 468 \\
\hline & Study Logger ID & 16 \\
\hline & Total Vehicle Days/Total Study Days & $18 / 31$ \\
\hline
\end{tabular}

\begin{tabular}{|l|c|c|c|c|}
\hline \multicolumn{5}{|c|}{ Vehicle G61-1509D Travel Summary } \\
\hline & $\begin{array}{c}\text { Per Day } \\
\text { Average/Peak }\end{array}$ & $\begin{array}{c}\text { Per Outing } \\
\text { Average/Peak }\end{array}$ & $\begin{array}{c}\text { Per Trip } \\
\text { Average/Peak }\end{array}$ & Total \\
\hline Travel Distance (Miles) & $24.8 / 66.2$ & $16.5 / 61.8$ & $6.3 / 44.0$ & 446 \\
\hline Travel Time (Minutes) & $58.1 / 137.0$ & $38.7 / 102.0$ & $14.7 / 96.0$ & 1,046 \\
\hline Idle Time (Minutes) & $2.4 / \mathrm{NA}$ & $1.6 / \mathrm{NA}$ & $0.6 / \mathrm{NA}$ & 44 \\
\hline
\end{tabular}

\begin{tabular}{|c|c|c|c|c|}
\hline \multicolumn{2}{|c|}{ Total Stops } & \multicolumn{3}{c|}{ Stop Duration } \\
\hline $\begin{array}{c}\text { Distance From } \\
\text { Home Base } \\
\text { (Miles) }\end{array}$ & Stops & Percentages & Stop Duration (Hours) & Stops \\
\hline Less than 10 & 65 & $98.5 \%$ & Less than 2 & 41 \\
\hline 10 to 20 & 0 & 0 & 2 to 4 & 5 \\
\hline 20 to 40 & 1 & $1.5 \%$ & & 4 to 8 \\
\hline 40 to 60 & 0 & 0 & & \\
\hline
\end{tabular}

Figure C-106. Vehicle G61-1509D stops.

Figure C-107. Vehicle G61-1509D history. 


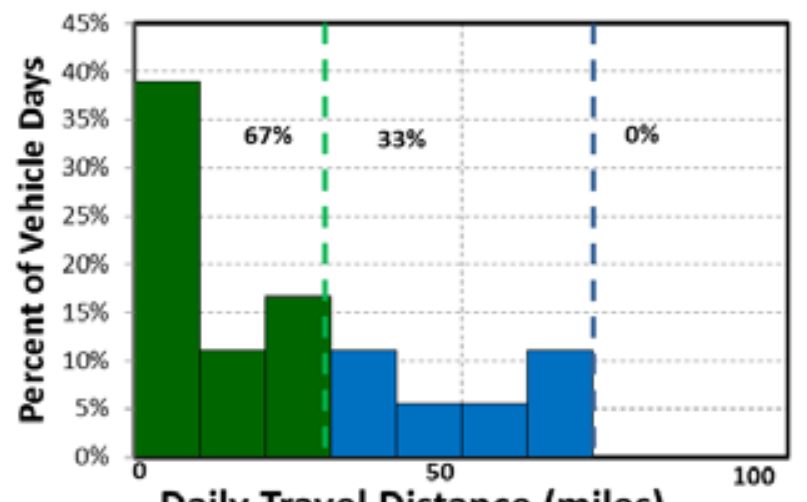

Daily Travel Distance (miles)

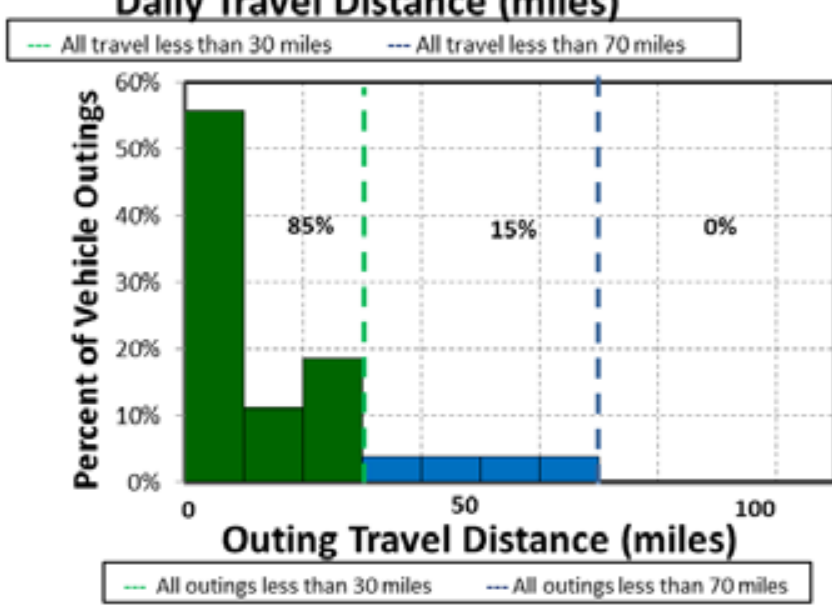

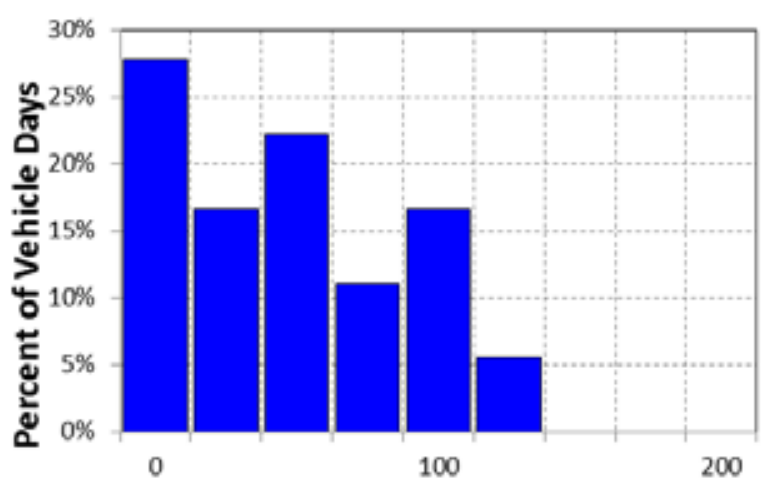

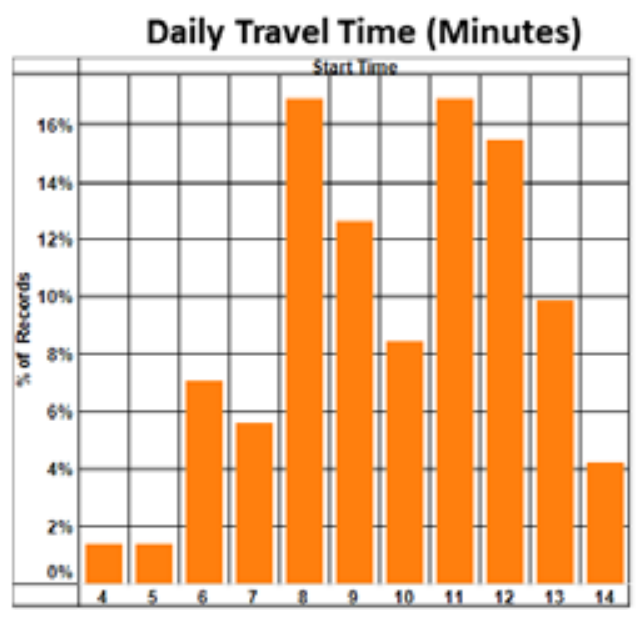

Figure C-108. Vehicle G61-1509D travel graphs.

\section{Vehicle G61-1509D Observations}

Logger 16 collected data on this vehicle for a period of 18 days of the 31-day study period.

Validation occurred on $100 \%$ of the input data. Data indicate that this vehicle has a pool mission for Motor Transport - C-Pool. This vehicle's data indicate it parks near Building 28211 near Bancroft Street as shown in the Google Earth figure to the right.

MCBCL reports that a recent vehicle odometer indicated 26,551 miles at the start of this study and an average annual mileage of 3,292 miles. The vehicle was used on $58 \%$ of the available days, with an average daily usage of 1.0 hours and a peak daily usage of 2.3 hours on the days it was used. The vehicle was used during day shift hours.

Figure C-108 shows that all daily travel was within

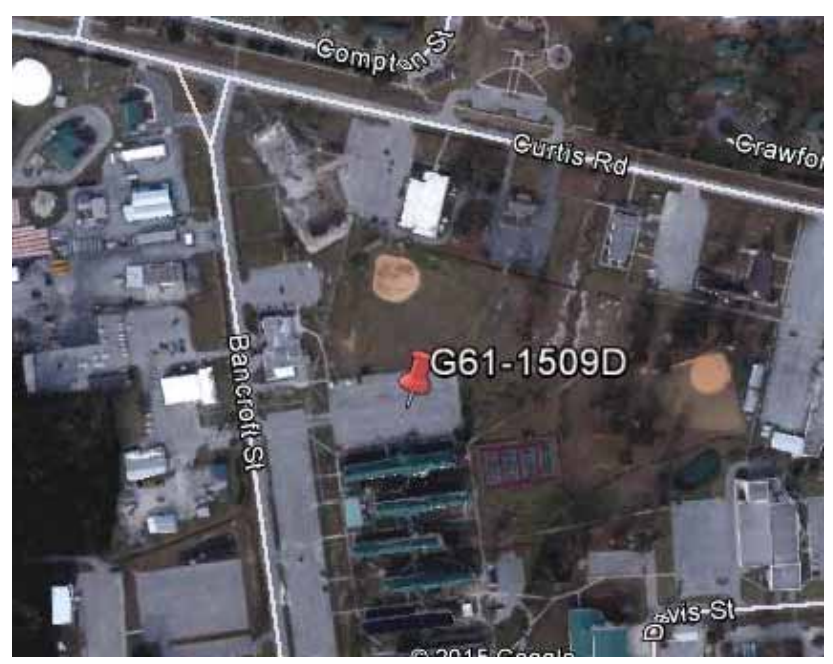
the typically advertised range of a BEV of approximately 70 miles. All outings were also within this range. Further, $67 \%$ of daily travel and $85 \%$ of outings were within the typically advertised CD mode of 30 miles for PHEVs.

A BEV could meet all daily travel without additional charging opportunities, assuming the vehicle was assigned a home base. A fleet of pool vehicles would likely contain a mix of BEVs and PHEVs. 
Sheet 56: Vehicle G62-1583G

\begin{tabular}{|l|l|c|}
\hline \multirow{4}{*}{ Make/Model/Year } & Chevrolet K1500 - 2008 \\
\hline EPA Class Size & Pickup \\
\hline Mission & Support \\
\hline Contact & Building 54 \\
\cline { 2 - 3 } & Parking Location & G62-1583G \\
\hline Fleet Vehicle ID & Gas \\
\hline Fuel Type & $15 / 20 / 17$ \\
\hline & EPA Label/MPG (City/Hwy/Combined) & 523 \\
\hline & EPA GHG Emissions (Grams $\left.\mathrm{CO}_{2} / \mathrm{Mi}\right)$ & 82 \\
\hline & Study Logger ID & $17 / 33$ \\
\hline
\end{tabular}

\begin{tabular}{|l|c|c|c|c|}
\hline \multicolumn{5}{|c|}{ Vehicle G62-1583G Travel Summary } \\
\hline & $\begin{array}{c}\text { Per Day } \\
\text { Average/Peak }\end{array}$ & $\begin{array}{c}\text { Per Outing } \\
\text { Average/Peak }\end{array}$ & $\begin{array}{c}\text { Per Trip } \\
\text { Average/Peak }\end{array}$ & Total \\
\hline Travel Distance (Miles) & $52.8 / 128.3$ & $39.1 / 102.9$ & $8.9 / 38.2$ & 898 \\
\hline Travel Time (Minutes) & $104.9 / 235.0$ & $77.5 / 179.0$ & $17.7 / 81.0$ & 1,783 \\
\hline Idle Time (Minutes) & $7.4 / \mathrm{NA}$ & $5.5 / \mathrm{NA}$ & $1.2 / \mathrm{NA}$ & 126 \\
\hline
\end{tabular}

\begin{tabular}{|c|c|c|c|c|}
\hline \multicolumn{2}{|c|}{ Total Stops } & \multicolumn{2}{c|}{ Stop Duration } \\
\hline $\begin{array}{c}\text { Distance From } \\
\text { Home Base (Miles) }\end{array}$ & Stops & Percentages & Stop Duration (Hours) & Stops \\
\hline Less than 10 & 90 & $100 \%$ & Less than 2 & 67 \\
\hline 10 to 20 & 0 & 0 & 2 to 4 & 6 \\
\hline 20 to 40 & 0 & 0 & 4 to 8 & 1 \\
\hline 40 to 60 & 0 & 0 & \\
\hline
\end{tabular}

Figure C-109. Vehicle G61-1583G stops.

Figure C-110. Vehicle G61-1583G history. 

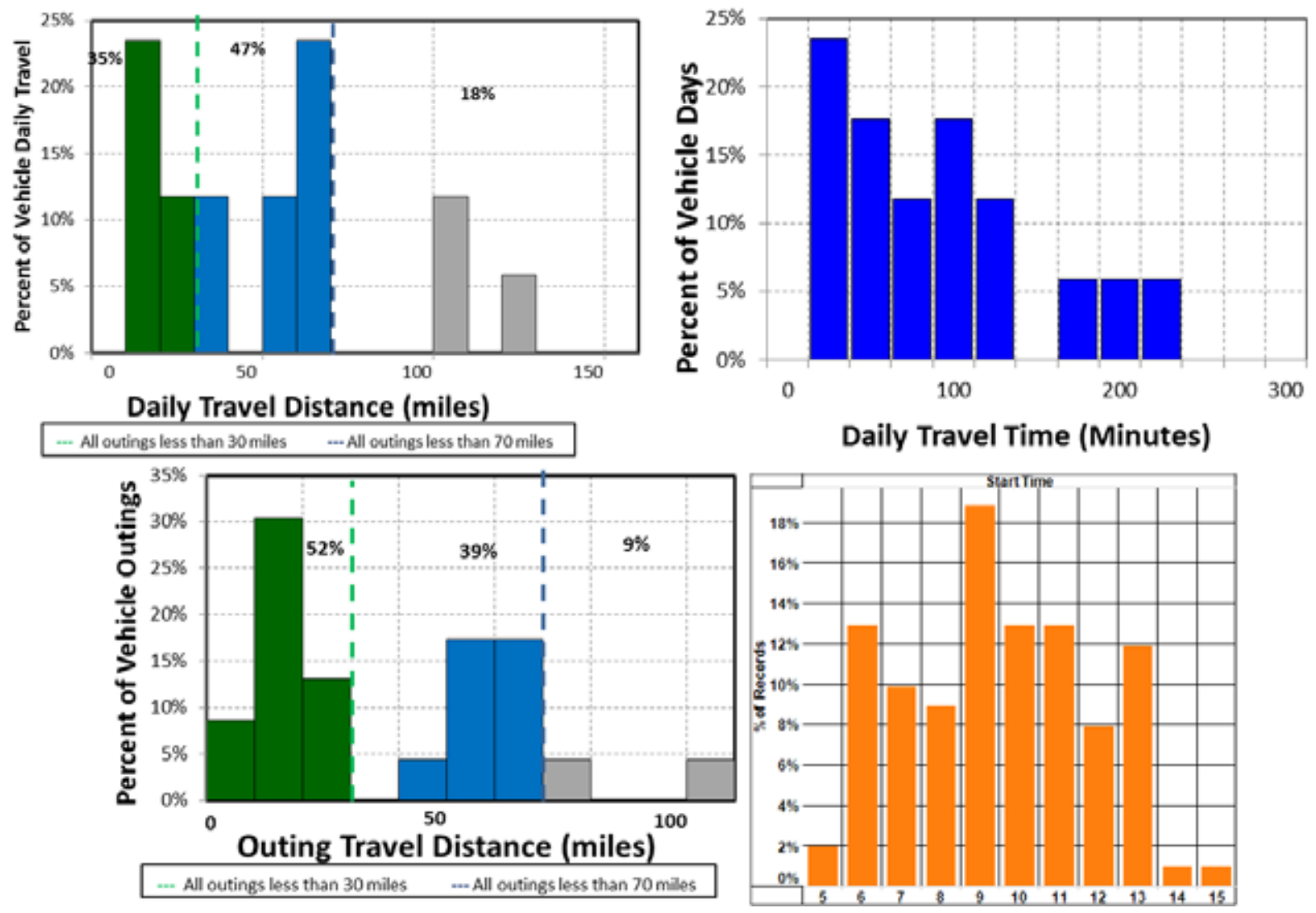

Figure C-111. Vehicle G62-1583G travel graphs.

\section{Vehicle G62-1583G Observations}

Logger 82 collected data on this vehicle for a period of 17 days of the 33-day study period. Validation occurred on $100 \%$ of the input data. Data indicate that this vehicle has a support mission for G3 - Operations and Training. This vehicle's data indicate it parks near Building 54 near Post Lane as shown in the Google Earth figure to the right.

MCBCL reports that a recent vehicle odometer indicated 60,381 miles at the start of this study and an average annual mileage of 10,816 miles. The vehicle was used on $52 \%$ of the available days, with an average daily usage of 1.7 hours and a peak daily usage of 3.9 hours on the days it was used. The vehicle was used during day shift hours.

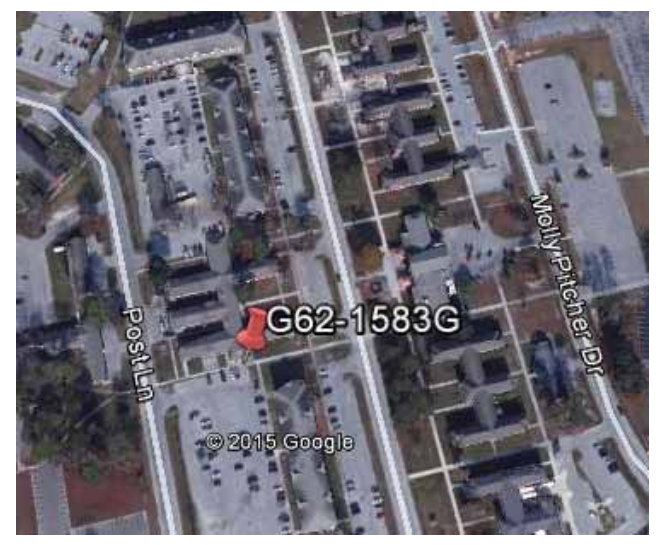

Figure C-111 shows that $82 \%$ of daily travel was within the typically advertised range of a BEV of approximately 70 miles and $91 \%$ of outings were also within this range. Further, $35 \%$ of daily travel and $52 \%$ of outings were within the typically advertised CD mode of 30 miles for PHEVs.

A BEV could not meet all daily travel without additional charging opportunities; however, there is not enough time each day for these charging opportunities. A significant amount of the daily travel was within the BEV range. Thus, a fleet of G-3 support vehicles would likely contain a mix of BEVs and PHEVs, favoring the BEVs. 
Sheet 57: Vehicle G62-4085L

\begin{tabular}{|c|c|c|}
\hline 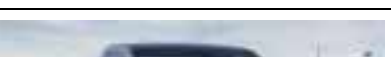 & Make/Model/Year & Dodge $1500-2012$ \\
\hline$a$ & EPA Class Size & Pickup \\
\hline$\theta_{0}=0=$ & Mission & Support \\
\hline 1 & Contact & Fire Department \\
\hline & Parking Location & Building 58 \\
\hline & Fleet Vehicle ID & G62-4085L \\
\hline & Fuel Type & E85 \\
\hline & EPA Label/MPG (City/Hwy/Combined) & $10 / 12 / 11$ \\
\hline & EPA GHG Emissions (Grams $\left.\mathrm{CO}_{2} / \mathrm{Mi}\right)$ & 564 \\
\hline & Study Logger ID & 46 \\
\hline & Total Vehicle Days/Total Study Days & $18 / 31$ \\
\hline
\end{tabular}

\begin{tabular}{|l|c|c|c|c|}
\hline \multicolumn{5}{|c|}{ Vehicle G62-4085L Travel Summary } \\
\hline & $\begin{array}{c}\text { Per Day } \\
\text { Average/Peak }\end{array}$ & $\begin{array}{c}\text { Per Outing } \\
\text { Average/Peak }\end{array}$ & $\begin{array}{c}\text { Per Trip } \\
\text { Average/Peak }\end{array}$ & Total \\
\hline Travel Distance (Miles) & $34.8 / 77.0$ & $19.6 / 67.8$ & $5.6 / 30.6$ & 626 \\
\hline Travel Time (Minutes) & $97.4 / 296.0$ & $54.8 / 213.0$ & $15.8 / 118.0$ & 1,754 \\
\hline Idle Time (Minutes) & $20.3 / \mathrm{NA}$ & $11.4 / \mathrm{NA}$ & $3.3 / \mathrm{NA}$ & 365 \\
\hline
\end{tabular}

\begin{tabular}{|c|c|c|}
\hline \multicolumn{3}{|c|}{ Total Stops } \\
\hline $\begin{array}{c}\text { Distance From } \\
\text { Home Base (Miles) }\end{array}$ & Stops & Percentages \\
\hline Less than 10 & 108 & $100 \%$ \\
\hline 10 to 20 & 0 & 0 \\
\hline 20 to 40 & 0 & 0 \\
\hline 40 to 60 & 0 & 0 \\
\hline
\end{tabular}

Figure C-112. Vehicle G62-4085L stops.

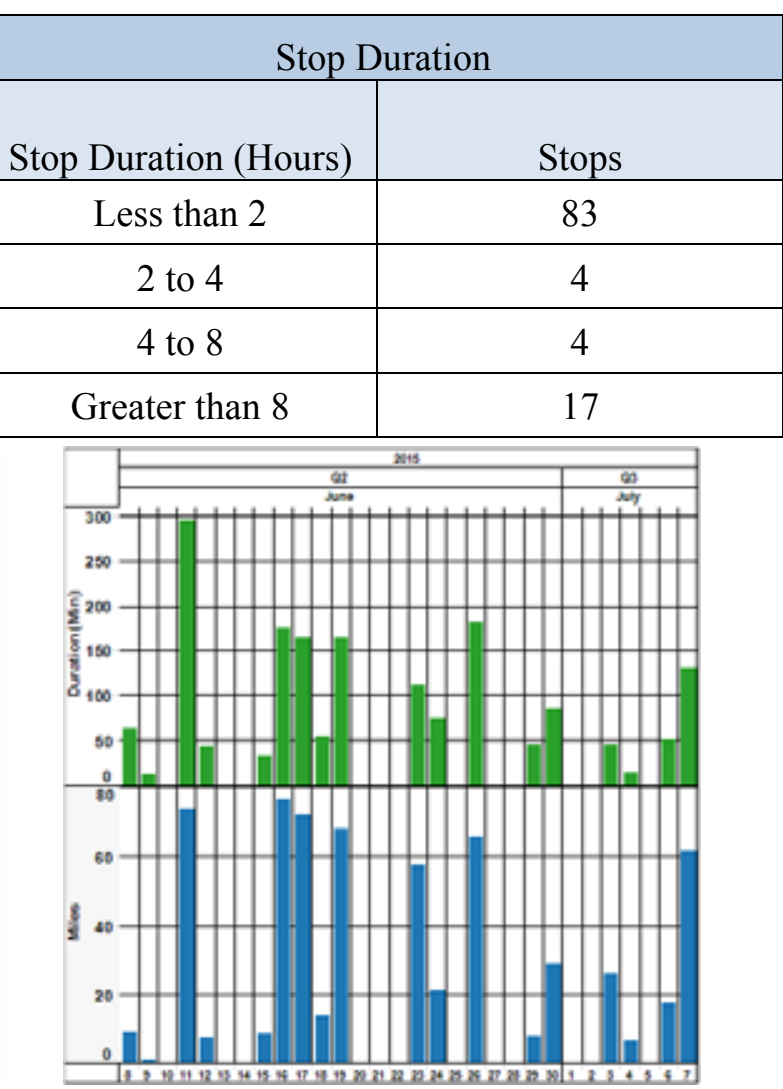

Figure C-113. Vehicle G62-4085L history. 


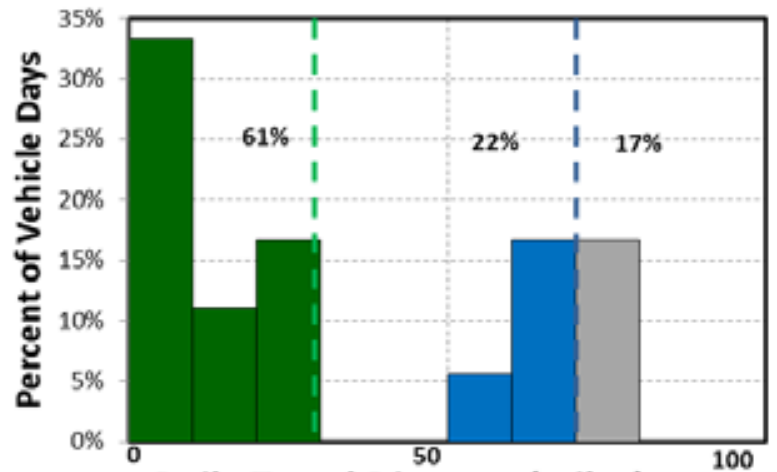

Daily Travel Distance (miles)

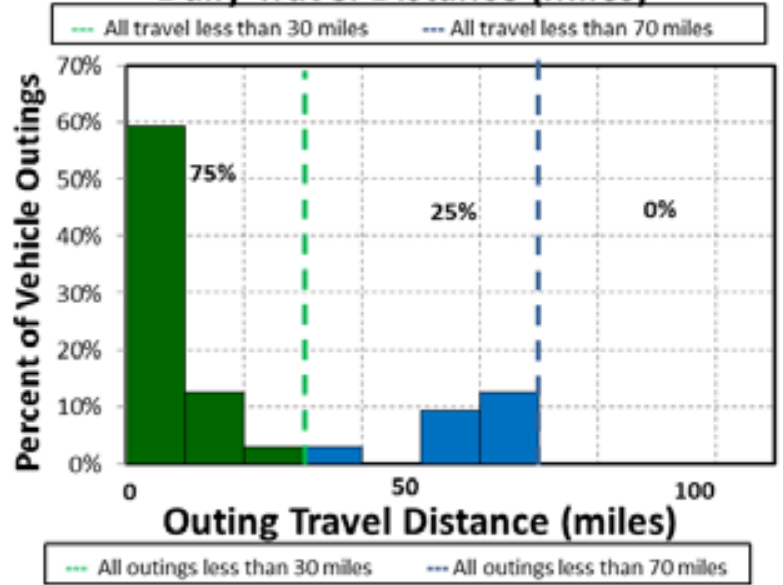

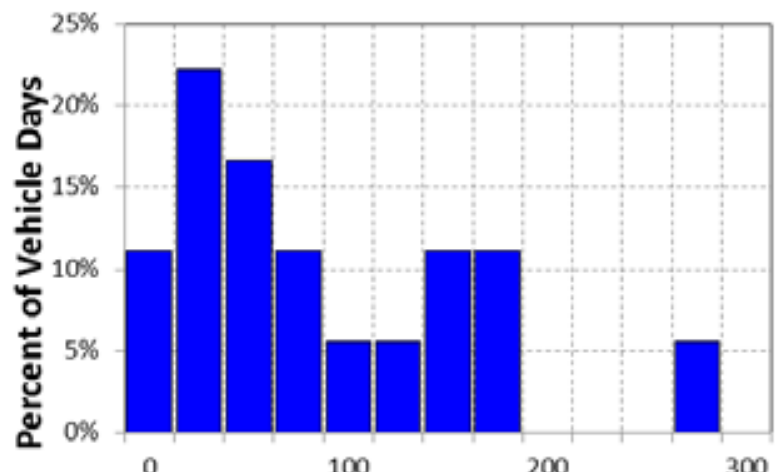

Daily Travel Time (Minutes)

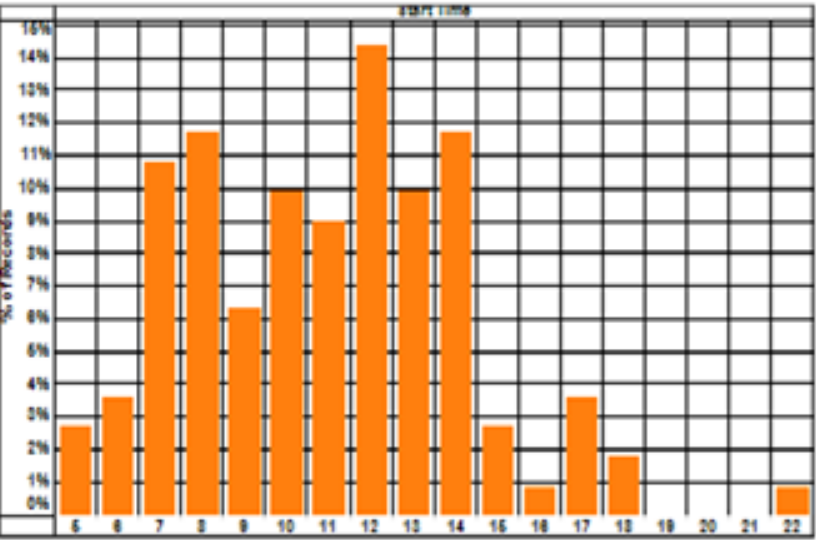

Figure C-114. Vehicle G62-4085L travel graphs.

\section{Vehicle G62-4085L Observations}

Logger 46 collected data on this vehicle for a period of 18 days of the 31-day study period. Validation occurred on $100 \%$ of the input data. Data indicate that this vehicle has a support mission for the Fire Department. This vehicle's data indicate it parks near Building 58 near Virginia Dare Drive as shown in the Google Earth figure to the right.

MCBCL reports that a recent vehicle odometer indicated 17,386 miles at the start of this study and an average annual mileage of 10,608 miles. The vehicle was used on $58 \%$ of the available days, with an average daily usage of 1.6 hours and a peak daily usage of 4.9 hours on the days it was used. The vehicle was used during extended day shift hours.

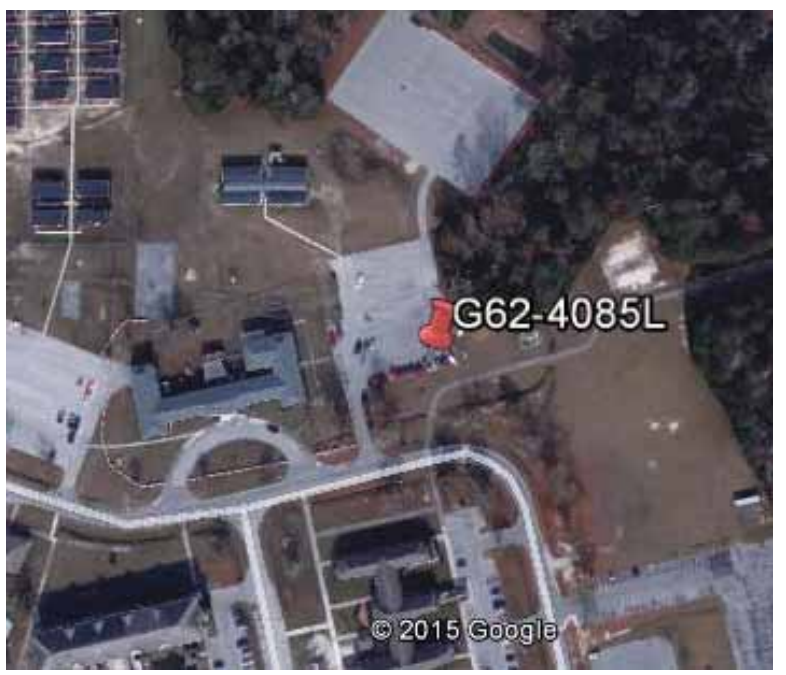

Figure C-114 shows that $83 \%$ of daily travel was within the typically advertised range of a BEV of approximately 70 miles. All outings were also within this range. Further, $61 \%$ of daily travel and $75 \%$ of outings were within the typically advertised CD mode of 30 miles for PHEVs.

A BEV could not meet all daily travel without additional charging opportunities and recharge time is available each day to accomplish this. However, fleet managers may desire their fleet of support vehicles to contain a mix of BEVs and PHEVs. 
Sheet 58: Vehicle G63-0163H

\begin{tabular}{|c|c|c|}
\hline \multirow{4}{*}{$\sum_{\log t \theta}$} & Make/Model/Year & Chevrolet K2500HD - 2009 \\
\hline & EPA Class Size & Pickup \\
\hline & Mission & Support \\
\hline & Contact & Marine Corps Air Station \\
\hline & Parking Location & Building AS427 \\
\hline & Fleet Vehicle ID & G63-0163H \\
\hline & Fuel Type & Gas \\
\hline & EPA Label/MPG (City/Hwy/Combined) & $14 / 20 / 16$ \\
\hline & EPA GHG Emissions (Grams $\left.\mathrm{CO}_{2} / \mathrm{Mi}\right)$ & 555 \\
\hline & Study Logger ID & 98 \\
\hline & Total Vehicle Days/Total Study Days & $18 / 33$ \\
\hline
\end{tabular}

\begin{tabular}{|l|c|c|c|c|}
\hline \multicolumn{5}{|c|}{ Vehicle G63-0163H Travel Summary } \\
\hline & $\begin{array}{c}\text { Per Day } \\
\text { Average/Peak }\end{array}$ & $\begin{array}{c}\text { Per Outing } \\
\text { Average/Peak }\end{array}$ & Per Trip Average/Peak & Total \\
\hline Travel Distance (Miles) & $28.2 / 51.6$ & $5.4 / 51.6$ & $2.4 / 50.0$ & 508 \\
\hline Travel Time (Minutes) & $127.2 / 269.0$ & $24.4 / 127.0$ & $10.6 / 123.0$ & 2,289 \\
\hline Idle Time (Minutes) & $22.5 / \mathrm{NA}$ & $4.3 / \mathrm{NA}$ & $1.9 / \mathrm{NA}$ & 405 \\
\hline
\end{tabular}

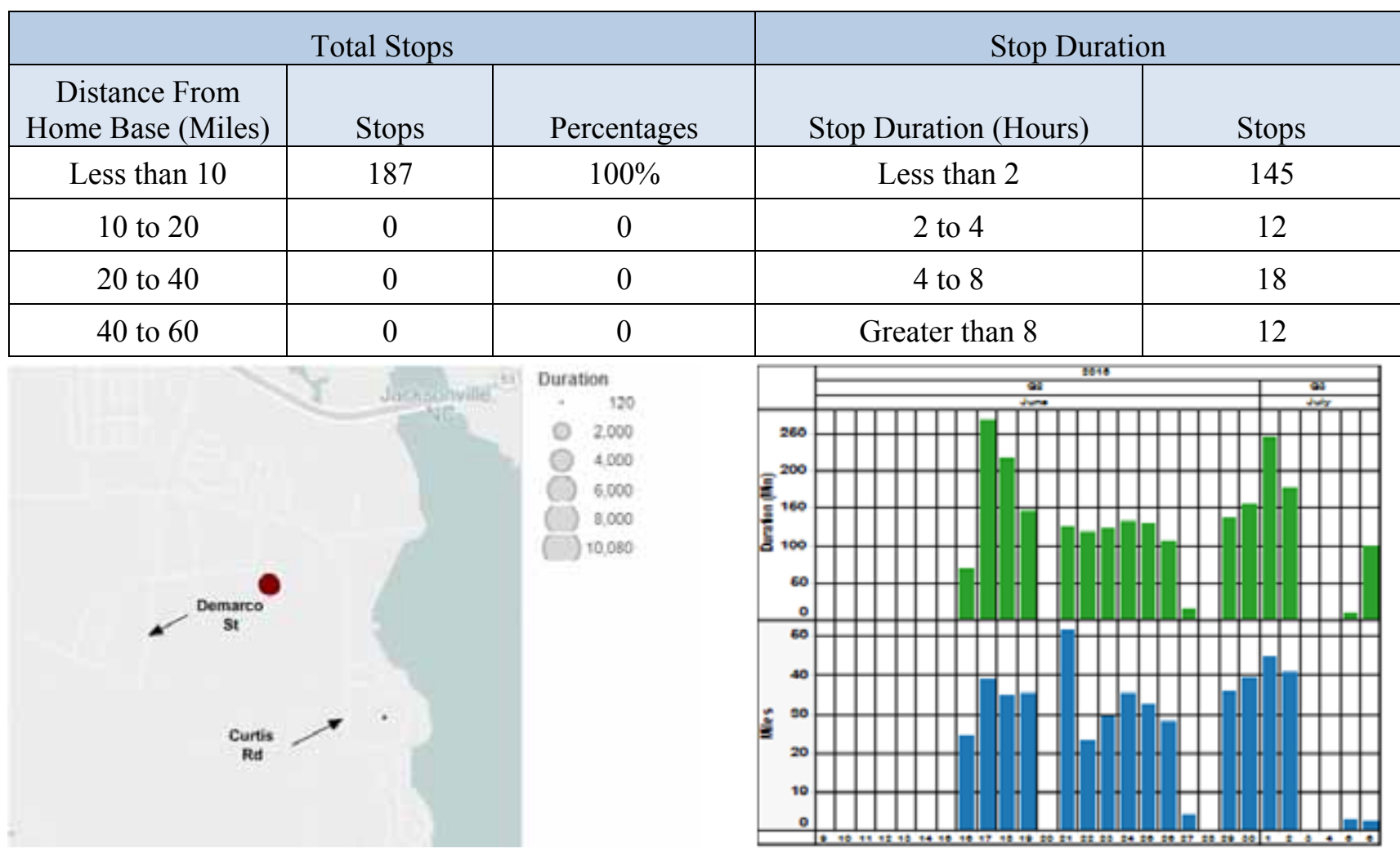

Figure C-115. Vehicle G63-0163H stops.

Figure C-116. Vehicle G63-0163H history. 


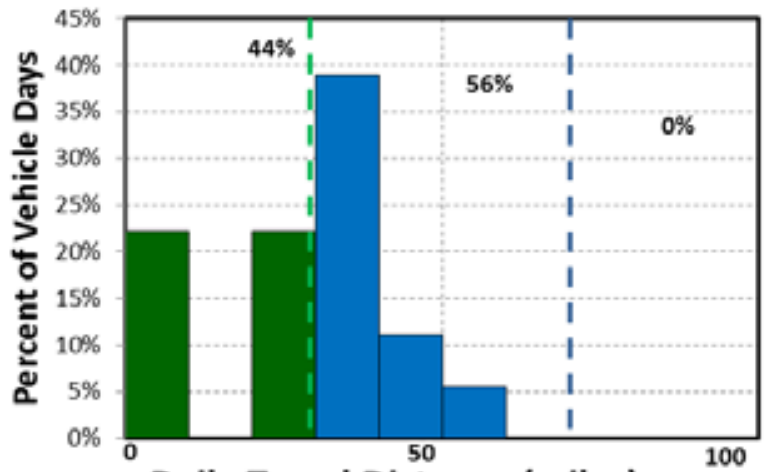

Daily Travel Distance (miles)

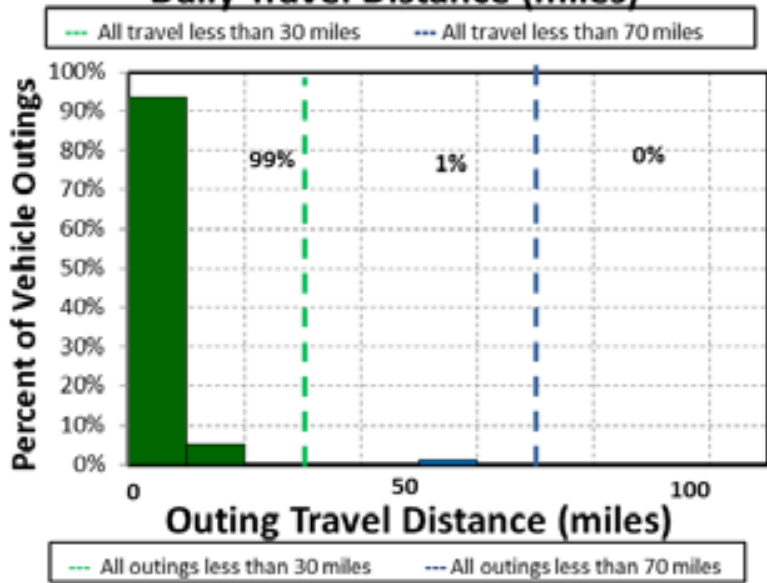

All outings less than 30 miles

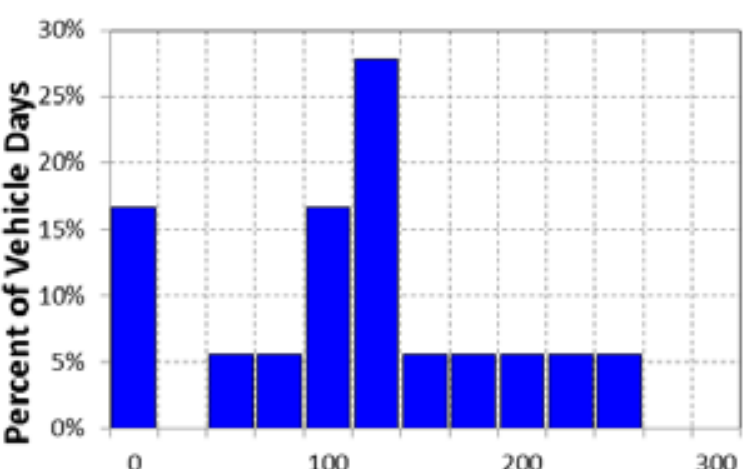

Daily Travel Time (Minutes)

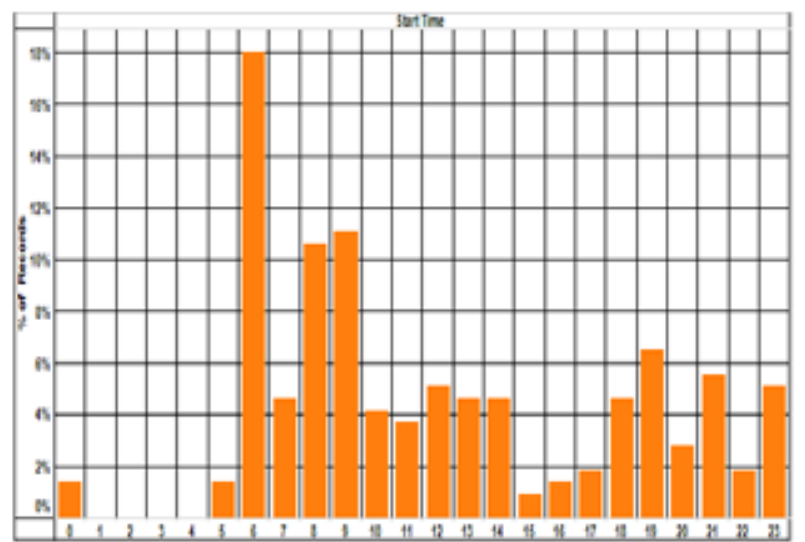

Figure C-117. Vehicle G63-0163H travel graphs.

\section{Vehicle G63-0163H Observations}

Logger 98 collected data on this vehicle for a period of 18 days of the 33-day study period. Validation occurred on $100 \%$ of the input data. Data indicate that this vehicle has a support mission for Marine Corps Air Station. This vehicle's data indicate it parks near Building AS427 near Campbell Street as shown in the Google Earth figure to the right.

MCBCL reports that a recent vehicle odometer indicated 57,812 miles at the start of this study and an average annual mileage of 9,018 miles. The vehicle was used on $55 \%$ of the available days, with an average daily usage of 2.1 hours and a peak daily usage of 4.5 hours on the days it was used. The vehicle was used during day and evening hours of the day.

Figure $\mathrm{C}-117$ shows that all daily travel was within the

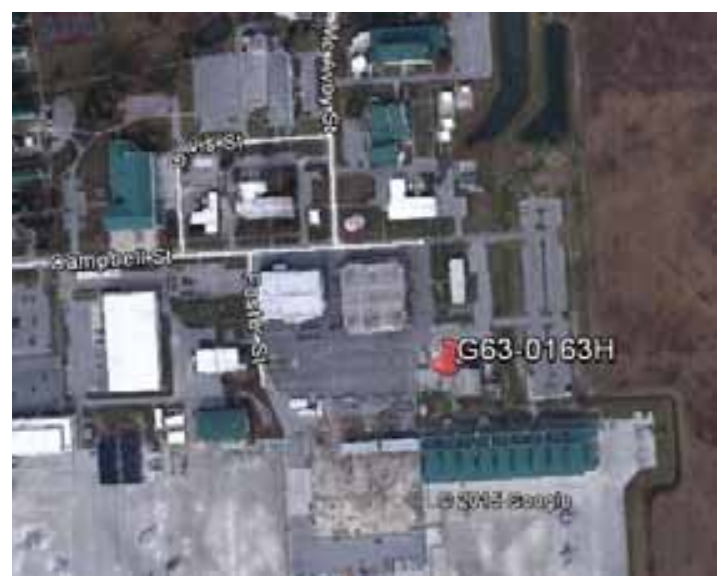
typically advertised range of a BEV of approximately 70 miles. All outings were also within this range. Further, $44 \%$ of daily travel and $99 \%$ of outings were within the typically advertised CD mode of 30 miles for PHEVs.

A BEV could meet all daily travel without additional charging opportunities, assuming the vehicle was assigned a home base. However, fleet managers typically prefer some support vehicles without range limitations. Thus, a fleet of support vehicles would likely contain a mix of BEVs and PHEVs. 
Sheet 59: Vehicle G63-2885L

\begin{tabular}{|l|l|c|}
\hline Make/Model/Year & Chevrolet K2500HD - 2012 \\
\hline EPA Class Size & Pickup \\
\hline Mission & Support \\
\hline & Contact & Fire Department \\
\cline { 2 - 3 } & Parking Location & Guilding 2600 \\
\cline { 2 - 3 } & Fleet Vehicle ID & E83-2885L \\
\hline & Fuel Type & $11 / 16 / 13$ \\
\hline & EPA Label/MPG (City/Hwy/Combined) & 477 \\
\hline & EPA GHG Emissions (Grams CO $/$ Mi) & 47 \\
\hline & Study Logger ID & $29 / 31$ \\
\hline
\end{tabular}

\begin{tabular}{|c|c|c|c|c|}
\hline \multicolumn{5}{|c|}{ Vehicle G63-2885L Travel Summary } \\
\hline & $\begin{array}{c}\text { Per Day } \\
\text { Average/Peak }\end{array}$ & $\begin{array}{c}\text { Per Outing } \\
\text { Average/Peak }\end{array}$ & $\begin{array}{c}\text { Per Trip } \\
\text { Average/Peak }\end{array}$ & Total \\
\hline Travel Distance (Miles) & $16.2 / 107.7$ & $9.2 / 103.4$ & $6.0 / 56.0$ & 470 \\
\hline Travel Time (Minutes) & $55.8 / 347.0$ & $31.7 / 345.0$ & $20.8 / 129.0$ & 1,619 \\
\hline Idle Time (Minutes) & $25.6 / \mathrm{NA}$ & $14.5 / \mathrm{NA}$ & $9.5 / \mathrm{NA}$ & 741 \\
\hline
\end{tabular}

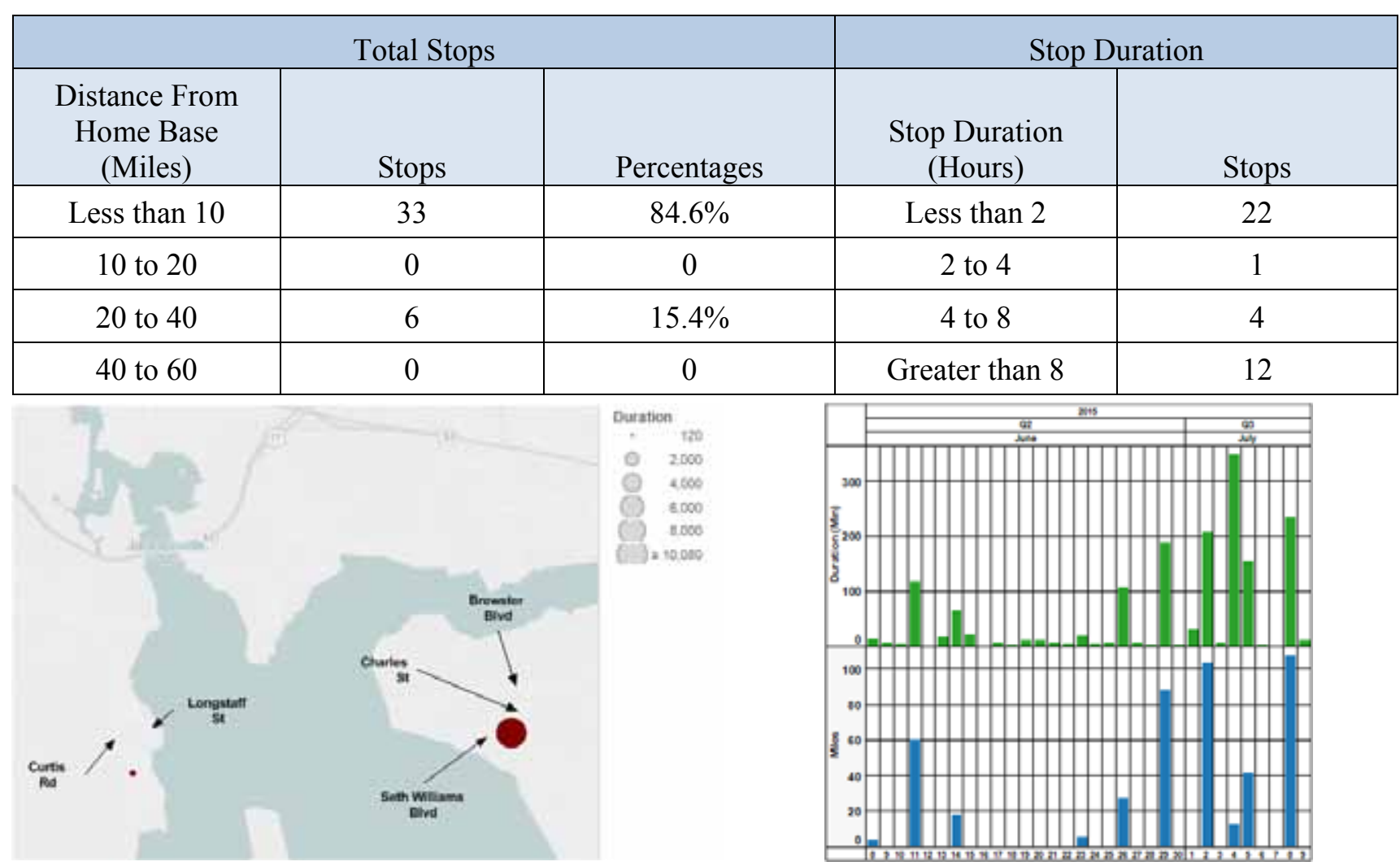

Figure C-118. Vehicle G63-2885L stops.

Figure C-119. Vehicle G63-2885L history. 

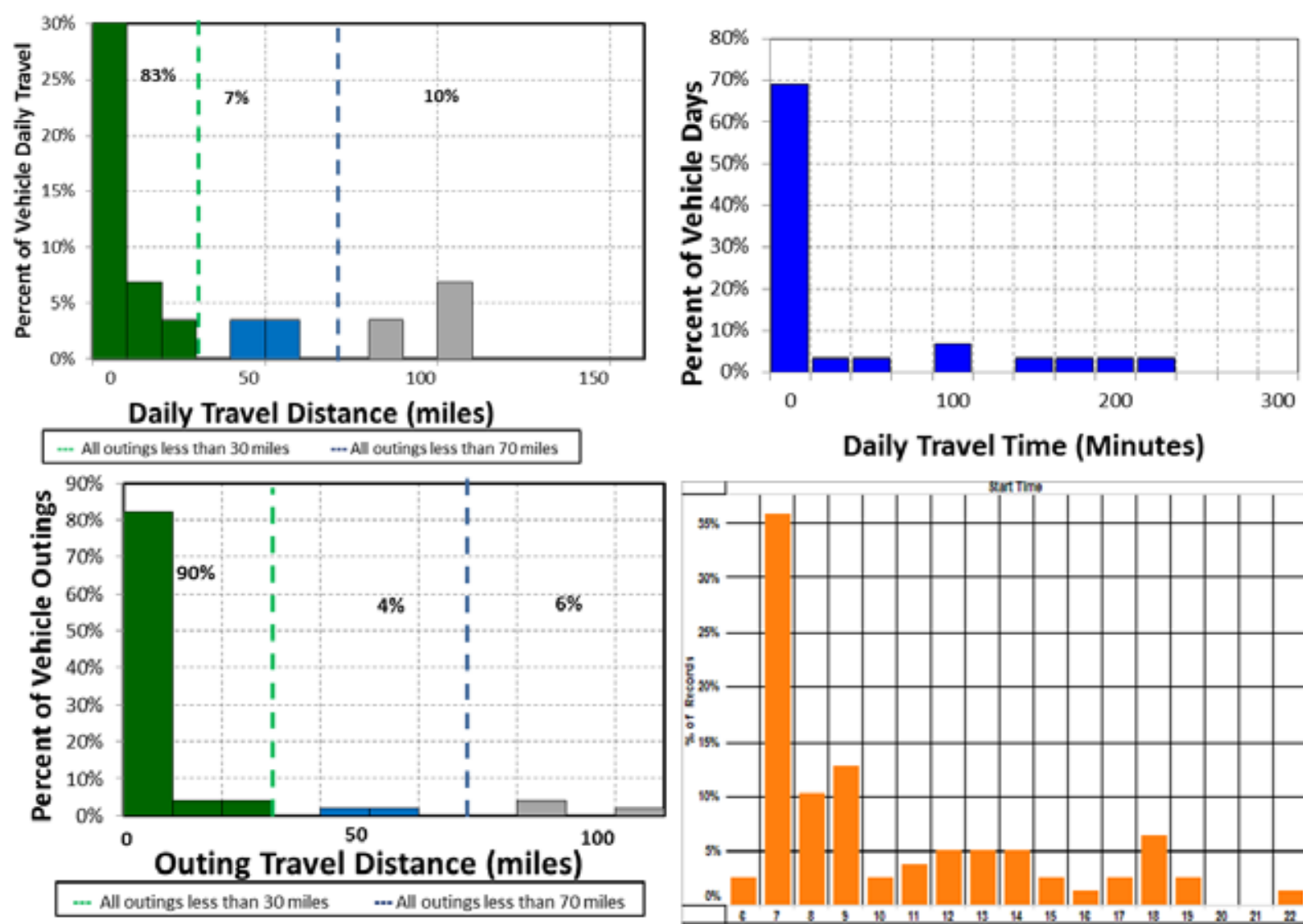

Daily Travel Time (Minutes)

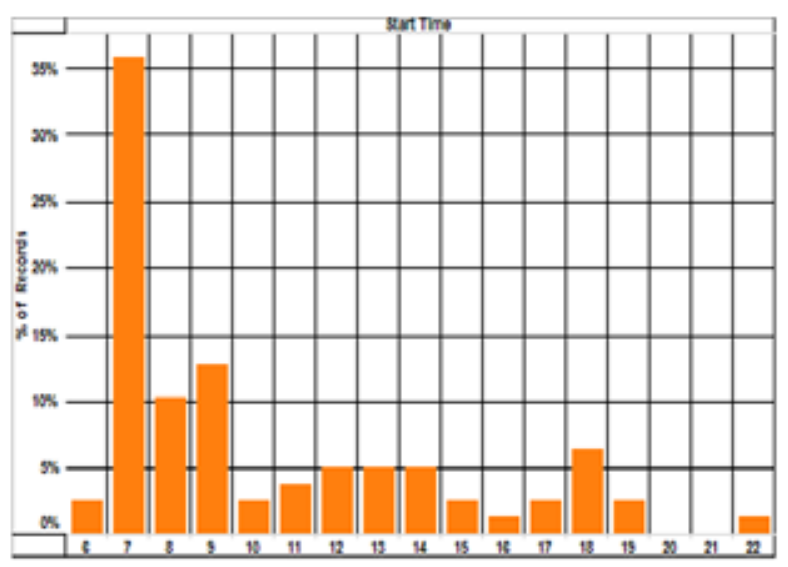

Figure C-120. Vehicle G63-2885L travel graphs.

\section{Vehicle G63-2885L Observations}

Logger 47 collected data on this vehicle for a period of 29 days of the 31-day study period. Validation occurred on $100 \%$ of the input data. Data indicate that this vehicle has a support mission for the Fire Department. This vehicle's data indicate it parks near Building 2600 near Charles Street as shown in the Google Earth figure to the right.

MCBCL reports that a recent vehicle odometer indicated 10,474 miles at the start of this study and an average annual mileage of 4,112 miles. The vehicle was used on $94 \%$ of the available days, with an average daily usage of 0.9 hours and a peak daily usage of 5.8 hours on the days it was used. The vehicle was used during extended day shift hours.

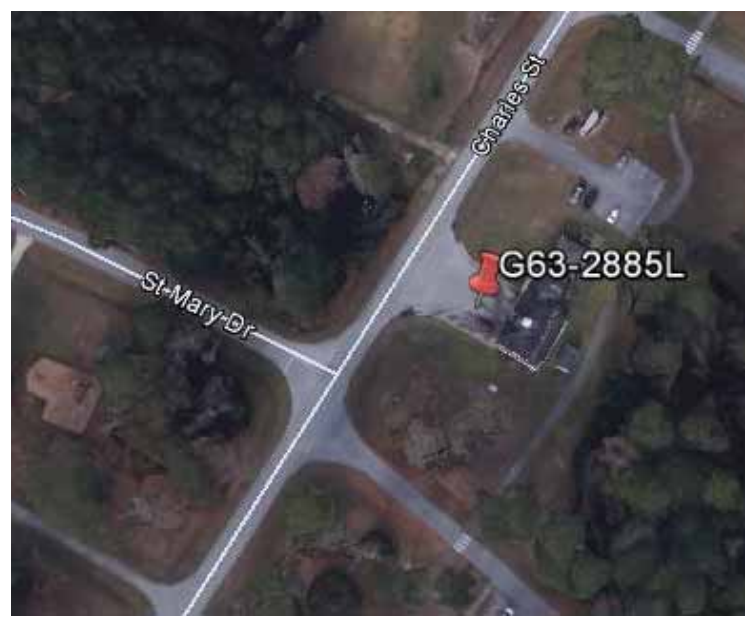

Figure C-120 shows that $90 \%$ of daily travel was within the typically advertised range of a BEV of approximately 70 miles and $94 \%$ of outings were also within this range. Further, $83 \%$ of daily travel and $90 \%$ of outings were within the typically advertised CD mode of 30 miles for PHEVs.

A BEV could not meet all daily travel without additional charging opportunities, but daily use shows sufficient time is available for recharging. All outings were within the range of the BEV, which supports a BEV in this operation. However, fleet managers typically prefer support vehicles that may not have range limitations. Thus, a fleet of support vehicles would likely contain a mix of BEVs and PHEVs, favoring BEVs. 
Sheet 60: Vehicle G63-2888L

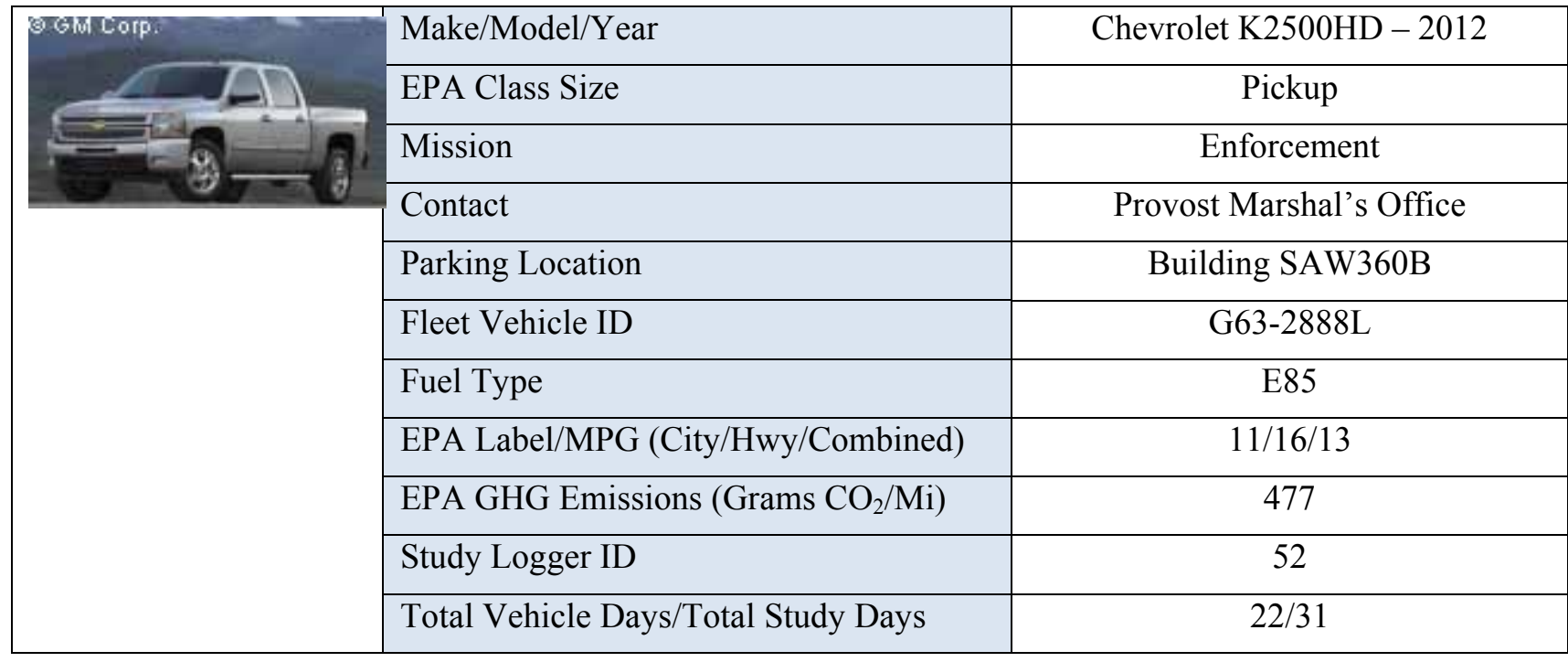

\begin{tabular}{|l|c|c|c|c|}
\hline \multicolumn{5}{|c|}{ Vehicle G63-2888L Travel Summary } \\
\hline & $\begin{array}{c}\text { Per Day } \\
\text { Average/Peak }\end{array}$ & $\begin{array}{c}\text { Per Outing } \\
\text { Average/Peak }\end{array}$ & $\begin{array}{c}\text { Per Trip } \\
\text { Average/Peak }\end{array}$ & Total \\
\hline Travel Distance (Miles) & $24.4 / 115.3$ & $15.7 / 110.2$ & $6.2 / 55.6$ & 533 \\
\hline Travel Time (Minutes) & $96.5 / 439.0$ & $62.4 / 231.0$ & $24.7 / 118.0$ & 2,122 \\
\hline Idle Time (Minutes) & $40.1 / \mathrm{NA}$ & $26.0 / \mathrm{NA}$ & $10.3 / \mathrm{NA}$ & 883 \\
\hline
\end{tabular}

\begin{tabular}{|c|c|c|c|c|c|}
\hline \multicolumn{3}{|c|}{ Total Stops } & \multicolumn{3}{c|}{ Stop Duration } \\
\hline $\begin{array}{c}\text { Distance From } \\
\text { Home Base (Miles) }\end{array}$ & Stops & Percentages & Stop Duration (Hours) & Stops \\
\hline Less than 10 & 85 & $94.4 \%$ & Less than 2 & 60 \\
\hline 10 to 20 & 0 & 0 & 2 to 4 & 6 \\
\hline 20 to 40 & 5 & $5.6 \%$ & 4 to 8 & 2 \\
\hline 40 to 60 & 0 & 0 & Greater than 8 & \\
\hline
\end{tabular}

Figure C-121. Vehicle G63-2888L stops.

Figure C-122. Vehicle G63-2888L history. 


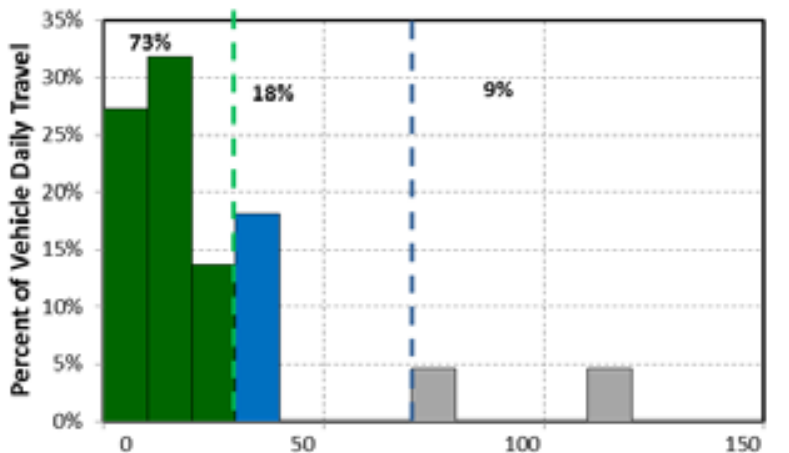

Daily Travel Distance (miles)

... All outings less than 30 miles .... All outings less than 70 miles

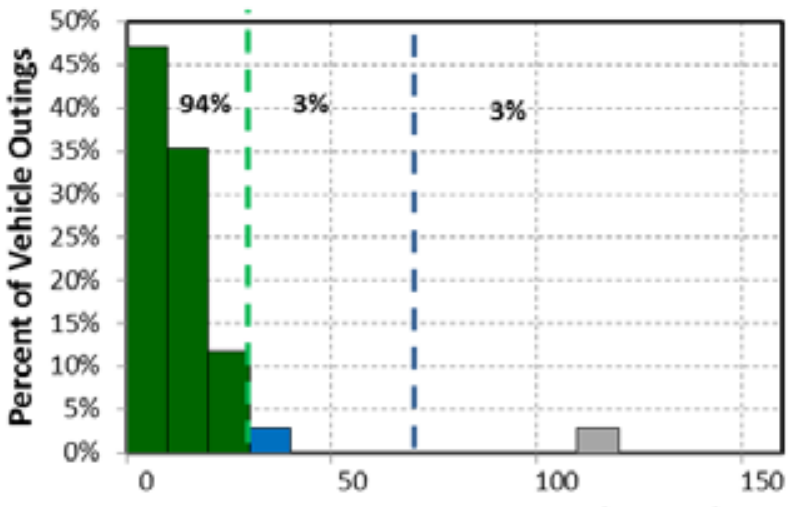

Outing Travel Distance (miles)

... All outings less than 30 miles $\quad$... All outings less than 70 miles

Figure C-123. Vehicle G63-2888L travel graphs.

\section{Vehicle G63-2888L Observations}

Logger 52 collected data on this vehicle for a period of 22 days of the 31-day study period. Validation occurred on $100 \%$ of the input data. Data indicate that this vehicle has a support mission for the Provost Marshal's Office. This vehicle's data indicate it parks near Building SAW360B near Sawmill Road as shown in the Google Earth figure to the right.

MCBCL reports that a recent vehicle odometer indicated 13,548 miles at the start of this study and an average annual mileage of 4,480 miles. The vehicle was used on $71 \%$ of the available days, with an average daily usage of 1.6 hours and a peak daily usage of 7.3 hours on the days it was used. The vehicle was used during day shift and evening hours.

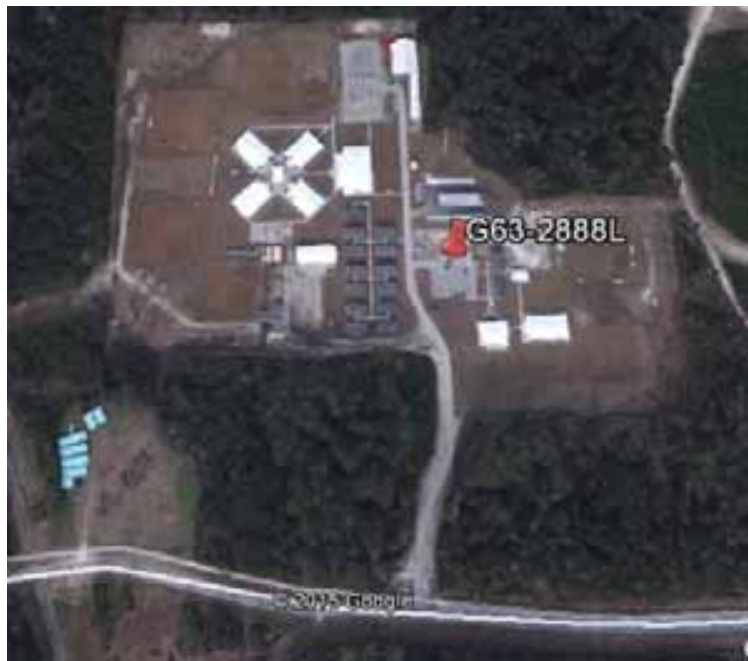

Figure C-123 shows that $91 \%$ of daily travel was within the typically advertised range of a BEV of approximately 70 miles and $97 \%$ of the outings were also within this range. Further, $73 \%$ of daily travel and $94 \%$ of outings were within the typically advertised CD mode of 30 miles for PHEVs.

A BEV could not meet all daily travel without additional charging opportunities; these charge opportunities are available. However, fleet managers typically do not prefer enforcement vehicles that contain range limitations. Thus, a fleet of enforcement vehicles would likely contain a mix of BEVs and PHEVs. 


\section{Appendix D}

\section{Greenhouse Gas Emissions Avoided and fuel Cost Reduction Analysis - Commands Group}

\section{D.1 Replacement Plug-In Electric Vehicles for Commands Group Fleet}

Section 4.1 provided the analysis results for the Commands group vehicles that were monitored during the study period based on the data recorded and reported in the vehicle data sheets found in Appendix B. For the study, PEV replacements are based on vehicle class. The observations of Section 4.1.2.3 suggest that replacing these vehicles with eight BEVs and 10 PHEVs would meet current mission requirements.

Specific vehicle cargo requirements have not been specified and were not considered in these replacement suggestions. Table D-1 identifies the PEVs suggested for these ICE vehicle replacements.

Table D-1. MCBCL Commands Group PEV replacements.

\begin{tabular}{|c|c|c|c|c|c|c|}
\hline \multicolumn{7}{|c|}{ Vehicle Replacements } \\
\hline Log & \multicolumn{2}{|c|}{ Current Vehicle } & EPA Class & \multicolumn{2}{|c|}{ Replacement PEV } & Mission \\
\hline 88 & Ford & E250 & Van - Pass & Nissan & eNV200 & Support \\
\hline 17 & Ford & F350 & Pickup & Nissan & eNV200 & Support \\
\hline 95 & Dodge & Grand Caravan & Minivan & Mitsubishi & Outlander & Support \\
\hline 86 & Dodge & Grand Caravan & Minivan & Mitsubishi & Outlander & Support \\
\hline 83 & Dodge & Dakota & Pickup & Nissan & eNV200 & Support \\
\hline 90 & Ford & E150 & Van - Pass & Nissan & eNV200 & Support \\
\hline 92 & Ford & E150 & Van - Pass & Via Motors & VTRUX Van & Support \\
\hline 84 & Ford & E150 & Van - Pass & Via Motors & VTRUX Van & Support \\
\hline 18 & Chevrolet & $2500 \mathrm{HD}$ & Pickup & Nissan & eNV200 & Support \\
\hline 103 & Chevrolet & G2300 & Van - Pass & Kia & Soul & Support \\
\hline 19 & Ford & F350 & Pickup & Via Motors & VTRUX PU & Support \\
\hline 20 & Ford & F250 & Pickup & Kia & Soul & Support \\
\hline 110 & Chevrolet & G2300 & Van - Pass & Nissan & eNV200 & Support \\
\hline 87 & Jeep & Patriot & SUV & Mitsubishi & Outlander & Support \\
\hline 94 & Jeep & Patriot & SUV & Mitsubishi & Outlander & Support \\
\hline 91 & Ford & Expedition & SUV & Mitsubishi & Outlander & Support \\
\hline 99 & Ford & F350 & Pickup & Via Motors & VTRUX PU & Support \\
\hline 120 & Chevrolet & K3500 & Pickup & Via Motors & VTRUX PU & Support \\
\hline
\end{tabular}

Section 5 provides the methodology and assumptions for calculations of the reduction in GHG emissions and fuel costs. The miles recorded by vehicles during the 31-day study are compared to the MCBCL reported annual miles and where available, the MCBCL annual miles are utilized. If the PEV replacing the monitored vehicle was a $\mathrm{BEV}$, all annual miles could potentially occur in $\mathrm{CD}$ mode. If the PEV is a PHEV, the total miles driven per day where all travel was less than 30 miles was calculated. Thirty miles per day for the balance of days where travel occurred was added and a percentage of total miles monitored was calculated. This represents the percentage of all vehicles miles that could be accomplished in CD mode. That percentage was multiplied by annual miles to identify total annual miles available in $\mathrm{CD}$ mode. Only these miles were used in the reduction calculations. For example, logger 95 recorded 22 days of use. Seven days recorded travel less than 30 miles for a total of 59.8 miles. The remaining 15 days recorded greater than 30 miles; therefore, at 30 miles per day, a total of 450 miles were added for a total of 509.8 miles potentially in CD mode. A total of 1,402 miles were recorded for this 
vehicle; therefore, $36 \%$ of all miles driven by this vehicle were potentially in CD mode. This percent was multiplied by the MCBCL-provided annual mileage to identify annual miles in CD mode.

This is conservative because the replacement PHEV is likely more fuel-efficient than the monitored vehicle when powered by the ICE and additional miles may be available if recharging occurs.

\section{D.2 Monitored Vehicle Fuel Cost Reduction}

Table D-2 identifies the calculated miles in CD mode for each replacement vehicle and the projected fuel cost reductions. As noted in Section 5, both the local cost of fuel and the national average were used for comparisons.

North Carolina fuel costs are close to the national average with gasoline and diesel slightly less but E85 slightly more. As noted in Section 5, Duke Energy Progress' electrical fuel costs are lower than the national average. Section 5 summarized these values.

The fuel costs and GHG emissions avoided are all based on the miles driven in CD mode and the resulting savings in petroleum-based fuels. Table D-2 shows the calculated results for each of the Commands vehicles replaced.

Table D-2. Monitored vehicle PEV replacement fuel savings.

\begin{tabular}{|c|c|c|c|c|c|}
\hline Log & Vehicle ID & $\begin{array}{l}\text { Vehicle } \\
\text { Class }\end{array}$ & $\begin{array}{c}\text { Replacement } \\
\text { PEV }\end{array}$ & $\begin{array}{l}\text { Annual Miles } \\
\text { CD Mode }\end{array}$ & $\begin{array}{c}\text { Gallons Fuel } \\
\text { Saved }\end{array}$ \\
\hline 88 & 291073 & Van - Pass & eNV200 & 2,935 & 183 \\
\hline 17 & 301321 & Pickup & eNV200 & 3,669 & 367 \\
\hline 95 & G41-0762M & Minivan & Outlander & 7,307 & 522 \\
\hline 86 & G41-1846K & Minivan & Outlander & 2,651 & 189 \\
\hline 83 & G41-2399K & Pickup & eNV200 & 10,754 & 566 \\
\hline 90 & G42-0216F & Van - Pass & eNV200 & 2,189 & 137 \\
\hline 92 & G42-0883M & Van - Pass & VTRUX Van & 5,120 & 512 \\
\hline 84 & G42-0898M & Van - Pass & VTRUX Van & 10,254 & 1,025 \\
\hline 18 & G43-0326H & Pickup & eNV200 & 4,863 & 286 \\
\hline 103 & G43-1453G & Van - Pass & Soul & 15,539 & 914 \\
\hline 19 & G43-1855P & Pickup & VTRUX PU & 2,242 & 149 \\
\hline 20 & G43-2025K & Pickup & Soul & 3,755 & 221 \\
\hline 110 & G43-4073F & Van - Pass & eNV200 & 4,712 & 277 \\
\hline 87 & G61-0594L & SUV & Outlander & 2,930 & 117 \\
\hline 94 & G61-2644P & SUV & Outlander & 915 & 38 \\
\hline 91 & G62-0791H & SUV & Outlander & 4,899 & 445 \\
\hline 99 & G63-0309R & Pickup & VTRUX PU & 9,160 & 611 \\
\hline 120 & G63-0934G & Pickup & VTRUX PU & 1,397 & 82 \\
\hline
\end{tabular}

Table D-3 shows the calculated fuel costs for North Carolina and nationally for the gallons of petroleum-based fuel identified in Table D-2.

Table D-3. Monitored vehicle PEV replacement fuel savings (North Carolina and national factors).

\begin{tabular}{|c|c|c|c|c|c|c|c|c|c|}
\hline Log & Vehicle ID & $\begin{array}{c}\text { Local } \\
\text { Fuel Cost }\end{array}$ & $\begin{array}{c}\text { Local } \\
\text { Elect. } \\
\text { Fuel Cost }\end{array}$ & $\begin{array}{l}\text { Local } \\
\text { Annual } \\
\text { Fuel } \\
\text { Savings }\end{array}$ & $\begin{array}{l}\text { Local Fuel } \\
\text { Cost } \\
\text { Reduction }\end{array}$ & $\begin{array}{l}\text { National } \\
\text { Fuel Cost }\end{array}$ & $\begin{array}{l}\text { National } \\
\text { Elect. } \\
\text { Fuel Cost }\end{array}$ & $\begin{array}{l}\text { National } \\
\text { Annual } \\
\text { Fuel } \\
\text { Savings }\end{array}$ & $\begin{array}{c}\text { National } \\
\text { Fuel Cost } \\
\text { Reduction }\end{array}$ \\
\hline 88 & 291073 & $\$ 486$ & $\$ 65$ & $\$ 421$ & $87 \%$ & $\$ 514$ & $\$ 121$ & $\$ 393$ & $76 \%$ \\
\hline 17 & 301321 & $\$ 796$ & $\$ 82$ & $\$ 714$ & $90 \%$ & $\$ 781$ & $\$ 151$ & $\$ 630$ & $81 \%$ \\
\hline 95 & G41-0762M & $\$ 1,133$ & $\$ 179$ & $\$ 954$ & $84 \%$ & $\$ 1,112$ & $\$ 332$ & $\$ 780$ & $70 \%$ \\
\hline 86 & G41-1846K & $\$ 411$ & $\$ 65$ & $\$ 346$ & $84 \%$ & $\$ 403$ & $\$ 120$ & $\$ 283$ & $70 \%$ \\
\hline 83 & G41-2399K & $\$ 1,228$ & $\$ 239$ & $\$ 989$ & $81 \%$ & $\$ 1,206$ & $\$ 444$ & $\$ 762$ & $63 \%$ \\
\hline 90 & $\mathrm{G} 42-0216 \mathrm{~F}$ & $\$ 363$ & $\$ 49$ & $\$ 314$ & $87 \%$ & $\$ 383$ & $\$ 90$ & $\$ 293$ & $76 \%$ \\
\hline
\end{tabular}




\begin{tabular}{|c|c|c|c|c|c|c|c|c|c|}
\hline $\log$ & Vehicle ID & $\begin{array}{c}\text { Local } \\
\text { Fuel Cost }\end{array}$ & $\begin{array}{c}\text { Local } \\
\text { Elect. } \\
\text { Fuel Cost }\end{array}$ & $\begin{array}{c}\text { Local } \\
\text { Annual } \\
\text { Fuel } \\
\text { Savings } \\
\end{array}$ & $\begin{array}{l}\text { Local Fuel } \\
\text { Cost } \\
\text { Reduction }\end{array}$ & $\begin{array}{l}\text { National } \\
\text { Fuel Cost }\end{array}$ & $\begin{array}{l}\text { National } \\
\text { Elect. } \\
\text { Fuel Cost }\end{array}$ & $\begin{array}{l}\text { National } \\
\text { Annual } \\
\text { Fuel } \\
\text { Savings }\end{array}$ & $\begin{array}{l}\text { National } \\
\text { Fuel Cost } \\
\text { Reduction }\end{array}$ \\
\hline 92 & G42-0883M & $\$ 1,111$ & $\$ 135$ & $\$ 976$ & $88 \%$ & $\$ 1,091$ & $\$ 251$ & $\$ 840$ & $77 \%$ \\
\hline 84 & G42-0898M & $\$ 2,225$ & $\$ 271$ & $\$ 1,954$ & $88 \%$ & $\$ 2,184$ & $\$ 503$ & $\$ 1,681$ & $77 \%$ \\
\hline 18 & G43-0326H & $\$ 758$ & $\$ 108$ & $\$ 650$ & $86 \%$ & $\$ 801$ & $\$ 201$ & $\$ 601$ & $75 \%$ \\
\hline 103 & G43-1453G & $\$ 2,422$ & $\$ 277$ & $\$ 2,145$ & $89 \%$ & $\$ 2,560$ & $\$ 513$ & $\$ 2,047$ & $80 \%$ \\
\hline 19 & G43-1855P & $\$ 324$ & $\$ 59$ & $\$ 265$ & $82 \%$ & $\$ 318$ & $\$ 110$ & $\$ 208$ & $65 \%$ \\
\hline 20 & G43-2025K & $\$ 585$ & $\$ 67$ & $\$ 518$ & $89 \%$ & $\$ 619$ & $\$ 124$ & $\$ 495$ & $80 \%$ \\
\hline 110 & G43-4073F & $\$ 735$ & $\$ 105$ & $\$ 630$ & $86 \%$ & $\$ 776$ & $\$ 195$ & $\$ 582$ & $75 \%$ \\
\hline 87 & G61-0594L & $\$ 311$ & $\$ 72$ & $\$ 239$ & $77 \%$ & $\$ 328$ & $\$ 133$ & $\$ 195$ & $59 \%$ \\
\hline 94 & G61-2644P & $\$ 101$ & $\$ 22$ & $\$ 79$ & $78 \%$ & $\$ 107$ & $\$ 42$ & $\$ 65$ & $61 \%$ \\
\hline 91 & G62-0791H & $\$ 966$ & $\$ 120$ & $\$ 846$ & $88 \%$ & $\$ 949$ & $\$ 222$ & $\$ 726$ & $77 \%$ \\
\hline 99 & G63-0309R & $\$ 1,325$ & $\$ 242$ & $\$ 1,083$ & $82 \%$ & $\$ 1,301$ & $\$ 449$ & $\$ 852$ & $65 \%$ \\
\hline 120 & G63-0934G & $\$ 218$ & $\$ 37$ & $\$ 181$ & $83 \%$ & $\$ 230$ & $\$ 68$ & $\$ 162$ & $70 \%$ \\
\hline
\end{tabular}

An example calculation for Logger 86 follows: the MCBCL reported annual miles for this vehicle is 12,317 miles. The suggested replacement PEV is a PHEV. The calculated potential miles in CD mode for the study period was $21.52 \%$; therefore, annual miles in CD mode is 2,651 miles. This vehicle uses E85 and EPA fuel economy for this vehicle is 14 MPG, implying 189 gallons of E85 are unused. North Carolina cost for E85 is $\$ 2.17 /$ gallon for an annual cost of $\$ 411$. The replacement PEV requires $440 \mathrm{Wh} / \mathrm{mile}$; therefore, $1,166 \mathrm{kWh}$ are required for recharging the battery. Local power cost is $\$ 0.05566 / \mathrm{kWh}$, resulting in annual electric cost of $\$ 65$. The savings are $\$ 346$ for an $84 \%$ reduction in fuel cost.

\section{D.3 Monitored Vehicle Greenhouse Gas Reduction}

Tables D-4 and D-5 identify the reduction in GHG emissions projected using local power production emissions and national emissions figures, respectively, when replacing the current vehicles with PEVs. The calculated miles in CD mode shown in Table D-2 are also used in the calculations of GHG emissions reduction. As noted in Section 5, emissions from burning petroleum-based fuel are known and emissions from the use of electricity are dependent on the power generation mix used to recharge the PEV battery. As before, both local power production emission figures and the national average are used for comparisons.

The emissions from Duke Energy Progress generation are lower than the national average. In addition, electrical emissions are significantly lower than gasoline emissions.

Table D-4. Monitored vehicle replacement on GHG emissions reduction (Jacksonville, North Carolina area figures).

\begin{tabular}{|c|c|c|c|c|c|c|}
\hline $\log$ & Vehicle ID & $\begin{array}{c}\text { Vehicle } \\
\text { Class }\end{array}$ & $\begin{array}{c}\text { Annual GHG } \\
\text { Emissions ICE } \\
\text { lb- } \mathrm{CO}_{2} \mathrm{e} \\
\end{array}$ & $\begin{array}{c}\text { Annual PEV } \\
\text { GHG Local } \\
\text { lb- } \mathrm{CO}_{2} \mathrm{e} \\
\end{array}$ & $\begin{array}{c}\text { Annual GHG } \\
\text { Local Savings } \\
\text { lb- } \mathrm{CO}_{2} \mathrm{e} \\
\end{array}$ & $\begin{array}{c}\text { Annual Local } \\
\text { GHG Reduction } \\
\% \\
\end{array}$ \\
\hline 88 & 291073 & Van - Pass & 3,591 & 1,331 & 2,260 & $63 \%$ \\
\hline 17 & 301321 & Pickup & 5,015 & 1,664 & 3,351 & $67 \%$ \\
\hline 95 & G41-0762M & Minivan & 7,136 & 3,646 & 3,490 & $49 \%$ \\
\hline 86 & G41-1846K & Minivan & 2,589 & 1,323 & 1,266 & $49 \%$ \\
\hline 83 & G41-2399K & Pickup & 14,699 & 4,878 & 9,821 & $67 \%$ \\
\hline 90 & G42-0216F & Van - Pass & 2,678 & 993 & 1,685 & $63 \%$ \\
\hline 92 & G42-0883M & Van - Pass & 6,999 & 2,758 & 4,241 & $61 \%$ \\
\hline 84 & G42-0898M & Van - Pass & 14,016 & 5,523 & 8,492 & $61 \%$ \\
\hline
\end{tabular}




\begin{tabular}{|c|c|c|c|c|c|c|}
\hline $\log$ & Vehicle ID & $\begin{array}{c}\text { Vehicle } \\
\text { Class }\end{array}$ & $\begin{array}{c}\text { Annual GHG } \\
\text { Emissions ICE } \\
\text { lb-CO } \mathrm{CO}_{2} \mathrm{e}\end{array}$ & $\begin{array}{c}\text { Annual PEV } \\
\text { GHG Local } \\
\text { lb-CO }_{2} \mathrm{e} \\
\end{array}$ & $\begin{array}{c}\text { Annual GHG } \\
\text { Local Savings } \\
\text { lb- } \mathrm{CO}_{2} \mathrm{e} \\
\end{array}$ & $\begin{array}{c}\text { Annual Local } \\
\text { GHG Reduction } \\
\% \\
\end{array}$ \\
\hline 18 & G43-0326H & Pickup & 6,347 & 2,206 & 4,141 & $65 \%$ \\
\hline 103 & G43-1453G & Van - Pass & 17,917 & 5,639 & 12,278 & $69 \%$ \\
\hline 19 & G43-1855P & Pickup & 2,071 & 1,208 & 863 & $42 \%$ \\
\hline 20 & G43-2025K & Pickup & 4,330 & 1,363 & 2,967 & $69 \%$ \\
\hline 110 & G43-4073F & Van - Pass & 5,433 & 2,137 & 3,296 & $61 \%$ \\
\hline 87 & G61-0594L & SUV & 2,293 & 1,462 & 831 & $36 \%$ \\
\hline 94 & G61-2644P & SUV & 741 & 457 & 284 & $38 \%$ \\
\hline 91 & G62-0791H & SUV & 6,092 & 2,444 & 3,647 & $60 \%$ \\
\hline 99 & G63-0309R & Pickup & 8,461 & 4,934 & 3,527 & $42 \%$ \\
\hline 120 & G63-0934G & Pickup & 1,611 & 753 & 858 & $53 \%$ \\
\hline
\end{tabular}

Table D-5. Monitored vehicle replacement on GHG emissions reduction (national figures).

\begin{tabular}{ccccccc} 
Log & Vehicle ID & $\begin{array}{c}\text { Vehicle } \\
\text { Class }\end{array}$ & $\begin{array}{c}\text { Annual GHG } \\
\text { Emissions ICE } \\
\text { lb-CO }\end{array}$ & $\begin{array}{c}\text { Annual PEV } \\
\text { GHG Local } \\
\text { lb-CO } \mathrm{CO}_{2} \mathrm{e}\end{array}$ & $\begin{array}{c}\text { Annual GHG } \\
\text { Local Savings } \\
{\mathrm{lb}-\mathrm{CO}_{2} \mathrm{e}}^{\mathrm{e}}\end{array}$ & $\begin{array}{c}\text { Annual Local } \\
\text { GHG Reduction } \\
\%\end{array}$ \\
\hline 88 & 291073 & Van - Pass & 3,591 & 1,796 & 1,795 & $50 \%$ \\
17 & 301321 & Pickup & 5,015 & 2,245 & 2,770 & $55 \%$ \\
95 & G41-0762M & Minivan & 7,136 & 4,919 & 2,217 & $31 \%$ \\
86 & G41-1846K & Minivan & 2,589 & 1,785 & 804 & $31 \%$ \\
83 & G41-2399K & Pickup & 14,699 & 6,581 & 8,118 & $55 \%$ \\
90 & G42-0216F & Van - Pass & 2,678 & 1,340 & 1,339 & $50 \%$ \\
92 & G42-0883M & Van - Pass & 6,999 & 3,721 & 3,278 & $47 \%$ \\
84 & G42-0898M & Van - Pass & 14,016 & 7,452 & 6,564 & $47 \%$ \\
18 & G43-0326H & Pickup & 6,347 & 2,976 & 3,371 & $53 \%$ \\
103 & G43-1453G & Van - Pass & 17,917 & 7,608 & 10,309 & $58 \%$ \\
19 & G43-1855P & Pickup & 2,071 & 1,629 & 442 & $21 \%$ \\
20 & G43-2025K & Pickup & 4,330 & 1,838 & 2,491 & $58 \%$ \\
110 & G43-4073F & Van - Pass & 5,433 & 2,884 & 2,549 & $47 \%$ \\
87 & G61-0594L & SUV & 2,293 & 1,972 & 321 & $14 \%$ \\
94 & G61-2644P & SUV & 741 & 616 & 124 & $17 \%$ \\
91 & G62-0791H & SUV & 6,092 & 3,298 & 2,793 & $46 \%$ \\
99 & G63-0309R & Pickup & 8,461 & 6,657 & 1,804 & $21 \%$ \\
120 & G63-0934G & Pickup & 1,611 & 1,015 & 596 & $37 \%$ \\
\hline
\end{tabular}

An example calculation for Logger 86 follows: as shown above, annual miles in CD mode is 2,651 miles and 189 gallons of E85 are unused. EPA reports this vehicle's emissions at $443 \mathrm{gm}-\mathrm{CO}_{2} \mathrm{e} / \mathrm{mile}$ so after converting grams to pounds; annual emissions for the monitored vehicle are $2,589 \mathrm{lb}-\mathrm{CO}_{2} \mathrm{e}$. Local power produces $1.134 \mathrm{lb}-\mathrm{CO}_{2} \mathrm{e} / \mathrm{kWh}$. As noted above, 1,166 kWh are required for recharging the battery, resulting in 1,323 $\mathrm{lb}-\mathrm{CO}_{2} \mathrm{e}$. The savings are $1,266 \mathrm{lb}-\mathrm{CO}_{2} \mathrm{e}$ for a $49 \%$ reduction in GHG emissions.

\section{D.4 Commands Group Full Fleet Evaluation}

Table 9 in Section 4.1.1 identifies 249 vehicles in the Commands Group fleet. Intertek suggests that a fleet of $143 \mathrm{BEVs}$ and 106 PHEVs conservatively meets vehicle travel requirements.

Using averages for these vehicles, the potential replacements offer fuel cost reductions and GHG emissions reductions shown in Tables D-6 and D-7 (summarized in Section 5). 
Table D-6. Commands Group full fleet PEV replacement reductions (Jacksonville, NC area figures).

\begin{tabular}{|c|c|c|c|c|c|c|c|c|}
\hline $\begin{array}{l}\text { Ann } \\
\text { Miles } \\
\text { Mod }\end{array}$ & & $\begin{array}{l}\text { Ann } \\
\text { Elec } \\
\text { Fuel C }\end{array}$ & $\begin{array}{r}\mathrm{An} \\
\mathrm{F} \\
\mathrm{Sav}\end{array}$ & $\begin{array}{r}\text { Ann } \\
\text { Fu } \\
\text { Savin }\end{array}$ & $\begin{array}{c}\text { Annual } \\
\text { GHG } \\
\text { Emissions } \\
\text { ICE } 1 \mathrm{~b}-\mathrm{CO}_{2} \mathrm{e}\end{array}$ & $\begin{array}{c}\text { Annual } \\
\text { PEV GHG } \\
\text { Local } \\
\text { lb-CO } \mathrm{CO}_{2} \mathrm{e}\end{array}$ & $\begin{array}{c}\text { Annual } \\
\text { GHG } \\
\text { Savings } \\
\text { lb- } \mathrm{CO}_{2} \mathrm{e}\end{array}$ & $\begin{array}{r}\mathrm{Al} \\
\text { Redu }\end{array}$ \\
\hline 417 & 31,822 & 1.799 & 200,023 & $86 \%$ & $, 702,381$ & 647,871 & 054,510 & $62 \%$ \\
\hline
\end{tabular}

Table D-7. Commands group full fleet PEV replacement reductions (national figures).

\begin{tabular}{|c|c|c|c|c|c|c|c|c|}
\hline $\begin{array}{l}\text { Annual } \\
\text { Miles CD } \\
\text { Mode }\end{array}$ & Ant & $\begin{array}{c}\text { Annual } \\
\text { Elect } \\
\text { Fuel Cost }\end{array}$ & $\begin{array}{l}\text { Annual } \\
\text { Fuel } \\
\text { Savings }\end{array}$ & $\begin{array}{c}\text { Annual } \\
\text { Fuel } \\
\text { Savings \% }\end{array}$ & $\begin{array}{c}\text { Annual } \\
\text { GHG } \\
\text { Emissions } \\
\text { ICE } 1 \mathrm{~b}-\mathrm{CO}_{2} \mathrm{e}\end{array}$ & $\begin{array}{c}\text { Annual } \\
\text { PEV GHG } \\
\text { lb-CO2e }\end{array}$ & $\begin{array}{l}\text { Annual } \\
\text { GHG } \\
\text { Savings } \\
\text { lb- } \mathrm{CO}_{2} \mathrm{e}\end{array}$ & $\begin{array}{c}\text { Annual } \\
\text { GHG } \\
\text { Reduction \% }\end{array}$ \\
\hline 417,634 & 234,983 & $\$ 58,960$ & $\$ 176,024$ & $75 \%$ & $1,702,381$ & 874,112 & 832,794 & $49 \%$ \\
\hline
\end{tabular}

\section{D.5 Commands Group Summary}

Tables D-8 and D-9 provide the average values for all monitored vehicles belonging to the Commands group.

Table D-8. Average fuel savings values for the Commands group's monitored vehicles (North Carolina figures).

\begin{tabular}{ccccc}
$\begin{array}{c}\text { Annual Miles } \\
\text { CD Mode }\end{array}$ & $\begin{array}{c}\text { Annual } \\
\text { Fuel Cost }\end{array}$ & $\begin{array}{c}\text { Annual Elect } \\
\text { Fuel Cost }\end{array}$ & $\begin{array}{c}\text { Annual Fuel } \\
\text { Savings }\end{array}$ & $\begin{array}{c}\text { Annual Fuel } \\
\text { Reduction \% }\end{array}$ \\
\hline 5,294 & $\$ 861$ & $\$ 122$ & $\$ 739$ & $86 \%$ \\
\hline
\end{tabular}

Table D-9. Average GHG emissions savings values for the Commands group's monitored vehicles (North Carolina figures).

\begin{tabular}{ccccc}
$\begin{array}{c}\text { Annual Miles } \\
\text { CD Mode }\end{array}$ & $\begin{array}{c}\text { Annual GHG } \\
\text { Emissions } \\
\text { ICE lb- } \mathrm{CO}_{2} \mathrm{e}\end{array}$ & $\begin{array}{c}\text { Annual PEV } \\
\text { GHG Local } \\
\text { lb- } \mathrm{CO}_{2} \mathrm{e}\end{array}$ & $\begin{array}{c}\text { Annual GHG } \\
\text { Savings } \\
\text { lb-CO } \mathrm{C}\end{array}$ & $\begin{array}{c}\text { Annual GHG } \\
\text { Reduction \% }\end{array}$ \\
\hline 5,294 & 6,223 & 2,484 & 3,739 & $60 \%$ \\
\hline
\end{tabular}

Tables D-8 and D-9 show that there is a significant opportunity for savings with the deployment of PEVs in this fleet, not only in fuel costs but in GHG emissions. 


\section{Appendix E \\ Greenhouse Gas Emissions Avoided and Fuel Cost Reduction Analysis - Marine Corps Installations East Group}

\section{E.1 Replacement Plug-In Electric Vehicles for Marine Corps Installations East Fleet}

Section 4.2 provided the analysis results for the MCIE fleet vehicles monitored during the study period based on data recorded and reported in the vehicle data sheets found in Appendix C. For the study, PEV replacements are based on vehicle class. The observations of Section 4.2.2.3 suggest that replacing these vehicles with $17 \mathrm{BEVs}$ and 24 PHEVs would meet current mission requirements. Specific vehicle cargo requirements have not been specified, thus, these vehicles were not considered in these replacement suggestions. Table E-1 identifies the PEVs suggested for these ICE vehicle replacements.

Table E-1. MCBCL MCIE fleet PEV replacements.

\begin{tabular}{|c|c|c|c|c|c|c|}
\hline \multicolumn{7}{|c|}{ Vehicle Replacements } \\
\hline $\log$ & \multicolumn{2}{|c|}{ Current Vehicle } & EPA Class & \multicolumn{2}{|c|}{ Replacement PEV } & Mission \\
\hline 4 & Ford & E350 & Van - Cargo & Via Motors & VTRUX Van & Pool \\
\hline 37 & Ford & F550 & SP/Refrig. & NA & NA & Specialty \\
\hline 35 & Chevrolet & Malibu & Sedan - Midsize & Nissan & Leaf & Support \\
\hline 48 & Chevrolet & HHR & SUV & Kia & Soul & Enforcement \\
\hline 42 & Chevrolet & 3500 & Pickup & Nissan & eNV200 & Support \\
\hline 54 & Chevrolet & HHR & SUV & Mitsubishi & Outlander & Support \\
\hline 53 & Ford & F550 & SP/Bucket & EDI & EDI & Specialty \\
\hline 55 & Ford & F250XL & Pickup & Via Motors & VTRUX PU & Support \\
\hline 56 & Ford & F250XL & Pickup & Via Motors & VTRUX PU & Support \\
\hline 79 & Ford & F350 Stake & Pickup & Via Motors & VTRUX PU & Support \\
\hline 5 & Chevrolet & Malibu & Sedan - Midsize & Nissan & Leaf & Pool \\
\hline 41 & Ford & Focus & Sedan - Compact & Chevrolet & Volt & Support \\
\hline 39 & Ford & Focus & Sedan - Compact & Chevrolet & Volt & Support \\
\hline 7 & Dodge & Grand Caravan & Minivan & Kia & Soul & Pool \\
\hline 40 & Dodge & Dakota & Pickup & Via Motors & VTRUX PU & Support \\
\hline 8 & Dodge & Grand Caravan & Minivan & Mitsubishi & Outlander & Pool \\
\hline 57 & Dodge & Caravan & Minivan & Mitsubishi & Outlander & Support \\
\hline 58 & Ford & Ranger & Pickup & Via Motors & VTRUX PU & Support \\
\hline 59 & Ford & Ranger & Pickup & Nissan & eNV200 & Support \\
\hline 49 & Ford & Ranger & Pickup & Via Motors & VTRUX PU & Enforcement \\
\hline 61 & Ford & Ranger & Pickup & Nissan & eNV200 & Support \\
\hline 9 & Ford & E150 & Van - Pass & Nissan & eNV200 & Pool \\
\hline 68 & Ford & F150 & Pickup & Via Motors & VTRUX PU & Support \\
\hline 69 & Ford & F150 & Pickup & Nissan & eNV200 & Support \\
\hline 10 & Chevrolet & $\mathrm{C} 1500$ & Pickup & Nissan & eNV200 & Pool \\
\hline 75 & Ford & F150 & Pickup & Nissan & eNV200 & Support \\
\hline 50 & Chevrolet & $\mathrm{C} 1500$ & Pickup & Via Motors & VTRUX PU & Enforcement \\
\hline 13 & Ford & E350 & Van - Pass & Via Motors & VTRUX Van & Pool \\
\hline 71 & Ford & E350 & Van - Cargo & Via Motors & VTRUX Van & Support \\
\hline 74 & Ford & E350 & Van - Cargo & Nissan & eNV200 & Support \\
\hline
\end{tabular}




\begin{tabular}{|c|c|c|c|c|c|c|}
\hline \multicolumn{7}{|c|}{ Vehicle Replacements } \\
\hline Log & \multicolumn{2}{|c|}{ Current Vehicle } & EPA Class & \multicolumn{2}{|c|}{ Replacement PEV } & Mission \\
\hline 36 & Chevrolet & CG3300 & Van - Cargo & Nissan & eNV200 & Support \\
\hline 14 & Ford & F250 & Pickup & Via Motors & VTRUX PU & Pool \\
\hline 77 & Dodge & Dakota & Pickup & Via Motors & VTRUX PU & Support \\
\hline 78 & Jeep & Liberty & SUV & Mitsubishi & Outlander & Support \\
\hline 51 & Chevrolet & Equinox & SUV & Mitsubishi & Outlander & Enforcement \\
\hline 15 & Jeep & Liberty & SUV & Mitsubishi & Outlander & Pool \\
\hline 16 & Jeep & Liberty & SUV & Kia & Soul & Pool \\
\hline 82 & Chevrolet & K1500 & Pickup & Via Motors & VTRUX PU & Support \\
\hline 46 & Dodge & 1500 & Pickup & Via Motors & VTRUX PU & Support \\
\hline 98 & Chevrolet & K2500HD & Pickup & Nissan & eNV200 & Support \\
\hline 47 & Chevrolet & K2500HD & Pickup & Nissan & eNV200 & Support \\
\hline 52 & Chevrolet & K2500HD & Pickup & Kia & Soul & Enforcement \\
\hline
\end{tabular}

Section 5 provides the methodology and assumptions for the reduction in GHG emissions and fuel costs calculations. The miles recorded by vehicles during the 31-day study were compared to the MCBCL reported annual miles and where available, the MCBCL annual miles were utilized. If the PEV replacing the monitored vehicle was a BEV, all annual miles could potentially occur in CD mode. If the PEV was a PHEV, the total miles driven per day where all travel was less than 30 miles was calculated. Thirty miles per day for the balance of days where travel occurred was added and a percentage of total miles monitored was calculated. This represented the percentage of all vehicles miles that could be accomplished in CD mode, with that percentage being multiplied by the annual miles to identify total annual miles available in CD mode. Only these miles were used in the reduction calculations. For example, Logger 40 recorded 13 days of use. Five days recorded travel less than 30 miles for a total of 20.7 miles. The remaining 8 days recorded greater than 30 miles; therefore, at 30 miles per day, a total of 240 miles was added for a total of 261 potential miles in CD mode. A total of 734 miles were recorded for this vehicle; therefore, $35.5 \%$ of all miles driven by this vehicle were potentially in CD mode. This percent was multiplied by the MCBCL-provided annual mileage to identify annual miles in CD mode.

This is conservative because the replacement PHEV is likely more fuel-efficient than the monitored vehicle when powered by the ICE and additional miles may be available if recharging occurs.

\section{E.2 Monitored Vehicle Fuel Cost Reduction}

Table E-2 identifies the calculated miles in CD mode for each of the MCIE fleet vehicles replaced. The fuel costs and GHG emissions avoided were all based on the miles driven in CD mode and the resulting savings in petroleum-based fuels.

Table E-2. Fuel savings for PEV replacement of monitored vehicles.

\begin{tabular}{cccccc}
\hline Log & Vehicle ID & Vehicle Class & Replacement PEV & $\begin{array}{c}\text { Annual Miles } \\
\text { CD Mode }\end{array}$ & $\begin{array}{c}\text { Gallons Fuel } \\
\text { Saved }\end{array}$ \\
\hline 4 & 290597 & Van - Cargo & VTRUX Van & 607 & 43 \\
37 & 291007 & S/Refrig. & NA & 0 & 0 \\
35 & 294285 & Sedan - Midsize & Leaf & 3,795 & 146 \\
48 & 294293 & SUV & Soul & 4,214 & 234 \\
42 & 294315 & Pickup & eNV200 & 3,208 & 229 \\
54 & 294324 & SUV & Outlander & 4,025 & 155 \\
53 & 300672 & SP Bucket Truck & EDI & 2,402 & 240 \\
55 & 302039 & Pickup & VTRUX PU & 2,478 & 177 \\
56 & 302040 & Pickup & VTRUX PU & 4,617 & 330 \\
79 & 302334 & Pickup & VTRUX PU & 1,047 & 70 \\
5 & G10-3327L & Sedan - Midsize & Leaf & 7,085 & 394 \\
\hline
\end{tabular}




\begin{tabular}{cccccc}
\hline Log & Vehicle ID & Vehicle Class & Replacement PEV & $\begin{array}{c}\text { Annual Miles } \\
\text { CD Mode }\end{array}$ & $\begin{array}{c}\text { Gallons Fuel } \\
\text { Saved }\end{array}$ \\
\hline 41 & G13-0325K & Sedan - Compact & Volt & 753 & 24 \\
39 & G13-7974P & Sedan - Compact & Volt & 3,256 & 105 \\
7 & G41-0379H & Minivan & Soul & 5,614 & 432 \\
40 & G41-0391H & Pickup & VTRUX PU & 2,664 & 266 \\
8 & G41-0754M & Minivan & Outlander & 1,164 & 83 \\
57 & G41-0806P & Minivan & Outlander & 4,884 & 349 \\
58 & G41-1689L & Pickup & VTRUX PU & 3,458 & 144 \\
59 & G41-3297K & Pickup & eNV200 & 5,368 & 224 \\
49 & G41-3300K & Pickup & VTRUX PU & 5,470 & 228 \\
61 & G41-3301K & Pickup & eNV200 & 7,306 & 304 \\
9 & G42-0644M & Van - Pass & eNV200 & 22,209 & 2,221 \\
68 & G42-0667P & Pickup & VTRUX PU & 4,364 & 312 \\
69 & G42-0671P & Pickup & eNV200 & 7,678 & 548 \\
10 & G42-0911L & Pickup & eNV200 & 7,978 & 614 \\
75 & G42-0915M & Pickup & eNV200 & 7,072 & 372 \\
50 & G42-2985H & Pickup & VTRUX PU & 7,947 & 467 \\
13 & G43-0310H & Van - Pass & VTRUX Van & 3,043 & 277 \\
71 & G43-0323H & Van - Cargo & VTRUX Van & 4,639 & 309 \\
74 & G43-0324H & Van - Cargo & eNV200 & 5,969 & 398 \\
36 & G43-1182M & Van - Cargo & eNV200 & 12,279 & 1,364 \\
14 & G43-4075P & Pickup & VTRUX PU & 7,486 & 535 \\
77 & G61-0161H & Pickup & VTRUX PU & 6,957 & 696 \\
78 & G61-0174H & SUV & Outlander & 4,997 & 278 \\
51 & G61-0879P & SUV & Outlander & 2,102 & 124 \\
15 & G61-1508D & SUV & Outlander & 681 & 36 \\
16 & G61-1509D & SUV & Soul & 3,292 & 173 \\
82 & G62-1583G & Pickup & VTRUX PU & 5,219 & 307 \\
46 & G62-4085L & Pickup & VTRUX PU & 6,098 & 554 \\
98 & G63-0163H & Pickup & eNV200 & 9,018 & 564 \\
47 & G63-2885L & Pickup & eNV200 & 4,112 & 316 \\
52 & G63-2888L & Pickup & Soul & 4,480 & 345 \\
\hline & & & & & \\
\end{tabular}

As noted in Section 5, both the local cost of fuel and the national average were used for comparisons. North Carolina fuel costs are close to the national average, with gasoline and diesel slightly less but E85 slightly more. As noted in Section 5 Duke Energy Progress' electrical fuel costs are lower than the national average. Section 5 summarized these values.

Table E-3 shows the calculated fuel costs both for North Carolina and nationally for the gallons of petroleum-based fuel identified in Table E-2.

Table E-3. Monitored vehicle PEV replacement fuel savings (North Carolina and national factors).

\begin{tabular}{cccccccccc}
\hline & & $\begin{array}{c}\text { Local } \\
\text { Fuel }\end{array}$ & $\begin{array}{c}\text { Local } \\
\text { Elect. } \\
\text { Log }\end{array}$ & $\begin{array}{c}\text { Annual } \\
\text { Fuel } \\
\text { Savings }\end{array}$ & $\begin{array}{c}\text { Local Fuel } \\
\text { Cost } \\
\text { Reduction }\end{array}$ & $\begin{array}{c}\text { National } \\
\text { Fuel Cost }\end{array}$ & $\begin{array}{c}\text { National } \\
\text { Elect. } \\
\text { Fuel Cost }\end{array}$ & $\begin{array}{c}\text { National } \\
\text { Annual } \\
\text { Fuel } \\
\text { Savings }\end{array}$ & $\begin{array}{c}\text { National } \\
\text { Fuel Cost } \\
\text { Reduction }\end{array}$ \\
\hline 4 & 290597 & $\$ 115$ & $\$ 16$ & $\$ 99$ & $86 \%$ & $\$ 121$ & $\$ 30$ & $\$ 92$ & $75 \%$ \\
37 & 291007 & NA & NA & NA & NA & NA & NA & NA & NA \\
35 & 294285 & $\$ 387$ & $\$ 63$ & $\$ 323$ & $84 \%$ & $\$ 409$ & $\$ 117$ & $\$ 291$ & $71 \%$ \\
48 & 294293 & $\$ 508$ & $\$ 75$ & $\$ 433$ & $85 \%$ & $\$ 499$ & $\$ 139$ & $\$ 359$ & $72 \%$ \\
42 & 294315 & $\$ 647$ & $\$ 71$ & $\$ 575$ & $89 \%$ & $\$ 651$ & $\$ 132$ & $\$ 519$ & $80 \%$ \\
54 & 294324 & $\$ 336$ & $\$ 99$ & $\$ 237$ & $71 \%$ & $\$ 330$ & $\$ 183$ & $\$ 147$ & $45 \%$ \\
53 & 300672 & $\$ 678$ & $\$ 120$ & $\$ 558$ & $82 \%$ & $\$ 683$ & $\$ 223$ & $\$ 460$ & $67 \%$ \\
55 & 302039 & $\$ 500$ & $\$ 66$ & $\$ 434$ & $87 \%$ & $\$ 503$ & $\$ 121$ & $\$ 382$ & $76 \%$ \\
\hline
\end{tabular}




\begin{tabular}{|c|c|c|c|c|c|c|c|c|c|}
\hline Log & Vehicle ID & $\begin{array}{c}\text { Local } \\
\text { Fuel } \\
\text { Cost }\end{array}$ & $\begin{array}{l}\text { Local } \\
\text { Elect. } \\
\text { Fuel Cost }\end{array}$ & $\begin{array}{l}\text { Local } \\
\text { Annual } \\
\text { Fuel } \\
\text { Savings }\end{array}$ & $\begin{array}{l}\text { Local Fuel } \\
\text { Cost } \\
\text { Reduction }\end{array}$ & $\begin{array}{c}\text { National } \\
\text { Fuel Cost }\end{array}$ & $\begin{array}{l}\text { National } \\
\text { Elect. } \\
\text { Fuel Cost }\end{array}$ & $\begin{array}{c}\text { National } \\
\text { Annual } \\
\text { Fuel } \\
\text { Savings }\end{array}$ & $\begin{array}{l}\text { National } \\
\text { Fuel Cost } \\
\text { Reduction }\end{array}$ \\
\hline 56 & 302040 & $\$ 931$ & $\$ 122$ & $\$ 809$ & $87 \%$ & $\$ 938$ & $\$ 226$ & $\$ 711$ & $76 \%$ \\
\hline 79 & 302334 & $\$ 152$ & $\$ 28$ & $\$ 124$ & $82 \%$ & $\$ 149$ & $\$ 51$ & $\$ 97$ & $65 \%$ \\
\hline 5 & G10-3327L & $\$ 854$ & $\$ 118$ & $\$ 736$ & $86 \%$ & $\$ 838$ & $\$ 219$ & $\$ 619$ & $74 \%$ \\
\hline 41 & G13-0325K & $\$ 64$ & $\$ 15$ & $\$ 50$ & $77 \%$ & $\$ 68$ & $\$ 27$ & $\$ 41$ & $60 \%$ \\
\hline 39 & G13-7974P & $\$ 228$ & $\$ 63$ & $\$ 164$ & $72 \%$ & $\$ 224$ & $\$ 118$ & $\$ 106$ & $47 \%$ \\
\hline 7 & $\mathrm{G} 41-0379 \mathrm{H}$ & $\$ 937$ & $\$ 100$ & $\$ 837$ & $89 \%$ & $\$ 920$ & $\$ 185$ & $\$ 734$ & $80 \%$ \\
\hline 40 & G41-0391H & $\$ 578$ & $\$ 70$ & $\$ 508$ & $88 \%$ & $\$ 567$ & $\$ 131$ & $\$ 437$ & $77 \%$ \\
\hline 8 & G41-0754M & $\$ 180$ & $\$ 29$ & $\$ 152$ & $84 \%$ & $\$ 177$ & $\$ 53$ & $\$ 124$ & $70 \%$ \\
\hline 57 & G41-0806P & $\$ 757$ & $\$ 120$ & $\$ 637$ & $84 \%$ & $\$ 743$ & $\$ 222$ & $\$ 521$ & $70 \%$ \\
\hline 58 & G41-1689L & $\$ 382$ & $\$ 91$ & $\$ 290$ & $76 \%$ & $\$ 404$ & $\$ 170$ & $\$ 234$ & $58 \%$ \\
\hline 59 & G41-3297K & $\$ 593$ & $\$ 120$ & $\$ 473$ & $80 \%$ & $\$ 626$ & $\$ 222$ & $\$ 405$ & $65 \%$ \\
\hline 49 & G41-3300K & $\$ 604$ & $\$ 145$ & $\$ 459$ & $76 \%$ & $\$ 638$ & $\$ 268$ & $\$ 370$ & $58 \%$ \\
\hline 61 & $\mathrm{G} 41-3301 \mathrm{~K}$ & $\$ 807$ & $\$ 163$ & $\$ 644$ & $80 \%$ & $\$ 853$ & $\$ 302$ & $\$ 551$ & $65 \%$ \\
\hline 9 & G42-0644M & $\$ 4,819$ & $\$ 494$ & $\$ 4,325$ & $90 \%$ & $\$ 4,731$ & $\$ 917$ & $\$ 3,814$ & $81 \%$ \\
\hline 68 & G42-0667P & $\$ 676$ & $\$ 115$ & $\$ 561$ & $83 \%$ & $\$ 664$ & $\$ 214$ & $\$ 450$ & $68 \%$ \\
\hline 69 & G42-0671P & $\$ 1,190$ & $\$ 171$ & $\$ 1,019$ & $86 \%$ & $\$ 1,168$ & $\$ 317$ & $\$ 851$ & $73 \%$ \\
\hline 10 & G42-0911L & $\$ 1,332$ & $\$ 178$ & $\$ 1,154$ & $87 \%$ & $\$ 1,307$ & $\$ 329$ & $\$ 978$ & $75 \%$ \\
\hline 75 & G42-0915M & $\$ 808$ & $\$ 157$ & $\$ 650$ & $81 \%$ & $\$ 793$ & $\$ 292$ & $\$ 501$ & $63 \%$ \\
\hline 50 & $\mathrm{G} 42-2985 \mathrm{H}$ & $\$ 1,239$ & $\$ 210$ & $\$ 1,029$ & $83 \%$ & $\$ 1,309$ & $\$ 390$ & $\$ 920$ & $70 \%$ \\
\hline 13 & G43-0310H & $\$ 600$ & $\$ 80$ & $\$ 520$ & $87 \%$ & $\$ 589$ & $\$ 149$ & $\$ 440$ & $75 \%$ \\
\hline 71 & G43-0323H & $\$ 819$ & $\$ 123$ & $\$ 697$ & $85 \%$ & $\$ 866$ & $\$ 227$ & $\$ 639$ & $74 \%$ \\
\hline 74 & G43-0324H & $\$ 1,055$ & $\$ 133$ & $\$ 922$ & $87 \%$ & $\$ 1,115$ & $\$ 246$ & $\$ 868$ & $78 \%$ \\
\hline 36 & G43-1182M & $\$ 2,961$ & $\$ 273$ & $\$ 2,687$ & $91 \%$ & $\$ 2,906$ & $\$ 507$ & $\$ 2,399$ & $83 \%$ \\
\hline 14 & G43-4075P & $\$ 1,160$ & $\$ 198$ & $\$ 962$ & $83 \%$ & $\$ 1,139$ & $\$ 367$ & $\$ 772$ & $68 \%$ \\
\hline 77 & G61-0161H & $\$ 1,510$ & $\$ 184$ & $\$ 1,326$ & $88 \%$ & $\$ 1,482$ & $\$ 341$ & $\$ 1,141$ & $77 \%$ \\
\hline 78 & G61-0174H & $\$ 736$ & $\$ 122$ & $\$ 613$ & $83 \%$ & $\$ 778$ & $\$ 227$ & $\$ 551$ & $71 \%$ \\
\hline 51 & G61-0879P & $\$ 268$ & $\$ 51$ & $\$ 217$ & $81 \%$ & $\$ 263$ & $\$ 95$ & $\$ 168$ & $64 \%$ \\
\hline 15 & G61-1508D & $\$ 95$ & $\$ 17$ & $\$ 78$ & $82 \%$ & $\$ 100$ & $\$ 31$ & $\$ 70$ & $69 \%$ \\
\hline 16 & G61-1509D & $\$ 459$ & $\$ 59$ & $\$ 401$ & $87 \%$ & $\$ 485$ & $\$ 109$ & $\$ 377$ & $78 \%$ \\
\hline 82 & G62-1583G & $\$ 814$ & $\$ 138$ & $\$ 676$ & $83 \%$ & $\$ 860$ & $\$ 256$ & $\$ 604$ & $70 \%$ \\
\hline 46 & G62-4085L & $\$ 1,203$ & $\$ 161$ & $\$ 1,042$ & $87 \%$ & $\$ 1,181$ & $\$ 299$ & $\$ 882$ & $75 \%$ \\
\hline 98 & G63-0163H & $\$ 1,494$ & $\$ 201$ & $\$ 1,293$ & $87 \%$ & $\$ 1,579$ & $\$ 372$ & $\$ 1,206$ & $76 \%$ \\
\hline 47 & G63-2885L & $\$ 686$ & $\$ 92$ & $\$ 595$ & $87 \%$ & $\$ 674$ & $\$ 170$ & $\$ 504$ & $75 \%$ \\
\hline 52 & G63-2888L & $\$ 748$ & $\$ 80$ & $\$ 668$ & $89 \%$ & $\$ 734$ & $\$ 148$ & $\$ 586$ & $80 \%$ \\
\hline
\end{tabular}

An example calculation for Logger 40 follows: The MCBCL reported annual miles for this vehicle is 7,507 miles. The suggested replacement PEV is a PHEV. As noted above, $35.5 \%$ of all miles driven by this vehicle were potentially in CD mode; therefore, annual miles in CD mode is 2,664 miles. This vehicle uses E85 and EPA fuel economy for this vehicle is $10 \mathrm{MPG}$, resulting in 266 gallons of E85 being unused. North Carolina cost for E85 is \$2.17/gallon for an annual cost of \$578. The replacement PEV requires $475 \mathrm{Wh} /$ mile; therefore, $1,265 \mathrm{kWh}$ are required for recharging the battery. Local power cost is $\$ 0.05566 / \mathrm{kWh}$, resulting in annual electric cost of $\$ 70$. The savings are $\$ 508$ for an $88 \%$ reduction in fuel cost.

\section{E.3 Monitored Vehicle Greenhouse Gas Emissions Reduction}

Tables E-4 and E-5 identify the reduction in GHG projected when replacing the current vehicles with PEVs. The calculated miles in CD mode shown in Table E-2 are also used in the calculation of GHG reduction. As noted in Section 5, emissions from burning petroleum-based fuel is known and emissions from use of electricity is dependent on the power generation mix that is used to recharge the PEV battery. As before, both the local power production emission figures and the national average are used for comparisons. 
Emissions from Duke Energy Progress generation are lower than the national average. In addition, electrical emissions are significantly lower than gasoline emissions.

Table E-4. GHG emissions reduction for replacement of monitored vehicles (Jacksonville, North Carolina area figures).

\begin{tabular}{|c|c|c|c|c|c|c|}
\hline $\log$ & Vehicle ID & Vehicle Class & $\begin{array}{c}\text { Annual GHG } \\
\text { Emissions ICE } \\
\text { lb- } \mathrm{CO}_{2} \mathrm{e}\end{array}$ & $\begin{array}{c}\text { Annual PEV } \\
\text { GHG Local } \\
\text { lb-CO }_{2} \mathrm{e}\end{array}$ & $\begin{array}{l}\text { Local } \\
\text { Savings } \\
\text { lb- } \mathrm{CO}_{2} \mathrm{e} \\
\end{array}$ & $\begin{array}{c}\text { Annual Local } \\
\text { GHG } \\
\text { Reduction \% } \\
\end{array}$ \\
\hline 4 & 290597 & Van - Cargo & 850 & 327 & 523 & $62 \%$ \\
\hline 37 & 291007 & SP/Refrig. & NA & NA & NA & NA \\
\hline 35 & 294285 & Sedan - Midsize & 2,861 & 1,291 & 1,570 & $55 \%$ \\
\hline 48 & 294293 & SUV & 3,205 & 1,529 & 1,676 & $52 \%$ \\
\hline 42 & 294315 & Pickup & 5,156 & 1,455 & 3,701 & $72 \%$ \\
\hline 54 & 294324 & SUV & 2,893 & 2,009 & 885 & $31 \%$ \\
\hline 53 & 300672 & SP/Bucket Truck & 5,406 & 2,451 & 2,955 & $55 \%$ \\
\hline 55 & 302039 & Pickup & 3,982 & 1,335 & 2,647 & $66 \%$ \\
\hline 56 & 302040 & Pickup & 7,420 & 2,487 & 4,933 & $66 \%$ \\
\hline 79 & 302334 & Pickup & 967 & 564 & 403 & $42 \%$ \\
\hline 5 & G10-3327L & Sedan - Midsize & 5,389 & 2,410 & 2,978 & $55 \%$ \\
\hline 41 & G13-0325K & Sedan - Compact & 476 & 299 & 177 & $37 \%$ \\
\hline 39 & G13-7974P & Sedan-Compact & 1,909 & 1,292 & 617 & $32 \%$ \\
\hline 7 & G41-0379H & Minivan & 5,904 & 2,037 & 3,866 & $65 \%$ \\
\hline 40 & G41-0391H & Pickup & 3,642 & 1,435 & 2,206 & $61 \%$ \\
\hline 8 & G41-0754M & Minivan & 1,137 & 581 & 556 & $49 \%$ \\
\hline 57 & G41-0806P & Minivan & 4,673 & 2,437 & 2,236 & $48 \%$ \\
\hline 58 & G41-1689L & Pickup & 2,821 & 1,863 & 958 & $34 \%$ \\
\hline 59 & G41-3297K & Pickup & 4,379 & 2,435 & 1,944 & $44 \%$ \\
\hline 49 & G41-3300K & Pickup & 4,462 & 2,946 & 1,515 & $34 \%$ \\
\hline 61 & G41-3301K & Pickup & 5,960 & 3,314 & 2,646 & $44 \%$ \\
\hline 9 & G42-0644M & Van - Pass & 30,357 & 10,074 & 20,283 & $67 \%$ \\
\hline 68 & G42-0667P & Pickup & 4,252 & 2,351 & 1,902 & $45 \%$ \\
\hline 69 & G42-0671P & Pickup & 7,482 & 3,483 & 3,999 & $53 \%$ \\
\hline 10 & G42-0911L & Pickup & 8,390 & 3,619 & 4,771 & $57 \%$ \\
\hline 75 & G42-0915M & Pickup & 6,907 & 3,208 & 3,699 & $54 \%$ \\
\hline 50 & G42-2985H & Pickup & 9,163 & 4,281 & 4,882 & $53 \%$ \\
\hline 13 & G43-0310H & Van - Pass & 3,784 & 1,639 & 2,145 & $57 \%$ \\
\hline 71 & G43-0323H & Van - Cargo & 6,054 & 2,499 & 3,555 & $59 \%$ \\
\hline 74 & G43-0324H & Van - Cargo & 7,790 & 2,708 & 5,083 & $65 \%$ \\
\hline 36 & G43-1182M & Van - Cargo & 18,652 & 5,570 & 13,082 & $70 \%$ \\
\hline 14 & G43-4075P & Pickup & 7,294 & 4,032 & 3,262 & $45 \%$ \\
\hline 77 & G61-0161H & Pickup & 9,510 & 3,748 & 5,762 & $61 \%$ \\
\hline 78 & G61-0174H & SUV & 5,442 & 2,493 & 2,949 & $54 \%$ \\
\hline 51 & G61-0879P & SUV & 1,738 & 1,049 & 689 & $40 \%$ \\
\hline 15 & G61-1508D & SUV & 703 & 340 & 363 & $52 \%$ \\
\hline 16 & G61-1509D & SUV & 3,397 & 1,195 & 2,202 & $65 \%$ \\
\hline 82 & G62-1583G & Pickup & 6,018 & 2,811 & 3,206 & $53 \%$ \\
\hline 46 & G62-4085L & Pickup & 7,582 & 3,284 & 4,297 & $57 \%$ \\
\hline 98 & G63-0163H & Pickup & 11,034 & 4,091 & 6,944 & $63 \%$ \\
\hline 47 & G63-2885L & Pickup & 4,324 & 1,865 & 2,459 & $57 \%$ \\
\hline 52 & G63-2888L & Pickup & 4,711 & 1,626 & 3,085 & $65 \%$ \\
\hline
\end{tabular}

Table E-5. GHG emissions reduction for replacement of monitored vehicles (national figures).

\begin{tabular}{|c|c|c|c|c|c|c|}
\hline Log & Vehicle ID & Vehicle Class & 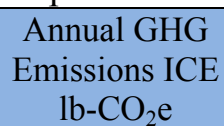 & 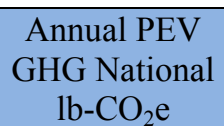 & 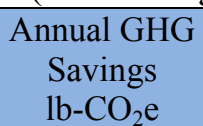 & $\begin{array}{c}\text { Annual } \\
\text { National GHG } \\
\text { Reduction \% }\end{array}$ \\
\hline 4 & 290597 & Van - Cargo & 850 & 441 & 409 & $48 \%$ \\
\hline 37 & 291007 & SP/Refrig. & - & - & - & - \\
\hline
\end{tabular}




\begin{tabular}{|c|c|c|c|c|c|c|}
\hline Log & Vehicle ID & Vehicle Class & $\begin{array}{c}\text { Annual GHG } \\
\text { Emissions ICE } \\
\text { lb- } \mathrm{CO}_{2} \mathrm{e}\end{array}$ & $\begin{array}{c}\text { Annual PEV } \\
\text { GHG National } \\
\text { lb- } \mathrm{CO}_{2} \mathrm{e}\end{array}$ & $\begin{array}{c}\text { Annual GHG } \\
\text { Savings } \\
\text { lb- } \mathrm{CO}_{2} \mathrm{e}\end{array}$ & $\begin{array}{c}\text { Annual } \\
\text { National GHG } \\
\text { Reduction \% }\end{array}$ \\
\hline 35 & 294285 & Sedan - Midsize & 2,861 & 1,742 & 1,119 & $39 \%$ \\
\hline 48 & 294293 & SUV & 3,205 & 2,063 & 1,142 & $36 \%$ \\
\hline 42 & 294315 & Pickup & 5,156 & 1,963 & 3,192 & $62 \%$ \\
\hline 54 & 294324 & SUV & 2,893 & 2,710 & 183 & $6 \%$ \\
\hline 53 & 300672 & SP/Bucket Truck & 5,406 & 3,307 & 2,099 & $39 \%$ \\
\hline 55 & 302039 & Pickup & 3,982 & 1,801 & 2,181 & $55 \%$ \\
\hline 56 & 302040 & Pickup & 7,420 & 3,355 & 4,065 & $55 \%$ \\
\hline 79 & 302334 & Pickup & 967 & 761 & 206 & $21 \%$ \\
\hline 5 & G10-3327L & Sedan - Midsize & 5,389 & 3,252 & 2,137 & $40 \%$ \\
\hline 41 & G13-0325K & Sedan - Compact & 476 & 403 & 73 & $15 \%$ \\
\hline 39 & G13-7974P & Sedan - Compact & 1,909 & 1,744 & 166 & $9 \%$ \\
\hline 7 & G41-0379H & Minivan & 5,904 & 2,749 & 3,155 & $53 \%$ \\
\hline 40 & G41-0391H & Pickup & 3,642 & 1,936 & 1,705 & $47 \%$ \\
\hline 8 & G41-0754M & Minivan & 1,137 & 784 & 353 & $31 \%$ \\
\hline 57 & G41-0806P & Minivan & 4,673 & 3,288 & 1,385 & $30 \%$ \\
\hline 58 & G41-1689L & Pickup & 2,821 & 2,513 & 308 & $11 \%$ \\
\hline 59 & G41-3297K & Pickup & 4,379 & 3,285 & 1,094 & $25 \%$ \\
\hline 49 & G41-3300K & Pickup & 4,462 & 3,975 & 487 & $11 \%$ \\
\hline 61 & G41-3301K & Pickup & 5,960 & 4,471 & 1,488 & $25 \%$ \\
\hline 9 & G42-0644M & Van - Pass & 30,357 & 13,592 & 16,765 & $55 \%$ \\
\hline 68 & G42-0667P & Pickup & 4,252 & 3,172 & 1,081 & $25 \%$ \\
\hline 69 & G42-0671P & Pickup & 7,482 & 4,699 & 2,783 & $37 \%$ \\
\hline 10 & G42-0911L & Pickup & 8,390 & 4,883 & 3,507 & $42 \%$ \\
\hline 75 & G42-0915M & Pickup & 6,907 & 4,328 & 2,579 & $37 \%$ \\
\hline 50 & G42-2985H & Pickup & 9,163 & 5,775 & 3,387 & $37 \%$ \\
\hline 13 & G43-0310H & Van - Pass & 3,784 & 2,212 & 1,572 & $42 \%$ \\
\hline 71 & G43-0323H & Van - Cargo & 6,054 & 3,371 & 2,683 & $44 \%$ \\
\hline 74 & G43-0324H & Van - Cargo & 7,790 & 3,653 & 4,137 & $53 \%$ \\
\hline 36 & G43-1182M & Van - Cargo & 18,652 & 7,515 & 11,137 & $60 \%$ \\
\hline 14 & G43-4075P & Pickup & 7,294 & 5,440 & 1,854 & $25 \%$ \\
\hline 77 & G61-0161H & Pickup & 9,510 & 5,056 & 4,454 & $47 \%$ \\
\hline 78 & G61-0174H & SUV & 5,442 & 3,364 & 2,078 & $38 \%$ \\
\hline 51 & G61-0879P & SUV & 1,738 & 1,415 & 323 & $19 \%$ \\
\hline 15 & G61-1508D & SUV & 703 & 459 & 244 & $35 \%$ \\
\hline 16 & G61-1509D & SUV & 3,397 & 1,612 & 1,785 & $53 \%$ \\
\hline 82 & G62-1583G & Pickup & 6,018 & 3,793 & 2,225 & $37 \%$ \\
\hline 46 & G62-4085L & Pickup & 7,582 & 4,431 & 3,150 & $42 \%$ \\
\hline 98 & G63-0163H & Pickup & 11,034 & 5,519 & 5,515 & $50 \%$ \\
\hline 47 & G63-2885L & Pickup & 4,324 & 2,517 & 1,808 & $42 \%$ \\
\hline 52 & G63-2888L & Pickup & 4,711 & 2,193 & 2,518 & $53 \%$ \\
\hline
\end{tabular}

An example calculation for Logger 40 follows: as shown above, annual miles in CD mode are 2,664 miles and 266 gallons of E85 are unused. EPA reports this vehicle's emissions at $620 \mathrm{gm}-\mathrm{CO}_{2} \mathrm{e} / \mathrm{mile}$; therefore, after converting grams to pounds, the annual emissions for the monitored vehicle are 3,642 lb- $\mathrm{CO}_{2} \mathrm{e}$. Local power produces $1.134 \mathrm{lb}-\mathrm{CO}_{2} \mathrm{e} / \mathrm{kWh}$. As above, 1,265 $\mathrm{kWh}$ are required for recharging the battery, resulting in $1,435 \mathrm{lb}-\mathrm{CO}_{2} \mathrm{e}$. The savings are $2,206 \mathrm{lb}-\mathrm{CO}_{2} \mathrm{e}$ for a $61 \%$ reduction in GHG emissions.

\section{E.4 Marine Corps Installations East Group Full Fleet Evaluation}

Table 13 in Section 4.2 identifies 535 vehicles in the MCIE fleet. Retaining most of the heavy-duty specialty vehicles, Intertek suggests that a fleet of 53 specialty vehicles, 275 BEVs, and 207 PHEVs would meet vehicle travel requirements. 
Using averages for these vehicles, potential replacements offer fuel cost reductions and GHG emissions reductions shown in Tables E-6 and E-7 (summarized in Section 5).

Table E-6. MCIE group's full fleet PEV replacement reductions (Jacksonville, North Carolina area figures).

\begin{tabular}{ccccccccc}
$\begin{array}{c}\text { Annual } \\
\text { Miles CD } \\
\text { Mode }\end{array}$ & $\begin{array}{c}\text { Annual } \\
\text { Fuel Cost }\end{array}$ & $\begin{array}{c}\text { Annual } \\
\text { Elect } \\
\text { Fuel Cost }\end{array}$ & $\begin{array}{c}\text { Annual } \\
\text { Fuel } \\
\text { Savings }\end{array}$ & $\begin{array}{c}\text { Annual } \\
\text { Fuel } \\
\text { Savings } \\
\%\end{array}$ & $\begin{array}{c}\text { Annual } \\
\text { GHG } \\
\text { Emissions } \\
\text { ICE lb-CO }\end{array}$ & $\begin{array}{c}\text { Annual } \\
\text { PEV GHG } \\
\text { Local } \\
\text { lb-CO }_{2} \mathrm{e}\end{array}$ & $\begin{array}{c}\text { Annual } \\
\text { GHG } \\
\text { Savings } \\
\text { lb-CO }_{2} \mathrm{e}\end{array}$ & $\begin{array}{c}\text { Annual } \\
\text { GHG }\end{array}$ \\
$\begin{array}{c}\text { Reduction } \\
\%\end{array}$ \\
\hline $3,004,441$ & $\$ 509,619$ & $\$ 67,239$ & $\$ 442,380$ & $87 \%$ & $3,445,465$ & $1,369,916$ & $2,075,550$ & $60 \%$ \\
\hline
\end{tabular}

Table E-7. MCIE group's full fleet PEV replacement reductions (national figures).

\begin{tabular}{|c|c|c|c|c|c|c|c|c|}
\hline $\begin{array}{c}\text { Annual } \\
\text { Miles CD } \\
\text { Mode }\end{array}$ & $\begin{array}{c}\text { Annual } \\
\text { Fuel Cost }\end{array}$ & $\begin{array}{c}\text { Annual } \\
\text { Elect } \\
\text { Fuel Cost }\end{array}$ & $\begin{array}{l}\text { Annual } \\
\text { Fuel } \\
\text { Savings }\end{array}$ & $\begin{array}{l}\text { Annual } \\
\text { Fuel } \\
\text { Savings } \\
\%\end{array}$ & $\begin{array}{c}\text { Annual } \\
\text { GHG } \\
\text { Emissions } \\
\text { ICE } \mathrm{lb}-\mathrm{CO}_{2} \mathrm{e}\end{array}$ & $\begin{array}{c}\text { Annual } \\
\text { PEV GHG } \\
\text { Local } \\
\text { lb- } \mathrm{CO}_{2} \mathrm{e}\end{array}$ & $\begin{array}{l}\text { Annual } \\
\text { GHG } \\
\text { Savings } \\
\text { lb- } \mathrm{CO}_{2} \mathrm{e}\end{array}$ & $\begin{array}{c}\text { Annual } \\
\text { GHG } \\
\text { Reduction } \\
\%\end{array}$ \\
\hline $3,004,441$ & $\$ 511,282$ & $\$ 124,670$ & $\$ 386,612$ & $76 \%$ & $3,445,465$ & $1,848,299$ & $1,618,365$ & $47 \%$ \\
\hline
\end{tabular}

\section{E.5 Marine Corps Installations East Group Summary}

Tables E-8 and E-9 provide the average values for all monitored vehicles belonging to the MCIE group.

Table E-8. MCIE group's monitored vehicles average fuel savings values (North Carolina figures).

\begin{tabular}{cccccc}
$\begin{array}{c}\text { Annual } \\
\text { Miles CD } \\
\text { Mode }\end{array}$ & $\begin{array}{c}\text { Gallons } \\
\text { Fuel Saved }\end{array}$ & $\begin{array}{c}\text { Annual } \\
\text { Fuel Cost }\end{array}$ & $\begin{array}{c}\text { Annual } \\
\text { Elect Fuel } \\
\text { Cost }\end{array}$ & $\begin{array}{c}\text { Annual Fuel } \\
\text { Savings }\end{array}$ & $\begin{array}{c}\text { Annual Fuel } \\
\text { Reduction \% }\end{array}$ \\
\hline 5,147 & 366 & $\$ 831$ & $\$ 117$ & $\$ 714$ & $86 \%$ \\
\hline
\end{tabular}

Table E-9. MCIE group's monitored vehicles average GHG savings values (North Carolina figures).

\begin{tabular}{cccccc}
$\begin{array}{c}\text { Annual Miles } \\
\text { CD Mode }\end{array}$ & $\begin{array}{c}\text { Gallons } \\
\text { Fuel Saved }\end{array}$ & $\begin{array}{c}\text { Annual GHG } \\
\text { Emissions } \\
\text { ICE lb-CO2e }\end{array}$ & $\begin{array}{c}\text { Annual PEV } \\
\text { GHG Local } \\
\text { lb-CO } \mathrm{CO}_{2} \mathrm{e}\end{array}$ & $\begin{array}{c}\text { Annual GHG } \\
\text { Savings } \\
\mathrm{Lb}^{-\mathrm{CO}_{2} \mathrm{e}}\end{array}$ & $\begin{array}{c}\text { Annual GHG } \\
\text { Reduction \% }\end{array}$ \\
\hline 5,147 & 366 & 5,807 & 2,450 & 3,356 & $58 \%$ \\
\hline
\end{tabular}

Tables E-8 and E-9 show that there is a significant opportunity for savings, not only in fuel costs, but also in GHG emissions with the deployment of PEVs in this fleet. 